Colección

ESTUDIOS

Y DOCUMENTOS

\title{
Panorama de las Administraciones Públicas 2017
}

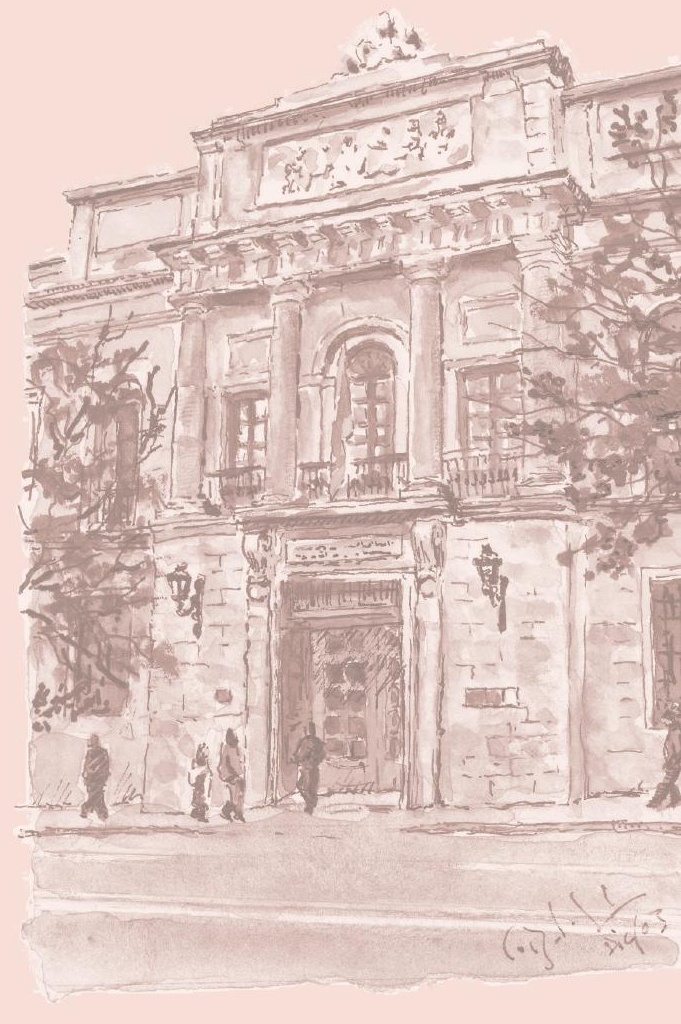




PANORAMA DE LAS ADMINISTRACIONES PÚBLICAS 2017 



\title{
PANORAMA DE LAS ADMINISTRACIONES PÚBLICAS 2017
}

\author{
Traducción* de \\ Instituto Nacional de Administración Pública \\ INAP
}

MADRID, 2018

* Esta TRADUCCIÓN se publica por acuerdo con la OCDE. No es una TRADUCCIÓN OFICIAL de la OCDE. La calidad de la TRADUCCIÓN y su coherencia con el texto en el idioma original de la obra son responsabilidad exclusiva de los autores de la TRADUCCIÓN. En caso de discrepancia entre el original y la TRADUCCIÓN, solo se considerará válido el texto de la obra original.

Publicación incluida en el programa editorial del suprimido Ministerio de Hacienda y Función Pública y editada por el Ministerio de Política Territorial y Función Pública (de acuerdo con la reestructuración ministerial establecida por Real Decreto 355/2018, de 6 de junio).

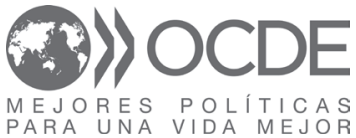




\section{Colección: ESTUDIOS Y DOCUMENTOS}

\section{FICHA CATALOGRÁFICA DEL CENTRO DE PUBLICACIONES DEL INAP}

PANORAMA de las Administraciones Públicas 2017 / OCDE ; traducción de Instituto Nacional de Administración Pública. - $1^{\mathrm{a}}$ ed. - Madrid : Instituto Nacional de Administración Pública : Organización para la Cooperación y el Desarrollo Económico, 2018. - 497 p. ; $24 \mathrm{~cm}$. - (Colección ESTUDIOS Y DOCUMENTOS)

ISBN 978-84-7351-623-5 (formato papel). - ISBN 978-84-7351-624-2 (formato electrónico). - NIPO 174-18-004-4 (formato papel)

1. España-Administración pública. I. Organización para la Cooperación y el Desarrollo Económicos. II. Instituto Nacional de Administración Pública (España). III. Serie

35(460)"2017"

338.465(460)"2017"

\section{Primera edición: Junio 2018}

Catálogo general de publicaciones oficiales: http://publicacionesoficiales.boe.es

La actividad editorial del Instituto Nacional de Administración Pública está reconocida por Scholary Publishers Indicators in Humanities and Social Sciences (SPI) en las disciplinas de Ciencias Políticas y Derecho. El listado SPI es aceptado como listado de referencia por la Agencia Nacional de Evaluación de la Calidad y Acreditación (ANECA), por la Comisión Nacional Evaluadora de la Actividad Investigadora CNEAI y por la ANEP (Agencia Nacional de Evaluación y Prospectiva).

Esta obra se publica bajo la responsabilidad de la Secretaría General de la OCDE. Las opiniones expresadas y los argumentos empleados en este documento no reflejan necesariamente las opiniones oficiales de los países miembros de la OCDE.

Este documento y cualquier mapa incluido en este documento no prejuzgan el estatus o la soberanía sobre cualquiera de los territorios, ni la delimitación de fronteras ni el nombre de cualquier territorio, ciudad o área.

Publicado originalmente por la OCDE en inglés con el siguiente título: Government at a Glance 2017.

(C) 2017 OECD.

(C) 2018 Instituto Nacional de Administración Pública para esta edición en español.

Los datos estadísticos relativos a Israel han sido suministrados por y bajo la responsabilidad de las autoridades israelíes competentes. El uso de estos datos por la OCDE no prejuzga la situación de los Altos del Golán, Jerusalén Este y los asentamientos israelíes en Cisjordania, en los términos del derecho internacional.

Queda prohibida, salvo excepción prevista en la ley, cualquier forma de reproducción, distribución, comunicación pública y transformación de esta obra sin contar con autorización de los titulares de propiedad intelectual. La infracción de los derechos mencionados puede ser constitutiva de delito contra la propiedad intelectual (arts. 270 y sigs. del Código Penal).

Edita:

INSTITUTO NACIONAL DE ADMINISTRACIÓN PÚBLICA

www.inap.es

ISBN 978-84-7351-623-5 (formato papel) - ISBN 978-84-7351-624-2 (formato electrónico) NIPO 174-18-004-4 (formato papel)

Depósito Legal: M-2273-2018

Preimpresión: Contenidos y Proyectos ISLIZ

Impresión: SAFEKAT

En esta publicación se ha utilizado papel reciclado libre de cloro de acuerdo con los criterios medioambientales de la contratación pública. 


\section{PREFACIO}

Los Gobiernos de los países de la OCDE (Organización para la Cooperación y el Desarrollo Económico) operan en un entorno económico, social y político cada vez más complejo e impredecible. En este contexto, los Gobiernos procuran diseñar e implementar reformas que apoyen un crecimiento inclusivo, mejoren el acceso y la calidad de los servicios públicos y obtengan, además, una buena relación calidad-precio para afrontar las continuas restricciones presupuestarias. Panorama de las Administraciones Públicas 2017 aporta abundante información de interés sobre las prácticas y procedimientos de gestión pública para implementar las reformas del sector en los países miembros y países socios. Esta edición contiene los datos más recientes sobre las finanzas y empleo públicos, además de datos de encuestas sobre prácticas y procedimientos de gestión pública (que incluyen, por ejemplo, prácticas y procedimientos presupuestarios, gestión de recursos humanos, integridad del sector público, gobernanza regulatoria, gobierno abierto y gestión del riesgo y comunicación) y dos capítulos sobre los resultados y efectos de las operaciones gubernamentales. En esta edición, el capítulo inicial ofrece indicadores incluidos en la publicación para facilitar orientaciones sobre acciones de política para enfrentar la complejidad, con especial énfasis en la integración del pensamiento sistémico y de las nuevas herramientas y métodos de trabajo en la práctica de gobierno, con el fin de aprovechar la abundancia de datos y estudios disponibles, fomentar la apertura de los procesos gubernamentales a todas las partes interesadas y obtener mejores resultados.

Este trabajo ha sido dirigido por Zsuzsanna Lonti, de la Dirección de Gobernanza Pública y Desarrollo Territorial de la OCDE (GOV), bajo la dirección de Rolf Alter y Edwin Lau. Constituye un componente importante del programa de trabajo de la GOV, que trata de ayudar a las Administraciones públicas a todos los niveles en el diseño y aplicación de políticas estratégicas, innovadoras y basadas en evidencias para fortalecer la gestión pública, responder eficazmente a diversos retos económicos, sociales y medioambientales y cumplir sus compromisos con los ciudadanos. La publicación ha sido redactada por Guillaume Lafortune, Alessandro Lupi y Rebecca Schultz. Especiales agradecimientos 
merecen también Reginald Dadzie y Julia Smadja por su asistencia en la elaboración del texto. Han aportado importantes contribuciones Edwin Lau, Stéphane Jacobzone, Julio Bacio Terracino, Frederic Boehm y Céline Kauffmann (capítulo 1, «Adoptar el cambio continuo en las Administraciones»); Nelson Amaya, Ronnie Downes y Luiz de Mello (capítulo 2, «Economía y finanzas públicas»); Daniel Gerson, Cristina Mendes, Maya Bacache Tatyana Teplova y Pinar Guven (capítulo 3, «Empleo y salarios públicos»); Andrew Davies, Andrea Urhammer y Teresa Deubelli (capítulo 4, «Instituciones»); Ronnie Downes, Lisa Von Trapp, Camilla Vammalle, Delphine Moretti, Juliane Jansen, Scherie Nicol y Rasha Alshatti (capítulo 5, «Prácticas y procedimientos presupuestarios»); Daniel Gerson, Cristina Mendes y Maya Bacache (capítulo 6, «Gestión de recursos humanos»); Janos Bertok, Julio Bacio Terracino, Frederic Boehm, Natalia Nolan-Flecha y Levke Jessen-Thiesen (capítulo 7, «Integridad del sector público»); Céline Kaufmann, Christiane Arndt, Rebecca Schultz, Faisal Naru, Filippo Cavassini y Daniel Trnka, (capítulo 8 «Gobernanza regulatoria»); Janos Bertok, , Paulo Magina, Mathieu Cahen y Minjoo Son (capítulo 9, «Contratación pública»); Alessandro Bellantoni, Maria Emma Cantera, Simon Schmitz, Barbara Ubaldi y Arturo Jacob Rivera Pérez (capítulo 10, «Gobierno abierto»); Piret Tonurist y Joao Vasconcelos (capítulo 11, «Innovación en el sector público y gobierno digital»), y Jack Radish, Catherine Gamper, Roberto Schiano Lomoriello y Stéphane Jacobzone (capítulo 12, «Gestión del riesgo y comunicación»).

Agradecemos a Kate Lancaster, Audrey Garrigoux, Carmen Fernandez Biezma, Marie-Claude Gohier y Laura Boutin su ayuda en la preparación del documento para su publicación. La traducción al francés fue posible gracias a Christophe Delprat, Frédéric Berri y Myriam Shalak-Graziani.

Esta publicación es el resultado de las contribuciones de una amplia gama de fuentes y experiencia. Se benefició de las aportaciones proporcionadas por el Comité de Gobernanza Pública de la OCDE y el Grupo Directivo de Panorama de las Administraciones Públicas (véanse detalles en el anexo G), el Comité de Estadísticas de la OCDE, el Grupo de Trabajo de Empleo y Gestión Públicos, el Grupo de Trabajo de Funcionarios Directivos de Presupuestos, el Grupo de Expertos de la OCDE sobre Conflictos de Interés, el Grupo de Trabajo de Funcionarios Directivos de Gobierno Digital (E-Leaders), el Grupo de Trabajo de Expertos en Contratación Pública, el Grupo de Expertos en Gobierno Innovador y Abierto, y el Grupo de Expertos de la OCDE en Datos de Libre Acceso. Se recibieron valiosos comentarios de Peter Van de Ven (Dirección de Estadísticas de la OCDE); Gaetan Lafortune (Dirección de Empleo, Trabajo y Asuntos Sociales de la OCDE); Corinne Heckman, Alfonso Echazarra, Carlos González-Sancho, Camila De Moraes, Daniel Sánchez Serra y Giovanni Maria Semeraro (Dirección de Educación de la OCDE), y MarieClaire Sodergren (Organización Internacional del Trabajo, Ginebra, Suiza) 


\section{ÍNDICE}

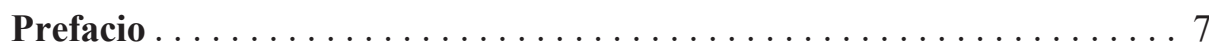

\section{Prólogo}

Conseguir que la globalización funcione para todos requiere una

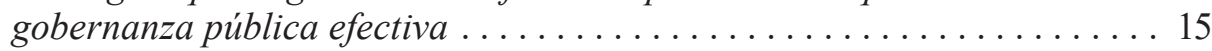

\section{Prólogo a la edición en español}

La elaboración de un nuevo relato de lo público ..................17

\section{Panorama de las Administraciones Públicas: un faro para nuestros} servicios públicos $\ldots \ldots \ldots \ldots \ldots \ldots \ldots \ldots \ldots \ldots \ldots \ldots \ldots \ldots \ldots \ldots \ldots \ldots \ldots$

Trayectoria de Panorama de las Administraciones Públicas: desarrollo de información sólida del sector público . . . . . . . . . . . . . 32 Panorama de las Administraciones Públicas: de la vanguardia al

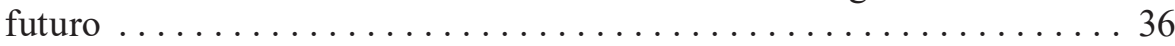

Resumen ejecutivo ............................. 39

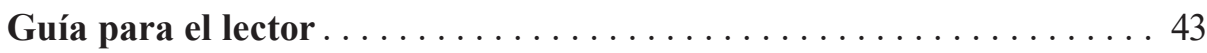

Calendario fiscal / Año fiscal en los datos de contabilidad nacional . . . 43

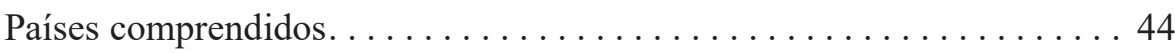

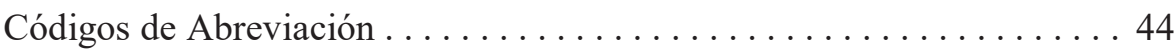

Promedios y totales de la OCDE .................... 45

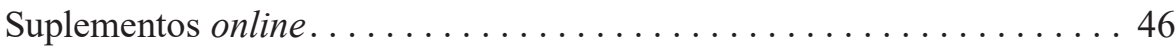

Indicadores per cápita. ....................... 46

Paridades de poder adquisitivo. .................. 47

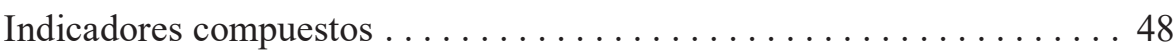

Signos y abreviaturas $\ldots \ldots \ldots \ldots \ldots \ldots \ldots \ldots \ldots \ldots \ldots \ldots \ldots$ 
Introducción . . . . . . . . . . . . . . . . . . . . . . . . . 49

Novedades en Panorama de las Administraciones Públicas 2017. . . . . 49

Definición de Administraciones públicas .................. 51

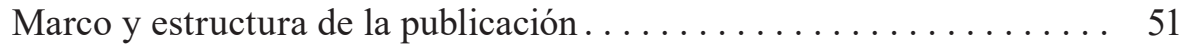

Actividades futuras. . . . . . . . . . . . . . . . . . . . . . . 54

Ediciones regionales y nacionales de Panorama de las Administraciones Públicas . ...................... 55

Todos los datos e indicadores sobre gobernanza pública están disponibles online......................... 56

Capítulo 1. Adoptar el cambio continuo en las Administraciones . . . 57

Introducción . . . . . . . . . . . . . . . . . . . . . 57

Los retos... y deficiencias de la reforma del sector público . . . . . . . 59

Los nuevos enfoques precisan visión, evidencias y capacidades a todos los niveles de gobierno . . . . . . . . . . . . . . . . . . 65

Un enfoque de cambio innovador y con sentido se basa en la transparencia y la participación $\ldots \ldots \ldots \ldots \ldots \ldots \ldots \ldots \ldots \ldots \ldots \ldots$

Más allá de las fronteras nacionales: abogar por la cooperación regulatoria internacional $\ldots \ldots \ldots \ldots \ldots \ldots \ldots \ldots \ldots . \ldots 3$

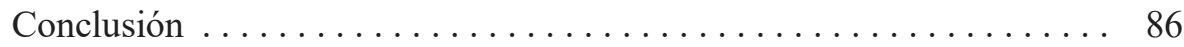

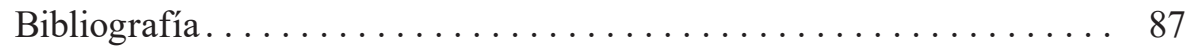

Capítulo 2. Economía y finanzas públicas $\ldots \ldots \ldots \ldots \ldots \ldots \ldots$. 91

Balance fiscal de la Administración general . . . . . . . . . . . . . . 91

Ahorro neto de la Administración general. . . . . . . . . . . . . 95

Balance estructural de la Administración general.............. 98

Deuda bruta de la Administración general. . . . . . . . . . . . 102

Patrimonio neto financiero de la Administración general . . . . . . . . 107

Balance fiscal y deuda por nivel de administración . . . . . . . . . 110

Ingresos de la Administración general. . . . . . . . . . . . . . . . . 114

Estructura de ingresos de la Administración general . . . . . . . . 118

Estructura de ingresos por nivel de administración. . . . . . . . . 122

Gastos de la Administración general . . . . . . . . . . . . . 126

Estructura de gastos de la Administración general por función (CFG). . 130

Estructura de gastos de la Administración general por transacción económica................................... 135

Estructura de gastos por nivel de administración . . . . . . . . . . . 139

Gasto en inversión de la Administración general ............. 143 
Costes de producción y externalización de la Administración general . 147 Apartado especial: Estructura de gastos de la Administración general por funciones de protección social y sanidad (CFG) . . . . . . . . . 151

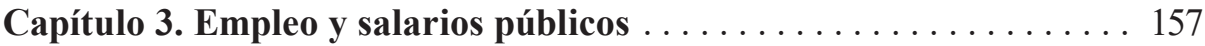

El empleo en la Administración general . . . . . . . . . . . . . . 157

El empleo en la Administración general por nivel de administración. . . 161

Envejecimiento de la fuerza de trabajo en la Administración central . . 164

Mujeres y empleo público . . . . . . . . . . . . . . . . . . . 167

Mujeres y política . . . . . . . . . . . . . . . . . . . 172

Mujeres y poder judicial . . . . . . . . . . . . . . . . . . . 175

Remuneración de altos funcionarios . . . . . . . . . . . . . . . . . . . 179

Remuneración de cargos intermedios. . . . . . . . . . . . . . . 182

Remuneración de profesionales de la Administración central....... 186

Remuneración de los puestos de secretariado . . . . . . . . . . . . 189

Remuneración de ocupaciones seleccionadas del sector servicios . . . . 193

Sueldos de maestros y profesores . . . . . . . . . . . . . . . . . . . 197

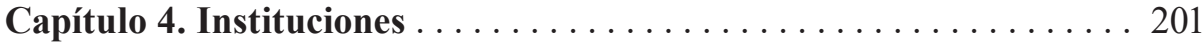

Apartado especial: Instituciones y prácticas para proteger a los reguladores de la influencia indebida. . . . . . . . . . . . . . 201 Apartado especial: Sistemas de asesoramiento independientes de las Administraciones públicas . . . . . . . . . . . . . . . . . . 205 Apartado especial: Disposición del centro de gobierno para implementar los Objetivos de Desarrollo Sostenible de la ONU. . . . . 210 Apartado especial: El papel de las organizaciones internacionales en la cooperación regulatoria internacional . . . . . . . . . . . . . . . 214

Capítulo 5. Prácticas y procedimientos presupuestarios . . . . . . . 221

Presupuestos basados en resultados . . . . . . . . . . . . . . . . 221

Apartado especial: Presupuestos con perspectiva de género . . . . . . . 225

Análisis de gastos . . . . . . . . . . . . . . . . . . . . . . . . 229

Gobernanza de las infraestructuras . . . . . . . . . . . . . . 233

Calidad de los informes financieros de las Administraciones públicas. . 238

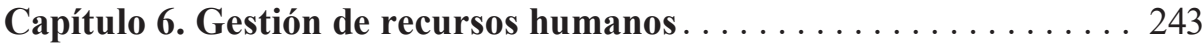

Delegación de competencias en la gestión de recursos humanos . . . . . 243

Gestión del rendimiento laboral . . . . . . . . . . . . . . . . . . . . . . . . 247 
Prácticas de gestión de recursos humanos específicas a los altos

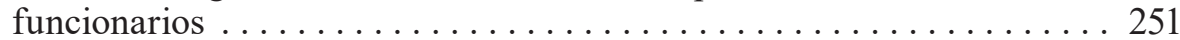

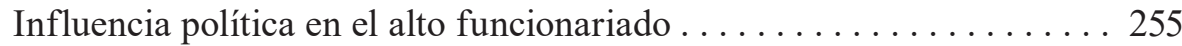

Gestión de recursos humanos basada en evidencias . . . . . . . . . . 259

Encuestas de empleados . . . . . . . . . . . . . . . . . . . . . 264

Capítulo 7. Integridad del sector público . . . . . . . . . . . . . . . . . 269

Medidas institucionales para los sistemas de integridad en el sector público. . . . . . . . . . . . . . . . . . . . . . . . . . . . . . . . . . . . 269

Mecanismos de coordinación para la implementación de políticas de integridad . . . . . . . . . . . . . . . . . . . . . . . . 274

Supervisión y evaluación de los sistemas de integridad . . . . . . . 278

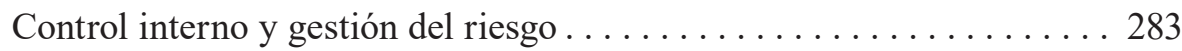

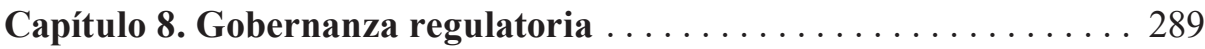

Compromiso de las partes interesadas en el desarrollo de la normativa. 289

Evaluación del impacto regulatorio . . . . . . . . . . . . . . . . . . . 293

Evaluación ex post de la normativa . . . . . . . . . . . . . . . 297

Apartado especial: Implementación de percepciones del

comportamiento en el diseño y aplicación de políticas . . . . . . . . 302

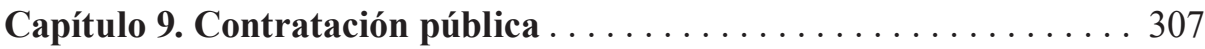

Volumen de la contratación pública . . . . . . . . . . . . . . . . . . . . 307

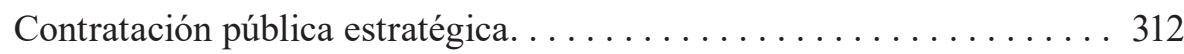

Contratación electrónica ........................ 316

Centrales de compras . . . . . . . . . . . . . . . . . . . 321

Contratación y realización de proyectos de infraestructuras . . . . . 326

Capítulo 10. Gobierno abierto $\ldots \ldots \ldots \ldots \ldots \ldots \ldots \ldots \ldots \ldots \ldots$

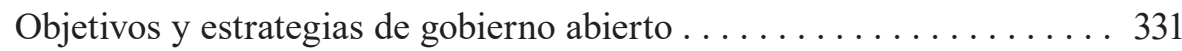

Coordinación de gobierno abierto y gestión de recursos humanos . . . . 335

Seguimiento y evaluación de las estrategias de gobierno abierto . . . . 340

Participación ciudadana en la formulación de políticas . . . . . . . . . 345

Datos de gobierno abierto. . . . . . . . . . . . . . . . . . . . 349

Capítulo 11. Innovación en el sector público y gobierno digital . . . . . 353

Innovación de las estrategias y programas de gestión de recursos

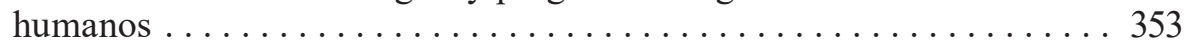

Estructuras de apoyo para la innovación en el sector público ...... 357 
Mecanismos de financiación para la innovación en el sector público . . 362 Transformación digital de la prestación de servicios públicos. . . . . . 366

Capítulo 12. Gestión del riesgo y comunicación . . . . . . . . . . . 371

Impacto socioeconómico de los desastres en los países de la OCDE . . 371

Gobernanza de riesgos críticos . . . . . . . . . . . . . . . . . 375

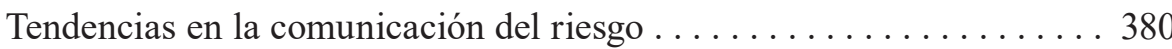

Capítulo 13. Resultados básicos de las administraciones públicas . . . 385

Confianza en el Gobierno............................... 385

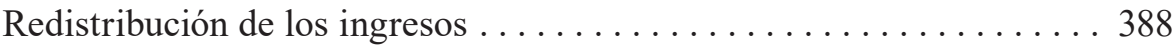

Estado de Derecho . . . . . . . . . . . . . . . . . . . . . . . . . . . . . . . . . 392

Eficiencia del sector público. . . . . . . . . . . . . . . . . . . . . 395

Relación coste-efectividad en el sector público . . . . . . . . . . . . . 398

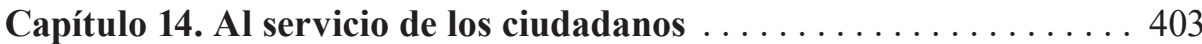

Tablas de puntuación de servicios a los ciudadanos . . . . . . . . 403

Satisfacción ciudadana con los servicios e instituciones públicos. . . . . 414

Acceso financiero y geográfico a la asistencia sanitaria . . . . . . . . 418

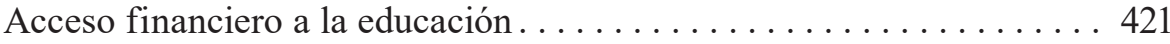

Acceso a los servicios jurídicos y de justicia ............. 426

Capacidad de respuesta de los sistemas sanitarios a las necesidades de

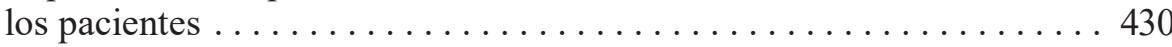

Capacidad de respuesta de los sistemas educativos a las necesidades de los estudiantes . . . . . . . . . . . . . . . . . . . . 434

Servicios de justicia civil sin dilaciones. . . . . . . . . . . . . 438

Calidad de la asistencia sanitaria . . . . . . . . . . . . . . . . . . . 442

Rendimiento de los estudiantes y equidad en la educación . . . . . . . 446

Efectividad e imparcialidad de los sistemas judiciales . . . . . . . . . 450

Anexo A Sistemas y fuentes de información de los países en las

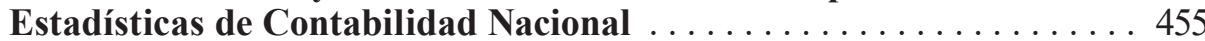

Anexo B Metodología de los ingresos agregados . . . . . . . . . . . 459

Anexo C Clasificación de las funciones del gobierno (CFG) . . . . . . . 461

Anexo D Metodología y notas adicionales sobre la remuneración de los empleados de la Administración. 
Anexo E Metodología de los índices compuestos de prácticas y procedimientos públicos ........................ 481

Anexo F Gráficos adicionales disponibles online ........... 483

Anexo G Miembros del grupo directivo . . . . . . . . . . . . . . . 487

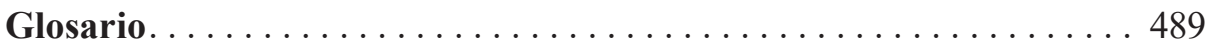




\section{PRÓLOGO \\ CONSEGUIR QUE LA GLOBALIZACIÓN FUNCIONE PARA TODOS REQUIERE UNA GOBERNANZA PÚBLICA EFECTIVA}

Esta edición del quinto aniversario de Panorama de las Administraciones Públicas coincide con momentos de gran incertidumbre política, económica y social. Diez años después de la crisis financiera global, la recuperación económica no es lo suficientemente robusta como para reflejar mejoras duraderas sobre el potencial de producción o reducir la persistencia de desigualdades. Los rápidos cambios tecnológicos, la innovación desestabilizadora y ciclos económicos más cortos son distintivos del mundo actual. Crean nuevas oportunidades, pero también hacen que las condiciones de vida sean más impredecibles e inseguras. Existe, además, la percepción generalizada entre la población de que los beneficios de la liberalización económica mundial han sido aprovechados, en gran medida, por unos pocos. Reducir las diferencias entre los más beneficiados por la globalización y la población menos favorecida, y avanzar con éxito en tiempos de incertidumbre requiere una gobernanza abierta, justa y efectiva.

Los Objetivos de Desarrollo Sostenible de las Naciones Unidas (ODS) enfatizan la importancia de reforzar las instituciones públicas y la gobernanza, con especial mención en el objetivo 16, sobre «Paz, justicia e instituciones fuertes». Sin embargo, el porcentaje de ciudadanos de países de la OCDE que afirman tener confianza en su Gobierno nacional continúa siendo bajo (42\%), todavía por debajo de los niveles anteriores a la crisis. La reconexión entre Gobiernos y ciudadanos exige medidas adicionales y este estudio puede ayudar a los Gobiernos a satisfacer esta exigencia.

Panorama de las Administraciones Públicas 2017 muestra importantes esfuerzos llevados a cabo por las Administraciones para comprometerse más con los ciudadanos, empresas y sociedad civil. Las Administraciones públicas avanzan hacia un gobierno abierto que mejore las políticas y servicios y que prevenga la captura política. En 2017, casi el 50\% de los países de la OCDE adoptaron una política de gobierno abierto. Sin embargo, los resultados del nuevo OURdata index (en español: 'índice OURdata') de la OCDE muestran que, aunque los países han progresado en el impulso de políticas de datos 
abiertos con la introducción de formatos abiertos y reutilizables, se puede hacer más para estimular activamente su uso entre ciudadanos y empresas. Las nuevas tecnologías y las aportaciones de nuevos enfoques, como los basados en las ciencias del comportamiento, pueden favorecer la colaboración ciudadana en el diseño y prestación de servicios, y mejorar la efectividad de las políticas públicas.

Esta publicación aporta, además, nueva evidencia sobre cuestiones fundamentales, como por ejemplo la representación de las mujeres en la vida pública. Las mujeres constituyen solo el $29 \%$ de los parlamentarios en los países de la OCDE y el $28 \%$ de ministros de Gobierno. De manera similar, a pesar de que el $58 \%$ de los trabajadores del sector público son mujeres, solo el $32 \%$ ocupa puestos de categoría superior. La lucha por la igualdad de género debe comenzar dentro de las instituciones públicas.

Este es solo un ejemplo de las muchas cuestiones clave que se recogen en el conjunto de indicadores presentado en esta 5. ${ }^{\mathrm{a}}$ edición, que incluye, además, información sobre finanzas y empleo públicos, prácticas y procedimientos presupuestarios, y gestión del riesgo y comunicación, entre otros. Los indicadores fomentan la toma de decisiones basada en evidencias y permiten que las Administraciones públicas comparen sus prácticas y rendimiento para, así, identificar cómo mejorar su actuación. Panorama de las Administraciones Públicas 2017 amplía el alcance e incrementa la accesibilidad y relevancia de los indicadores y análisis de gobernanza, presentándolos en diversos formatos digitales, por lo que supone un recurso fundamental para responsables políticos, ciudadanos e investigadores en aras de una gobernanza mejor y políticas más inclusivas para una vida mejor.

Atentamente,

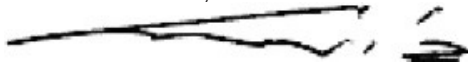

Ángel Gurría 


\section{PRÓLOGO A LA EDICIÓN EN ESPAÑOL LA ELABORACIÓN DE UN NUEVO RELATO DE LO PÚBLICO}

Esta nueva edición de Panorama de las Administraciones Públicas consolida la tendencia de las últimas entregas de elevar el discurso sobre la Administración para transcender su actividad gestora. Tras décadas de formalismo normativo o gerencial que han reforzado la visión instrumental del aparato administrativo, la línea emprendida hace unos años por la Organización para la Cooperación y el Desarrollo Económicos (OCDE) destaca la naturaleza política y social de la Administración pública y pone énfasis en su decisiva colaboración en la gobernanza y en la consecución de los grandes objetivos de la sociedad y de la agenda mundial. En este sentido, en esta edición se enfatiza en la necesidad de conectar la acción administrativa con la Agenda 2030 y los Objetivos de Desarrollo Sostenible (ODS), robusteciendo así el enfoque que se inició en la edición de 2015. De esta manera, la Organización de las Naciones Unidas (ONU) y la OCDE nos presentan una agenda básica y común para los gobiernos y las Administraciones públicas y establecen unas metas que tienen como fin garantizar el cumplimiento efectivo de los derechos y libertades de los ciudadanos, mejorar su bienestar y asegurar la sostenibilidad del planeta, la solidaridad y la construcción de alianzas, el logro de la paz y la justicia. Estas metas se resumen en una afortunada expresión: «que nadie se quede atrás».

La OCDE, en realidad, lo que viene realizando en sus numerosos informes es la construcción de un aparato teórico que orienta sus estudios y subyace en su amplio y útil manejo de los datos y la información. Existe una manera «OCDE» de entender la realidad social, política y administrativa. Su principal acierto es que arroja luz en unos momentos de incertidumbre crítica que pueden avocar a la parálisis de la acción pública o — no se sabe bien qué es peora dejarse llevar por la inercia seguida en las últimas décadas y que ha conducido al mal de la desconfianza ciudadana. Casi se podría decir que la OCDE, junto con unos pocos organismos internacionales más, se ha convertido en la fuente principal de pensamiento administrativo y parcialmente político para la mayoría de los gobiernos. Ha sido capaz de que converjan especialistas y teóricos de las más diversas disciplinas y distintas redes de investigación administrativa. 
Con ser esto ya notable, lo más interesante es que ese encuentro para lograr un conocimiento transformador se ha puesto al servicio de los principios de pensamiento público y de buena gestión pública. Estos hechos representan una gran aportación frente a la tan a veces volátil e inaprensible reflexión científica. Con ello la OCDE ha logrado, como se señalaba, transcender la mera gestión administrativa y fortalecer una agenda común de transformación de nuestra sociedad.

Para llegar a convertirse en una plataforma de conocimiento compartido orientada a la transformación de la realidad, la OCDE ha tenido en cuenta los profundos cambios que se están produciendo a nuestro alrededor y que obligan a replantear la naturaleza y el alcance de lo público. Por eso, hoy pedimos al Estado y a sus instituciones públicas, en especial a los gobiernos y las Administraciones, que tengan capacidad para liderar las transformaciones sociales; desempeñen un papel activador de la sociedad, de las organizaciones sociales y las empresas; cuenten con unos recursos necesarios y con una posición que les permitan convertirse en plataformas para la co-creación y para la innovación social; desarrollen la capacidad de determinar formalmente el campo de actuación de los actores implicados en la coproducción de servicios; cumplan con la función de legitimar la adopción de acuerdos que tengan naturaleza pública desde la garantía de los derechos y libertades de los ciudadanos.

El Estado y la Administración pública necesitan redefinir su papel, que debe ir más allá de atender sus funciones tradicionales y de afrontar los nuevos retos que afectan a la manera en la que se relacionan con la sociedad. Ahora deben activarla para que se comprometa con el bien común; articular redes de políticas orientadas al aprendizaje y la generación y compartición de conocimiento con el fin de posibilitar la innovación, el cambio y la transformación social; otorgar capacidad de actuación en el ámbito público a los más diversos actores; evitar que estos diluyan sus responsabilidades con la comunidad cuando intervengan en las diversas redes de políticas; garantizar los derechos y libertades de todos los ciudadanos, participen o no en esas redes; tener un papel variable en estas, que no siempre será de dominio; establecer que los procesos participativos sean inclusivos y democráticos; garantizar que las comunidades, las familias, las empresas y los ciudadanos logren un crecimiento en su bienestar; legitimar la adopción de acuerdos que tengan naturaleza pública; extender al conjunto de la sociedad las soluciones encontradas por determinadas redes de políticas; y actuar como mediadores de los conflictos.

Los cambios acaecidos en el Estado, la sociedad y en el mercado conllevan que el Estado deba aceptar su finitud y la de sus organizaciones para atender las necesidades sociales. Esto conlleva una mayor y nueva implicación con las organizaciones sociales y las empresas en la consecución del bien común. De esta manera, el cumplimiento de los objetivos, necesidades y demandas de la sociedad corresponde a una alianza variable de actores de toda naturaleza y lo 
público pasa a tener una naturaleza ampliada que compromete a todos los actores y recursos existentes en una sociedad.

Esta realidad ampliada de lo público ya no puede identificarse con lo administrativo o lo estatal. Nuestras sociedades son más capaces, por lo que pueden asumir una mayor responsabilidad en la satisfacción de las necesidades sociales. Así, el gran reto público actual es construir una nueva legitimidad y un nuevo relato de lo público que contenga que el cumplimiento de los fines que tradicionalmente tenían atribuidas las instituciones públicas deben satisfacerse ahora en compañía de «otros»: organizaciones de la sociedad civil, empresas privadas, organizaciones de la economía social, familias y ciudadanos.

El alineamiento del enfoque de la OCDE de lo público y lo social con la Agenda 2030 para el Desarrollo Sostenible de la ONU concretada en los ODS conforma la actual agenda pública de las Administraciones públicas. Esta agenda, a diferencia de lo que ha podido suceder en el pasado, cuenta con grandes posibilidades de llevarse a cabo, al menos en muchos países, ya que suministra un amplio sistema de metas, variables e indicadores, el contraste y seguimiento de los mismos entre los países y la elaboración de rankings. A esta cultura de la medición y el contraste ha contribuido decisivamente la OCDE en las últimas décadas.

La combinación entre los objetivos tradicionales de la gestión pública, sintetizados en la eficacia y la eficiencia, con la orientación que nos ofrecen los ODS a los principios de inclusión, diversidad y al más habitual de participación supone una elevación del discurso de la Administración. Ya no es suficiente tratar de ser eficaces u optimizar los recursos públicos, cumplir con los objetivos establecidos y gestionar con criterios profesionales, sino que es preciso alcanzar la efectividad, esto es, comprometerse con una sociedad mejor.

\section{LO QUE DE VERDAD IMPORTA}

El nuevo relato de lo público debe, por tanto, transcender la gestión pública como la hemos venido entendiendo hasta ahora y contrastar sus resultados con las necesidades reales de la sociedad, con lo que de verdad importa a los ciudadanos.

La crisis económica y financiera reciente ha evidenciado la dificultad o incapacidad de muchos gobiernos para contrarrestar sus efectos catastróficos en la vida de los ciudadanos en términos de desempleo, desigualdad y pobreza. El efecto de esta realidad es el debilitamiento del Estado en términos de legitimidad, esto es, de si es capaz de cohesionar eficazmente la sociedad. También surgen amplias dudas sobre si puede garantizar la sostenibilidad de sus políticas de bienestar, atender la diversidad de las demandas y necesidades ciudadanas e integrar en la acción pública a toda la sociedad. Esto ha incrementado la tendencia previa a la crisis de pérdida de confianza de los ciudadanos en 
sus instituciones públicas e integrantes. Esta incapacidad o impotencia se resume en que la brecha entre los más ricos y los más pobres ha crecido en el seno de los países de la OCDE.

Panorama constata que «la desigualdad de ingresos ha crecido durante las últimas décadas en muchos países de la OCDE y registra un récord histórico» en muchas economías y que esta situación repercute en las condiciones de vida de las personas y las familias, en sus estados de salud, en la igualdad de oportunidades, en la cohesión social y en la confianza en las instituciones.

Si antes se señalaba que los efectos de la crisis habían sido catastróficos, las cifras que ofrece la OCDE para sus países miembros son elocuentes: en 2009 el balance fiscal alcanzó el -8,4 por ciento, siendo en 2015 el -2,8 por ciento; el nivel medio de la deuda bruta alcanzó en 2015 el 112 por ciento, mientras que en 2007 era del 73 por ciento; los gastos de las Administraciones públicas representaron en 2017 en promedio el 40,9 por ciento del PIB (producto interior bruto), mientras que en 2009 fue del 44,2 por ciento. Finalmente, la distribución de gastos entre 2007 y 2015 ha supuesto la disminución en los servicios públicos generales, defensa, orden público y seguridad, asuntos económicos, educación, y ocio, cultura y religión, y el incremento en sanidad y protección social (pensiones, seguros de desempleo...).

Una manera de afrontar los resultados del sector público es medir su costeefectividad. En esta edición se contempla la relación entre el gasto en sanidad y la esperanza de vida resultando que existe una correlación positiva, al igual que existe entre las puntuaciones del Programme for International Student Assessment (PISA) en ciencias y lectura y el gasto por estudiante. No obstante, y esto tiene gran interés para generar un cambio cultural en el gasto público, por encima de cierto umbral (alrededor de 80.000 USD de paridad de poder adquisitivo [PPA]) el rendimiento de los estudiantes parece depender de factores como la calidad de los profesores, su entorno socioeconómico y las prácticas de gestión de los centros, entre otros.

En algunos países los presupuestos públicos no son suficientes para garantizar los servicios básicos como la sanidad o la educación; la cobertura universal alcanza a determinados bienes y servicios y en otros casos deben complementarlos con aportaciones privadas que pueden ser elevadas. En esta línea, en algunos países las barreras financieras de acceso a la justicia son significativas.

El rendimiento del sistema también se mide en tiempos de espera de acceso a la atención sanitaria primaria o a la especializada; en la prevención, el diagnóstico precoz y el tratamiento de las principales causas de muerte; en la duración estimada de los procedimientos para resolver un recurso contencioso-administrativo; en el rendimiento en las destrezas educativas; en la disponibilidad de servicios sanitarios de calidad en la ciudad o zona donde se vive; en la satisfacción con el sistema y los centros educativos próximos; y en la confianza en el sistema judicial. 
La OCDE nos señala que las personas con bajos ingresos son más propensas a manifestar necesidades sanitarias insatisfechas; que la distribución desigual de los médicos es un motivo de preocupación creciente en los países miembros; que las personas de ingresos bajos indicaron mayores tiempos de espera para acceder a la atención necesitada; que existe una mayor percepción de mala calidad educativa en colegios de zonas socioeconómicas bajas o en zonas rurales; que los gastos privados en educación preescolar y superior son relativamente altos; que en varios países más del 50 por ciento de los gastos en educación superior son sufragados por los hogares u otras fuentes privadas; que la dilación en los procesos contencioso-administrativos varían entre 4 meses y más de dos años según el país considerado; y que el 13 por ciento de la variación en el rendimiento de los estudiantes en ciencias en los países de la OCDE se puede explicar por la situación socioeconómica de los alumnos.

La relación de variables anteriores implica grandes retos para la gestión pública tradicional y hace que se precisen nuevos conocimientos, capacidades y recursos para atenderlas. Se podría decir que las «preguntas del examen» para los responsables e integrantes de las Administraciones han cambiado y son muy distintas a las que tuvieron que responder en el ya muchas veces lejano ingreso en la Administración.

\section{RECUPERANDO LA CONFIANZA DE LOS CIUDADANOS}

La OCDE viene dedicando una atención especial al grave problema de la pérdida de confianza de los ciudadanos en sus instituciones públicas y en sus integrantes. Solo el 42 por ciento de los ciudadanos de los países de la OCDE confía en su gobierno nacional, aunque en algunos países la desconfianza es mayor. El efecto de esta pérdida de confianza es la falta de efectividad de la Administración, manifestada en muchas de las variables tratadas en el apartado anterior; la ralentización del desarrollo económico; un menor cumplimiento de la normativa y del sistema fiscal; la dificultad de lograr el consenso social y político; la resistencia a aceptar políticas que requieren el sacrificio; y la desmovilización del compromiso ciudadano con los procesos abiertos e inclusivos. El informe vincula la confianza con los resultados de la acción de gobierno mediante la valoración que los ciudadanos hacen del mismo; si lo consideran fiable, receptivo e imparcial; si es capaz de proteger a la población de los riesgos y de proporcionar servicios públicos de manera efectiva. Además, existe una alta correlación entre la confianza y la aprobación ciudadana del liderazgo político y la percepción del alcance de la corrupción en las Administraciones públicas. De esta manera, al descomponer el concepto de confianza en estas variables es posible abordar este problema perverso, complejo o mal estructurado con ciertas probabilidades de éxito. 
Hay otros resultados de la actuación pública que inciden en la confianza. Panorama trata la efectividad del Estado de derecho a través de la responsabilidad del gobierno y de los funcionarios ante la ley; la claridad de las leyes y su aplicación de manera igualitaria orientada a proteger los derechos humanos; un proceso accesible y justo de creación de las leyes; y una Administración de justicia imparcial. La enseñanza extraída de la aplicación de estas variables en la OCDE es que el control y equilibrio de los poderes del gobierno también garantizan los derechos fundamentales. En definitiva, podemos afirmar que es probable que una combinación de transparencia, ejemplaridad, accountability, responsabilidad, legalidad, accesibilidad y legitimidad hagan mejorar la confianza ciudadana en sus instituciones públicas.

Esta edición de Panorama muestra qué ha sucedido en las Administraciones públicas durante la crisis económica y financiera. Así, señala que existe la percepción de que las reformas de los gobiernos no son efectivas ni se implementan adecuadamente, quizá porque no tienen en cuenta la creciente complejidad ni a los probables ganadores y perdedores. La OCDE afirma que después de muchos años de reformas del sector público «superpuestas unas encima de otras a menudo no han logrado los efectos deseados y pueden conllevar políticas incoherentes e incluso contradictorias». Además, el enfoque tradicional de la reforma administrativa ha dejado de ser relevante por su orientación a la parcialidad y a su captura por intereses privados o corporativos. Frente a esto propugna un enfoque de las reformas caracterizado por el cambio continuo, la innovación y la colaboración, la transparencia y la coproducción con empresas y sociedad.

Del contraste del marco teórico que subyace al informe con las deficiencias de la realidad surgen una serie de retos para el sector público. Estos comienzan por la necesidad de que la Administración vaya por delante o acompañe a los avances sociales. Para ello precisa de políticas más inclusivas, abrirse a más actores que intervengan en ellas, la comprensión de los ciudadanos como coproductores y co-diseñadores de las políticas y servicios de las Administraciones y una visión a largo plazo e integral que comprenda todas las funciones y sectores políticos. A esto ayudaría notablemente que el enfoque de algunos desafíos actuales pasase de su consideración sectorial y tecnocrática actual a uno sistémico con el fin de reducir «el actual ambiente de creciente desigualdad y descontento político»; esto es, se trataría de pasar del énfasis en el diseño orgánico y los procesos a «la búsqueda de un espacio común sobre cómo lograr resultados».

Para construir ese espacio común es preciso cambiar la relación entre funcionarios y ciudadanos, como propone la OCDE. A ello puede contribuir el enfoque de Gobierno Abierto mediante la implementación de sus principios de transparencia, rendición de cuentas y participación. Cada país pone énfasis en alguno o algunos de estos aspectos y puede convertir este enfoque en una herramienta para alcanzar objetivos políticos más amplios, como aumentar la 
confianza de los ciudadanos en las instituciones. Casi todos los países despliegan iniciativas para desarrollar las capacidades de los funcionarios con el fin de apoyar las reformas basadas en el Gobierno Abierto. Para ello desarrollan programas de capacitación de los empleados públicos, redactan códigos de conducta e incorporan los principios de Gobierno Abierto al desarrollo de la acción del gobierno. Para lograr la efectividad de estas medidas se precisa la implantación de mecanismos de supervisión como la medición de políticas y las encuestas de opinión, el recurso a las organizaciones no gubernamentales (ONG) y la participación directa de la ciudadanía. Sin embargo, pocos países hacen un uso óptimo de la información suministrada por los ciudadanos para evaluar si su participación en la formulación de políticas tiene un impacto positivo en ellas y, por tanto, en su calidad de vida.

El capítulo dedicado al cambio continuo en las Administraciones públicas concluye llamando a la necesidad de que los responsables políticos asuman riesgos y un liderazgo fuerte y que las reformas se basen en evidencias que deben ser comunicadas a la población para revertir su desconfianza en las autoridades.

A recuperar la confianza contribuye también la provisión de una gran cantidad de datos en un formato abierto, libre y accesible, su reutilización y la elaboración de plataformas de colaboración e intercambio. La OCDE señala acertadamente que los datos públicos permiten pasar de un enfoque centrado en los ciudadanos a uno impulsado por ellos al permitir que las Administraciones puedan adaptar los servicios públicos a las necesidades de los usuarios. Ahora bien, advierte que el nivel de ingresos y la edad de las personas, entre otros factores, condicionan el uso de la Administración digital.

\section{EL NECESARIO REFUERZO DE LA INSTITUCIONALIDAD}

Tanto la ONU como la OCDE ponen énfasis, y así lo hace de nuevo esta edición de Panorama, en la necesidad de un marco institucional fuerte y seguro que genere confianza y legitimidad en las organizaciones públicas. Las instituciones estables posibilitan a su vez estabilidad y certidumbre política, social y económica entre los actores que, de esta manera, ven rentable invertir en las habilidades, tecnologías y organizaciones que son apropiadas para esas instituciones. Los informes de la OCDE, y en particular las ediciones de $\mathrm{Pa}$ norama, nos ofrecen la reflexión necesaria y un conjunto de variables e indicadores, con el análisis correspondiente, que orientan a la consecución de las instituciones eficaces, responsables e inclusivas a las que se refiere el objetivo 16 de los ODS. La presente edición presta una atención especial al aspecto institucional como clave para organizar y conseguir estos, en concreto vuelve a recalcar la importancia del papel activo de los centros de gobierno $(\mathrm{CdG})$. Este aspecto se complementa con la cooperación regulatoria internacional, 
aunque el informe reconoce que hay que realizar mayores esfuerzos en el desarrollo de una cultura evaluativa de los instrumentos de las organizaciones internacionales.

Para lograr el cambio propuesto, la OCDE vuelve a plantear en esta edición la importancia del análisis del impacto social, medioambiental y distributivo de las políticas. A esto añade el apoyo a la capacidad de los funcionarios para alcanzar mejores resultados y comprometerse con la innovación y el desempeño mediante, por ejemplo, la reforma de las estructuras laborales, la realización de encuestas periódicas y de programas de formación orientados a impulsar el rol proactivo del alto funcionario y la aplicación de las percepciones del comportamiento. Estas medidas se verían reforzadas si se adoptasen mecanismos de seguridad que garanticen la independencia del sector público y eviten las influencias indebidas. Este aspecto va cobrando peso en los últimos informes de la OCDE y en este le dedica el capítulo 4. En el se aborda los reguladores y los sistemas de asesoramiento independiente de las Administraciones públicas.

La edición actual amplía la atención a la gobernanza regulatoria con el enfoque de que la normativa ha de elaborarse en beneficio del interés público y de las necesidades ciudadanas, para lo que es preciso que se cuente con la participación de las partes afectadas, incluyendo ciudadanos, empresas, sociedad civil, y otros miembros de la comunidad. No todos los países utilizan los diversos mecanismos existentes como la consulta on line; la consulta formal a los actores; un marco transparente de participación de los interesados; o los mecanismos de supervisión y control de la calidad. Se destaca que no siempre se publican los comentarios de los interesados en los procesos de participación abiertos al público.

La evaluación del impacto regulatorio (EIR) forma parte de la gobernanza regulatoria y ayuda a los responsables políticos a decidir cómo y cuándo regular y a elegir entre las distintas alternativas posibles regulatorias o no regulatorias, aunque no todos los países realizan consultas públicas o evalúan el progreso de la regulación con el fin de garantizar que son relevantes y que cumplen con el propósito por el que se dictaron. Sin embargo, las evaluaciones ex post tiene una menor prioridad que las herramientas ex ante de gobernanza regulatoria en muchos países de la OCDE. La mayoría de estos se orienta a reducir las cargas administrativas y los gastos de cumplimiento o a estimular la competencia. Finalmente, pocos países aplican una evaluación acumulativa del marco regulatorio en su totalidad.

El continuo crecimiento de los desastres obliga a asumir una gestión del riesgo como estrategia nacional; una visión conjunta de todas las fases del ciclo de gestión del riesgo; una fuerte capacidad institucional; recursos; un liderazgo permanente del centro del gobierno; y una comunicación efectiva de los riesgos que involucre a toda la sociedad. Por desgracia, el informe señala que las mayores pérdidas se producen en los países con un menor índice PIB per cápita. 
La contratación pública es un mecanismo importante del gasto público en la OCDE. Alcanzó el 12 por ciento de media del PIB de sus miembros en 2015, aunque con grandes variaciones entre ellos debido al enfoque político de cada país. Más allá de su contenido económico, Panorama relaciona la contratación pública con los riesgos relacionados con el desaprovechamiento de los recursos, la gestión inadecuada y la corrupción; la priorización del gasto público; el logro de objetivos políticos adicionales vinculados con retos medioambientales, económicos y sociales; la participación y el desarrollo de la pequeña y mediana empresa; la innovación; la integración en los procesos globales de gestión de las finanzas, presupuestos y prestación de servicios; y el logro de la eficiencia.

Siguiendo con el apartado de la contratación, el informe presta atención a la implantación de las centrales de compras con el fin de lograr mejores precios, economías de escala, costes transaccionales menores, aumento de capacidades y conocimientos, mayor eficiencia y relación coste-beneficio en el proceso de contratación pública mediante la competencia y poder adquisitivo. Finalmente, fija su atención en el desarrollo de políticas para los proyectos de infraestructuras constatando que no todos los países disponen de este mecanismo de actuación. Esto puede generar dificultades para aplicar una metodología consistente para la selección de las modalidades de ejecución de proyectos.

Panorama incluye en esta ocasión la gobernanza de las infraestructuras desde la contemplación de su rentabilidad. Esta es definida como lo que el gobierno considera una combinación óptima de cantidad, calidad, características y precio (es decir, los costes), a lo largo del ciclo completo de cada proyecto de infraestructuras. No obstante, la OCDE reconoce que solo la mitad de sus miembros cuentan con un proceso sistemático para garantizar la rentabilidad absoluta de estas.

Indudablemente el factor presupuestario es un elemento central en el fortalecimiento institucional y de la gestión pública y una fuente de información clave para alcanzar su rentabilidad mediante la evaluación de sus resultados. Entendido así, el presupuesto transciende su mera contemplación contable y es un firme aliado para fomentar la cultura del rendimiento y el progreso en materia de rendición de cuentas y de transparencia. Además, como pone de manifiesto Panorama, su consideración sistémica permite introducir principios y prioridades de carácter transversal que afectan a distintas políticas sectoriales. Este sería el caso de la inclusión de la perspectiva de género en el proceso presupuestario. En este se ha introducido también, especialmente desde la crisis financiera mundial, la práctica del análisis de gastos, de modo que ha dejado de ser una simple respuesta ad hoc a las presiones fiscales.

Los aspectos financieros son abordados también desde la calidad de los informes que fundamentan las decisiones fiscales. Aunque se reconoce que la mayoría de los países de la OCDE han mejorado la exhaustividad de sus informes financieros, se señala que las Administraciones públicas todavía pueden 
mejorar considerablemente la calidad de sus prácticas de información con el fin de garantizar la transparencia.

\section{LA ATRACCIÓN, LA RETENCIÓN Y LA GESTIÓN DEL TALENTO PÚBLICO}

En esta edición de Panorama se retoman una serie de variables sobre el empleo público que no se habían tratado desde 2011 o 2013, lo que permite continuar algunas series históricas de gran interés.

La crisis económica y financiera no ha afectado significativamente al empleo en las Administraciones públicas en el conjunto de los países de la OCDE en relación con el empleo total, pasando del 17,9 por ciento en 2007 al 18,1 por ciento en 2015. Sin embargo, las diversas medidas adoptadas en materia de contención del empleo público han incrementado el envejecimiento de los empleados públicos. En la actualidad existen más funcionarios con edades por encima de los 55 años que por debajo de los 34 años (24 por ciento y 18 por ciento, respectivamente). Por lo que respecta a las mujeres, la paridad de género sigue sin alcanzarse en los niveles altos de la Administración; y su representación política ha avanzado poco en los últimos 15 años, aunque se ha alcanzado la paridad y superado en la mayoría de los países por lo que respecta a los jueces. Finalmente, se constata la existencia de una brecha considerable entre las retribuciones de los altos cargos y las de los cargos intermedios, aunque, claro es, existen grandes diferencias entre los diversos países.

Respecto a la gestión de las personas que se emplean en las Administraciones públicas, la OCDE sigue incidiendo en la conveniencia de la delegación de competencias combinada con la creación o el refuerzo de las unidades centrales de gestión de recursos humanos. Ya es un clásico que Panorama recalque la necesidad de la gestión del rendimiento laboral con el fin de mejorar la calidad, la accesibilidad y la capacidad de respuesta de los servicios públicos y una administración cuidadosa de los recursos. Pocos países, España e Islandia, escapan a las evaluaciones obligatorias, aunque no todos vinculan las evaluaciones de rendimiento con ascensos, retribuciones o bonificaciones.

En consonancia con el llamamiento a la necesidad de contar con el mejor talento en las Administraciones públicas, la OCDE viene manteniendo la utilidad de contar con una política de gestión de recursos humanos diferenciada de los altos funcionarios. Las prácticas comparadas en esta cuestión nos ofrecen los siguientes aspectos: remuneración por rendimiento; acuerdos sobre el rendimiento; despido como consecuencia del desempeño deficiente; contratos de duración determinada; o la evaluación de 360 grados. También encontramos en la mayoría de los países el desarrollo de perfiles de competencias específicas para los altos funcionarios, aunque están menos extendidas las políticas 
para la identificación de posibles altos funcionarios o programas de captación y de formación de jóvenes universitarios.

La OCDE se ocupa en numerosos informes de la profesionalización de la alta función pública. Sostiene la necesidad de contar con un servicio público profesional e imparcial que garantice un alto nivel de competencia e integridad, a la vez que la existencia de unos niveles apropiados de transparencia y de rendición de cuentas. Se trata de evitar la proliferación de favoritismos y clientelismos, un alto grado de rotación profesional y la contratación de agentes políticos. Caer en estas tentaciones, advierte, puede producir la pérdida de confianza en las instituciones públicas si los ciudadanos consideran que pesan más en la elección de los administradores públicos las afiliaciones políticas que la capacidad de liderazgo y de competencia. Así, en Chile, España y Turquía, los dos niveles superiores de los cargos de la Administración cambian por completo con la elección de un nuevo gobierno. Esto contrasta con el hecho de que en la mitad de los países de la OCDE la rotación de personal derivada de los cambios de gobierno en los cuatro niveles de alta gestión es nula o casi nula.

Esta atención hacia los problemas de la profesionalización de la Administración pública, en especial de sus directivos, no deriva de la transcendencia que pueda tener internamente en las organizaciones públicas, sino de cómo afecta a la consecución del propósito de la Administración y a la función que cumplen en el sistema político-administrativo y en la sociedad. Así, la definición de qué se entiende por directivo público; su selección; su localización en el organigrama político-administrativo; su delimitación con los puestos de los políticos; la atribución de las funciones que debe desempeñar; la definición de su carrera; la provisión de sus puestos; el establecimiento de sus retribuciones; sus incompatibilidades; las condiciones de su cese; en definitiva, su estatuto, tiene un alto contenido «técnico»o «gerencial», pero su transcendencia se encuentra en que el directivo público desempeña funciones superiores de dirección en organizaciones que ejercen la dominación propia del poder político sobre la sociedad. A esto hay que añadir que se encuentran en contacto directo con los políticos, con quienes compiten en la ocupación de los puestos superiores de la Administración y a los que apoyan en la toma de decisiones públicas. Precisamente la concreción de la delimitación del reparto de los puestos entre políticos y directivos públicos nos muestra el grado de politización de una Administración.

El adjetivo «público» detrás de «directivo» lo sustantiva de una manera determinante cualificándolo frente a sus homólogos «privados». Con estos comparte una serie de competencias, pero lo significativo es que poseen unas características condicionadas por el entorno de actuación del directivo público y la finalidad o propósito que debe cumplir. Este no es sino el fortalecimiento de la democracia, la garantía de los derechos y libertades de los ciudadanos; la aceptación del ejercicio del poder político por los ciudadanos; el logro de la 
cohesión y la integración social y el desarrollo económico y social; y la mejora efectiva de la vida de las personas, las organizaciones sociales y las empresas.

En esta edición de Panorama se incluye el aspecto de la gestión de los recursos humanos basada en evidencias aprovechando las enormes posibilidades que ofrece la transformación digital. El informe considera que contar con datos de la fuerza de trabajo del servicio público es esencial para una planificación y gestión estratégica efectivas de los recursos humanos que además, cuando esta información está centralizada, constituye una herramienta eficaz para el análisis comparado de las organizaciones y para orientar las reformas. No obstante, menos de la mitad de los países de la OCDE utiliza esta información para diseñar planes de formación o para evaluar el rendimiento de la gestión.

El informe señala que queda mucho por hacer en sistemas capaces de relacionar los datos necesarios para gestionar las carreras de los empleados públicos y para mejorar la gestión de recursos humanos, especialmente en aspectos como el carácter inclusivo de la función pública en términos de edad o de sector demográfico. Esta situación mueve a la OCDE a proponer que se apliquen encuestas periódicamente que contengan aspectos relacionados con el compromiso con el trabajo y con los empleados; el bienestar laboral; las percepciones con respecto a la gestión; el liderazgo; las reformas administrativas; la integridad; la diversidad; la inclusión; el acoso laboral; y la discriminación en el trabajo. En este sentido, destaca que pocos países utilizan las encuestas para evaluar y abordar cuestiones relacionadas con la diversidad y la inclusión.

Para lograr un cambio cultural en las Administraciones públicas se precisa orientarlas a la innovación. Para ello la gestión de los recursos humanos debe incluir estructuras de incentivos y recompensas; enfoques de gestión y liderazgo; prácticas organizativas relacionadas con la contratación, formación, movilidad y remuneración de los empleados; y factores sobre el diseño laboral, como la autonomía y las distintas maneras de trabajar. La formación tiene un importante peso en la orientación a la innovación junto con el desarrollo de liderazgo y los premios a la innovación. El necesario cambio cultural se refuerza mediante la creación de equipos, unidades, laboratorios o redes centrados en la innovación. Algunos países cuentan además con fondos dedicados a la innovación a nivel central y diferentes fuentes de financiación con el fin de realizar proyectos, apoyar soluciones innovadoras, experimentar y evaluar los proyectos en marcha.

Panorama continúa incidiendo en la implantación, supervisión y evaluación de los sistemas de integridad. La razón es que el fraude y la corrupción «pueden erosionar la confianza de la ciudadanía en los servicios públicos y en las Administraciones». Constata la existencia en varios países de oficinas especializadas en el control de la integridad de los empleados públicos, así como de mecanismos de coordinación dentro de un mismo gobierno y entre los distintos niveles gubernamentales, como las reuniones periódicas, la participación de las Administraciones estatales y subnacionales en el diseño de 
las políticas propias o la orientación por parte de un organismo central de integridad. Considera que la medición del rendimiento de las políticas de integridad es fundamental y se suele hacer en los países miembros de la OCDE a través de los datos administrativos internos de las organizaciones y los datos de opinión. No obstante, no todos los países tienen funciones centrales de auditoría interna o incluyen los objetivos de integridad en las distintas políticas.

En la edición anterior, Panorama aportó una razón de gran peso para atender la diversidad en el interior de las organizaciones públicas desde el punto de vista de la gestión pública: evitar políticas sistemáticamente sesgadas. Hasta ese momento las cuestiones relacionadas con la diversidad o la inclusión se había entendido que eran propias de algunas políticas sectoriales, como la de servicios sociales. Es cierto que el enfoque de género había puesto el foco en la diversidad y la inclusión desde la perspectiva de la igualdad entre mujeres y varones, pero es posible que esto se hubiese entendido más desde la perspectiva de la efectividad de los derechos humanos que desde el efecto en la gestión pública, muy especialmente en la toma de decisiones. A lo que la OCDE nos mueve con el enfoque de diversidad es a que no basta ponerse en el papel y las necesidades de los «otros» sino que la Administración pública ha de ser representativas de la sociedad a la que sirve. Esto ha de constatarse en la inclusión efectiva de la diversidad social en la toma de decisiones mediante las personas que la representan. Cuando esto no sucede, la consecuencia es la merma de los derechos civiles, la fragmentación de la sociedad y la expulsión de la participación en la vida social de quienes lo padecen.

La transcendencia de este enfoque para la gestión pública estriba en que se concede una gran importancia a la cultura de las organizaciones y esto conlleva revisar los procesos de selección y de formación; considerar atentamente el entorno en el que actúa la Administración; en definitiva, reconocer que todos estamos condicionados por nuestros orígenes, relaciones e intereses. Este reconocimiento muestra una Administración formada por personas que son seleccionadas con unos determinados filtros que hay que supervisar para que se garantice efectivamente la igualdad de acceso y la pluralidad social. De ahí que la realización de encuestas periódicas en el interior de las organizaciones y el énfasis en el análisis de los datos sean medidas que es necesario adoptar y generalizar para garantizar, por ejemplo, que las personas con discapacidad, las minorías raciales, étnicas y religiosas o que los distintos territorios estén debidamente representados en unas organizaciones públicas que ejercen poder sobre el conjunto de la sociedad y en su nombre. El incentivo para esforzarse en el logro de la diversidad se encuentra en mejorar la confianza de la sociedad en sus instituciones públicas y en sus integrantes y acertar con las decisiones y las políticas públicas.

Manuel Arenilla Sáez

Director del Instituto Nacional de Administración Pública 



\section{PANORAMA DE LAS ADMINISTRACIONES PÚBLICAS: UN FARO PARA NUESTROS SERVICIOS PÚBLICOS}

En la quinta edición de Panorama de las Administraciones Públicas, resulta oportuno reflexionar sobre el rol de la publicación, su progreso en el tiempo y sus diferencias con respecto a otras publicaciones sobre gobernanza pública. Es incluso más oportuno si consideramos el nuevo papel que juegan las pruebas y evidencias en la formulación de políticas. Por un lado, existe el enfoque racional, donde la evidencia se utiliza para saber dónde nos encontramos y adónde queremos ir. Las políticas y reformas están, o aspiran a estar, basadas en evidencias. Por otro lado, existe rechazo hacia el uso de evidencia científica y, en casos extremos, se ha llegado a crear «evidencia» falsa.

En este contexto, es esencial que las instituciones generen datos e información no solo válidos y fiables, sino también legítimos y fidedignos. A nivel nacional, hay dos instituciones que cumplen estas condiciones: las entidades fiscalizadoras superiores (EFS) y las oficinas nacionales de estadística. A nivel internacional, la OCDE es una de las organizaciones responsables de producir evidencia relevante, válida y fiable que ayude a los Gobiernos en la formulación de políticas y reformas. En el ámbito de las Administraciones públicas y gobernanza, la publicación Panorama de las Administraciones Públicas desempeña esta función.

En 2009, la OCDE lanzó un nuevo e innovador proyecto llamado Panorama de las Administraciones Públicas, que dio pie a la publicación, acompañada desde 2015 de una base de datos gratis online. Por primera vez se ofrecía un amplio conjunto de datos comparativos, combinados de manera coherente y accesible, sobre las Administraciones públicas. Con el tiempo, Panorama de las Administraciones Públicas se ha convertido en un «panel de control» donde los Gobiernos determinan, de un vistazo, su posición en términos de reforma de la gobernanza pública. Este panel sigue una lógica de «cadena de producción», y tiene, además, en cuenta valores públicos. Este sistema de posicionamiento gubernamental, o GPS, puede ser utilizado por las Administraciones para evaluar su desempeño en comparación con otros Gobiernos, decidir cómo mejorar, y diseñar reformas basadas en evidencias. Las edicio- 
nes posteriores han continuado desarrollando, ampliando y profundizando esta importante iniciativa.

\section{TRAYECTORIA DE PANORAMA DE LAS ADMINISTRACIONES PÚBLICAS: DESARROLLO DE INFORMACIÓN SÓLIDA DEL SECTOR PÚBLICO}

Las ediciones de Panorama de las Administraciones Públicas demuestran una trayectoria que incluye seis componentes clave.

1. Ampliar el alcance: de un enfoque centrado en insumos y procesos a uno centrado en productos y resultados

La estructura básica de los indicadores sigue y describe el proceso público de producción e identifica cinco categorías principales: contexto, insumos, procesos, productos y resultados. Mientras que la primera edición contenía únicamente indicadores de contexto, insumos y procesos, desde entonces se ha establecido una clara estrategia para ampliar y profundizar el ámbito de consideración e incluir también productos y resultados. Esto ha permitido, además, un cambio de enfoque, de uno centrado en una maquinaria limitada de Gobierno - o Administraciones públicas - a uno que abarca un sector público más amplio. Por ejemplo, los capítulos que presentan resultados básicos de Gobierno incluyen indicadores sobre el conjunto de las Administraciones, como puede ser la confianza pública en el Gobierno, la redistribución de las rentas, la sostenibilidad fiscal, el Estado de derecho, y la eficacia y rentabilidad del sector público.

Además, el capítulo sobre el servicio que se presta a los ciudadanos destaca indicadores sobre la calidad de la prestación de servicios en una amplia gama de ámbitos de actuación, principalmente sanidad, educación, justicia y administración tributaria. Los indicadores de este capítulo se apoyan en un nuevo marco para medir la prestación de servicios públicos a los ciudadanos y evalúan aspectos como la accesibilidad del servicio, su capacidad de respuesta y fiabilidad, así como la satisfacción ciudadana. Este marco proporciona un sólido entorno pluridimensional no solo para los indicadores, sino también para mostrar cómo los insumos y procesos derivan en productos y resultados. Permite la modelización sistemática de los productos y resultados de servicios, comparaciones entre distintos servicios y el desarrollo de tablas de puntuación.

Por ejemplo, en el ámbito de la capacidad de respuesta de los sistemas de sanidad a las necesidades de los pacientes, Panorama de las Administraciones Públicas proporciona indicadores de los tiempos de espera, de la comprensibilidad de las explicaciones médicas, de la participación de los pacientes en las decisiones sobre cuidados y tratamientos, y del uso por parte de los médicos 
del email para comunicarse con los pacientes. Estos indicadores muestran cómo la reorganización de procesos puede afectar de manera inmediata la calidad de los productos.

Al profundizar y enriquecer el conjunto de indicadores, es posible vincular los recursos y procesos con los productos e incluso resultados. Panorama de las Administraciones Públicas ha abandonado de esta manera la perspectiva limitada de que al Gobierno le conciernen únicamente presupuestos y gastos.

2. Profundizar la imagen de gestión: de un conjunto estándar de indicadores a un conjunto renovado de indicadores

Más que ninguna otra iniciativa, Panorama de las Administraciones Públicas ha sido capaz de demostrar la complejidad de la gestión pública. Esta complejidad administrativa, de gestión y de gobernanza se hace evidente a través de los indicadores sobre las funciones clave de las Administraciones. Dentro de cada función, la creciente variedad de indicadores proporciona evaluaciones matizadas y substanciales del desempeño de cada país.

Los indicadores se presentan no solo para el conjunto estándar de procesos y procedimientos de empleo público, gestión de recursos humanos y presupuestos, sino también para aspectos tales como la gestión regulatoria, gestión de contratación y gobierno digital, y para mostrar cómo la apertura, transparencia e integridad se organizan y gestionan en todas las funciones de Gobierno. Panorama de las Administraciones Públicas incluye indicadores sobre dimensiones sistémicas de gobernanza pública más amplias, como pueden ser la función de los centros de gobierno, el liderazgo, la previsión, y las distintas formas de poner en práctica la integración. Dentro de estos procesos, la diversidad de indicadores proporciona una visión única y caleidoscópica que permite una mejor valoración de todas las funciones de Gobierno y asuntos emergentes relacionados.

Por ejemplo, la gestión de recursos humanos no se limita exclusivamente a indicadores de delegación, sistemas de contratación, compensación por rendimiento y la existencia de una práctica de funcionarios de alto rango separada del resto, también se centra en aspectos como el género, la edad, la flexibilidad y movilidad, las relaciones industriales y condiciones laborales. Al estudiar la participación de las mujeres en las Administraciones, los indicadores no solo muestran el porcentaje de mujeres en empleo público, sino también su representación por sectores ocupacionales clave, como por ejemplo en posiciones de alto rango, como juezas, políticas, parlamentarias y ministras.

En materia de gobernanza regulatoria, se presentan indicadores no solo relativos al impacto de análisis regulatorio, simplificación y consultas, sino también relativos a organismos de supervisión normativa, la transparencia de las normativas, cumplimiento y aplicación, y la gobernanza de los propios reguladores. 


\section{Aumentar la pertinencia politica de los indicadores}

Los indicadores de Panorama de las Administraciones Públicas no son solo descriptivos, son además pertinentes de manera inmediata a las políticas públicas.

Indicadores como «porcentaje de casos de primera instancia que reciben asistencia jurídica»o "porcentaje de personas que consideran estar muy informadas acerca de los procedimientos legales», ambos pertenecientes al área de accesibilidad de los sistemas judiciales, establecen de manera inmediata la necesidad de mejorar el acceso y calidad de los sistemas legales aumentando el apoyo financiero, la comunicación y la información. Desde este punto de vista, Panorama de las Administraciones Públicas adopta una postura clara sobre qué constituye un buen y mejor gobierno.

Cada vez más indicadores de la publicación están basados en recomendaciones y principios de buenas prácticas suscritos por los países miembros, lo cual otorga un carácter normativo a la estructura del texto. Por ejemplo, los indicadores de gobernanza regulatoria reflejan la Recomendación del Consejo de la OCDE sobre política y gobernanza regulatoria de 2012 y se utilizan para supervisar su implementación. El OURdata index de la OCDE está basado en la Carta de Datos Abiertos.

Conectar información: de indicadores separados a indicadores más compuestos o combinados

Combinar y correlacionar indicadores introduce un nuevo planteamiento que puede ser llevado a la práctica. Aun cuando no sugiera causalidad, al menos la correlación de conceptos clave se hace evidente y puede, consecuentemente, influir en los debates. Cuando el índice de «derechos fundamentales» se vincula con el índice de «poderes limitados de gobierno», se plantea una hipótesis: los países con un alto nivel de derechos fundamentales tienen también sistemas donde los poderes de gobierno no son ilimitados.

Incluir indicadores de productos y resultados también hace posible conectar insumos con productos para demostrar niveles de eficiencia, o insumos con resultados para evaluar la rentabilidad. Por ejemplo, al combinar «gasto total en sanidad por persona» (insumo) con «esperanza de vida al nacer» (resultado), o «gasto acumulado por estudiante» (insumo) con una «puntuación PISA» (resultado), creamos indicadores de rentabilidad del sector público.

Otras publicaciones de indicadores han desarrollado índices compuestos sin enumerar de manera clara sus variables de componentes y las opciones metodológicas utilizadas. Panorama de las Administraciones Públicas es muy transparente en este sentido y muestra claramente las variables de componentes que conforman los indicadores compuestos - y los valores de país para cada uno de ellos-, así como las opciones metodológicas escogidas para combinarlos. Esta información detallada permite a los países identificar en 
qué ámbitos hay espacio para la mejora, lo cual hace que los indicadores compuestos sean prácticos $\mathrm{y}$, por tanto, más útiles.

Establecer agendas: de proporcionar datos a centrarse en temas emergentes

Poner de relieve las nuevas tendencias a través de sus indicadores es un aspecto central de Panorama de las Administraciones Públicas. A lo largo de los años los temas emergentes y apartados especiales de la publicación han incluido la reestructuración laboral, la contratación ecológica y la colaboración con los ciudadanos en la prestación de servicios en 2011; o los gastos de las Administraciones centrales en TIC en 2013, entre otros. La diversidad de temas muestra que su selección refleja la necesidad de indicadores que 1) traten ámbitos políticos emergentes (por ejemplo, contratación ecológica y participación ciudadana en prestación de servicios), 2) aborden los nuevos retos políticos (financiación de la asistencia sanitaria), 3) reaccionen a cambios en el entorno exterior, siendo el más destacado la última crisis económica y financiera (reestructuración laboral) y 4) subsanen ausencia de datos (gastos en TIC).

Las últimas elecciones generales en países miembros de la OCDE han puesto de manifiesto el descontento popular con las élites políticas. Este descontento a menudo pertenece a sectores de la población que se sienten excluidos de las oportunidades laborales o atrapados en empleos de bajo salario, que no tienen voz y que están segregados geográficamente. Varios indicadores de Panorama de las Administraciones Públicas se centran en la integración o en su ausencia. Entre estos se incluyen datos sobre el papel de las Administraciones en la redistribución de los ingresos e indicadores de acceso económico y geográfico a la asistencia sanitaria, educación y justicia.

Organizar la propiedad de los indicadores: de la provisión pasiva de datos a la participación interactiva de los encuestados

Una de las principales ventajas de Panorama de las Administraciones Públicas es que no solo recopila datos de una gama de fuentes fiables, también lleva a cabo su propia recogida de datos basados en encuestas. Esta recogida se hace principalmente en ámbitos de procesos de gobernanza, tales como presupuestos, gestión de recursos humanos, gobernanza regulatoria, integridad pública, gobierno abierto, gobierno digital, gestión del riesgo, etc. En muchos de estos ámbitos, la OCDE es la única fuente de este tipo de información (por ejemplo, en gestión de recursos humanos, gobierno abierto, integridad, etc.). Saca provecho de su posición privilegiada para involucrar en las encuestas a funcionarios de las Administraciones que son responsables y expertos en la materia. Toda posible parcialidad en las respuestas es mitigada por los expertos técnicos de la OCDE, que revisan los datos y garantizan el control de su calidad comparando las respuestas con versiones anteriores, respuestas de otros países y otras fuentes de datos. La red de expertos y funcionarios de 
Gobierno de la OCDE también participa activamente en el desarrollo de instrumentos de encuesta y en su periodo de prueba, así como en la discusión de resultados.

\section{PANORAMA DE LAS ADMINISTRACIONES PÚBLICAS: DE LA VANGUARDIA AL FUTURO}

Panorama de las Administraciones Públicas de la OCDE está también a la vanguardia de al menos tres grandes cambios en la gobernanza de los servicios públicos.

El primer cambio está relacionado con los indicadores incluidos en Panorama de las Administraciones Públicas y en la lógica que sigue su selección. Desde los años 80, el desempeño del sector público se ha equiparado con la economía, la eficacia y la efectividad (las tres es). Sin embargo, este enfoque basado en la lógica de consecuencias - donde los insumos se transforman en actividades, productos $\mathrm{y}$, finalmente, resultados deseados - es necesario, aunque no suficiente, para evaluar el rendimiento de las Administraciones. El sector público también debe actuar según la lógica de lo apropiado para así ser percibido como legítimo y fiable.

Esta lógica de lo apropiado enfatiza tres capas de lo que se considera apropiado. La primera se centra en los valores de comportamiento personal que los funcionarios públicos y civiles deben poner en práctica, es decir, lo apropiado a nivel individual. Esto se refleja en los códigos de conducta, que exigen un comportamiento ético por parte de los agentes de Estado y se muestra, por ejemplo, en los indicadores de conflictos de intereses y de normas de declaración de patrimonio para ciertos puestos. Otra capa sería lo apropiado a nivel sistémico y de organización, que incluye elementos de sostenibilidad, resiliencia y solidez del sistema. Mientras que inicialmente esto se reflejaba en indicadores relativos a gobierno abierto y receptivo, Panorama de las Administraciones Públicas ha extendido el concepto para incluir indicadores sobre el Estado de derecho, el rol de los centros de gobierno, la previsión estratégica y el liderazgo, la transparencia y la gestión del riesgo. Se ha añadido una tercera capa a la lógica de lo apropiado con el desarrollo de indicadores y capítulos sobre lo apropiado a nivel político, que se centra en la equidad, la igualdad, el gobierno inclusivo y la formulación de políticas integradoras. Esta última capa es especialmente relevante para entender los recientes debates políticos sobre reformas.

Así pues, a lo largo del tiempo, Panorama de las Administraciones Públicas ha conseguido que ambas lógicas (de consecuencias y de lo apropiado) sean visibles de manera significativa. 
El segundo cambio implica la manera de recolectar los datos. El movimiento de cocreación y coproducción también ha afectado a las ciencias sociales y su manera de manejar datos. Las ciencias participativas incluyen la cocreación de datos y el crowdsourcing ('colaboración masiva') en la recogida de datos. Por ejemplo, los nuevos tipos de datos e indicadores basados en encuestas de hogares por internet podrían generar nuevas formas de abordar la prestación de los servicios públicos y evaluar la satisfacción ciudadana. Combinar diferentes tipos de datos, como la estadística clásica con opiniones expertas y crowdsourcing, facilita la triangulación de datos e información. Combina, además, las características y virtudes de los datos con la propiedad a través de la participación. El tercer cambio está relacionado con la visión del papel del Estado, es decir, del sector público, en la sociedad. Existen dos visiones rivales sobre este papel. Por un lado, está el Estado minimalista con impuestos bajos y una prestación limitada de servicios; por otro, está un concepto de Estado más flexible, donde el sector público puede tener un rol y tamaño variables. El supuesto implícito en Panorama de las Administraciones Públicas parece ser que el tamaño, al fin y al cabo, no importa siempre y cuando el sector público desempeñe correctamente sus funciones y refleje positivamente las expectativas sociales. Cuando un sector público se considera una inversión en lugar de un gasto, y parte de la solución en lugar de un problema, existe la responsabilidad implícita de conseguir que funcione correctamente como actor importante de la economía. La horizontalidad de la gobernanza pública para la implementación de los 17 Objetivos de Desarrollo Sostenible (ODS) es un argumento adicional para posicionar Panorama de las Administraciones Públicas en el centro de atención, como un «faro» de los servicios públicos.

Geert Bouckaert 



\section{RESUMEN EJECUTIVO}

Aunque el crecimiento económico se va recuperando lentamente en el entorno de la OCDE, la reacción en contra de la globalización es real y las Administraciones públicas deben afrontarla. La confianza en las instituciones públicas es baja y la percepción de que las políticas públicas favorecen los intereses de determinados grupos ha aumentado drásticamente. Los ciclos económicos más cortos, los cambios tecnológicos y la innovación desestabilizadora han suscitado llamamientos a favor de reformas en los mercados laborales nacionales y en los sistemas de protección social, mientras que el cambio climático, la evasión fiscal y el terrorismo exigen la adopción de medidas concertadas a nivel global. La polarización política y la desconfianza de los ciudadanos en las instituciones públicas hacen impredecible la realización de estas reformas. Fortalecer y establecer el diálogo con los ciudadanos a través de procesos abiertos y participativos de formulación de políticas, y aumentar la capacidad de las Administraciones para elegir las políticas más apropiadas entre las diversas opciones, resultan medidas clave para reconectar a los Gobiernos con sus ciudadanos e impulsar un crecimiento más inclusivo y sostenible. Panorama de las Administraciones Públicas aporta las evidencias necesarias para dichas reformas de la gestión pública.

\section{Aunque la estabilización se mantiene, los niveles de deuda fiscal continúan siendo altos y la inversión pública ha disminuido}

- El déficit fiscal promedio alcanzó el 2,8\% del PIB en los países de la OCDE en 2015, una mejora con respecto al 8,4\% de 2009, que refleja la estabilización de las finanzas públicas tras la crisis financiera.

- El saldo estructural en los países de la OCDE mejoró de un -6,3\% del PIB potencial en 2009 a un $-2,4 \%$ en 2015 , que representa un retorno a las tendencias a largo plazo. 
- El promedio de la deuda bruta de las Administraciones públicas alcanzó en 2015 el 112\% del PIB en los países de la OCDE, con once países que alcanzaron niveles de deuda iguales o superiores al PIB.

- La inversión pública en 2015 alcanzó un promedio del 3,2\% del PIB, con un valor máximo del 6,7\% en Hungría y un valor mínimo del 1,5\% en Israel. Esto supone un descenso con respecto al 4,1\% registrado en 2009, cuando se introdujo la política de expansión fiscal. Un tercio de la inversión pública va dirigida a asuntos económicos, principalmente a transporte, seguido de defensa $(15,2 \%)$.

\section{Ha aumentado el gasto público en sanidad y protección social}

- Entre 2007 y 2015, el gasto público en los países de la OCDE aumentó más en protección social (2,6 p. p.) y sanidad (1,7 p. p.).

- Teniendo en cuenta que un tercio de los gastos de contratación pública se dedica a asistencia sanitaria, resulta esencial fomentar la transparencia y eficiencia de la contratación pública de productos farmacéuticos, tecnología y suministros médicos, con el fin de proporcionar servicios sanitarios a menor coste.

\section{El empleo público es en general estable, pero existen variaciones importantes a nivel nacional}

- Aunque muchos países de la OCDE presentan una reducción significativa del empleo en la Administración central debido a las medidas de austeridad poscrisis, el empleo en el sector público en relación con el empleo total en los países de la OCDE creció ligeramente entre 2007 y 2015, del 17,9\% al 18,1\%.

- Este promedio oculta variaciones entre los países. Donde más disminuyó el empleo público con respecto al empleo total entre 2007 y 2015 fue en el Reino Unido e Israel (más de 2,5 p. p.). Por el contrario, España, Estonia, Hungría, la República Checa y la República de Eslovenia experimentaron incrementos iguales o superiores a 2 p. p. durante el mismo periodo.

- Además, la ratio (empleo público en relación con el empleo total) oculta cambios en el empleo público en términos absolutos. De 2014 a 2015, el empleo público en Turquía creció un 3,9\%, mientras que en los Países Bajos cayó un 3,6\%. Estos cambios no se reflejan en la ratio ya que el empleo público cambió a un ritmo similar al del empleo total.

- En promedio, los altos funcionarios (D1) ganan un 27\% más que los funcionarios del nivel inmediatamente inferior (D2), un $72 \%$ más que 
los mandos intermedios (D3), más del doble que los mandos de nivel más bajo (D4) y 2,6 veces más que los profesionales de nivel alto. Esto sugiere que los incentivos para la obtención de responsabilidades directivas son significativamente mayores que para la especialización técnica. Los puestos de secretariado ganan en promedio 4 veces menos que los altos funcionarios D1.

\section{Las mujeres están infrarrepresentadas en los puestos públicos de liderazgo}

- De media, las mujeres representan solo el $29 \%$ de parlamentarios y el $28 \%$ de ministros de Gobierno en los países de la OCDE en 2017.

- De manera similar, aunque las mujeres representan el $58 \%$ del total de trabajadores del sector público, ocupan solo el $32 \%$ de los puestos superiores.

- La representación equitativa de las mujeres en la vida y empleo públicos a todos los niveles aumenta la reserva de talento disponible y contribuye a la capacidad organizativa.

\section{Las herramientas de rendimiento y las percepciones del comportamiento mejoran la eficiencia y efectividad del sector público}

- Casi todos los países realizan evaluaciones del rendimiento obligatorias a los empleados de la Administración pública central. Vincular el rendimiento con recompensas continúa siendo un desafío, y las prácticas de retribución por productividad o rendimiento permanecen estables desde 2010.

- Los análisis de gastos se utilizan cada vez más en los países de la OCDE para mejorar el control de gastos y su priorización. 22 países de la OCDE realizaron al menos un análisis de gastos entre 2008 y 2016, comparado con solo 5 entre 2000 y 2007.

- El uso de percepciones del comportamiento se está introduciendo en muchos países de la OCDE, principalmente para mejorar la implementación de políticas.

\section{Las iniciativas de gobierno abierto cobran impulso, pero se necesita más evaluación}

- Los países están institucionalizando cada vez más los principios de transparencia, rendición de cuentas y participación. Alrededor de la mi- 
tad de los países de la OCDE (17 de los 35 países) han adoptado una estrategia nacional de gobierno abierto.

- La mayoría de los países de la OCDE han adoptado una política de acceso abierto, mediante la cual todos los datos de las Administraciones públicas son de libre acceso, a no ser que exista una justificación legítima para lo contrario.

- Sin embargo, el grado en que los países favorecen la reutilización de datos tanto fuera de las Administraciones públicas (en hackáthones o eventos de cocreación) como dentro (en sesiones informativas o de formación) varía significativamente.

- Pocos países evalúan si las iniciativas de gobierno abierto logran el impacto deseado en el ámbito económico, social y de productividad y responsabilidad del sector público.

\section{Se necesita hacer más para restaurar la confianza en las Administraciones públicas y garantizar la accesibilidad de los servicios}

- La confianza en las Administraciones públicas permanece por debajo de los niveles anteriores a la crisis. En los países de la OCDE, una media del $42 \%$ de los ciudadanos afirmó tener confianza en su Gobierno nacional en 2016, comparado con el $45 \%$ en 2007.

- Existen persistentes desigualdades en el acceso, capacidad de respuesta y calidad de los servicios por grupos de población. En todos los países de la OCDE, las personas pertenecientes a grupos de bajos ingresos manifiestan tener más necesidades sanitarias insatisfechas que las personas de mayores ingresos. De manera similar, los estudiantes de entornos socioeconómicos desfavorables tienen casi tres veces más probabilidades de no alcanzar el nivel básico de competencia en ciencias.

- Las Administraciones públicas también deben prevenir la emergencia de nuevas formas de exclusión digital. Aunque el número de ciudadanos que utiliza los medios digitales para interactuar con las Administraciones va en aumento, hay deficiencias persistentes en los niveles de uso de internet que dependen del nivel educativo, lugar de residencia y edad. 


\section{GUÍA PARA EL LECTOR}

Para que el lector pueda interpretar de forma precisa los datos contenidos en Panorama de las Administraciones Públicas 2017, debe tener en cuenta las siguientes consideraciones metodológicas, que afectan a varios indicadores. El formato estándar para la presentación de indicadores es el siguiente. La primera parte de cada apartado contiene el texto que explica la relevancia del tema y destaca algunas de las principales diferencias que se observan entre los países de la OCDE. Le sigue una sección de «Metodología y definiciones», que describe las fuentes de datos y proporciona información necesaria para interpretarlos. Finalmente, esta primera parte contiene una sección de «Otras publicaciones», que cita literatura de utilidad para contextualizar los datos mostrados. La segunda parte presenta los datos que muestran los niveles actuales y, cuando es posible, las tendencias en el tiempo. En el capítulo final del libro puede encontrarse el glosario de las principales definiciones de la publicación.

\section{CALENDARIO FISCAL / AÑO FISCAL EN LOS DATOS DE CONTABILIDAD NACIONAL}

Salvo que se indique lo contrario, los datos de contabilidad nacional de la OCDE se refieren a años naturales.

Los datos de Australia y Nueva Zelanda se refieren a años fiscales: del 1 de julio del año indicado al 30 de junio para Australia, y del 1 de abril del año indicado al 31 de marzo para Nueva Zelanda. En el caso de Japón, los datos relativos a los subsectores de la Administración general y a los gastos por clasificación de las funciones del Gobierno (CFG) se refieren al año fiscal.

Los datos basados en el sistema de contabilidad nacional (SCN) fueron extraídos de las estadísticas de contabilidad nacional de la OCDE (base de datos) y de las estadísticas de finanzas públicas de Eurostat (base de datos) el 9 de mayo de 2017. 


\section{PAÍSES COMPRENDIDOS}

Panorama de las Administraciones Públicas 2017 incluye los datos de los 35 países miembros de la OCDE basándose en la información disponible. Los datos estadísticos relativos a Israel han sido suministrados por y bajo la responsabilidad de las autoridades israelíes competentes. El uso de estos datos por la OCDE no prejuzga la situación de los Altos del Golán, Jerusalén Este y los asentamientos israelíes en Cisjordania, en los términos de Derecho Internacional.

Algunos países que no pertenecen a la OCDE, como Colombia, Costa Rica, Lituania y la Federación Rusa ${ }^{1}$ (en proceso de adhesión a la OCDE), así como otras importantes economías del mundo (Brasil, India, Indonesia, la República Popular China y Sudáfrica), también han proporcionado datos para algunos indicadores. Los datos de los países no miembros se presentan por separado al final de las tablas e ilustraciones.

\section{CÓDIGOS DE ABREVIACIÓN}

\begin{tabular}{|l|c|l|c|}
\hline \multicolumn{1}{|c|}{ Países de la OCDE } & & & \\
\hline Alemania & DEU & Noruega & NOR \\
\hline Australia & AUS & Nueva Zelanda & NZL \\
\hline Austria & AUT & Países Bajos & NLD \\
\hline Bélgica & BEL & Polonia & POL \\
\hline Canadá & CAN & Portugal & PRT \\
\hline Chile & CHL & Reino Unido & GBR \\
\hline Corea & KOR & República Checa & CZE \\
\hline Dinamarca & DNK & República Eslovaca & SVK \\
\hline España & ESP & Suiza & CHE \\
\hline Estados Unidos & USA & Turquía & TUR \\
\hline Estonia & EST & & \\
\hline
\end{tabular}

${ }^{1}$ En relación con la Federación Rusa, el 12 de marzo de 2014, el Consejo de la OCDE propuso posponer de manera temporal las actividades relacionadas con su proceso de integración $(<\mathrm{http}: / / \mathrm{www}$. oecd.org/newsroom/statement-by-the-oecd-regarding-the-status-of-the-accession-process-with-russiaand-co-operationwith-ukraine.htm>). 


\begin{tabular}{|l|c|l|c|}
\hline Finlandia & FIN & \multicolumn{2}{|c|}{ Países en trámite de adhesión* } \\
\hline Francia & FRA & Colombia & COL \\
\hline Grecia & GRC & Costa Rica & CRI \\
\hline Hungría & HUN & Federación Rusa (en adelante, Rusia) & RUS \\
\hline Irlanda & IRL & Lituania & LTU \\
\hline Islandia & ISL & \multicolumn{2}{|c|}{ Otras economías importantes } \\
\hline Israel & ISR & \multicolumn{1}{|c|}{} \\
\hline Italia & ITA & $\begin{array}{l}\text { Brasil (participante del Comité de } \\
\text { Gobernanza Pública de la OCDE) }\end{array}$ & BRA \\
\hline Japón & JPN & India & IND \\
\hline Letonia & LVA & Indonesia & IDN \\
\hline Luxemburgo & LUX & $\begin{array}{l}\text { República Popular China (en adelante, } \\
\text { China) }\end{array}$ & CHN \\
\hline México & MEX & $\begin{array}{l}\text { Sudáfrica (participante del Comité de } \\
\text { Gobernanza Pública de la OCDE) }\end{array}$ & ZAF \\
\hline República de Eslovenia & SVN & Suecia & SWE \\
\hline
\end{tabular}

\section{PROMEDIOS Y TOTALES DE LA OCDE}

\section{Promedios}

En las ilustraciones, los promedios de la OCDE se presentan o como la media aritmética no ponderada o como la media ponderada de los países miembros de los que hay datos disponibles. No se incluyen los datos de los países no miembros. En las notas se mencionan los países miembros de la OCDE sin datos disponibles.

Cuando una ilustración recoge información relativa a uno o más años, el promedio de la OCDE incluye a todos los países miembros con datos disponibles. Por ejemplo, un promedio de la OCDE para el año 2009 presentado en esta edición incluye a todos los países actualmente miembros con información disponible para el año en cuestión, aunque no fueran miembros en ese momento.

En el caso de los datos de contabilidad nacional de la OCDE, los promedios se refieren a la media ponderada, a no ser que se indique lo contrario. Además, los promedios de la OCDE se calculan hasta el año 2015 ya que no todos los países de la OCDE (principalmente los países miembros no europeos) tienen datos disponibles para 2016. 


\section{Totales}

Los totales de la OCDE se recogen normalmente en las tablas y representan la suma de los datos en la columna correspondiente para los países de la OCDE de los que hay datos disponibles. Los totales no incluyen datos de los países no miembros. En las notas se mencionan los países miembros de la OCDE sin datos disponibles.

\section{SUPLEMENTOS ONLINE}

Hay varios indicadores para los que se incluyen tablas e ilustraciones complementarias en la página web que proporcionan datos concretos por país o anexos con información adicional sobre la metodología utilizada para el indicador. Cuando esta información está disponible, se menciona en la sección «Metodología y definiciones» del indicador. Panorama de las Administraciones Públicas 2017 también ofrece acceso a StatLinks, un servicio que permite a los lectores descargar los archivos Excel correspondientes a los datos presentados. StatLinks está disponible en la esquina inferior derecha de las tablas o ilustraciones y se puede introducir en el navegador de internet o, en una versión electrónica de la publicación, pinchar directamente.

De manera adicional, el siguiente material complementario está disponible online en <www.oecd.org/gov/govataglance $>$ :

- Fichas de datos nacionales que recogen datos clave por país en comparación con el promedio de la OCDE.

- La base de datos estadísticos Panorama de las Administraciones Públicas (Government at a Glance) que incluye datos actualizados periódicamente para una selección de indicadores a través de OECD.Stat y la publicación de datos cualitativos de las encuestas GOV a través de una plataforma web específica.

- Notas contextuales por país que presentan información descriptiva de algunas de las principales características de las estructuras políticas y administrativas de cada país miembro.

\section{INDICADORES PER CÁPITA}

Algunos indicadores (por ejemplo, de gastos, ingresos y deuda pública) se muestran per cápita. Las estimaciones de población subyacente se basan en el concepto de residencia del sistema de contabilidad nacional. Incluyen a las personas que residen en un país durante un año o más, independientemente de su nacionalidad, y también al personal diplomático extranjero y al personal de 
defensa junto con sus familias, a los estudiantes desplazados y a los pacientes que están recibiendo tratamiento fuera de su país, incluso si permanecen en el extranjero durante más de un año. Esta regla de un año significa que los residentes habituales que viven en el extranjero durante menos de un año están incluidos en la población, mientras que los visitantes extranjeros (por ejemplo, turistas) que se encuentran en el país durante menos de un año están excluidos. Es importante destacar en este contexto que las personas pueden figurar como trabajadores de un país (contribuyendo al PIB de ese país a través de la producción), pero como residentes en otro (de manera que sus sueldos y salarios están reflejados en el ingreso nacional bruto de su país de residencia).

\section{PARIDADES DE PODER ADQUISITIVO}

Las paridades de poder adquisitivo (PPA) son las ratios de conversión de moneda que equiparan el poder adquisitivo de los distintos países eliminando las diferencias entre los niveles de precios. Cuando se convierten por medio de las PPA, los gastos en todos los países se expresan, en efecto, dentro del mismo rango de precios, lo que significa que un mismo conjunto de bienes y servicios tendrá el mismo coste en todos ellos, lo que permite comparaciones que reflejan solo las diferencias en el volumen de bienes y servicios adquiridos.

Las PPA de las series actuales e históricas son producidas y actualizadas por la OCDE mediante un procedimiento específico.

Para los últimos años, los siguientes resultados de PIB, del consumo individual efectivo de los hogares (CIE) y del consumo individual de los hogares (CIH) fueron publicados en diciembre de 2016:

- Resultados finales del año 2013, cuartas estimaciones para el año 2014, terceras estimaciones para el año 2015.

- En febrero de 2017 se publicarán las primeras estimaciones para el año 2016.

Los datos históricos de las PPA hasta el año 2012 pueden ser revisados en diciembre de cada año para incorporar revisiones en los deflactores de contabilidad nacional. En diciembre de 2016, los datos históricos de las PPA de todos los países europeos hasta el año 2012 fueron revisados de manera excepcional.

Se puede encontrar más información sobre las series temporales históricas a continuación:

- 2008, 2011: las PPA de todos los países europeos y Rusia son resultados de referencia calculados de manera conjunta por la OCDE y Eurostat. 
- 2006-2007, 2009-2010, 2012: las PPA de los países europeos son resultados anuales de referencia proporcionados por Eurostat. Las PPA de los países no europeos y Rusia son estimaciones de la OCDE basadas en la extrapolación global.

Se puede encontrar más información sobre las PPA en la página web de la OCDE: <www.oecd.org/std/prices-ppp>.

\section{INDICADORES COMPUESTOS}

Esta publicación incluye varios índices compuestos descriptivos relativos a áreas estrictamente definidas y relacionadas con la gestión de recursos humanos, presupuestos por resultados, datos de gobierno abierto y gobernanza regulatoria. Estos indicadores compuestos son una manera práctica de resumir información cualitativa y diferenciada. Los indicadores compuestos que se presentan en esta publicación fueron creados de acuerdo con las medidas identificadas en la publicación Handbook on Constructing Composite Indicators (Nardo et al., 2008).

La información sobre las variables y ponderaciones utilizadas para elaborar los distintos indicadores compuestos está disponible en el Anexo E. Los indicadores compuestos se desarrollaron en cooperación con los países miembros y se basan en la teoría y/o en las mejores prácticas, mientras que las variables que se incluyen en los índices y sus pesos relativos se basan en opiniones expertas y, en consecuencia, pueden cambiar con el tiempo.

\section{SIGNOS Y ABREVIATURAS}

$\begin{array}{ll}\ldots & \text { Datos no disponibles } \\ \text { x } & \text { No aplicable (a menos que se indique) } \\ \text { p. p. } & \text { Puntos porcentuales } \\ \text { PPA } & \text { Paridades de poder adquisitivo } \\ \text { EUR } & \text { Euros } \\ \text { USD } & \text { Dólares de Estados Unidos }\end{array}$




\section{INTRODUCCIÓN}

La serie Panorama de las Administraciones Públicas tiene como objetivo proporcionar datos fiables y comparativos a nivel internacional sobre las actividades de las Administraciones públicas y sus resultados en países de la OCDE, así como en otros países. Estos datos pueden, a su vez, ser utilizados por los países como referentes de rendimiento de las Administraciones, como evidencia para la formulación de políticas públicas y para realizar un seguimiento del desarrollo nacional e internacional. Los indicadores de Panorama de las Administraciones Públicas se están convirtiendo en un estándar de medición en muchos ámbitos de la gestión pública. Además de los indicadores básicos que constituyen la seña de identidad de la publicación, esta quinta edición incluye una selección de indicadores nuevos y fuentes de datos adicionales, que permiten una visión más completa del trabajo y resultados de las Administraciones públicas en los países de la OCDE.

\section{NOVEDADES EN PANORAMA DE LAS ADMINISTRACIONES PÚBLICAS 2017}

Panorama de las Administraciones Públicas 2017 incluye capítulos centrales que se repiten en todas las ediciones además de capítulos y apartados nuevos. Los capítulos centrales de Panorama de las Administraciones Públicas son el capítulo 2, «Economía y finanzas públicas»; el capítulo 3, «Empleo y salarios públicos»; el capítulo 5, «Prácticas y procedimientos presupuestarios»; el capítulo 6, «Gestión de recursos humanos»; el capítulo 7, «Integridad del sector público»; el capítulo 8, «Gobernanza regulatoria»; el capítulo 9, «Contratación pública»; el capítulo 13, «Resultados básicos de las Administraciones públicas», y el capítulo 14, «Al servicio de los ciudadanos». Además de estos, la edición presenta una serie de capítulos y apartados, algunos nuevos y otros ya consolidados: 
- Dos capítulos nuevos tienen como tema central la innovación en el sector público y la gobernanza del riesgo. Ambos temas son esenciales para fomentar que las Administraciones aborden con éxito los retos de gobierno y las situaciones de crisis, al mismo tiempo que se benefician de los avances tecnológicos que facilitan acciones más eficientes y efectivas. El capítulo sobre la gestión del riesgo y la comunicación aporta información sobre cómo los países de la OCDE evalúan, previenen y responden al impacto de los riesgos críticos, incluyendo desastres naturales y otro tipo de riesgos. Se basa en dos nuevas encuestas de la OCDE sobre la comunicación del riesgo y la gestión de riesgos críticos. El capítulo sobre la innovación en el sector público contiene una visión general de los esfuerzos llevados a cabo por los países de la OCDE para promover la práctica de enfoques innovadores en las Administraciones públicas con el fin de que sean más abiertas, colaborativas y participativas.

- Panorama de las Administraciones Públicas 2017 se apoya en una amplia gama de datos nuevos sobre la gestión de recursos humanos, y empleo y salarios públicos. Esta comprende:

- Una actualización de la Encuesta sobre gestión estratégica de recursos humanos e indicadores compuestos (presentados por última vez en 2011) que incluyen temas tratados previamente, como la delegación en la gestión de recursos humanos, la gestión del desempeño laboral y las prácticas establecidas para el funcionariado de alto rango, así como nuevos ámbitos tales como la gestión de recursos humanos basada en evidencias;

- Una actualización de la Encuesta sobre la remuneración de los empleados en las Administraciones centrales/federales (presentada por última vez en 2013), que recoge información sobre los salarios de los empleados y las cotizaciones de los empleadores en distintos sectores ocupaciones.

- Nuevos datos de encuesta sobre la composición laboral de las Administraciones centrales/federales por sector ocupacional, edad y género.

- Esta edición también aporta nuevos indicadores compuestos que proporcionan una visión de las prácticas por país en ámbitos específicos de gestión pública. La actualización del indicador compuesto de datos de gobierno abierto proporciona información sobre el nivel de disponibilidad, accesibilidad y apoyo de las Administraciones públicas para la reutilización de datos. Se basa en la Carta Internacional de Datos Abiertos y en el marco analítico desarrollado por la OCDE. Los indicadores de política y gobernanza regulatoria (iREG) se muestran por primera vez en el capítulo sobre la gobernanza regulatoria. Proporcionan información sobre las prácticas existentes en los países de la OCDE en materia de evaluación del impacto regulatorio (EIR), participación de las partes 
interesadas y evaluación ex post de la normativa, y se apoyan en la $R e$ comendación del Consejo de la OCDE sobre política y gobernanza regulatoria de 2012.

- La publicación también proporciona una serie de indicadores nuevos sobre diferentes aspectos de la gestión pública. El capítulo sobre las instituciones ofrece datos recientes de los sistemas de asesoramiento político y del papel del centro de gobierno en la implementación de los Objetivos de Desarrollo Sostenible (ODS) en los países de la OCDE. El capítulo sobre gobierno abierto incluye nuevos indicadores relativos a las estrategias de gobierno abierto de los países de la OCDE, el entorno propicio para su implementación y la participación ciudadana. Otros indicadores cubren aspectos como la infraestructura de la gobernanza desde una perspectiva presupuestaria y de la contratación pública, los presupuestos con perspectiva de género, así como ámbitos innovadores en la gobernanza regulatoria, como pueden ser el uso de las percepciones del comportamiento y la cooperación regulatoria internacional entre organizaciones.

- Finalmente, para destacar el creciente interés en resultados, esta edición presenta por primera vez tablas de puntuación de servicios a los ciudadanos que comparan los niveles de acceso, capacidad de respuesta y calidad de la sanidad, educación y del sistema judicial.

\section{DEFINICIÓN DE ADMINISTRACIONES PÚBLICAS}

Los datos de las finanzas públicas se basan en la definición de Administración general que se puede encontrar en el sistema de contabilidad nacional (SCN). Por consiguiente, la Administración general comprende los ministerios/ departamentos, organismos, oficinas y algunas instituciones sin ánimo de lucro a nivel central, estatal y local, así como las entidades de la seguridad social. Se presentan datos sobre ingresos y gastos de la Administración a nivel central y subcentral (estatal y local) y, en su caso, de las entidades de la seguridad social. Sin embargo, los datos de empleo se refieren al sector público y, por tanto, incluyen también las corporaciones públicas, como bancos de propiedad pública, puertos y aeropuertos. Por último, los datos sobre las prácticas y procesos de gestión pública recogen solo información de la Administración a nivel central.

\section{MARCO Y ESTRUCTURA DE LA PUBLICACIÓN}

Panorama de las Administraciones Públicas comprende los 35 países miembros de la OCDE, y contiene datos de los países en trámite de adhesión (Colombia, Costa Rica, Lituania y Rusia), así como de otras economías 
importantes como Brasil, China, India, Indonesia y Sudáfrica, que juegan un papel cada vez más decisivo en la economía mundial y en las estructuras políticas internacionales.

Esta quinta edición de Panorama de las Administraciones Públicas incluye información de contexto y de los insumos, procesos, productos y resultados. El Gráfico 0.1 presenta el marco conceptual de Panorama de las Administraciones Públicas.

\section{Gráfico 0.1. Marco conceptual de Panorama de las Administraciones Públicas 2017}

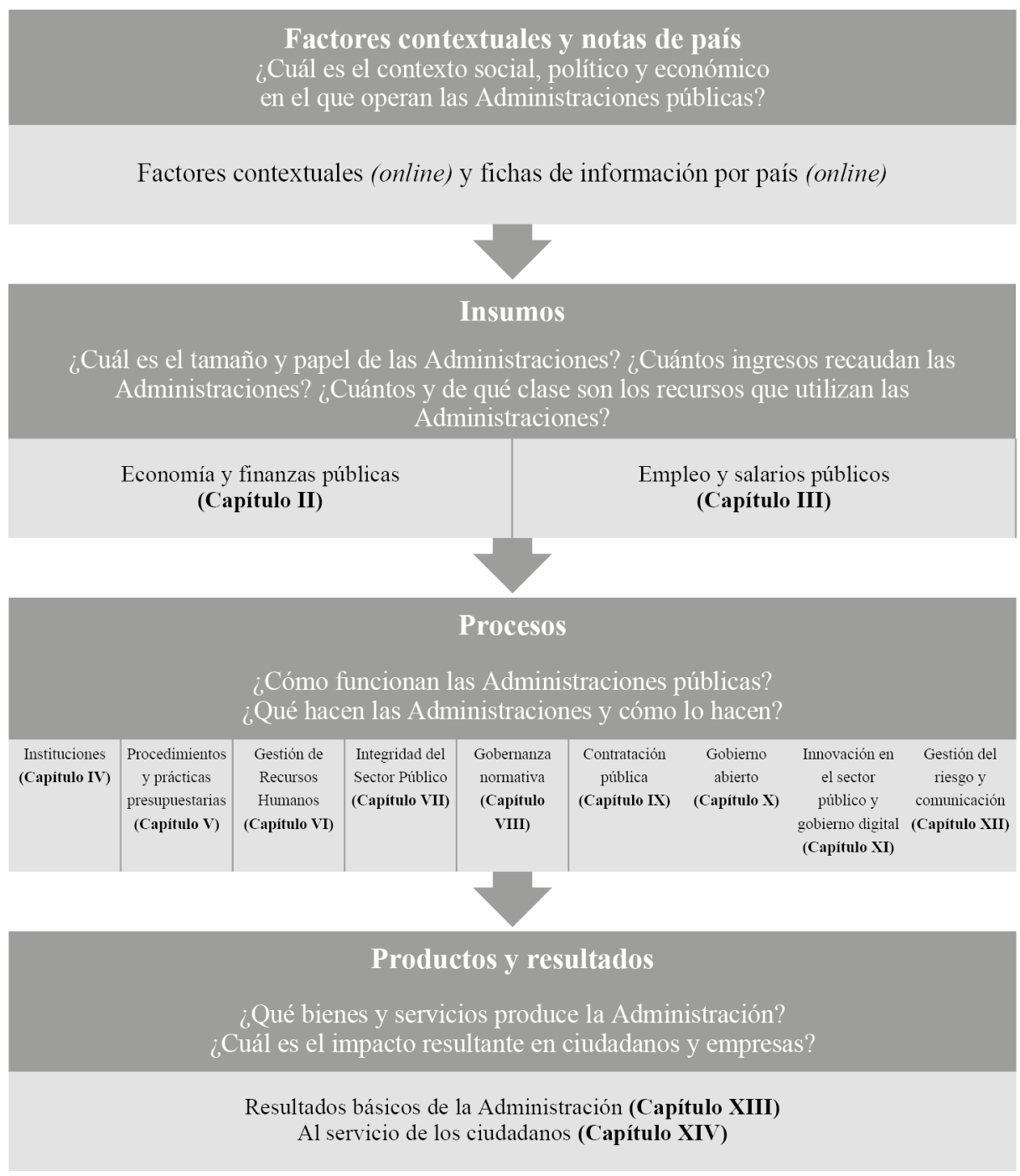




\section{Contexto}

Los factores contextuales (online) ofrecen información sobre las características clave de las estructuras políticas y administrativas de cada país de la OCDE. Tener en cuenta esta información permite entender las principales diferencias y similitudes institucionales entre países y, por tanto, identificar comparadores a título de referencia. Además, las fichas de información nacional (online) proporcionan antecedentes históricos de cada país que explican la relevancia de los datos de Panorama de las Administraciones Públicas en el contexto específico de las reformas del sector público, tanto en los países de la OCDE como en otros en proceso de adhesión.

\section{Insumos}

El término insumos se refiere a los recursos utilizados por las Administraciones en su función de producción, así como la forma en que se combinan; estos recursos corresponden a mano de obra y capital. Los capítulos que describen estos insumos son «Economía y finanzas públicas» y «Empleo y salarios públicos», e incluyen indicadores de los gastos de las Administraciones públicas, costes de producción, empleo, y de la composición laboral del sector público. Las diferencias entre estos indicadores pueden ayudar a entender las distintas capacidades de las Administraciones públicas en materia de producción y prestación de bienes públicos a los ciudadanos.

\section{Procesos}

Los procesos se refieren a las prácticas y procedimientos de gestión pública llevados a cabo por las Administraciones públicas para implementar las políticas, es decir, a las formas y maneras utilizadas para cumplir con sus deberes y conseguir sus metas. En consecuencia, a menudo son esenciales para garantizar el Estado de derecho, la responsabilidad y la imparcialidad, así como la transparencia de las actividades administrativas. Las reformas del sector público suelen tener como finalidad la mejora de los procesos y, por tanto, captan la atención del público. Esta edición incluye información sobre las instituciones de las Administraciones públicas, las prácticas y procedimientos presupuestarios, la gestión de recursos humanos, integridad del sector público (sistemas de integridad pública, de control interno y de gestión del riesgo), gobernanza regulatoria, contratación pública, gobierno abierto, la innovación en el sector público, y sobre la gestión del riesgo y la comunicación. 


\section{Productos y resultados}

La línea divisoria entre productos y resultados puede ser borrosa. Mientras que los productos son la cantidad de bienes y servicios producidos por los Gobiernos, los resultados muestran los efectos de las políticas y prácticas en los ciudadanos y empresas. El éxito de una política específica se debe medir, en una primera fase, sobre la base de los productos resultantes, pero a largo plazo debe ser juzgado por los resultados conseguidos. En general, los resultados se refieren a los efectos de los programas y servicios públicos en los ciudadanos, en términos de aumento de bienestar, beneficios para la salud, mejoras educativas / de aprendizaje, etc. Sin duda, estos resultados se ven afectados por la calidad de los programas y servicios proporcionados, aunque también hay que tener en cuenta otros factores de impacto, como el entorno socioeconómico de la población y el comportamiento individual de las personas.

Panorama de las Administraciones Públicas 2017 proporciona medidas de productos y resultados en dos capítulos distintos:

- El capítulo «Resultados básicos de las Administraciones públicas»se centra en aspectos relativos al conjunto de las Administraciones, tales como la confianza de los ciudadanos en su Gobierno nacional, la percepción de la corrupción, el Estado de derecho, la redistribución de ingresos y las mediciones de eficiencia del sector público (basadas en los productos) y su rentabilidad (basada en los resultados).

- El capítulo «Al servicio de los ciudadanos» sigue un enfoque sectorial para la medición de los productos y resultados de las actividades del sector público. Sobre la base de un marco consolidado desarrollado horizontalmente con otras direcciones de la OCDE y en colaboración con sus países miembros, el capítulo proporciona medidas de los servicios a los ciudadanos en términos de acceso, capacidad de respuesta y calidad. La edición de este año se centra en tres sectores: sanidad, educación y el sistema judicial.

\section{ACTIVIDADES FUTURAS}

Para elaborar Panorama de las Administraciones Públicas, la OCDE trabaja en estrecha colaboración con otras organizaciones, como la Organización Internacional del Trabajo (OIT), el Proyecto Justicia Mundial, la Comisión Europea para la Eficiencia de la Justicia (CEPEJ), Gallup y la Comisión Europea, con el fin de proporcionar una visión integral de lo que hacen las Administraciones públicas y de cómo lo hacen, y evitar la duplicación en la recogida de datos. 
Debe fortalecerse la cooperación como forma de garantizar la comparabilidad de los datos de los países comprendidos en la publicación.

El equipo de Panorama de las Administraciones Públicas está trabajando en los siguientes puntos para las próximas ediciones de la publicación:

- Proporcionar nuevos indicadores compuestos en el ámbito de prácticas y procedimientos presupuestarios.

- Actualizar y aumentar los datos recogidos de gobernanza regulatoria, incluyendo del marco institucional para la política regulatoria.

- Repetir la recogida de datos relativos a las instituciones del centro de gobierno.

- Desarrollar nuevos indicadores que midan la implementación de las Recomendaciones del Consejo para el Desarrollo de Estrategias de Gobierno Digital de 2014.

- Reforzar los indicadores de gobierno abierto y de prácticas participativas de formulación de políticas, así como de la innovación en el sector público.

\section{EDICIONES REGIONALES Y NACIONALES DE PANORAMA DE LAS ADMINISTRACIONES PÚBLICAS}

La segunda edición de Panorama de las Administraciones Públicas: América Latina y el Caribe se publicó en diciembre de 2016. La edición proporciona los últimos datos disponibles de las Administraciones públicas de esta región y la compara con los países de la OCDE. Contiene indicadores nuevos de finanzas públicas, centros de gobierno, gobernanza regulatoria, gobierno abierto, gobierno digital y contratación, además de un apartado especial sobre presupuestos para sanidad.

En junio de 2016 se publicó la segunda edición nacional de Government at a Glance: How Korea Compares, que aporta una serie de indicadores sobre las prácticas de formulación de políticas en Corea y sobre el desempeño de sus Administraciones en comparación con otros países de la OCDE y con los países del G7. La primera publicación de la edición regional Government at a Glance: Southeast Asia está prevista a finales de 2017. 


\section{TODOS LOS DATOS E INDICADORES SOBRE GOBERNANZA PÚBLICA ESTÁN DISPONIBLES ONLINE}

Todos los datos recogidos por la Dirección de Gobernanza Pública de la OCDE para la elaboración de Panorama de las Administraciones Públicas (a partir de la edición de 2015) y para otros fines están disponibles online en la página web de la OCDE. Se anima a los lectores interesados a usar los datos presentados en esta publicación para su posterior análisis e investigación, y a consultar online la documentación completa de definiciones, fuentes y métodos presentados en Panorama de las Administraciones Públicas. Esta base de datos incluye indicadores tanto cualitativos como cuantitativos sobre los insumos, procesos, productos y resultados del sector público y se actualiza de forma regular a medida que hay nuevos datos disponibles. 


\section{CAPÍTULO 1. \\ ADOPTAR EL CAMBIO CONTINUO EN LAS \\ ADMINISTRACIONES}

\section{INTRODUCCIÓN}

Los Gobiernos nacionales de los países de la OCDE se enfrentan a un entorno político, económico y social cada vez más impredecible y complejo, que va más allá de las fronteras nacionales. Muchos trabajan bajo presión para contrarrestar el impacto de la globalización y dar respuesta a las reacciones críticas de amplios sectores de la población. Están llamados a liberar a las economías nacionales de la trampa actual del bajo crecimiento mediante un aumento de la productividad, garantizando al mismo tiempo que los resultados - en términos de trabajo e ingresos - se distribuyan de manera más equitativa entre la población. Se espera que den respuesta a los efectos desestabilizadores del cambio tecnológico. El envejecimiento de la población, la alta tasa de desempleo juvenil y los elevados niveles de deuda pública persistentes, junto con los actuales retos políticos $-\mathrm{y}$ la falta de respuestas adecuadas - han llevado a la polarización y fragmentación de la opinión pública con respecto a una serie de problemas sociales, como la integración económica y el control de flujos migratorios.

Las Administraciones públicas están en un continuo proceso de reforma para ser más efectivas, eficientes, abiertas y receptivas a los desafíos políticos. Pero ¿obtienen las reformas los resultados esperados? Las evidencias sobre el impacto de los paquetes de reforma integral introducidos en varios países de la OCDE en respuesta a la crisis de 2008 sugieren que, a pesar de las medidas de austeridad y de los recortes en gastos y programas, el endeudamiento de las Administraciones no ha disminuido demasiado. Por otro lado, el empleo público y salarios se mantienen, en general, estables en los países de la OCDE, pese a los importantes recortes realizados en los países más afectados. Al mismo tiempo, la recuperación económica no ha hecho más que comenzar en varios países miembros, y el desempleo, especialmente entre los jóvenes, sigue siendo alto. Aunque esto se puede atribuir en parte al legado de la crisis, la situación se ve agravada por la percepción de que las reformas de los Gobiernos 
no son efectivas ni se implementan adecuadamente, y no tienen en cuenta a los probables ganadores y perdedores.

Todo esto plantea la duda de si las reformas se diseñan en función de la creciente complejidad y se combinan e implementan adecuadamente. Los 1lamados problemas perversos - es decir, problemas que se caracterizan por la incertidumbre y complejidad, por los valores divergentes y procesos independientes - no se pueden abordar mediante soluciones parciales o transaccionales, sino que requieren enfoques concertados, adaptables y cuidadosamente dirigidos (OCDE, 2017c). El cambio climático, la globalización, los cambios demográficos y los avances tecnológicos han dado lugar a problemas políticos cuyas causas y efectos son difíciles de identificar, y que no se pueden abordar a través de los esfuerzos de un único actor o sector político. Este entorno político, económico y social de incertidumbre conlleva varios retos para las Administraciones y su modus operandi. Los procesos de formulación de políticas también se han tornado más complejos, con un creciente número de participantes no tradicionales que provienen de la sociedad civil, interrogantes sobre el impacto que tiene el dinero y otro tipo de influencias en la dirección política. La polarización de la opinión pública se refleja en la fragmentación política, con el establecimiento de Gobiernos en minoría o de coalición en varios países de la OCDE que tienen menor poder de intervención. Por otro lado, los responsables políticos tienen que elegir, entre innumerables opciones, las correctas para enfrentar estos y otros desafíos políticos, a menudo sin la oportunidad de valorar adecuadamente todas sus consecuencias. Frente a estos retos, los enfoques y reformas parciales, diseñados de manera aislada, ya no son suficientes.

Este capítulo sostiene que el enfoque tradicional de reforma resulta cada vez menos relevante en un contexto global lleno de desafíos políticos, cada vez más fluido y complejo. Además, sin procesos abiertos y participativos, los enfoques tradicionales de reforma pueden ser capturados por intereses privados o incluso por miembros de las Administraciones públicas que se resisten a los nuevos modelos de trabajo. Por el contrario, los Gobiernos tienen que preparar a sus Administraciones públicas para el cambio continuo, identificando claramente los resultados deseados y las medidas de progreso, estableciendo sistemas que promuevan la innovación y colaboración para alcanzar los objetivos y fomentando la transparencia y la coproducción con empresas y sociedad, con el fin de garantizar que el sector público continúe trabajando para el bien común. Esta quinta edición de Panorama de las Administraciones Públicas contiene una serie de parámetros clave que apoyan el cambio en los sistemas de gobierno y la formulación de políticas basadas en resultados. 


\section{LOS RETOS... Y DEFICIENCIAS DE LA REFORMA DEL SECTOR PÚBLICO}

\section{1. ¿Se necesita un nuevo enfoque que ayude a las Administraciones públicas a adaptarse al cambio?}

Los Gobiernos están en un proceso continuo de reforma. Aunque la palabra se utiliza de manera muy general y puede significar cualquier cambio llevado a cabo por las Administraciones en materia de políticas públicas y prácticas de gestión, existen sin embargo muchas razones que motivan las reformas. La más obvia es el contexto de cambio en el que operan las Administraciones, que conlleva cambios en las políticas y prácticas que aplican. Los cambios en el contexto pueden ser debidos al entorno económico o social, o a la tecnología. A menudo proceden del cambio político; por ejemplo, cuando un nuevo partido político llega al poder después de elecciones y recibe el mandato del electorado de aplicar nuevas soluciones políticas a los problemas existentes. Las reformas también pueden ser necesarias cuando las soluciones actuales no funcionan debido a su diseño defectuoso. A menudo también, las reformas provienen de la imitación y aprendizaje entre iguales: muchas de las nuevas prácticas de gestión pública se extendieron de esta manera durante los años 80 y 90, y las organizaciones internacionales —incluida la OCDE- jugaron un papel importante en su expansión. Algunas reformas surgen de la difusión de ideologías, como las que reflejan las políticas de Thatcher y Reagan, o de modas en las prácticas de gestión. Por último, a veces se plantean problemas que precisan nuevas formas de intervención política.

Pero es posible que los enfoques tradicionales de reforma del sector público ya no sean capaces de adaptarse a un mundo complejo, interdependiente y en cambio continuo. En primer lugar, porque, en un contexto caracterizado por ciclos económicos más cortos impulsados por innovaciones desestabilizadoras, los Gobiernos necesitan tener una capacidad de respuesta mucho más rápida a los nuevos desafíos y a las exigencias de los ciudadanos, empresas y sociedad civil. Esto requiere previsión y liderazgo efectivos para anticipar los nuevos retos, e incluir, por ejemplo, la regulación de las nuevas tecnologías, como la inteligencia artificial, el big data y la economía colaborativa, y también agilidad para integrar los nuevos modelos de trabajo y las tecnologías en las prácticas de gobierno. La incapacidad en las Administraciones de adaptarse al cambio continuo y a la flexibilidad puede reforzar la percepción de la gente de que los Gobiernos siempre van por detrás de los avances sociales. Al mismo tiempo, las Administraciones deben satisfacer las expectativas de adaptación rápida y constante, con la práctica de una formulación de políticas más inclusiva que ofrezca, en sus primeras fases de proceso, información y acceso a una amplia gama de interesados.

En segundo lugar, a medida que crece la comprensión mundial sobre los problemas complejos, se está llegando a un consenso sobre el fracaso de las 
reformas parciales desarrolladas de manera aislada a nivel sectorial y nacional para lograr resultados a largo plazo. Abordar algunos de los Objetivos de Desarrollo Sostenible (ODS) relacionados con el cambio climático o la igualdad de género, y también problemas como la evasión fiscal, requiere reformas diseñadas e implementadas en todas las funciones y sectores políticos (por ejemplo, integrar la igualdad de género en las prácticas y procedimientos presupuestarios, en la evaluación del impacto regulatorio, en la contratación pública y en la gestión de recursos humanos) en estrecha sinergia con la comunidad internacional. En lugar de avanzar de manera lenta y estable, las Administraciones públicas deben guiarse por objetivos políticos claros para dar respuesta a cambios rápidos y constantes y a los nuevos retos políticos.

Puesto que las reformas invariablemente conllevan ganadores y perdedores, la influencia indebida que ejercen ciertos grupos de interés en la formulación de políticas puede disminuir el grado en que las reformas se diseñan e implementan para el bien público. Las reformas pueden también no llegar a ponerse en práctica debido a intereses creados y a la resistencia al cambio, por ejemplo, para proteger límites y responsabilidades institucionales. Este tipo de comportamientos derivan en reformas fragmentadas y partidistas que debilitan aún más la confianza de la población y reducen la capacidad de efectuar nuevas reformas. Cuanto más se limita el número de participantes en los procesos de formulación de políticas, más se fomenta que las reformas resultantes reflejen solo los intereses de unos pocos. La apertura de los procesos y su alineación con los resultados, de manera pública y visible, permiten ir más allá de los intereses creados y ayudan a mitigar la captura política, desde dentro y fuera de las Administraciones públicas. Esto ayuda a superar barreras que obstaculizan el servicio al interés público, como la incapacidad de colaborar u obvios conflictos de intereses. En el actual ambiente de creciente desigualdad y descontento político, la captura por parte de poderosos grupos de interés puede socavar los procesos democráticos fundamentales de toma de decisiones justas basadas en la apertura, el diálogo y el consenso (OCDE, 2017d).

\section{Los problemas complejos e interdependientes requieren enfoques de pensamiento sistémico para evitar la captura por parte de los procesos y sectores existentes}

La búsqueda de maneras de anticipar y gestionar los cambios está dando lugar a enfoques sistémicos, que analizan los distintos elementos del sistema que subyace al problema político, así como las dinámicas e interacciones de estos elementos que producen un resultado específico. El término enfoques sistémicos implica un conjunto de procesos, métodos y prácticas que tienen como objetivo un cambio de sistema (OCDE, 2017c). Este análisis holístico se centra en el impacto y resultados de las políticas, y va más allá de la lógica lineal insumo-producto-resultado de los enfoques tradicionales de diseño de políticas. Destaca la participación de todos los actores afectados dentro y fue- 
ra de las Administraciones públicas, así como la importancia de dar cabida a procesos iterativos para tener en cuenta la incertidumbre asociada a los problemas perversos.

Los enfoques tradicionales de formulación de políticas tienden a descomponer los problemas complejos en sus partes constituyentes para, posteriormente, abordar cada parte mediante intervenciones políticas aisladas. Estos enfoques pueden ser incapaces de captar la complejidad de las interrelaciones y la naturaleza cambiante de los problemas políticos que transcienden fronteras administrativas y territoriales. Es más, décadas de reformas del sector público superpuestas unas encima de otras a menudo no han logrado los efectos deseados y pueden conllevar políticas incoherentes e incluso contradictorias.

Los enfoques sistémicos no precisan necesariamente que todos los elementos del sistema sean cambiados, sino más bien una amplia perspectiva sistémi$c a$ del problema en cuestión y de los factores causantes, así como una evaluación basada en objetivos de las posibles soluciones. Estos enfoques son especialmente útiles en casos en los que existe discordancia entre la estructura de las Administraciones públicas y la estructura del problema. En estos casos, el problema se puede solucionar rompiendo el aislamiento de las unidades administrativas, es decir, con la participación de los actores y conocimientos de los distintos ámbitos políticos y sectores del Gobierno. Eliminar el aislamiento no solo implica el trabajo transversal de las carteras existentes, también requiere cambiar las carteras en su totalidad para crear estructuras permanentes y horizontales de carácter menos jerárquico. Por ejemplo, Bélgica ha creado un servicio público federal que agrupa las funciones de recursos humanos, integridad, gestión, presupuestos, contabilidad y contratación pública en un solo órgano que presta servicio a todas las organizaciones federales.

Los enfoques sistémicos ponen gran énfasis en las necesidades, opiniones y mentalidades de los usuarios, y permiten una comprensión de los ciudadanos como coproductores y codiseñadores de las políticas y servicios de las Administraciones. Los enfoques sistémicos pueden resultar especialmente útiles para la mejora de las prestaciones de los servicios públicos en ámbitos como el cuidado de mayores, la movilidad o la educación, y pueden incluso mejorar la gestión de la vida pública facilitando, por ejemplo, la reorganización de departamentos y organismos (OCDE, 2017c), o la implementación de los Objetivos de Desarrollo Sostenible (ODS).

Incluso cuando las organizaciones públicas tienen un entendimiento claro de los objetivos que se han establecido y de las medidas pertinentes para su ejecución, pueden carecer de la agilidad estratégica necesaria para cambiar su forma de trabajar. Desarrollada por primera vez en el sector privado, la agilidad estratégica consta de tres componentes: sensibilidad estratégica, unidad de liderazgo y fluidez de recursos. Aplicar estos componentes al sector público significa garantizar que los Gobiernos pueden anticipar y planear los desa- 
fíos futuros, alinear las políticas en la Administración pública para compartir objetivos estratégicos comunes y el interés público y reubicar los recursos a medida que cambian las necesidades. Esto precisa un cambio interno de las estructuras, procesos y culturas organizativas, así como cambios en las formas que tienen las Administraciones públicas de interactuar con los ciudadanos y empresas. Estos cambios, a su vez, requieren nuevas capacidades ya que los funcionarios deberán tomar decisiones personales sobre cómo lograr resultados en un entorno menos jerárquico y más tecnológico.

Dentro de las organizaciones, la capacidad de aumentar la agilidad estratégica depende de procesos más abiertos, basados en evidencias, e iterativos. El Observatorio de la OCDE de Innovación en el Sector Público (OPSI, por sus siglas en inglés) ha presentado un marco para la transformación sistémica en el sector público que especifica una serie de elementos interconectados que las Administraciones públicas deben tener en consideración (OCDE, 2017c; véase el Gráfico 1.1).

\section{Gráfico 1.1. Elementos clave de un proceso de transformación sistémico}
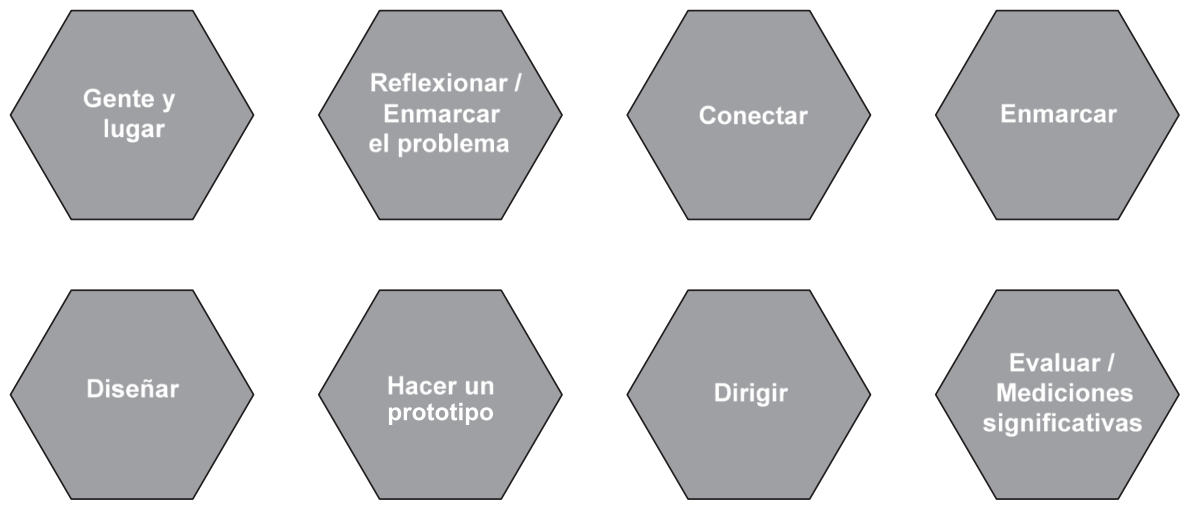

Fuente: Representación propia basada en la OCDE, 2017c.

- Gente y lugar: un requisito clave para iniciar un cambio sistémico es tener un equipo interdisciplinar de expertos, tanto de las Administraciones como externos, motivados en la mejora substancial del sistema y que dispongan de un entorno de trabajo adecuado.

- Reflexionar, conectar y enmarcar: dedicar tiempo y recursos para una mejor compresión y estudio del problema desde distintos ángulos permite definir con precisión los propósitos y objetivos del cambio sistémico previsto. Conectar con un conjunto diverso de interesados y 
ciudadanos es también esencial para obtener percepciones valiosas. Esto da, además, legitimidad al proceso de cambio e involucra a las partes interesadas, dándoles la oportunidad de reflexionar sobre el problema sin presentar soluciones preconcebidas.

- Diseñar y hacer un prototipo: mientras que el método concreto se ha de elegir según el contexto específico, el proceso de diseño debe especificar los elementos principales de la solución propuesta y las acciones que se deben llevar a cabo para obtener el resultado deseado. El diseño también debe ser testado para obtener evidencia adicional sobre el problema en cuestión y sobre los efectos de la intervención, con el fin de mejorar la solución propuesta.

- Dirigir (stewarding): del inglés stewardship ('administración'), en este contexto se refiere a una forma de liderazgo ágil o liderazgo transformador que guía y monitoriza la implementación del diseño propuesto, y adapta y calibra la solución en función del desarrollo, nueva información e imprevistos que puedan surgir durante la puesta en marcha. Esto exige una distribución equitativa de los recursos entre las fases de diseño e implementación del proyecto de cambio sistémico.

- Evaluar: evaluar los esfuerzos de la transformación sistémica puede resultar difícil, ya que los procesos pueden ser largos y progresivos. Así como en las primeras fases del proyecto de cambio sistémico, se deben tener en cuenta diversas fuentes de evidencia. La evaluación es útil para calibrar si el proyecto tiene el efecto deseado, aunque también es una parte esencial del proceso de cambio sistémico, ya que los resultados guían las actividades cotidianas de los implementadores hacia la consecución del cambio.

Las siguientes secciones de este capítulo describen los pilares base para el éxito en la implementación del enfoque sistémico, tomando como punto de partida la necesidad de visión y liderazgo del centro, mediante prácticas que ayuden a reunir evidencias relevantes y a potenciar la capacidad de sus trabajadores para actuar sobre estas pruebas, y liberando el sistema para estimular la innovación. En lugar de adoptar un enfoque tecnocrático en la formulación de políticas, el enfoque sistémico precisa la participación de los ciudadanos y partes interesadas, en un contexto de transparencia, rendición de cuentas y datos abiertos. Por último, puesto que los desafíos políticos tienen un alcance cada vez más global, este capítulo incluye algunas propuestas que ofrecen soluciones globales. Los indicadores de esta edición de Panorama de las Administraciones Públicas se utilizarán para poner de relieve la postura de los países en relación con estas prácticas. 


\section{Cuadro 1.1. Reforma de los servicios de protección del menor en los Países Bajos mediante un enfoque sistémico}

La organización Jeugdbescherming Regio Amsterdam (en español 'Servicios de Protección de la Infancia y de la Juventud del área de Ámsterdam') de los Países Bajos cuida 10000 niños en riesgo al año con la ayuda de un equipo de 600 trabajadores. En 2008 se impuso una estrecha supervisión del centro, ya que no cumplía su misión principal de evaluar los riesgos de niños en situación de vulnerabilidad y proporcionar la ayuda oportuna. En 2011 se llevó a cabo un amplio y nuevo diseño de la organización bajo el eslogan «Todos los niños seguros». Se otorgó autoridad a un grupo central de diez trabajadores sociales, dos responsables de equipo, dos psicólogos y un asesor formado en el método vanguard ${ }^{1}$, para reformar los procesos internos del centro.

En tres meses, el grupo llevó a cabo las fases de chequear, planear y hacer del método vanguard e implementaron un nuevo método de trabajo. El chequeo mostró que la organización estaba dividida en distintas funciones aisladas: asistentes sociales trabajando con padres de manera voluntaria, tutores legales con responsabilidad sobre los niños, y funcionarios trabajando con delincuentes juveniles en libertad vigilada. No existía, por tanto, un punto de contacto con las familias, y los trabajadores sociales no tenían claro quién debía actuar cuando había indicios de situaciones de peligro. Los trabajadores sociales seguían los protocolos establecidos y presentaban los informes pertinentes, en ningún caso fundamentales para la misión del centro: garantizar la seguridad de los niños. En la fase de planificación, se consideraron nuevos principios básicos de actuación: un trabajador social se encargaría de toda la unidad familiar y establecería comunicación directa con todos sus miembros (servicios de vigilancia familiar funcional), y se fijarían fases de intervención. El modelo de trabajo aislado fue suprimido y se introdujo el trabajo en equipo organizado en torno a posibles casos. Los esfuerzos se centraron en la intervención temprana y en el cuidado holístico de toda la familia.

Tras completar el análisis inicial, se formaron tres equipos similares de voluntarios que debían poner en práctica las conclusiones alcanzadas en un periodo de tres semanas, y que se vieron inmersos en su propio proceso de aprendizaje. Esto fue seguido de una fase de puesta en marcha en la que 40 equipos comenzaron el proceso de reforma, llevando a cabo las fases de chequear, planear y hacer. Esta fase duró un año completo y supuso cambios adicionales a los servicios de apoyo, instalaciones, etc.

El proceso superó con creces las expectativas iniciales: mejoró la calidad del servicio público y redujo sus costes. Por ejemplo, el número de niños que tuvieron que ser separados de sus familias se redujo en un $50 \%$. Los cambios supusieron, además, un ahorro de gastos de 30 millones de euros anuales. En 2015, Jeugdbescherming Regio Amsterdam fue elegida Mejor Organización del Sector Público de los Países Bajos.

A pesar de las mejoras en su trabajo, la organización se enfrentó a varios desafíos en la implementación y seguimiento del proceso de cambio sistémico. Resultó difícil encontrar el personal adecuado para realizar el enfoque basado en objetivos. En total, alrededor de un $40 \%$ de los trabajadores abandonaron su empleo durante el proceso 
de cambio, y la rotación actual de personal, del $20 \%$, es elevada. Para dar solución a estos problemas, se están llevando a cabo nuevos procesos de contratación y métodos de formación.

1. Método vanguard: el enfoque Vanguard comienza con las situaciones en las que se encuentra la gente, y sus prácticas y formas de pensar son expuestas a un método estructurado para estudiar «la forma en que funciona el trabajo» (Seddon, 2003, p. 14). Esto frecuentemente muestra que la organización produce resultados poco óptimos para los usuarios del servicio. A continuación, los trabajadores participan en una consulta colaborativa para determinar nuevos objetivos desde el punto de vista del usuario, antes de realizar de forma conjunta un nuevo diseño del sistema que logre alcanzar los objetivos propuestos (O'Donovan, 2012). Fuente: OCDE (2017c).

\section{LOS NUEVOS ENFOQUES PRECISAN VISIÓN, EVIDENCIAS Y CAPACIDADES A TODOS LOS NIVELES DE GOBIERNO}

\section{El papel del centro de gobierno}

Los enfoques sistémicos desvían el eje del debate de las barreras organizativas y de procesos hacia la búsqueda de un espacio común sobre cómo lograr resultados. Focalizar los cambios en resultados deseados requiere que los Gobiernos entiendan lo que realmente importa a los ciudadanos - es decir, el impacto de las reformas en la satisfacción ciudadana, la confianza en las instituciones y el bienestar - y asuman el mando en los sectores de competencia tradicionales. El centro de gobierno ${ }^{1}(\mathrm{CdG})$ se está perfilando como un agente principal en la articulación de prioridades generales del Gobierno y en el apoyo de un enfoque centrado en resultados para lograr esta visión.

El CdG juega un papel crítico en garantizar que las políticas apoyan el programa del Gobierno elegido. Su rol e importancia ha aumentado significativamente en los últimos años, debido en parte a una necesidad reconocida de enfoques que perciban las Administraciones públicas como un conjunto y que dejen de lado la compartimentación de los procesos de reforma (OCDE, 2013a; 2015a). El CdG tiene una variedad de funciones clave. Una encuesta reciente de la OCDE (OCDE, 2013a) identifica cuatro tareas prioritarias: apoyar la toma de decisiones del jefe de Gobierno o gabinete, coordinar las políticas del Gobierno y liderar las estrategias prioritarias interdepartamentales, monitorizar el progreso de la reforma política, y la planificación estratégica, estrechamente alineada con el desarrollo de políticas y la asignación de recursos (véase el capítulo 4, «Instituciones»).

Está en una posición única para desarrollar una visión estratégica a largo plazo y debe comunicar las prioridades políticas resultantes a todas las Administraciones públicas, para que sean integradas en el conjunto de acciones del Gobierno. En la práctica, el CdG puede proporcionar directrices estratégicas a los departamentos y organismos, y verificar que el trabajo es acorde a ellas. 
Como resultado de la crisis mundial y de las fuertes restricciones presupuestarias en varios países de la OCDE, los Gobiernos han reforzado la coordinación entre la formulación de presupuestos y de políticas para garantizar que los recursos limitados apoyan las prioridades establecidas. En Austria, la Administración federal pública promueve activamente el principio de formulación de políticas basadas en resultados desde 2013. La Oficina Federal para la Gestión del Desempeño situada en la Cancillería, en colaboración con participantes clave (incluyendo el Parlamento, el Tribunal de Cuentas, el Ministerio Federal de Finanzas, los Órganos Supremos de la Federación, los ministerios competentes y otros órganos de las Administraciones públicas), tiene como objetivo garantizar que el énfasis en resultados se implementa en todas las Administraciones. Presta asistencia y asesoramiento a los ministerios cuando ponen en marcha programas de gestión orientados al rendimiento - y resultados - y garantiza la calidad de los objetivos e indicadores identificados por los ministerios y organismos para medir sus resultados. Supervisa, además, la consecución de objetivos y pone los resultados a disposición del Parlamento en un formato estándar.

La coordinación entre las distintas partes de las Administraciones públicas es esencial para garantizar la coherencia de las políticas y evitar duplicaciones, ineficiencias e incluso actuaciones políticas contradictorias. Tradicionalmente, el CdG apoya la coordinación a través de organismos interministeriales. Dado el creciente número de proyectos de políticas interministeriales para tratar problemas complejos, el CdG en muchos países de la OCDE ha asumido, de manera reciente, mayor responsabilidad en la definición de prioridades estratégicas y en el desarrollo de planes de actuación interdepartamentales, además de participar más activamente en la implementación de políticas horizontales, por ejemplo, mediante las unidades de cumplimiento. Esta evolución no implica necesariamente una mayor centralización, sino más bien un papel de asistencia y asesoramiento por parte del CdG, que capacita a los ministerios competentes a contribuir en proyectos horizontales sin cuestionar su autonomía y experiencia.

El rol del CdG en la implementación de los Objetivos de Desarrollo Sostenible (ODS) describe claramente su función de apoyo a las Administraciones públicas en la resolución de problemas complejos. Los 17 objetivos cubren una gama de retos diferentes pero interrelacionados, que abarcan desde la disminución de la pobreza y la desigualdad hasta la igualdad de género, la protección medioambiental, la paz y la justicia. Mientras que estos objetivos son relevantes para todos los países, incluyendo los países de la OCDE, su implementación plantea desafíos distintos en cada país, dependiendo de su punto de partida. Todos estos problemas políticos han de ser abordados de manera universal en los próximos 15 años. Dado el alcance y complejidad, así como el carácter a largo plazo de los ODS, progresar en su implementación exige que los Gobiernos coordinen todos sus ámbitos políticos y niveles de gestión (OCDE, 2016b). Los países de la OCDE reconocen el papel del CdG en la 
consecución de los ODS (véase el Gráfico 1.2). En 16 países de la OCDE, el $\mathrm{CdG}$ dirige la implementación de los ODS, bien por sí solo o junto con los ministerios competentes (véase el capítulo 4, «Instituciones»).

\section{Gráfico 1.2. Liderazgo y coliderazgo en la implementación de los Objetivos de Desarrollo Sostenible de la ONU, 2016}

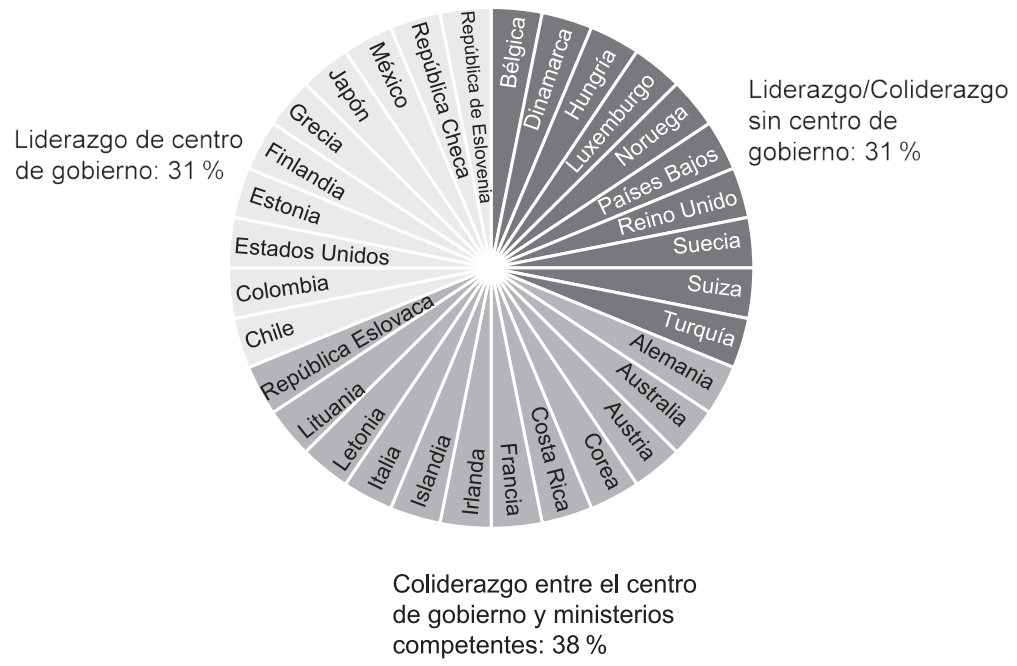

Fuente: Encuesta de la OCDE sobre la planificación y coordinación de la implementación de los Objetivos de Desarrollo Sostenible (ODS), 2016.

Para más información véase Panorama de las Administraciones Públicas 2017, capítulo 4, «Instituciones».

<http://dx.doi.org/10.1787/888933532637>

El CdG puede ser reforzado de varias maneras que le permiten jugar un papel más proactivo en la coordinación de respuestas del Gobierno a problemas políticos perversos (OCDE, 2015a). Primero, se ha de definir un marco intergubernamental con una visión y objetivos estratégicos claros, como puede ser la implementación de los Objetivos de Desarrollo Sostenible de la ONU. El apoyo político de alto nivel para la consecución de estos objetivos y un mandato claro para que el CdG pueda implementar sus estrategias ayudan a reforzar su aceptación y crean el marco de condiciones apropiado para su ejecución. En segundo lugar, en las primeras fases del proceso de implementación y en estrecha cooperación con todos los departamentos, se deben identificar los desafíos relativos a la consecución de los objetivos y las maneras de superarlos. Se debe supervisar la implementación de manera constante $\mathrm{y}$, en caso de ser necesario, debe ser modificada. En tercer lugar, el CdG juega un papel importante en la eliminación de obstáculos durante la implementación, por ejemplo, estableciendo equipos de cumplimiento que gestionen la 
implementación y resuelvan los problemas que surjan. El CdG también debe enfatizar la importancia de los objetivos estratégicos a todos los actores que participan en su implementación, y fomentar la cultura del cumplimiento en todas las estructuras gubernamentales, ofreciendo además su apoyo técnico, asesoramiento y conocimientos.

Finalmente, desde un principio, el CdG debería comunicar claramente la división de tareas a las distintas partes de las Administraciones públicas, conseguir el apoyo de todos los agentes involucrados, colaborar con los interesados externos para tener una mejor comprensión de cómo abordar el problema y diseñar las soluciones más apropiadas. El CdG y todo su personal debe contar con capacidades analíticas, políticas y administrativas específicas que garanticen la gestión efectiva de los recursos limitados y la capacidad de aprovechar la cooperación gubernamental (OCDE, 2013a).

\section{Reunir evidencia para apoyar el cambio}

Con el fin de dirigir las Administraciones públicas de manera efectiva, los Gobiernos deben ser capaces de medir los objetivos deseados y supervisar el progreso de su consecución. Centrarse en los resultados supone una herramienta útil para evaluar si las actuaciones en marcha apoyan las prioridades estratégicas. Los programas de reforma previos - así como la propia tendencia de las organizaciones a añadir nuevas responsabilidades - pueden conducir al aumento de actividades secundarias que absorben recursos que podrían ser utilizados en ámbitos de acción más prioritarios. Cada vez más países de la OCDE utilizan análisis de gastos para evaluar periódicamente que la asignación de recursos es acorde con los objetivos del Gobierno. A medida que los países dejan atrás el periodo de crisis, los análisis de gastos adquieren el potencial de apoyar la productividad en términos de reducción del déficit y de inversiones orientadas a la consecución de resultados prioritarios.

La evidencia recogida por la OCDE muestra que el número y frecuencia de los análisis de gastos ha aumentado considerablemente desde 2007. Veintidós países de la OCDE confirmaron haber realizado al menos un análisis de gastos durante el periodo 2008-2016, comparado con solo cinco países miembros para el periodo 2000-2007 (véase Gráfico 1.3). Hasta el momento, los nuevos usuarios prefieren los análisis globales a los más específicos (véase el capítulo 5, «Prácticas y procedimientos presupuestarios»).

Sin embargo, a pesar de su creciente popularidad, pocos países tienen información sobre la implementación de las recomendaciones incluidas en los análisis de gastos previos, o sobre sus resultados fiscales. Un mejor seguimiento de la implementación y efectividad de los análisis de gastos es, por tanto, un ámbito en el que se puede mejorar. 


\section{Gráfico 1.3. Número total de análisis de gastos en los países de la OCDE, 2000-2007 y 2008-2016}
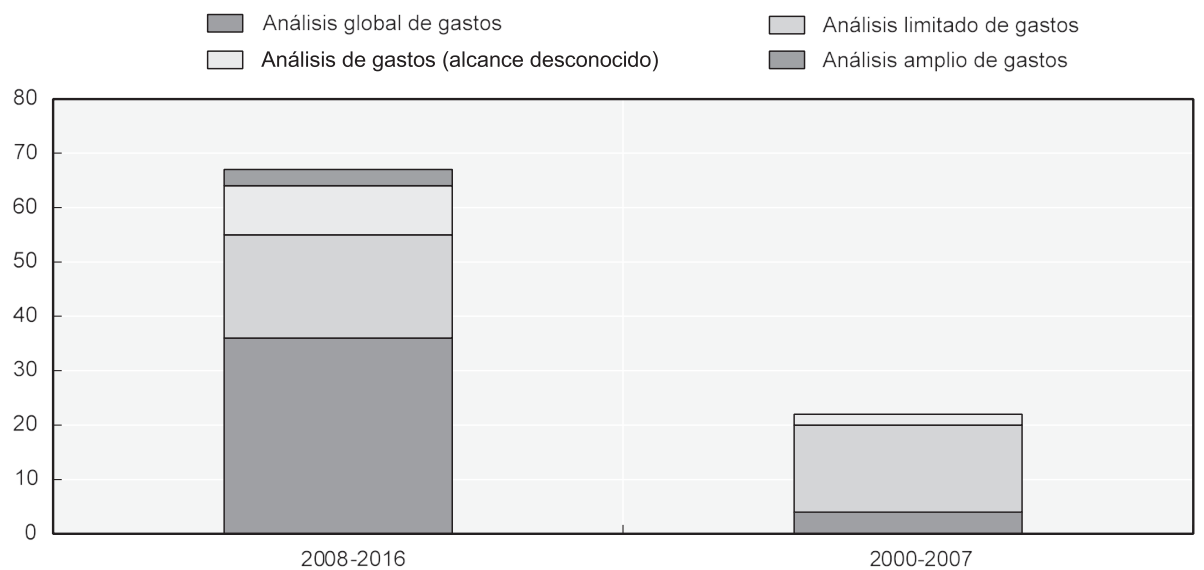

Fuente: Encuesta de la OCDE sobre presupuestos por resultados, 2016.

Para más información véase Panorama de las Administraciones Públicas 2017, capítulo 5, «Prácticas y procedimientos presupuestarios».

El uso de evaluaciones de impacto es también una práctica extendida en los países de la OCDE que apoya la formulación de políticas basadas en evidencias, y mejora los resultados. Se utilizan principalmente en el ámbito de la reforma regulatoria. La Recomendación del Consejo de la OCDE sobre política y gobernanza regulatoria de 2012 define la evaluación del impacto regulatorio (EIR) como «una herramienta y proceso de decisión para informar a los responsables políticos sobre la posibilidad y el modo de lograr los objetivos de las políticas públicas». Recomienda que los países adopten prácticas de evaluación del impacto ex ante, que incluyan análisis de costes y beneficios. Estos análisis deben considerar el impacto de la regulación sobre el bienestar, teniendo en cuenta el impacto económico, social y medioambiental, e incluyendo los efectos distributivos a lo largo del tiempo (OCDE, 2012). Asimismo, el enfoque analítico de la EIR puede ayudar a evaluar el impacto de otras herramientas políticas aparte de la regulación, como gastos y medidas fiscales. La EIR ayuda a calcular los costes y beneficios de las distintas soluciones a los problemas políticos, evalúa una gama de los diferentes impactos de las soluciones propuestas e identifica a los ganadores y perdedores. Ayuda a los responsables políticos a elegir la regulación u otra herramienta política como mejor opción para abordar un problema específico, y describe las compensaciones y riesgos de las distintas opciones.

La EIR puede ser aplicada al análisis del impacto social de las políticas, más allá del mero análisis de los costes de la regulación (Deighton-Smith et 
al., 2016). Durante los últimos 10 años, se han ampliado los requisitos y directrices relativos a la práctica de la EIR, de manera que los impactos sociales, medioambientales y distributivos han pasado a ser una parte integral de la evaluación en muchos países de la OCDE (véase el capítulo 8, «Gobernanza regulatoria»). A pesar de ello, todavía se evalúan de manera más amplia los impactos económicos, por ejemplo, en los presupuestos, la competencia o en el sector público, que los impactos sociales y distributivos, es decir, en la igualdad de género, en los grupos sociales o zonas regionales específicos y en la desigualdad de ingresos y pobreza, entre otros.

\section{Gráfico 1.4. Evaluación de impactos en la EIR}

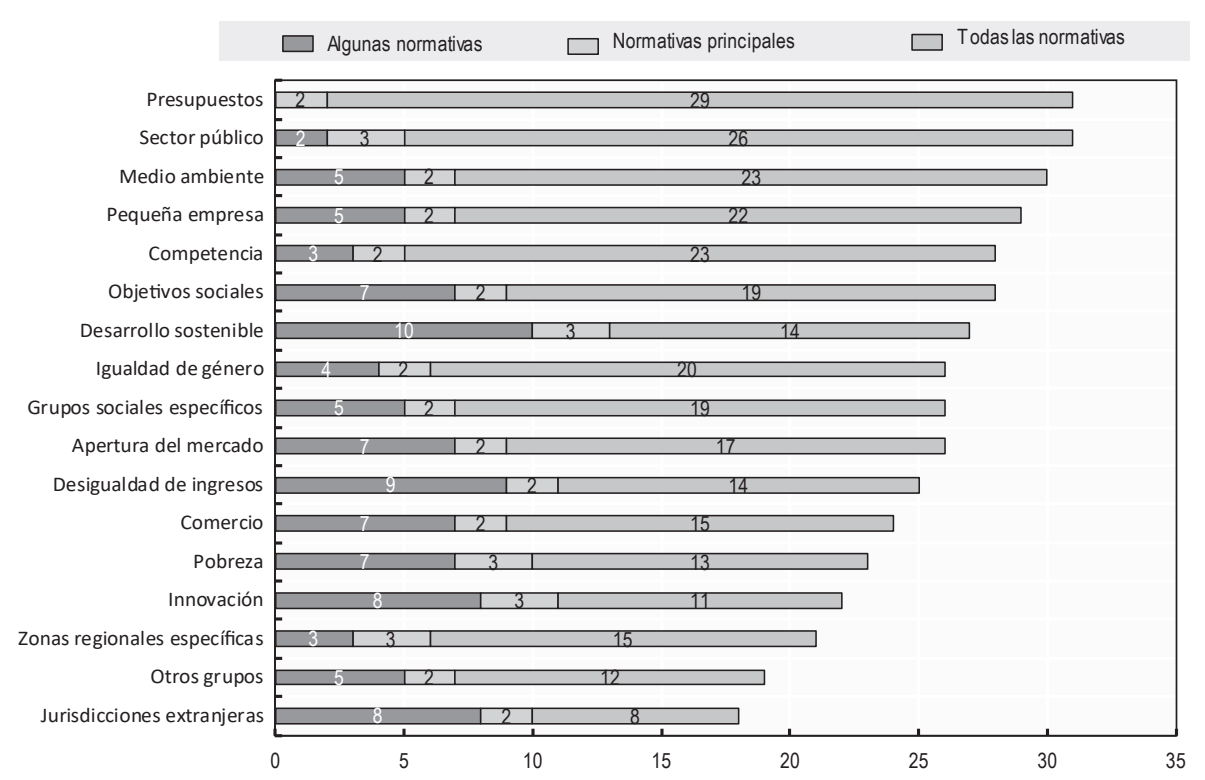

Fuente: OCDE (2015b), Panorama de Política Regulatoria 2015 de la OCDE, <http://www.oecd.org/gov/ regulatory-policy/indicators-regulatory-policy-and-governance.htm $>$.

Para más información véase Panorama de las Administraciones Públicas 2017, capitulo 8, «Gobernanza regulatoria».

$<$ http://dx.doi.org/10.1787/888933531345>

La implementación práctica de esta evaluación global de diferentes impactos parece quedarse rezagada con respecto a sus requisitos. Los impactos sociales, distributivos y medioambientales no se evalúan siempre de manera sistemática y de acuerdo con los requisitos formales. Esto apunta a un problema de cumplimiento que se debe corregir, aunque también puede ser debido a una falta de conocimientos metodológicos, o de directrices o datos adecuados 
para la evaluación de los impactos, que normalmente solo se pueden medir con datos cualitativos y no pueden ser cuantificados o valorados en términos monetarios. La formación y el desarrollo de habilidades dentro de las Administraciones públicas ayudaría a aprovechar el potencial de la EIR. Considerando la limitación de recursos y tiempo disponibles para realizar EIR globales a todas las propuestas políticas, un enfoque selectivo ayudaría a centrar las capacidades en aquellas políticas con más probabilidad de tener un mayor impacto sobre la economía y la sociedad.

Por último, los responsables políticos deben asegurarse de que la EIR se utiliza para apoyar la formulación de políticas basadas en evidencias, en lugar de la formulación de evidencias basadas en la política. El uso de la EIR debe ir más allá de un enfoque procedimental que lo limite a un ejercicio de «marcar la casilla». Los resultados de la EIR deberían ayudar a los responsables políticos a tomar decisiones más informadas relativas a las opciones políticas disponibles, y no ser utilizados como una herramienta de legitimación que aporta argumentos de apoyo para decisiones que ya han sido tomadas (OCDE, 2015b).

El desarrollo de nuevas fuentes de evidencia es constante, incluido el big data, crowdsourcing, la investigación científica y los programas de experimentación. La OCDE está estudiando cómo los Gobiernos reúnen evidencias y asesoramiento con el fin de transformarlos en formatos oportunos, coherentes, adaptados y utilizables para los responsables políticos.

\section{Reforzar las capacidades de los funcionarios para actuar sobre la base de evidencias}

Una visión clara y estratégica, combinada con la recolección y análisis de evidencia sólida, puede no ser suficiente para conseguir cambios efectivos si no se complementa con esfuerzos adicionales que apoyen la capacidad de los funcionarios de realizar acciones concretas para alcanzar mejores resultados. La gestión pública orientada hacia la acción y el cambio continuo requiere una evolución de la cultura laboral en las Administraciones públicas que deje más espacio para la experimentación y el riesgo y fomente la participación y bienestar de los empleados, aspectos más favorables a la innovación.

La OCDE ha estado trabajando en la identificación de las características clave de un funcionariado profesional, estratégico e innovador (véase el Gráfico 1.5). Las organizaciones innovadoras tienen en común la práctica de la experimentación y el aprendizaje mediante ensayo y error. El desafío, en especial para las organizaciones del sector público, consiste en encontrar maneras de trabajo que combinen la experimentación con una atenuación de los 
riesgos asumidos por el conjunto de la sociedad. Un desafío asociado reside en encontrar modos de recompensar a los funcionarios que lleven a cabo actuaciones de experimentación bien estructuradas, incluso cuando no obtienen los resultados esperados.

Motivar a los funcionarios públicos a desarrollar capacidades de innovación requiere tomar en consideración una gama de incentivos y desincentivos que funcionen de manera simultánea dentro de las organizaciones. Esto puede incluir factores extrínsecos, como la estructura de salarios y concesión de ascensos. También puede incluir la calidad de las relaciones entre el personal y el equipo directivo, el trabajo en equipo y el reconocimiento de esfuerzos. La motivación intrínseca se puede estimular concienciando a los empleados respecto al impacto de su trabajo - su cercanía a los beneficiarios de las políticas que desarrollan, la oportunidad de verificar los resultados de sus ideas y trabajo-.

Para ser innovadores, los profesionales de los servicios públicos deben tener las habilidades adecuadas para dar respuesta a los problemas. Los empleados que se sientan menos capaces de cumplir sus tareas estarán menos motivados a realizarlas, mientras que aquellos que hayan desarrollado nuevas capacidades querrán ponerlas en práctica. Algunas de estas habilidades están probablemente relacionadas con capacidades técnicas, como la habilidad de comprender y manipular big data, o de manejar prototipos o enfoques experimentales para el diseño de servicios. Otras habilidades incluyen la capacidad de establecer conexiones entre ideas que no son evidentes, hacer preguntas apropiadas y establecer contactos con gente. Adquirir y reforzar estas capacidades entre el personal del sector público supone encontrar formas nuevas y creativas de reflexionar sobre el desarrollo de los empleados y de sus destrezas.

Tabla 1.5. Avanzar hacia un servicio público profesional, estratégico e innovador

\begin{tabular}{|l|l|l|l|}
\hline & \multicolumn{1}{|c|}{ Profesional } & \multicolumn{1}{c|}{ Estratégico/a } & \multicolumn{1}{c|}{ Innovador/a } \\
\hline & & & $\begin{array}{l}\text { Iterativo } \\
\text { Que maneje datos } \\
\text { Centrado en los } \\
\text { ciudadanos } \\
\text { Que tenga } \\
\text { Necesita un } \\
\text { funcionariado: }\end{array}$ \\
& $\begin{array}{l}\text { Cualificado } \\
\text { Independiente } \\
\text { Orientado a valores } \\
\text { Ético }\end{array}$ & $\begin{array}{l}\text { Orientado a resultados } \\
\text { Basado en evidencias } \\
\text { Orientado al futuro } \\
\text { Proactivo } \\
\text { Con contactos }\end{array}$ & \\
& & & Insurgente \\
\hline
\end{tabular}




\begin{tabular}{|c|c|c|c|}
\hline & Profesional & Estratégico/a & Innovador/a \\
\hline $\begin{array}{l}\text { En una función } \\
\text { pública: }\end{array}$ & $\begin{array}{l}\text { Basada en el mérito } \\
\text { Capaz de integrar } \\
\text { destrezas sociales, } \\
\text { ética, gestión de } \\
\text { talento (potencial } \\
\text { futuro vs. resultados } \\
\text { obtenidos en el } \\
\text { pasado) } \\
\text { Capaz de estructurar } \\
\text { de manera equilibrada } \\
\text { las profesiones } \\
\text { generales y } \\
\text { especializadas, y las } \\
\text { carreras profesionales }\end{array}$ & $\begin{array}{l}\text { Ágil } \\
\text { Atractiva para } \\
\text { personas cualificadas } \\
\text { que buscan empleo } \\
\text { Planificada y } \\
\text { gestionada para } \\
\text { garantizar que las } \\
\text { capacidades y } \\
\text { competencias } \\
\text { adecuadas sean } \\
\text { eficazmente asignadas } \\
\text { a áreas de necesidad } \\
\text { presente o emergente } \\
\text { Orientada al futuro y } \\
\text { reactiva }\end{array}$ & $\begin{array}{l}\text { De cultura, } \\
\text { liderazgo y gestión } \\
\text { abierta y } \\
\text { colaborativa } \\
\text { Comprometida } \\
\text { Autónoma (por } \\
\text { ejemplo, en el } \\
\text { diseño del trabajo) } \\
\text { Móvil } \\
\text { Diversa } \\
\text { Orientada al } \\
\text { aprendizaje }\end{array}$ \\
\hline $\begin{array}{l}\text { Dirigido por } \\
\text { un alto } \\
\text { funcionariado: }\end{array}$ & $\begin{array}{l}\text { De asesores políticos } \\
\text { de confianza y líderes } \\
\text { transaccionales } \\
\text { efectivos }\end{array}$ & $\begin{array}{l}\text { De líderes } \\
\text { transformacionales y } \\
\text { gestores del cambio }\end{array}$ & $\begin{array}{l}\text { De líderes } \\
\text { colaborativos y } \\
\text { gestores flexibles }\end{array}$ \\
\hline
\end{tabular}

Fuente: OCDE.

Supervisar el compromiso de los empleados, principalmente a través de encuestas periódicas, puede ser de utilidad para motivar el cambio e identificar actuaciones que apoyen positivamente la innovación y el desempeño a niveles de organización, división y unidad. Los indicios muestran que el compromiso de los empleados, además de ser un fin en sí mismo, se da en lugares de trabajo público más diversos y atractivos en el contexto de un mercado laboral competitivo y constituye un aporte fundamental para la gestión de recursos humanos basada en evidencias. Diecinueve países de la OCDE realizan encuestas centralizadas al personal de todas las Administraciones públicas periódicamente. En cambio, solo cinco países manifiestan no usar encuestas de personal (OCDE, 2016e, véase Panorama de las Administraciones Públicas 2017, capítulo 6, "Gestión de recursos humanos»).

La innovación y experimentación — bases de un sector público adaptabletambién deben dar cabida a los errores de las Administraciones públicas y a su rápida corrección. La cuestión clave es reconocer que la innovación conlleva riesgos y que el espíritu emprendedor invariablemente va ligado a ciertos fracasos. En los últimos años, se ha incrementado significativamente el tipo y número de organizaciones y estructuras dedicadas al apoyo de la innovación en el sector público (OCDE, 2017c), conocidas como equipos, unidades, laboratorios o redes. En 11 países de la OCDE, estas estructuras proporcionan espacios para la experimentación, creando de esta manera un entorno seguro para la toma de riesgos (véase Panorama de las Administraciones Públicas 2017, capítulo 11, «Innovación en el sector público y gobierno digital»). 
El funcionariado de alto rango se halla en muy buena posición para favorecer este cambio de cultura y valores basado en el logro de objetivos comunes, en las organizaciones públicas y sectores políticos. En determinadas condiciones, puede tener un efecto positivo en el rendimiento, la motivación y la satisfacción de sus equipos de trabajo (Orazi et al., 2013). La creación de un funcionariado de alto nivel, generalmente desarrollado a través de programas centralizados y gestionado como conjunto en todos los organismos, es una tendencia clara en los países de la OCDE. Estos grupos de hombres y mujeres trabajan en puestos de gran influencia y unen las esferas políticas y administrativas para alcanzar resultados de manera eficiente, efectiva y legal. Las estructuras laborales y programas de formación pueden impulsar el rol proactivo del alto funcionariado y estimular la innovación en el sector público.

Gráfico 1.6. Alcance del uso de prácticas específicas de gestión de recursos humanos para los altos funcionarios de la Administración central, 2016

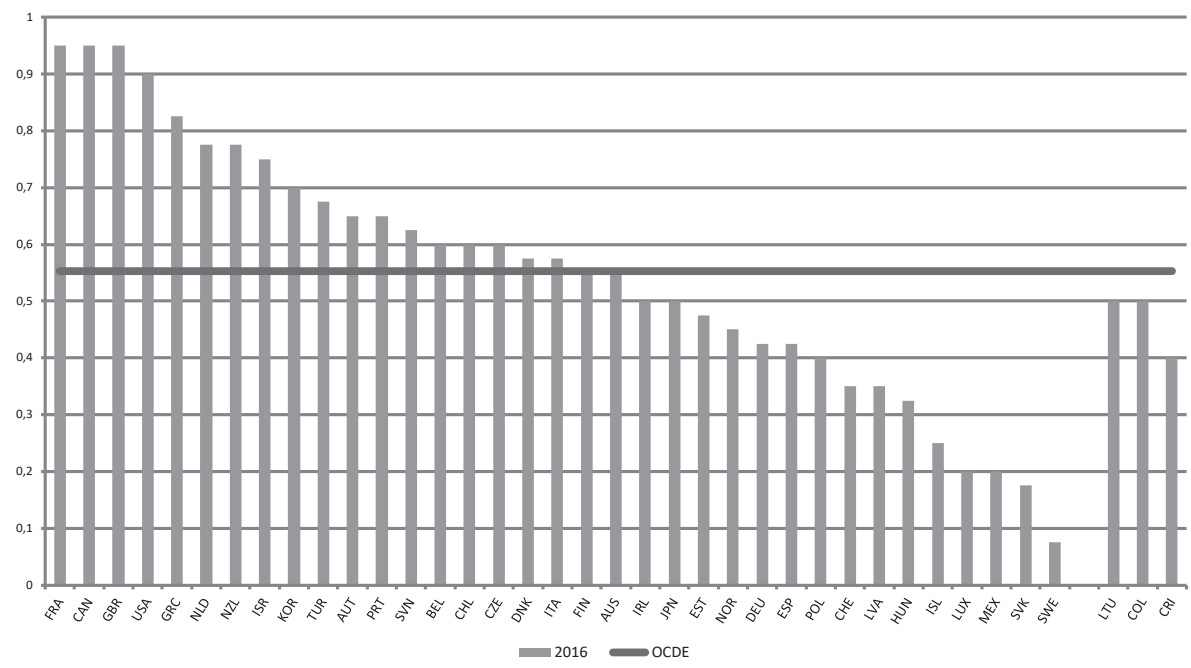

Fuente: Encuesta de la OCDE sobre gestión estratégica de recursos humanos, 2016.

Para más información véase Panorama de las Administraciones Públicas 2017, capítulo 6, «Gestión de recursos humanos».

$<$ http://dx.doi.org/10.1787/888933532922>

A medida que surgen nuevos retos en un contexto de creciente digitalización e innovación del sector público, los líderes han de asumir distintos roles con el fin de gestionar la cada vez más compleja realidad del proceso de políticas públicas (Rosenbaum, 2002). Por ejemplo, la mayor participación de los ciudadanos y de organizaciones de la sociedad civil precisa el desarrollo de 
aptitudes de liderazgo en niveles inferiores para gestionar equipos y redes (Orazi et al., 2013), y destaca la importancia de que los altos funcionarios tengan capacidad de liderazgo horizontal y colaborativo (Wart, 2013).

Alinear los sistemas de gestión del rendimiento del alto funcionariado con los objetivos organizacionales es fundamental para la consecución de resultados. Lo ideal sería que los regímenes de rendición de cuentas del alto funcionariado favorecieran que los resultados identificados en la planificación estratégica y presupuestos se tradujeran en objetivos viables para los líderes y les orientaran, además, en la consecución de estos objetivos. Las Administraciones se enfrentan a un doble reto: alinear los objetivos de rendimiento e incentivos del alto funcionariado con los objetivos organizacionales complejos y crear las condiciones favorables para que los altos funcionarios puedan adaptarse a cambios de contexto y de orientaciones políticas que no siempre pueden ser anticipados; al mismo tiempo que nuevas partes interesadas se introducen en el ámbito de la política pública.

\section{Ejemplo de un enfoque innovador en la formulación de políticas: percepciones del comportamiento}

Un ejemplo útil de la incorporación de la innovación a los métodos de trabajo es el uso de las percepciones del comportamiento. Mientras que las políticas a menudo asumen respuestas de comportamiento basadas en explicaciones teóricas, un enfoque centrado en percepciones del comportamiento puede probar estas hipótesis en la vida real o mediante ensayos de laboratorio para determinar cuáles serán las respuestas a las soluciones políticas. Como resultado, el uso de percepciones del comportamiento puede proporcionar soluciones innovadoras que aumentan la capacidad de las Administraciones públicas de abordar problemas complejos. Este enfoque de formulación de políticas basadas en evidencias es de naturaleza inductiva y se apoya en distintos tipos de experimentos, que incluyen ensayos controlados aleatorizados, pruebas piloto y experimentos de laboratorio, online o naturales. Las percepciones del comportamiento se basan en resultados e identifican patrones de conducta; por tanto, reemplazan y cuestionan los supuestos tradicionales de lo que supone el comportamiento racional. Las percepciones del comportamiento combinan estrategias tradicionales de Economía y conocimientos de Psicología, Ciencia Cognitiva y otras ciencias sociales. Enfrentan de manera directa los sesgos de comportamiento que a menudo impiden que las intervenciones del Gobierno logren los resultados deseados (OCDE, 2017a, véase Panorama de las Administraciones Públicas 2017, capítulo 8, «Gobernanza regulatoria»).

Las percepciones del comportamiento están creciendo en popularidad entre los Gobiernos como una herramienta útil para la creación de soluciones nuevas, relativamente sencillas y especialmente efectivas (véase el Cuadro 1.2, que describe un ejemplo del Reino Unido). La OCDE (2017a) ha publicado 
recientemente una serie de estudios de casos relativos a la aplicación de las percepciones del comportamiento que incluye 23 países y varios ámbitos políticos, como la protección del consumidor, la educación, la energía, el medio ambiente, las finanzas, la salud y seguridad, el mercado laboral, la prestación de los servicios públicos, los impuestos y las telecomunicaciones.

\section{Cuadro 1.2. Uso de las normas sociales para reducir la prescripción excesiva de antibióticos en el Reino Unido}

Public Health England (en español 'Salud Pública Inglaterra'), un organismo ejecutivo del Departamento de Salud, y el Equipo de Percepciones del Comportamiento (BIT, por sus siglas en inglés) del Reino Unido pusieron en práctica ensayos controlados aleatorizados entre septiembre de 2014 y marzo de 2015 para probar si la comunicación de normas sociales podía ayudar a reducir la prescripción excesiva de antibióticos. La intervención tenía como objetivo reducir el riesgo de resistencia a los antibióticos causada por su alto consumo, que conlleva tasas de mortalidad y morbilidad más elevadas, así como un aumento de los costes del sector sanitario. La idea principal en la que se basaba el enfoque es que la percepción del comportamiento de otros en una situación determinada influye en la propia conducta de la gente. Por ejemplo, informar a las personas de que un comportamiento beneficioso está más extendido de lo que suponen puede motivarles a poner en práctica ese comportamiento. De manera similar, saber que su comportamiento no es común puede llevar a que la gente cambie su conducta.

El método comprobó el efecto de dos tipos distintos de tratamiento para estudiar el impacto de la retroalimentación de normas sociales en las tasas de prescripción de antibióticos de los médicos de cabecera. Consultando datos públicos disponibles, se identificaron las consultas con el $20 \%$ de tasas más elevadas en la prescripción de antibióticos. El enfoque dividió de manera aleatoria las consultas en un grupo de tratamiento y otro de control. El grupo de tratamiento recibió una carta del director general de Salud en septiembre de 2014 que informaba de que sus tasas de prescripción de antibióticos estaban por encima del $80 \%$ del resto de consultas en la zona, mientras que el grupo de control no recibió comunicación alguna. Posteriormente, el ensayo reasignó aleatoriamente las consultas en nuevos grupos de tratamiento y de control. En diciembre de 2014, las consultas del grupo de tratamiento recibieron información centrada en pacientes que fomentaba una disminución en el uso de antibióticos, mientras que el grupo de control no recibió nada.

Uno de los tratamientos tuvo un efecto significativo en las tasas de prescripción de antibióticos. A lo largo del periodo de prueba de seis meses, los médicos que recibieron la carta sobre su tasa elevada de prescripción de antibióticos la redujeron notablemente - en un 3,3\% - comparado con el grupo de control. Si el método se hubiera aplicado a nivel nacional en todas las consultas con tasas de prescripción elevadas, el descenso estimado de antibióticos prescritos sería del 0,85\%. Además, el coste de la intervención fue bajo, 4335 libras esterlinas, mientras que el ahorro estimado en costes directos de prescripción asciende a casi 100000 libras. La distribución de información sobre pacientes no tuvo un efecto significativo.

Fuente: OCDE (2017a) 
Sobre la base de los casos estudiados, la OCDE recomienda una serie de pautas que los países pueden seguir para ampliar y reforzar el uso de percepciones del comportamiento en la formulación de políticas públicas:

- Extender la aplicación de las percepciones del comportamiento de un enfoque centrado en la conducta individual a uno centrado en los procesos que gobiernan el trabajo de las organizaciones públicas, así como en el comportamiento de las empresas reguladas (por ejemplo, mercados de capital / bancos, consumo de energía de grandes empresas industriales, medios de transporte utilizados por grandes empresas, etc.). Los Gobiernos pueden también tener en cuenta soluciones políticas basadas en el comportamiento que se adapten a las necesidades de grupos específicos de la población.

- Utilizar las percepciones del comportamiento en todo el ciclo político. Frecuentemente se ponen en práctica en un momento tardío del diseño de políticas. Existe también la posibilidad de aplicar las percepciones del comportamiento para evaluar la efectividad de las políticas, así como en las primeras fases del diseño de políticas para tener una mejor comprensión del problema que se ha de abordar.

- Desarrollar metodologías de capacidad coherente y procesos de control de calidad en la aplicación de las percepciones del comportamiento. Esto incluye el desarrollo de procesos que determinen cuándo se puede abordar un problema mediante percepciones del comportamiento (y cuándo no), medidas de fomento de la capacidad interna de las Administraciones públicas mediante programas de información y formación, invertir en una recogida de datos e información sólidos para establecer las intervenciones conductuales sobre evidencia fiable y fomentar los esfuerzos de validación de los resultados experimentales a través de la repetición y aplicación de las soluciones identificadas en distintos contextos.

- Supervisar el impacto de los enfoques basados en percepciones del comportamiento para identificar los efectos a corto y largo plazo.

- Mejorar la transparencia y responsabilidad en el uso de percepciones del comportamiento divulgando información tanto de sus éxitos como de sus fracasos, así como información sobre los costes y beneficios reales de su implementación. Esto ayuda a solventar cuestiones éticas sobre su uso y aumenta la credibilidad y aceptación pública de la herramienta. 


\section{UN ENFOQUE DE CAMBIO INNOVADOR Y CON SENTIDO SE BASA EN LA TRANSPARENCIA Y LA PARTICIPACIÓN}

Los mejores elementos técnicos para la toma de decisiones e implementación en el sector público no darán lugar a mejores políticas si no se ponen en funcionamiento mecanismos de seguridad que garanticen su independencia y verifiquen que no hay influencias indebidas dentro y fuera del Gobierno. Incluso los canales legítimos de defensa pueden ser manipulados para la captura de los procesos de formulación de políticas y su implementación si se utilizan de manera exclusiva o con falta de transparencia, o si solo son accesibles para grupos o personas privilegiadas (OCDE, 2017d). Además de políticas integradoras específicas a nivel organizacional, la interacción de tres estrategias amplias que se refuerzan mutuamente puede ayudar a prevenir y afrontar el riesgo de la captura política: (1) garantizar la igualdad de condiciones (involucración y participación de todas las partes interesadas), (2) respetar el derecho a saber (transparencia) y (3) fomentar la responsabilidad (especialmente a través de autoridades de competencia, organismos reguladores e instituciones supremas de auditoría). Esta edición de Panorama de las Administraciones Públicas contiene una serie de indicadores que proporcionan información de utilidad sobre estas estrategias.

\section{Compromiso y participación de las partes interesadas}

El compromiso y la participación de las partes interesadas aumentan las probabilidades de que los resultados políticos tengan un impacto positivo en la mayoría y no solo en una minoría (OCDE, 2017d). La participación activa de las partes interesadas en el proceso de formulación de políticas, en la ejecución de presupuestos y en la supervisión de la prestación de servicios puede ayudar a guiar y garantizar la implementación efectiva de reformas.

Los países de la OCDE prestan cada vez más atención a las diversas maneras de obtener la participación de las partes interesadas en el diseño, implementación y revisión de políticas y normativas. Sin embargo, la evidencia recogida por la OCDE sugiere que todavía existen importantes diferencias entre países en cuanto a la participación de interesados en la elaboración de políticas (véase el Gráfico 1.7). Además, las partes interesadas no se suelen consultar hasta el último momento, cuando ya existe un proyecto de regulación o de política, en lugar de durante la fase inicial de debate sobre la naturaleza del problema y posibles soluciones (OCDE, 2015b, véase el capítulo 8, «Gobernanza regulatoria»). Está cada vez más demostrado que la colaboración de ciudadanos y usuarios puede ayudar a subsanar las deficiencias de los servicios e impulsar la innovación. De la misma manera, se puede reforzar la rendición de cuentas y la evaluación a través de mecanismos de participación. Sin embargo, a menudo los ciudadanos y los usuarios de servicios no pueden o quieren reunirse para crear un grupo de interés. Esto disminuye considera- 
blemente la posibilidad de que sus intereses difusos se tomen en cuenta en la formulación de políticas, y puede llevar a decisiones públicas partidistas que favorecen aquellos intereses que consiguieron movilizar la acción colectiva. En este caso, puede ser de interés para los Gobiernos explorar soluciones innovadoras que disminuyan los costes de este compromiso y participación, como fomentar el uso de las redes sociales para llegar a más personas y ayudarlas a expresar sus preocupaciones e intereses.

Además, las partes interesadas deben aprender cómo interactuar con las Administraciones públicas para aumentar su probabilidad de ser escuchadas. Esto se puede conseguir proporcionando información sobre cuándo y en qué situaciones tienen la oportunidad de influir en las decisiones de Gobierno. Reforzar la educación cívica en edades tempranas también puede fomentar la involucración y participación en el proceso de elaboración de políticas (Print y Lange, 2013).

\section{Gráfico 1.7. Participación de las partes interesadas en el desarrollo de normativas, 2014}

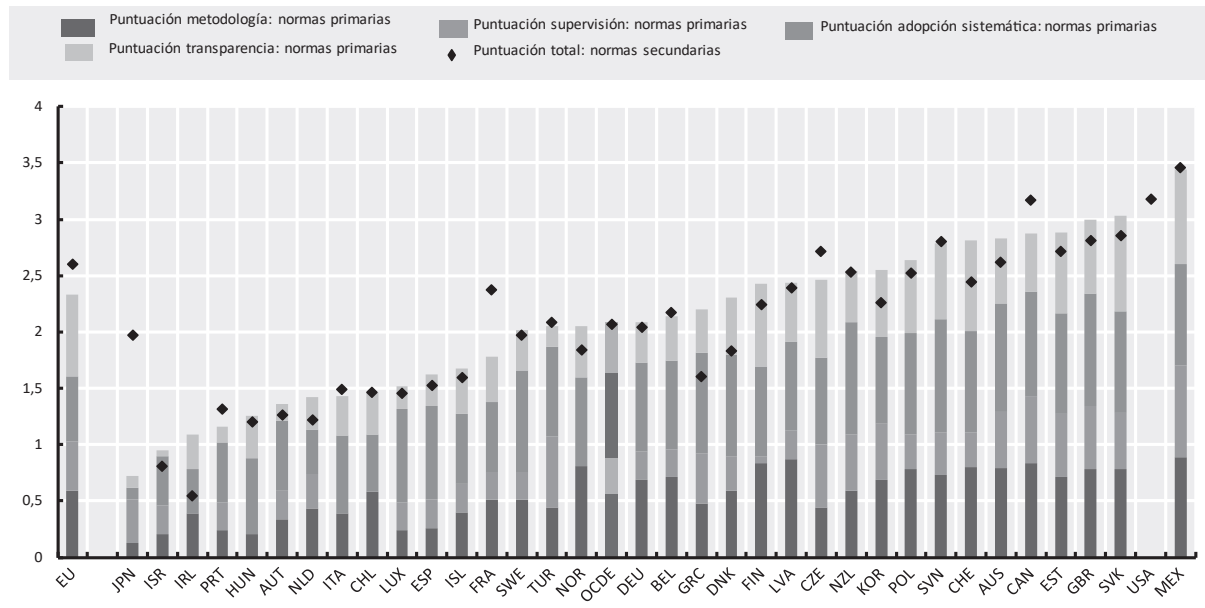

Fuente: Indicadores de la OCDE de política y gobernanza regulatoria (iREG).

Para más información véase Panorama de las Administraciones Públicas 2017, capitulo 8, «Gobernanza regulatoria».

$<$ http://dx.doi.org/10.1787/888933532998>

Los Gobiernos deben, además, crear condiciones favorables que estimulen la confianza en el proceso de participación proporcionando suficiente retroalimentación y evitando la captura de las consultas por lobbies fuertes e intereses particulares. Las dudas sobre el alcance real de las actividades de participación siguen siendo motivo de preocupación y pueden limitar su efec- 
tividad. Mitigar esta preocupación supone la evaluación y medida del éxito de las iniciativas de participación. Sin embargo, pocos países han desarrollado metodologías sólidas para evaluar los resultados de las consultas realizadas online y a través de los medios sociales, incluyendo el ámbito de prevención de riesgos y comunicación (OCDE, 2016d).

\section{La transparencia en la formulación de políticas}

La transparencia en la elaboración de políticas es necesaria para evitar y encarar los riesgos de la captura política. Los países miembros de la OCDE suelen exigir que los funcionarios realicen una declaración patrimonial para evitar posibles conflictos de intereses. La evidencia incluida en Panorama de las Administraciones Públicas 2015 (capítulo 7, «Integridad del sector público») muestra que todavía existen diferencias entre países en cuanto al alcance y magnitud de los requisitos de estas declaraciones y de sus mecanismos de revisión. Dentro de los países también se dan diferencias importantes entre los organismos de las Administraciones, niveles profesionales y sectores políticos, con requisitos más estrictos para los funcionarios políticos que operan en áreas de riesgo, como pueden ser la contratación y la política fiscal y aduanera. A medida que se continúen desarrollando los mecanismos de regulación y control de las declaraciones patrimoniales, se hará más evidente la necesidad de conseguir un equilibrio correcto entre la divulgación pública y el derecho de privacidad de los funcionarios.

Asimismo, resulta de vital importancia crear un marco de transparencia sólido para las actividades de los lobbies, con el fin de proteger los intereses públicos y fomentar la igualdad de condiciones (OCDE, 2017d). El número de países que ha introducido normativas para regular el lobbying desde 2008 ha sido mayor que en los sesenta años previos (OCDE, 2014c). Los códigos de conducta y registros de estos grupos de presión son dos herramientas importantes introducidas por varios países de la OCDE para llevar un control más estricto y aumentar la transparencia del proceso de promoción de políticas.

Sin embargo, pese a los esfuerzos constantes realizados para supervisar estrechamente las prácticas de los lobbies, todavía existen lagunas y deficiencias en las estrategias de cumplimiento y aplicación. El último informe de la OCDE - Lobbyists, Gobiernos y confianza pública: Implementando los principios de transparencia e integridad de la OCDE en el lobbying - destaca que la aplicación de las normas de integridad y códigos de conducta sigue siendo relativamente débil, y la mayoría de los grupos de presión consultados por la OCDE indicaron que el incumplimiento de las normas o códigos de conducta a menudo no son sancionados y que, en el caso de serlo, las sanciones no resultan suficientemente disuasorias. 


\section{Rendición de cuentas y control}

Los mecanismos de auditoría externos e internos son fundamentales para salvaguardar la integridad en la formulación de políticas públicas y garantizar una asignación efectiva de recursos. La Recomendación del Consejo de la OCDE sobre integridad pública de 2017 subraya el papel crucial de la supervisión externa y de los órganos de control para fomentar la toma de decisiones públicas responsables. Señala que los riesgos de captura de las leyes y políticas se pueden mitigar mediante el seguimiento efectivo por parte de las instituciones supremas de auditoría (ISA), que pueden supervisar y pedir cuentas a los agentes del sector público.

Los sistemas de control interno y las actividades efectivas de gestión del riesgo también son fundamentales, especialmente en ámbitos de alto riesgo, como la gestión financiera, las tecnologías de la información y la contratación pública. Varios países de la OCDE han creado funciones centralizadas de auditoría interna con objetivos estratégicos de integridad que supervisan la imparcialidad de la elaboración de políticas en todos los sectores políticos y organizaciones gubernamentales (véase el capítulo 7, «Integridad del sector público»). Esta función central de auditoría interna, en especial si incluye la integridad entre sus objetivos estratégicos, puede reforzar la coherencia de la respuesta del Gobierno en materia de riesgos a la integridad.

\section{Datos de gobierno abierto}

La tecnología está teniendo un profundo impacto en la apertura de las Administraciones públicas. En los últimos veinte años, el rápido avance tecnológico se ha traducido en un aumento de los datos recopilados y producidos en la sociedad, por parte de organizaciones gubernamentales y otro tipo de entidades. Esto ayuda a que haya más información disponible a efectos de responsabilidad gubernamental. También proporciona a un amplio abanico de usuarios, dentro y fuera de las Administraciones públicas, las herramientas necesarias para participar en los debates políticos y aprovechar esta abundante fuente de información.

La publicación proactiva de los datos de gobierno abierto (DGA) está transformando los servicios públicos en materia de sanidad, educación, transporte y medio ambiente (contaminación, gestión de residuos) a nivel nacional y subnacional. Contribuye a mejorar el proceso de elaboración de políticas poniendo los datos y evidencias a disposición de los departamentos y ministerios del Gobierno, ayudando así a romper con el aislamiento de las Administraciones. Empodera también a las empresas y sociedad civil a contribuir de manera más activa en la formulación de políticas. La proliferación de aplicaciones para teléfonos móviles que usan datos geoespaciales es solo un ejemplo de 
cómo la disponibilidad de datos empodera a ciudadanos y empresas, mejorando la accesibilidad y generando nuevos servicios.

El OURdata index 2016, basado en la Carta Internacional de Datos Abiertos y en el marco desarrollado por la OCDE, mide los esfuerzos de las Administraciones públicas en promocionar la disponibilidad y accesibilidad de datos, y en estimular su reutilización dentro y fuera del ámbito político. Países como Corea, Francia y el Reino Unido han avanzado de manera significativa en el uso de los DGA para generar un impacto socioeconómico. Por el contrario, Turquía está todavía pendiente de introducir e implementar las buenas prácticas identificadas a nivel internacional con respecto a los DGA (véase el capítulo 10, «Gobierno abierto»).

\section{Gráfico 1.8. Índice de datos de gobierno abiertos, útiles y reutilizables (OURdata index), 2017}

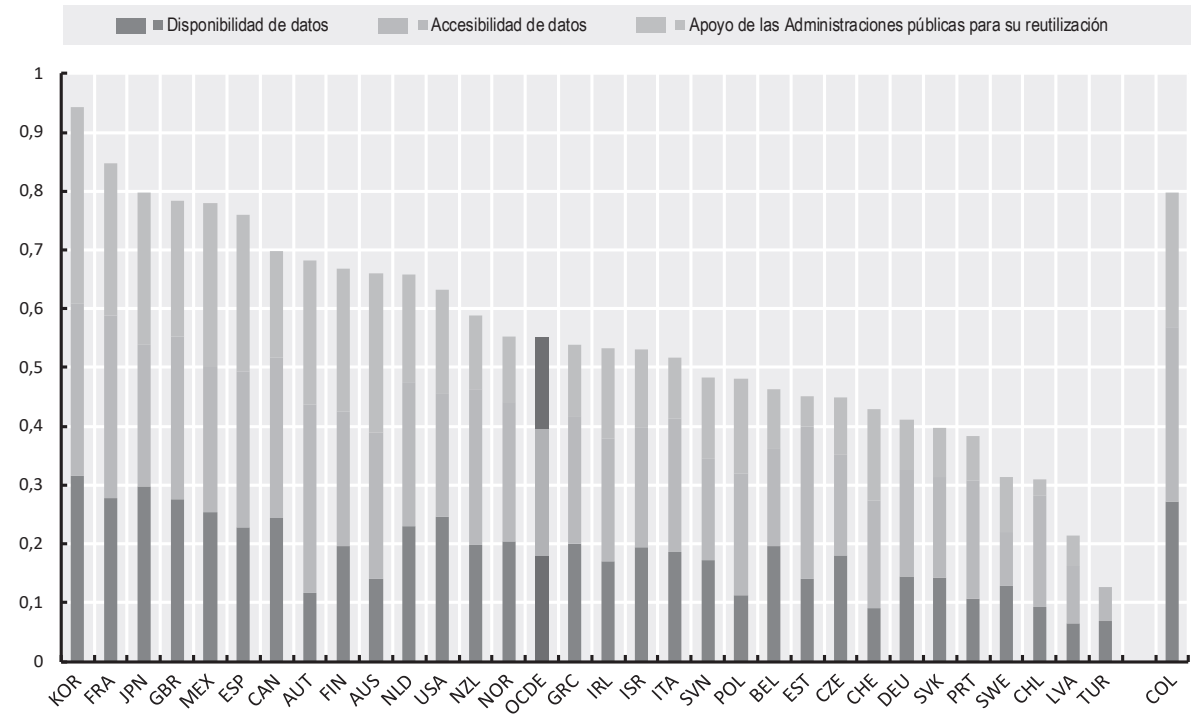

Fuente: Encuesta de la OCDE sobre datos de gobierno abierto, 2016.

Para más información véase Panorama de las Administraciones Públicas 2017, capítulo 10, «Gobierno abierto».

$<$ http://dx.doi.org/10.1787/888933533378>

El OURdata index de este año destacó una serie de conclusiones clave:

- Se podría reforzar el apoyo proactivo de la reutilización de los DGA. Las Administraciones públicas han dedicado un gran esfuerzo en establecer los requisitos formales necesarios para revelar una cantidad importante de conjuntos de datos en formatos abiertos, sin restricciones y 
reutilizables. Sin embargo, pocos países adoptan un enfoque proactivo que fomente la reutilización de datos tanto fuera del sector público (a través de iniciativas de concienciación, hackáthones y eventos de cocreación) como dentro (mediante sesiones informativas y formativas de funcionarios).

- Los países que han adoptado recientemente las políticas y prácticas de DGA tienen deficiencias en su implementación. Los últimos países en introducir reformas de DGA están pendientes de implementar algunas de sus políticas, como es el caso de Letonia, la República Checa, la República Eslovaca y la República de Eslovenia. Por el contrario, los primeros reformadores, como Canadá, Corea, los Estados Unidos, Francia y el Reino Unido, han implementado sus políticas en mayor medida, sobre todo en lo que respecta a la disponibilidad y accesibilidad de datos en un portal central/federal.

- Las consultas con las partes interesadas se llevan a cabo de manera habitual para respaldar las políticas de DGA, pero pocos países han habilitado plataformas donde los ciudadanos puedan participar activamente en la supervisión de su calidad y completar la información de los datos disponibles.

- Pocos países supervisan de cerca el impacto económico y social de los DGA, así como sus repercusiones en el rendimiento y productividad del sector público. Esta supervisión garantiza el progreso continuo y una mejor comprensión del impacto de las reformas de los DGA.

La OCDE está estudiando las maneras de fomentar la productividad y efectividad de las políticas mediante una reutilización más extensa de datos, pero, a medida que se amplían las fronteras de la tecnología, surgen nuevas cuestiones sobre si la publicación de conjuntos de datos abiertos resulta suficiente o si, por el contrario, también se debería reforzar la transparencia de los métodos de su recogida — que incluyen algoritmos informáticos operados por las Administraciones y por agencias de prestación de servicios-.

\section{MÁS ALLÁ DE LAS FRONTERAS NACIONALES: ABOGAR POR LA COOPERACIÓN REGULATORIA INTERNACIONAL}

Los problemas más complejos a los que se enfrentan los países en la actualidad trascienden las fronteras nacionales. Las amenazas que suponen el cambio climático, las epidemias, la evasión fiscal, los flujos financieros ilícitos, además de las crisis económicas y sociales, tienen causas y efectos globales. Más que nunca, los países necesitan coordinar sus enfoques para abordar los retos comunes, gestionar los bienes mundiales y garantizar la prosperidad compartida y la seguridad. La cooperación regulatoria internacional (CRI) 
proporciona un enfoque más efectivo para afrontar los problemas perversos que van más allá de las fronteras nacionales. Esto se recoge en el principio 12 de la Recomendación del Consejo de la OCDE sobre política y gobernanza regulatoria (OCDE, 2012).

Hay un amplio abanico de instrumentos que apoyan la cooperación regulatoria internacional. La OCDE (2013c) identifica 11 mecanismos distintos, que van desde la armonización de las normas y leyes en todos los países hasta tratados y acuerdos, actividades conjuntas en materia normativa y acuerdos de reconocimiento mutuo; además de instrumentos más informales, como pueden ser las herramientas de Derecho indicativo, entre las que se incluyen principios o directrices, el diálogo informal y el intercambio de información. Las Administraciones públicas suelen utilizar una combinación de estos instrumentos en sus prácticas de CRI.

Los casos de éxito muestran que la CRI ofrece grandes ventajas (véase el Cuadro 1.3). Al mismo tiempo, existe margen para una aplicación más sistemática de la CRI como un elemento más de buenas prácticas regulatorias y para su incorporación en los procesos de formulación de políticas. Sería de interés desarrollar sistemas de asesoramiento para que los países entendieran mejor cuándo la CRI proporciona soluciones prometedoras a los problemas políticos, así como los beneficios, costes y desafíos de sus diferentes mecanismos.

Las organizaciones internacionales (OI) juegan un papel fundamental en la promoción de la CRI. Existe gran diversidad de tipos de gobernanza de OI y de maneras con las que establecen las normas y estándares. La mayoría de las organizaciones se centran, en gran medida, en instrumentos políticos que no son legalmente vinculantes y funcionan como una plataforma para desarrollar directrices e intercambiar información. Las OI participan activamente en la planificación, diseño y desarrollo de normas y estándares internacionales, y recogen aportaciones y comentarios de las partes interesadas. Solo algunas OI hacen un seguimiento sistemático de sus instrumentos o evalúan sus resultados políticos. Esto se debe principalmente a problemas metodológicos, a una falta de recursos y competencias y a que esta responsabilidad suele recaer en los miembros. Es esencial aumentar los esfuerzos en desarrollar una cultura de evaluación de los instrumentos de las OI y de coordinación entre sus secretarías y destinatarios, con el fin de ampliar la cantidad de información recogida sobre la efectividad de sus actuaciones en materia de cooperación regulatoria internacional (OCDE, 2016a). 


\section{Cuadro 1.3. Armonización de las herramientas y políticas de seguridad química mediante el Programa de Medio Ambiente, Salud y Seguridad de la OCDE}

Los países de la OCDE tienen marcos regulatorios integrales para la prevención o la reducción de los riegos para la salud y el medio ambiente derivados de las sustancias químicas. Estos marcos garantizan que los productos químicos disponibles en el mercado se manejan de manera segura y que las nuevas sustancias químicas son evaluadas correctamente antes de su introducción en el mercado. Sin embargo, las distintas políticas nacionales de control químico pueden conducir a la duplicación de pruebas. Además, pueden crear barreras no arancelarias o técnicas en el comercio de sustancias químicas; desalentar la investigación, innovación y crecimiento, y aumentar el tiempo que supone introducir nuevos productos en el mercado.

El sistema de aceptación mutua de datos (AMD) desarrollado por el Programa de Medio Ambiente, Salud y Seguridad (EHS, por sus siglas en inglés) de la OCDE ayuda a minimizar las divergencias innecesarias entre los marcos regulatorios y facilita el trabajo conjunto de los Gobiernos. Establecido en 1981, el sistema AMD consta de tres Decisiones del Consejo de la OCDE que son vinculantes para los países miembros de la OCDE y los países en proceso de adhesión. El sistema supone la aceptación mutua de los datos sobre seguridad química generados de acuerdo con los estándares de la OCDE en cualquier país miembro. Asimismo, las reuniones periódicas entre representantes de las Administraciones y expertos del sector privado y la sociedad civil, en el contexto del Programa EHS, facilitan el desarrollo de nuevos instrumentos, directrices y bases de datos que apoyan la armonización de los programas químicos y fomentan el trabajo conjunto.

El sistema AMD ayuda a reducir y evitar las barreras comerciales no arancelarias impuestas por diversos requisitos regulatorios. También permite repartir las cargas de los ensayos de sustancias químicas entre los países miembros, lo que aporta eficiencia económica y mejora la gestión de riesgos, ya que los efectos del uso de productos químicos pueden rebasar las fronteras nacionales.

Un estudio de la OCDE de 2010 estima el ahorro neto anual generado por el Programa EHS en 153 millones de euros. Este ahorro se debe principalmente a que el programa evita la repetición de pruebas en distintos países e impone el uso de formatos estándares para la documentación y evaluaciones. Además, esta estimación no tiene en cuenta aspectos importantes que no se pueden cuantificar, como pueden ser los beneficios medioambientales y de salud debidos a una mejor evaluación de las sustancias químicas, la disminución de tiempos en la introducción de nuevos productos en el mercado y la fusión de conocimientos y experiencia para desarrollar métodos más eficaces de evaluación de las sustancias.

Fuente: OCDE (2013b) 


\section{CONCLUSIÓN}

La reforma del sector público - aunque supone una herramienta importante- - está cada vez más sujeta a las fuerzas fragmentadoras del mundo moderno. Todavía queda por ver si las estrategias de reforma tradicionales pueden ser reemplazadas por enfoques nuevos basados en resultados, medidas y evidencias, y por métodos de trabajo que permitan la experimentación, modificación e innovación continuas. La capacidad de adaptación de los países a un mundo en constante cambio depende en gran medida de su habilidad para movilizar la maquinaria del Gobierno y el capital humano de sus instituciones públicas. Es esencial que los responsables políticos y el CdG muestren un liderazgo fuerte para garantizar la coordinación e implementación efectivas en todos los sectores políticos y para asegurar que las reformas centradas en evidencias son de beneficio para todos. Los conocimientos que aportan los nuevos métodos de trabajo, como los enfoques sistémicos y las ciencias del comportamiento, pueden fomentar nuevas formas de rendimiento, aprovechando las ventajas de las nuevas tecnologías. Un elemento esencial de la adaptabilidad, sin embargo, es la capacidad y voluntad de los Gobiernos de arriesgar y ajustarse según proceda.

Las normas y regulaciones pueden asistir a los capacitadores y conductores del cambio fomentando la integridad, la elaboración de políticas basadas en evidencias y en la apertura; sin embargo, los resultados muestran que, por sí solas, pueden no ser suficientes para cultivar la adhesión sostenida a valores. Se debe complementar y reforzar la participación ciudadana en la formulación de políticas y prestación de servicios con recursos como los datos de gobierno abierto, además de con iniciativas de concienciación como las que se llevan a cabo en colegios para promover los valores de compromiso cívico y de integridad. El liderazgo efectivo de los cargos más elevados debe capacitar a los funcionarios para actuar sobre la base de evidencias abundantes, facilitando aspectos clave del cambio continuo, como son la formación constante y la transformación cultural. El compromiso de los funcionarios es fundamental para adoptar esta nueva cultura de la innovación, y es necesario que estos sean consultados en mayor medida para garantizar que el cambio sea duradero.

Por último, es de vital importancia evaluar los resultados del sector público y comunicarlos a la población, con el fin de revertir la desconfianza de los ciudadanos en las autoridades. El cambio político depende de la participación de los ciudadanos y partes interesadas en diálogos públicos sobre los objetivos del Gobierno, lo que se hace por conseguirlos y cuáles son los resultados, con el fin de alcanzar un consenso sobre alternativas políticas. La publicación sistemática de los resultados de las evaluaciones de las políticas, y el anuncio público de sus consecuencias positivas a través de los medios tradicionales y de las redes sociales, pueden también fomentar un mayor nivel de cohesión social, estimular el debate público y aumentar la tolerancia al riesgo, reforzando, en definitiva, la capacidad de efectuar cambios. 


\section{Nota}

El término centro de gobierno se refiere a la estructura administrativa que sirve al Ejecutivo (presidente o primer ministro, y el gabinete a nivel colectivo). Tiene una gran variedad de nombres dependiendo del país, como Secretaría General, Oficina del Gabinete, Cancillería, Oficina/Ministerio del Presidente, Oficina del Consejo de Ministros, etc. En muchos países, el CdG está formado por más de una unidad, que desempeñan distintas funciones. Una unidad que comparten prácticamente todos los centros de gobierno es la unidad que sirve de manera específica al jefe de Gobierno. Esta también tiene una variedad de nombres, como Gabinete del Primer Ministro u Oficina Privada (OCDE, 2013a).

\section{BIBLIOGRAFÍA}

Batie, S. S., y Schweikhardt, David B. (2010), «Societal concerns as wicked problems: The case of trade liberalisation», Policy responses to societal concerns in food and agriculture. Proceedings of an OECD Workshop, OECD Publishing, París.

Deighton-Smith, R., A. Erbacci, y Kauffmann, C. (2016), «Promoting inclusive growth through better regulation: The role of regulatory impact assessment», OECD Regulatory Policy Working Papers, n. ${ }^{\circ}$ 3, OECD Publishing, París.

O' Donovan, Brendan (2014). «Editorial for special issue of SPAR: The vanguard method in a systems thinking context», Syst Pract action Res (2014) 27:1-20 DOI 10.1007/s11213-012-9247-7.

OECD, Policy advisory systems: A cross country public governance perspective, OECD Publishing, París (de próxima publicación).

OECD (2017a), Behavioural insights and public policy: Lessons from around the world, OECD Publishing, París.

OECD (2017b), Recommendation of the Council on public integrity, OECD Publishing, París.

OECD (2017c), Working with change. Systems approaches to public sector challenges, <www.oecd.org/media/oecdorg/satellitesites/opsi/contents/files/SystemsApproachesDraft.pdf $>$.

OECD (2017d), Preventing policy capture: Integrity in public decision making, OECD Public Governance Reviews, OECD Publishing, París, $<$ http:// dx.doi.org/10.1787/9789264065239-en>. 
OECD (2016a), International regulatory co-operation: The role of international organisations in fostering better rules of globalisation, OECD Publishing, París.

OECD (2016b), OECD Survey on Planning and Co-ordinating the Implementation of the SDGs: First results and key issues, <www.oecd.org/gov/cobsdg-survey-overview-of-results.pdf $>$.

OECD (2016c), Recommendation of the Council on gender equality in public life, OECD Publishing, París.

OECD (2016d), Trends in risk communication policies and practices, OECD Reviews of Risk Management Policies, OECD Publishing, París, <http:// dx.doi.org/10.1787/9789264260467-en>.

OECD (2016e), Engaging public employees for a high-performing civil service, OECD Public Governance Reviews, OECD Publishing, París, <http:// dx.doi.org/10.1787/9789264267190-en>.

OECD (2015a), Delivering from the centre. Strengthening the role of the centre of government in driving priority strategies, <www.oecd.org/gov/cog2015-delivering-priority-strategies.pdf $>$.

OECD (2015b), OECD regulatory policy outlook 2015, OECD Publishing, París.

OECD (2015c), Slovak Republic: Better co-ordination for better policies, services and results, OECD Publishing, París.

OECD (2014a), Recommendation of the Council on digital government strategies, OECD Publishing, París.

OECD (2014b), Recommendation of the Council on the governance of critical risks, OECD Publishing, París.

OECD (2014c), OECD (2014), Lobbyists, Governments and public trust: Implementing the OECD principles for transparency and integrity in lobbying, vol. 3, OECD Publishing. DOI: 10.1787/ 9789264214224-en.

OECD (2013a), Centre stage. Driving better policies from the centre of government, <www.oecd.org/gov/Centre-Stage-Report.pdf>.

OECD (2013b), "Chemical safety», International regulatory co-operation: Case Studies, vol. 1: Chemicals, consumer products, tax and competition, OECD Publishing, París.

OECD (2013c), International regulatory co-operation: Addressing global challenges, OECD Publishing, París.

OECD (2012), Recommendation of the Council on regulatory policy and governance, OECD Publishing, París. 
Orazi, Davide Christian, ET aL. (2013), «Le leadership du secteur public: Nouvelles perspectives pour la recherche et la pratique», Revue Internationale des Sciences Administratives, 2013/3 (vol. 79), págs. 521-541, DOI: 10.3917/risa.793.0521.

Print, M., y Lange, D. (eds.) (2013), Civic education and competences for engaging citizens in democracies, Sense Publishers, Rotterdam.

Rosenbaum, Walter A. (2002), Environmental politics and policy, 5. edición, CQ Press, Washington, D. C.

WART, M. V. (2013), «Lessons from leadership theory and contemporary challenges of leaders», Public Administration Review, 73(4), págs. 553-564. 



\section{CAPÍTULO 2. ECONOMÍA Y FINANZAS PÚBLICAS}

\section{BALANCE FISCAL DE LA ADMINISTRACIÓN GENERAL}

El balance fiscal es la diferencia entre los ingresos y los gastos generales de la Administración general y muestra la cantidad de gastos financiados por los fondos recaudados en un año determinado. Si en un año concreto las Administraciones ingresan más de lo que gastan, se produce un superávit. A la inversa, cuando las Administraciones gastan más de lo que ingresan, hay un déficit. Los déficits consecutivos darán lugar a niveles de deuda crecientes y, en consecuencia, a mayores gastos en intereses.

En general, los balances fiscales de los países de la OCDE han continuado estabilizándose después de la crisis financiera internacional. A medida que la necesidad de consolidación fiscal que se dio al principio de la crisis disminuye, mejoran los balances fiscales: entre los países de la OCDE, el balance medio en 2015 alcanzó el $-2,8 \%$ del PIB, recuperándose considerablemente del mínimo de $-8,4 \%$ marcado en 2009. En 2015, Noruega tuvo el mayor superávit fiscal, con un $6 \%$ del PIB, como consecuencia de la normativa fiscal del país, seguida de Luxemburgo (1,4\%), Corea (1,4\%), Turquía (1,3\%) y Chile $(1,1 \%)$. Por el contrario, el mayor déficit fiscal se dio en Grecia $(5,9 \%)$, debido a su pobre crecimiento, seguida de España (5,1\%), Portugal (4,4\%), el Reino Unido (4,3\%) y los Estados Unidos (4,2\%).

En cuanto al año 2016, los balances fiscales variaron de un déficit del $-4,5 \%$ en España a un superávit del 17,2\% en Islandia. La consolidación fiscal en Grecia ha conseguido un superávit del 0,7\% del PIB por primera vez, después de marcar un mínimo en 2009 con un déficit del 15,1\% del PIB. El elevado superávit de Islandia fue producto de los ingresos extraordinarios derivados de contribuciones estatales por parte de bancos protagonistas de la crisis financiera del país, que supusieron un aumento del 52\% de los ingresos fiscales totales.

El balance primario - es decir, el balance fiscal total excluyendo los pagos netos por intereses de la deuda pública - es un factor especialmente impor- 
tante de la sostenibilidad a corto plazo, ya que muestra hasta qué punto pueden las Administraciones cumplir sus obligaciones sin contraer deudas adicionales. Junto con los pagos netos por intereses del servicio de la deuda, que constituyen una parte inflexible de los presupuestos públicos, el balance primario proporciona una idea más clara del estado de la gestión fiscal de un país.

En 2015, del déficit promedio del 2,8\% del PIB en los países de la OCDE, el $2 \%$ del PIB representó pagos netos por intereses, que derivan en un balance primario medio del $-0,8 \%$ del PIB. El mayor déficit primario se dio en Japón (3,1\%), seguido de Grecia (2,6\%), Finlandia (2,5\%), España $(2,4 \%)$ y el Reino Unido $(2,3 \%)$, mientras que los mayores superávits primarios los tuvieron Noruega $(3,1 \%)$, Islandia $(2,9 \%)$ y Turquía $(2,9 \%)$. Los pagos netos por intereses fueron más elevados en Portugal (4,2\%), Italia (4\%), Islandia $(3,8 \%)$ y Grecia (3,4\%). Además, según la información disponible para 2016, Islandia tuvo el mayor superávit primario entre los países de la OCDE, con un 20,6\% del PIB, como consecuencia de los mencionados aumentos de ingresos extraordinarios, y Grecia registró un superávit primario del 3,8\%, mientras que los mayores incrementos en los pagos netos por intereses como proporción del PIB entre 2015 y 2016 se dieron en Finlandia, Noruega y el Reino Unido (0,1 p. p. en los tres países). De los países en proceso de adhesión en 2015, Colombia tuvo el déficit más elevado, con un 3,2\% del PIB, seguida de Costa Rica $(1,5 \%)$ y Lituania $(0,2 \%)$.

\section{Metodología y definiciones}

Los datos de balance fiscal se obtienen de las estadísticas de contabilidad nacional de la OCDE (base de datos), que se basan en el sistema de contabilidad nacional (SCN), un conjunto de conceptos, definiciones, clasificaciones y reglas acordados internacionalmente para la contabilidad nacional. El marco actualizado del SCN del año 2008 ha sido ya implementado en todos los países de la OCDE (véase el anexo A para detalles sobre sistemas y fuentes de información). De acuerdo con la terminología del SCN, la Administración general se compone de la Administración central, Administraciones estatales y locales, y de las entidades de la seguridad social. El balance fiscal, también conocido como capacidad de financiación neta $(+)$ o necesidad de endeudamiento neto (-) de la Administración general, se calcula tomando los ingresos totales y restándoles los gastos totales. Los ingresos comprenden los im- 
puestos, las cotizaciones sociales netas, las subvenciones y otros ingresos. Los gastos comprenden el consumo intermedio, las retribuciones de los empleados públicos, los subsidios, los ingresos sobre la propiedad (incluyendo los pagos por intereses), las prestaciones sociales, otros gastos corrientes (principalmente las transferencias corrientes) y los gastos de capital (es decir, las transferencias e inversiones de capital). El balance primario es el balance fiscal excluyendo los pagos netos por intereses sobre los pasivos de la Administración general (es decir, los pagos por intereses menos los ingresos procedentes de intereses). El producto interior bruto (PIB) es la medida estándar del valor de los bienes y servicios producidos por un país durante un periodo determinado.

\section{Otras publicaciones}

OECD (2015), National Accounts at a Glance 2015, OECD, París, <http://dx. doi.org/10.1787/na_glance-2015-en>.

Statistics Iceland (2017), General Government finances 2016, Statistics Iceland, Reikiavik, <http://www.statice.is/publications/publicationdetail?id=57984>.

\section{Notas de los gráficos}

Los datos de Brasil, Costa Rica y Sudáfrica corresponden a 2014 en lugar de 2015.

2.1: Los datos de Chile y Turquía no se incluyen en la media de la OCDE ya que faltan series temporales o los principales agregados no financieros de las Administraciones públicas. Los datos de China y Rusia corresponden a 2014 en lugar de a 2015.

2.2: Los datos de Chile no están disponibles. Los datos de Turquía no se incluyen en la media de la OCDE puesto que faltan series temporales. El valor del balance primario de Islandia del 20,6\% del PIB para el año 2016 no se muestra en el gráfico.

Información sobre los datos de Israel: <http:/dx.doi.org/10.1787/888932315602>. 


\section{Gráfico 2.1. Balance fiscal de la Administración general como porcentaje del PIB, 2007, 2009, 2015 y 2016}

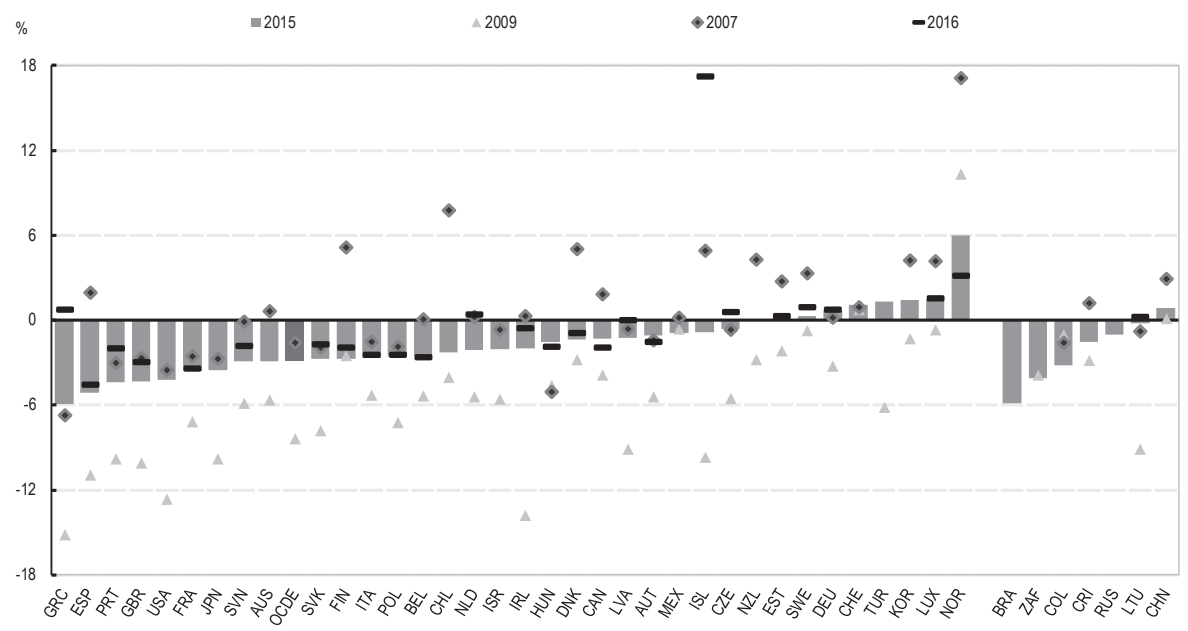

Fuente: Estadísticas de contabilidad nacional de la OCDE (base de datos). Los datos de India e Indonesia son del Economic Outlook del FMI (abril 2017).

Gráfico 2.2. Balance primario y gastos netos por intereses de la Administración general como porcentaje del PIB, 2015 y 2016

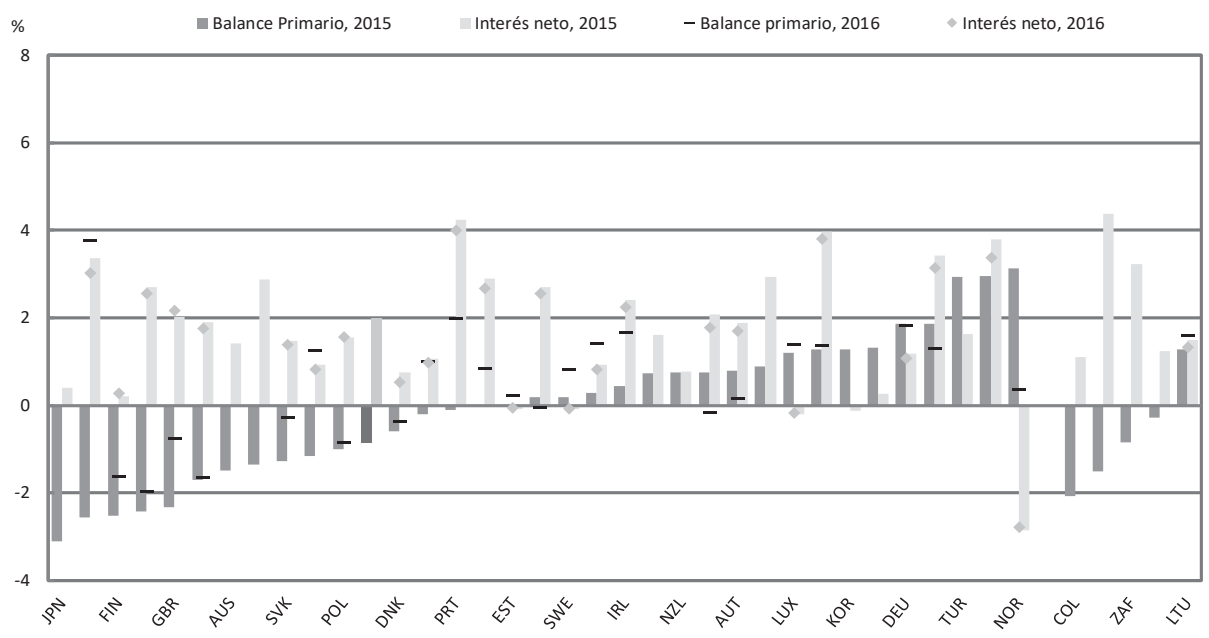

Fuente: Estadísticas de contabilidad nacional de la OCDE (base de datos). 


\section{AHORRO NETO DE LA ADMINISTRACIÓN GENERAL}

El ahorro neto surge, y se acumula a lo largo del tiempo, cuando los ingresos exceden los gastos sin tener en cuenta los gastos de capital, como la inversión pública y las transferencias a empresas públicas o a instituciones financieras (por ejemplo, sus rescates durante la crisis financiera).

El ahorro neto de las Administraciones públicas se asocia también con el concepto de la regla de oro, por la cual los ingresos corrientes de las Administraciones deberían, en general, cubrir los gastos corrientes durante el curso de un ciclo económico. El cumplimiento de esta regla puede ayudar a evitar que los balances fiscales se vuelvan insostenibles y comprometan el crecimiento a largo plazo, hasta tal punto que los gastos de capital financiados por el déficit se dedican a inversiones evaluadas cuidadosamente y que estimulan el crecimiento.

En 2015, en los países de la OCDE, el ahorro neto promedio alcanzó el $-2,2 \%$ del PIB, una mejora con respecto al $-6,2 \%$ de 2009 , aunque lejos todavía del nivel precrisis del $-0,1 \%$ de 2007 . España tuvo el mayor ahorro neto negativo en 2015 , con un $-5,2 \%$ del PIB. Por el contrario, Noruega tuvo el mayor ahorro neto positivo, con un $7,7 \%$ del PIB.

Según los datos disponibles de 2016, ocho de los treinta y cuatro países de la OCDE registraron un ahorro neto positivo en 2016; de ellos, Islandia $(19,2 \%)$, Noruega (5,1\%), Luxemburgo (3,7\%), Suecia (2,3\%), Estonia (1,7\%) y Alemania $(1,2 \%)$ obtuvieron los valores más elevados. El mayor ahorro neto negativo de este año se dio en España $(-4,6 \%)$, Portugal $(-3,4 \%)$, Francia $(-2,6 \%)$, Bélgica $(-2,4 \%)$, la República Eslovaca $(-2,3 \%)$ e Italia $(-2 \%)$.

Si se compara 2015 con 2007, el año previo a la crisis financiera y económica, los mayores cambios en ahorro neto tuvieron lugar en Noruega, con un descenso del 18,3\% en 2007 al, todavía positivo, 7,7\% en 2015; España experimentó el segundo mayor cambio durante este periodo, pasando de un ahorro neto positivo del 5,2\% del PIB en 2007 a uno negativo del $-5,2 \%$ en 2015. De manera similar, si se compara el ahorro neto de 2015 con el de 2009, Grecia marcó la mayor reducción en ahorro neto, pasando de un $-13,2 \%$ a un $-4 \%$, seguida de Irlanda, que pasó de un $-9,1 \%$ a un $-0,6 \%$, e Islandia, que incrementó su ahorro neto de un $-6,6 \%$ a un $1,5 \%$.

La capacidad o necesidad de financiación neta es equivalente al ahorro neto cuando se tienen en cuenta los gastos de capital. Como consecuencia, las diferencias entre los dos balances pueden apuntar a gastos de inversión o a fugas por transferencias de capital. En promedio, entre los países de la OCDE, el déficit (capacidad/necesidad de financiación neta) fue 0,6 p. p. más elevado que el ahorro neto en 2015. Las mayores diferencias negativas se dieron en Grecia (2,2 p. p.) y en el Reino Unido (1,5 p. p.). En el caso de Grecia, la diferencia se debe en parte a transferencias de capital ( $0,9 \%$ del PIB) y se explica 
principalmente por la capitalización bancaria que tuvo lugar durante ese año. En el caso del Reino Unido, donde se observa un patrón similar, la diferencia se debió parcialmente a algunas ayudas pendientes a bancos que se desembolsaron en efectivo. Según los datos de 2016, la situación de ambos países está evolucionando y, mientras que en Grecia la diferencia entre la capacidad/necesidad de financiación neta casi se equilibró debido a una transferencia neta de capital positivo (1,4\% del PIB), en el Reino Unido disminuyó ligeramente $(1,4$ p. p.). No obstante, en este último caso las transferencias netas de capital se mantuvieron constantes $(0,5 \%$ del PIB).

\section{Metodología y definiciones}

Los datos se obtienen de las estadísticas de contabilidad nacional de la OCDE (base de datos), que se basan en el sistema de contabilidad nacional (SCN), un conjunto de conceptos, definiciones, clasificaciones y reglas acordados internacionalmente para la contabilidad nacional. El marco actualizado del SCN del año 2008 ha sido ya implementado en todos los países de la OCDE (véase el anexo A para detalles sobre sistemas y fuentes de información). El ahorro neto de las Administraciones públicas corresponde a los ingresos corrientes menos los gastos corrientes incluyendo la depreciación. En el caso del ahorro bruto, los costes de depreciación no se deducen de los gastos corrientes. El ahorro bruto más las transferencias netas de capital (es decir, las transferencias de capital recibidas menos las abonadas) menos las inversiones públicas (es decir, la formación bruta de capital y adquisiciones menos las cesiones de activos no financieros no producidos) es igual al balance fiscal de la capacidad/necesidad de financiación neta (para más información sobre el balance fiscal de las Administraciones, véase la sección «Metodología y definiciones» de este indicador). En este sentido, la capacidad/necesidad de financiación neta refleja la posición fiscal después de contabilizar los gastos de capital: una capacidad de financiación neta, o superávit público, significa que las Administraciones están proporcionando recursos financieros a otros sectores, mientras que una necesidad de financiación neta, o déficit público, significa que las Administraciones requieren recursos financieros de otros sectores para financiar parte de sus gastos. En comparación con la capacidad/necesidad de financiación neta, el ahorro neto tiene la ventaja de evitar posibles distorsiones puntuales provocadas por transferencias extraordinarias de capital, a menudo, muy elevadas. También evita poner demasiada presión sobre las inversiones públicas en tiempos de programas de austeridad y déficits crecientes. El Gráfico 2.5, «Transferencias netas de capital como porcentaje del PIB», está disponible online en el anexo F. 


\section{Otras publicaciones}

OECD (2015), National Accounts at a Glance 2015, OECD, París, $<$ http://dx.doi.org/10.1787/na_glance-2015-en>.

\section{Notas de los gráficos}

Los datos de Chile no están disponibles. Los datos de Turquía no se incluyen en la media de la OCDE puesto que faltan series temporales.

2.3: Los datos de Colombia y Rusia corresponden a 2012 en lugar de a 2013.

2.4: Los valores de Islandia de 2016 no se muestran en el gráfico (ahorro neto y endeudamiento neto, con un $19,2 \%$ y un $17,2 \%$ del PIB, respectivamente). Los datos de Costa Rica, Rusia y Sudáfrica corresponden a 2014 en lugar de a 2015.

Información sobre los datos de Israel: <http://dx.doi.org/10.1787/888932315602>.

\section{Gráfico 2.3. Ahorro neto de la Administración general como porcentaje del PIB, 2007, 2009, 2015 y 2016}

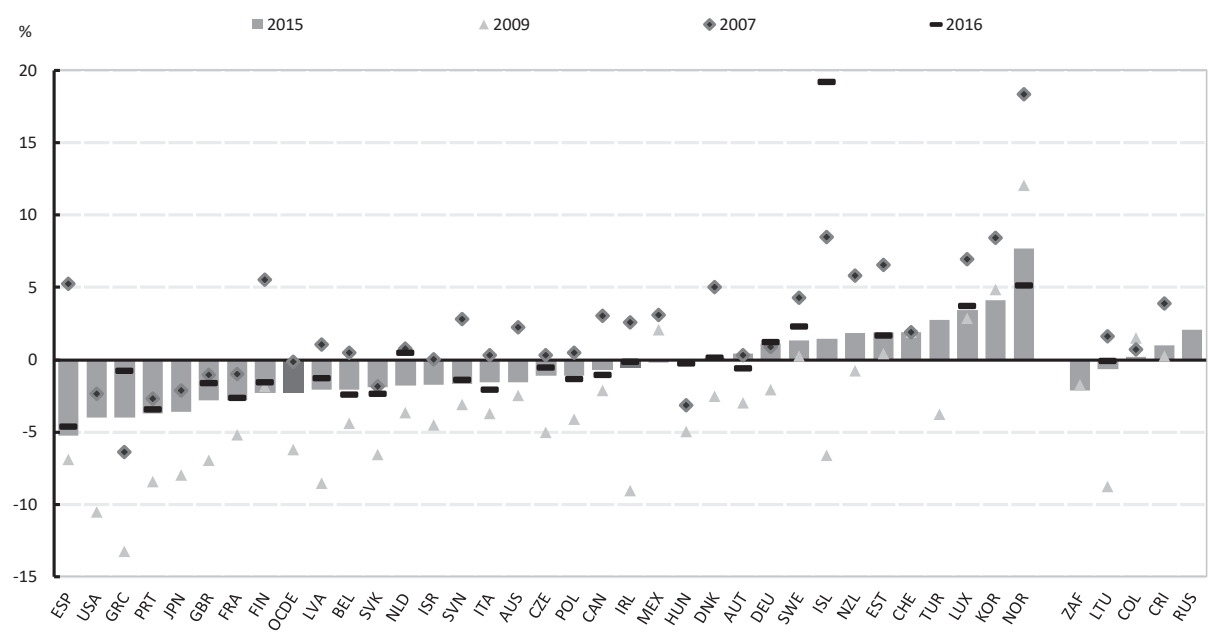

Fuente: Estadísticas de contabilidad nacional de la OCDE (base de datos). 
Gráfico 2.4. Ahorro neto de la Administración general versus capacidad/necesidad de financiación neta como porcentaje del PIB, 2015 y 2016

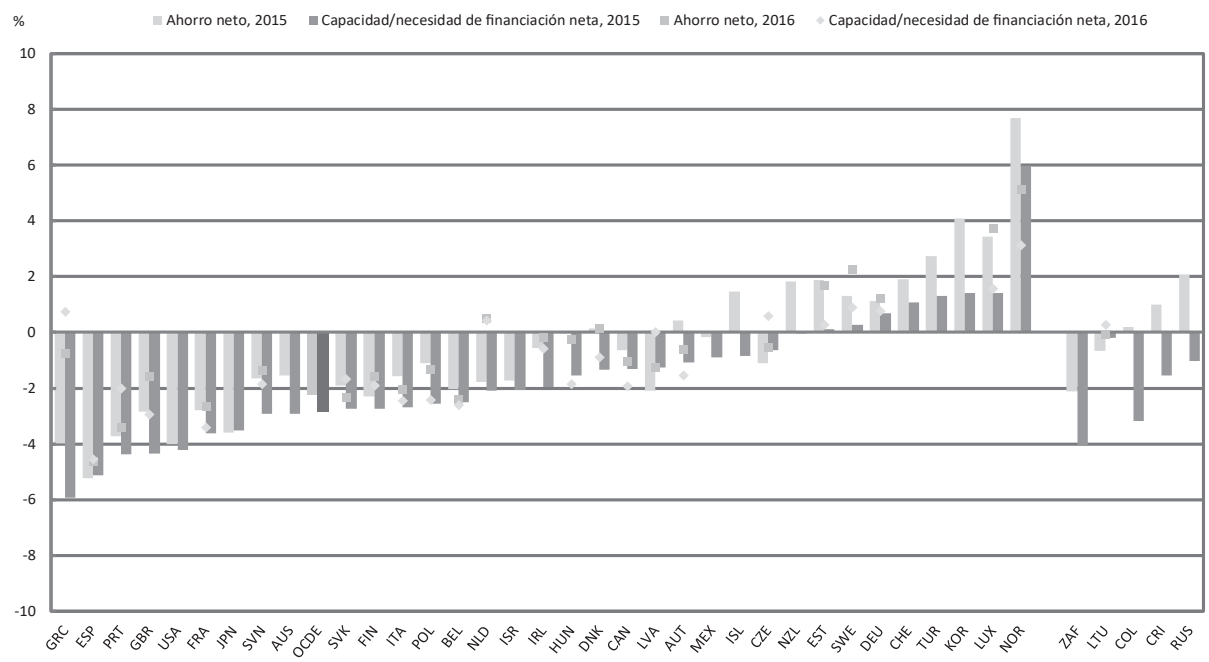

Fuente: Estadísticas de contabilidad nacional de la OCDE (base de datos).

$<$ http://dx.doi.org/10.1787/888933531421>

\section{BALANCE ESTRUCTURAL DE LA ADMINISTRACIÓN GENERAL}

Los ingresos y gastos de la Administración general son muy sensibles a los ciclos de las actividades económicas. Los ingresos (especialmente los fiscales) tienden a disminuir durante las recesiones económicas, al mismo tiempo que los gastos pueden aumentar debido al creciente número de personas que pierden su empleo y reciben prestaciones y ayudas sociales. Por el contrario, las finanzas públicas mejoran durante los periodos de bonanza, puesto que los ingresos fiscales aumentan y el número de personas que perciben subsidios sociales disminuye. Estas variaciones de los ingresos y gastos públicos - en ausencia de cambios discrecionales de política - dificultan evaluar si la política fiscal es expansionista, neutra o restrictiva durante un periodo de tiempo determinado, y decidir si los balances fiscales son sostenibles a largo plazo.

Estos factores se tienen en cuenta en el cálculo del balance estructural de las Administraciones públicas, que resulta de extraer los mencionados efectos cíclicos en la economía, además de los eventos puntuales, de los gastos e ingresos públicos. Separar los componentes estructurales de los cíclicos proporciona una visión más clara de la solvencia y sostenibilidad subyacentes de la política fiscal. 
Para calcular el balance estructural se necesita estimar los componentes estructurales y cíclicos, tanto del balance fiscal como de la producción (es decir, el PIB potencial). En el caso de las cuentas fiscales, los gastos e ingresos estructurales están separados de los gastos e ingresos discrecionales, respectivamente. En el caso del PIB potencial, se estima la tendencia de producción a largo plazo para distinguir entre la producción estructural y la cíclica.

Aunque en general el balance fiscal estructural se vio deteriorado por la crisis financiera, desde 2015 la magnitud de los déficits estructurales ha decrecido en los países de la OCDE: en promedio, estos países experimentaron un balance estructural del $-2,4 \%$ del PIB potencial en 2015, lo que supone una mejora con respecto al $-6,3 \%$ alcanzado en 2009 y al $-3,2 \%$ de 2007 . El contraste entre 2009 y 2016 es evidente: solo Finlandia y Hungría experimentaron un deterioro de sus balances estructurales, que resultó en déficits estructurales del $0,1 \%$ y $3,0 \%$ respectivamente en 2016 , mientras que el resto de los países de la OCDE mejoraron su balance estructural. En 2016, el mayor déficit estructural se dio en Japón (4,8\%), seguido de los Estados Unidos (4,3\%) y el Reino Unido (4,1\%). En cambio, los mayores superávits estructurales se dieron en Grecia $(6,1 \%)$, principalmente debido a una caída del PIB potencial, Corea (2,5\%), Luxemburgo (1,6\%) y Estonia (1,5\%).

El balance estructural estimado se entiende mejor en relación con el balance fiscal y las posiciones de capacidad/necesidad de financiación neta, ya que el contraste ayuda a calibrar las diferencias entre la sostenibilidad de las finanzas públicas a corto y largo plazo. Entre 2007 y 2015, a pesar de que el déficit estructural medio de los países de la OCDE disminuyó de un 3,2\% a un $2,4 \%$ del PIB, mientras que el déficit fiscal observado aumentó de un $1,8 \%$ a un $2,8 \%$ del PIB, ambos niveles tendieron a converger a medida que las economías se aproximaban a sus cotas de producción a largo plazo después de la crisis. Por ejemplo, Irlanda registró un déficit del 13,8\% del PIB en 2009 y un déficit estructural del $8,7 \%$ del PIB potencial en el mismo año y, sin embargo, en 2015 el déficit observado decreció a un 2\% del PIB y el déficit estructural alcanzó un $1,2 \%$.

Puesto que el balance fiscal estructural indica las tendencias a largo plazo más que las variaciones a corto plazo, se puede combinar con otras proyecciones macroeconómicas de futuro cercano. Las estimaciones de la OCDE apuntan a que la consolidación fiscal se ha paralizado puesto que se espera un deterioro promedio de $-0,4$ p. p. del PIB en el balance primario estructural de la mayoría de los países de la OCDE entre 2016 y 2018. Durante este periodo, los mayores cambios se prevén en Grecia $(-2,7$ p. p.), Hungría $(-2,2$ p. p.) y Luxemburgo (-2,1 p. p.). 


\section{Metodología y definiciones}

Los datos se han extraído de la base de datos del Economic Outlook de la OCDE, n. ${ }^{\circ}$ 101. El balance fiscal estructural, o saldo subyacente, representa el saldo fiscal establecido en el marco del sistema de contabilidad nacional ( $\mathrm{SCN}$ ) ajustándose a dos factores: el estado del ciclo económico (medido por la brecha de producción) y las operaciones fiscales puntuales. El balance primario estructural está también ajustado al impacto de los pagos netos por intereses sobre los pasivos de la Administración general (es decir, los pagos por intereses menos los ingresos procedentes de intereses). La brecha de producción mide la diferencia entre el PIB real y el potencial, siendo este último una estimación del nivel de PIB que se obtendría si la economía estuviera rindiendo a plena capacidad. El PIB potencial no se puede observar directamente y las estimaciones están sujetas a márgenes substanciales de error. Los factores puntuales incluyen tanto transacciones fiscales excepcionales e irregulares como desviaciones de tendencia en las transferencias netas de capital. Para más información, véase la base de datos del Economic Outlook de la OCDE, sección «Sources and Methods» (<www.oecd.org/eco/sourcesand-methods $>$ ).

\section{Otras publicaciones}

OECD (2017), OECD Economic Outlook, volumen 2017, Edición 1, OECD, París, <http://dx.doi.org/10.1787/eco_outlook-v2017-1-en>.

\section{Notas de los gráficos}

Los datos de Chile, México y Turquía no están disponibles.

Información sobre los datos de Israel: <http://dx.doi.org/10.1787/888932315602>. 
Gráfico 2.6. Balance estructural de la Administración general como porcentaje del PIB potencial, 2007, 2009, 2015 y 2016

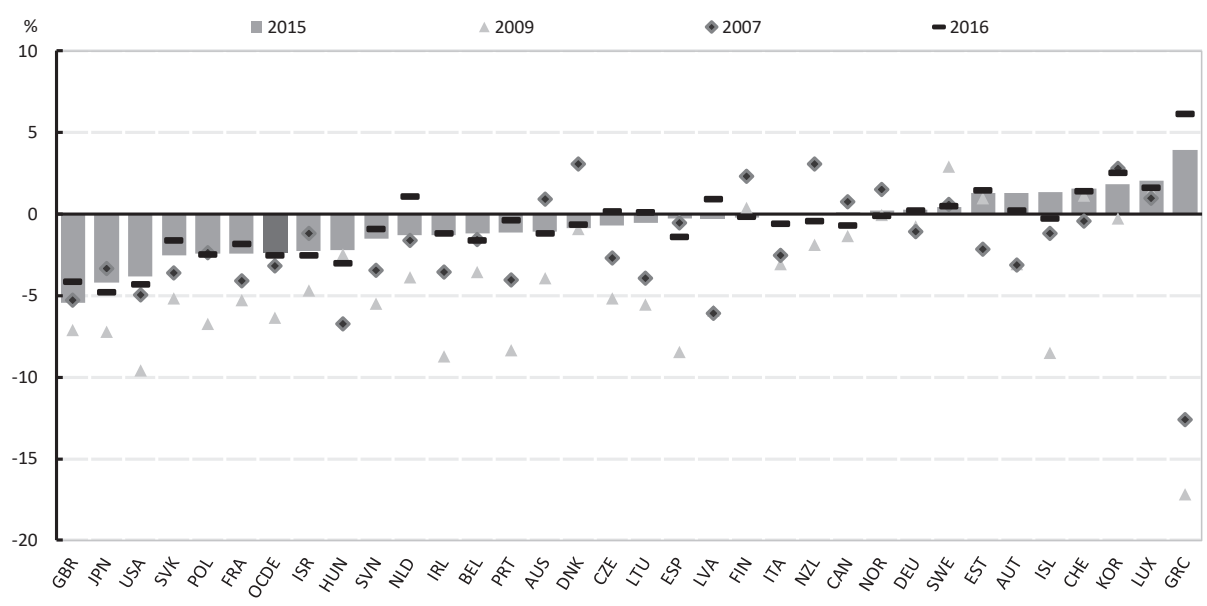

Fuente: OCDE Economic Outlook, n. ${ }^{\circ}$ 101, junio de 2017.

Gráfico 2.7. Balance primario estructural de la Administración general como porcentaje del PIB potencial, 2007, 2009, 2015 y 2016

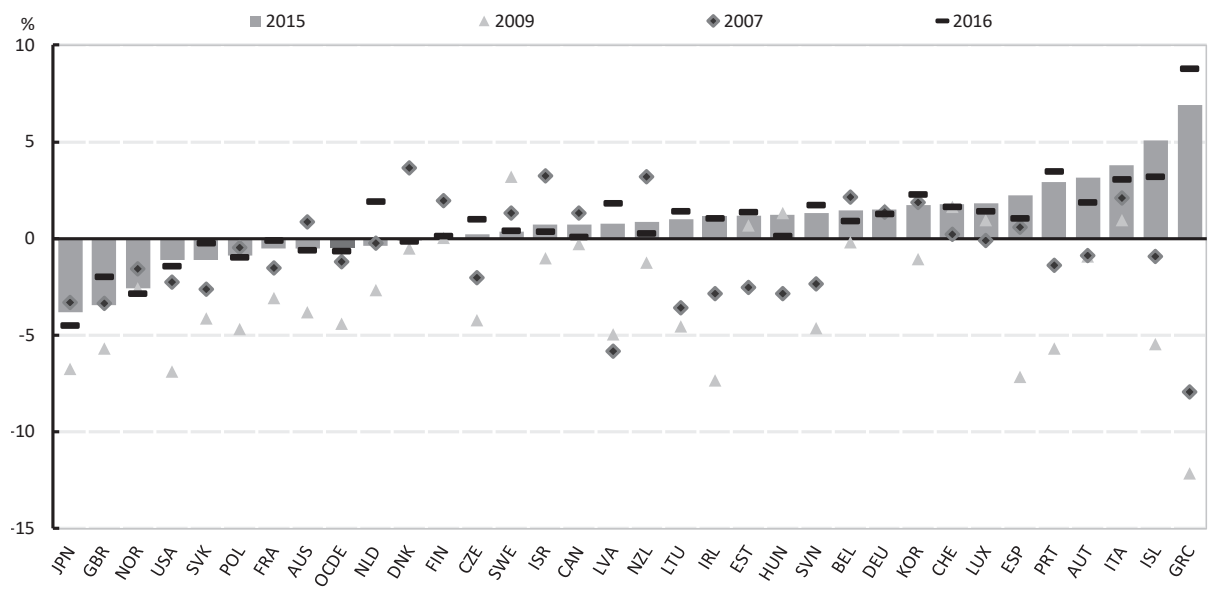

Fuente: OCDE Economic Outlook, n. ${ }^{\circ}$ 101, junio de 2017. 
Gráfico 2.8. Proyección del balance primario estructural de la Administración general como porcentaje del PIB potencial en 2017 y 2018 y variaciones desde 2016

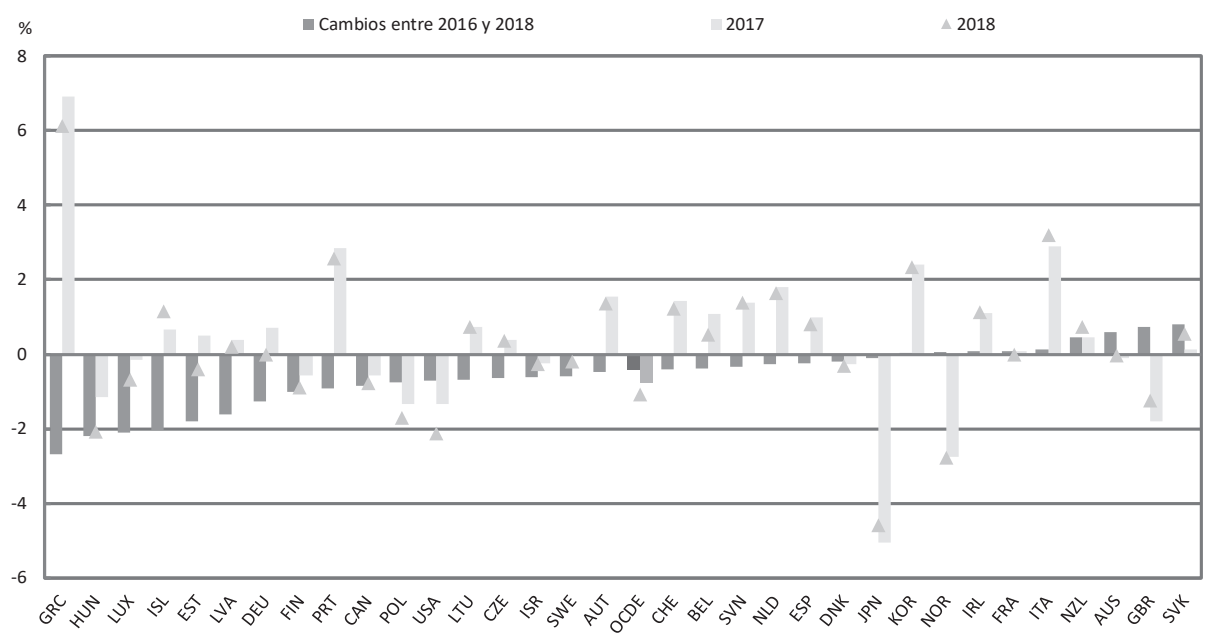

Fuente: OCDE Economic Outlook, n. ${ }^{\circ}$ 101, junio de 2017.

\section{DEUDA BRUTA DE LA ADMINISTRACIÓN GENERAL}

La deuda bruta de las Administraciones públicas incluye todas las obligaciones financieras contraídas. Las Administraciones acumulan deuda para financiar los gastos que exceden sus ingresos. La deuda soberana, a largo plazo, puede fomentar la acumulación de capital físico, especialmente cuando los tipos de interés son bajos; pero puede impedir la acumulación de capital cuando los tipos de interés aumentan. Si se utiliza una gran porción de los ingresos corrientes para satisfacer los pagos por intereses de la deuda, la política fiscal se ve limitada. Por tanto, los niveles de deuda pública pueden ser críticos para la estabilidad de la economía.

En 2015, el nivel medio de la deuda pública bruta en los países de la OCDE alcanzó el $112 \%$ del PIB, un aumento con respecto al $73 \%$ de 2007 antes de la crisis financiera. Durante este periodo, los mayores incrementos de deuda pública se registraron en España (75,1 p. p.), la República de Eslovenia (73 p. p.), Portugal (71,1 p. p.) y Grecia (68,8 p. p.). Después de la crisis griega, los niveles de deuda aumentaron rápidamente a raíz del incremento del rendimiento en 2010, cuando se anunció el primer rescate. En 2011, el 
rendimiento también aumentó en Portugal y España, debido a que Portugal solicitó un rescate en ese año y en España coincidieron la crisis bancaria y de deuda soberana. En la República de Eslovenia, el crecimiento del PIB fue negativo en 2009 y 2012, tras una breve recuperación en 2010 y 2011, de manera que los niveles de deuda aumentaron a medida que se llevaron a cabo las recapitalizaciones de bancos.

De 2007 a 2015, los niveles de deuda solo descendieron en Noruega $(-16,7$ p. p.), Suiza ( $-5,2$ p. p.) e Israel $(-2,1$ p. p.). El país que registró mayor deuda pública durante este periodo fue Japón, que alcanzó el 221,8\% del PIB en 2015 , seguido de Grecia (181,6\%), Italia $(157,5 \%)$ y Portugal $(149,2 \%)$. Aunque los niveles de deuda ralentizan la economía, la propiedad de la deuda también es un factor que se ha de tener en cuenta: si la deuda está en manos de inversores externos puede estar sujeta a una rebaja en la calificación crediticia de la deuda del país, y por tanto a aumentos en los tipos de interés, pero, si es contraída por la población, como en el caso de Japón, este riesgo es menos probable. Por otro lado, los países de la OCDE con niveles de deuda más bajos fueron Estonia (13\%), Chile (24,5\%), Turquía (27,4\%) y Luxemburgo $(30,7 \%)$.

La deuda bruta per cápita alcanzó una media de 50245 USD PPA en 2015, lo que supone una tasa anual de crecimiento de la deuda pública real per cápita del 5,9\% desde 2007. No obstante, la renta bruta per cápita varía significativamente entre los países de la OCDE, con niveles superiores que multiplican casi por treinta los niveles más bajos: en 2015, la deuda bruta per cápita en Japón se estimó en 90234 USD PPA, mientras que en Estonia fue de 3761 USD PPA. En 2015, la mayor parte de la deuda bruta de las Administraciones públicas en los países de la OCDE se compuso de títulos de deuda, que representaron en promedio el $83 \%$ de toda la deuda pública, con variaciones por país que van del $92 \%$ de los Estados Unidos al 8,7\% de Estonia. Los préstamos supusieron una media del $8,9 \%$ de la deuda bruta en los países de la OCDE, aunque fueron una parte mucho más importante de la composición de pasivos en países como Grecia (79,2\%) y Estonia (67,3\%).

\section{Metodología y definiciones}

Los datos se han obtenido de las estadísticas de contabilidad nacional de la OCDE (base datos) y de las estadísticas de finanzas públicas de Eurostat (base de datos), que se basan en el sistema de contabilidad nacional (SCN). El marco actualizado del SCN del año 2008 ha sido ya implementado en todos los países de la OCDE (véase el anexo A para detalles sobre sistemas y fuentes de información). La deuda es un concepto comúnmente utilizado, definido como un conjunto específico de 
pasivos identificados de acuerdo con los tipos de instrumentos financieros incluidos o excluidos. En general, se define como todos los pasivos que exigen el pago o pagos por intereses o de capital por el deudor al acreedor en una fecha o fechas futuras. Todos los instrumentos de deuda son pasivos, pero algunos pasivos, tales como acciones, otras participaciones de capital y derivados financieros, no se consideran deuda. De este modo, la deuda se obtiene sumando las siguientes categorías de pasivos, siempre que estén disponibles o se contabilicen en el balance financiero de la Administración general: efectivo y depósitos, títulos de deuda, préstamos y otros pasivos (es decir, seguros, pensiones y planes normalizados de garantía, otras cuentas por pagar, así como, en algunos casos, derechos de giro especiales - DEG-). De acuerdo con el SCN, la mayoría de los instrumentos de deuda se valoran a precios de mercado, cuando es apropiado (aunque algunos países podrían no aplicar esta valoración, en particular para los títulos de deuda).

El tratamiento de los pasivos de las Administraciones públicas en relación con los planes de pensiones de sus empleados varía según los países, por lo que la comparabilidad internacional se hace difícil. Algunos países de la OCDE, por ejemplo, Australia, Canadá, los Estados Unidos, Islandia y Suecia, registran los pasivos relativos a las pensiones, financiadas o no, en los datos de deuda pública. Para estos países, se calcula una ratio de endeudamiento público que excluye de la deuda estos pasivos de pensiones no financiadas. StatLinks proporciona más información sobre este contexto. La deuda pública se registra en términos brutos, no ajustada por el valor de los activos en poder de la Administración. La definición de la deuda en el SNC difiere de la definición aplicada en virtud del Tratado de Maastricht, que se utiliza para evaluar la situación fiscal de la UE. Se puede obtener más información sobre el cálculo de la deuda pública per cápita en la sección del indicador de los ingresos de las Administraciones públicas. El Gráfico 2.12, «Tasa de crecimiento medio anual de la deuda pública real per cápita», está disponible online en el anexo F. 


\section{Notas de los gráficos}

Los datos de Australia, Canadá, los Estados Unidos, Islandia y Suecia se presentan sobre una base ajustada (es decir, excluyen los pasivos de pensiones no financiadas).

Los datos de Nueva Zelanda no están disponibles.

Los datos de México y Turquía no se incluyen en la media de la OCDE por falta de series temporales o por discrepancias en el registro de instrumentos financieros.

Los datos de Brasil corresponden a 2014 en lugar de a 2015.

2.9 y 2.10: Los datos de 2015 de Islandia están basados en estimaciones de la OCDE. Los datos de 2007 de Corea están basados en estimaciones de la OCDE.

2.11: Los datos de Islandia no están disponibles.

Información sobre los datos de Israel: <http://dx.doi.org/10.1787/888932315602>.

\section{Gráfico 2.9. Deuda bruta de la Administración general como porcentaje del PIB, 2007, 2009, 2015 y 2016}

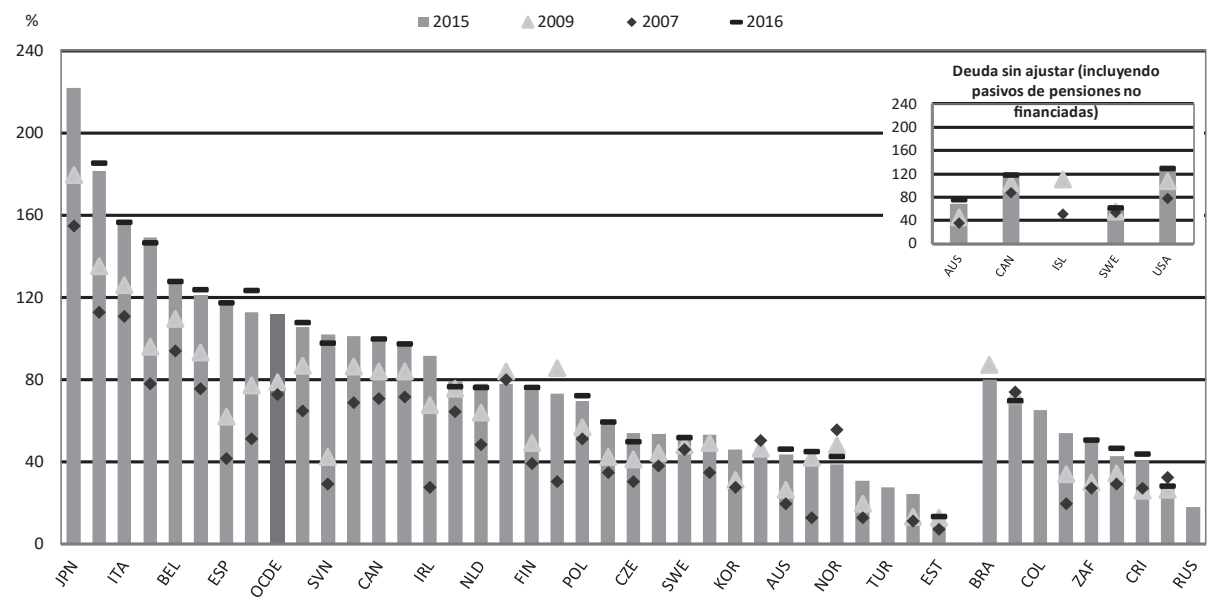

Fuentes: Estadísticas de contabilidad nacional de la OCDE (base de datos); estadísticas de finanzas públicas de Eurostat (base de datos). Los datos de otras economías importantes (aparte de Brasil) y de Costa Rica proceden del Economic Outlook del FMI (abril de 2017). 


\section{Gráfico 2.10. Deuda bruta per cápita de la Administración general, 2009, 2015 y 2016}

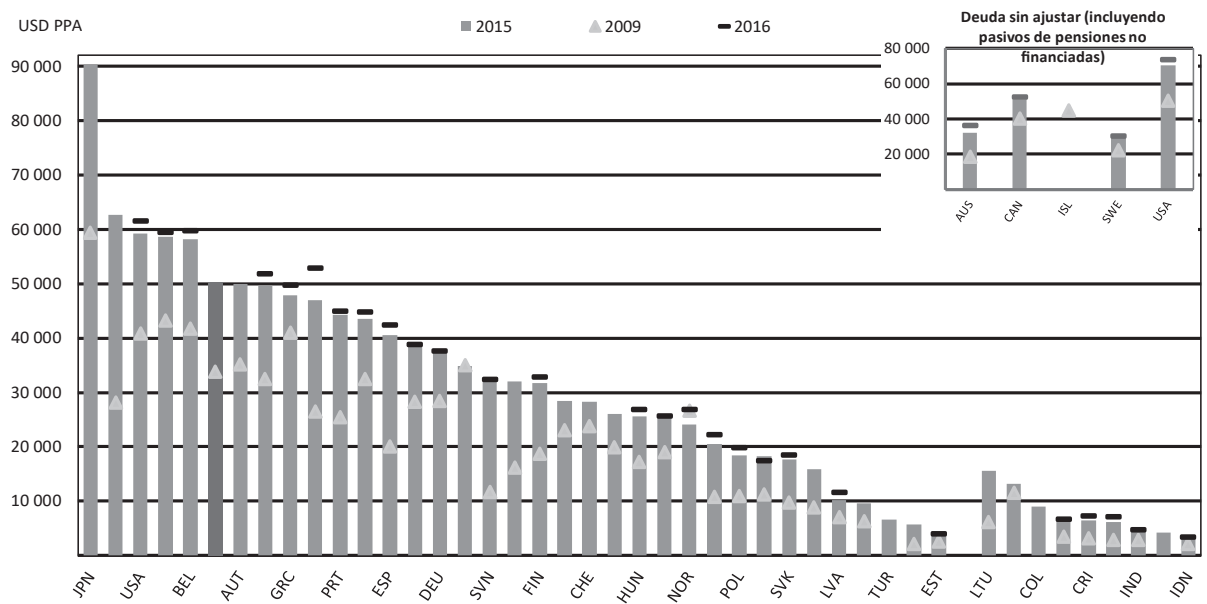

Fuentes: Estadísticas de contabilidad nacional de la OCDE (base de datos); estadísticas de finanzas públicas de Eurostat (base de datos). Los datos de otras economías importantes (aparte de Brasil) y de Costa Rica proceden del Economic Outlook del FMI (abril de 2017).

$<$ http://dx.doi.org/10.1787/888933531516>

\section{Gráfico 2.11. Estructura de la deuda pública por instrumento financiero, 2015}

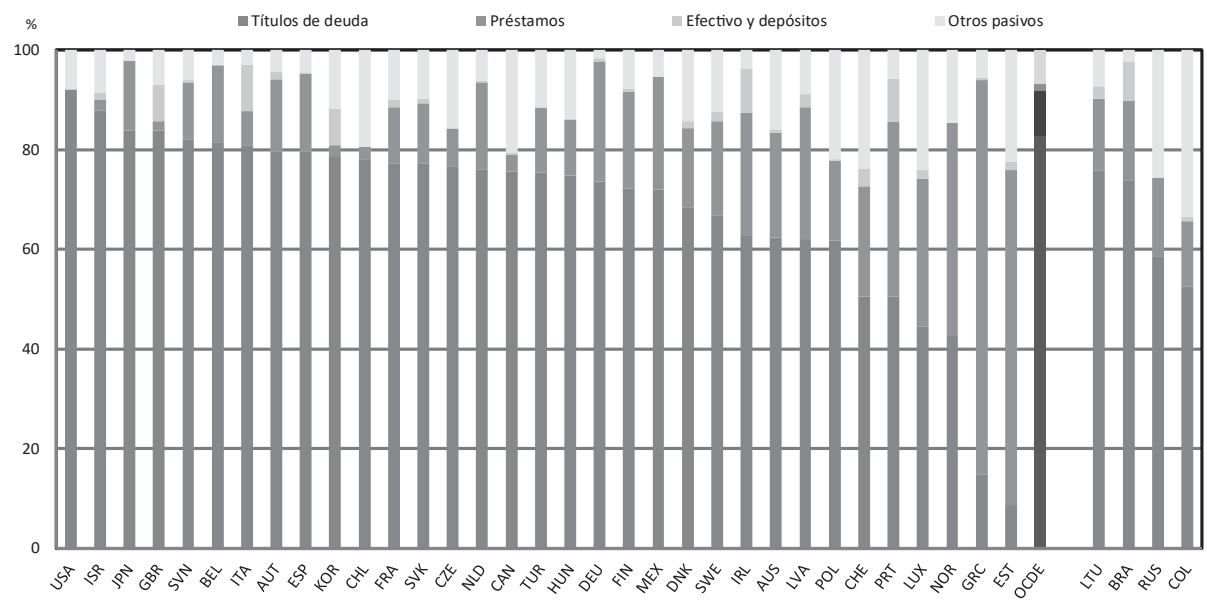

Fuentes: Estadísticas de contabilidad nacional de la OCDE (base de datos); estadísticas de finanzas públicas de Eurostat (base de datos). 


\section{PATRIMONIO NETO FINANCIERO DE LA ADMINISTRACIÓN GENERAL}

Las diferencias entre los activos y los pasivos pendientes de pago de las Administraciones públicas constituyen su patrimonio neto financiero, que supone la capacidad de las Administraciones de asumir plenamente sus obligaciones - ya que los activos complementan los ingresos futuros previstos y se podrían vender y utilizar para pagar o reducir las deudas existentes (esto último se considera una descripción general de la deuda neta de las Administraciones) - - Un patrimonio neto financiero positivo significa que el estado de las finanzas públicas no pone en peligro la sostenibilidad fiscal, mientras que un empeoramiento del patrimonio neto financiero es señal de una situación fiscal frágil que requiere aumentos fiscales, reducciones de gastos o una combinación de ambos.

En 2015, los países de la OCDE registraron en promedio un patrimonio neto financiero negativo equivalente al $72 \%$ del PIB, que significa que, por cada $1 \%$ del PIB en activos públicos, las Administraciones públicas debían un 1,72\% del PIB. El país con el patrimonio neto financiero más bajo en 2015 fue Grecia con un $-148,1 \%$ del PIB, seguida de Italia $(-132,5 \%)$, Japón $(-126,1 \%)$ y Portugal $(-109,4 \%)$, mientras que siete países registraron un patrimonio neto financiero positivo; entre ellos, los valores más elevados se dieron en Noruega $(284,4 \%)$, Finlandia (53,5\%), Luxemburgo (49,5\%), Estonia (42\%) y Suecia (27,6\%).

Desde la crisis financiera, el patrimonio neto financiero en los países de la OCDE ha sufrido un deterioro: ha descendido 31,7 p. p. entre 2007 y 2015 y ha reflejado una combinación de crecimiento negativo, déficits mayores y deuda pública más elevada. El mayor descenso se dio en Grecia ( -67 p. p.), seguida de España (-64,3 p. p.), mientras que el mayor aumento se dio en Noruega, con valores positivos que pasaron del 139,8\% en 2007 al 284,4\% en 2015. Aparte de Noruega, desde 2007 solo tres países han mejorado su patrimonio neto financiero: Estonia (+13,5 p. p.), Suecia (+6,6 p. p.) y Suiza $(+2,9$ p. p.).

Entre 2015 y 2016, los cambios más notables se dieron en el Reino Unido, donde el patrimonio neto financiero pasó de un $-82,4 \%$ a un $-92,9 \%$ del PIB, seguido de la República de Eslovenia ( $-3,4$ p. p.), Portugal $(+4,9$ p. p.) y Noruega $(+4,7$ p. p.). El incremento de los valores negativos de patrimonio neto financiero en el Reino Unido y la República de Eslovenia se debió al impacto sobre los títulos de deuda en el primero y a una reducción de activos en el segundo, mientras que el aumento de los valores positivos en Portugal y Noruega fue causado por el incremento de activos de las Administraciones públicas.

Por último, en promedio, el patrimonio neto financiero per cápita representó -32 692 USD PPA en 2015 entre los países de la OCDE, que supone un empeoramiento con respecto al nivel de 2009 (-20637 USD PPA). Japón mostró el mayor patrimonio neto financiero negativo en 2015, con -51 359 USD PPA, mientras que el país con el mayor patrimonio neto financiero positivo per cápita fue Noruega, con 176378 USD PPA. 


\section{Metodología y definiciones}

Los datos se han obtenido de las estadísticas de contabilidad nacional de la OCDE (base de datos) y de las estadísticas de finanzas públicas de Eurostat (base de datos), que se basan en el sistema de contabilidad nacional (SCN). El marco actualizado del SCN del año 2008 ha sido ya implementado en todos los países de la OCDE (véase el anexo A para detalles sobre sistemas y fuentes de información). El patrimonio neto financiero del sector de la Administración general es el valor total de sus activos financieros menos el valor total de sus obligaciones pendientes de pago. El SNC define los activos financieros y los pasivos correspondientes cuando procede / están disponibles en el balance financiero del sector público: oro monetario y derechos especiales de giro (DEG); efectivo y depósitos; títulos de deuda; préstamos; acciones y participaciones de capital en fondos de inversión; seguros, pensiones y planes normalizados de garantía; derivados financieros y opciones sobre acciones para empleados, y otras cuentas por cobrar/pagar. De acuerdo con el SCN, los stocks de activos y pasivos financieros se valoran a precios de mercado cuando procede (aunque algunos países podrían no aplicar esta valoración, en particular para los títulos de deuda). Los datos se basan en activos y pasivos financieros consolidados, con excepción de Chile, Brasil y Rusia. Este indicador se puede utilizar como medida aproximada de la deuda pública neta, en la medida en que, de manera similar a la definición de la deuda bruta, la deuda neta se puede restringir a la deuda bruta menos los activos financieros correspondientes a instrumentos de deuda (así se define el concepto en las Estadísticas de la deuda del sector público: Guía para compiladores y usuarios). El sistema institucional, a la hora de registrar los pasivos no financiados de los empleados públicos, puede tener un impacto en el patrimonio neto financiero de la Administración general en diversos países, lo cual dificulta la comparabilidad internacional. Este es el caso de algunos países de la OCDE, como Australia, Canadá, los Estados Unidos, Islandia y Suecia. Por esta razón, al igual que con la deuda bruta, se calcula un patrimonio neto financiero ajustado para estos países. Se puede obtener más información sobre el cálculo del patrimonio neto financiero per cápita en la sección del indicador de los ingresos de las Administraciones públicas. 


\section{Otras publicaciones}

OECD (2015), Accounts at a Glance 2015, OECD, París,

$<$ http://dx.doi.org/10.1787/na_glance-2015-en>.

\section{Notas de los gráficos}

Los datos de Australia, Canadá, los Estados Unidos, Islandia y Suecia se presentan sobre una base ajustada (es decir, excluyen los pasivos de pensiones no financiadas).

Los datos de Corea, Islandia y Nueva Zelanda no están disponibles.

Los datos de México y Turquía no se incluyen en la media de la OCDE por falta de series temporales o por discrepancias en el registro de instrumentos financieros.

Los datos de Brasil corresponden a 2014 en lugar de a 2015.

Información sobre los datos de Israel: <http://dx.doi.org/10.1787/888932315602>.

\section{Gráfico 2.13. Patrimonio neto financiero de la Administración general como porcentaje del PIB, 2007, 2009, 2015 y 2016}

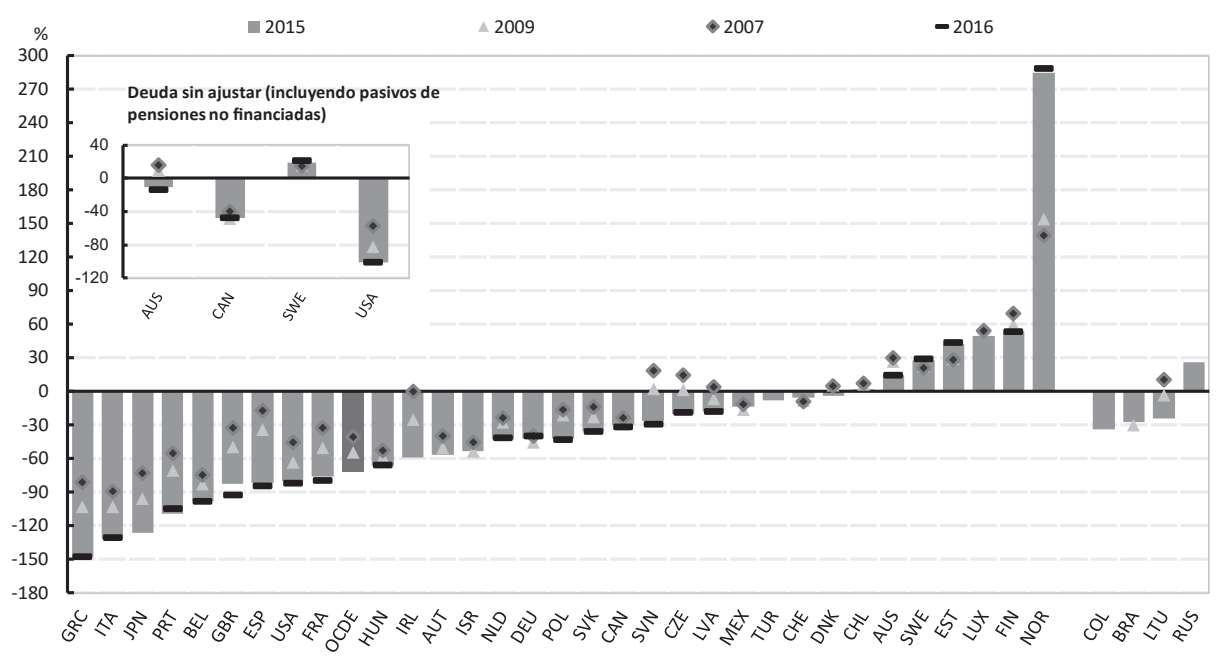

Fuentes: Estadísticas de contabilidad nacional de la OCDE (base de datos); estadísticas de finanzas públicas de Eurostat (base de datos). 


\section{Gráfico 2.14. Patrimonio neto financiero de la Administración general per cápita, 2009, 2015 y 2016}

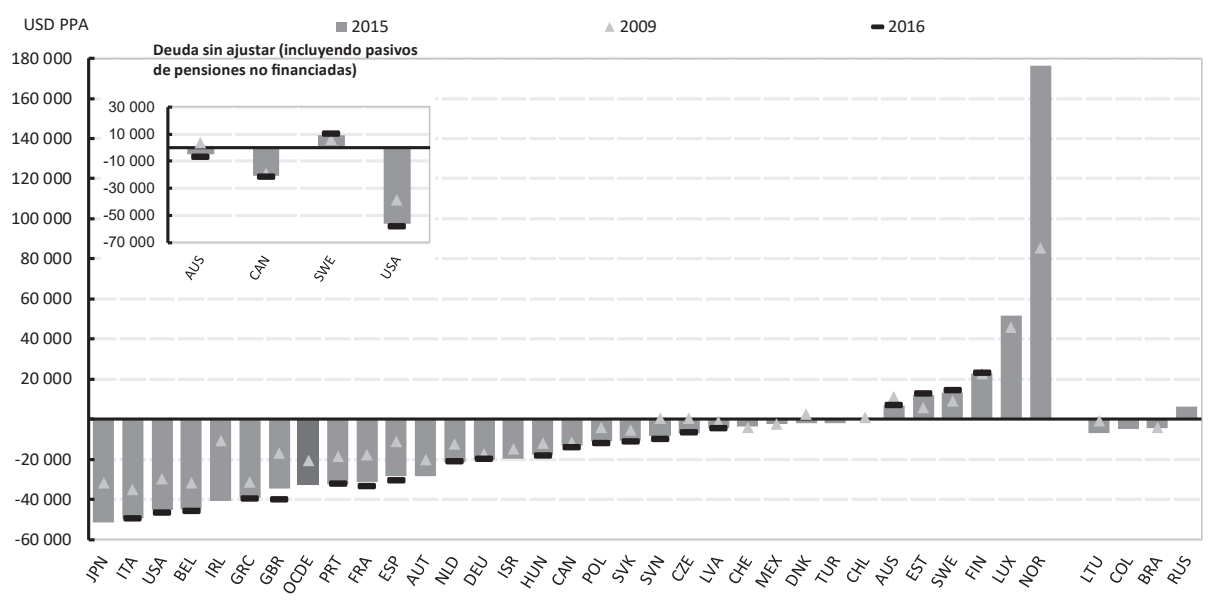

Fuentes: Estadísticas de contabilidad nacional de la OCDE (base de datos); estadísticas de finanzas públicas de Eurostat (base de datos).

$<$ http://dx.doi.org/10.1787/888933531573>

\section{BALANCE FISCAL Y DEUDA POR NIVEL DE ADMINISTRACIÓN}

La mayoría de los países tienen múltiples jurisdicciones que determinan el balance fiscal global. Dependiendo del grado de descentralización fiscal, tanto de los gastos como de los ingresos de las Administraciones públicas, el balance fiscal de los distintos niveles de gobierno puede no ser el mismo, aunque en su conjunto sumen el balance fiscal global. Esto puede aportar volatilidad a los pasivos de las Administraciones; por ejemplo, cuando los gastos superan los ingresos a nivel local en muchos municipios, que a su vez financian el déficit emitiendo deuda adicional, los niveles globales de deuda pueden aumentar rápidamente a medida que más localidades se unan a esta respuesta. Por esta razón, las Administraciones subcentrales a menudo operan dentro de unos límites de deuda más restrictivos que la Administración central.

La descomposición del balance fiscal por niveles de administración muestra la relación entre la descentralización fiscal nacional y el balance fiscal global. En los países de la OCDE, las Administraciones centrales tuvieron un déficit fiscal promedio del 2,6\% del PIB en 2015, mientras que las Administraciones subcentrales registraron un déficit del $0,5 \%$ en el mismo año. Los balances de las Administraciones centrales oscilaron entre el déficit de Grecia, del 5,9\%, y el superávit de Noruega, del 6,4\%. Entre los países federales de la OCDE, las Administraciones estatales de Austria, Alemania, México y 
Suiza obtuvieron superávits del $0,07 \%, 0,15 \%, 0,23 \%$ y $0,34 \%$ respectivamente, como proporción del PIB en 2015. El mayor déficit entre las Administraciones centrales en 2015 se dio en España, que alcanzó el 1,7\% del PIB, seguida de Canadá, con un 1,6\%, y Bélgica, con un 1,4\%. A nivel local, todos los déficits y superávits en los países de la OCDE se mantuvieron entre un $0,5 \%$ de superávit y un $-0,6 \%$ de déficit, puesto que las restricciones de acumulación de deuda a este nivel a menudo son obligatorias.

En promedio, las Administraciones centrales de los países de la OCDE en 2015 registraron una deuda bruta del 97,1\% del PIB, comparado con el 21,5\% del PIB de las Administraciones subcentrales. Los países con los mayores niveles de deuda bruta en las Administraciones centrales fueron también los países con los niveles más elevados de deuda brutal global: Japón (197,8\%) y Grecia (184\%). A nivel subcentral, los mayores niveles de deuda bruta de las Administraciones estatales se dieron en Canadá (47\%) y en España (27\%), mientras que los mayores niveles de deuda bruta de las Administraciones locales se registraron en Japón (34\%). Con respecto a la composición de los niveles de deuda, en 2015 las Administraciones centrales tuvieron la mayor proporción de deuda bruta, con un promedio del 80,5\%, mientras que las Administraciones estatales registraron el $11,4 \%$, las Administraciones locales el $6,4 \%$ y las entidades de la seguridad social el 1,7\%. Países como Grecia y Hungría registraron más del $98 \%$ de su deuda en las Administraciones centrales, mientras otros como Canadá y Noruega contabilizaron el $45 \%$ de su deuda en las Administraciones estatales y el $43,1 \%$ en las Administraciones locales, respectivamente.

Esta composición ha cambiado significativamente desde 2007, antes de la crisis, cuando la deuda bruta de las Administraciones centrales en los países de la OCDE suponía un promedio del $73 \%$, valor que ha aumentado paralelamente con la deuda durante los últimos años en respuesta a la crisis financiera.

\section{Metodología y definiciones}

Los datos se han obtenido de las estadísticas de contabilidad nacional de la OCDE (base de datos) y de las estadísticas de finanzas públicas de Eurostat (base de datos), que se basan en el sistema de contabilidad nacional (SCN). El marco actualizado del SCN del año 2008 ha sido ya implementado en todos los países de la OCDE (véase el anexo A para detalles sobre sistemas y fuentes de información). De acuerdo con la terminología del SCN, la Administración general se compone de la Administración central, Administraciones estatales y locales, y de las entidades de la seguridad social. Las Administraciones estatales solo existen en los nueve países de la OCDE que son Estados federales: 
Alemania, Australia, Austria, Bélgica, Canadá, España (considerado un país cuasifederal), los Estados Unidos, México y Suiza. El balance fiscal, también conocido como capacidad de financiación neta $(+)$ o necesidad de endeudamiento neto (-) de la Administración general, se calcula tomando los ingresos totales y restándoles los gastos totales. Para más información sobre la deuda, véase la sección del indicador de deuda pública bruta.

\section{Otras publicaciones}

OECD (2015), National Accounts at a Glance 2015, OCDE, París, $<$ http://dx.doi.org/10.1787/na_glance-2015-en>.

\section{Notas de los gráficos}

Los datos de Chile y Turquía no se incluyen en la media de la OCDE ya que faltan series temporales. La Administración local se incluye en la Administración estatal en Australia y en los Estados Unidos. Australia no gestiona un sistema público de seguridad social. En Japón, los datos de los subsectores de la Administración general se refieren al año fiscal. Las entidades de la seguridad social se incluyen en las Administraciones públicas en los Estados Unidos, Noruega y el Reino Unido.

2.15: Los datos de Costa Rica corresponden a 2014 en lugar de a 2015. Véase también el Statlinks para más información.

2.16: Los datos de Islandia no están disponibles. Los datos de 2015 de las Administraciones locales y estatales de Suiza se basan en estimaciones de la OCDE.

2.16 y 2.17: Los datos de Corea, México y Nueva Zelanda no están disponibles. Los datos de Australia, Canadá, los Estados Unidos y Suecia se presentan sobre una base ajustada (es decir, excluyen los pasivos de pensiones no financiadas). Los datos de los Estados Unidos se presentan sobre una base no consolidada.

2.17: Los datos están consolidados dentro de los subsectores de la Administración general. Sin embargo, a este nivel, se incluyen los movimientos entre los distintos sectores de la Administración. Los datos de 2015 de las Administraciones locales y estatales de Suiza se basan en estimaciones de la OCDE.

Información sobre los datos de Israel: <http://dx.doi.org/10.1787/888932315602>. 


\section{Gráfico 2.15. Balance fiscal de las Administraciones por nivel de administración como porcentaje del PIB, 2015 y 2016}

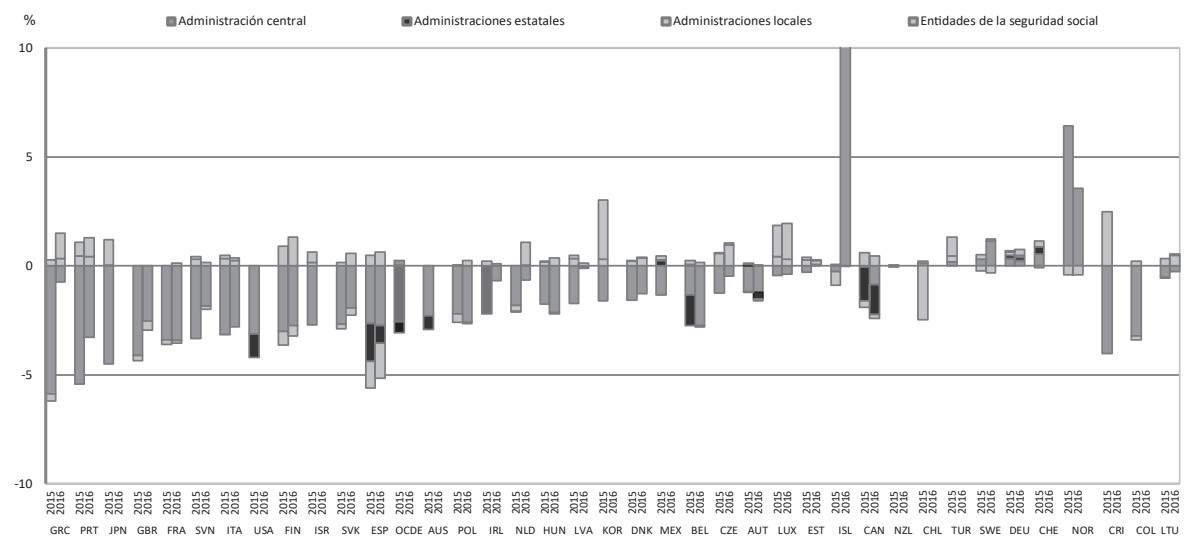

Fuente: Estadísticas de contabilidad nacional de la OCDE (base de datos).

$<$ http://dx.doi.org/10.1787/888933531592>

Gráfico 2.16. Deuda pública bruta por nivel de administración como porcentaje del PIB, 2015 y 2016

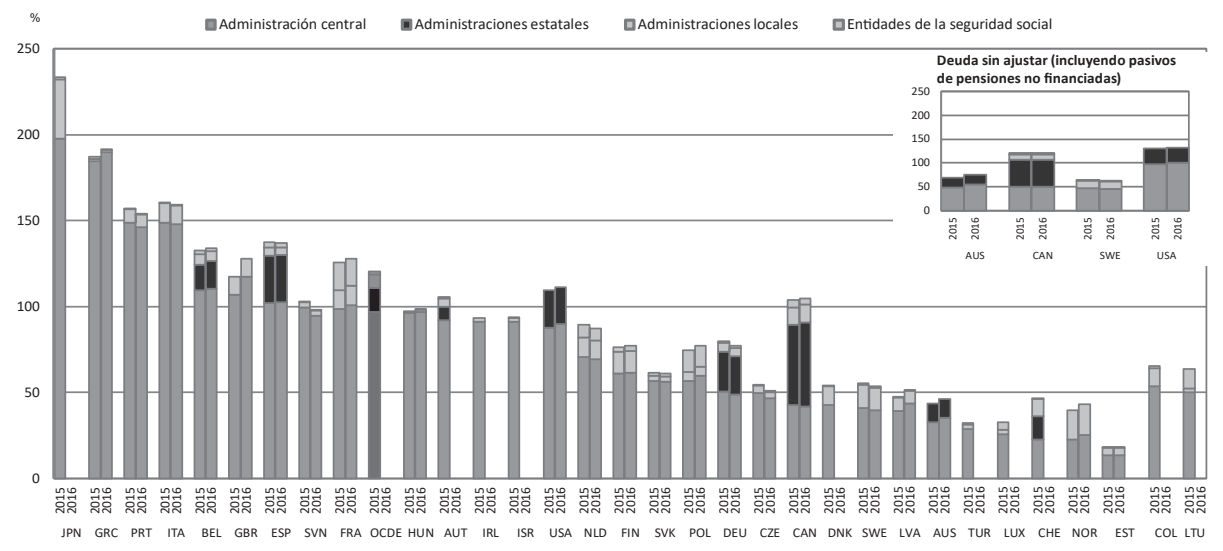

Fuentes: Estadísticas de contabilidad nacional de la OCDE (base de datos); estadísticas de finanzas públicas de Eurostat (base de datos). 


\section{Gráfico 2.17. Distribución de la deuda pública bruta por nivel de administración, 2007 y 2015}

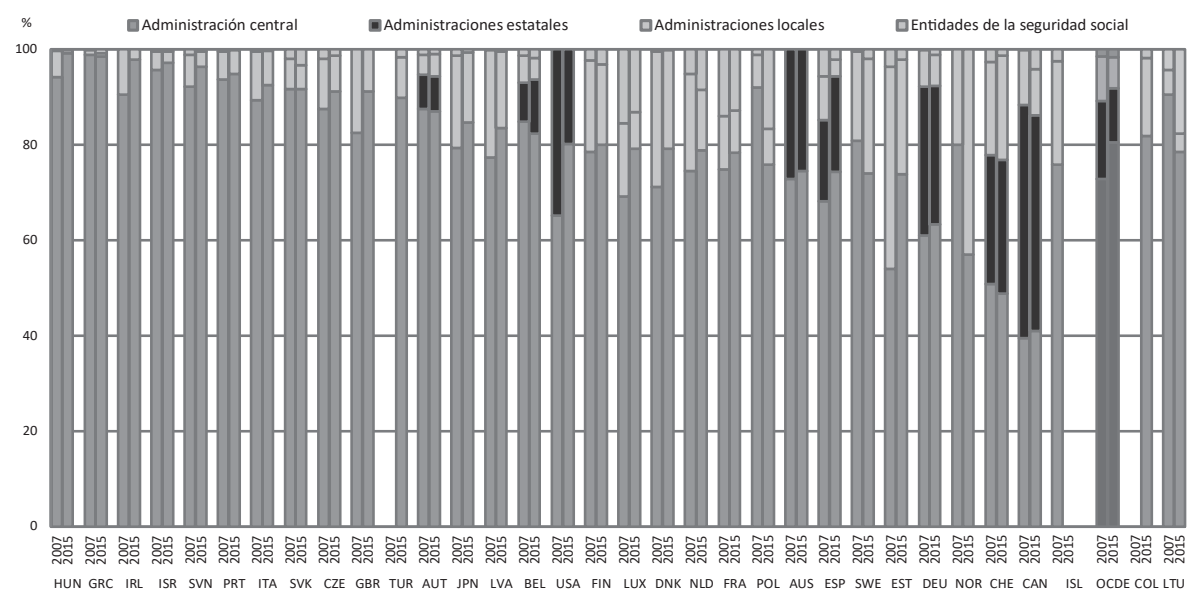

Fuentes: Estadísticas de contabilidad nacional de la OCDE (base de datos); estadísticas de finanzas públicas de Eurostat (base de datos).

\section{INGRESOS DE LA ADMINISTRACIÓN GENERAL}

Los ingresos de las Administraciones públicas financian los bienes y servicios proporcionados y permiten que el Estado lleve a cabo su papel redistributivo, ya que las dos principales fuentes de ingresos son los impuestos y las cotizaciones sociales. Basándose en las opciones políticas históricas y actuales, así como en las variaciones de los ciclos económicos, existen diferencias significativas entre países sobre cómo y hasta qué punto sus Administraciones públicas cumplen estas dos funciones fundamentales $\mathrm{y}$, consecuentemente, existen también diferencias importantes en cuanto a la cantidad de ingresos obtenidos.

En los países de la OCDE, con algunas excepciones, los ingresos de la Administración general como proporción del PIB se han reestablecido a niveles anteriores a la crisis financiera: en promedio, los ingresos marcaron un 37,3\% del PIB en 2007, descendieron a un 35,8\% en 2009 y ascendieron a un 38,1\% en 2015. Los ingresos de las Administraciones públicas representaron por lo menos la mitad del PIB en siete de los treinta y cuatro países de la OCDE en 2015: Noruega $(54,8 \%)$, Finlandia (54,2\%), Dinamarca (53,5\%), Francia $(53,4 \%)$, Bélgica $(51,4 \%)$, Austria $(51,6 \%)$ y Suecia $(50,5 \%)$, mientras que solo dos países registraron ingresos fiscales por debajo de un tercio de los ingresos anuales totales: Irlanda $(27,6 \%)$ y México $(23,7 \%)$. Los ingresos de 
Grecia superaron los niveles precrisis, pasando de un 40,4\% en 2007 a un $48,3 \%$ en 2015; sin embargo, el nivel de ingresos también refleja el gran descenso del PIB como consecuencia de la crisis, ya que el PIB nominal en Grecia en 2015 supuso un $76 \%$ del PIB del país en 2007. Durante este mismo periodo, 2007-2015, entre los países de la OCDE, Colombia registró el mayor aumento de ingresos fiscales, de un $31,1 \%$ del PIB a un $34,1 \%$, debido a ingresos petroleros, recaudación de impuestos y sucesivas reformas.

Entre 2015 y 2016, de los países con datos disponibles, los mayores aumentos de ingresos se dieron en Islandia, donde los ingresos de las Administraciones públicas ascendieron del $42,2 \%$ al $58,4 \%$ debido a los ingresos extraordinarios para contribuir a la estabilidad procedentes de bancos en quiebra, mientras que los ingresos como proporción del PIB marcaron mínimos en la República Eslovaca ( $-2,9$ p. p.) y Hungría $(-2,9$ p. p.), ya que ambos países demoraron la inversión de fondos de la UE debido al inicio de un nuevo periodo de programación.

Los ingresos de las Administraciones públicas per cápita han tenido un comportamiento paralelo al de los ingresos generales, aumentando de manera uniforme con la disminución de la crisis. En promedio, los ingresos per cápita aumentaron desde 2009 a 16094 USD PPA en 2015. Los países con mayores ingresos per cápita mantuvieron su posición con respecto a 2009: Luxemburgo (44485 USD PPA), Noruega (33 977 USD PPA) y Dinamarca (26203 USD PPA). En el caso de Luxemburgo esto se puede deber a las contribuciones fiscales de trabajadores transfronterizos que no cotizan como residentes, mientras que en el caso de Noruega es debido al impacto de ingresos petroleros. Por otra parte, en Letonia, México y Turquía los ingresos per cápita fueron inferiores a 10000 USD PPA.

Entre 2007 y 2015, la tasa de crecimiento medio anual de los ingresos reales de las Administraciones públicas per cápita fue del 0,6\% en los países de la OCDE, pero para el periodo 2009-2015 fue del 2,3\%. Los países que registraron mayores aumentos de ingresos reales per cápita durante este periodo fueron Turquía ( $+5,9 \%)$, la República Eslovaca $(+5,8 \%)$, Japón y Letonia (ambos $+4,2 \%)$. En cambio, la tasa de crecimiento medio de los ingresos reales per cápita fue negativa durante este periodo $2009-2015$ en Grecia $(-0,3 \%)$ y Noruega $(-0,2 \%)$.

\section{Metodología y definiciones}

Los datos de ingresos se obtienen de las estadísticas de contabilidad nacional de la OCDE (base de datos), que se basan en el sistema de contabilidad nacional (SCN), un conjunto de conceptos, definiciones, clasificaciones y reglas acordados internacionalmente para la contabilidad 
nacional. El marco actualizado del SCN del año 2008 ha sido ya implementado en todos los países de la OCDE (véase el anexo A para detalles sobre sistemas y fuentes de información). De acuerdo con la terminología del SCN, la Administración general se compone de la Administración central, Administraciones estatales y locales, y de las entidades de la seguridad social. Los ingresos comprenden los impuestos, las cotizaciones sociales netas, las subvenciones y otros ingresos. El producto interior bruto (PIB) es la medida estándar del valor de los bienes y servicios producidos por un país durante un periodo determinado. Los ingresos públicos per cápita se calcularon mediante la conversión de los ingresos totales a USD utilizando las paridades de poder adquisitivo (PPA) de la OCDE/Eurostat para el PIB y dividiéndolos por la población. Para los países cuya fuente de datos es el Economic Outlook del FMI se utilizó un tipo de conversión PPA implícita. Las PPA son el número de unidades de la moneda del país B que se necesita para comprar la misma cantidad de bienes y servicios en el país A.

\section{Otras publicaciones}

OECD (2015), National Accounts at a Glance 2015, OECD, París, <http://dx. doi.org/10.1787/na_glance-2015-en>.

OECD (2016), OECD Factbook 2015-2016: Economic,

environmental and social statistics, OECD, París, <http:// dx.doi.org/10.1787/ factbook-2015-en>.

Statistics Iceland (2017), General Government finances 2016, Statistics Iceland, Reikiavik, <http://www.statice.is/ publications/publicationdetail?id=57984>.

\section{Notas de los gráficos}

Los datos de Chile no están disponibles.

Los datos de Turquía no se incluyen en la media de la OCDE ya que faltan series temporales.

Los datos de Costa Rica y Rusia corresponden a 2014 en lugar de a 2015.

Información sobre los datos de Israel: <http://dx.doi.org/10.1787/888932315602>. 
Gráfico 2.18. Ingresos de la Administración general como porcentaje del PIB, 2007, 2009, 2015 y 2016

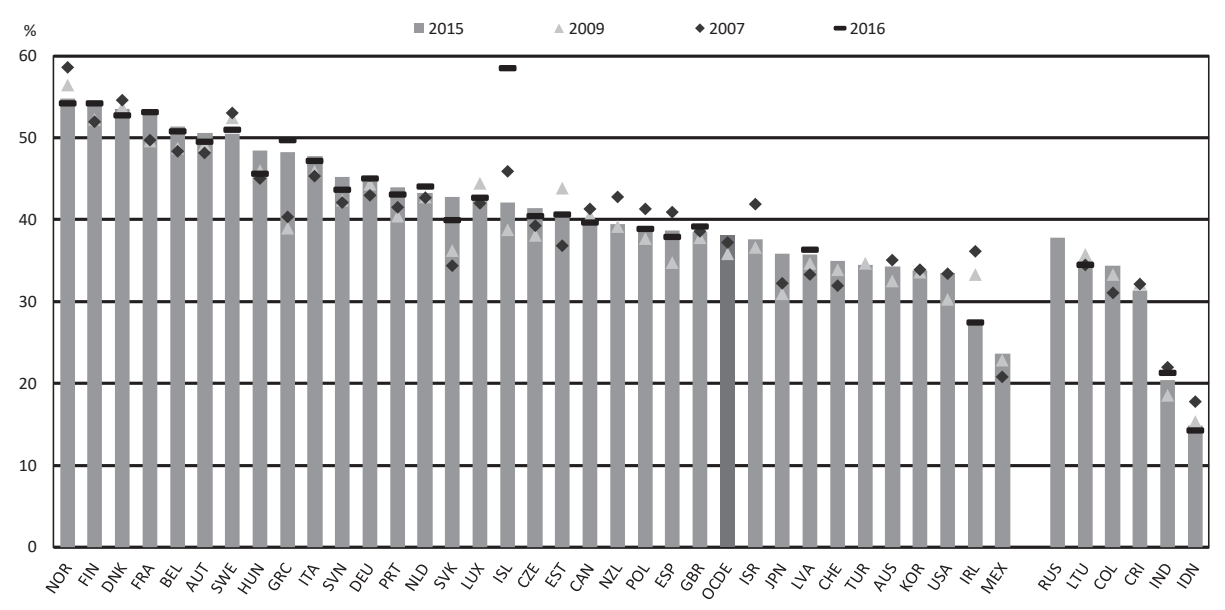

Fuentes: Estadísticas de contabilidad nacional de la OCDE (base de datos). Los datos de India e Indonesia son del Economic Outlook del FMI (abril de 2017).

Gráfico 2.19. Ingresos de la Administración general per cápita, 2009, 2015 y 2016

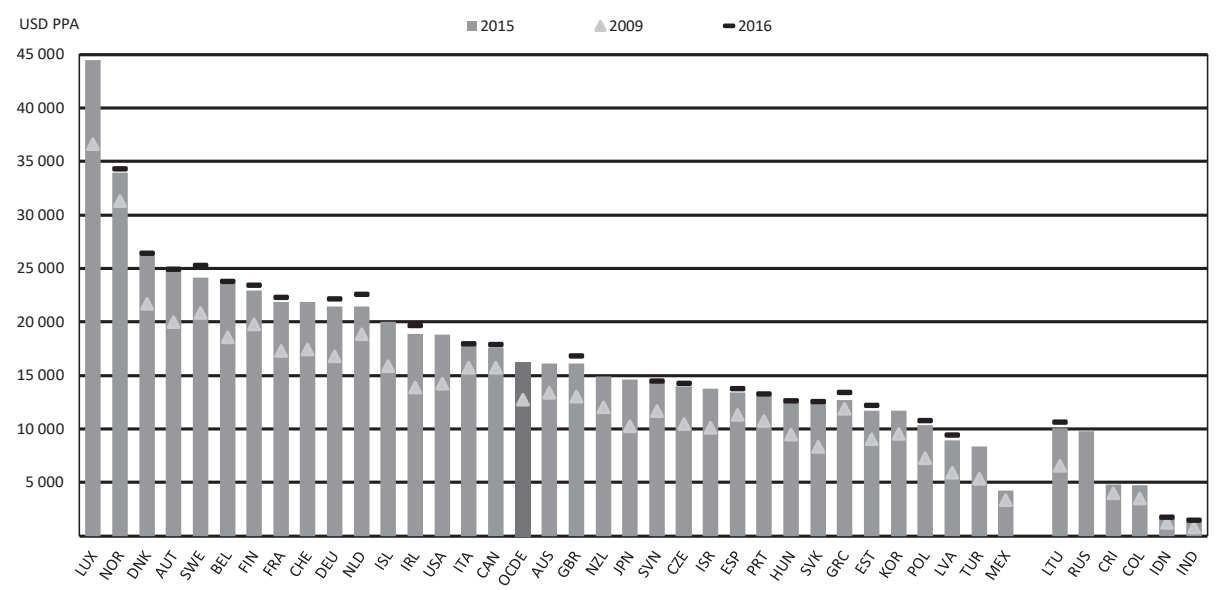

Fuentes: Estadísticas de contabilidad nacional de la OCDE (base de datos). Los datos de India e Indonesia son del Economic Outlook del FMI (abril de 2017). 


\section{Gráfico 2.20. Tasa de crecimiento medio anual de los ingresos reales de la Administración general per cápita, 2007-2015, 2009-2015 y 2015-2016}

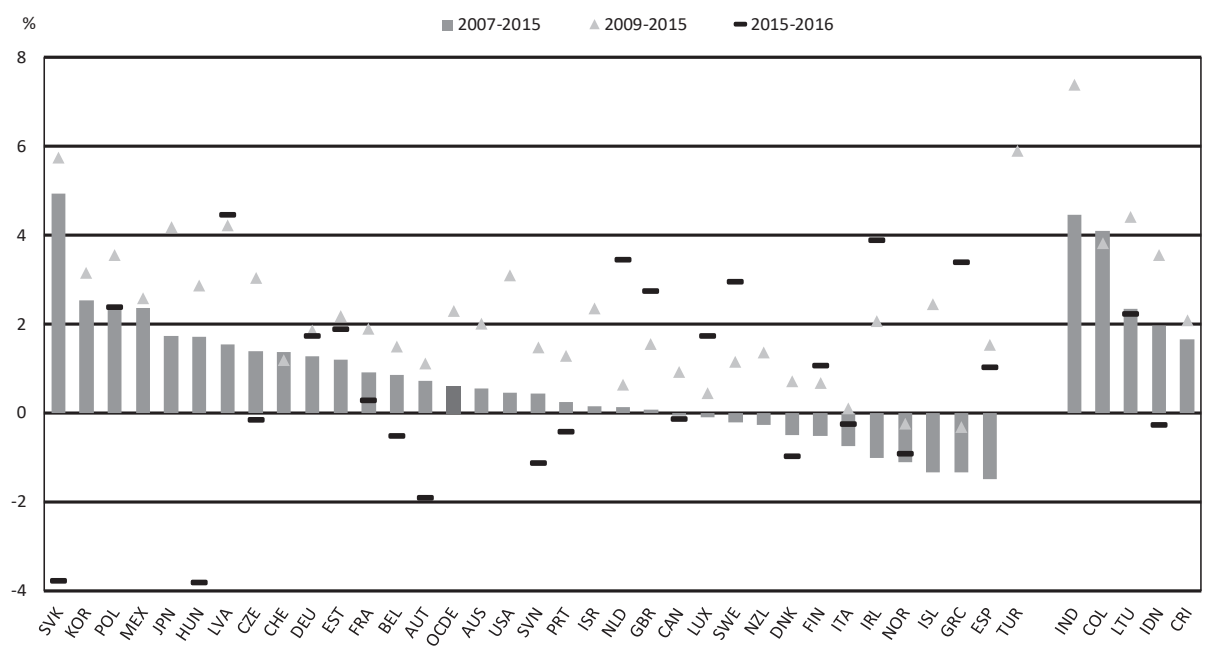

Fuentes: Estadísticas de contabilidad nacional de la OCDE (base de datos). Los datos de India e Indonesia son del Economic Outlook del FMI (abril de 2017).

$<$ http://dx.doi.org/10.1787/888933531687>

\section{ESTRUCTURA DE INGRESOS DE LA ADMINISTRACIÓN GENERAL}

El desglose estructural de los ingresos de las Administraciones públicas muestra cómo se recaudan los ingresos y ayuda a identificar la contribución relativa de los ciudadanos o sectores de la economía al pago de gastos públicos.

En los países de la OCDE, los impuestos representaron la mayor proporción de los ingresos públicos, con un promedio del 59,3\% en 2015, mientras que alrededor de una cuarta parte se recaudaron a través de cotizaciones sociales netas, y el resto a través de subvenciones $(8,5 \%)$ y ventas $(7,3 \%)$. La proporción de ingresos procedentes de impuestos varió del 87,8\% registrado en Dinamarca al 42,4\% de la República Eslovaca, mientras que las cotizaciones sociales netas oscilaron entre el $37 \%$ de Alemania y el 1,9\% de Dinamarca. Los ingresos derivados de ventas variaron entre el $14 \%$ de Suiza y el $0,3 \%$ de México; México, a su vez, recibió la mayor proporción de ingresos procedentes de subvenciones y de otros ingresos, con un $32,2 \%$, mientras que solo un $2,9 \%$ de los ingresos de Francia provino de estas fuentes.

Entre 2007 y 2015, en promedio, los impuestos representaron -1,2 p. p. menos de los ingresos de las Administraciones públicas, contrarrestado por aumentos en las cotizaciones sociales netas $(0,6$ p. p.), ventas $(0,3$ p. p.) y 
subvenciones y otros ingresos $(0,2$ p. p.). Durante este periodo, la ratio de impuestos con respecto a ingresos no fiscales registró su mayor descenso en la República Eslovaca (8,1 p. p.), compensado por incrementos en ventas (1,7 p. p.) y subvenciones y otros ingresos (7,5 p. p.). En cambio, México aumentó sus impuestos en proporción similar a su reducción de subvenciones y otros ingresos entre 2007 y 2015 (+8,1 p. p. y -7,3 p. p., respectivamente).

Muchos responsables políticos incluyen las cotizaciones a la seguridad social como impuestos. Esta es la base de las medidas de ingresos fiscales en las estadísticas de ingresos de la OCDE (véase «Metodología y definiciones»). En 2014, los impuestos sobre la renta y beneficios supusieron en promedio (no ponderado) un $33,7 \%$ de los ingresos fiscales, mientras que los impuestos sobre bienes y servicios, como el impuesto sobre el valor añadido (IVA), representaron el $32,6 \%$, la seguridad social el $26,2 \%$ y el restante $7,4 \%$ se compuso de impuestos sobre nóminas, propiedades y otros impuestos. Los países que recaudaron la mayor parte de sus ingresos fiscales mediante impuestos sobre la renta y beneficios fueron Dinamarca (64,9\%), Australia $(57,9 \%)$ y Nueva Zelanda $(55,4 \%)$, mientras que los que obtuvieron la menor proporción fueron Hungría $(17,7 \%$ ) y la República de Eslovenia (17,9\%). Por el contrario, los países con una mayor proporción de ingresos fiscales procedentes de bienes y servicios fueron Chile (55,3\%), Hungría y Turquía (alrededor del $44 \%$ ), y el país con menor proporción fue los Estados Unidos (17,4\%).

Si se compara 2007 con 2014, en promedio, los impuestos sobre la renta y beneficios descendieron 2,3 p. p., mientras que se registraron aumentos en seguridad social $(1,4$ p. p.) y bienes y servicios $(0,7$ p. p.). Los mayores cambios durante este periodo se dieron en Chile, donde los impuestos sobre la renta y beneficios se redujeron en 11,5 p. p. Por otra parte, en Corea y Turquía las cotizaciones a la seguridad social como fuente de ingresos fiscales aumentaron 6,1 p. p. y 6,8 p. p. respectivamente.

\section{Metodología y definiciones}

Los datos de ingresos se obtienen de las estadísticas de contabilidad nacional de la OCDE (base de datos), que se basan en el sistema de contabilidad nacional (SCN), un conjunto de conceptos, definiciones, clasificaciones y reglas acordados internacionalmente para la contabilidad nacional. El marco actualizado del SCN del año 2008 ha sido ya implementado en todos los países de la OCDE (véase el anexo A para detalles sobre sistemas y fuentes de información). Los ingresos comprenden los impuestos (por ejemplo, impuestos sobre el consumo, la renta, el patrimonio, la propiedad y el capital), las cotizaciones sociales netas (por ejemplo, las cotizaciones para pensiones, sanidad y seguridad social; netas significa una vez deducidos, en su caso, los cargos por servicios de los 
sistemas de seguros sociales), las ventas de bienes y servicios (por ejemplo, la producción para el mercado de empresas y organizaciones de las Administraciones, cuotas de entrada), y subvenciones y otros ingresos (por ejemplo, subvenciones corrientes y de capital, rentas del patrimonio y subsidios). Estos agregados se elaboraron con las subcuentas de las partidas (véase el anexo B). Los datos presentados en el Gráfico 2.23 proceden de las Estadísticas de Ingresos de la OCDE. Las Estadísticas de Ingresos de la OCDE y el SCN difieren en sus definiciones de los ingresos fiscales. En el SCN, los impuestos son pagos obligatorios sin contrapartida, en efectivo o en especie, efectuados por unidades institucionales a las Administraciones. Las cotizaciones sociales netas son los pagos reales o imputados a los sistemas de seguridad social para provisionar las prestaciones que deben abonarse. Estas cotizaciones pueden ser obligatorias o voluntarias y los sistemas pueden ser financiados o no. Las estadísticas de ingresos de la OCDE incluyen las cotizaciones sociales obligatorias como impuestos, mientras que el SCN las considera cotizaciones sociales netas debido a que la recepción de prestaciones de la seguridad social depende, en la mayoría de los países, de que se hayan realizado las contribuciones apropiadas, a pesar de que el importe de las prestaciones no esté necesariamente relacionado con el importe de las cotizaciones.

\section{Otras publicaciones}

OECD (2016), Revenue statistics 2016, OECD, París, <http://dx.doi. org/10.1787/rev_stats-2016-en-fr>.

\section{Notas de los gráficos}

2.21 y 2.22: Los datos de Chile no están disponibles. Australia no recauda ingresos a través de cotizaciones sociales ya que no gestiona sistemas públicos de seguridad social. Los datos de Costa Rica y Rusia corresponden a 2014 en lugar de a 2015.

2.21: Los datos de Turquía no se incluyen en la media de la OCDE ya que faltan series temporales.

2.22: Los datos de Turquía no están disponibles.

2.23: En los países de la OCDE miembros de la Unión Europea, la tributación total incluye los derechos aduaneros recaudados en nombre de la Unión Europea. El último año con datos disponibles para todos los países de la OCDE es 2014. La media de la OCDE no es ponderada.

Información sobre los datos de Israel: <http://dx.doi.org/10.1787/888932315602>. 
Gráfico 2.21. Estructura de ingresos de la Administración general, 2015 y 2016

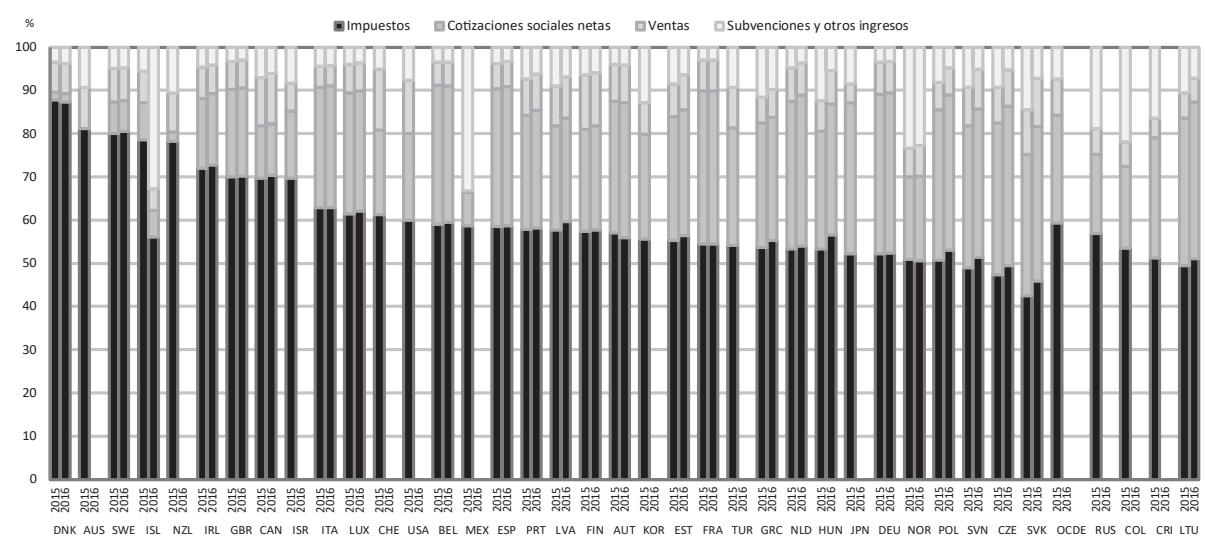

Fuente: Estadísticas de contabilidad nacional de la OCDE (base de datos).

$<$ http://dx.doi.org/10.1787/888933531706>

Gráfico 2.22. Cambios en la estructura de ingresos de la Administración general, de 2007 a 2015

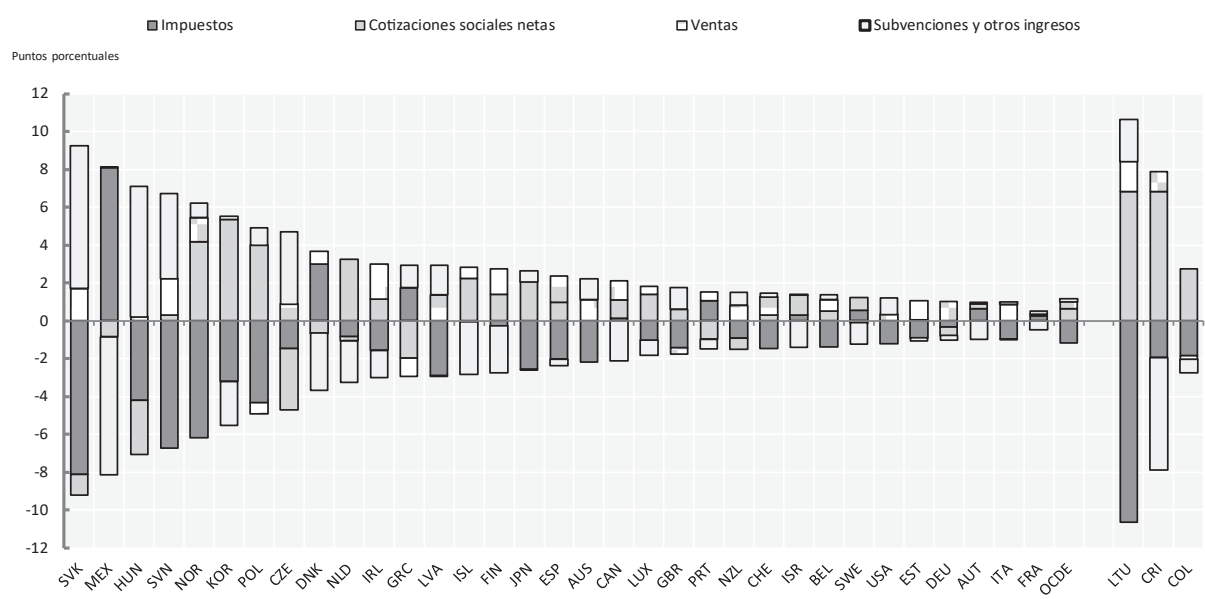

Fuente: Estadísticas de contabilidad nacional de la OCDE (base de datos). 


\section{Gráfico 2.23. Desglose de los ingresos fiscales como porcentaje de la tributación total, 2007 y 2014}

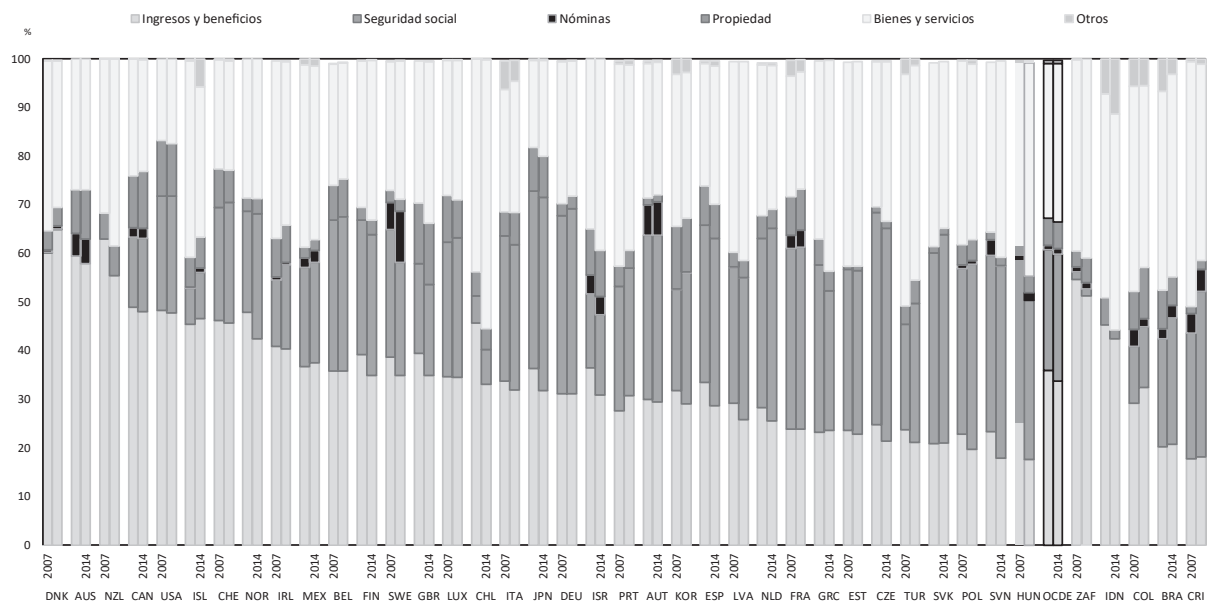

Fuente: Estadísticas de ingresos de la OCDE (2016).

$<$ http://dx.doi.org/10.1787/888933531744>

\section{ESTRUCTURA DE INGRESOS POR NIVEL DE ADMINISTRACIÓN}

Los ingresos de las Administraciones públicas son recaudados por la Administración central y las Administraciones estatales y locales, dependiendo del grado de federalismo fiscal del país. Como con otro tipo de ingresos, la recaudación de impuestos también se lleva a cabo por los distintos niveles de administración en función de la naturaleza económica y tipo de base imponible, las ventajas administrativas y la autonomía fiscal. Sin embargo, en muchos países existen límites legales en cuanto a la capacidad de las Administraciones subcentrales de establecer sus propias bases imponibles, tipos y desgravaciones en los impuestos locales, reduciendo así su poder de generar fuentes de ingresos $\mathrm{y}$, potencialmente, su capacidad de suministrar bienes y servicios más adaptados a las necesidades. Al mismo tiempo, algunos de estos límites tienen como objetivo reducir la competencia fiscal entre regiones, con el fin de disminuir las desigualdades entre ellas.

Por término medio, las Administraciones centrales recaudaron ligeramente más de la mitad (52,5\%) de los ingresos de las Administraciones generales en 2015, las entidades de la seguridad social el 17,7\%, las Administraciones estatales el 19,1\% y las Administraciones locales el 10,7\%. Los países en donde la Administración central concentra la mayor proporción de ingresos son Irlanda 
(95\%), el Reino Unido (90,9\%) y Nueva Zelanda (89\%), mientras que los ingresos estatales y locales suponen una proporción mayor de los ingresos totales en Canadá $(55,5 \%)$ y Chile $(48,5 \%)$.

Entre 2007 y 2015, la composición de ingresos muestra pequeños cambios en los países de la OCDE: en promedio, los ingresos de las Administraciones centrales descendieron $-0,4$ p. p., los de las Administraciones estatales $-0,6 \%$ y los de las Administraciones locales -0,1 p. p., mientras que los ingresos de las entidades de la seguridad social aumentaron 1,1 p. p. Durante este periodo, la proporción de ingresos a nivel central se desplazó en mayor medida hacia otros niveles de administración en México y Corea ( $-4,6$ p. p. y $-4,5$ p. p. respectivamente). Los ingresos estatales aumentaron 4,6 p. p. en México, mientras que los ingresos de las Administraciones locales y entidades de la seguridad social se incrementaron 4,5 p. p. en Corea. Por el contrario, Grecia y Hungría experimentaron los mayores aumentos en la proporción de ingresos a nivel central, con 4,7 p. p. y 4,2 p. p. respectivamente, con un descenso importante en la proporción de ingresos procedentes de la seguridad social $(-5,0$ p. p.) en Grecia, y en la proporción de ingresos a nivel local $(-4,1$ p. p.) en Hungría, durante este mismo periodo.

En los países de la OCDE en 2015, los ingresos de las Administraciones centrales procedieron principalmente de impuestos: en promedio, el 72,5\% de los ingresos totales a nivel central total fueron generados por tributos, y oscilaban entre el $47,6 \%$ de Noruega y el $91 \%$ de Bélgica. Por término medio, las cotizaciones sociales netas a la seguridad social representaron el 16,1\%, y los mayores valores se dieron en los Estados Unidos (33,7\%) y la República Checa $(30,9 \%)$. Las ventas representaron el 3,5\% de los ingresos, y el 7,9\% restante lo contabilizaron las subvenciones y otros ingresos. Las subvenciones y otros ingresos variaron significativamente en los países de la OCDE en 2015, del 2,8\% de los ingresos a nivel central en Bélgica al 26,1\% en Noruega.

\section{Metodología y definiciones}

Los datos de ingresos se han obtenido de las estadísticas de contabilidad nacional de la OCDE (base de datos) y de las estadísticas de finanzas públicas de Eurostat (base de datos), que se basan en el sistema de contabilidad nacional (SCN). El marco actualizado del SCN del año 2008 ha sido ya implementado en todos los países de la OCDE (véase el anexo A para detalles sobre sistemas y fuentes de información). De acuerdo con la terminología del SCN, la Administración general se compone de la Administración central, Administraciones estatales y locales, y de las entidades de la seguridad social. Las Administraciones estatales 
solo existen en los nueve países de la OCDE que son Estados federales: Alemania, Australia, Austria, Bélgica, Canadá, España (considerado un país cuasifederal), los Estados Unidos, México y Suiza. Los datos de los Gráficos 2.24 y 2.25 excluyen las transferencias entre los niveles de administración para mostrar la contribución de cada subsector en los ingresos totales de la Administración general, que están consolidados a este nivel. Sin embargo, los datos sobre la estructura de los ingresos a nivel central, estatal y local incluyen las transferencias entre los niveles de administración. Los Gráficos 2.27 y 2.28 (estructura de los ingresos de las Administraciones estatales y locales) están disponibles online en el anexo F. Los ingresos comprenden los impuestos (por ejemplo, impuestos sobre el consumo, la renta, el patrimonio, la propiedad y el capital), las cotizaciones sociales netas (por ejemplo, las cotizaciones para pensiones, sanidad y seguridad social; netas significa una vez deducidos, en su caso, los cargos por servicios de los sistemas de seguros sociales), las ventas de bienes y servicios (por ejemplo, la producción para el mercado de empresas y organizaciones de las Administraciones, cuotas de entrada), y subvenciones y otros ingresos (por ejemplo, subvenciones corrientes y de capital, rentas del patrimonio y subsidios). Estos agregados se elaboraron con las subcuentas de las partidas (véase el anexo B).

\section{Notas de los gráficos}

Los datos de Chile no están disponibles.

Los datos de Turquía no se incluyen en la media de la OCDE ya que faltan series temporales.

Australia no gestiona un sistema público de seguridad social.

2.24 y 2.25: Se excluyen las transferencias entre los distintos niveles de administración (excepto en Australia, Corea, Japón y Turquía). En Japón, los datos de los subsectores de la Administración general se refieren al año fiscal. La Administración local está incluida en la Administración estatal en Australia y los Estados Unidos. Las entidades de la seguridad social están incluidas en la Administración central en los Estados Unidos, Irlanda, Noruega, Nueva Zelanda y el Reino Unido.

2.24 y 2.26: Los datos de Costa Rica corresponden a 2014 en lugar de a 2015. Información sobre los datos de Israel: <http://dx.doi.org/10.1787/888932315602>. 
Gráfico 2.24. Distribución de los ingresos de la Administración general por nivel de administración, 2015 y 2016

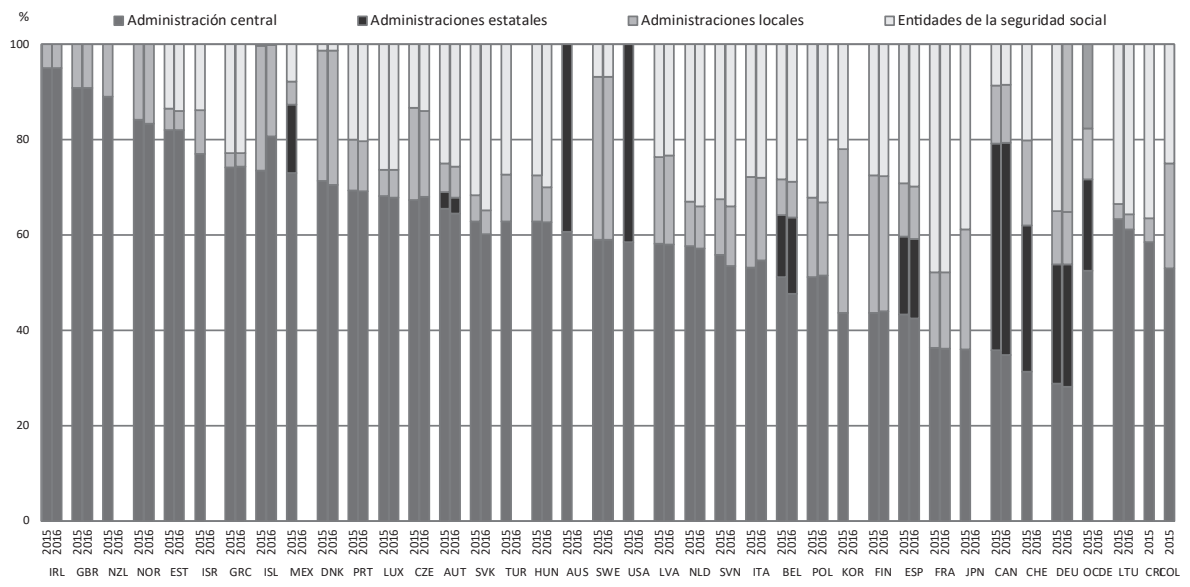

Fuente: Estadísticas de contabilidad nacional de la OCDE (base de datos).

$<$ http://dx.doi.org/10.1787/888933531763>

Gráfico 2.25. Cambios en la distribución de ingresos de la Administración general por nivel de administración, de 2007 a 2015

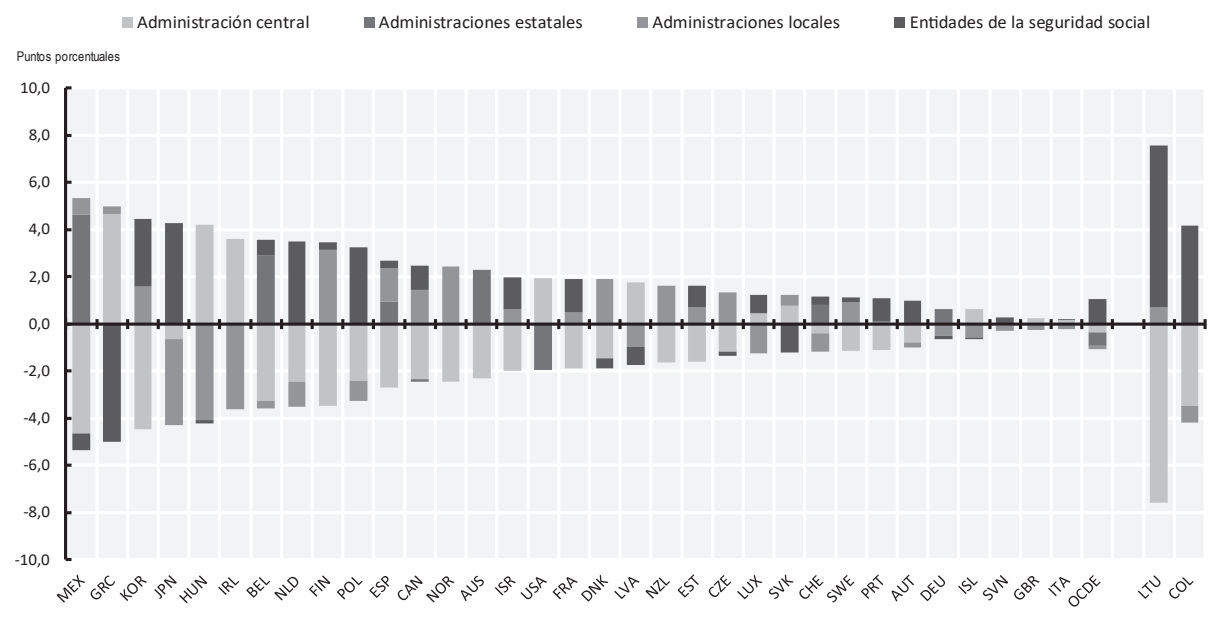

Fuente: Estadísticas de contabilidad nacional de la OCDE (base de datos). 


\section{Gráfico 2.26. Estructura de ingresos de la Administración central, 2015 y 2016}

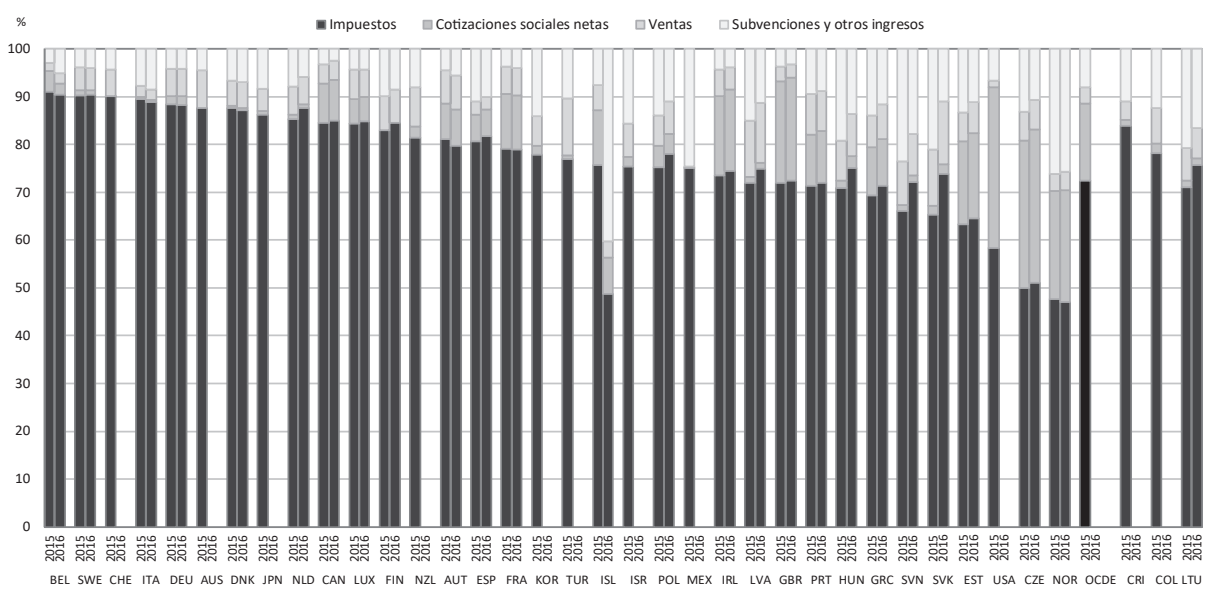

Fuente: Estadísticas de contabilidad nacional de la OCDE (base de datos).

$<$ http://dx.doi.org/10.1787/888933531801>

\section{GASTOS DE LA ADMINISTRACIÓN GENERAL}

Los gastos públicos proporcionan los medios para implementar la amplia gama de objetivos de gobierno y mandatos, desde los servicios prestados a la población, como la justicia o la logística electoral, hasta el pago de los salarios del funcionariado y de las infraestructuras de transporte, entre otras muchas actividades. Los gastos de la Administración general proporcionan una indicación de su tamaño puesto que financian, por ejemplo, los costes policiales, las licencias ocupacionales, el registro de empresas, la prestación del servicio de transporte público, la asistencia sanitaria, las pensiones, las prestaciones por desempleo, etc. Aunque los gastos públicos suelen ser menos flexibles que los ingresos, también son sensibles a los ciclos políticos y reflejan las decisiones políticas actuales y del pasado.

Los gastos de las Administraciones públicas representaron en promedio el $40,9 \%$ del PIB en los países de la OCDE. Este nivel de gastos ha aumentado con respecto al 38,8\% de 2007, antes de la crisis financiera, y descendido con respecto al 44,2\% de 2009, año en que la política fiscal expansionista se puso en práctica en respuesta a la crisis, ya que la recuperación del crecimiento del PIB superó el ritmo del crecimiento de los gastos públicos. Los mayores niveles de gastos públicos, como proporción del PIB en 2015, se dieron en Finlandia y Francia (el $57 \%$ en ambas), seguidas de Dinamarca (54,8\%), Grecia $(54,2 \%)$, Bélgica $(53,9 \%)$ y Austria $(51,7 \%)$. Francia continuó siendo el país 
con el mayor nivel de gastos públicos desde 2007, aunque Finlandia la superó en 2015 debido a que los gastos aumentaron con mayor rapidez que el crecimiento del PIB. Los menores niveles de gastos se dieron en México (24,5\%), Irlanda (29,5\%), Corea (32,4\%), Turquía $(33,1 \%)$ y Chile $(33,9 \%)$.

Aunque los gastos públicos como proporción del PIB descendieron un promedio de 3,3 p. p. en los países de la OCDE entre 2009 y 2015, hubo variaciones significativas entre países. El mayor incremento en los gastos públicos tuvo lugar en Noruega (2,7 p. p.); por el contrario, los mayores descensos entre 2009 y 2015 los experimentaron Irlanda (-17,6 p. p.), Turquía (-7,7 p. p.) y Letonia $(-6,7$ p. p.). El descenso en la ratio de gastos de Irlanda fue principalmente debido al crecimiento excepcionalmente elevado del PIB en 2015 ( $+32 \%$ en comparación con 2014 , en términos nominales), derivado de las transferencias de activos intangibles de empresas multinacionales, puesto que los niveles de gastos decrecieron solo un $5 \%$ entre 2009 y 2015.

Según los datos disponibles de 2016, el gasto público como proporción del PIB descendió $-5,2$ p. p. con respecto a 2015 en Grecia, como consecuencia de la consolidación fiscal, y -3,9 p. p. en la República Eslovaca debido a una absorción menor de los fondos de la UE. Durante el mismo periodo, los mayores aumentos en los niveles de gasto público se dieron en Noruega con 2,3 p. p., seguida de Canadá, con 0,5 p. p.

En promedio en toda la OCDE, el gasto público supuso 17353 USD PPA per cápita en 2015. Sin embargo, entre los países de la OCDE hay grandes diferencias, que van desde los 43010 USD PPA en Luxemburgo hasta los 4391 USD PPA en México.

Si se comparan las tasas de crecimiento medio anual de los gastos públicos reales per cápita desde la crisis financiera, entre 2009 y 2015 el mayor índice se dio en la República Eslovaca con una media del 3,5\% por año, seguida de México con un 2,8\% y Turquía con un 2,4\%, mientras que, durante el mismo periodo, el crecimiento medio fue negativo en Grecia (una media de $-3,8 \%$ por año) e Irlanda $(-2,6 \%)$.

De los países en proceso de adhesión, Colombia registró los mayores niveles de gastos en 2015 , con un $37,5 \%$ del PIB, seguida de Lituania $(35,1 \%)$ y Costa Rica (32,9\%).

\section{Metodología y definiciones}

Los datos de gastos se obtienen de las estadísticas de contabilidad nacional de la OCDE (base de datos), que se basan en el sistema de contabilidad nacional (SCN), un conjunto de conceptos, definiciones, clasificaciones y reglas acordados internacionalmente para la contabilidad 
nacional. El marco actualizado del SCN del año 2008 ha sido ya implementado en todos los países de la OCDE (véase el anexo A para detalles sobre sistemas y fuentes de información). De acuerdo con la terminología del SCN, la Administración general se compone de la Administración central, Administraciones estatales y locales, y de las entidades de la seguridad social. Los gastos comprenden el consumo intermedio, las retribuciones de los empleados públicos, los subsidios, los ingresos sobre la propiedad (incluyendo los pagos por intereses), las prestaciones sociales, otros gastos corrientes (principalmente las transferencias corrientes) y los gastos de capital (es decir, las transferencias e inversiones de capital). El producto interior bruto (PIB) es la medida estándar del valor de los bienes y servicios producidos por un país durante un periodo determinado. Los ingresos públicos per cápita se calcularon mediante la conversión de los ingresos totales a USD utilizando las paridades de poder adquisitivo (PPA) de la OCDE/Eurostat para el PIB y dividiéndolos por la población (para los países cuya fuente de datos es el Economic Outlook del FMI se utilizó un tipo de conversión PPA implícita). Las PPA son el número de unidades de la moneda del país B que se necesita para comprar la misma cantidad de bienes y servicios en el país A.

\section{Otras publicaciones}

OECD (2015), National Accounts at a Glance 2015, OECD, París, <http://dx. doi.org/10.1787/na_glance-2015-en>.

OECD (2016), OECD Insights: Are the Irish 26.3\% better off?, OECD, París, $<$ http://www.oecd.org/std/na/Irish-GDP-up-in-2015-OECD.pdf>.

\section{Notas de gráficos}

Los datos de Chile no están disponibles.

Los datos de Turquía no se incluyen en la media de la OCDE ya que faltan series temporales.

Los datos de Costa Rica y Rusia corresponden a 2014 en lugar de a 2015.

Información sobre los datos de Israel: <http://dx.doi.org/10.1787/888932315602>. 
Gráfico 2.29. Gastos públicos como porcentaje del PIB, 2007, 2009, 2015 y 2016

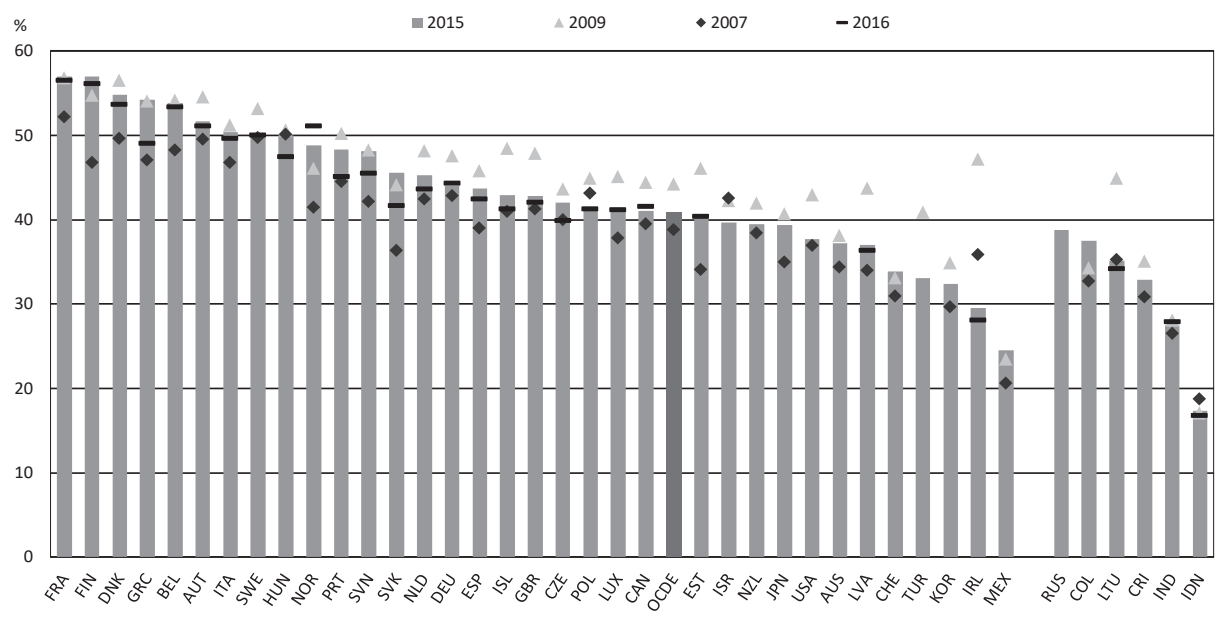

Fuentes: Estadísticas de contabilidad nacional de la OCDE (base de datos). Los datos de India e Indonesia son del Economic Outlook del FMI (abril de 2017).

Gráfico 2.30. Gastos públicos per cápita, 2009, 2015 y 2016

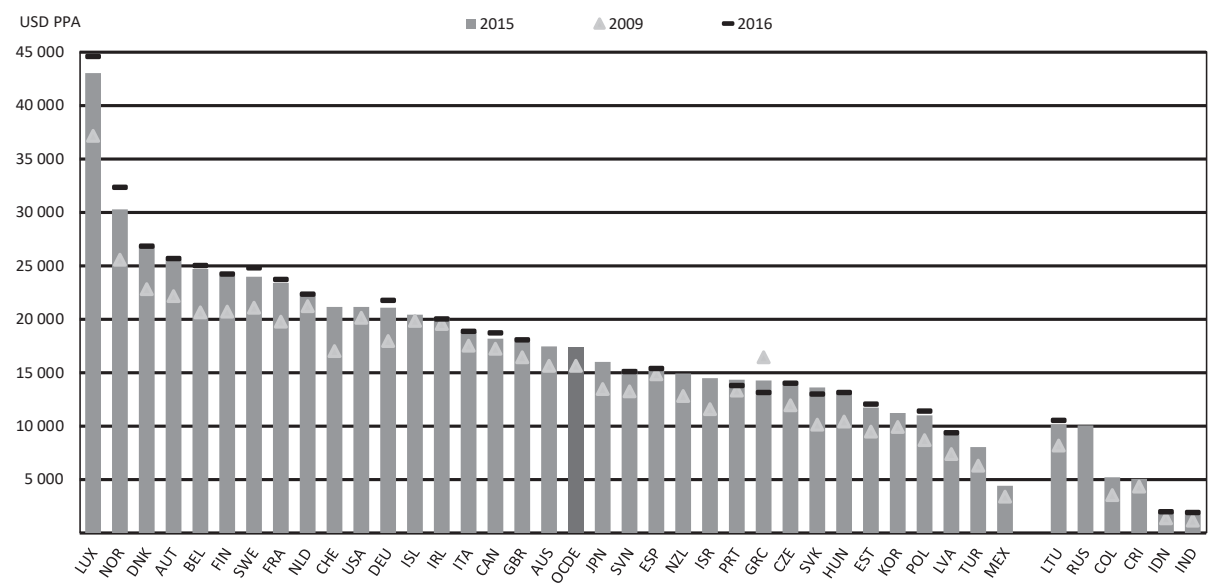

Fuentes: Estadísticas de contabilidad nacional de la OCDE (base de datos). Los datos de India e Indonesia son del Economic Outlook del FMI (abril de 2017). 


\section{Gráfico 2.31. Tasas de crecimiento medio anual de los gastos públicos reales per cápita, 2007-2015, 2009-2015 y 2015-2016}

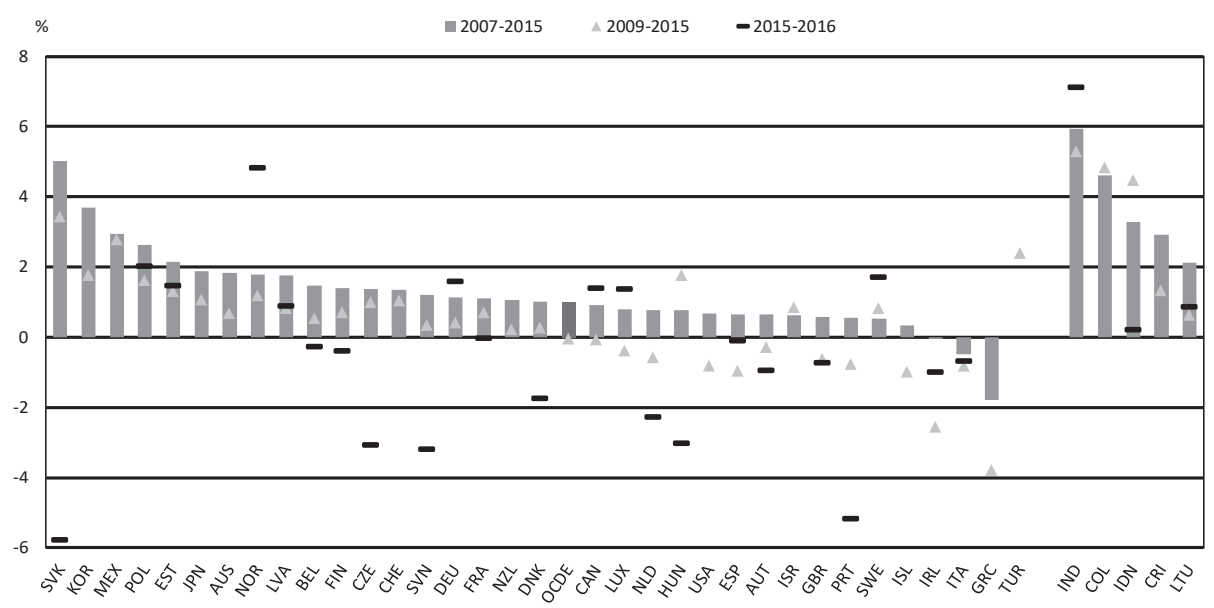

Fuentes: Estadísticas de contabilidad nacional de la OCDE (base de datos). Los datos de India e Indonesia son del Economic Outlook del FMI (abril de 2017).

$<$ http://dx.doi.org/10.1787/888933531858>

\section{ESTRUCTURA DE GASTOS DE LA ADMINISTRACIÓN GENERAL POR FUNCIÓN (CFG)}

Los gastos públicos por función muestran lo que gastan las Administraciones públicas en áreas clave, como educación, sanidad, defensa, protección social u orden público y seguridad. Estas funciones distintas suman gastos de acuerdo con unas categorías predefinidas, permitiendo comparaciones informativas de prioridades nacionales entre Gobiernos.

En 2015, la protección social supuso la mayor proporción de gastos públicos en los países de la OCDE, con una media del 32,6\%, que osciló entre el $44,9 \%$ en Finlandia y el 19,4\% en Corea. En promedio, las pensiones contabilizaron más de la mitad de todos los gastos en protección social en 2015 (véase el indicador sobre estructura de gastos de protección social).

La sanidad representó la segunda mayor proporción de gasto público con una media del 18,7\% durante el mismo año, que varió desde el 24,2\% de los Estados Unidos hasta el 6,5\% de Suiza. El nivel relativamente bajo del gasto público en sanidad de Suiza fue resultado del sistema de cobertura privada de riesgos relacionados con la salud de este país. 
Los servicios públicos generales — que incluyen el pago de la deudacontabilizaron el 13,2\% de los gastos públicos, mientras que la educación representó el 12,6\%. El gasto en defensa, junto con los gastos en orden público y seguridad, supusieron una media del $9,4 \%$ de los gastos públicos en los países de la OCDE en 2015; el gasto en defensa fue mayor en Israel (14,9\%), los Estados Unidos $(8,8 \%)$ y Corea $(7,8 \%)$, mientras que los mayores gastos en orden público y seguridad se dieron en los Estados Unidos y Letonia (un 5,4\% en ambos).

El gasto en asuntos económicos en 2015 alcanzó una media del 9,3\% en los países de la OCDE, oscilando entre el 17,3\% de Hungría y el 5,9\% de Israel. El transporte representa en promedio la mayor proporción de gastos en asuntos económicos, con un 47,6\%, seguido de asuntos económicos, comerciales y laborales en general, con un $22 \%$.

El gasto público en las demás funciones es relativamente bajo, con una media del 1,5\% invertido en ocio, cultura y religión en 2015, que varió del 7,5\% registrado en Islandia hasta el $0,7 \%$ de los Estados Unidos. La protección medioambiental supuso en promedio el 1,3\% del gasto público, y marcó su mayor registro en los Países Bajos, con un 3,2\%, mientras que los gastos en vivienda y servicios comunitarios representaron una media del $1,4 \%$ de los gastos públicos: del 2,6\% marcado en Corea y Letonia al 0,1\% de Israel.

Las comparaciones a medio o largo plazo de los gastos públicos por función muestran, hasta cierto punto, las reorganizaciones de gastos. En los países de la OCDE, la distribución de gastos ha experimentado cambios entre 2007 y 2015, con disminuciones en los servicios públicos generales, defensa, orden público y seguridad, asuntos económicos, educación, y ocio, cultura y religión, y aumentos en sanidad y protección social. El mayor aumento se dio en protección social $(+2,6$ p. p.), y el mayor descenso se registró en los servicios públicos generales $(-1,2$ p. p.). En los países de la OCDE, los mayores cambios en materia de protección social incluyeron aumentos en Letonia (7,6 p. p.) y España (6,2 p. p.), mientras que el mayor descenso de gasto en servicios públicos generales lo marcó Grecia $(-6,9$ p. p.).

De los países en proceso de adhesión, Costa Rica registró la mayor proporción de gastos tanto en educación (23,3\%) como en sanidad (19,3\%), mientras que Lituania gastó más en protección social (31,7\%). Colombia y Costa Rica invirtieron más que la media de los países de la OCDE en orden público y seguridad, un $6,8 \%$ y un $8 \%$ respectivamente. Costa Rica, como Islandia, no tiene gasto en defensa puesto que suprimió sus fuerzas armadas en 1948. 


\section{Metodología y definiciones}

Los datos de gastos se han obtenido de las estadísticas de contabilidad nacional de la OCDE (base de datos) y de las estadísticas de finanzas públicas de Eurostat (base de datos), que se basan en el sistema de contabilidad nacional (SCN). El marco actualizado del SCN del año 2008 ha sido ya implementado en todos los países de la OCDE (véase el anexo A para detalles sobre sistemas y fuentes de información). Los datos de gastos se desglosan de acuerdo con la clasificación de las funciones del Gobierno (CFG), que divide los gastos en diez funciones: servicios públicos generales; defensa; seguridad y orden público; asuntos económicos; protección medioambiental; vivienda y servicios comunitarios; sanidad; ocio, cultura y religión; educación, y protección social. Para más información sobre los tipos de gastos incluidos, véase el anexo C. Los Gráficos 2.34 y 2.35 (gasto público por función como porcentaje del PIB y sus cambios de 2007 a 2015) están disponibles online en el anexo F. La estructura de las Administraciones por funciones prioritarias seleccionadas de nivel II de la CFG se muestra en el indicador de gastos en protección social y sanidad, y en la Tabla 2.36 (servicios públicos generales), Tabla 2.37 (seguridad y orden público), Tabla 2.38 (asuntos económicos) y en la Tabla 2.39 (educación). Estás tablas están disponibles online en el anexo F.

\section{Notas de gráficos}

Los datos de Canadá, Chile, México, Nueva Zelanda y Turquía no están disponibles. Los datos de Corea corresponden a 2014 en lugar de a 2015.

2.32: Los datos de Islandia no se incluyen en la media de la OCDE ya que faltan series temporales. Los datos de Colombia y Costa Rica corresponden a 2014 en lugar de a 2015.

Los datos de Islandia no se incluyen en la media de la OCDE ya que faltan series temporales.

Los datos de Canadá, Chile, México, Nueva Zelanda y Turquía no están disponibles.

Los datos de Corea corresponden a 2014 en lugar de a 2015.

Información sobre los datos de Israel: <http://dx.doi.org/10.1787/888932315602>. 
Tabla 2.32. Estructura del gasto público por función, 2015

\begin{tabular}{|c|c|c|c|c|c|c|c|c|c|c|}
\hline & $\begin{array}{l}\text { Servicios } \\
\text { públicos } \\
\text { generales }\end{array}$ & Defensa & $\begin{array}{c}\text { Orden } \\
\text { público y } \\
\text { seguridad }\end{array}$ & $\begin{array}{c}\text { Asuntos } \\
\text { económicos }\end{array}$ & $\begin{array}{l}\text { Protección } \\
\text { del medio } \\
\text { ambiente }\end{array}$ & $\begin{array}{c}\text { Vivienda y } \\
\text { servicios } \\
\text { comunitarios }\end{array}$ & Sanidad & $\begin{array}{c}\text { Ocio, } \\
\text { cultura y } \\
\text { religión }\end{array}$ & Educación & $\begin{array}{l}\text { Protección } \\
\text { social }\end{array}$ \\
\hline Alemania & 13,5 & 2,3 & 3,6 & 7,1 & 1,4 & 0,9 & 16,3 & 2,3 & 9,6 & 43,1 \\
\hline Australia & 12,5 & 4,4 & 4,9 & 10,0 & 2,4 & 1,6 & 19,4 & 2,0 & 14,6 & 28,2 \\
\hline Austria & 13,3 & 1,1 & 2,7 & 11,9 & 0,9 & 0,7 & 15,5 & 2,4 & 9,6 & 42,0 \\
\hline Bélgica & 15,1 & 1,6 & 3,3 & 12,0 & 1,6 & 0,6 & 14,2 & 2,2 & 11,9 & 37,5 \\
\hline Corea & 16,6 & 7,8 & 4,0 & 16,1 & 2,5 & 2,6 & 12,5 & 2,1 & 16,3 & 19,4 \\
\hline Dinamarca & 13,5 & 2,0 & 1,8 & 6,7 & 0,8 & 0,4 & 15,6 & 3,2 & 12,8 & 43,0 \\
\hline España & 14,9 & 2,2 & 4,6 & 10,0 & 2,0 & 1,1 & 14,2 & 2,6 & 9,3 & 39,1 \\
\hline $\begin{array}{l}\text { Estados } \\
\text { Unidos }\end{array}$ & 13,8 & 8,8 & 5,4 & 8,7 & 0,0 & 1,4 & 24,2 & 0,7 & 16,2 & 20,8 \\
\hline Estonia & 10,6 & 4,7 & 4,5 & 11,8 & 1,7 & 0,9 & 13,7 & 4,9 & 15,1 & 32,1 \\
\hline Finlandia & 14,9 & 2,4 & 2,2 & 8,3 & 0,4 & 0,7 & 12,6 & 2,6 & 11,0 & 44,9 \\
\hline Francia & 11,0 & 3,1 & 2,9 & 10,0 & 1,8 & 1,9 & 14,3 & 2,3 & 9,6 & 43,1 \\
\hline Grecia & 17,8 & 4,9 & 3,8 & 16,0 & 2,7 & 0,4 & 8,2 & 1,3 & 7,8 & 37,0 \\
\hline Hungría & 17,8 & 1,1 & 4,1 & 17,3 & 2,5 & 2,2 & 10,6 & 4,3 & 10,3 & 29,9 \\
\hline Irlanda & 13,9 & 1,2 & 3,7 & 11,5 & 1,4 & 2,0 & 19,3 & 2,0 & 12,4 & 32,7 \\
\hline Islandia & 18,0 & 0,0 & 3,6 & 11,6 & 1,3 & 1,1 & 17,4 & 7,5 & 17,4 & 22,1 \\
\hline Israel & 13,6 & 14,9 & 3,9 & 5,9 & 1,2 & 0,1 & 12,7 & 3,5 & 17,1 & 27,0 \\
\hline Italia & 16,6 & 2,4 & 3,7 & 8,1 & 1,9 & 1,2 & 14,1 & 1,5 & 7,9 & 42,6 \\
\hline Japón & 10,4 & 2,3 & 3,2 & 9,5 & 2,9 & 1,7 & 19,4 & 0,9 & 8,7 & 40,7 \\
\hline Letonia & 14,0 & 2,7 & 5,4 & 11,5 & 1,9 & 2,6 & 10,3 & 4,4 & 16,2 & 31,0 \\
\hline Luxemburgo & 10,5 & 0,7 & 2,4 & 11,9 & 2,6 & 1,2 & 10,9 & 2,8 & 12,4 & 44,8 \\
\hline Noruega & 9,6 & 3,1 & 2,2 & 10,5 & 1,8 & 1,5 & 17,2 & 3,0 & 11,2 & 39,8 \\
\hline Países Bajos & 11,1 & 2,5 & 4,0 & 8,8 & 3,2 & 0,7 & 17,7 & 3,1 & 12,0 & 36,8 \\
\hline Polonia & 11,8 & 3,8 & 5,3 & 11,1 & 1,5 & 1,7 & 11,2 & 2,7 & 12,6 & 38,3 \\
\hline Portugal & 16,8 & 2,2 & 4,3 & 10,5 & 0,8 & 1,0 & 12,7 & 1,6 & 12,4 & 37,8 \\
\hline Reino Unido & 10,6 & 5,0 & 4,7 & 7,1 & 1,8 & 1,1 & 17,8 & 1,5 & 12,0 & 38,4 \\
\hline $\begin{array}{c}\text { República } \\
\text { Checa }\end{array}$ & 10,3 & 2,2 & 4,4 & 15,6 & 2,6 & 1,6 & 18,2 & 3,2 & 11,8 & 30,1 \\
\hline $\begin{array}{c}\text { República } \\
\text { Eslovaca }\end{array}$ & 14,2 & 2,3 & 5,2 & 13,9 & 2,3 & 1,9 & 15,7 & 2,3 & 9,3 & 33,0 \\
\hline $\begin{array}{l}\text { República de } \\
\text { Eslovenia }\end{array}$ & 14,2 & 1,8 & 3,2 & 12,4 & 2,1 & 1,3 & 14,0 & 3,4 & 11,6 & 36,1 \\
\hline Suecia & 14,1 & 2,3 & 2,6 & 8,4 & 0,6 & 1,5 & 13,8 & 2,2 & 13,0 & 41,6 \\
\hline Suiza & 12,6 & 2,8 & 5,0 & 11,0 & 2,1 & 0,6 & 6,5 & 2,4 & 17,2 & 39,9 \\
\hline OCDE & 13,2 & 5,1 & 4,3 & 9,3 & 1,3 & 1,4 & 18,7 & 1,5 & 12,6 & 32,6 \\
\hline Colombia & 14,1 & 5,0 & 6,8 & 11,9 & 1,4 & 1,7 & 15,2 & 2,3 & 14,3 & 27,2 \\
\hline Costa Rica & 10,4 & 0,0 & 8,0 & 8,8 & 1,4 & 2,6 & 19,3 & 0,8 & 23,3 & 25,4 \\
\hline Lituania & 12,5 & 3,8 & 4,5 & 10,4 & 1,5 & 0,9 & 16,5 & 2,7 & 15,4 & 31,7 \\
\hline
\end{tabular}

Fuentes: Estadísticas de contabilidad nacional de la OCDE (base de datos); estadísticas de finanzas públicas de Eurostat (base de datos). Los datos de Australia se basan en las estadísticas financieras públicas proporcionadas por la Oficina de Estadísticas de Australia. 


\section{Tabla 2.33. Cambios en la estructura del gasto público por función, de 2007 a 2015}

\begin{tabular}{|c|c|c|c|c|c|c|c|c|c|c|}
\hline & $\begin{array}{l}\text { Servicios } \\
\text { públicos } \\
\text { generales }\end{array}$ & Defensa & $\begin{array}{c}\text { Orden } \\
\text { público y } \\
\text { seguridad }\end{array}$ & $\begin{array}{c}\text { Asuntos } \\
\text { económicos }\end{array}$ & $\begin{array}{c}\text { Protección } \\
\text { medioambiental }\end{array}$ & $\begin{array}{c}\text { Vivienda y } \\
\text { servicios } \\
\text { comunitarios }\end{array}$ & Sanidad & $\begin{array}{c}\text { Ocio, } \\
\text { cultura y } \\
\text { religión }\end{array}$ & Educación & $\begin{array}{c}\text { Protección } \\
\text { social }\end{array}$ \\
\hline Alemania & $-0,7$ & 0,1 & 0,1 & $-0,5$ & 0,2 & $-1,0$ & 1,5 & 0,5 & 0,4 & $-0,7$ \\
\hline Austria & $-2,1$ & $-0,4$ & 0,0 & $-0,1$ & $-0,1$ & $-0,1$ & 0,5 & $-0,5$ & 0,1 & 2,6 \\
\hline Bélgica & $-3,0$ & $-0,5$ & $-0,2$ & 0,5 & 0,2 & $-0,3$ & 0,4 & $-0,3$ & 0,5 & 2,8 \\
\hline Corea & $-1,0$ & $-0,1$ & $-0,2$ & $-4,0$ & $-0,5$ & $-1,1$ & 2,0 & $-0,2$ & 0,8 & 4,2 \\
\hline Dinamarca & 0,0 & $-0,8$ & 0,0 & 0,8 & $-0,2$ & $-0,2$ & 0,2 & $-0,2$ & 0,9 & $-0,3$ \\
\hline España & 2,2 & $-0,4$ & $-0,2$ & $-3,3$ & $-0,6$ & $-1,2$ & $-0,4$ & $-1,5$ & $-1,0$ & 6,2 \\
\hline $\begin{array}{l}\text { Estados } \\
\text { Unidos }\end{array}$ & $-1,4$ & $-1,9$ & $-0,4$ & $-1,0$ & 0,0 & $-0,4$ & 3,5 & $-0,2$ & $-0,9$ & 2,6 \\
\hline Estonia & 0,8 & 1,0 & $-1,8$ & $-0,9$ & $-0,8$ & $-0,9$ & 0,9 & $-1,1$ & $-2,2$ & 4,9 \\
\hline Finlandia & 0,7 & $-0,5$ & $-0,3$ & $-1,0$ & $-0,3$ & 0,0 & $-1,5$ & 0,4 & $-1,4$ & 4,0 \\
\hline Francia & $-2,6$ & $-0,2$ & 0,1 & 1,9 & 0,1 & $-0,3$ & 0,1 & $-0,2$ & $-0,5$ & 1,7 \\
\hline Grecia & $-6,9$ & $-1,0$ & 0,6 & 7,1 & 1,0 & 0,0 & $-4,6$ & $-0,1$ & 0,2 & 3,7 \\
\hline Hungría & $-1,3$ & $-1,4$ & 0,2 & 4,3 & 1,2 & 0,2 & 0,7 & 1,3 & $-0,7$ & $-4,5$ \\
\hline Irlanda & 4,1 & 0,0 & $-0,6$ & 0,7 & $-1,7$ & $-3,6$ & 0,0 & $-0,1$ & 0,0 & 1,1 \\
\hline Israel & $-4,2$ & $-1,6$ & 0,3 & 0,1 & $-0,1$ & $-0,7$ & 1,3 & 0,4 & 2,5 & 2,1 \\
\hline Italia & $-1,7$ & $-0,1$ & $-0,3$ & $-0,9$ & 0,3 & $-0,2$ & $-0,2$ & $-0,3$ & $-1,8$ & 5,1 \\
\hline Japón & $-2,0$ & $-0,1$ & $-0,2$ & $-0,3$ & $-0,3$ & $-0,5$ & 1,9 & 0,0 & $-1,0$ & 2,6 \\
\hline Letonia & 2,7 & $-1,4$ & $-1,8$ & $-3,0$ & $-0,7$ & $-0,9$ & $-1,6$ & $-0,6$ & $-0,1$ & 7,6 \\
\hline Luxemburgo & $-1,8$ & 0,0 & 0,0 & $-0,3$ & $-0,3$ & $-0,4$ & $-0,5$ & $-0,5$ & 0,5 & 3,2 \\
\hline Noruega & $-4,6$ & $-0,6$ & 0,1 & 1,4 & 0,4 & 0,1 & 0,4 & 0,1 & $-0,5$ & 3,1 \\
\hline Países Bajos & $-1,8$ & $-0,5$ & $-0,3$ & $-1,1$ & $-0,5$ & $-0,2$ & 1,9 & $-0,5$ & 0,0 & 3,0 \\
\hline Polonia & $-0,8$ & $-0,7$ & 0,1 & 0,3 & 0,1 & $-0,8$ & 0,8 & 0,0 & $-0,7$ & 1,7 \\
\hline Portugal & 1,5 & $-0,5$ & 0,3 & 1,1 & $-0,6$ & $-1,1$ & $-3,0$ & $-0,7$ & $-2,0$ & 5,0 \\
\hline Reino Unido & 0,3 & $-0,3$ & $-1,0$ & 0,0 & $-0,4$ & $-1,3$ & 2,0 & $-0,6$ & $-2,0$ & 3,4 \\
\hline $\begin{array}{l}\text { República } \\
\text { Checa }\end{array}$ & $-0,5$ & $-0,6$ & $-0,4$ & $-0,3$ & 0,2 & $-0,8$ & 1,7 & 0,3 & 0,0 & 0,3 \\
\hline $\begin{array}{c}\text { República } \\
\text { Eslovaca }\end{array}$ & 1,9 & 0,2 & 0,1 & 2,0 & 0,2 & 0,0 & $-1,0$ & 0,0 & $-0,4$ & $-3,0$ \\
\hline $\begin{array}{c}\text { República de } \\
\text { Eslovenia }\end{array}$ & 1,3 & $-1,5$ & $-0,7$ & 2,7 & 0,3 & $-0,1$ & 0,1 & 0,5 & $-2,4$ & 0,0 \\
\hline Suecia & $-1,4$ & $-0,8$ & 0,0 & 0,5 & $-0,1$ & 0,1 & 1,0 & 0,1 & 0,3 & 0,3 \\
\hline Suiza & $-0,3$ & $-0,2$ & 0,2 & $-1,9$ & 0,5 & $-0,1$ & 0,4 & 0,1 & $-0,2$ & 1,4 \\
\hline OCDE & $-1,2$ & $-0,9$ & $-0,3$ & $-0,5$ & 0,0 & $-0,5$ & 1,7 & $-0,1$ & $-0,7$ & 2,6 \\
\hline Lituania & 1,0 & $-1,4$ & $-0,3$ & $-1,5$ & $-1,0$ & 0,1 & 1,6 & $-0,3$ & 0,4 & 1,3 \\
\hline
\end{tabular}

Fuentes: Estadísticas de contabilidad nacional de la OCDE (base de datos); estadísticas de finanzas públicas de Eurostat (base de datos). Los datos de Australia se basan en las estadísticas financieras públicas proporcionadas por la Oficina de Estadísticas de Australia. 


\section{ESTRUCTURA DE GASTOS DE LA ADMINISTRACIÓN GENERAL POR TRANSACCIÓN ECONÓMICA}

Los gastos públicos también se pueden clasificar por la naturaleza de su transacción, que incluye desde las retribuciones del funcionariado, gastos puntuales de capital, el financiamiento de un subsidio o una transferencia de liquidez - como en el caso de pensiones o prestaciones por desempleo - hasta la adquisición de bienes y servicios del sector público que se utilizan como insumos en la producción de las Administraciones públicas (es decir, el consumo intermedio). Esta clasificación es complementaria a los gastos públicos por función, ya que distingue categorías más amplias de la función de producción de las Administraciones y su relación con la economía.

La composición de los gastos de las Administraciones según esta clasificación muestra que, en 2015, las prestaciones sociales representaron una media del $41,1 \%$ de los gastos en los países de la OCDE, las retribuciones de los empleados públicos el 23,1\%, el consumo intermedio el 13,9\%, los gastos de capital el 9,4\% y los ingresos sobre la propiedad el 6,4\%, mientras que el 6,1\% restante se dedicó a subsidios y otros gastos corrientes. Las mayores proporciones de gastos públicos en prestaciones sociales en 2015 se dieron en Alemania $(54,2 \%)$ y Japón $(53,9 \%)$, y las menores se registraron en México, con un $10,2 \%$, e Islandia, con un $14,9 \%$. Por otro lado, los mayores porcentajes de gastos en retribuciones de los empleados públicos se marcaron en México e Islandia, con un $37 \%$ y un $32,4 \%$ respectivamente, mientras que el porcentaje más bajo se dio en Japón (14\%). El consumo intermedio alcanzó sus cuotas más elevadas en Islandia e Israel, con el $25,4 \%$ y el $23 \%$, respectivamente.

De 2009 a 2015, la estructura de gastos por transacción económica sufrió cambios relativos en los países de la OCDE. En promedio, la proporción de gastos dedicados a prestaciones sociales aumentó 3,1 p. p., mientras que hubo descensos en las partidas de retribuciones del funcionariado ( $-0,1$ p. p.), consumo intermedio $(-0,4 \%)$ y gastos de capital $(-2,7 \%)$; este último fue debido a las medidas fiscales anticíclicas que se adoptaron en respuesta a la crisis en 2009. Durante este periodo, los mayores cambios en la composición de gastos se dieron en Hungría, que aumentó 8,8 p. p. la partida de gastos de capital, principalmente fondos de la UE, mientras que disminuyó 7 p. p. las prestaciones sociales, y en Corea, donde la proporción de gastos de capital descendió 7,7 p. p., mientras que las prestaciones sociales aumentaron 7,2 p. p. 
Desde una perspectiva a largo plazo, comparando la composición de las transacciones económicas de los gastos públicos entre 2007 y 2015, se constata que varios países experimentaron cambios importantes. Por ejemplo, las retribuciones de los empleados públicos en relación con el gasto total aumentaron 3,2 p. p. en la República Checa, y descendieron -6,1 p. p. en Portugal debido a recortes salariales. Además, la proporción de prestaciones sociales aumentó 7,5 p. p. en Letonia, 6,9 p. p. en Corea y los Estados Unidos y 6,7 p.p. en España, mientras que descendió $-5,5$ p. p. en Hungría y -5 p. p. en la República Checa. Los gastos de capital, aunque supusieron una media del $9,4 \%$ de los gastos totales en los países de la OCDE en 2015, alcanzaron cifras elevadas en Corea (19\%) y Hungría (18,1\%).

De los países en proceso de adhesión a la OCDE, Costa Rica gastó más en retribuciones de empleados públicos, con un $43,6 \%$, seguida de Lituania, con un $27,5 \%$. En cuanto a prestaciones sociales, Lituania y Colombia invirtieron un $35,6 \%$ y $34,9 \%$ de los gastos públicos en esta categoría, respectivamente.

\section{Metodología y definiciones}

Los datos de gastos se han obtenido de las estadísticas de contabilidad nacional de la OCDE (base de datos) y de las estadísticas de finanzas públicas de Eurostat (base de datos), que se basan en el sistema de contabilidad nacional (SCN). El marco actualizado del SCN del año 2008 ha sido ya implementado en todos los países de la OCDE (véase el anexo A para detalles sobre sistemas y fuentes de información). Los gastos comprenden las siguientes transacciones económicas: el consumo intermedio, las retribuciones de los empleados públicos, los subsidios, los ingresos sobre la propiedad (incluyendo los pagos por intereses), las prestaciones sociales (prestaciones sociales distintas de las transferencias sociales en especie y transferencias sociales en especie proporcionadas a los hogares a través de productores del mercado), otros gastos corrientes (principalmente las transferencias corrientes, pero también otros gastos 
menores, como impuestos sobre la producción, impuestos corrientes sobre la renta y el patrimonio, etc., y el ajuste por la variación de los derechos de pensión) y los gastos de capital (es decir, las transferencias e inversiones de capital). Todas estas transacciones se registran en una base consolidada (es decir, las transacciones entre los niveles de administración se calculan en cifras netas). El Gráfico 2.41, «Cambios en la estructura del gasto público por transacción económica, de 2009 a 2015», está disponible online en el anexo F.

\section{Otras publicaciones}

OECD (2015), National Accounts at a Glance 2015, OECD, París, <http://dx. doi.org/10.1787/na_glance-2015-en>.

OECD (2016), OECD Factbook 2015-2016: Economic, environmental and social statistics, OECD, París, <http:// dx.doi.org/10.1787/factbook-2015-en>.

OECD (2012), Public sector compensation in times of austerity,

OECD, París, <http://dx.doi.org/10.1787/9789264177758-en>.

\section{Notas de los gráficos}

Los datos de Chile no están disponibles.

Los datos de Turquía no se incluyen en la media de la OCDE ya que faltan series temporales.

Los datos de Costa Rica y Rusia corresponden a 2014 en lugar de a 2015.

Información sobre los datos de Israel: <http://dx.doi.org/10.1787/888932315602>. 


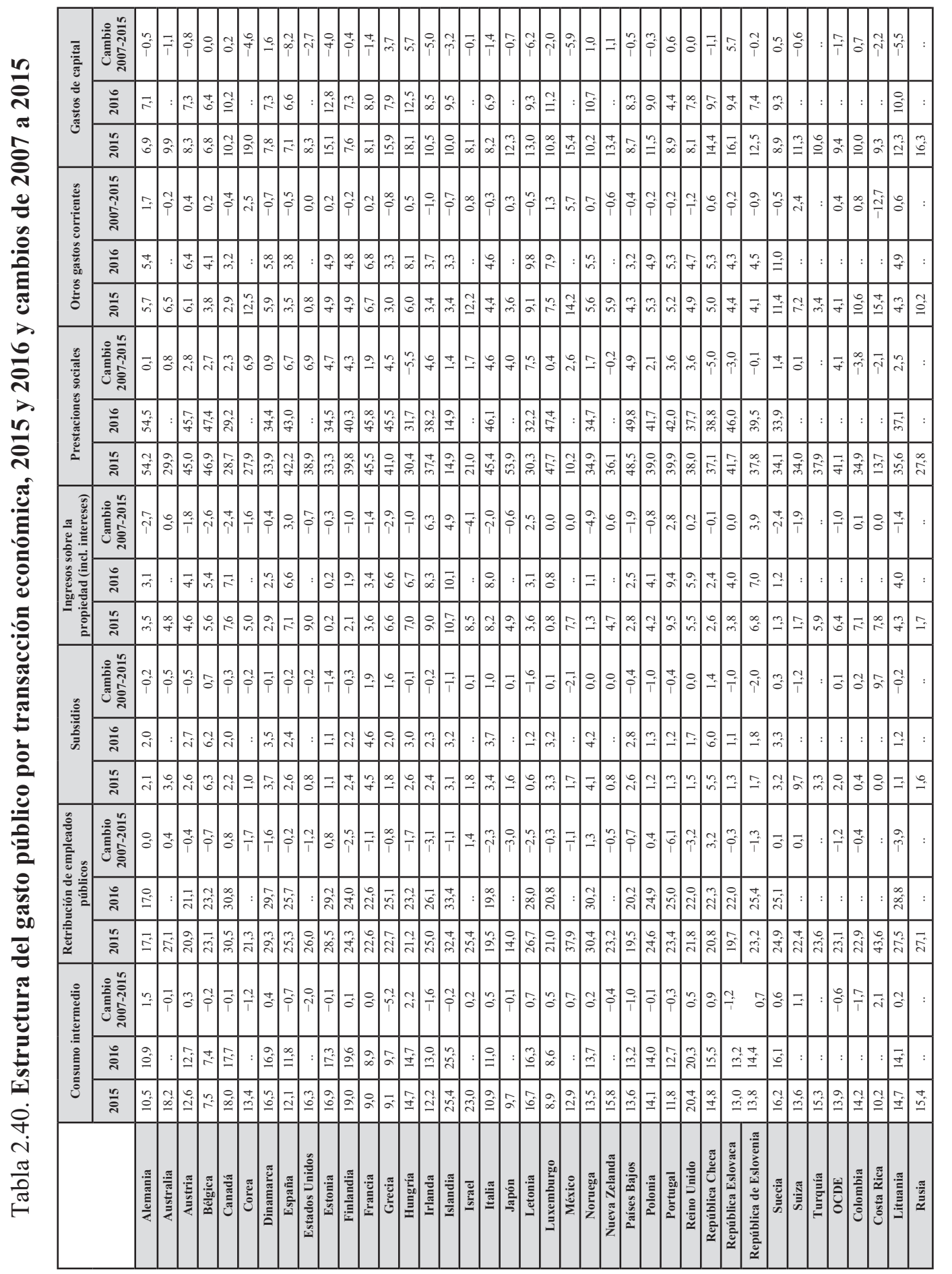




\section{ESTRUCTURA DE GASTOS POR NIVEL DE ADMINISTRACIÓN}

El grado de descentralización fiscal determina el tipo de gastos llevado a cabo por cada nivel de las Administraciones públicas. Todos los niveles están conectados y comparten competencias, como la financiación de los bienes y servicios que proporcionan, la configuración de los estándares de calidad de las prestaciones, etc. El solapamiento de responsabilidades entre los distintos niveles de las Administraciones depende del marco constitucional de los países, de la uniformidad de los bienes y servicios que proporcionan y de las necesidades de la población, así como de sus objetivos redistributivos. Aunque la descentralización de gastos responde a la variedad de preferencias a nivel local, y puede conllevar una mejor rendición de cuentas en materia de resultados, también puede limitar la medida en que las economías de escala son explotadas para la prestación de servicios, puede crear ineficiencias y exacerbar las desigualdades geográficas.

En 2015, en promedio, el $41 \%$ de todo el gasto público fue realizado por las Administraciones centrales, el 38,9\% por las Administraciones estatales y locales, y el restante $20,1 \%$ por las entidades de la seguridad social.

Entre 2007 y 2015, aunque con grandes variaciones entre países, la composición de gastos de los distintos niveles de las Administraciones públicas favoreció a las entidades de la seguridad social: en promedio, la proporción de gastos correspondientes a estas entidades aumentó 1,4 p. p. - probablemente como reflejo del envejecimiento de la población y de los efectos de la crisis-, mientras que la proporción relativa a las Administraciones centrales se mantuvo estable $(-0,1$ p. p.) y la proporción de las Administraciones subcentrales descendió ligeramente en $-1,3$ p. p. Los mayores cambios durante este periodo se dieron en Irlanda y Hungría, que experimentaron incrementos en la proporción de gastos realizados por las Administraciones centrales, 10,5 p. p. y 8,9 p. p. respectivamente, que en el caso de Irlanda se compensó con una reducción similar de gastos a nivel local, mientras que en Hungría la reducción se registró a nivel local ( $-7,4$ p. p.) y de la seguridad social $(-1,5$ p. p.). La reorganización de la administración territorial en Hungría ha sido la principal causa de estos cambios, puesto que las responsabilidades en la prestación de servicios clave se han visto desplazadas de las Administraciones subcentrales a entidades desconcentradas a nivel central.

Las Administraciones centrales en 2015 gastaron una media del 16,8\% de sus presupuestos en retribuciones de los empleados públicos, con variaciones que van desde el 30,2\% en Japón hasta el 6,6\% en Turquía. Las prestaciones sociales representaron de media un $16,6 \%$, con mayores porcentajes en los Estados Unidos, que registró un 48,3\%, seguido de la República Checa, con un $41,5 \%$, los Países Bajos, con un 40,6\%, y Noruega, con un 39,6\%. La proporción de gastos corrientes que incluye transferencias a otras unidades institucionales alcanzó una media del 35,6\% de los gastos de las Administraciones 
centrales. Estas divergencias entre países podrían reflejar diferencias entre las responsabilidades de los niveles de administración, distintas decisiones políticas sobre la prestación de servicios públicos, así como las distintas opciones de distribución de las prestaciones sociales entre los ciudadanos.

\section{Metodología y definiciones}

Los datos de gastos se han obtenido de las estadísticas de contabilidad nacional de la OCDE (base de datos) y de las estadísticas de finanzas públicas de Eurostat (base de datos), que se basan en el sistema de contabilidad nacional (SCN). El marco actualizado del SCN del año 2008 ha sido ya implementado en todos los países de la OCDE (véase el anexo A para detalles sobre sistemas y fuentes de información). Los gastos comprenden el consumo intermedio, las retribuciones de los empleados públicos, los subsidios, los ingresos sobre la propiedad (incluyendo los pagos por intereses), las prestaciones sociales, otros gastos corrientes (principalmente las transferencias corrientes) y los gastos de capital (es decir, las transferencias e inversiones de capital). La Administración general se compone de la Administración central, de las Administraciones estatales y locales y de las entidades de la seguridad social. Las Administraciones estatales solo existen en los nueve países de la OCDE que son Estados federales: Alemania, Australia, Austria, Bélgica, Canadá, España (considerado un país cuasifederal), los Estados Unidos, México y Suiza. Los datos de los Gráficos 2.42 y 2.43 no incluyen las transferencias entre los niveles de las Administraciones y, por tanto, proporcionan una representación aproximada de la responsabilidad general de cada nivel de administración en la prestación de bienes y servicios. Sin embargo, los datos del Gráfico 2.44 y la estructura de gastos por función a nivel central, estatal y local (Tablas $2.45,2.46$ y 2.47 ) incluyen las transferencias entre los niveles de la Administración y, por tanto, ilustran mejor cuánto se gasta en cada función por nivel de administración. Las Tablas $2.45,2.46$ y 2.47 están disponibles online en el anexo F.

\section{Otras publicaciones}

OECD (2016), OECD Factbook 2015-2016: Economic, environmental and social statistics, OECD, París, <http:// dx.doi.org/10.1787/factbook-2015-en>. 


\section{Notas de los gráficos}

Los datos de Chile no están disponibles.

Los datos de Turquía no se incluyen en la media de la OCDE ya que faltan series temporales.

2.42 y 2.43: Se excluyen las transferencias entre los distintos niveles de administración (excepto en Australia, Corea, Japón y Turquía). En Japón, los datos de los subsectores de la Administración general se refieren al año fiscal. La Administración local está incluida en la Administración estatal en Australia y los Estados Unidos. Australia no gestiona un sistema público de seguridad social. Las entidades de la seguridad social están incluidas en la Administración central en los Estados Unidos, Irlanda, Nueva Zelanda, Noruega y en el Reino Unido.

2.42 y 2.44: Los datos de Costa Rica corresponden a 2014 en lugar de a 2015.

2.44: Los datos de Australia no están disponibles.

Información sobre los datos de Israel: <http://dx.doi.org/10.1787/888932315602>.

\section{Gráfico 2.42. Distribución del gasto público por nivel de} administración, 2015 y 2016

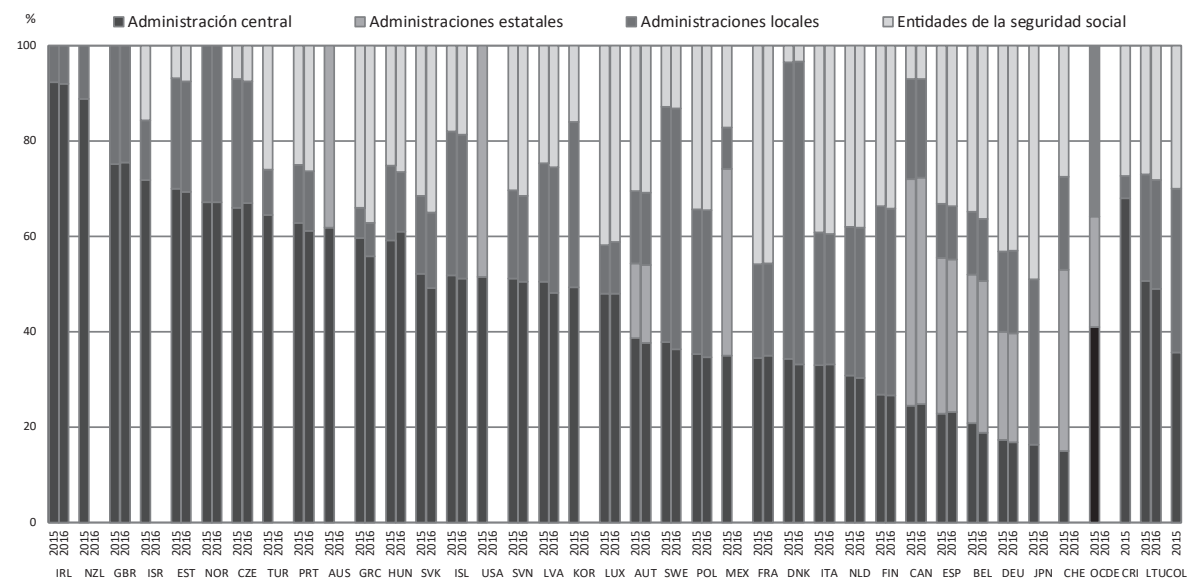

Fuente: Estadísticas de contabilidad nacional de la OCDE (base de datos). 
Gráfico 2.43. Cambios en la distribución del gasto público por nivel de administración, de 2007 a 2015

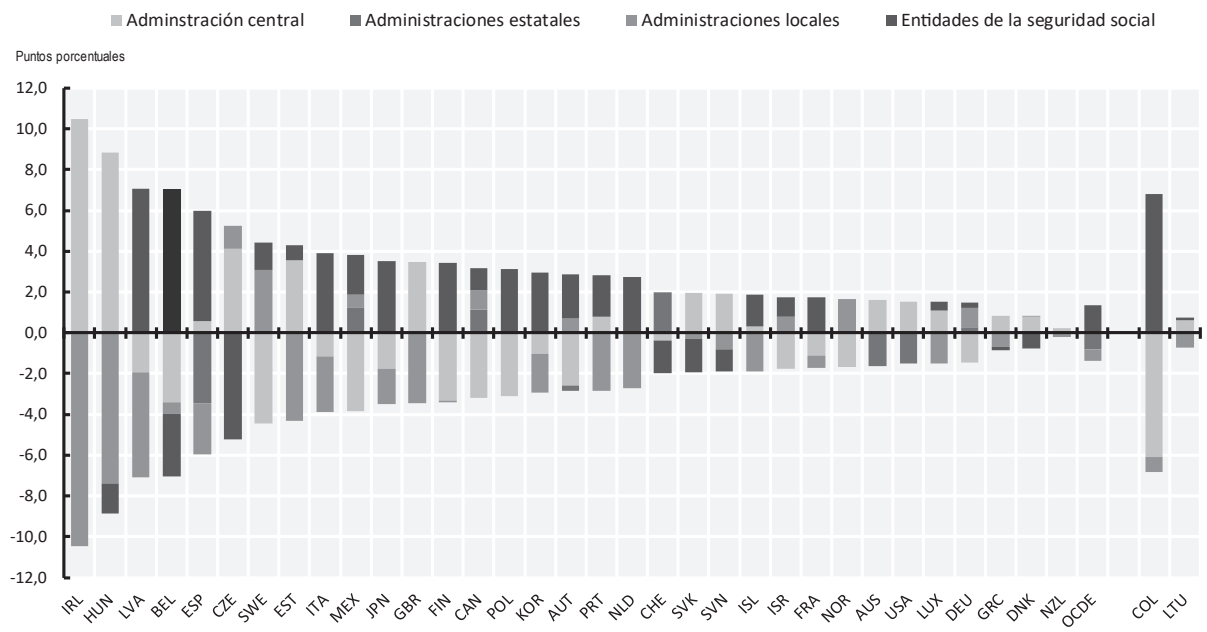

Fuente: Estadísticas de contabilidad nacional de la OCDE (base de datos).

$<$ http://dx.doi.org/10.1787/888933531896>

\section{Gráfico 2.44. Estructura de gastos de la Administración central por transacción económica, 2015 y 2016}

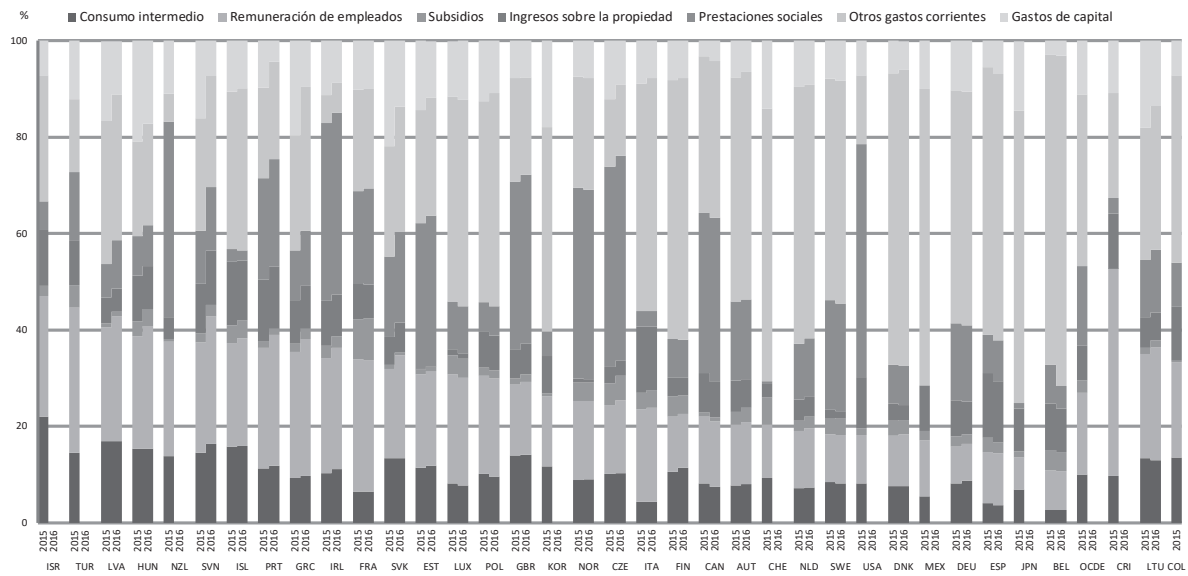

Fuente: Estadísticas de contabilidad nacional de la OCDE (base de datos). 


\section{GASTO EN INVERSIÓN DE LA ADMINISTRACIÓN GENERAL}

Los gastos públicos tienen distintos horizontes temporales y, por tanto, distinguir entre los gastos de consumo e inversión es especialmente relevante, puesto que el aumento del capital físico mediante, por ejemplo, gastos en infraestructuras de transporte es clave para el crecimiento y la productividad de la economía a largo plazo. Esto se ha visto reflejado en los recientes llamamientos para incrementar la inversión pública como modo de mejorar la productividad lenta.

En 2015, en promedio, el gasto público en inversión en los países de la OCDE supuso el 3,2\% del PIB, un descenso con respecto al 4,1\% de 2009 y por debajo también del 3,6\% de 2007. El país con mayor gasto público en inversión fue Hungría, con un 6,7\%, seguida de la República Eslovaca (6,4\%), Estonia (5,2\%) y de la República Checa (5,1\%); todos ellos países de Europa del Este que reciben importantes fondos estructurales de la UE para financiar inversiones. En 2015, el gasto en inversión registró sus niveles más bajos en Israel $(1,5 \%)$, Irlanda $(1,7 \%)$ y México $(1,8 \%)$.

Entre 2007 y 2015, los mayores aumentos de gastos en inversión como proporción del PIB se dieron en la República Eslovaca, con $+3,3$ p. p., y en Hungría, con $+2,4$ p. p., aunque en ambos países la inversión pública disminuyó en 2016. Por el contrario, los mayores descensos de gastos en inversión los registraron Irlanda ( $-2,8$ p. p.) y España $(-2,3$ p. p.). Durante el mismo periodo, otras economías importantes, como China, incrementaron su inversión pública del $1,9 \%$ al $4,1 \%$.

En términos de gasto total, la inversión pública representó una media del $7,7 \%$ en los países de la OCDE en 2015, un descenso con respecto al 9,3\% registrado tanto en 2007 como en 2009. Durante este periodo, la proporción de gastos en inversión fue mayor en Corea, donde alcanzó un 15,2\% en 2015, un descenso con respecto al $22,5 \%$ de 2009 (y al $20 \%$ de 2007); el 54,5\% de esta inversión se asignó a asuntos económicos y defensa. Las menores proporciones de gastos en inversión se dieron en Israel $(3,8 \%)$ y Bélgica $(4,4 \%)$.

La distribución de la inversión pública en los distintos niveles de las Administraciones refleja, en gran medida, la estructura política y administrativa. En los países de la OCDE, alrededor del $40 \%$ de la inversión pública la realizan las Administraciones centrales, mientras que el $60 \%$, aproximadamente, la llevan a cabo las Administraciones subcentrales - ya que muchos bienes públicos tienen un alcance local más que central- El gasto en inversión por parte de las Administraciones centrales oscila entre el $81 \%$ del gasto público total en Grecia y el 7,2\% en Canadá. Sin embargo, los países federales de Bélgica y Canadá asignaron alrededor del $90 \%$ de su gasto público en inversiones a las Administraciones subcentrales. 
En 2015, en los países de la OCDE, la inversión pública por función se centró en los asuntos económicos, como transporte y energía, con una proporción media del $34,6 \%$, seguidos de defensa $(15,2 \%)$, educación $(14,7 \%)$, servicios públicos generales $(9,3 \%)$, sanidad $(8,4 \%)$ y, en menor medida, vivienda $(5,1 \%)$, protección medioambiental $(4,5 \%)$, orden público y seguridad $(3,5 \%)$ y protección social $(1,6 \%)$.

\section{Metodología y definiciones}

Los datos se han obtenido de las estadísticas de contabilidad nacional de la OCDE (base de datos) y de las estadísticas de finanzas públicas de Eurostat (base de datos), que se basan en el sistema de contabilidad nacional (SCN). El marco actualizado del SCN del año 2008 ha sido ya implementado en todos los países de la OCDE (véase el anexo A para detalles sobre sistemas y fuentes de información). La inversión pública comprende la formación bruta de capital y adquisiciones, menos las cesiones de activos no financieros no producidos. La formación bruta de capital fijo (también denominada inversión fija) es el principal componente de la inversión en las Administraciones, y consiste principalmente en las infraestructuras de transporte, aunque también incluye otras infraestructuras, como edificios de oficinas, viviendas, escuelas, hospitales, etc. Por otra parte, de acuerdo con el marco del SCN de 2008, el gasto en investigación y desarrollo también se ha incluido en la inversión fija. La inversión pública y las transferencias de capital constituyen la categoría de gastos de capital de las Administraciones. La Administración general se compone de la Administración central, de las Administraciones estatales y locales, y de las entidades de la seguridad social. Las Administraciones estatales solo existen en los nueve países de la OCDE que son Estados federales: Alemania, Australia, Austria, Bélgica, Canadá, España (considerado un país cuasifederal), los Estados Unidos, México y Suiza. Los Gráficos 2.51, «Inversión pública como proporción de la inversión total, 2007, 2009 y 2015», y 2.52, «Estructura de la inversión pública por función, 2015», están disponibles online en el anexo F.

\section{Otras publicaciones}

OECD (2014), Recommendation of the Council on effective public investment across levels of government, OECD, París $<$ www.oecd.org/regional/regional-policy/Principles-PublicInvestment.pdf $>$.

OECD (2015), National Accounts at a Glance 2015, OECD, París, $<$ http://dx.doi.org/10.1787/na_glance-2015-en>. 


\section{Notas de los gráficos}

Los datos de Chile no están disponibles. Los datos de Turquía no se incluyen en la media de la OCDE ya que faltan series temporales.

Los datos de Costa Rica corresponden a 2014 en lugar de a 2015.

2.48: Los datos de Brasil, China, Rusia y Sudáfrica corresponden a 2014 en lugar de a 2015.

2.49: Los datos de Rusia corresponden a 2014 en lugar de a 2015.

2.50: La Administración local está incluida en la Administración estatal en Australia y los Estados Unidos. Australia no gestiona un sistema público de seguridad social. Las entidades de la seguridad social están incluidas en la Administración central en los Estados Unidos, Irlanda, Noruega, Nueva Zelanda y en el Reino Unido.

Información sobre los datos de Israel: <http://dx.doi.org/10.1787/888932315602>.

\section{Gráfico 2.48. Inversión pública como porcentaje del PIB, 2007, 2009,} 2015 y 2016

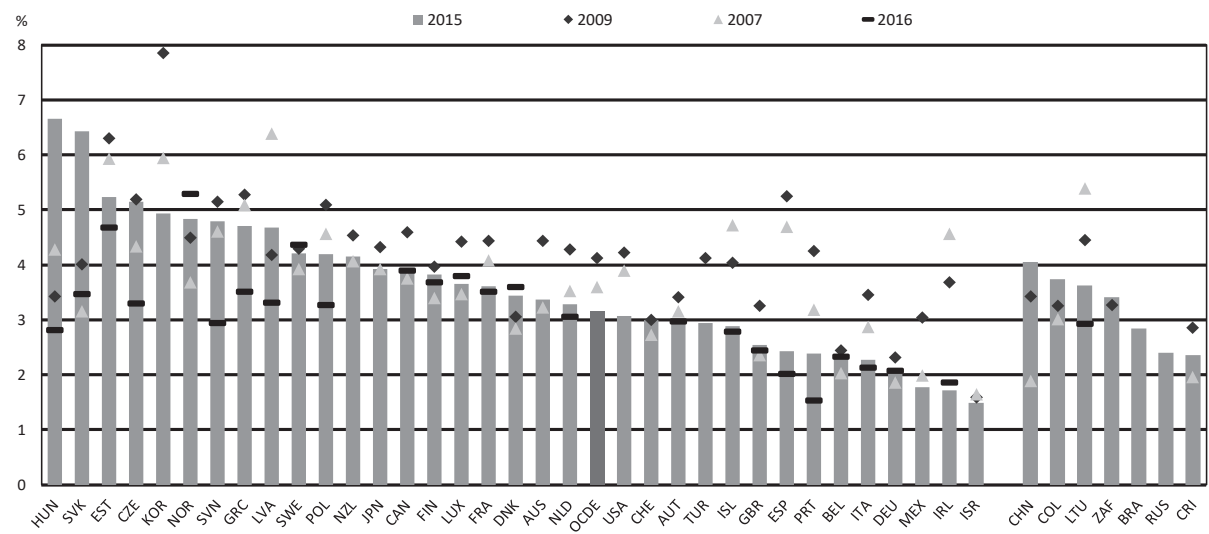

Fuente: Estadísticas de contabilidad nacional de la OCDE (base de datos). 
Gráfico 2.49. Inversión pública como proporción del gasto público total, 2007, 2009, 2015 y 2016

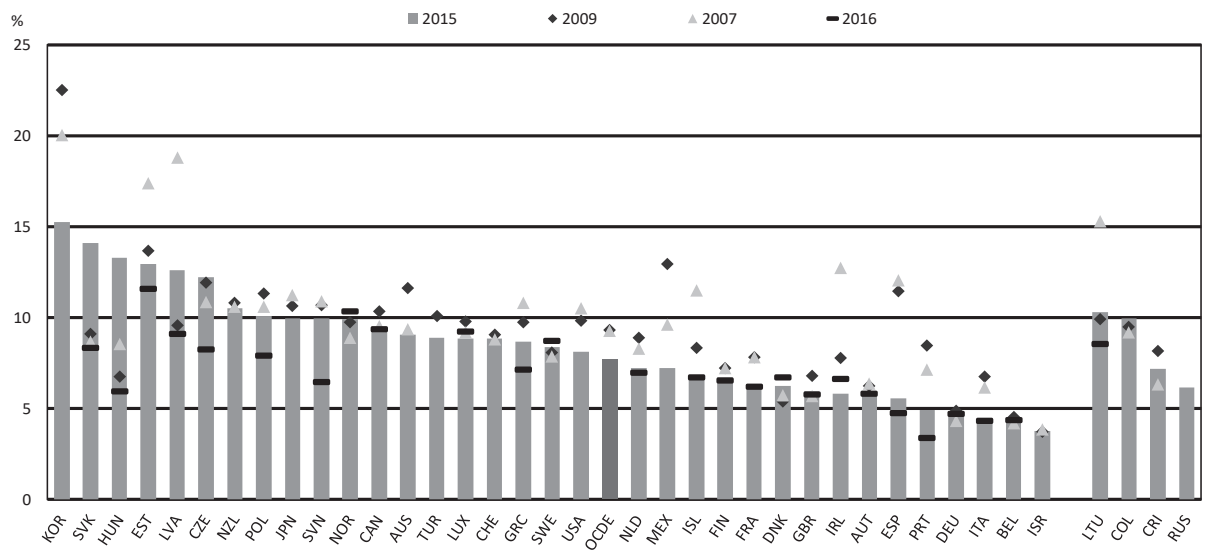

Fuente: Estadísticas de contabilidad nacional de la OCDE (base de datos).

Gráfico 2.50. Distribución de la inversión pública por nivel de administración, 2015 y 2016

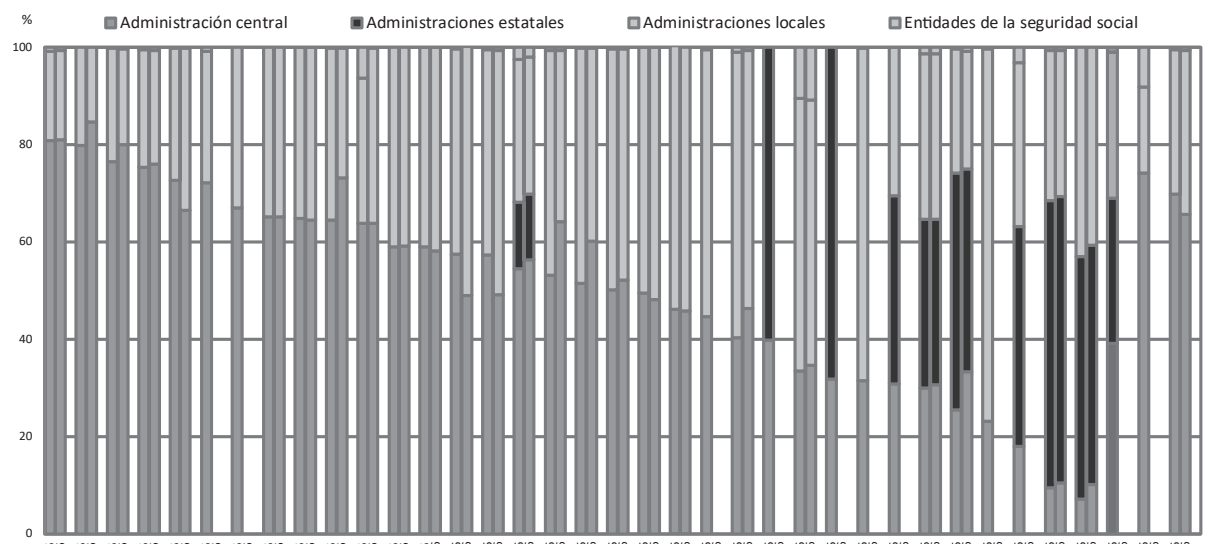

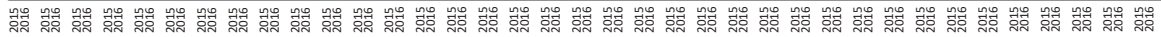
GRC IRL SVK EST LVA TUR NZL GBR ISL HUN LUX NOR DNK PRT SVN AUT POL CZE NLD SWE FIN KOR ITA USA FRA AUS JPN CHE DEU ESP ISR MEX BEL CAN OCDE CRI LTU

Fuente: Estadísticas de contabilidad nacional de la OCDE (base de datos). 


\section{COSTES DE PRODUCCIÓN Y EXTERNALIZACIÓN DE LA ADMINISTRACIÓN GENERAL}

Los costes totales de producción de la Administración general incluyen las retribuciones del personal, lo que adquieren del sector privado y otro tipo de costes, como la depreciación del capital. Esta distinción de costes ayuda a identificar la medida en que las Administraciones externalizan o subcontratan la producción, mediante la adquisición directa de insumos del sector privado o delegando en entidades privadas (por ejemplo, en organizaciones sin ánimo de lucro) la prestación de los bienes y servicios a los usuarios.

Los costes de producción varían entre los países de la OCDE, del $31 \%$ del PIB registrado en Finlandia al 12,6\% del PIB en México, con un promedio del 20,9\% del PIB en 2015. La retribución de los empleados públicos representó en los países de la OCDE una media del 9,5\% del PIB en 2015, que osciló entre el $16,1 \%$ del PIB en Dinamarca y el 5,5\% del PIB en Japón. Los bienes y servicios utilizados y financiados por las Administraciones supusieron un promedio del 8,7\% del PIB en 2015, con variaciones que fueron desde el 16,6\% del PIB marcado en los Países Bajos al 3,2\% del PIB en México. En otras economías importantes, como Brasil y China, las retribuciones de los empleados públicos contabilizaron el $12,8 \%$ y el $6,4 \%$ del PIB, respectivamente.

Entre 2007 y 2015, los costes de producción aumentaron en los países de la OCDE una media de 0,7 p. p., y alcanzaron el 20,9\% del PIB en 2015. Durante este periodo, los mayores incrementos se dieron en Noruega $(+5$ p. p.), Estonia $(+4,9$ p. p.) y Finlandia (+4,5 p. p.), mientras que el mayor descenso lo registró Irlanda ( $-4,5$ p. p.), motivado principalmente por los cambios en las retribuciones de los empleados públicos. Noruega marcó el mayor aumento en las retribuciones de los empleados, con 2,8 p. p., seguida de Chile $(2,4$ p. p.) y Estonia (2,1 p. p.), mientras que el mayor descenso lo registró Irlanda ( $-2,7$ p. p.).

La estructura de los costes de producción en los países de la OCDE se concentra principalmente en las retribuciones de los empleados públicos $(45,3 \%)$ y en costes de bienes y servicios utilizados y financiados por las Administraciones públicas $(41,7 \%)$, mientras que otros costes de producción representan el $13,1 \%$ de los costes totales de producción. Los costes relaciones con las retribuciones de los empleados públicos varían entre el $74 \%$ de los costes totales de producción marcado en México y el 25,7\% de Japón.

La externalización o subcontratación pública se compone de bienes y servicios utilizados y financiados por las Administraciones públicas en un año determinado. La externalización total alcanzó una media del 8,7\% del PIB en los países de la OCDE en 2015, y osciló entre el 16,6\%, en los Países Bajos, y el 3,2\%, en México. La mayoría de los países de la OCDE tienen una mayor proporción de gastos de externalización de bienes y servicios utilizados por las Administraciones en comparación con los bienes y servicios financiados por las Administraciones. En países como Dinamarca y Letonia, más del $80 \%$ 
de los gastos de externalización se asignan a bienes y servicios utilizados por las Administraciones, mientras que países como Alemania, Bélgica, Japón y los Países Bajos dependen más del sector no gubernamental para la prestación de servicios a la comunidad (más del $60 \%$ de los gastos de externalización).

\section{Metodología y definiciones}

El concepto y la metodología de los costes de producción se basa en la clasificación del gasto público del sistema de contabilidad nacional (SCN). El marco actualizado del SCN del año 2008 ha sido ya implementado en todos los países de la OCDE (véase el anexo A para detalles sobre sistemas y fuentes de información). En concreto, los costes de producción de las Administraciones públicas incluyen:

- Las retribuciones de los empleados públicos, incluidas las remuneraciones en efectivo y en especie, además de todas las cotizaciones sociales obligatorias (e imputadas) a cargo del empleador y las cotizaciones voluntarias pagadas en nombre de los empleados.

- Los bienes y servicios utilizados por las Administraciones, que son el primer componente de la externalización o subcontratación pública. En términos del SCN, esto incluye el consumo intermedio (adquisición de productos intermedios necesarios para la producción, tales como servicios de contabilidad o de tecnologías de la información).

- Los bienes y servicios financiados por las Administraciones, que son el segundo componente de la externalización o subcontratación pública. En términos del SCN, esto incluye las transferencias sociales en especie a través de productores del mercado pagados por las Administraciones públicas (incluidos aquellos que inicialmente pagan los ciudadanos, pero que finalmente son reembolsados por las Administraciones públicas, tales como los tratamientos médicos abonados por las cotizaciones a la seguridad social).

- Otros costes de producción, que incluyen los componentes restantes del consumo de capital fijo (depreciación del capital) y otros impuestos sobre la producción, menos otras subvenciones a la producción.

Los datos incluyen el empleo público y el consumo intermedio de los bienes producidos por las Administraciones para su propio uso. Los costes de producción que aquí se muestran no son iguales al valor de la producción en el SCN. El Gráfico 2.56, «Estructura de los gastos en externalización de la Administración general, 2015 y 2016», está disponibles online en el anexo F. 


\section{Otras publicaciones}

OECD (2015), National Accounts at a Glance 2015, OECD, París, <http://dx. doi.org/10.1787/na_glance-2015-en>.

Pilichowski, E., y Turkisch, E. (2008), «Employment in Government in the perspective of the production costs of goods and services in the public domain», OECD Working Papers on Public Governance, n. 8, OECD, París, $<$ http:// dx.doi.org/10.1787/245160338300>.

\section{Notas de los gráficos}

Los datos de Chile y Turquía no se incluyen en la media de la OCDE ya que faltan series temporales o los principales agregados no financieros de las Administraciones públicas.

Los datos de Costa Rica, Rusia y Sudáfrica corresponden a 2014 en lugar de a 2015.

2.53: Los datos de Brasil corresponden a 2014 en lugar de a 2015.

2.55: Los Estados Unidos, Islandia, México y Sudáfrica no contabilizan por separado los bienes y servicios financiados por la Administración general en sus cuentas nacionales.

Información sobre los datos de Israel: <http://dx.doi.org/10.1787/888932315602>.

\section{Gráfico 2.53. Costes de producción como porcentaje del PIB, 2007, 2015 y 2016}

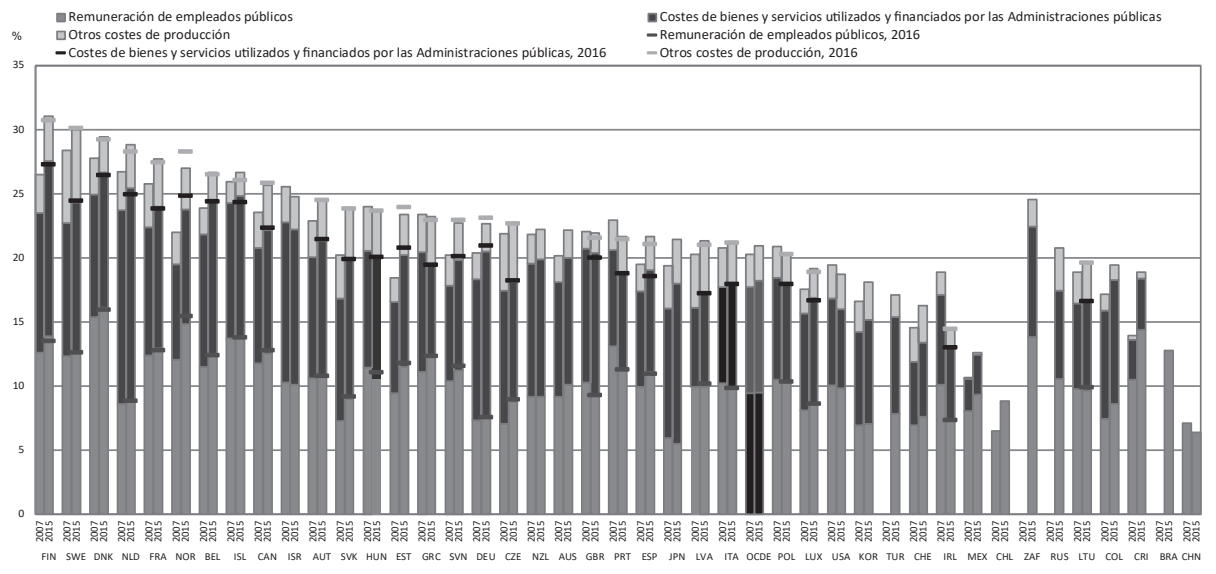

Fuentes: Estadísticas de contabilidad nacional de la OCDE (base de datos). Los datos de Australia se basan en una combinación de datos de la contabilidad nacional y de las estadísticas financieras públicas proporcionados por la Oficina de Estadísticas de Australia. 


\section{Gráfico 2.54. Estructura de costes de producción, 2015 y 2016}

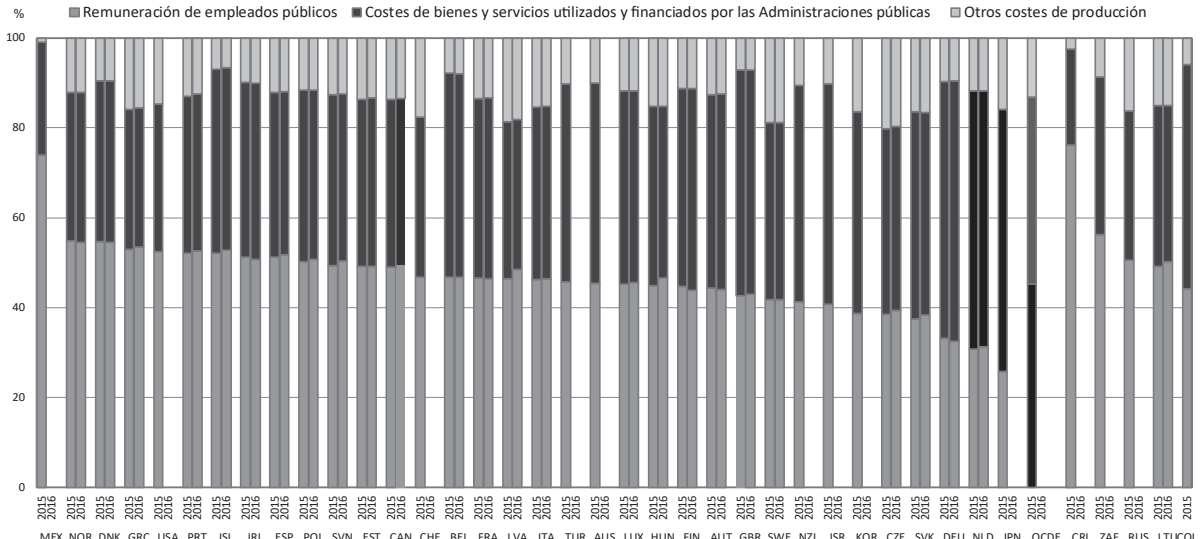

Fuentes: Estadísticas de contabilidad nacional de la OCDE (base de datos). Los datos de Australia se basan en una combinación de datos de la contabilidad nacional y de las estadísticas financieras públicas proporcionados por la Oficina de Estadísticas de Australia.

$<$ http://dx.doi.org/10.1787/888933532010>

\section{Gráfico 2.55. Gastos en externalización pública como porcentaje del PIB, 2015 y 2016}

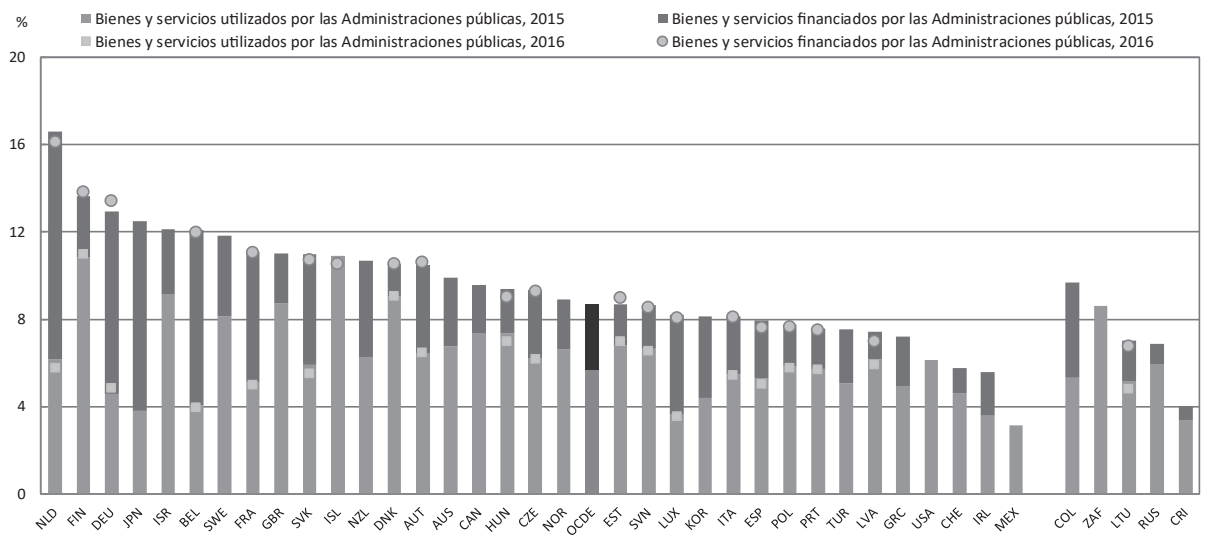

Fuentes: Estadísticas de contabilidad nacional de la OCDE (base de datos). Los datos de Australia se basan en una combinación de datos de la contabilidad nacional y de las estadísticas financieras públicas proporcionados por la Oficina de Estadísticas de Australia. 


\section{APARTADO ESPECIAL: ESTRUCTURA DE GASTOS DE LA ADMINISTRACIÓN GENERAL POR FUNCIONES DE PROTECCIÓN SOCIAL Y SANIDAD (CFG)}

Uno de los objetivos clave de las Administraciones públicas es proteger a los vulnerables y compartir los riesgos que puedan surgir en las comunidades relacionados con la salud, la pérdida de empleo y el envejecimiento. Esto se ve reflejado en el gasto público dedicado a protección social (es decir, pensiones, seguros de desempleo, etc.) y sanidad, cuyos programas a menudo reciben la mayor parte de la inversión pública. La oferta y la demanda de protección social y servicios de asistencia sanitaria están sujetas a evoluciones demográficas, fluctuaciones económicas y cambios tecnológicos, y la complejidad resultante de su interrelación puede tener un gran impacto sobre la sostenibilidad de las finanzas públicas a largo plazo.

La dinámica de la protección social y de los servicios sanitarios, y la composición del gasto público que reciben, son especialmente importantes por dos motivos. En primer lugar, la ralentización de la productividad total en los países de la OCDE se ha acentuado. Mientras que entre 1985 y 1999 la productividad total de los factores creció de media un $1,45 \%$ al año, entre 2000 y 2015 descendió a un 0,58\% (OCDE, 2016a). Esta dinámica impone un tope al crecimiento a largo plazo, con un efecto directo en los gastos en protección social y sanidad. Un segundo motivo es el aumento de los costes, producido tanto por el envejecimiento de la población como por los cambios tecnológicos.

En 2015, en los países de la OCDE con datos disponibles, los gastos en protección social se concentraron en las pensiones, con un promedio del $53,5 \%$, un aumento con respecto al 51,1\% registrado en 2009, debido a las reformas introducidas para garantizar la sostenibilidad de los sistemas de pensiones y de otros planes de pensiones personalizados (OCDE, 2016b). Las pensiones suponen la mayor partida de la protección social en Grecia (76\%), Portugal (67\%), Italia (64\%) y Letonia (63\%), y la menor partida en Irlanda $(25 \%)$ e Islandia (26\%). Las prestaciones por enfermedad o discapacidad contabilizaron el $14 \%$ de los gastos en protección social, y oscilaron entre el 34\% en Noruega y el $6 \%$ en Portugal. Los gastos relacionados con la familia y los niños representaron de media el $9 \%$ de los gastos en protección social en los países de la OCDE, y fueron mayores en países con permisos parentales amplios como Islandia (23\%) y Luxemburgo (22\%), seguidos de Irlanda (20\%), Dinamarca (19\%) y Noruega $(18 \%)$. Las prestaciones por desempleo supusieron una media del $7 \%$ del gasto público en protección social, alcanzando el $19 \%$ en Irlanda, donde las prestaciones a largo plazo son generosas, y el $11 \%$

en Dinamarca. Los componentes restantes de la protección social (supervivientes, vivienda, I+D relacionado, entre otros) suman un promedio del $16 \%$ de los gastos en protección social en los países de la OCDE. 
En cuanto a la asistencia sanitaria en 2015, los servicios hospitalarios representaron una media del 46,5\% de los gastos en los países de la OCDE, seguidos de los servicios ambulatorios $(31,8 \%$ ) y los gastos en productos y materiales médicos (14\%). La mayor proporción de gastos dedicados a los servicios hospitalarios se registró en el Reino Unido (75,2\%), seguido de Estonia $(74,1 \%)$ y Dinamarca $(71,1 \%)$. Los servicios ambulatorios en 2015 representaron la mayor proporción de los gastos en sanidad en Luxemburgo $(85,6 \%)$ y España $(77,4 \%)$, mientras que los gastos en productos, instrumentos y equipos médicos fueron proporcionalmente mayores en Grecia (30,8\%) y Alemania $(22,5 \%)$. Finalmente, tanto los servicios de asistencia sanitaria como la investigación y desarrollo (I+D) en salud representaron un $1,9 \%$ del gasto público en atención sanitaria.

\section{Metodología y definiciones}

Los datos se han obtenido de las estadísticas de contabilidad nacional de la OCDE (base de datos) y de las estadísticas de finanzas públicas de Eurostat (base de datos), que se basan en el sistema de contabilidad nacional ( $\mathrm{SCN}$ ), un conjunto de conceptos, definiciones, clasificaciones y reglas acordados internacionalmente para la contabilidad nacional. El marco actualizado del SCN del año 2008 ha sido ya implementado en todos los países de la OCDE (véase el anexo A para detalles sobre sistemas y fuentes de información). Los datos de gastos se desglosan de acuerdo con la clasificación de las funciones del Gobierno (CFG), que divide los gastos en diez funciones (véase el anexo C para más información).

De estas funciones, los gastos en sanidad se dividen a su vez en seis subfunciones: productos, instrumentos y equipos médicos; servicios ambulatorios; servicios hospitalarios; servicios de asistencia sanitaria; I+D en salud, y salud (n. c. o. p.). Los gastos en protección social se dividen a su vez en nueve subfunciones: enfermedad y discapacidad; tercera edad (es decir, pensiones); supervivientes; familia y menores; desempleo; vivienda; exclusión social (n. c. o. p.); I+D en protección social; protección social (n. c. o. p.).

Los gráficos 2.59 y 2.60 , «Cambios en la estructura del gasto público por función pública de protección social, de 2009 a 2015» y «Cambios en la estructura del gasto público por función pública de sanidad, de 2009 a 2015», están disponibles online en el anexo F.

\section{Otras publicaciones}

OECD (2016a), OECD Compendium of Productivity Indicators 2016, OECD, París.

OECD (2016b), OECD Pensions Outlook 2016, OECD, París, 
$<$ http://dx.doi.org/10.1787/pens_outlook-2016-en>.

\section{Notas de los gráficos}

Los datos de los países de la OCDE no europeos (aparte de Israel) y de Suiza y Turquía no están disponibles.

OCDE Europa incluye los países europeos miembros de la OCDE; los datos de Islandia no están incluidos en la media de la OCDE puesto que faltan series temporales.

Los datos de Colombia y Costa Rica corresponden a 2014 en lugar de a 2015.

Información sobre los datos de Israel: <http://dx.doi.org/10.1787/888932315602>. 


\section{Tabla 2.57. Estructura del gasto público por función pública de protección social, 2015}

\begin{tabular}{|c|c|c|c|c|c|c|c|c|c|}
\hline & $\begin{array}{l}\text { Enfermedad y } \\
\text { discapacidad }\end{array}$ & $\begin{array}{c}\text { Tercera } \\
\text { edad }\end{array}$ & Supervivientes & $\begin{array}{r}\text { Familia y } \\
\text { menores }\end{array}$ & Desempleo & Vivienda & $\begin{array}{l}\text { Exclusión } \\
\text { social n. } \\
\text { c. o. p. }\end{array}$ & $\begin{array}{c}\text { I+D en } \\
\text { protección } \\
\text { social }\end{array}$ & $\begin{array}{c}\text { Protección } \\
\text { social n. c. } \\
\text { o. p. }\end{array}$ \\
\hline Alemania & 16,1 & 48,3 & 9,8 & 8,4 & 9,2 & 2,4 & 2,2 & 0,0 & 3,6 \\
\hline Austria & 9,0 & 60,4 & 6,8 & 10,8 & 6,8 & 0,5 & 4,7 & 0,0 & 1,0 \\
\hline Bélgica & 17,4 & 44,9 & 8,9 & 11,9 & 9,8 & 1,0 & 5,0 & 0,0 & 1,0 \\
\hline Dinamarca & 20,2 & 35,4 & 0,0 & 19,3 & 11,5 & 3,0 & 8,4 & 0,0 & 2,1 \\
\hline España & 13,8 & 53,5 & 13,7 & 3,8 & 11,8 & 0,2 & 1,6 & 0,0 & 1,6 \\
\hline Estonia & 16,4 & 54,5 & 0,5 & 17,9 & 8,3 & 0,2 & 1,0 & 0,1 & 1,1 \\
\hline Finlandia & 13,8 & 52,4 & 3,1 & 12,6 & 10,4 & 1,7 & 3,6 & 0,1 & 2,3 \\
\hline Francia & 11,4 & 55,2 & 6,4 & 10,1 & 8,1 & 3,8 & 4,2 & 0,0 & 0,8 \\
\hline Grecia & 7,8 & 76,6 & 8,2 & 3,1 & 3,3 & 0,2 & 0,1 & 0,1 & 0,6 \\
\hline Hungría & 20,3 & 48,4 & 7,4 & 13,1 & 2,5 & 1,8 & 5,2 & 0,0 & 1,4 \\
\hline Irlanda & 17,2 & 25,1 & 6,6 & 20,3 & 19,2 & 8,5 & 0,8 & 0,0 & 2,4 \\
\hline Islandia & 30,3 & 26,4 & 0,2 & 22,6 & 5,9 & 6,0 & 4,3 & 0,0 & 4,4 \\
\hline Israel & 23,7 & 46,2 & 5,7 & 10,2 & 2,9 & 1,6 & 5,5 & 0,0 & 4,2 \\
\hline Italia & 8,7 & 64,3 & 12,9 & 7,1 & 5,5 & 0,2 & 1,2 & 0,0 & 0,0 \\
\hline Letonia & 18,4 & 63,6 & 1,5 & 5,7 & 4,2 & 0,9 & 3,5 & 0,0 & 2,1 \\
\hline Luxemburgo & 7,9 & 55,5 & 0,0 & 21,7 & 10,6 & 0,2 & 3,7 & 0,0 & 0,3 \\
\hline Noruega & 34,5 & 36,0 & 1,0 & 18,2 & 2,6 & 0,6 & 4,5 & 0,2 & 2,4 \\
\hline Países Bajos & 27,3 & 41,0 & 0,6 & 6,4 & 10,3 & 2,8 & 11,3 & 0,2 & 0,1 \\
\hline Polonia & 16,4 & 57,3 & 11,3 & 8,9 & 3,5 & 0,3 & 1,6 & 0,0 & 0,7 \\
\hline Portugal & 6,6 & 67,0 & 9,6 & 5,8 & 6,7 & 0,1 & 1,2 & 0,0 & 2,9 \\
\hline Reino Unido & 16,1 & 53,7 & 0,4 & 9,0 & 0,9 & 8,0 & 9,9 & 0,0 & 2,0 \\
\hline $\begin{array}{l}\text { República } \\
\text { Checa }\end{array}$ & 17,1 & 60,5 & 4,8 & 8,7 & 1,7 & 2,1 & 3,5 & 0,0 & 1,5 \\
\hline $\begin{array}{c}\text { República } \\
\text { Eslovaca }\end{array}$ & 18,7 & 52,8 & 5,7 & 8,7 & 1,4 & 0,0 & 3,2 & 0,0 & 9,6 \\
\hline $\begin{array}{c}\text { República de } \\
\text { Eslovenia }\end{array}$ & 13,0 & 57,0 & 8,1 & 11,3 & 3,5 & 0,1 & 4,9 & 0,0 & 2,1 \\
\hline Suecia & 21,3 & 51,0 & 1,4 & 11,9 & 6,3 & 1,5 & 6,1 & 0,0 & 0,4 \\
\hline OCDE & 14,7 & 53,5 & 7,5 & 9,0 & 7,0 & 2,6 & 4,1 & 0,0 & 1,6 \\
\hline Colombia & 1,4 & 69,1 & , & 10,7 & , & 5,1 & 11,9 & , & 1,7 \\
\hline Lituania & 24,9 & 52,0 & 3,1 & 8,8 & 5,0 & 0,5 & 4,2 & 0,0 & 1,5 \\
\hline
\end{tabular}

Fuentes: Estadísticas de contabilidad nacional de la OCDE (base de datos); estadísticas de finanzas públicas de Eurostat (base de datos). 


\section{Tabla 2.58. Estructura del gasto público por función pública de sanidad, 2015}

\begin{tabular}{|c|c|c|c|c|c|c|}
\hline & $\begin{array}{c}\text { Productos, instrumentos } \\
\text { y equipos médicos }\end{array}$ & $\begin{array}{c}\text { Servicios } \\
\text { ambulatorios }\end{array}$ & $\begin{array}{c}\text { Servicios } \\
\text { hospitalarios }\end{array}$ & $\begin{array}{c}\text { Servicios de } \\
\text { asistencia sanitaria }\end{array}$ & $I+D$ en salud & Salud n. c. o. p. \\
\hline Alemania & 22,5 & 29,5 & 38,6 & 0,8 & 1,1 & 7,4 \\
\hline Austria & 14,1 & 18,3 & 55,7 & 2,2 & 5,7 & 3,9 \\
\hline Bélgica & 10,9 & 34,8 & 49,6 & 1,9 & 0,1 & 2,7 \\
\hline Dinamarca & 6,8 & 13,9 & 71,1 & 1,6 & 2,3 & 4,2 \\
\hline España & 16,1 & 77,4 & 0,0 & 1,4 & 4,4 & 0,7 \\
\hline Estonia & 12,4 & 8,9 & 74,1 & 0,5 & 2,3 & 1,7 \\
\hline Finlandia & 9,3 & 45,7 & 42,4 & 0,3 & 1,6 & 0,6 \\
\hline Francia & 17,6 & 35,4 & 43,2 & 1,4 & 1,2 & 1,2 \\
\hline Grecia & 30,8 & 10,3 & 57,6 & 0,0 & 0,4 & 0,8 \\
\hline Hungría & 19,2 & 28,7 & 41,5 & 2,7 & 0,4 & 7,4 \\
\hline Irlanda & 16,7 & 31,7 & 39,8 & 2,8 & 0,2 & 8,7 \\
\hline Islandia & 7,4 & 22,0 & 67,9 & 0,3 & 0,0 & 2,3 \\
\hline Israel & 11,5 & 29,5 & 55,1 & 2,2 & 0,0 & 1,7 \\
\hline Italia & 11,5 & 37,9 & 44,0 & 3,9 & 1,1 & 1,5 \\
\hline Letonia & 12,7 & 26,5 & 55,8 & 1,7 & 0,0 & 3,3 \\
\hline Luxemburgo & 0,1 & 85,6 & 8,5 & 0,8 & 3,6 & 1,4 \\
\hline Noruega & 6,5 & 23,2 & 59,6 & 3,1 & 4,5 & 3,3 \\
\hline Países Bajos & 10,4 & 27,2 & 51,5 & 2,6 & 3,9 & 4,3 \\
\hline Polonia & 1,3 & 32,1 & 60,8 & 1,5 & 1,8 & 2,5 \\
\hline Portugal & 5,5 & 31,3 & 58,1 & 0,6 & 1,2 & 3,4 \\
\hline Reino Unido & 5,7 & 10,3 & 75,2 & 2,9 & 2,1 & 3,7 \\
\hline República Checa & 12,4 & 21,2 & 44,9 & 18,1 & 0,6 & 2,8 \\
\hline $\begin{array}{l}\text { República } \\
\text { Eslovaca }\end{array}$ & 19,6 & 32,1 & 42,9 & 0,6 & 0,0 & 4,8 \\
\hline $\begin{array}{c}\text { República de } \\
\text { Eslovenia }\end{array}$ & 14,5 & 32,9 & 41,8 & 5,2 & 1,1 & 4,5 \\
\hline Suecia & 10,5 & 42,9 & 37,9 & 3,1 & 2,6 & 2,9 \\
\hline OCDE & 14,0 & 31,8 & 46,5 & 2,3 & 1,9 & 3,6 \\
\hline Colombia & 93,2 &, & , & 4,3 & 0,5 & 2,0 \\
\hline Costa Rica & 3,3 & 38,8 & 48,9 & 2,3 & 2,0 & 4,8 \\
\hline Lituania & 13,2 & 25,9 & 37,5 & 1,3 & 0,1 & 22,0 \\
\hline
\end{tabular}

Fuentes: Estadísticas de contabilidad nacional de la OCDE (base de datos); estadísticas de finanzas públicas de Eurostat (base de datos). 



\section{CAPÍTULO 3. EMPLEO Y SALARIOS PÚBLICOS}

\section{EL EMPLEO EN LA ADMINISTRACIÓN GENERAL}

Las Administraciones públicas en los países de la OCDE llevan a cabo una amplia gama de funciones, todas las cuales dependen de una fuerza de trabajo dedicada y especializada. Las grandes diferencias en el tamaño relativo del empleo en el sector público de los países de la OCDE reflejan la gran variedad de actividades realizadas por sus Administraciones públicas y las distintas formas en que se prestan los servicios. La prestación de servicios se lleva a cabo en gran medida por los empleados públicos o mediante una serie de alianzas con el sector privado o con entidades sin ánimo de lucro. En algunos países, la gran mayoría de los profesionales de la salud, maestros y profesores, y trabajadores de los servicios de emergencia, por ejemplo, son contratados directamente por las Administraciones públicas. En otros países existen mecanismos de ejecución alternativos y muchos de estos profesionales son empleados por organizaciones que no son propiedad del Estado, o por contratistas privados. La externalización de servicios, el volumen relativo y la estructura de los sectores del voluntariado, de las entidades sin ánimo de lucro o de la beneficencia, así como la disponibilidad de proveedores en el sector privado, determinan conjuntamente los usos del empleo en el sector público.

El volumen de empleo en la Administración general varía considerablemente entre los países de la OCDE. Los países nórdicos, como Dinamarca, Noruega y Suecia, registran los mayores niveles de empleo en la Administración general, con cerca del 30\% del empleo total. Por otra parte, los países de la OCDE de la región de Asia dependen menos de los empleados del sector público. El empleo en la Administración general supone solo alrededor del $6 \%$ del empleo total de Japón, mientras que en Corea contabiliza el 7,6\%.

Aunque muchos países de la OCDE han sufrido reducciones considerables de empleo en las Administraciones centrales como resultado de las medidas de austeridad impuestas tras la crisis financiera, el empleo en la 
Administración general en relación con el empleo total en los países de la OCDE ha permanecido relativamente estable: ha aumentado ligeramente entre 2007 y 2015 , del 17,9\% al 18,1\%. Este promedio esconde algunas variaciones entre los países. Donde más disminuyó el empleo público con respecto al empleo total entre 2007 y 2015 fue en Israel y en el Reino Unido (más de 2,5 p. p.). Por el contrario, España, Estonia, Hungría, la República Checa y la República de Eslovenia experimentaron incrementos iguales y por encima de 2 p. p. durante el mismo periodo (en el caso de España, el aumento en la ratio es principalmente debido al descenso en el empleo total).

Si se considera la tasa de crecimiento anual del empleo en la Administración general, el promedio de la OCDE también permaneció relativamente estable, al mostrar un aumento del 0,6\% entre 2007-2009, un descenso del 0,4\% en 2011-2012 y un ligero ascenso en 2014-2015. De hecho, en general, los efectos de la reducción del empleo público en respuesta a la crisis se pudieron observar en 2012, es decir, después del impacto financiero. Muchos países muestran un comportamiento similar, con una evolución negativa del empleo público durante el periodo 2011-2012 debido a las medidas de austeridad, y una recuperación en 2014-2015. Sin embargo, si se analizan los países de manera individual, los resultados muestran una situación más dinámica. Por ejemplo, Turquía registra el mayor crecimiento en 2014-2015, con un 3,9\%, mientras que los Países Bajos marcan un descenso de más del 3,6\% durante el mismo periodo. El motivo por el cual estos resultados no se reflejan en el primer gráfico es probablemente porque el empleo en la Administración general ha cambiado, en estos países, a un ritmo paralelo al empleo total. Las tasas más extremas tuvieron lugar en el periodo 2011-2012, cuando algunos países estaban en pleno auge de recortes por austeridad, como Grecia, que registró reducciones del $7 \%$ en el empleo público, y el Reino Unido, con una reducción del 4,7\%.

\section{Metodología y definiciones}

Los datos proceden de las estadísticas de contabilidad nacional de la OCDE (base de datos), que se basan en el sistema de contabilidad nacional (SCN), un conjunto de conceptos, definiciones, clasificaciones y reglas acordados internacionalmente para la contabilidad nacional. El empleo en la Administración general abarca el empleo en todos los niveles de gobierno (central, estatal, local y de las entidades de la seguridad 
social) e incluye los ministerios centrales, organismos, departamentos e instituciones sin ánimo de lucro controlados por las autoridades públicas. Los datos representan el número total de personas empleadas directamente por estas instituciones.

El empleo total comprende a todas las personas que desarrollan una actividad productiva dentro de los límites de producción de la contabilidad nacional. Se considera empleados a todas aquellas personas que, durante un breve periodo de tiempo determinado, se encontraban en las siguientes categorías: empleo remunerado o trabajo autónomo.

En comparación con la edición previa de Panorama de las Administraciones Públicas, los datos de este indicador proceden del marco del SCN y se refieren al empleo en la Administración general, mientras que antes los datos se recogían por la Organización Internacional del Trabajo (OIT) y se referían al empleo en el sector público (es decir, la Administración general más las corporaciones públicas).

\section{Otras publicaciones}

OECD (2016), Engaging public employees for a high-performing civil service, OECD Public Governance Reviews, OECD Publishing, París.

\section{Notas de los gráficos}

El empleo total se refiere al empleo nacional. Los datos de Australia, Chile, Islandia, Nueva Zelanda y Polonia no están disponibles. Los datos de Corea y Suiza no se incluyen en la media de la OCDE por falta de series temporales. Los datos de Luxemburgo previos a 2010 se basan en estimaciones. Los datos de Canadá de 2015 se basan en estimaciones. Los datos de Portugal, Suiza y Costa Rica corresponden a 2014 en lugar de a 2015. Los datos de los Estados Unidos corresponden a 2008 en lugar de a 2009.

3.2: Los datos de 2007-2009 se refieren a la tasa de crecimiento anual. 


\section{Gráfico 3.1. Empleo en la Administración general como porcentaje del empleo total, 2007, 2009 y 2015}

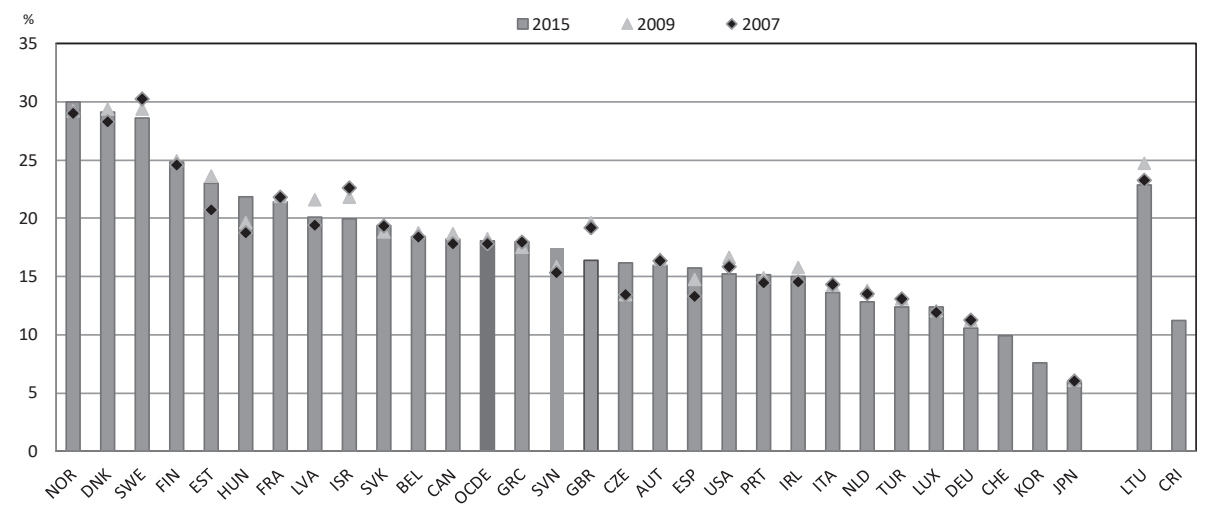

Fuentes: Estadísticas de contabilidad nacional de la OCDE (base de datos). Los datos de los Estados Unidos, Japón, Suiza y Turquía proceden de la Organización Internacional del Trabajo (OIT), ILOSTAT (base de datos), Empleo público por sector y subsector de la contabilidad nacional. Los datos de Corea proceden de sus autoridades nacionales.

$<$ http://dx.doi.org/10.1787/888933532048>

\section{Gráfico 3.2. Tasa de crecimiento anual del empleo en la Administración general, 2007-2009, 2011-2012 y 2014-2015}

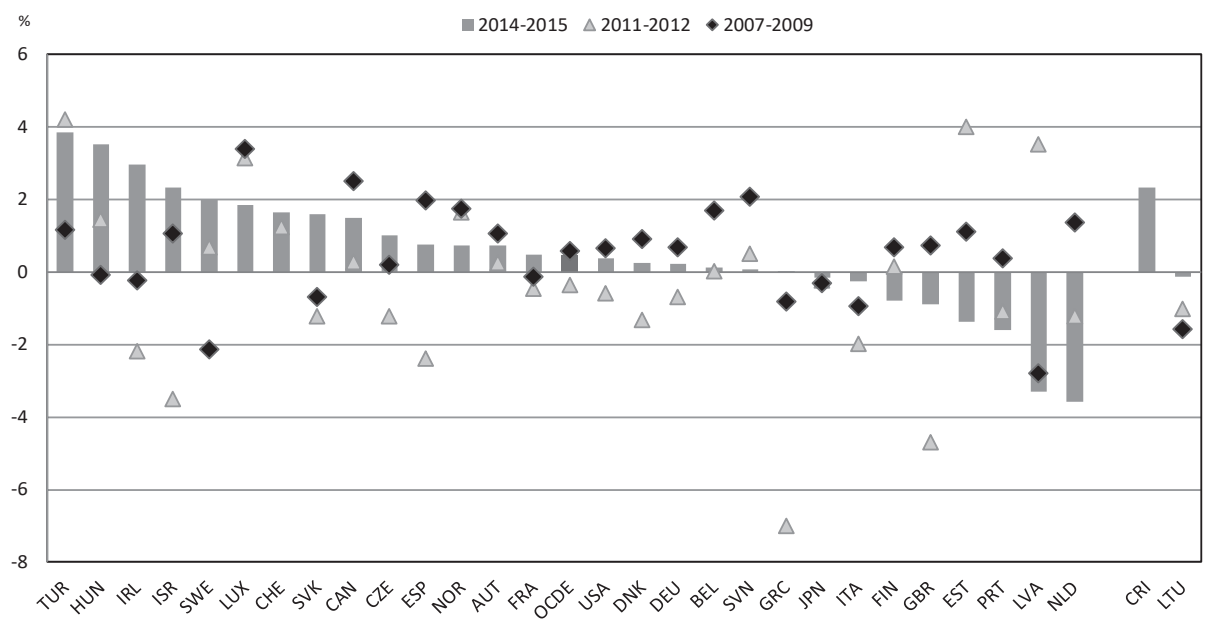

Fuentes: Estadísticas de contabilidad nacional de la OCDE (base de datos). Los datos de los Estados Unidos, Japón, Suiza y Turquía proceden de la Organización Internacional del Trabajo (OIT), ILOSTAT (base de datos), Empleo público por sector y subsector de la contabilidad nacional.

<http://dx.doi.org/10.1787/888933532067> 


\section{EL EMPLEO EN LA ADMINISTRACIÓN GENERAL POR NIVEL DE ADMINISTRACIÓN}

La proporción del personal contratado a nivel subcentral es un indicador del grado de descentralización de las Administraciones públicas. En general, una mayor proporción de empleados públicos a nivel subcentral indica una mayor delegación de responsabilidades en las Administraciones regionales y locales en materia de prestación de servicios públicos. Aunque la descentralización puede aumentar la capacidad de respuesta de las Administraciones a las necesidades y prioridades locales, también puede causar variaciones en la prestación de servicios dentro de los países.

En 2014, la mayoría de los países tenían más empleados a nivel subcentral que a nivel central de las Administraciones públicas. Los Estados federales emplean alrededor de un tercio de todos los empleados de las Administraciones a nivel central, lo cual indica un mayor grado de descentralización. Las diferencias en la proporción de empleados de las Administraciones que trabajan a nivel central son considerablemente mayores en los Estados unitarios, oscilando entre menos del $20 \%$ en Japón y Suecia y alrededor del $90 \%$ en Irlanda y Turquía.

Entre 2009 y 2014, el porcentaje de personal de las Administraciones públicas contratado a nivel central ha permanecido relativamente estable. Esto sugiere que en los países que experimentaron ajustes en los niveles de empleo público (véase la página anterior), estos ajustes se implementaron, generalmente, de manera similar a nivel central y subcentral. Solo Hungría ha sufrido cambios significativos durante este periodo, con una proporción de empleados a nivel central que ha aumentado casi 30 p. p., debido a la reorganización de las Administraciones públicas territoriales. La Administración central organizó la prestación de servicios en áreas clave - en particular, en sanidad y educación - para mejorar la calidad de los servicios en zonas pobres y homogeneizar la calidad en todo el país. Hungría llevó esto a cabo mediante la concentración de responsabilidades relacionadas con la prestación de servicios en las Administraciones subcentrales desconcentradas, liberando a las autoridades locales de estas obligaciones.

\section{Metodología y definiciones}

Los datos fueron recopilados por la Organización Internacional del Trabajo (OIT), en ILOSTAT (base de datos). Los datos se basan en las definiciones del sistema de contabilidad nacional (SCN) y abarcan el empleo a nivel central y subcentral de las Administraciones públicas.

Las Administraciones subcentrales se componen de las 
Administraciones estatales y locales, incluyendo regiones, provincias y municipios. Los niveles central y subcentral constituyen la Administración general. Además, los países proporcionaron información sobre el empleo en las entidades de la seguridad social, que incluyen todas las unidades institucionales centrales, estatales y locales cuya actividad principal es proporcionar prestaciones sociales. Puesto que las entidades de la seguridad social operan en distintos niveles de las Administraciones, esta categoría de empleo se ha registrado por separado, a no ser que se indique lo contrario. Sin embargo, en la mayoría de los países, exceptuando Alemania, Francia y México, las entidades de la seguridad social contratan un número reducido de personal y representan un porcentaje pequeño de la fuerza de trabajo total. Los datos representan el número total de personas que son empleadas directamente por cada una de las distintas instituciones.

Los siguientes países del conjunto de datos son Estados federales: Alemania, Canadá, España (considerado un país cuasifederal), los Estados Unidos y Suiza.

\section{Otras publicaciones}

OECD (2016), Engaging public employees for a high-performing civil service, OECD Public Governance Reviews, OECD, París.

\section{Notas de los gráficos}

Los datos de Dinamarca corresponden a 2013 en lugar de a 2014. Los datos de Corea corresponden a 2014 en lugar de a 2015. Las entidades de la seguridad social no se identifican de manera separada (es decir, están registradas bajo la Administración central o las Administraciones subcentrales) en el caso de Canadá, España, los Estados Unidos, Estonia, Irlanda, Japón, Noruega y Suiza.

3.3: Los datos de Lituania corresponden a 2010 en lugar de a 2009. 


\section{Gráfico 3.3. Distribución del empleo en la Administración general por nivel de administración, 2014}

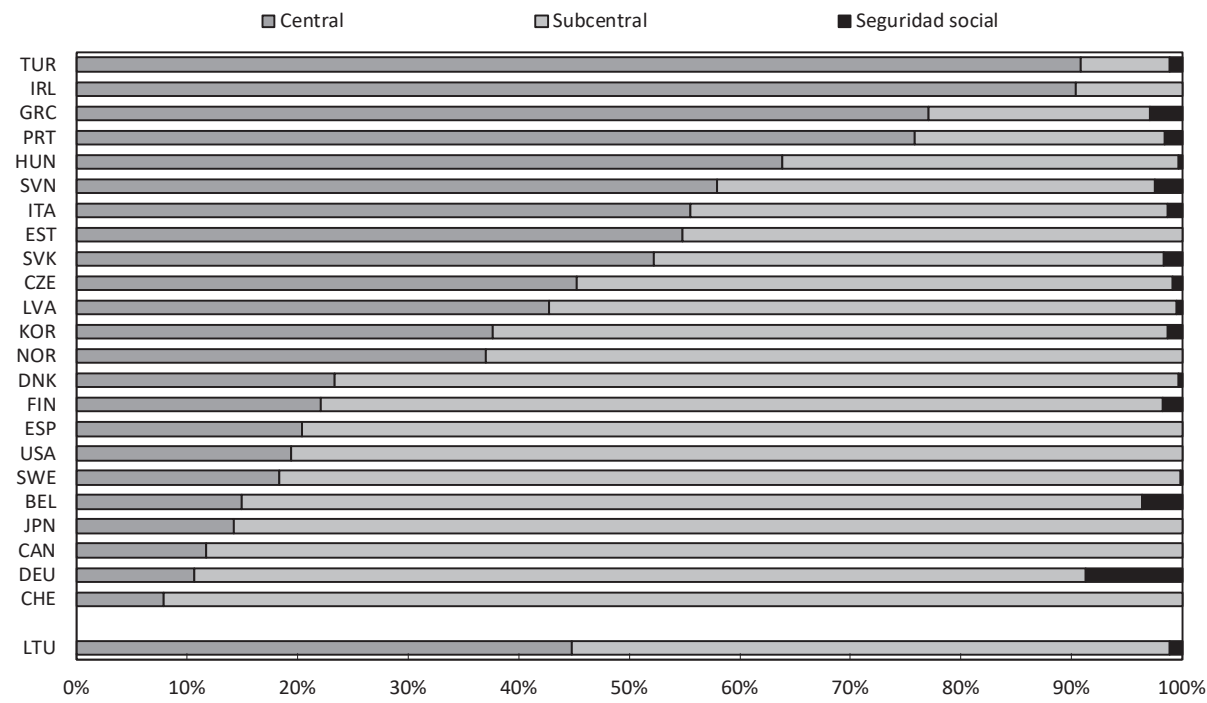

Fuentes: Organización Internacional del Trabajo (OIT), ILOSTAT (base de datos), Empleo público por sector y subsector de la contabilidad nacional. Los datos de Corea y Portugal proceden de sus autoridades nacionales.

\section{Gráfico 3.4. Porcentaje de personal de la Administración general empleado a nivel central, de 2009 a 2014}

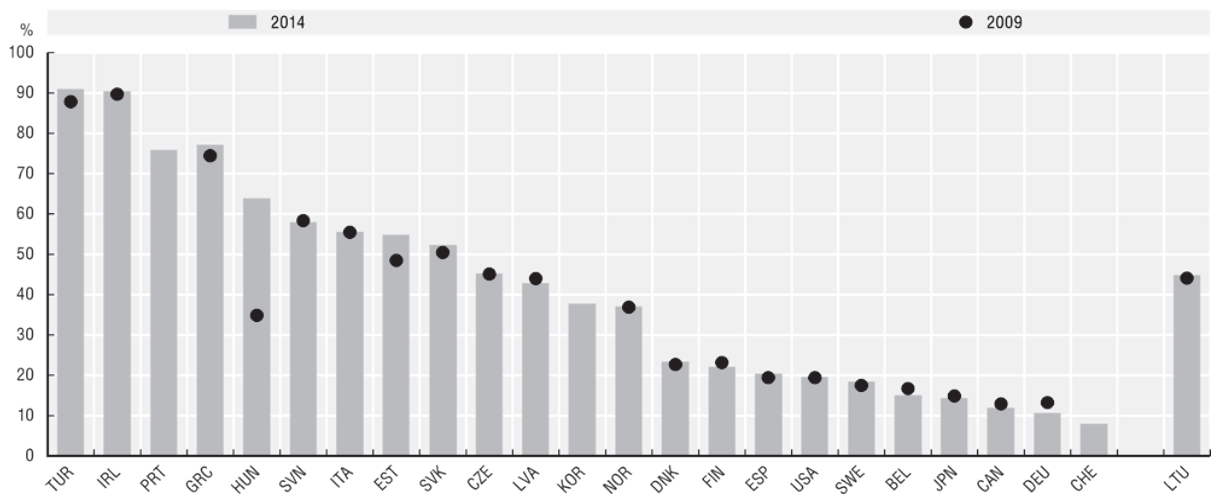

Fuentes: Organización Internacional del Trabajo (OIT), ILOSTAT (base de datos), Empleo público por sector y subsector de la contabilidad nacional. Los datos de Corea y Portugal proceden de sus autoridades nacionales. 


\section{ENVEJECIMIENTO DE LA FUERZA DE TRABAJO EN LA ADMINISTRACIÓN CENTRAL}

El envejecimiento de la fuerza de trabajo plantea retos y oportunidades a las Administraciones públicas, ya que necesitan asegurar que las altas tasas de jubilación no afectan la calidad y capacidad de los servicios. Las jubilaciones ofrecen, además, la oportunidad de introducir en las organizaciones nuevo talento y perspectivas. Una cuota reducida de empleados jóvenes supone un factor de riesgo asociado a una baja capacidad de las Administraciones de crear oportunidades de renovación. Puede, además, ser señal del bajo atractivo del sector público como empleador. Aunque se precisa una planificación correcta de la fuerza de trabajo para evitar la pérdida de conocimientos y experiencia, la salida de trabajadores puede también posibilitar su reestructuración. Por ejemplo, las Administraciones pueden fomentar la movilidad horizontal para reasignar recursos de acuerdo con las prioridades políticas o para crear oportunidades de formación. La jubilación de altos funcionarios ofrece también la oportunidad de replantear el modelo de liderazgo en términos de equilibrio de género o de rendición de cuentas.

Las Administraciones públicas centrales en los países de la OCDE con datos disponibles tienen de media más funcionarios con edades por encima de los 55 años que por debajo de los 34 años (24\% y $18 \%$, respectivamente). De estos países, la proporción de personas de 55 años o más que trabajan en la Administración central ha aumentado en Italia desde 2010, de en torno al $31 \%$ al $45 \%$. Esto convierte a Italia en el país con la proporción más elevada de empleados de más de 55 años. España registra el segundo mayor aumento de empleados en este grupo de edad, del $25 \%$ al $35 \%$, y la tercera mayor proporción de trabajadores mayores de 55 años, por detrás de Islandia, que está en segundo lugar con un 40\%. La distribución por edad de las Administraciones públicas centrales de Dinamarca, los Estados Unidos, Noruega y Suiza se ha mantenido relativamente estable entre 2010 y 2015.

El envejecimiento de la fuerza de trabajo no supone una preocupación en todos los países de la OCDE. En Australia, Chile, Corea, Hungría, Japón y la República de Eslovenia, menos del 20\% de los empleados de las Administraciones centrales es mayor de 55 años. Chile es, además, el país con la mayor proporción de personas con edades comprendidas entre los 18 y 34 años (32\%), seguido de Hungría (31\%), Alemania y Letonia (30\%). Por el contrario, en Corea, España, Grecia, Italia y Polonia, menos del 10\% de los empleados de las Administraciones centrales tiene edades comprendidas entre los 18 y 34 años. Estonia es el país donde el porcentaje de personas menores de 35 años ha aumentado más entre 2010 y 2015 (8\%).

Generalmente, la proporción de altos funcionarios (puestos D1 y D2) de al menos 55 años es mayor que en otras categorías. Más del $60 \%$ de los funcionarios directivos pertenecen a este grupo de edad en Grecia (67\%), Italia 
(66\%), los Países Bajos (66\%), Finlandia (63\%) y Bélgica (60\%). Italia y España también cuentan con una proporción elevada de funcionarios mayores de 55 años ( $42 \%$ y $41 \%$, respectivamente).

\section{Metodología y definiciones}

Los datos se recopilaron mediante la Encuesta de la OCDE sobre la composición de la fuerza del trabajo en las Administraciones centrales/ federales de 2016. Los encuestados eran predominantemente funcionarios directivos de departamentos de GRH, y los datos se refieren a la composición de la fuerza de trabajo en las Administraciones centrales/ federales por edad y puesto. Todos los países de la OCDE, excepto Luxemburgo y Nueva Zelanda, completaron la encuesta. El anexo D recoge más información sobre la clasificación y definición de las ocupaciones.

Las definiciones de función pública, así como de las organizaciones gobernadas por la Administración a nivel central, difieren entre los países y esto se debe tener en cuenta al establecer comparaciones. Los términos función pública, servicio público y funcionariado/funcionarios se utilizan indistintamente en este capítulo. Las comparaciones entre los datos de Panorama de las Administraciones Públicas 2011 y 2017 se deben realizar con cautela, ya que el alcance y número de respuestas de los países varía entre las dos publicaciones. Los puestos de altos funcionarios incluyen los niveles D1 y D2.

\section{Otras publicaciones}

OECD (2016), OECD Pensions Outlook 2016, OECD, París.

\section{Notas de los gráficos}

Los datos de Grecia y el Reino Unido corresponden a 2016 en lugar de a 2016. Los datos de Francia e Italia corresponden a 2014 en lugar de a 2015. Los grupos de edad en el caso de Polonia son los siguientes: 1. menos de 30 años; 2 . entre 31 y 50 años; 3 . más de 51 años. En el caso de Suecia, las cifras se refieren a los equivalentes a tiempo completo, no al número de empleados. Los datos de empleados de menos de 34 años en los Estados Unidos también incluyen a trabajadores menores de 18 años. Los datos de Francia corresponden a los empleados de los servicios públicos que trabajan en los ministerios de la región de la Isla de Francia (exceptuando las instituciones públicas administrativas —établissements publics administratifs-). 
Los datos de las Administraciones centrales de Corea, Grecia, Irlanda, México, Polonia, la República de Eslovenia, Colombia y Lituania incluyen solo los puestos de alta gestión (de D1 a D4) y profesionales (seniors y juniors).

3.6: Los datos de 2010 de Austria, Grecia, Israel, Japón y la República Eslovaca no están disponibles. Los datos de Estonia de 2015 se refieren a los equivalentes a tiempo completo, y en 2010 al número de empleados. En 2010, los grupos de edad de Estonia son los siguientes: 1. menos de 30 años; 2. entre 31 y 50 años; 3 . más de 51 años. Los datos de Estonia no incluyen funcionarios superiores, como ministros, canciller de justicia o controlador del Estado. Los datos de Portugal y Suiza corresponden a 2011 en lugar de a 2010. Los datos de 2015 pueden no ser comparables con los datos de 2010 en el caso de Hungría dadas las reformas totales y exhaustivas de las Administraciones públicas (reorganizaciones a nivel central y territorial, etc.).

Información sobre los datos de Israel: <http://dx.doi.org/10.1787/888932315602>.

\section{Gráfico 3.5. Proporción de personas empleadas en la Administración central por grupo de edad, 2015}

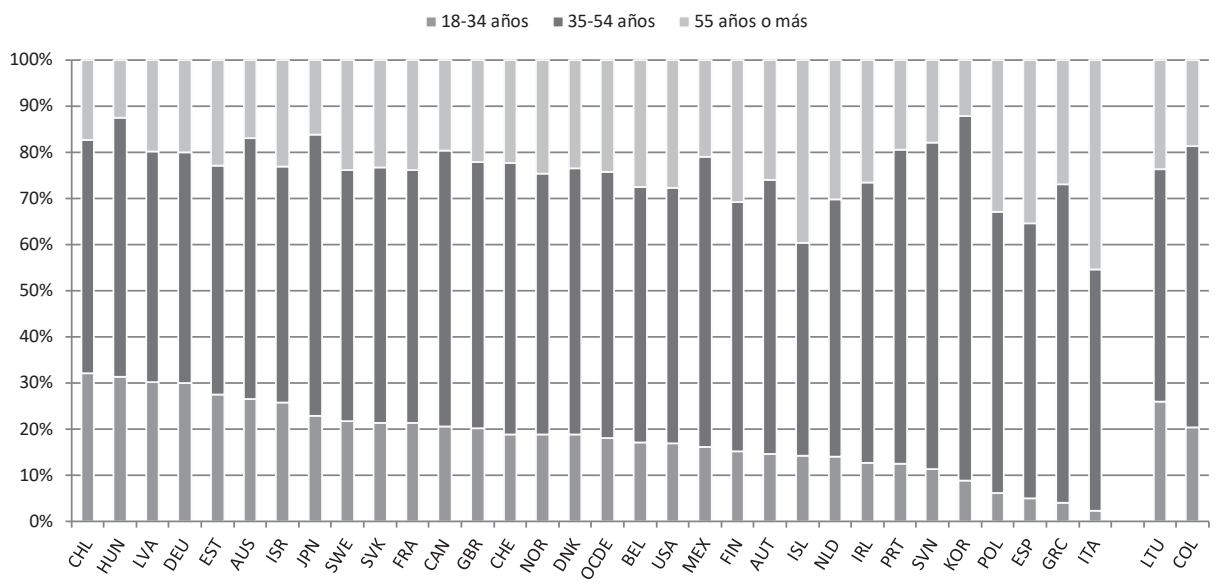

Fuente: OCDE (2016), Encuesta sobre la composición de la fuerza de trabajo en las Administraciones centrales/federales. 


\section{Gráfico 3.6. Porcentaje de empleados de la Administración central de} 55 años o más, de 2015 a 2010

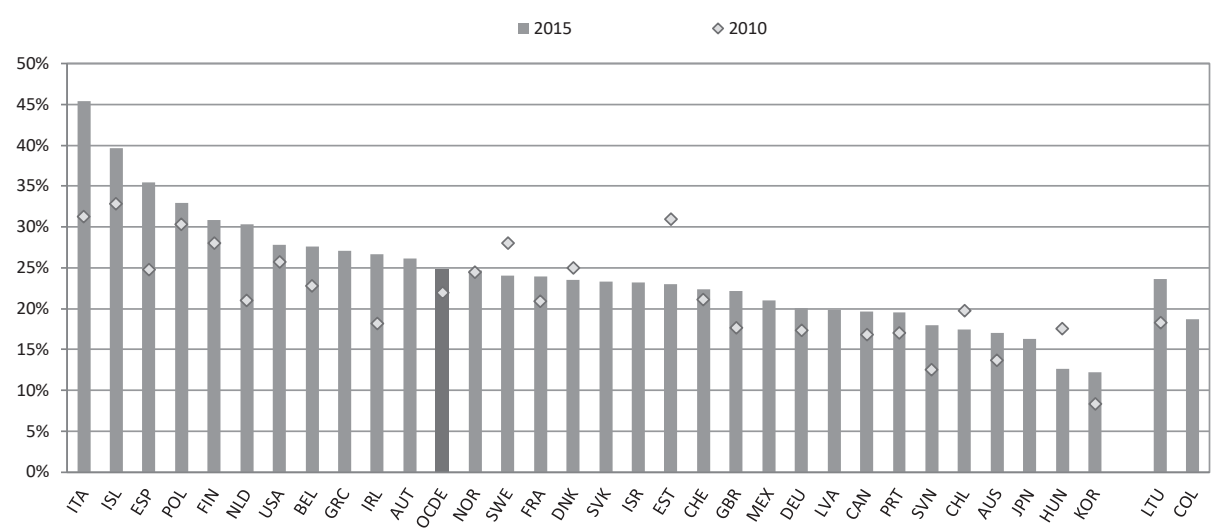

Fuente: OCDE (2016), Encuesta sobre la composición de la fuerza de trabajo en las Administraciones centrales/federales.

\section{MUJERES Y EMPLEO PÚBLICO}

La representación equitativa de las mujeres en el empleo público supone un indicador importante de los avances en pos de una fuerza de trabajo más diversa e inclusiva. La diversidad, cuando se gestiona bien, ayuda a aumentar el talento disponible y contribuye a mejorar el rendimiento de las organizaciones. La diversidad de puntos de vista y experiencia en las organizaciones del sector público puede ayudar a que las políticas y servicios reflejen mejor las necesidades de los ciudadanos. En los niveles más altos de la función pública, el equilibrio de género es un indicador importante del papel que juegan las mujeres en los procesos de toma de decisiones y de formulación de políticas.

En los países de la OCDE, la representación de las mujeres en el empleo público es mayor (58\%) que en el empleo total (45\%). Una de las razones es que en ciertas ocupaciones del sector público relacionadas con la educación y la asistencia sanitaria (profesores, maestros, enfermeros) predominan las mujeres. Esta mayor representación también podría apuntar a unas condiciones laborales más flexibles en el sector público que en el privado. Por ejemplo, en 16 países de la OCDE el sector público ofrece mejores condiciones de conciliación familiar y laboral que el sector privado. En las Administraciones centrales, las mujeres contabilizan una media del 53\% de empleados (2015). Bélgica, Dinamarca, España, Grecia e Italia tienen un equilibrio de género relativo (entre el $51 \%$ y $52 \%$ de mujeres). Hungría registra la mayor proporción de mujeres en la Administración central (72\%), seguida de Polonia (69\%) y la 
República Eslovaca (68\%). Al otro lado del espectro, se encuentran Japón $(18 \%)$, Corea (29\%) y Suiza (31\%).

La medida en que las mujeres ejercen puestos de alto rango en las Administraciones públicas varía considerablemente entre países. Los datos muestran que, en la mayoría de los países, cuanto más alto es el rango profesional, menor es el número de mujeres que trabaja en él. Muy pocos países logran la paridad de género: Grecia, Islandia, Letonia y Polonia tienen la mayor proporción de mujeres en puestos de categoría superior (entre el $50 \%$ y el $54 \%$ ). Las menores proporciones se encuentran en Japón (3\%), Corea $(6 \%)$ y Turquía $(8 \%)$. La proporción de mujeres que ocupan altos cargos ha aumentado más desde 2010 en Islandia y Noruega (12 p. p. y 11 p. p., respectivamente). En Dinamarca, España y Portugal la proporción de mujeres en altos cargos ha disminuido alrededor de 3-4 p. p. La formulación de políticas que tienen como objetivo la paridad de género en los niveles superiores de las Administraciones aumenta el atractivo del sector público para las mujeres. En 2015, el equilibrio de género fue el objetivo principal de las estrategias de diversidad en 15 países de la Unión Europea (de los cuales 11 son miembros de la OCDE). Diez países de la OCDE llevan a cabo estrategias de contratación de mujeres, y seis países de la OCDE estrategias de promoción de mujeres.

\section{Metodología y definiciones}

Los datos fueron recopilados por la Organización Internacional del Trabajo (OIT), en ILOSTAT (base de datos). Los datos se basan en la Encuesta sobre la fuerza de trabajo, a no ser que se indique lo contrario. El empleo del sector público comprende el empleo en el sector de las Administraciones públicas y en las empresas y compañías residentes de propiedad pública. Los datos representan el número total de personas contratadas directamente por estas instituciones, con independencia del tipo específico de contrato de trabajo. Se considera empleados a todas aquellas personas que, durante un breve periodo de tiempo determinado, se encontraban en las siguientes categorías: empleo remunerado o trabajo autónomo.

Los datos sobre la proporción de mujeres en las Administraciones centrales se recopilaron mediante la Encuesta de la OCDE sobre la composición de la fuerza del trabajo en las Administraciones centrales/federales de 2016. Los encuestados eran predominantemente funcionarios directivos de departamentos de GRH, y los datos se refieren a la composición de la fuerza de trabajo en las Administraciones centrales/federales por edad y puesto. Todos los países de la OCDE, excepto Luxemburgo y 
Nueva Zelanda, completaron la encuesta. El anexo D recoge más información sobre la clasificación y definición de las ocupaciones.

Las definiciones de función pública, así como de las organizaciones gobernadas por la Administración a nivel central, difieren entre los países y esto se debe tener en cuenta al establecer comparaciones. Los términos función pública, servicio público y funcionariado/funcionarios se utilizan indistintamente en este capítulo.

Los datos sobre la proporción de mujeres con respecto al empleo total (3.10) y sobre las políticas que apoyan la igualdad de oportunidades para las mujeres (3.11) están disponibles online en el anexo F.

\section{Otras publicaciones}

OECD (2014), Women, Government and policy making in OECD countries: Fostering diversity for inclusive growth, OECD, París.

\section{Notas de los gráficos}

3.7: Los datos de Australia, Austria, los Estados Unidos, Irlanda, Islandia, Israel, Luxemburgo, Nueva Zelanda, la República Checa y Turquía no están disponibles. Los datos de Alemania, Dinamarca y la República de Eslovenia se basan en registros administrativos y fuentes relacionadas. Los datos de Corea, Finlandia, Letonia, Portugal y Suecia no se incluyen en la media puesto que faltan series temporales. Los datos de Lituania, la República de Eslovenia y Suiza corresponden a 2014 en lugar de a 2015. Los datos de Dinamarca, el Reino Unido y Costa Rica corresponden a 2013 en lugar de a 2015.

3.8 y 3.9: Los datos de Alemania, Estonia y Hungría no están disponibles. Los datos de Francia e Italia corresponden a 2014 en lugar de a 2015. Los datos del Reino Unido corresponden a 2016 en lugar de a 2015. En el caso de Corea, los datos de puestos de alto funcionariado corresponden a 2016 en lugar de a 2015. En el caso de Austria, solo están disponibles los datos de los puestos D1. La categoría D4 no existe en Dinamarca. En el caso de Japón, los datos de los puestos D4 y de los economistas seniors y juniors no están disponibles. En el caso de Israel, los datos de los economistas seniors y juniors no están disponibles. Los datos de Francia corresponden a los empleados de los servicios públicos que trabajan en los ministerios de la región de la Isla de Francia (exceptuando las instituciones públicas administrativas —établissements publics administratifs-). Un amplio sector 
del funcionariado irlandés no se ajusta a la descripción de cargo superior o intermedio y el término personal administrativo u operativo se ha considerado el más apropiado.

3.9: Los datos de 2010 de Austria, Grecia, Israel, Japón, Letonia, México, la República Eslovaca, Colombia y Lituania no están disponibles. Los datos de Estonia de 2015 se refieren a los equivalentes a tiempo completo, y en 2010 al número de empleados. Los datos de 2015 pueden no ser comparables con los datos de 2010 en el caso de Hungría dadas las reformas totales y exhaustivas de las Administraciones públicas (reorganizaciones a nivel central y territorial, etc.). En el caso de Polonia, los datos de 2010 de puestos de alta gestión incluyen los puestos D3. Los datos de Portugal y Suiza corresponden a 2011 en lugar de a 2010. En el caso de Suecia, las cifras se refieren a los equivalentes a tiempo completo. Los datos de Corea corresponden a 2016 en lugar de a 2015.

Información sobre los datos de Israel: <http://dx.doi.org/10.1787/888932315602>.

\section{Gráfico 3.7. Proporción de empleo en el sector público ocupado por mujeres, 2009 y 2015}

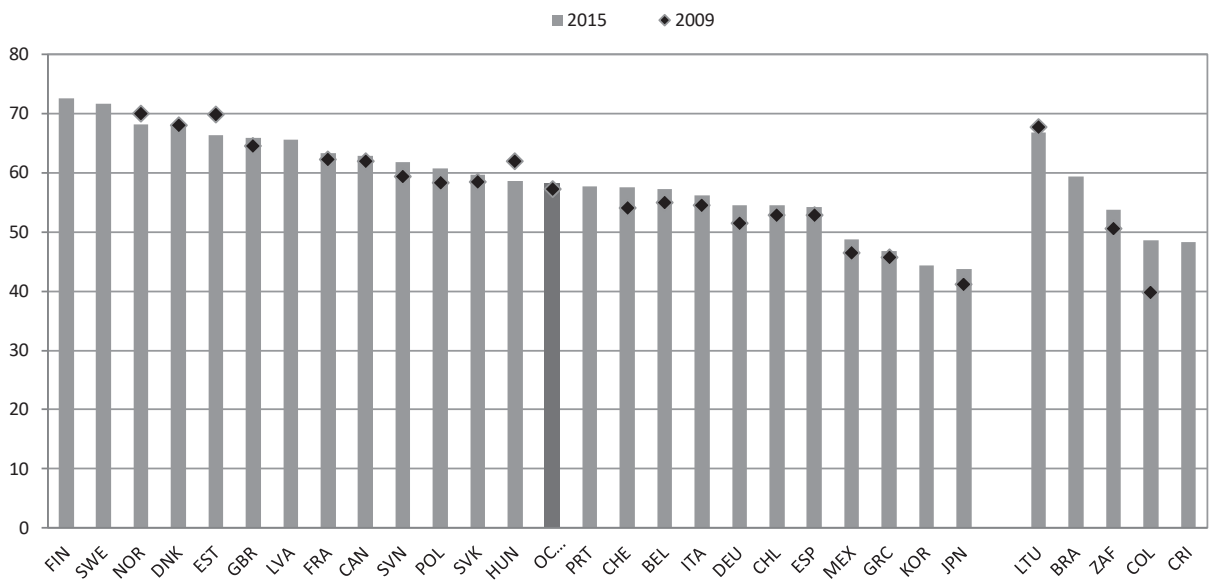

Fuentes: Organización Internacional del Trabajo (OIT), ILOSTAT (base de datos), Empleo por sexo y sector institucional. Los datos de Corea, Italia y Portugal proceden de sus autoridades nacionales. 
Gráfico 3.8. Proporción de mujeres en puestos seleccionados de la Administración central, 2015

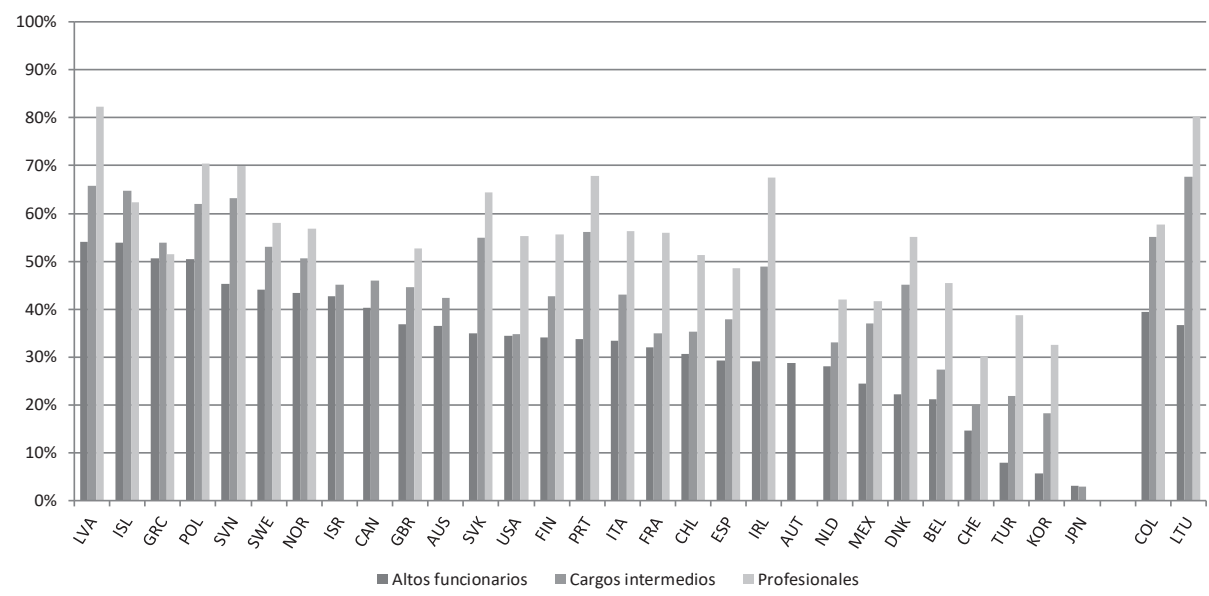

Fuente: OCDE (2016), Encuesta sobre la composición de la fuerza de trabajo en las Administraciones centrales/federales.

Gráfico 3.9. Proporción de mujeres en puestos del alto funcionariado de la Administración central, 2010 y 2015

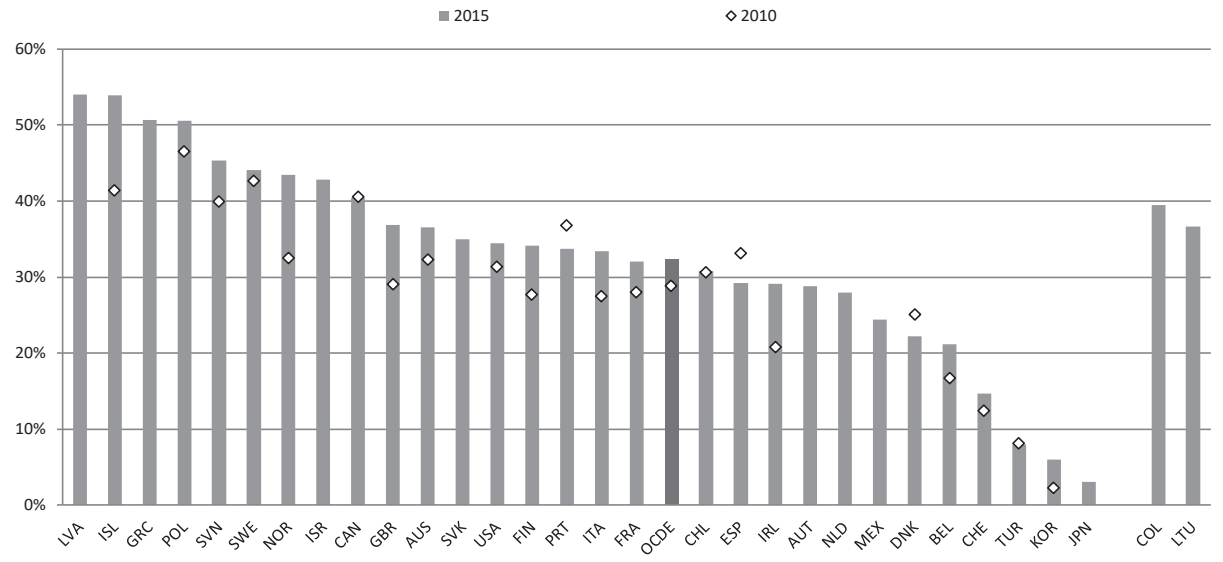

Fuente: OCDE (2016), Encuesta sobre la composición de la fuerza de trabajo en las Administraciones centrales/federales. 


\section{MUJERES Y POLÍTICA}

Los gabinetes y Parlamentos se encuentran en el centro de la vida pública y política. Conseguir la igualdad de género en estos ámbitos resulta un paso esencial para garantizar que las políticas y presupuestos públicos reflejan las perspectivas e intereses tanto de mujeres como de hombres. Al adoptar los Objetivos de Desarrollo Sostenible de la ONU (ODS), los países se han comprometido a lograr la igualdad de género en el liderazgo político. A pesar de ello, la representación política de las mujeres ha aumentado poco en los últimos 15 años, las mujeres continúan estando infrarrepresentadas a nivel ministerial y, en promedio, apenas ocupan un tercio de los escaños parlamentarios de las Cámaras Bajas en las asambleas legislativas de la OCDE. Fomentar la participación plena de las mujeres en el liderazgo político requiere una respuesta integral y coordinada que va más allá de las medidas que se centran en las mujeres como sector infrarrepresentado en el ámbito político. Impulsar la perspectiva de género en los órganos legislativos y en las Administraciones públicas como lugares de trabajo, y establecer mecanismos de rendición de cuentas y seguimiento, son pasos esenciales para continuar avanzando en la igualdad de género.

En promedio, las mujeres ocuparon el $29 \%$ de los escaños de las Cámaras Bajas o únicas de las legislaturas, que supone un aumento moderado del $1 \%$ con respecto a 2015. La representación de las mujeres osciló entre más del $47 \%$ en Islandia y menos del $10 \%$ en Japón. Ninguno de los países de la OCDE ha conseguido la paridad de género y solo 17 lograron o superaron el $30 \%$ de representación de mujeres. De los 18 países de la OCDE que han tenido elecciones parlamentarias desde 2015, 13 países han registrado aumentos en la representación de mujeres ( $4 \%$ de media), con incrementos de 6 p. p. en Estonia, Irlanda e Islandia. En España y Grecia, la representación de las mujeres en el Parlamento ha disminuido ligeramente desde las últimas elecciones parlamentarias, en 2 p. p. y 5 p. p. respectivamente. La mayoría de los países de la OCDE ha fijado algún tipo de cuota política de género mediante, por ejemplo, cuotas legales de candidatos y cuotas voluntarias de los partidos políticos, aunque estas medidas varían en cuanto al formato y alcance. En 2017, diez países de la OCDE funcionaron con cuotas legisladas en sus Cámaras Bajas o únicas del Parlamento. Entre 2015 y 2017, no hubo cambios en el número de países con cuotas legisladas, aunque México sustituyó el requisito mínimo de 40-60\% de representación de uno u otro sexo en el Parlamento por la paridad de género (OCDE, 2017). Desde que el requisito de paridad de género entró en vigor en 2014, la representación de mujeres en el Parlamento mexicano ha aumentado un $5 \%$ en comparación con las elecciones de 2012. 
En 2017, una media del 28\% de los puestos ministeriales de las Administraciones centrales/federales se ocuparon por mujeres, que supone una caída del 1,3\% en comparación con 2015. Existen variaciones significativas entre países: mientras Canadá, Francia, la República de Eslovenia y Suecia han alcanzado la paridad de género en los puestos de gabinete, las mujeres no formaron parte del gabinete en Hungría y ocuparon solo 1 de los 26 escaños en Turquía. En promedio, las mujeres suponen un tercio de los puestos de gabinete en 14 países de la OCDE. Entre 2015 y 2017, la representación de las mujeres en puestos de gabinete descendió más de 15 p. p. en Estonia, Finlandia e Italia, mientras que el número de mujeres ministras a nivel federal aumentó considerablemente en Canadá y Dinamarca. Hasta el momento, ningún país de la OCDE ha legislado las cuotas de los nombramientos ejecutivos.

\section{Metodología y definiciones}

Los datos sobre mujeres parlamentarias se refieren a las Cámaras Bajas o únicas del Parlamento y se han obtenido de la base de datos PARLINE de la Unión Interparlamentaria. Los datos se refieren a la proporción de mujeres parlamentarias registradas a 1 de enero de 2017 y 1 de diciembre de 2015. Los países en gris claro representan los Parlamentos con Cámara Baja o única con cuotas de candidatos legisladas a partir de enero de 2017. Las cuotas legislativas están consagradas en la ley electoral y de partidos políticos, o en otras leyes comparables de cada país. Por definición, las cuotas basadas en la ley electoral y de partidos políticos se atienen a disposiciones legales y obligan a todas las formaciones políticas que participan en las elecciones a aplicarlas por igual. Los datos sobre las cuotas de género se han obtenido de la Base de datos global de cuotas de género del Instituto para la Democracia y la Asistencia Electoral (IDEA, por sus siglas en inglés).

Los datos sobre las ministras de Gobierno nacional se han obtenido de la Unión Interparlamentaria y de la base de datos de la ONU Mujeres, Mujeres en política. Los datos representan el porcentaje de mujeres ministras nombradas a partir del 1 de enero de 2017 y 1 de enero de 2015. Los datos muestran a las mujeres como proporción del total de ministros, e incluye a los viceprimeros ministros y viceministros del Gobierno. Los primeros ministros/jefes de Gobierno también están incluidos cuando desempeñan una cartera ministerial. Los vicepresidentes y jefes de organismos gubernamentales o públicos no se han incluido en el total. 


\section{Otras publicaciones}

OECD (2014), Women, Government and policy making in OECD countries: Fostering diversity for inclusive growth, OECD, París, <http://dx.doi. org/10.1787/9789264210745-en>.

OECD (2016), 2015 OECD Recommendation of the Council on gender equality in public life, OECD, París, <http:// dx.doi.org/10.1787/9789264252820en>.

OECD (2017), Building an inclusive Mexico: Policies and good governance for gender equality, OECD, París. <http:// dx.doi.org/10.1787/9789264265493-en>.

\section{Notas de los gráficos}

3.12: Las barras en gris claro representan los países con Parlamentos con Cámara Baja o única que tienen cuotas de candidatos legisladas a partir de marzo de 2017.

3.13: Los datos de 2017 de Islandia han sido proporcionados por el Gobierno de Islandia.

Información sobre los datos de Israel: <http://dx.doi.org/10.1787/888932315602>.

\section{Gráfico 3.12. Proporción de mujeres parlamentarias y cuotas de género} legisladas, 2015 y 2017 (Cámara Baja o única del Parlamento)

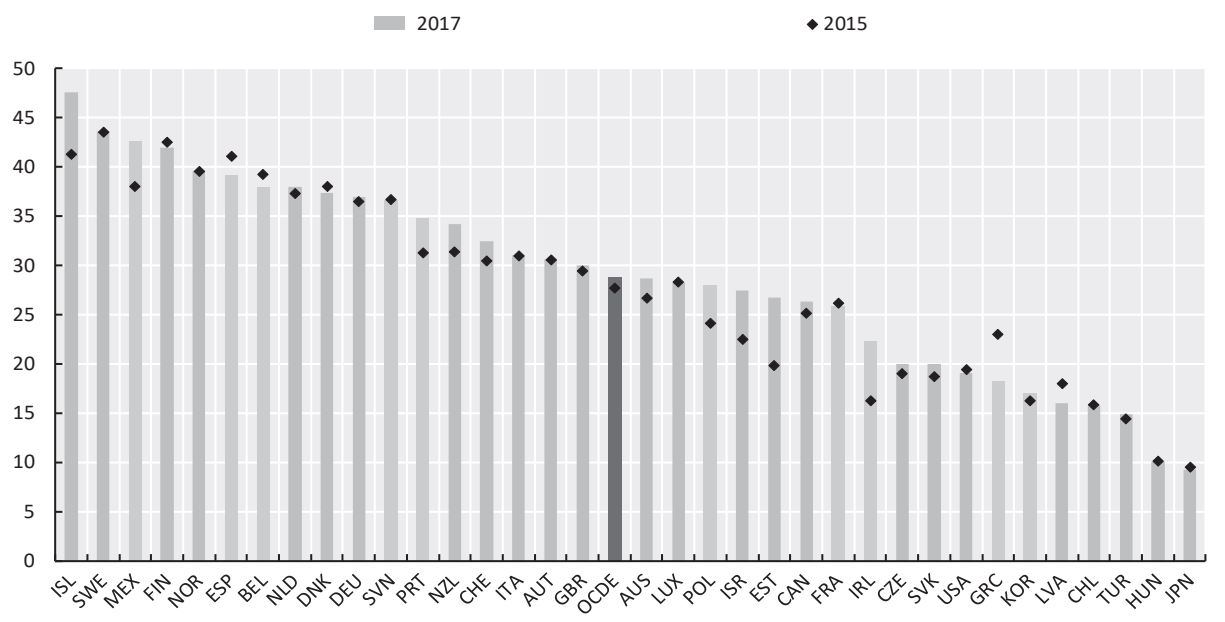

Fuentes: Unión Interparlamentaria (UIP) PARLINE (base de datos); IDEA, Base de datos global de cuotas de género. 


\section{Gráfico 3.13. Proporción de mujeres ministras, 2015 y 2017}

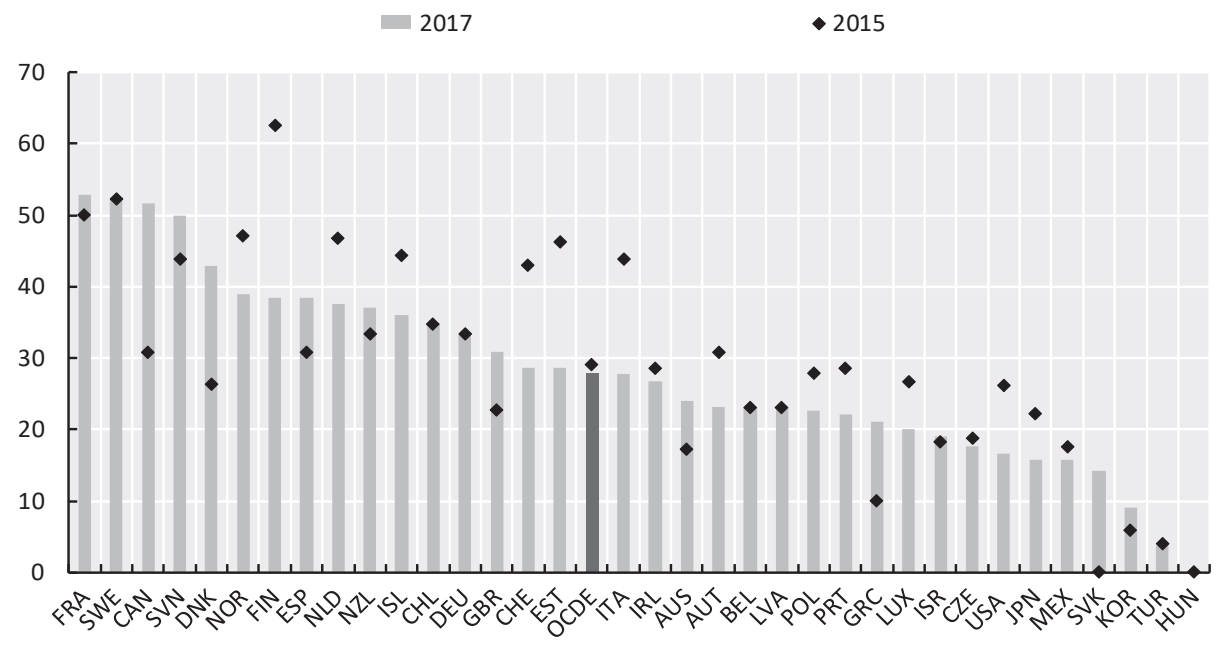

Fuentes: Unión Interparlamentaria (UIP), y ONU Mujeres, Mujeres en política, 2015 y 2017.

$<$ http://dx.doi.org/10.1787/888933532238>

\section{MUJERES Y PODER JUDICIAL}

Garantizar el equilibrio de género en el liderazgo judicial ha sido destacado por los países de la OCDE como un aspecto clave de la gobernanza, estrechamente vinculado a la transparencia y la efectividad del Estado de derecho. Los nombramientos judiciales de mujeres, especialmente en los niveles superiores, pueden ayudar a cambiar los estereotipos de género y fomentar que las mujeres hagan valer sus derechos.

En términos de la ratio total de jueces profesionales, los datos disponibles muestran que la paridad de género se ha alcanzado y superado en la mayoría de países de la OCDE, con una media de representación de las mujeres del $53 \%$ en 2014, que supone un aumento del $1 \%$ con respecto a 2012. En algunos casos, como el de Suiza e Irlanda, la proporción de mujeres ha aumentado considerablemente, en un $5 \%$ y un $7 \%$, respectivamente. En la última década, se ha fomentado el equilibrio de género en el sistema judicial mediante esfuerzos para establecer tribunales de nombramiento con una composición igualada de ambos sexos que garanticen procesos de selección de jueces imparciales, la introducción de fórmulas de trabajo flexibles y una mayor promoción del acceso de las mujeres a las profesiones jurídicas.

La representación de género varía entre los distintos niveles de los tribunales. Las mujeres ocupan de media el $59 \%$ de los puestos en los tribunales de 
primera instancia y el $50 \%$ en los tribunales de apelación, pero solo el $32 \%$ de las judicaturas en los tribunales supremos. Además, el $77 \%$ de los países con datos disponibles tienen una mayoría de juezas en tribunales de primera instancia, mientras que en el caso de los tribunales de apelación la cifra disminuye a un $48 \%$. En los tribunales supremos, la ratio desciende drásticamente a un $15 \%$. El nivel de exigencia de los requisitos necesarios para la designación de jueces parece plantear dificultades adicionales al liderazgo judicial de mujeres. En los países del Commonwealth, por ejemplo, la noción de que solo los abogados de alto nivel pueden optar a puestos de juez limita de manera evidente el número de candidatos y penaliza en especial a las mujeres, que suelen tener que enfrentarse a retos relacionados con la conciliación familiar y laboral si quieren avanzar en su carrera profesional, y es, por tanto, más probable que la abandonen.

Durante la última década, los países de la OCDE han aumentado su concienciación y capacidad de respuesta para reducir los obstáculos que dificultan el progreso de las carreras judiciales de las mujeres. Varios países han adoptado medidas positivas que garantizan el equilibrio de género en el sistema judicial, incluyendo los puestos de alta responsabilidad. Siguiendo el ejemplo de otros países (por ejemplo, Canadá y el Reino Unido), Irlanda está trabajando en el establecimiento de una comisión de nombramiento de personal judicial que tiene entre sus objetivos la implementación del equilibrio de género. El Consejo General del Poder Judicial en España aprobó el Plan de Igualdad de la Carrera Judicial en 2013 con el fin de eliminar cualquier tipo de discriminación de género en el acceso y desarrollo de las carreras judiciales, garantizar el desempeño laboral de las mujeres, mejorar las condiciones de conciliación de la vida familiar y laboral y aumentar la participación femenina en la toma de decisiones. Algunos países de la OCDE, como Alemania, Dinamarca, Noruega y el Reino Unido, indicaron que habían fomentado procesos de contratación sensibles al género en 2014, que incluían la adopción de medidas como la implantación de comités de selección con equilibrio de género y el aumento de la diversidad en el conjunto de candidatos.

\section{Metodología y definiciones}

Los datos presentados han sido recogidos por la Comisión Europea para la Eficacia de la Justicia (CEPEJ). Los datos corresponden a 2012 y 2014 y comprenden a todos los países de la OCDE que son miembros del Consejo de Europa. El estudio n. ${ }^{\circ} 23$ de la CEPEJ, Sistemas judiciales europeos: Eficacia y calidad de justicia (ediciones de 2014 y 2016), proporciona más información sobre los datos.

Los tribunales de primera instancia son donde los procedimientos judiciales comienzan o son expuestos por primera vez; los tribunales de apelación revisan las decisiones emitidas por tribunales inferiores; los 
tribunales supremos son los organismos máximos dentro de una jerarquía con numerosas jurisdicciones legales y funcionan principalmente como tribunales de apelación, revisando las decisiones de tribunales inferiores y de apelación intermedios.

Los jueces profesionales son contratados, formados y remunerados para desempeñar las funciones de juez como su principal ocupación. Esta categoría incluye jueces profesionales de los tribunales de primera instancia, de apelación y supremos.

El término sensible al género se utiliza para destacar la consideración y capacidad de respuesta a las distintas necesidades y circunstancias de cada persona que se ven afectadas por los roles de género (es decir, políticas, tribunales y lugares de trabajo sensibles al género).

Las medidas positivas se refieren a políticas que favorecen a miembros de grupos desfavorecidos que sufren o han sufrido discriminación. En la vida pública, las medidas positivas a menudo conllevan requisitos y procesos específicos (relacionados con la contratación, promoción, nombramiento y selección) que apoyan a grupos infrarrepresentados en varias ocupaciones y cargos.

\section{Otras publicaciones}

OECD (2016), 2015 OECD Recommendation of the Council on gender equality in public life, OECD, París, <http://dx.doi.org/10.1787/9789264252820-en>.

\section{Notas de los gráficos}

Los datos de Canadá, Corea, los Estados Unidos, México, Nueva Zelanda y el Reino Unido no están disponibles.

3.14: No hay datos disponibles de Chile, de Polonia en 2014 y de Luxemburgo en 2012. Los datos de Japón han sido proporcionados por el Gobierno de Japón. Los datos de Islandia han sido proporcionados por el Gobierno de Islandia. Los datos de Islandia corresponden a 2013 en lugar de a 2014.

3.15: Los datos de los tribunales supremos de los Países Bajos y Polonia no están disponibles. Los datos de los tribunales de primera instancia y de apelación de Alemania y Chile no están disponibles. Los datos de los tribunales de apelación de Islandia, Luxemburgo y Turquía no están disponibles. Los datos de Chile han sido proporcionados por el Gobierno de Chile. Los datos de Islandia han sido proporcionados por el Gobierno de Islandia.

Información sobre los datos de Israel: <http://dx.doi.org/10.1787/888932315602>. 
Gráfico 3.14. Proporción femenina de jueces profesionales, 2012 y 2014

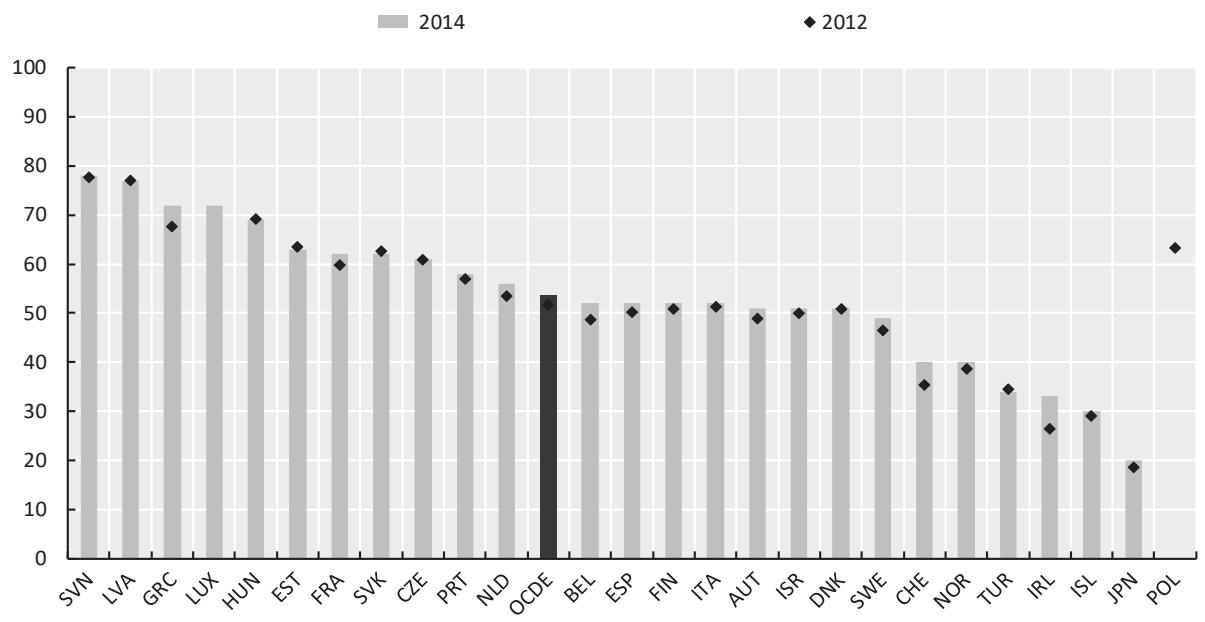

Fuente: Sistemas judiciales europeos: Eficacia y calidad de la justicia, ESTUDIOS CEPEJ, n. ${ }^{\circ} 23$, edición de 2014 (datos de 2012), edición 2016 (datos de 2014).

$<$ http://dx.doi.org/10.1787/888933532257>

\section{Gráfico 3.15. Proporción femenina de jueces profesionales por nivel de tribunal, 2014}

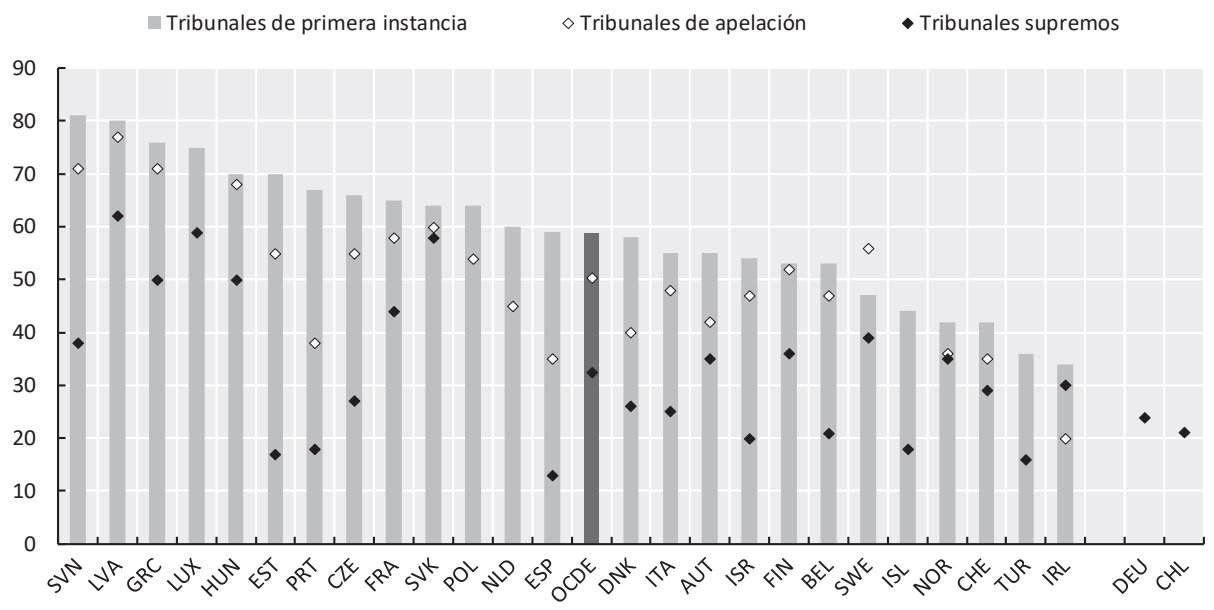

Fuente: Sistemas judiciales europeos: Eficacia y calidad de la justicia, ESTUDIOS CEPEJ, n. 23 (edición de 2016, datos de 2014). 


\section{REMUNERACIÓN DE ALTOS FUNCIONARIOS}

Se espera que los altos funcionarios de la Administración central tengan capacidad de reacción política, un conocimiento profundo de los ciudadanos a los que sirven y sean gestores efectivos capaces de dirigir organizaciones públicas saludables y de alto rendimiento. Su retribución es un indicador del valor que tienen estos puestos $\mathrm{y}$, junto con la motivación intrínseca relacionada con la naturaleza del trabajo, repercute en su atractivo y en la capacidad de retención de personas muy competentes.

Existen varios factores que pueden explicar las diferencias entre los niveles de remuneración de puestos muy similares en los países de la OCDE. Por ejemplo, la retribución puede ser distinta dependiendo de las diferencias en la estructura nacional de los mercados laborales para competir por el talento con el sector privado. El mercado laboral interior también puede ser un factor de influencia, puesto que los niveles de retribución pueden motivar que los candidatos más cualificados soliciten puestos de trabajo de mayor reconocimiento. Al mismo tiempo, las Administraciones públicas buscan el equilibrio entre la necesidad de mantener la estabilidad de los salarios internos y el sentido de la justicia. La composición de la fuerza de trabajo puede también repercutir en los niveles de remuneración, con factores como, por ejemplo, la antigüedad de los altos cargos o la proporción de mujeres (que generalmente ganan menos que sus homólogos masculinos) en puestos de alta gestión.

La Encuesta de la OCDE sobre la remuneración de los empleados en las Administraciones centrales/federales de 2016 define las categorías ocupacionales de manera precisa con el fin de comparar puestos similares, y tiene en cuenta los niveles de retribución, incluyendo los sueldos y salarios brutos y las cotizaciones a la seguridad social. Los cargos D1 son funcionarios superiores por debajo de ministros y secretarios de Estado, y los D2 son altos funcionarios de nivel inmediatamente inferior al D1. En promedio, la remuneración de los funcionarios superiores de nivel D1 asciende a 231546 USD PPA en los países de la OCDE. Además de sueldos y salarios, la remuneración incluye las cotizaciones sociales del empleador (el 17\% de la remuneración; 39281 USD PPA) y la corrección del tiempo de trabajo (14\% de la remuneración; 31638 USD PPA). La remuneración de los altos funcionarios del nivel D2 asciende a una media de 182246 USD PPA en los países de la OCDE. En promedio, los cargos D1 ganan un $27 \%$ más que los cargos D2. Sin embargo, en los Estados Unidos, los cargos D1 ganan menos que los D2, muy probablemente debido a que los gestores D1 son nombramientos políticos y, por tanto, pueden ser más jóvenes o tener menos experiencia en las Administraciones públicas que los gestores D2.

Los altos funcionarios ganan más en Australia e Italia, y menos en Corea, Grecia, Letonia y la República de Eslovenia. Cuando los sueldos son corregidos por el PIB per cápita para contabilizar las diferencias entre el nivel de de- 
sarrollo económico de los países, los resultados muestran que los gestores D1 en México y Colombia perciben la mayor remuneración, mientras que en Islandia y Noruega perciben la menor.

\section{Metodología y definiciones}

Los datos corresponden a 2015 y se recopilaron mediante la Encuesta de la OCDE sobre la remuneración de los empleados en las Administraciones centrales/federales de 2016. Los funcionarios de los ministerios y organismos centrales respondieron a través de la Red de Empleo y Gestión Públicos de la OCDE.

Los datos corresponden a seis ministerios/departamentos de la Administración central (Interior, Hacienda, Justicia, Educación, Sanidad y Medio Ambiente, o sus equivalentes). La clasificación y definición de las ocupaciones son una adaptación de los códigos CIUO-08 desarrollados por la Organización Internacional del Trabajo (OIT). Los niveles de remuneración son el promedio de la retribución del personal existente.

La remuneración total incluye sueldos y salarios, y las cotizaciones sociales de los empleadores, tanto financiadas como no financiadas. Las cotizaciones sociales se limitan a los sistemas sanitario y de pensiones para presentar datos consistentes de los países.

La remuneración se convirtió a USD utilizando las paridades de poder adquisitivo (PPA) para el consumo privado de la base de datos de las estadísticas de contabilidad nacional de la OCDE. Los datos no se ajustan al número de horas trabajadas por semana, puesto que se espera que los gestores, de manera formal o informal, trabajen más horas, sino que están ajustados al promedio de días de vacaciones.

La comparación con los resultados de recopilaciones de datos previos se ve limitada debido a pequeños cambios de metodología. Para más información sobre la metodología, véase el anexo D.

\section{Otras publicaciones}

OECD (2016), Engaging public employees for a high-performing civil service, OECD Public Governance Reviews, OECD, París.

OECD (2012), Public sector compensation in times of austerity, OECD, París. 


\section{Notas de los gráficos}

Los datos de Hungría, Irlanda, Luxemburgo, Nueva Zelanda, Polonia, la República Checa, la República Eslovaca, Suiza y Turquía no están disponibles.

Los datos de remuneración de los cargos D2 están mezclados con los de los cargos D1 en el caso de Finlandia y la República de Eslovenia, y faltan en el caso de Lituania. Alemania: los datos se basan en estimaciones de acuerdo con la escala salarial y no en las remuneraciones reales. Australia: no se incluye el Ministerio del Interior. Bélgica: no se incluyen los ministerios de Educación y Medio Ambiente puesto que no pertenecen a la autoridad federal. Corea: los datos no incluyen las asignaciones fijas en concepto de dietas y categoría de trabajo que se proporcionan en todos estos puestos; la retribución por vacaciones no utilizadas tampoco se incluye. Estonia: los datos del Ministerio de Medio Ambiente no están disponibles. Francia: los datos corresponden a 2014 (utilizando las PPA de 2014). Islandia: el Ministerio de Justicia pertenece al Ministerio del Interior. Japón: los datos se proporcionan en términos de entrada y nivel máximo de remuneración; la media aritmética se ha tenido en cuenta y ha sido incluida en el promedio de la OCDE. Noruega: no se incluye a los empleados no cubiertos por el convenio colectivo básico de la función pública. Países Bajos: se incluye a todos los empleados de la Administración central. Suecia: el Ministerio del Interior no existe y, por tanto, no se incluye en los datos.

\section{Gráfico 3.16. Remuneración media anual de los altos funcionarios de la Administración central, 2015 (Ajustado a las diferencias de vacaciones)}

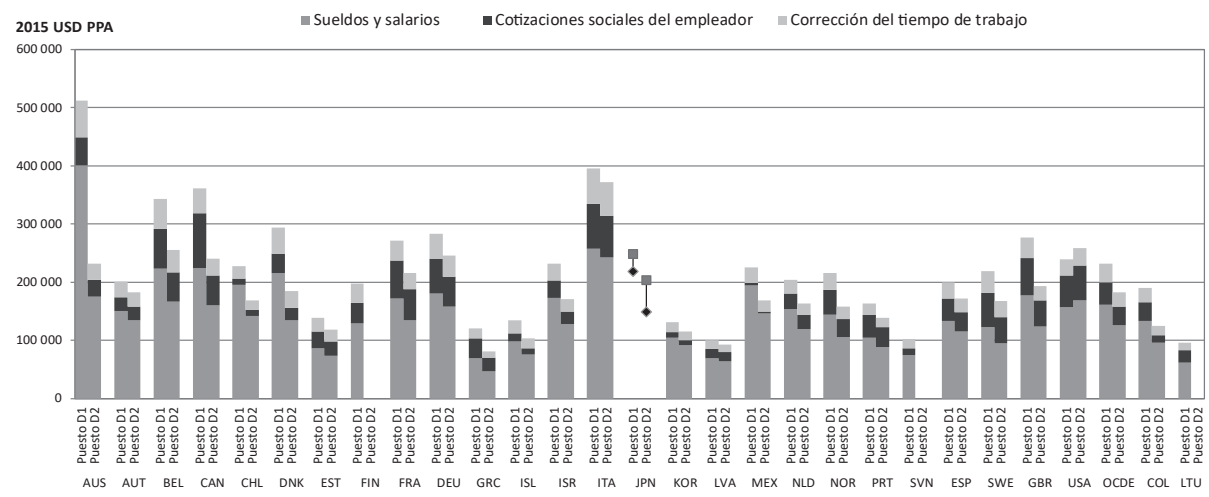

Fuentes: OCDE (2016), Encuesta sobre la remuneración de los empleados en las Administraciones centrales/federales; OCDE STAN / estadísticas de contabilidad nacional (base de datos). 


\section{Gráfico 3.17. Remuneración media anual de los altos funcionarios de la Administración central en relación con el PIB per cápita}

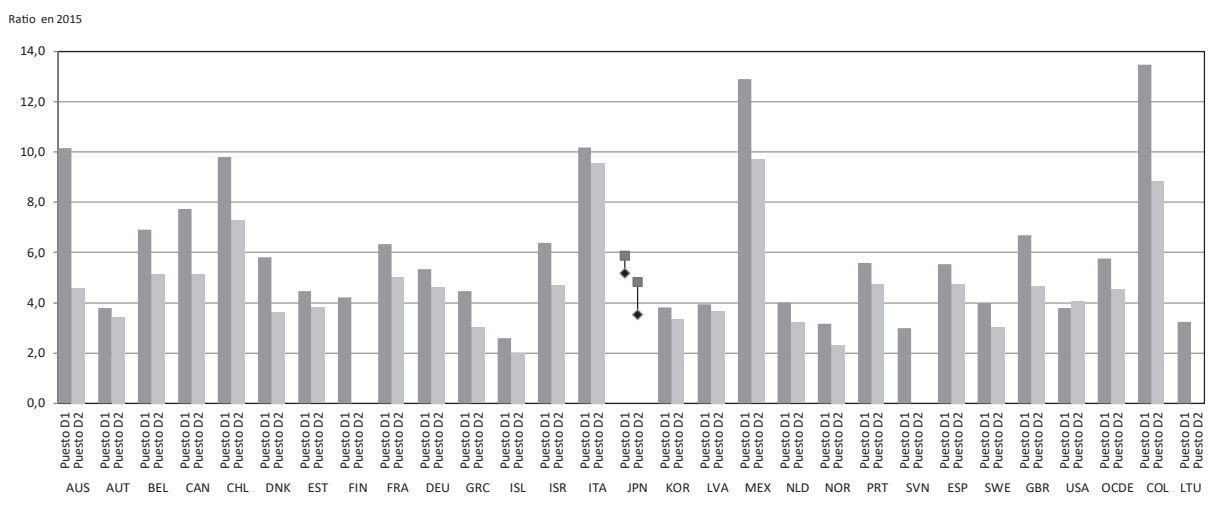

Fuentes: OCDE (2016), Encuesta sobre la remuneración de los empleados en las Administraciones centrales/federales; OCDE STAN / estadísticas de contabilidad nacional (base de datos).

$<$ http://dx.doi.org/10.1787/888933532314>

\section{REMUNERACIÓN DE CARGOS INTERMEDIOS}

Los cargos intermedios juegan un papel clave en la jerarquía de la fuerza de trabajo, traduciendo la visión estratégica de sus superiores en acciones concretas que son implementadas por los empleados públicos a su cargo. Por tanto, los cargos intermedios influyen de manera directa en el clima de trabajo, en la efectividad de los sistemas y reformas de la gestión pública y, en última instancia, en la capacidad organizativa de ofrecer resultados a los ciudadanos.

La cantidad y estructura de la remuneración de los cargos intermedios puede estar relacionada con factores políticos e históricos, así como con los procesos de determinación del salario base y sus aumentos. Por ejemplo, algunos países establecen los salarios base mediante decretos gubernamentales, basados en cálculos relacionados con el desarrollo de los mercados laboral y económico (es decir, la inflación), mientras que en otros países el salario base de los cargos intermedios se establece a través de negociaciones colectivas con los sindicatos. Los países también difieren en cuanto al consenso político sobre cómo financiar el sistema de la seguridad social y los tipos de beneficios que se proporcionan. En algunos países, la cantidad de cotizaciones sociales que se pagan es más elevada, mientras que en otros países el número de días de vacaciones es mayor. En Francia, Grecia y Suecia los empleadores pagan la mayor proporción de cotizaciones sociales en relación con la remuneración total. Esta proporción es más baja en Chile, Corea y México. 
En los países de la OCDE, la remuneración media de los mandos intermedios de nivel D3 asciende a 134522 USD PPA, incluyendo las cotizaciones sociales del empleador (24209 USD PPA) y la corrección del tiempo de trabajo (18416 USD PPA). La remuneración total de los mandos intermedios D4 alcanza los 112114 USD PPA. Las diferencias entre países son menores en la remuneración de cargos intermedios que en la de altos funcionarios. Al mismo tiempo, los gestores D3 ganan de media un $20 \%$ más que los gestores D4; de ahí que la diferencia de remuneración entre los cargos intermedios sea menor que la diferencia entre los funcionarios superiores (los gestores D1 ganan un $27 \%$ más que los gestores D2). Hay una brecha considerable entre las retribuciones de los altos cargos y las de los cargos intermedios. Los puestos superiores D1 ganan un $72 \%$ más que los puestos intermedios D3, y más del doble que los gestores D4. La diferencia entre los niveles de remuneración de puestos D1 y D4 es mayor en Australia, Chile, Canadá y el Reino Unido.

La corrección de datos por PIB per cápita permite tener en cuenta los niveles heterogéneos de desarrollo y el ingreso promedio de los países. Los cargos intermedios en México y Colombia perciben la mayor remuneración corregida por PIB per cápita, mientras que en Noruega perciben la menor.

\section{Metodología y definiciones}

Los datos corresponden a 2015 y se recopilaron mediante la Encuesta de la OCDE sobre la remuneración de los empleados en las Administraciones centrales/federales de 2016. Los funcionarios de los ministerios y organismos centrales respondieron a través de la Red de Empleo y Gestión Públicos de la OCDE.

Los datos corresponden a seis ministerios/departamentos de la Administración central (Interior, Hacienda, Justicia, Educación, Sanidad y Medio Ambiente, o sus equivalentes). La clasificación y definición de las ocupaciones son una adaptación de los códigos CIUO-08 desarrollados por la Organización Internacional del Trabajo (OIT). Los niveles de remuneración son el promedio de la retribución del personal existente.

La remuneración total incluye sueldos y salarios, y las cotizaciones sociales de los empleadores, tanto financiadas como no financiadas. Las cotizaciones sociales se limitan a los sistemas sanitario y de pensiones para presentar datos consistentes de los países.

La remuneración se convirtió a USD utilizando las paridades de poder adquisitivo (PPA) para el consumo privado de la base de datos de las estadísticas de contabilidad nacional de la OCDE. Los datos no se ajustan al número de horas trabajadas por semana, puesto que se espera que 
los gestores, de manera formal o informal, trabajen más horas, sino que están ajustados al promedio de días de vacaciones.

La comparación con los resultados de recopilaciones de datos previos se ve limitada debido a pequeños cambios de metodología. Para más información sobre la metodología, véase el anexo D.

\section{Otras publicaciones}

OECD (2016), Engaging public employees for a high-performing civil service, OECD Public Governance Reviews, OECD, París.

OECD (2012), Public sector compensation in times of austerity, OECD, París.

\section{Notas de los gráficos}

Los datos de Hungría, Irlanda, Islandia, Israel, Luxemburgo, Nueva Zelanda, Polonia, la República Checa, la República Eslovaca, Suiza y Turquía no están disponibles.

Los datos de remuneración de los cargos D4 están mezclados con los de los cargos D3 en el caso de Estonia, Finlandia, Italia y la República de Eslovenia. Alemania: los datos se basan en estimaciones de acuerdo con la escala salarial y no en las remuneraciones reales. Australia: no se incluye el Ministerio del Interior. Bélgica: no se incluyen los ministerios de Educación y Medio Ambiente puesto que no pertenecen a la autoridad federal. Corea: los datos no incluyen las asignaciones fijas en concepto de dietas y categoría de trabajo que se proporcionan en todos estos puestos; la retribución por vacaciones no utilizadas tampoco se incluye. Estonia: los datos del Ministerio de Medio Ambiente no están disponibles. Francia: los datos corresponden a 2014 (utilizando las PPA de 2014). Islandia: el Ministerio de Justicia pertenece al Ministerio del Interior. Japón: los datos se proporcionan en términos de entrada y nivel máximo de remuneración; la media aritmética se ha tenido en cuenta y ha sido incluida en el promedio de la OCDE. Noruega: no se incluye a los empleados no cubiertos por el convenio colectivo básico de la función pública. Paises Bajos: se incluye a todos los empleados de la Administración central. Suecia: el Ministerio del Interior no existe y, por tanto, no se incluye en los datos. 
Gráfico 3.18. Remuneración media anual de los cargos intermedios de la Administración central, 2015 (Ajustado a las diferencias de vacaciones)

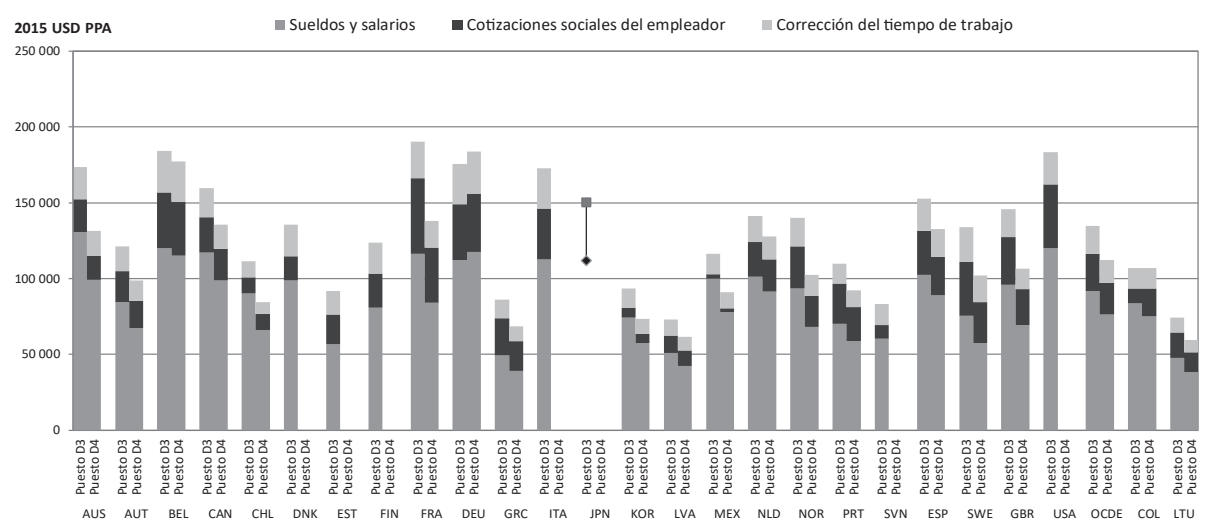

Fuentes: OCDE (2016), Encuesta sobre la remuneración de los empleados en las Administraciones centrales/federales; OCDE STAN / estadísticas de contabilidad nacional (base de datos).

\section{Gráfico 3.19. Remuneración media anual de los cargos intermedios de la Administración central en relación con el PIB per cápita}

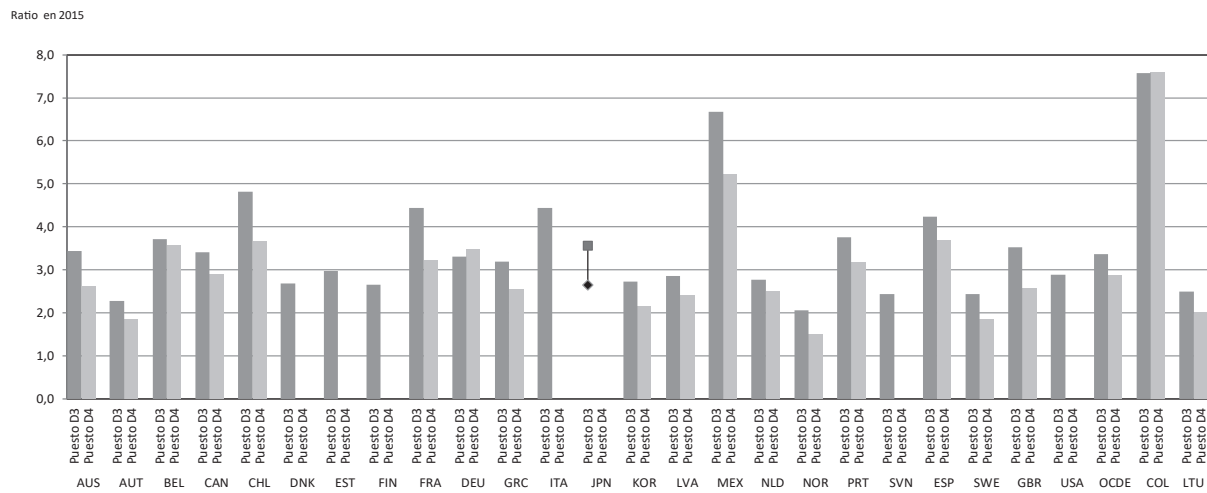

Fuentes: OCDE (2016), Encuesta sobre la remuneración de los empleados en las Administraciones centrales/federales; OCDE STAN / estadísticas de contabilidad nacional (base de datos).

<http://dx.doi.org/10.1787/888933532352> 


\section{REMUNERACIÓN DE PROFESIONALES DE LA ADMINISTRACIÓN CENTRAL}

Los profesionales del sector público, como los analistas políticos, proporcionan habilidades esenciales para llevar a cabo el análisis basado en evidencias que se requiere con el fin de desarrollar políticas efectivas y programas que responden a las necesidades y expectativas de los ciudadanos. El nivel de remuneración de los puestos profesionales refleja el grado en que las Administraciones valoran y retribuyen sus capacidades. Algunos profesionales ofrecen destrezas y competencias que son apreciadas tanto por el sector público como por el privado; por tanto, el nivel de remuneración puede ser un indicador de la capacidad de competir por talento de las Administraciones públicas. La retención por parte de las Administraciones de este tipo de empleados es esencial para mejorar la elaboración de políticas públicas y la prestación de servicios. Las diferencias entre los niveles de remuneración de los países pueden ser resultado de varios factores que no se pueden medir, como diferencias de los requisitos de cualificación y la representación de género en estas profesiones, así como diferencias de ubicación de los lugares de trabajo.

En promedio, la remuneración de los profesionales seniors asciende a 88667 USD PPA en los países de la OCDE, incluyendo 16103 USD PPA en concepto de cotizaciones del empleador y 15461 USD PPA por corrección del tiempo de trabajo. La remuneración media de los profesionales juniors se establece en 68453 USD PPA. Por consiguiente, los profesionales juniors ganan un $23 \%$ menos que los profesionales seniors. Esta diferencia se debe principalmente a factores relacionados con la antigüedad y la experiencia. La diferencia de remuneración entre los dos niveles es mayor en Chile, Dinamarca, México y Colombia, y menor en Corea.

Los altos funcionarios D1 ganan de media 2,6 veces más que los profesionales seniors. Esto sugiere que las responsabilidades de gestión se recompensan significativamente más que la especialización técnica. Las diferencias retributivas entre los funcionarios superiores D1 y los profesionales seniors son mayores en Italia, México y el Reino Unido, y menores en Islandia, los Países Bajos y la República de Eslovenia. Cuando los sueldos son corregidos por el PIB per cápita, los resultados muestran que los profesionales perciben una mayor remuneración en Chile y Colombia, y una menor en Lituania y Noruega. 


\section{Metodología y definiciones}

Los datos corresponden a 2015 y se recopilaron mediante la Encuesta de la OCDE sobre la remuneración de los empleados en las Administraciones centrales/federales de 2016. Los funcionarios de los ministerios y organismos centrales respondieron a través de la Red de Empleo y Gestión Públicos de la OCDE.

Los datos corresponden a seis ministerios/departamentos de la Administración central (Interior, Hacienda, Justicia, Educación, Sanidad y Medio Ambiente, o sus equivalentes). La clasificación y definición de las ocupaciones son una adaptación de los códigos CIUO-08 desarrollados por la Organización Internacional del Trabajo (OIT). Los niveles de remuneración son el promedio de la retribución del personal existente.

La remuneración total incluye sueldos y salarios, y las cotizaciones sociales de los empleadores, tanto financiadas como no financiadas. Las cotizaciones sociales se limitan a los sistemas sanitario y de pensiones para presentar datos consistentes de los países.

La remuneración se convirtió a USD utilizando las paridades de poder adquisitivo (PPA) para el consumo privado de la base de datos de las estadísticas de contabilidad nacional de la OCDE. Los ajustes por el tiempo de trabajo compensan las diferencias del tiempo trabajado, y tienen en cuenta tanto la media de horas laborales como la media de días de vacaciones.

La comparación con los resultados de recopilaciones de datos previos se ve limitada debido a pequeños cambios de metodología. Para más información sobre la metodología, véase el anexo D.

\section{Otras publicaciones}

OECD (2012), Public sector compensation in times of austerity, OECD, París. 


\section{Notas de los gráficos}

Los datos de Australia, Los Estados Unidos, Irlanda, Israel, Japón, Luxemburgo, Nueva Zelanda, Polonia, la República Checa, la República Eslovaca, Suiza y Turquía no están disponibles.

Los profesionales seniors y juniors están mezclados en los datos de Austria, España, Estonia, Islandia, Italia y Portugal. Alemania: los datos se basan en estimaciones de acuerdo con la escala salarial y no en las remuneraciones reales. Australia: no se incluye el Ministerio del Interior. Bélgica: no se incluyen los ministerios de Educación y Medio Ambiente puesto que no pertenecen a la autoridad federal. Corea: los datos no incluyen las asignaciones fijas en concepto de dietas y categoría de trabajo que se proporcionan en todos estos puestos; la retribución por vacaciones no utilizadas tampoco se incluye. Estonia: los datos del Ministerio de Medio Ambiente no están disponibles. Francia: los datos corresponden a 2014 (utilizando las PPA de 2014). Islandia: el Ministerio de Justicia pertenece al Ministerio del Interior. Italia: el número de empleados incluye empleados a tiempo parcial, no solo empleados a tiempo completo. Noruega: no se incluye a los empleados no cubiertos por el convenio colectivo básico de la función pública. Paises Bajos: se incluye a todos los empleados de la Administración central. Suecia: el Ministerio del Interior no existe y, por tanto, no se incluye en los datos.

\section{Gráfico 3.20. Remuneración media anual de profesionales seniors y juniors de la Administración central, 2015 (Ajustado a las diferencias de horario laboral y vacaciones)}

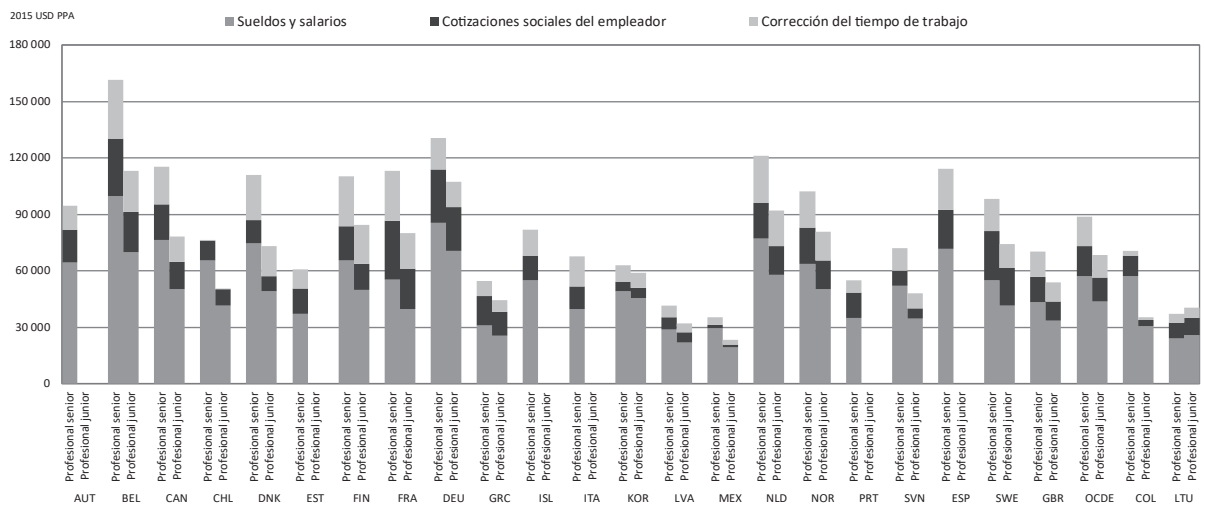

Fuentes: OCDE (2016), Encuesta sobre la remuneración de los empleados en las Administraciones centrales/federales; OCDE STAN / estadísticas de contabilidad nacional (base de datos). 
Gráfico 3.21. Remuneración media anual de profesionales seniors y juniors de la Administración central en relación con el PIB per cápita

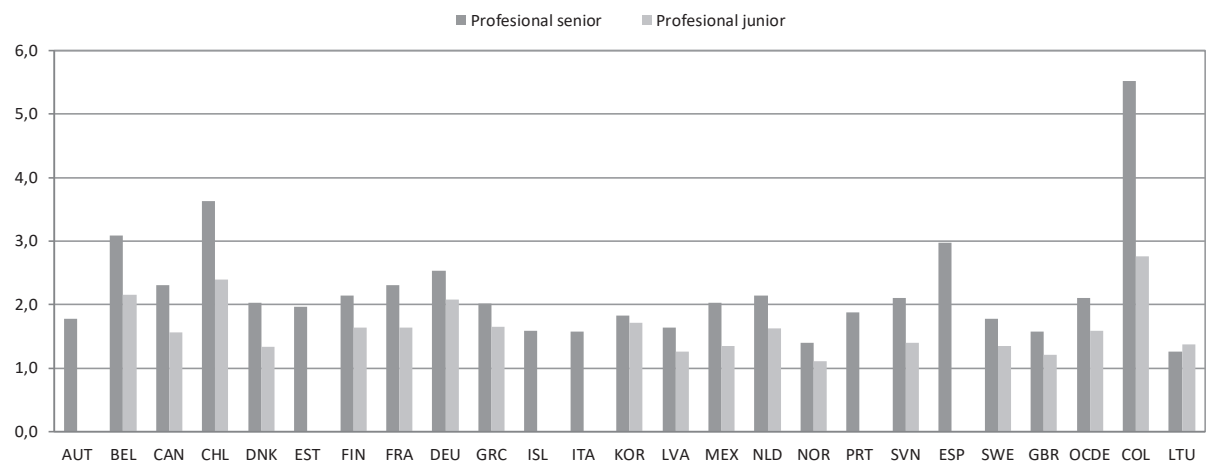

Fuentes: OCDE (2016), Encuesta sobre la remuneración de los empleados en las Administraciones centrales/federales; OCDE STAN / estadísticas de contabilidad nacional (base de datos).

$<$ http://dx.doi.org/10.1787/888933532390>

\section{REMUNERACIÓN DE LOS PUESTOS DE SECRETARIADO}

Los puestos de secretariado representan el nivel más bajo de la jerarquía de profesionales para los que la OCDE recoge datos de remuneración. En general, estos puestos requieren un nivel de competencia menor, menos formación, y a menudo los ocupan mujeres. En promedio, la remuneración de secretarios asciende a 52748 USD PPA, incluyendo 9823 USD PPA en concepto de cotizaciones del empleador y 9445 USD PPA por corrección del tiempo de trabajo. Las cotizaciones sociales del empleador y la corrección del tiempo de trabajo suponen, cada una, alrededor del $18 \%$ de la remuneración total. La remuneración puede variar en función de las condiciones laborales y el ámbito local, y también del horario laboral. Los datos mostrados han sido ajustados a las diferencias de horario laboral y vacaciones. El número de horas de trabajo es mayor en Chile.

En comparación con las otras categorías ocupacionales analizadas, en el caso de los puestos de secretariado los niveles de cotizaciones sociales de los empleadores son muy diversos en los países de la OCDE. Estas diferencias pueden explicarse por variables culturales y políticas, y por preferencias nacionales sobre la cuantía de prestaciones sociales establecida y la manera de financiar el sistema de la seguridad social. Las cotizaciones sociales se pueden considerar como sueldos diferidos (pensiones) y planes de seguros (sanidad) apoyados en la organización colectiva. Para contabilizar la cantidad total de cotizaciones a los sistemas de la seguridad social, se necesita sumar las cotizaciones sociales de los empleadores incluidas en el sueldo bruto. Por otro 
lado, la cantidad de cotizaciones sociales no necesariamente refleja la calidad del sistema de la seguridad social. En lo que respecta a otras ocupaciones, la proporción de cotizaciones sociales del empleador es muy baja en México y Colombia, y especialmente alta en Francia y Suecia. Cuando los sueldos son corregidos por el PIB per cápita, los resultados muestran que la remuneración de secretarios es mayor en Grecia y Colombia, mientras que es menor en la Islandia y la República de Eslovenia.

Los sueldos relativos son un componente importante del bienestar y motivación de los trabajadores. Son clave para la percepción de imparcialidad y, consecuentemente, influyen en la motivación. La distribución salarial dentro de la fuerza de trabajo repercute en la desigualdad social y en la confianza en las Administraciones. Los secretarios ganan de media cuatro veces menos que los altos funcionarios (D1). Esta brecha salarial es más pronunciada en Australia, Chile, México y Colombia, donde los altos cargos ganan por encima de ocho veces más que los secretarios, y menor en Finlandia, Grecia, Islandia, Noruega y los Países Bajos, donde los funcionarios superiores ganan por debajo de tres veces y media lo que ganan los secretarios.

\section{Metodología y definiciones}

Los datos corresponden a 2015 y se recopilaron mediante la Encuesta de la OCDE sobre la remuneración de los empleados en las Administraciones centrales/federales de 2016. Los funcionarios de los ministerios y organismos centrales respondieron a través de la Red de Empleo y Gestión Públicos de la OCDE.

Los datos corresponden a seis ministerios/departamentos de la Administración central (Interior, Hacienda, Justicia, Educación, Sanidad y Medio Ambiente, o sus equivalentes). La clasificación y definición de las ocupaciones son una adaptación de los códigos CIUO-08 desarrollados por la Organización Internacional del Trabajo (OIT). Los niveles de remuneración son el promedio de la retribución del personal existente.

La remuneración total incluye sueldos y salarios, y las cotizaciones sociales de los empleadores, tanto financiadas como no financiadas. Las cotizaciones sociales se limitan a los sistemas sanitario y de pensiones para presentar datos consistentes de los países. 
La remuneración se convirtió a USD utilizando las paridades de poder adquisitivo (PPA) para el consumo privado de la base de datos de las estadísticas de contabilidad nacional de la OCDE. Los ajustes por el tiempo de trabajo compensan las diferencias del tiempo trabajado, y tienen en cuenta tanto la media de horas laborales como la media de días de vacaciones.

La comparación con los resultados de recopilaciones de datos previos se ve limitada debido a pequeños cambios de metodología. Para más información sobre la metodología, véase el anexo D.

\section{Otras publicaciones}

OECD (2012), Public sector compensation in times of austerity, OECD, París.

\section{Notas de los gráficos}

Los datos de los Estados Unidos, Estonia, Hungría, Irlanda, Israel, Japón, Letonia, Luxemburgo, Nueva Zelanda, la República Checa, la República Eslovaca, Suiza y Turquía no están disponibles.

Alemania: los datos se basan en estimaciones de acuerdo con la escala salarial y no en las remuneraciones reales. Australia: no se incluye el Ministerio del Interior. Bélgica: no se incluyen los ministerios de Educación y Medio Ambiente puesto que no pertenecen a la autoridad federal. Corea: los datos no incluyen las asignaciones fijas en concepto de dietas y categoría de trabajo que se proporcionan en todos estos puestos; la retribución por vacaciones no utilizadas tampoco se incluye. Francia: los datos corresponden a 2014 (utilizando las PPA de 2014). Grecia: los puestos de secretariado pueden incluir ocupaciones realizadas por otros profesionales. Islandia: el Ministerio de Justicia pertenece al Ministerio del Interior. Italia: el número de empleados incluye empleados a tiempo parcial, no solo empleados a tiempo completo. Noruega: no se incluye a los empleados no cubiertos por el convenio colectivo básico de la función pública. Países Bajos: se incluye a todos los empleados de la Administración central. Suecia: el Ministerio del Interior no existe y, por tanto, no se incluye en los datos. 
Gráfico 3.22. Remuneración media anual de empleados en puestos de secretariado, 2015 (Ajustado a las diferencias de horario laboral y vacaciones)

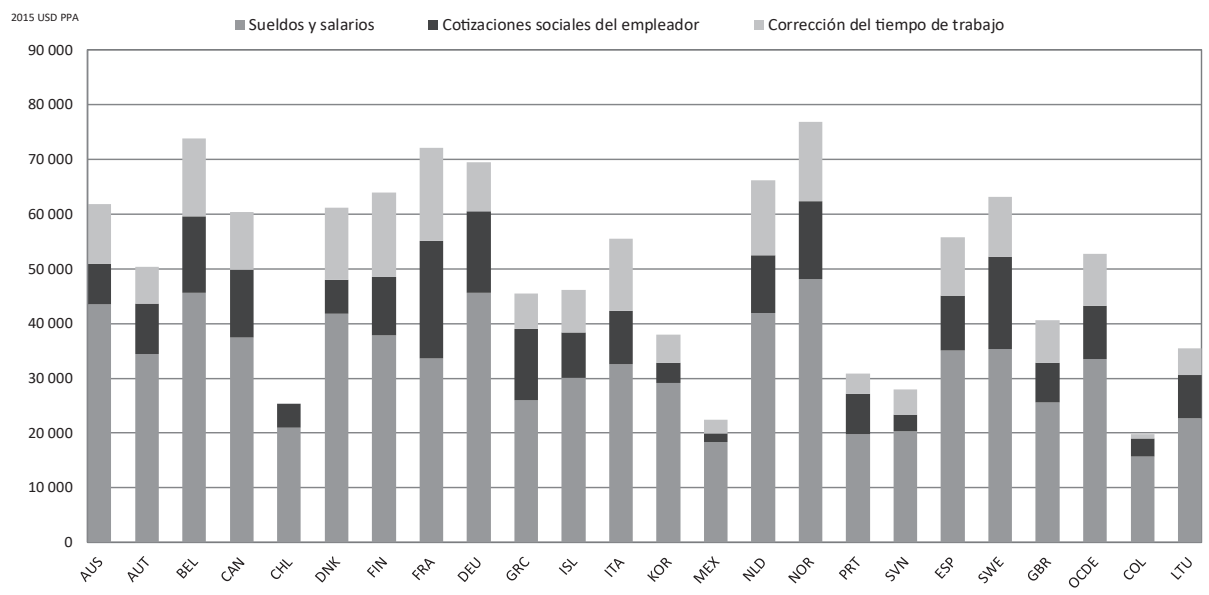

Fuentes: OCDE (2016), Encuesta sobre la remuneración de los empleados en las Administraciones centrales/federales; OCDE STAN / estadísticas de contabilidad nacional (base de datos).

$<$ http://dx.doi.org/10.1787/888933532409>

\section{Gráfico 3.23. Remuneración media anual de empleados en puestos de secretariado en relación con el PIB per cápita}

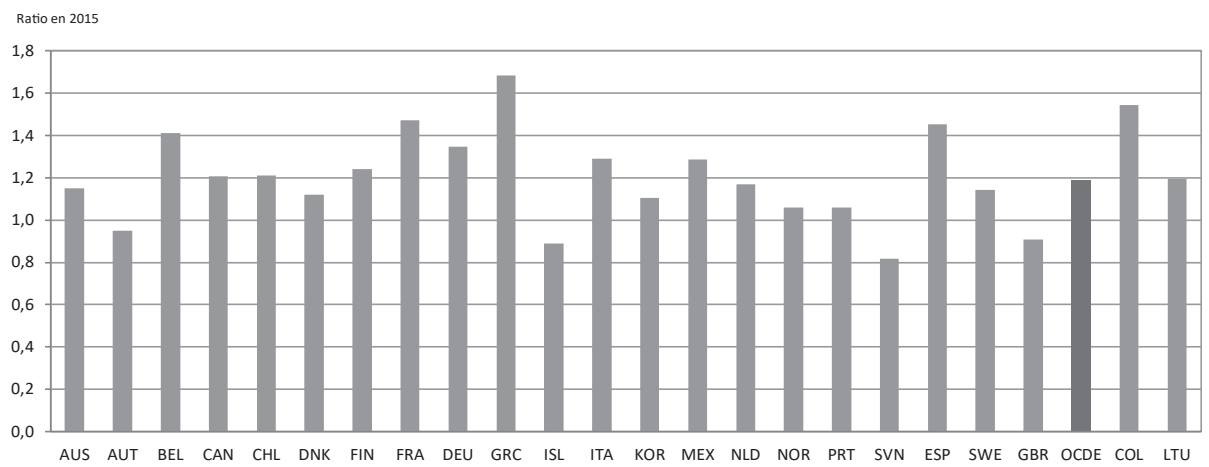

Fuentes: OCDE (2016), Encuesta sobre la remuneración de los empleados en las Administraciones centrales/federales; OCDE STAN / estadísticas de contabilidad nacional (base de datos).

$<$ http://dx.doi.org/10.1787/888933532428> 


\section{REMUNERACIÓN DE OCUPACIONES SELECCIONADAS DEL SECTOR SERVICIOS}

Los funcionarios que trabajan de cara al público en la prestación de servicios son la imagen que tiene la mayoría de la gente de las Administraciones y, por tanto, su comportamiento y su competencia repercuten directamente en la percepción ciudadana de las instituciones públicas. Los agentes e inspectores de Policía interactúan con los usuarios en la coproducción de unos servicios públicos eficientes y efectivos. Consecuentemente, su compromiso y motivación son esenciales para potenciar tanto la calidad de la prestación de los servicios públicos como la confianza de los empleados públicos y usuarios en sus Administraciones.

Se incluyen datos de las ocupaciones relacionadas con el orden público y la administración tributaria, concretamente: inspectores e investigadores de Policía, agentes de Policía, funcionarios de inmigración, inspectores de aduanas e inspectores de Hacienda. Aunque estas ocupaciones existen en todos los países, sus funciones pueden, en algunos casos, llevarse a cabo por las Administraciones subcentrales para las que no se recopilan datos.

La remuneración de los inspectores de Policía asciende de media a 81952 USD PPA en los países de la OCDE. Un inspector de Policía gana en promedio un $26,5 \%$ más que un agente de Policía. Esto refleja la compensación por el mayor grado de responsabilidades. En Australia, España y Francia la brecha entre la remuneración de los inspectores de Policía y los agentes de Policía es mayor. Por el contrario, en Estonia e Islandia, los agentes e inspectores de Policía ganan prácticamente lo mismo.

Las diferencias entre los niveles de remuneración de las cinco ocupaciones son relativamente pequeñas, lo cual podría indicar que los requisitos de estos trabajos son en gran medida similares. La remuneración de una ocupación especializada en relación con la de una ocupación general supone un indicador del atractivo relativo de las ocupaciones especializadas. Estas profesiones pueden, además, mostrarse propensas a la corrupción menor. Por consiguiente, el pago adecuado de la Policía podría reducir su incidencia. Los inspectores de Hacienda ganan de media un 19\% menos que los inspectores de Policía y solo un $2 \%$ más que los agentes de Policía. La brecha entre los inspectores de Hacienda y los agentes de Policía es mayor en Australia, Francia e Islandia, donde los inspectores de Policía ganan por encima del 30\% más que los inspectores de Hacienda. La brecha entre los inspectores de Hacienda y los agentes de Policía es más pronunciada en España, Portugal y la República de Eslovenia. Los inspectores de Policía ganan una media del 33\% más que los inspectores de aduanas. Esta brecha es mayor en Australia y Noruega y menor en Corea, Portugal y Suecia. En promedio, en los países de la OCDE, los funcionarios de inmigración ganan solo un $5 \%$ menos que los agentes de Policía. En España, Letonia y Portugal la remuneración de los funcionarios de inmi- 
gración es mayor que la de los agentes de Policía, mientras que es menor en Australia, Grecia y el Reino Unido.

Cuando los datos son corregidos por el PIB per cápita, Chile y Portugal pagan las remuneraciones más altas en algunas de estas cinco ocupaciones. Por el contrario, en Letonia y Lituania las remuneraciones de varias de estas ocupaciones seleccionadas registraron sus menores cuantías.

\section{Metodología y definiciones}

Los datos corresponden a 2015 y se recopilaron mediante la Encuesta de la OCDE sobre la remuneración de los empleados en las Administraciones centrales/federales de 2016. Los funcionarios de los ministerios y organismos centrales respondieron a través de la Red de Empleo y Gestión Públicos de la OCDE.

Los datos corresponden a funcionarios específicos que trabajan de cara al público en la prestación de servicios (inspectores e investigadores de Policía, agentes de Policía, funcionarios de inmigración, inspectores de aduanas e inspectores de Hacienda). La clasificación y definición de las ocupaciones son una adaptación de los códigos CIUO-08 desarrollados por la Organización Internacional del Trabajo (OIT). Aunque todos los países tienen empleados a cargo de estas tareas, en algunos países las funciones específicas no se pueden distinguir.

La remuneración total comprende los sueldos y salarios base, las cotizaciones sociales de los empleadores, financiadas y no financiadas, incluyendo los pagos de pensiones abonados a través del presupuesto del Estado, en lugar de por las cotizaciones sociales del empleador (principalmente en el caso de sistemas de reparto). Las cotizaciones sociales se limitan a los sistemas sanitario y de pensiones para presentar datos consistentes de los países.

La remuneración se convirtió a USD utilizando las paridades de poder adquisitivo (PPA) para el consumo privado de la base de datos de las estadísticas de contabilidad nacional de la OCDE. Los ajustes por el tiempo de trabajo compensan las diferencias del tiempo trabajado, y tienen en cuenta tanto la media de horas laborales como la media de días de vacaciones. 
La comparación con los resultados de recopilaciones de datos previos se ve limitada debido a pequeños cambios de metodología. Para más información sobre la metodología, véase el anexo D.

\section{Otras publicaciones}

OECD (2012), Public sector compensation in times of austerity, OECD, París.

\section{Notas de los gráficos}

Los datos de Alemania, los Estados Unidos, Hungría, Irlanda, Israel, Japón, Luxemburgo, México, Nueva Zelanda, los Países Bajos, Polonia, la República Checa, la República Eslovaca, Suiza y Turquía no están disponibles.

Los funcionarios de inmigración se incluyen como agentes de Policía en el caso de Austria, Dinamarca, Islandia e Italia. Los inspectores e investigadores de Policía y los agentes de Policía están mezclados en los datos de Corea y la República de Eslovenia. Los inspectores e investigadores de Policía se incluyen como agentes de Policía y funcionarios de inmigración en el caso de Grecia.

Corea: los datos no incluyen las asignaciones fijas en concepto de dietas y categoría de trabajo que se proporcionan en todos estos puestos; la retribución por vacaciones no utilizadas tampoco se incluye. Francia: los datos corresponden a 2014 (utilizando las PPA de 2014). Italia: el número de empleados incluye empleados a tiempo parcial, no solo empleados a tiempo completo. Noruega: no se incluye a los empleados no cubiertos por el convenio colectivo básico de la función pública.

3.24. Los inspectores de aduanas se incluyen como funcionarios de inmigración en el caso de Canadá.

3.25. Los datos de Canadá y Chile no están disponibles.

3.26. Los datos de Dinamarca no están disponibles. Los inspectores de aduanas se incluyen como funcionarios de inmigración en el caso de Canadá. 
Gráfico 3.24. Remuneración media anual de empleados en ocupaciones de servicios seleccionadas, 2015 (Ajustado a las diferencias de horario laboral y vacaciones)

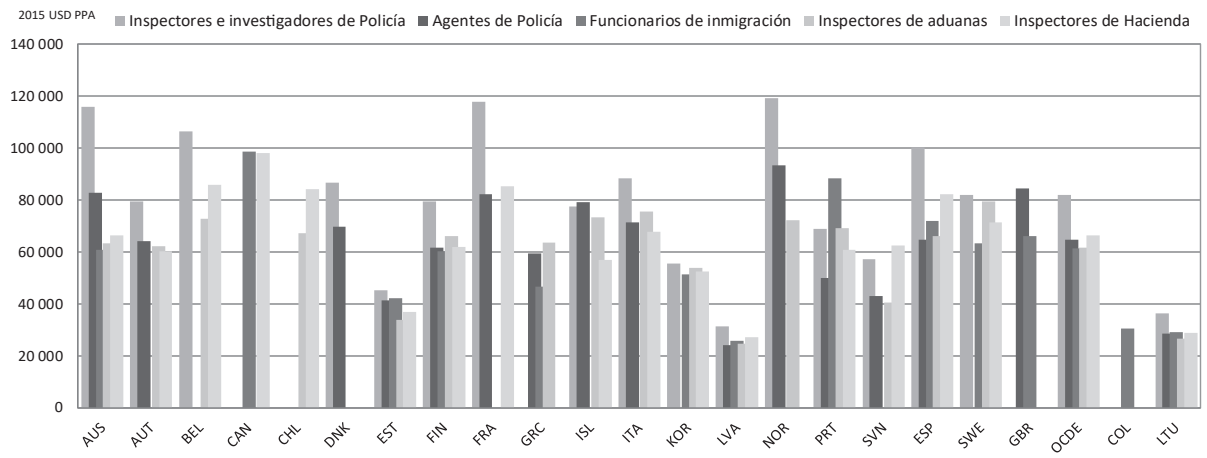

Fuentes: OCDE (2016), Encuesta sobre la remuneración de los empleados en las Administraciones centrales/federales; OCDE STAN / estadísticas de contabilidad nacional (base de datos).

$<$ http://dx.doi.org/10.1787/888933532447>

Gráfico 3.25. Remuneración media anual de los inspectores, investigadores y agentes de Policía de la Administración central en relación con el PIB per cápita

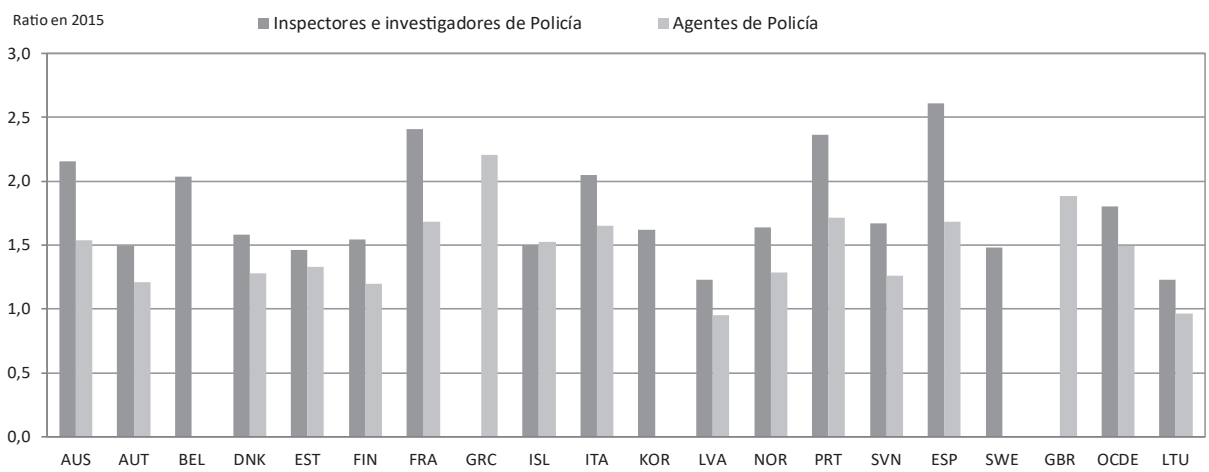

Fuentes: OCDE (2016), Encuesta sobre la remuneración de los empleados en las Administraciones centrales/federales; OCDE STAN / estadísticas de contabilidad nacional (base de datos).

$<$ http://dx.doi.org/10.1787/888933532466> 
Gráfico 3.26. Remuneración media anual de los funcionarios de inmigración e inspectores de aduanas y Hacienda en relación con el PIB per cápita

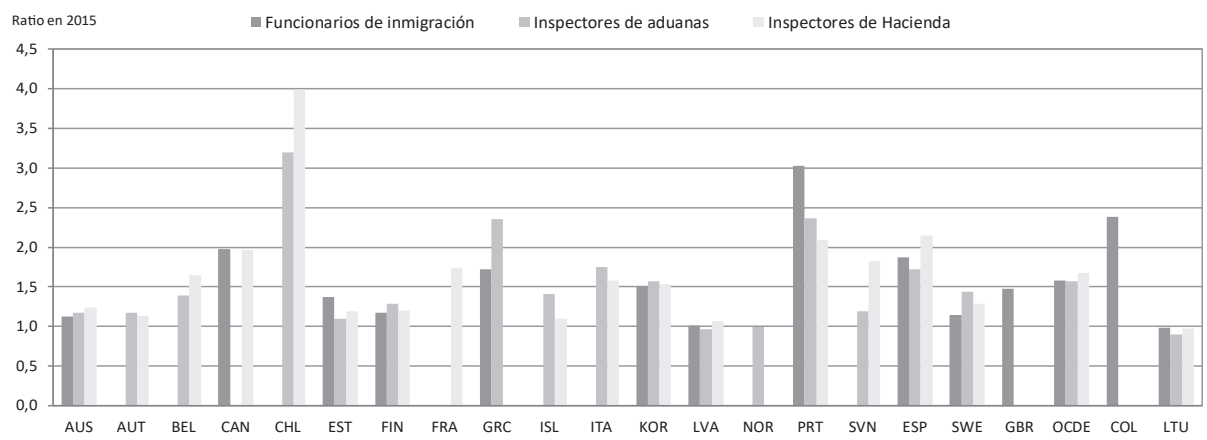

Fuentes: OCDE (2016), Encuesta sobre la remuneración de los empleados en las Administraciones centrales/federales; OCDE STAN / estadísticas de contabilidad nacional (base de datos).

$<$ http://dx.doi.org/10.1787/888933532485>

\section{SUELDOS DE MAESTROS Y PROFESORES}

Los salarios de los maestros y profesores representan la mayor partida de gasto e inversión en educación reglada y pueden tener un gran impacto en la estructura del profesorado y en la calidad de la enseñanza. El sector educativo compite con otros sectores en la contratación del personal mejor cualificado. El salario de los maestros y profesores puede influir notablemente en la elección de la profesión docente por parte de los licenciados, y en la decisión de los docentes de continuar en el sector. Por tanto, una estructura de salarios atractiva ayudaría a cubrir las crecientes necesidades de docentes cualificados derivada del envejecimiento del profesorado o del crecimiento de la población en edad escolar, asegurando así que aquellos con las mejores condiciones para la enseñanza elijen su carrera profesional adecuadamente (OCDE, 2016).

A efectos de hacer una comparación de salarios del profesorado, el análisis debe tener en cuenta el tipo y nivel de educación, si es primaria, secundaria o bachillerato, en el que ejercen los docentes. Los datos comparan los salarios brutos iniciales, los de mitad de trayecto profesional y los máximos establecidos por ley, para profesores de educación secundaria con cualificaciones típicas en instituciones de educación públicas. La comparación incluye una advertencia en cuanto a que, a nivel internacional, debe tenerse en consideración que el salario es solo uno de los componentes, si bien importante, de la remuneración que perciben los profesores. Las diferencias entre países en cuanto a las prestaciones sociales, cotizaciones sociales de empleados y empleadores, e impuestos, así como en cuanto a bonificaciones y subsidios, pue- 
den producir variaciones en la retribución total. Asimismo, los salarios de los docentes tampoco se han ajustado a diferencias de horario laboral contratado $\mathrm{y}$ vacaciones, que pueden ser relevantes en comparaciones nacionales e internacionales. Aun así, esta información puede ser una indicación de las diferencias entre las ganancias derivadas del ejercicio de la enseñanza en los países de la OCDE.

El salario de los profesores aumenta con el nivel de experiencia. En promedio, en el año 2014 el salario anual establecido por ley en los países de la OCDE para profesores con 15 años de experiencia docente ascendió a 44407 USD. Existen grandes diferencias de salario entre los países: en Luxemburgo los profesores ganan alrededor de 113000 USD al año, mientras en Hungría, la República Checa y la República de Eslovenia ganan menos de 20000 USD. Los aumentos establecidos por ley para los docentes a lo largo de su trayectoria profesional también varían considerablemente. Mientras que la diferencia de salarios en la escala asciende a 58000 USD en Luxemburgo, el posible aumento de salario en Dinamarca, Noruega, la República Checa, la República de Eslovenia y Turquía está por debajo de 10000 USD.

En los países de la OCDE con datos disponibles, los profesores cobran de media un $91 \%$ del sueldo de los empleados con estudios superiores. En siete de los países de la OCDE, los salarios de los profesores son más elevados que los de empleados con estudios superiores, con México a la cabeza, donde los docentes ganan un $74 \%$ más. Los salarios de los profesores son prácticamente iguales a los de los empleados con estudios superiores en Alemania, Grecia y Suiza. Los salarios de los docentes son inferiores a la media de los salarios de los trabajadores con estudios superiores en 21 países de la OCDE. Por ejemplo, en la República de Eslovenia y la República Checa, los docentes cobran menos de la mitad del salario de un empleado con estudios superiores.

\section{Metodología y definiciones}

Los salarios establecidos por ley se refieren a los salarios planificados de acuerdo con las escalas de salarios oficiales. Se listan los salarios brutos (la suma total pagada por el empleador antes de impuestos), menos la cotización del empleador a la seguridad social (según las escalas de salarios existentes). Los datos corresponden a profesores a tiempo completo con las cualificaciones típicas al inicio de la carrera docente, tras 15 años de experiencia y al salario máximo anual (límite superior de la escala). Los salarios establecidos por ley listados en este indicador deben diferenciarse de los gastos reales en salarios de las Administraciones públicas y de los salarios medios de los profesores. Asimismo, este indicador no es directamente comparable con los datos de remuneración de empleados de las Administraciones centrales/federales presentados en este capítulo. 
Los salarios brutos de los docentes se convirtieron a USD utilizando las paridades de poder adquisitivo (PPA) para el consumo privado de la base de datos de las estadísticas de contabilidad nacional de la OCDE.

Las cualificaciones típicas de los profesores se refieren al nivel de cualificaciones que los docentes suelen tener (es decir, las cualificaciones que tienen la mayoría de docentes en un año determinado). Estas cualificaciones pueden incluir certificados y títulos obtenidos durante el ejercicio de la profesión docente que van más allá de las cualificaciones básicas. La definición varía de un país a otro. Para más información, véase el Cuadro D3.2 de Panorama de la Educación 2016.

El indicador del salario relativo se ha tomado de la tabla D3.2b de $\mathrm{Pa}$ norama de la Educación 2016 (online). Los salarios de los docentes referencian los salarios establecidos por ley a partir de 15 años de experiencia laboral. Los sueldos de trabajadores con estudios superiores son los sueldos medios anuales para empleados a tiempo completo, durante un año completo, con edades comprendidas entre 25 y 64 años, con niveles de educación CINE 5/6/7 u 8.

\section{Otras publicaciones}

OECD (2016), Education at a Glance 2016: OECD Indicators, OECD, París. DOI: <http://dx.doi.org/10.1787/eag-2016-en>.

\section{Notas de los gráficos}

Bélgica está presentada como Bélgica (Fr.) y Bélgica (Fl.). El Reino Unido está presentado como Inglaterra y Escocia. Los datos presentan sueldos base reales para EE. UU.

3.27: Los datos de Estonia, Islandia y Letonia, y de los salarios después de 15 años de experiencia en Suiza, no están disponibles. En el caso de Suecia, los datos corresponden a salarios base reales de 2013.

3.28: Los datos de Estonia, Islandia, Japón, Letonia y Suecia no están disponibles. Los datos de Finlandia y Francia corresponden a 2013 en lugar de a 2014.

Información sobre los datos de Israel: <http:/dx.doi.org/10.1787/888932315602>. 
Gráfico 3.27. Salarios establecidos por ley, basados en las cualificaciones típicas, para profesores de educación secundaria en instituciones públicas (2014)

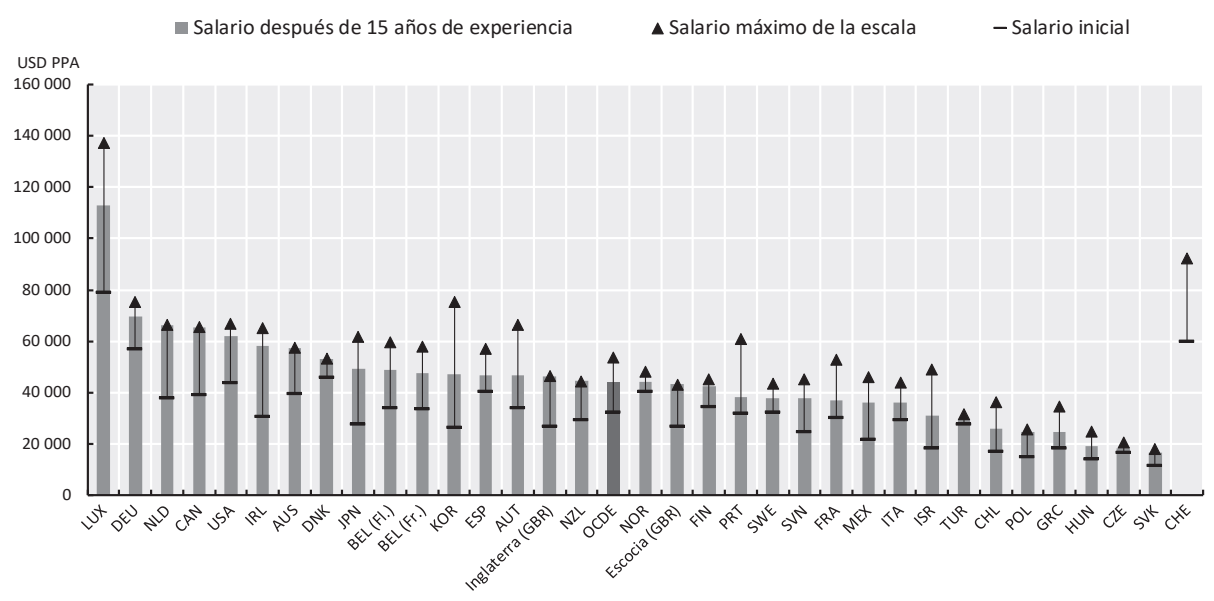

Fuente: OCDE (2016), Education at a Glance 2016: OECD Indicators, OECD Publishing, París. DOI: $<$ http://dx.doi.org/10.1787/eag-2016-en>.

$<$ http://dx.doi.org/10.1787/888933532504>

\section{Gráfico 3.28. Salario de profesores en relación con el salario de trabajadores con estudios superiores (2014)}

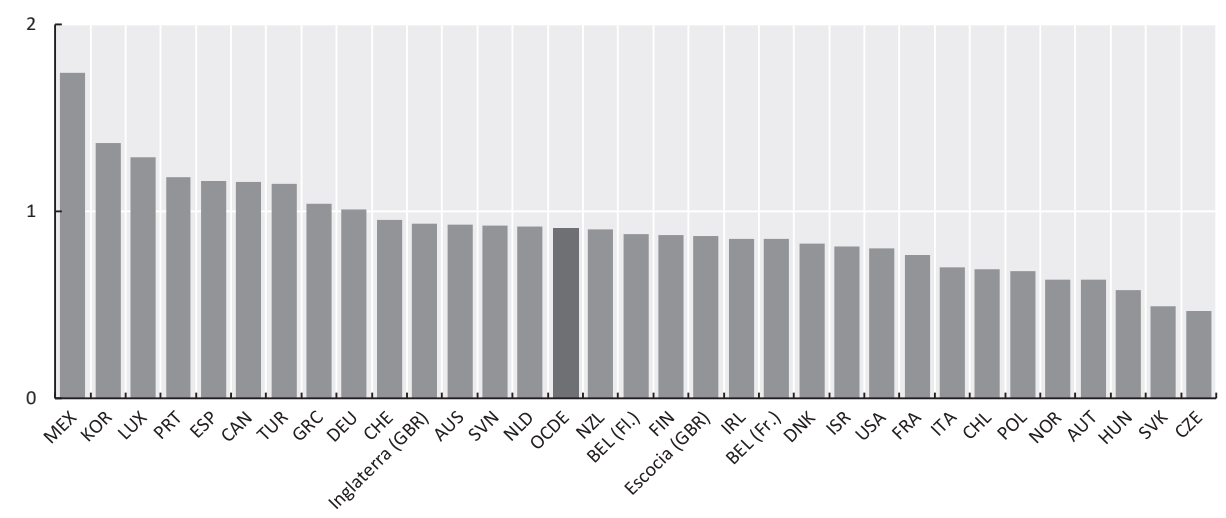

Fuente: OCDE (2016), Education at a Glance 2016: OECD Indicators, OECD Publishing, París. DOI: $<$ http://dx.doi.org/10.1787/eag-2016-en>. 


\section{CAPÍTULO 4. INSTITUCIONES}

\section{APARTADO ESPECIAL: INSTITUCIONES Y PRÁCTICAS PARA PROTEGER A LOS REGULADORES DE LA INFLUENCIA INDEBIDA}

Los reguladores garantizan el acceso a mercados y sectores clave que prestan servicios esenciales a los ciudadanos y empresas. Supervisan la calidad, facilitan la gestión de infraestructuras y fomentan la efectividad del mercado. De su trabajo depende también que los trenes sean puntuales, el agua del grifo salga limpia y funcione la luz o la banda ancha, ya que operan en el campo de intersección entre las autoridades públicas, el sector privado y los usuarios finales. Estas partes interesadas tienen potentes incentivos para influir en las políticas regulatorias. La cuestión fundamental es cómo limitar la influencia indebida, de manera que los reguladores puedan actuar de manera objetiva, imparcial y consistente, sin conflictos de intereses ni arbitrariedad.

Las disposiciones de gobernanza formales o de jure son importantes para proteger a los reguladores de la influencia indebida. Los datos sobre los reguladores de sectores de red se recopilaron en forma de indicador en la base de datos de la Regulación del Mercado de Productos (RMP) de la OCDE. El indicador refleja las estructuras formales que aíslan al regulador de la influencia indebida, incluyendo aspectos como que el regulador reciba o no instrucciones del poder ejecutivo, si su independencia está establecida por ley, qué organismos pueden revocar sus decisiones y cómo se contrata y despide al personal. Las puntuaciones van del 0 al 6 , de la estructura de gobernanza más independiente a la menos independiente. Los datos muestran que, aunque la mayoría de reguladores son formalmente independientes, existe cierto grado de variedad entre las organizaciones institucionales. A pesar de la independencia formal, es bastante común que las Administraciones públicas desempeñen una función correctiva o de comprobación, y que proporcionen orientación e instrucciones al regulador. Por ejemplo, la organización alemana Bundesnetzagentur muestra la mayor independencia dentro de los sectores de electricidad, gas y telecomunicaciones, solo recibe instrucciones de las Administraciones 
en circunstancias excepcionales y sus decisiones se pueden apelar en los tribunales exclusivamente en última instancia.

La manera en que las disposiciones formales se traducen a la práctica puede tener un impacto significativo en la independencia del regulador. Los datos de estas prácticas se reunieron mediante una encuesta que incluía aspectos organizativos, relacionales y contextuales que informan sobre el comportamiento real de los organismos reguladores. Los resultados muestran que hay momentos críticos en la vida de un regulador en los que la percepción de proximidad o dependencia podría perjudicar su capacidad de actuar de manera independiente. Uno de estos momentos críticos es el nombramiento del jefe del consejo u organismo. En la mayoría de los casos, el Ejecutivo es responsable de nombrar a los miembros del consejo. El nombramiento lo puede realizar el gabinete, el primer ministro o los ministros del sector. Solo en el caso de seis reguladores, como el regulador de telecomunicaciones mexicano, existe un comité de selección (completamente independiente, o compuesto por miembros del Gobierno e independientes) que propone candidatos para el consejo. El proceso de nombramiento parece más transparente. En el caso de nueve reguladores, como la Comisión Regulatoria de Energía en Francia, el candidato tiene que someterse a una audiencia parlamentaria y a la votación formal de las comisiones parlamentarias.

\section{Metodología y definiciones}

Los datos de la RMP sobre la independencia de los reguladores en seis sectores de red (electricidad, gas, telecomunicaciones, infraestructura de transporte ferroviario, aeropuertos y puertos) se recopilaron en 2013 mediante un cuestionario que incluía alrededor de 300 preguntas sobre las prácticas de gestión regulatoria. La cobertura de datos de estas preguntas es del $90 \%$ y en muchos países del $100 \%$. Hay países con una baja cobertura de datos — Japón (35\%), Luxemburgo (46\%) y Canadá (58\%) - normalmente porque las respuestas no incorporaban a todos los sectores. Se puede encontrar más información sobre la base de datos de la RMP en <www.oecd.org/eco/pmr $>$. 
Los datos sobre los aspectos prácticos de la independencia de los reguladores se reunieron en 2015 mediante un cuestionario sobre las disposiciones de facto. Los resultados presentados corresponden a 44 reguladores de 23 países, incluidos 19 de la OCDE (Alemania, Australia, Austria, Canadá, España, Estonia, Francia, Hungría, Irlanda, Italia, Letonia, México, Noruega, los Países Bajos, Portugal, el Reino Unido, Suecia, Suiza y Turquía), 3 en proceso de adhesión (Colombia, Lituania y Rusia) y Sudáfrica. Los servicios de red incluían los sectores de energía $(33 \%)$, transportes $(13 \%)$, comunicaciones $(15 \%)$, agua $(6 \%)$ y servicios de pago (2\%). Se puede encontrar más información sobre la encuesta en $<$ www.oecd.org/gov/regulatorypolicy/independence-of-regulators $>$.

\section{Otras publicaciones}

Koske, I., et al. (2016), «Regulatory management practices in OECD countries», OECD Economics Department Working Papers, n. ${ }^{\circ}$ 1296, OECD Publishing, París.

OECD (2016), Being an independent regulator, OECD Publishing, París.

OECD (2014), The governance of regulators, OECD Publishing, París.

\section{Notas de los gráficos}

4.1: Cuando faltan datos de un sector específico (debido a que el país no proporcionó datos o a que no existe regulador del sector), se utiliza el promedio del resto de países. No existe regulador económico en los casos siguientes: gas (Islandia), transporte ferroviario (Chile, Islandia, Nueva Zelanda), aeropuertos (Alemania, Japón), puertos (Alemania, Bélgica, Finlandia, Hungría, Irlanda, Japón, Noruega, Nueva Zelanda, Polonia, el Reino Unido, la República Checa, la República Eslovaca y Suecia). Los datos de Letonia y los Estados Unidos no están disponibles.

4.2: En el caso de 13 reguladores no existe información sobre las autoridades de selección.

Información sobre los datos de Israel: <http://dx.doi.org/10.1787/888932315602>. 


\section{Gráfico 4.1. Independencia de reguladores en seis sectores de red, 2013}

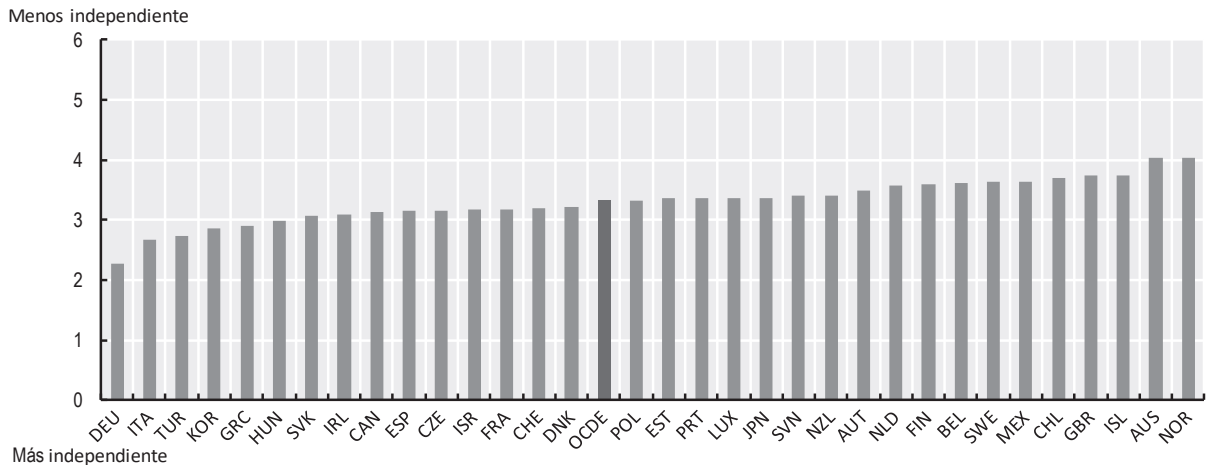

Fuente: OCDE (2013), Base de datos de la regulación del mercado de productos (RMP), OCDE, París, $<$ www.oecd.org/eco/pmr>.

\section{Gráfico 4.2. Autoridad que propone candidatos para la comisión/jefe del regulador, 2015}

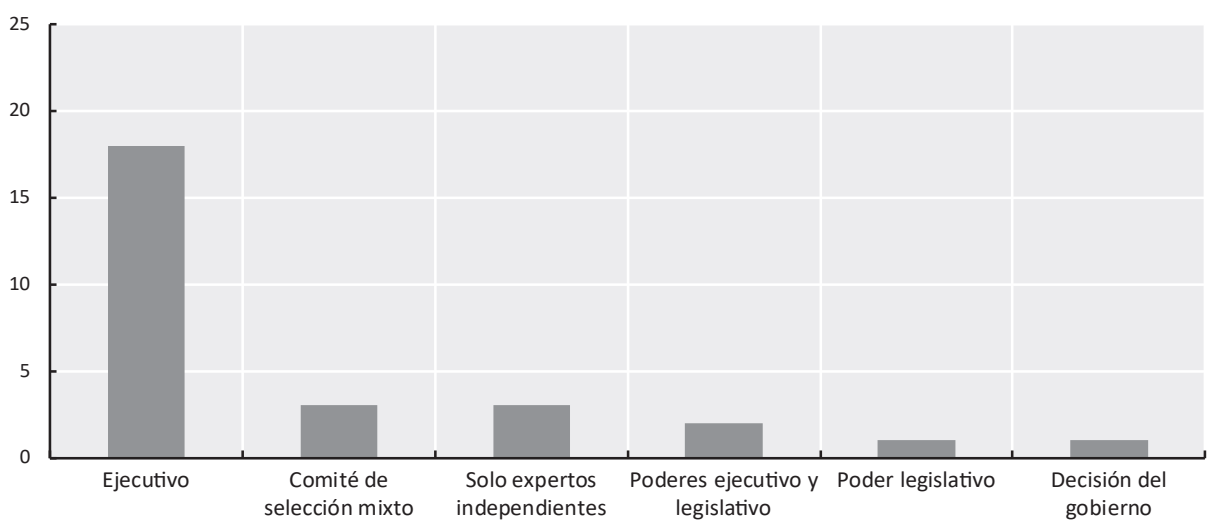

Fuente: OCDE (2015), Encuesta sobre la independencia de los reguladores económicos, OCDE, París.

$<$ http://dx.doi.org/10.1787/888933532561> 


\section{Gráfico 4.3. Autoridad que nombra a la comisión/jefe del regulador, 2015}

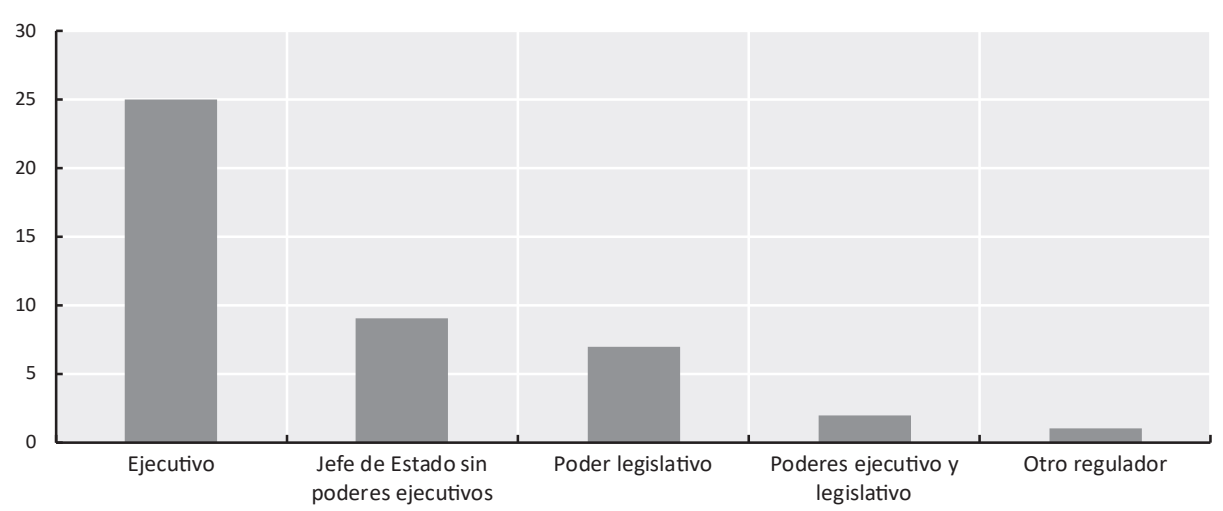

Fuente: OCDE (2015), Encuesta sobre la independencia de los reguladores económicos, OCDE, París.

$<$ http://dx.doi.org/10.1787/888933532580>

\section{APARTADO ESPECIAL: SISTEMAS DE ASESORAMIENTO INDEPENDIENTES DE LAS ADMINISTRACIONES PÚBLICAS}

Las Administraciones públicas y los legisladores enfrentan retos de complejidad creciente derivados de políticas cada vez más interrelacionadas que requieren soluciones adecuadas. Es necesario contar con una base de conocimiento fiable basada en datos empíricos y asesoramiento que respalde el desarrollo de políticas para superar los retos y tender puentes que eviten los enfoques aislados y fragmentarios. Las redes de asesoramiento u organismos consultivos constituyen un pilar fundamental de esta infraestructura del conocimiento. Ofrecen a las Administraciones análisis exhaustivos basados en evidencias durante el ciclo completo de las políticas, en particular en las etapas de diseño y puesta en marcha de estas. Las redes de asesoramiento pueden incluir organismos consultivos especiales o permanentes, y diferir en cuanto a duración, estructura y cometido. Pueden estar dentro de la estructura de la Administración o ser organismos independientes.

La Encuesta de la OCDE sobre sistemas de asesoramiento de 2016 se centra en los organismos independientes de las Administraciones. A pesar de no pertenecer a la Administración, estos organismos de asesoramiento intervienen en el desarrollo de políticas. Suelen situarse próximos a las Administraciones y tener información actualizada de los retos políticos del momento. Tienen el potencial de actuar como agentes de conocimiento, capaces de aportar asesoramiento imparcial e independiente en las distintas fases de las políticas públicas y contribuyen a mantener la confianza en las instituciones. La 
naturaleza de estos organismos es variada. En algunos países existen organismos permanentes que llevan décadas asesorando a las Administraciones. En otros casos, su carácter es ad hoc y ofrecen asesoramiento relativo a desafíos políticos puntuales durante cortos periodos de tiempo. Los resultados de la encuesta muestran que el impacto de los organismos de asesoramiento ad hoc es significativo en los países encuestados, ya que está calificado como alto en un tercio de la muestra y como medio en la mitad de esta.

La influencia de los organismos de asesoramiento y su estrecha relación con el desarrollo de políticas públicas requiere que estos funcionen de forma clara y transparente. La encuesta de la OCDE evidencia que los países están tomando iniciativas para abordar esta cuestión. En el $60 \%$ de los países encuestados (9 países), los organismos independientes de asesoramiento están regulados formalmente, con directivas que establecen mandatos claros, definen la duración de estos y determinan el criterio de selección del personal. En el $94 \%$ de los países encuestados (15 países), las recomendaciones de los organismos permanentes de asesoramiento se hacen públicas en todos o casi todos los casos, para evitar, mediante el escrutinio público, la selección parcial de los resultados por parte de las Administraciones. Los resultados se publican en los medios oficiales, como sitios web y comunicados de las Administraciones, así como a través de las redes sociales y periódicos para alcanzar mayor audiencia. Aunque muchos países tienen mecanismos de transparencia y rendición de cuentas, son susceptibles de mejora. Por ejemplo, casi el $62 \%$ de los países encuestados ( 8 países) permite a sus políticos solicitar asesoramiento oral. Esto pone en tela de juicio el proceso, puesto que la falta de documentación hace muy difícil el rastreo de los motivos y el contenido de las recomendaciones, así como identificar el organismo que las proporcionó. Al mismo tiempo, el $87 \%$ de los países encuestados (13 países) indicó que los organismos permanentes de asesoramiento emiten en ocasiones recomendaciones no solicitadas, lo cual es un indicador positivo de la proactividad de un entorno capaz de ofrecer una variedad de propuestas políticas inclusivas.

Garantizar que los organismos independientes de asesoramiento no producen información sesgada es importante para reducir el riesgo de influencia indebida. Aproximadamente el $78 \%$ de los países (7 países) tiene disposiciones para evitar los conflictos de intereses en los organismos permanentes de asesoramiento, mientras que solo alrededor del 54\% (7 países) tiene este tipo de disposiciones para los organismos ad hoc. El 23\% de los países encuestados (3 países) exige a los miembros de los organismos independientes de asesoramiento ad hoc que ofrezcan información sobre sus contactos con grupos de interés y lobbies, mientras que en el caso de los organismos permanentes de asesoramiento este requisito se reduce al $11 \%$ de los países (1 país). Las disposiciones relativas a la aceptación de obsequios por parte de los miembros de los organismos de asesoramiento se aplican en un $67 \%$ de los organismos permanentes (6 países) y en un $54 \%$ de los organismos de carácter ad hoc ( 7 países). Aunque en algunos casos no existen normativas generales, en ciertos 
países, como Francia, los organismos permanentes de asesoramiento están sujetos a leyes específicas sobre transparencia en la gestión pública. Los resultados actuales complementan las observaciones anteriores de la OCDE que indicaron que en la mayor parte de los países de la OCDE no existe obligación de tener una composición equilibrada de intereses en los organismos de asesoramiento (OCDE, 2014). Evitar la captura política requiere un sistema integral que promueva la cultura de la integridad y de la responsabilidad en la toma de decisiones (OCDE, 2017).

\section{Metodología y definiciones}

Los datos proceden de la Encuesta de la OCDE de 2016 sobre sistemas de asesoramiento independientes del Gobierno realizada en 15 países y Lituania, complementada con entrevistas cualitativas (con excepción de Austria, Grecia, Irlanda y la República Checa). Los encuestados eran delegados del Comité de Gobernanza Pública y altos directivos de organismos de asesoramiento, que brindaron información desde la perspectiva central/federal de las Administraciones.

\section{Otras publicaciones}

OECD (de próxima publicación), Shaping policy advisory systems for strategic advice: A comparative public governance perspective.

OECD (2017), Preventing policy capture: Integrity in public decision making, OECD Public Governance Reviews.

OECD (2014), Lobbyists, Governments and public trust: Implementing the OECD principles for transparency and integrity in lobbying, vol. 3, OECD Publishing, París.

\section{Notas de los gráficos}

Los datos de Alemania, Bélgica, Canadá, Chile, Corea, Dinamarca, los Estados Unidos, Estonia, Hungría, Israel, Italia, Japón, Luxemburgo, Nueva Zelanda, Polonia, el Reino Unido, la República Eslovaca, la República de Eslovenia y Turquía no están disponibles. 


\section{Gráfico 4.4. Disponibilidad pública del asesoramiento (organismos permanentes de asesoramiento), 2016}

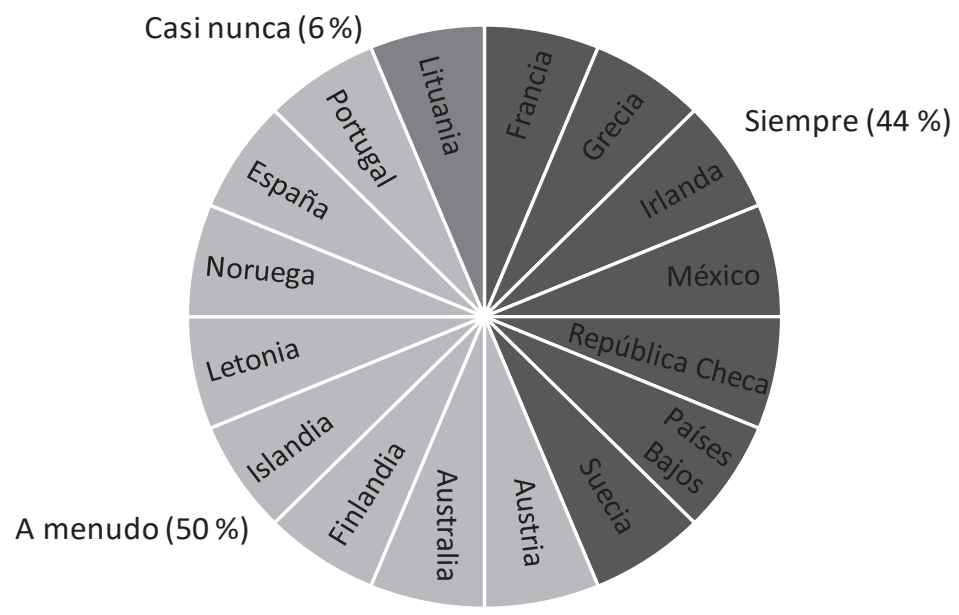

Fuente: OCDE (2016), Encuesta sobre sistemas de asesoramiento político, OCDE, París.

$<$ http://dx.doi.org/10.1787/888933532618>

\section{Gráfico 4.5. Impacto de los organismos ad hoc de asesoramiento en el desarrollo de políticas, 2016}

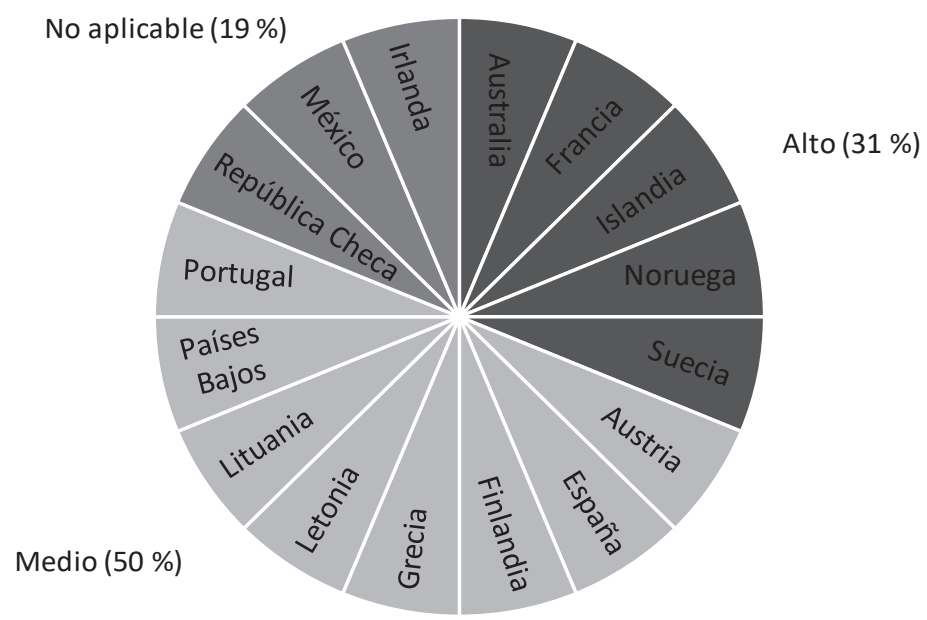

Fuente: OCDE (2016), Encuesta sobre sistemas de asesoramiento politico, OCDE, París.

$<$ http://dx.doi.org/10.1787/888933532599> 
Tabla 4.6. Gestión del riesgo de la influencia indebida: Organismos permanentes y ad hoc de asesoramiento político independientes del

Gobierno, 2016

\begin{tabular}{|c|c|c|c|c|c|c|}
\hline Normativa formal & $\begin{array}{l}\text { Conflicto de } \\
\text { intereses }\end{array}$ & $\begin{array}{c}\text { Aceptación de } \\
\text { obsequios por } \\
\text { parte de los } \\
\text { miembros }\end{array}$ & $\begin{array}{l}\text { Declaración de } \\
\text { contactos con } \\
\text { grupos de interés }\end{array}$ & $\begin{array}{c}\text { Declaración de } \\
\text { contactos con } \\
\text { lobbies }\end{array}$ & $\begin{array}{c}\text { Formato de las } \\
\text { solicitudes de } \\
\text { asesoramiento } \\
\text { (organismos } \\
\text { permanentes) }\end{array}$ & $\begin{array}{c}\text { Opción de } \\
\text { publicar el } \\
\text { asesoramiento no } \\
\text { solicitado } \\
\text { (organismos } \\
\text { permanentes) }\end{array}$ \\
\hline
\end{tabular}

\begin{tabular}{|c|c|c|c|c|c|c|c|c|c|c|c|c|c|}
\hline $\begin{array}{c}\text { Tipo de } \\
\text { organismos de } \\
\text { asesoramiento } \\
\text { político }\end{array}$ & 䒕 & $\frac{\mathscr{g}}{\frac{\pi}{z}}$ & हัँّ & $\frac{\mathscr{g}}{2}$ & 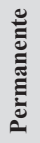 & $\frac{\mathscr{g}}{\square}$ & 苋 & $\frac{\mathscr{g}}{\square}$ & हूँ & $\frac{\mathscr{g}}{\check{g}}$ & 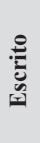 & $\overline{\tilde{\sigma}}$ & \\
\hline Australia & $\bullet$ & $\bullet$ & • & $\bullet$ & $\bullet$ & $\bullet$ & $\bullet$ & $\bullet$ & $\bullet$ & $\bullet$ & $\bullet$ & $x$ & $\bullet$ \\
\hline Austria & 0 & 0 & $x$ & $x$ & $x$ & $x$ & $x$ & $x$ & $x$ & $x$ & $\bullet$ & $\bullet$ & O \\
\hline España & $\bullet$ & $\bullet$ & $\bullet$ & $\bullet$ & $\bullet$ & $\bullet$ & 0 & 0 & O & 0 & $\bullet$ & $\bullet$ & $\bullet$ \\
\hline Finlandia & 0 & 0 & $\times$ & O & $x$ & O & $\times$ & O & $x$ & ○ & $\bullet$ & $\bullet$ & $\bullet$ \\
\hline Francia & $\bullet$ & ○ & $\bullet$ & O & O & O & O & O & O & O & $\bullet$ & O & • \\
\hline Grecia & 0 & $\bullet$ & $x$ & $\bullet$ & $x$ & 0 & $x$ & 0 & $x$ & 0 & • & $\bullet$ & $\bullet$ \\
\hline Irlanda & 0 & $\bullet$ & $x$ & $\bullet$ & $x$ & $\bullet$ & $\times$ & $\bullet$ & $x$ & $\bullet$ & $\bullet$ & $\bullet$ & O \\
\hline Islandia & 0 & ○ & $x$ & O & $x$ & O & $x$ & O & $\times$ & 0 & $\bullet$ & 0 & $\bullet$ \\
\hline Letonia & $\bullet$ & $\bullet$ & 0 & O & ○ & O & ○ & O & 0 & O & $\bullet$ & $\bullet$ & $\bullet$ \\
\hline México & $\bullet$ & $x$ & O & $x$ & O & $x$ & ○ & $x$ & O & $x$ & $\bullet$ & O & • \\
\hline Noruega & $\bullet$ & $\bullet$ & $\bullet$ & O & $\bullet$ & O & - & O & 0 & 0 & • & $\bullet$ & • \\
\hline Países Bajos & $\bullet$ & $\bullet$ & $\bullet$ & O & $\bullet$ & $\bullet$ & O & ○ & O & O & • & O & $\bullet$ \\
\hline Portugal & O & O & $x$ & $\bullet$ & $x$ & $\bullet$ & $x$ & O & $\times$ & O & O & 0 & $\bullet$ \\
\hline $\begin{array}{l}\text { República } \\
\text { Checa }\end{array}$ & - & - & - & • & - & - & 0 & - & 0 & - & $x$ & $x$ & - \\
\hline Suecia & $\bullet$ & $\bullet$ & $\bullet$ & $\bullet$ & $\bullet$ & $\bullet$ & O & O & O & O & $\bullet$ & $\bullet$ & $\bullet$ \\
\hline \multicolumn{14}{|l|}{ Total OCDE } \\
\hline - Sí & 9 & 9 & 7 & 7 & 6 & 7 & 2 & 3 & 1 & 3 & 13 & 8 & 13 \\
\hline ○ No & 6 & 5 & 2 & 6 & 3 & 6 & 7 & 10 & 8 & 10 & 1 & 5 & 2 \\
\hline X No aplicable & -- & 1 & 6 & 2 & 6 & 2 & 6 & 2 & 6 & 2 & 1 & 2 & - \\
\hline Lituania & • & 0 & - & - & - & • & - & - & 0 & 0 & - & • & • \\
\hline
\end{tabular}

Fuente: OCDE (2016), Encuesta sobre sistemas de asesoramiento político, OCDE, París.

$<$ http://dx.doi.org/10.1787/888933534879> 


\section{APARTADO ESPECIAL: DISPOSICIÓN DEL CENTRO DE GOBIERNO PARA IMPLEMENTAR LOS OBJETIVOS DE DESARROLLO SOSTENIBLE DE LA ONU}

Los Objetivos de Desarrollo Sostenible (ODS) de las Naciones Unidas se adoptaron en septiembre de 2015. Comprenden objetivos sociales, medioambientales y económicos e instan a todos los países - de ingresos altos, medios y bajos - a realizar mejoras en las condiciones de vida de los ciudadanos. Dado el alcance, la complejidad y la naturaleza a largo plazo de los ODS, lograr avances en su implementación requiere que los Gobiernos trabajen de manera transversal en todos los ámbitos y a diversos niveles de actuación pública para coordinar estrategias y actuaciones y superar obstáculos, como las presiones económicas y sociales que desplazan a las iniciativas de política estratégica con vistas hacia el futuro.

El centro de gobierno $(\mathrm{CdG})$ puede desempeñar un papel importante al prestar apoyo a las Administraciones públicas en la organización y consecución de los ODS. Mientras que los ministerios competentes podrían tener una experiencia limitada en la práctica de políticas transversales, el centro de gobierno normalmente conjuga capacidad de coordinación con sensibilidad política.

Los resultados de una encuesta reciente de la OCDE sugieren que los países reconocen el papel de los centros de gobierno en la consecución de los ODS. En 19 países de la OCDE, el centro de gobierno ayuda a dirigir la implementación de los ODS, bien de manera independiente o junto con los ministerios competentes. En 10 países de la OCDE, el liderazgo o liderazgo compartido de la implementación se asigna a uno o varios ministerios competentes, siendo el Ministerio de Asuntos Exteriores el más usual, seguido del Ministerio de Fomento, el Ministerio de Medio Ambiente y el Ministerio de Hacienda. La participación del Ministerio de Asuntos Exteriores implica la necesidad de que el centro de gobierno garantice sinergias entre las prioridades nacionales y las internacionales. La decisión de nominar al centro de gobierno como actor clave en la coordinación de la implementación de los ODS depende también de sus funciones, que varían entre los distintos países (OCDE, 2014).

Los centros de gobierno identifican un número de oportunidades y desafíos importantes resultantes de la implementación de los ODS. Resulta interesante que algunos de los retos clave identificados se perciben también como oportunidades. De hecho, 19 países de la OCDE consideran los ODS como firmes incentivos y exigen que los distintos sectores se alineen para llevar a cabo las políticas, cuando tradicionalmente la mayoría de los centros de gobierno ejercen solo una influencia moderada sobre los ministerios competentes en materia de coordinación (OCDE, 2014). De manera similar, 12 países de 
la OCDE perciben el horizonte de planificación a largo plazo de los ODS, más allá de los ciclos electorales, como una oportunidad.

Ocho países mencionaron la necesidad de movilizar recursos adicionales como uno de los desafíos principales de la organización para la implementación de los ODS. Sin embargo, algunos países ya han adoptado medidas para garantizar que los recursos se obtienen y utilizan con un impacto máximo. En Noruega, por ejemplo, la responsabilidad de cada uno de los 17 ODS se asigna a un ministerio determinado, que informa sobre el progreso de su objetivo correspondiente en su propuesta presupuestaria. Este sistema permite que los ODS estén totalmente integrados en el proceso ordinario de elaboración de presupuestos y que los ministerios sean responsables de los resultados. Un número de países vincula los ODS con el proceso de rendimiento. En Suecia se han integrado 27 prioridades políticas clave en el sistema de elaboración de presupuestos basados en resultados (Shaw, 2016).

\section{Metodología y definiciones}

La Encuesta sobre la planificación y coordinación de la implementación de los Objetivos de Desarrollo Sostenible (ODS) se completó en 2016 por 28 países de la OCDE y 3 países en proceso de adhesión. Los encuestados eran predominantemente altos funcionarios de centros de gobierno.

El término centro de gobierno se refiere a las organizaciones y unidades que sirven al jefe del Ejecutivo (presidente o primer ministro, y el gabinete a nivel colectivo) y desempeñan funciones intersectoriales (planificación estratégica, coordinación política, supervisión y mejora del desempeño, gestión de la política de las políticas públicas, y comunicaciones y rendición de cuentas). El CdG incluye una gran variedad de unidades, dependiendo del país, como pueden ser la Secretaría General, Oficina del Gabinete, Oficina/Ministerio del Presidente, Oficina del Consejo de Ministros, etc.

Los 17 Objetivos de Desarrollo Sostenible tienen como objetivo terminar con la pobreza, luchar contra la desigualdad y la injusticia y atajar el cambio climático antes de 2030, como parte de la Agenda 2030 para el Desarrollo Sostenible adoptada por líderes mundiales en la Cumbre de las Naciones Unidas sobre el Desarrollo Sostenible del 25 de septiembre de 2015. Más información en <https://sustainabledevelopment.un.org/ sdgs $>$. 


\section{Otras publicaciones}

OECD (2016), OECD survey on planning and co-ordinating the implementation of the SDGs: First results and key issues, OECD, París.

OECD (2014), Centre stage: Driving better policies from the centre of government, OECD, París.

Shaw, T. (2016), «Performance budgeting practices and procedures», $O E C D$ Journal on Budgeting, vol. 15/3, OECD Publishing, París.

\section{Notas de los gráficos}

Los datos de Canadá, España, Israel, Nueva Zelanda, Polonia y Portugal no están disponibles.

4.8: Las respuestas reflejan las contestaciones a la pregunta «¿Cuáles considera que son los dos aspectos más positivos del proceso organizativo de la planificación para la implementación de los ODS desde la perspectiva del centro de gobierno?». La opción de respuesta «Otros» no se muestra. Los datos de Bélgica y Francia no están disponibles.

4.9: Las respuestas reflejan las contestaciones a la pregunta «¿Cuáles considera que son los dos desafíos principales en la organización de la planificación para la implementación de los ODS desde la perspectiva del centro de gobierno?». La opción de respuesta «Otros» no se muestra. Los datos de Bélgica no están disponibles. 


\section{Gráfico 4.7. Liderazgo y coliderazgo en la implementación de los Objetivos de Desarrollo Sostenible de la ONU, 2016}

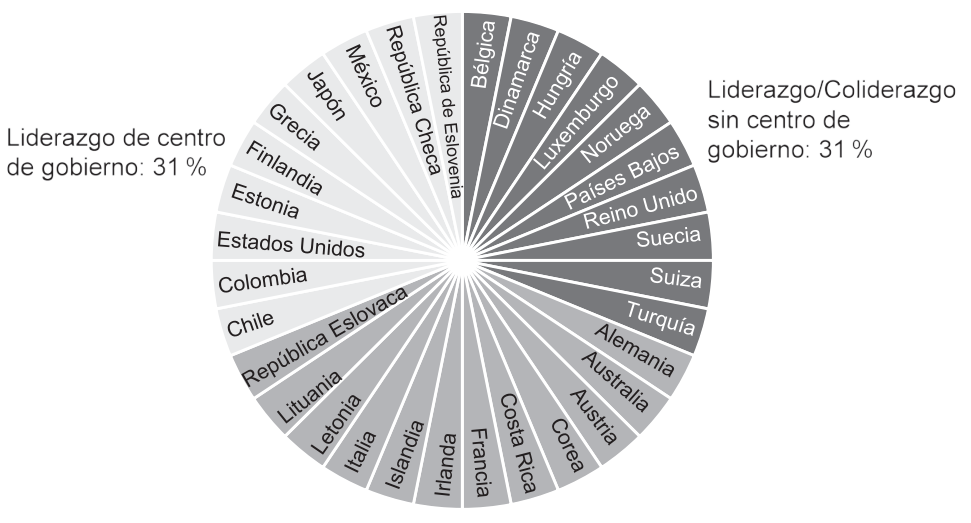

Coliderazgo entre el centro de gobierno y ministerios competentes: $38 \%$

Fuente: OCDE (2016), Encuesta sobre la planificación y coordinación de la implementación de los Objetivos de Desarrollo Sostenible, OCDE, París.

Gráfico 4.8. Aspectos más positivos de la organización de la planificación para la implementación de los ODS mencionados por los centros de gobierno, 2016

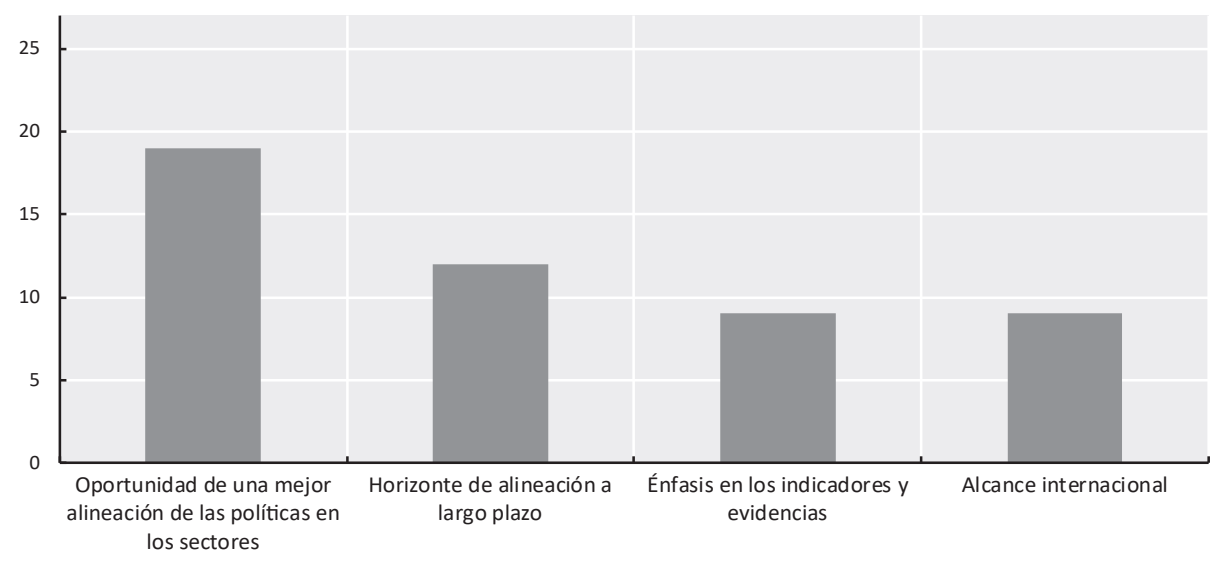

Fuente: OCDE (2016), Encuesta sobre la planificación y coordinación de la implementación de los Objetivos de Desarrollo Sostenible, OCDE, París. 


\section{Gráfico 4.9. Aspectos que suponen un mayor desafío en la planificación para la implementación de los ODS mencionados por los centros de gobierno, 2016}

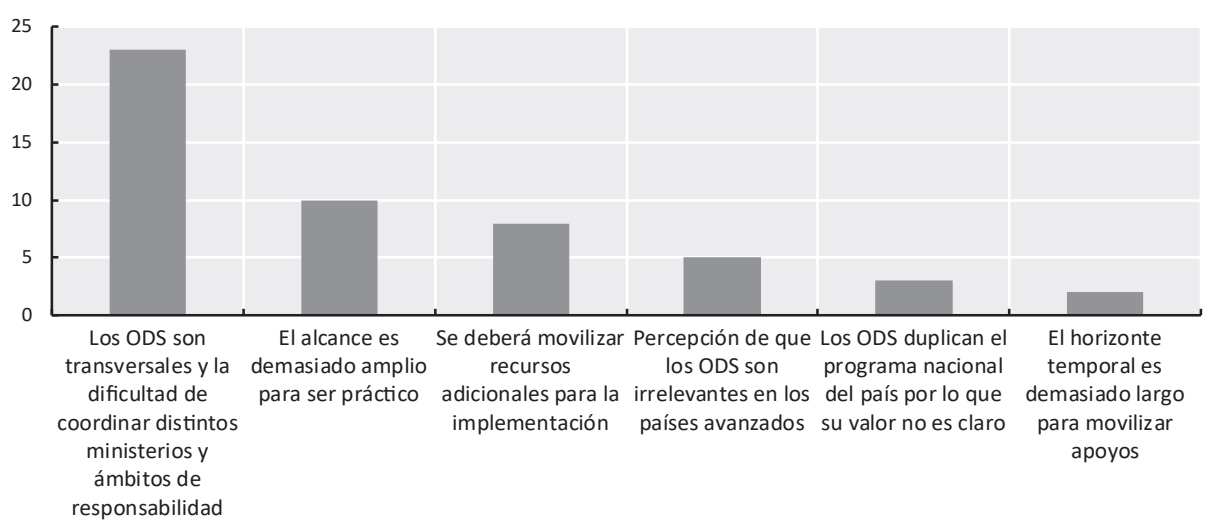

Fuente: OCDE (2016), Encuesta sobre la planificación y coordinación de la implementación de los Objetivos de Desarrollo Sostenible, OCDE, París.

\section{APARTADO ESPECIAL: EL PAPEL DE LAS ORGANIZACIONES INTERNACIONALES EN LA COOPERACIÓN REGULATORIA INTERNACIONAL}

En la actualidad, los principales retos de los países trascienden sus fronteras. Los riesgos derivados del cambio climático, epidemias, terrorismo, evasión de impuestos, flujos financieros internacionales, así como las crisis sociales y económicas, tienen causas y efectos globales. Hoy más que nunca, es necesario que los países coordinen sus respuestas para afrontar los retos comunes, gestionar de forma global los recursos y asegurar la prosperidad y seguridad compartidas. Los países de la OCDE reconocen la Cooperación Regulatoria Internacional (CRI) como un componente esencial de la calidad regulatoria nacional, de acuerdo con el principio 12 de la Recomendación del Consejo de la OCDE sobre política y gobernanza regulatoria de 2012.

El apoyo de las organizaciones internacionales (OI) es esencial para la CRI y para evitar la fragmentación que puede minar la eficacia de las Administraciones públicas. Las normas internacionales que desarrollan las OI constituyen los pilares de un sistema eficaz de gobernanza global que supone la base de una economía mundial sostenible. Es por tanto clave garantizar la calidad 
de esta legislación. El informe de la OCDE International regulatory co-operation: The role of international organisations in fostering better rules of globalisation ('Cooperación regulatoria internacional: El papel de las organizaciones internacionales en promover normas de globalización mejores') presenta las prácticas de gobernanza pública y regulatoria de 50 reguladores internacionales. El informe muestra la diversidad de OI que trabajan en la formulación de normas y estándares internacionales, a la vez que resalta los aspectos comunes en la elaboración de estos.

Las OI están involucradas principalmente en las etapas de planificación, diseño y desarrollo de normas y estándares internacionales. Posibilitan el intercambio de información, favorecen el desarrollo de normas basadas en evidencias mediante la recolección de datos, el estudio y análisis de políticas, y promueven debates sobre buenas prácticas regulatorias. Su actividad principal se centra en el desarrollo de normas, estándares y buenas prácticas y utilizan, sobre todo, instrumentos que no son jurídicamente vinculantes. Estos instrumentos son utilizados principalmente por los organismos reguladores del sector privado y redes multinacionales, mientras que los organismos intergubernamentales disponen de una variedad más amplia de herramientas con distintos efectos legales. En consecuencia, las OI están menos involucradas en el desarrollo de instrumentos jurídicamente vinculantes, así como en su aplicación y en otras actividades relativas a la implementación de políticas y leyes. Solo hay cinco OI dedicadas sistemáticamente a la aplicación de políticas y leyes y a la resolución de disputas. Existen pocas organizaciones con la estructura necesaria para realizar estas actividades, siendo la OMC una excepción notable al respecto. Por otra parte, la gestión de crisis es sistemática en solo cuatro organizaciones, entre ellas la CE y el OIEA.

Para ser efectiva, la acción de las OI requiere un alto grado de integración en la formulación de políticas nacionales y debe contar con una cultura sólida de gestión de la calidad y de la eficacia en el desarrollo de los instrumentos regulatorios y legales. La mayoría de las OI han implementado mecanismos de recolección de datos y valoraciones de las partes interesadas. Solo hay tres organizaciones que nunca ofrecen a las partes interesadas la oportunidad de valorar los instrumentos desarrollados. Sin embargo, los procedimientos de evaluación para garantizar la calidad de los estándares son menos utilizados por las OI. La evaluación ex post a la implementación y sus efectos se utiliza algo más que las revisiones del cuerpo regulatorio y que la evaluación ex ante de impactos potenciales. Las OI no suelen tener la autoridad, capacidad metodológica e información necesarias para realizar las evaluaciones. Existe, pues, poca evidencia estructurada del impacto de estas. Es crucial realizar mayores esfuerzos en el desarrollo de una cultura evaluativa de los instrumentos de las OI, así como fomentar la coordinación entre sus secretarías y destinatarios, con el fin de obtener evidencias de la eficacia de sus acciones. 


\section{Metodología y definiciones}

La OCDE organizó una plataforma de OI que se reunió de manera anual entre 2014 y 2016 para debatir el papel regulatorio de estos organismos. En este contexto, la OCDE realizó en 2015 una encuesta a 50 OI para examinar sus modelos de gobernanza, modalidades operativas, prácticas de elaboración de normas y enfoques de evaluación de la implementación y de sus impactos. Los resultados se recogieron en el informe International regulatory co-operation: The role of international organisations in fostering better rules of globalisation y fueron analizados por el grupo de OI y países de la OCDE.

A los efectos del presente documento, el término organizaciones internacionales hace referencia a cualquier organismo internacional —organización intergubernamental (por ejemplo, la OCDE, la OMC, la FAO), supranacional (la Comisión Europea), redes intergubernamentales de reguladores (por ejemplo, la OICV, la RICE) y formuladores de normativas del sector privado (por ejemplo, la ASTM, la ISO) - que mantenga una secretaría, dirección postal y página web permanentes y se dedique a algún tipo de actividad regulatoria (por ejemplo, diseño, monitorización o aplicación de instrumentos legales y estándares políticos). El informe, por tanto, incluye una multitud de actores internacionales con naturalezas, mandatos y ámbitos distintos. En el anexo F (4.12) se muestra la lista completa de OI que participaron en la encuesta de la OCDE.

La cooperación regulatoria internacional se define como «cualquier acuerdo o disposición organizacional, formal o informal, entre países (a nivel bilateral, regional o multilateral) para promover algún tipo de cooperación en el diseño, monitorización, aplicación o gestión ex post de una regulación, con el objetivo de promover la convergencia y coherencia normativa entre fronteras» (OCDE, 2013). CRI contempla acuerdos voluntarios y no vinculantes además de obligaciones legales.

\section{Otras publicaciones}

OECD (2016), International regulatory co-operation: The role of international organisations in fostering better rules of globalisation, OECD Publishing, París.

OECD (2013), International regulatory co-operation: Addressing global challenges, OECD Publishing, París.

OECD (2014), International regulatory co-operation and international organisations: The cases of the OECD and the IMO, OECD Publishing, París. 
Tabla 4.10. La naturaleza de la elaboración de normas en las organizaciones internacionales, 2015

\begin{tabular}{|c|c|c|c|c|c|c|c|c|c|}
\hline & 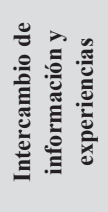 & 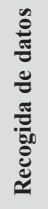 & 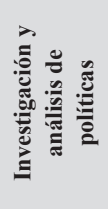 & 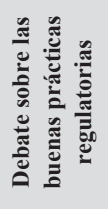 & 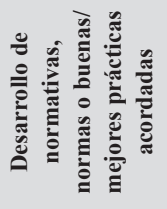 & 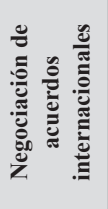 & 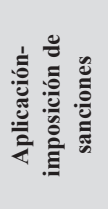 & 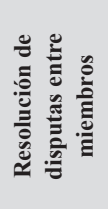 & 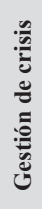 \\
\hline AHWP & - & - & - & - & - & - & o & O & O \\
\hline \multirow[t]{2}{*}{$\begin{array}{c}\text { APEC } \\
\text { ASTM International }\end{array}$} & - & $\bullet$ & 口 & $\square$ & ב & $\mathrm{O}$ & O & O & $\mathrm{O}$ \\
\hline & ם & a & $\bullet$ & $\bullet$ & - & $\bullet$ & o & O & o \\
\hline \multirow[t]{2}{*}{$\begin{array}{l}\text { BRS Conventions } \\
\text { CARICOM }\end{array}$} & - & - & - & - & - & - & O & O & O \\
\hline & ם & - & - & - & - & ם & o & ם & O \\
\hline \multirow[t]{2}{*}{$\begin{array}{l}\text { CBD } \\
\text { CITES }\end{array}$} & - & घ & $\bullet$ & - & - & $\bullet$ & O & O & $\mathrm{O}$ \\
\hline & - & घ & - & - & - & o & - & घ & ! \\
\hline \multirow[t]{2}{*}{ COMESA EC } & - & घ & - & व & 口 & $\bullet$ & O & 口 & 口 \\
\hline & - & घ & - & - & - & - & $\bullet$ & - & - \\
\hline \multirow[t]{2}{*}{ ESCWA FAO } & $\bullet$ & $\bullet$ & ם & $\bullet$ & $\bullet$ & $\bullet$ & O & O & 0 \\
\hline & " & " & - & व & a & a & o & $\bullet$ & $\bullet$ \\
\hline \multirow[t]{2}{*}{ IAEA IAF } & - & - & $\bullet$ & - & - & $\bullet$ & O & O & घ \\
\hline & - & $\square$ & $\bullet$ & व & - & - & - & $\bullet$ & $\bullet$ \\
\hline \multirow[t]{2}{*}{$\begin{array}{l}\text { IAIS } \\
\text { IATA }\end{array}$} & - & घ & - & - & ב & $\square$ & O & O & $\mathrm{O}$ \\
\hline & - & - & - & - & - & O & O & O & $\bullet$ \\
\hline \multirow[t]{2}{*}{ ICN IEC } & ם & $\bullet$ & व & व & 口 & O & O & O & 0 \\
\hline & $\bullet$ & O & ם & ם & - & O & O & O & O \\
\hline \multirow[t]{2}{*}{$\begin{array}{l}\text { IFAC } \\
\text { ILAC }\end{array}$} & - & घ & - & a & - & O & $\bullet$ & O & $\bullet$ \\
\hline & ם & a & ם & ם & - & - & - & $\bullet$ & $\bullet$ \\
\hline \multirow[t]{2}{*}{ IMDRF IMF } & - & $\bullet$ & व & - & ! & O & O & O & O \\
\hline & - & घ & - & व & 口 & $\bullet$ & $\bullet$ & O & 口 \\
\hline \multirow[t]{2}{*}{ IMO IOSCO } & - & घ & व & व & - & a & o & O & O \\
\hline & - & $\bullet$ & - & ם & - & - & $\bullet$ & $\bullet$ & $\bullet$ \\
\hline \multirow[t]{2}{*}{ ISO ITU } & $\bullet$ & $\bullet$ & $\bullet$ & $\bullet$ & - & O & O & O & O \\
\hline & ם & $\bullet$ & $\bullet$ & व & a & $\bullet$ & O & O & $\bullet$ \\
\hline
\end{tabular}




\begin{tabular}{|c|c|c|c|c|c|c|c|c|c|}
\hline NATO OAS & घ & $\bullet$ & a & $\bullet$ & $\square$ & $\bullet$ & $\mathrm{O}$ & O & a \\
\hline & घ & घ & - & घ & 口 & $\bullet$ & $\bullet$ & 口 & a \\
\hline \multirow[t]{2}{*}{ OCDE OIE } & घ & $\square$ & घ & घ & 口 & $\bullet$ & $\mathrm{O}$ & $\bullet$ & O \\
\hline & घ & ! & - & घ & घ & $\bullet$ & O & $\bullet$ & $\bullet$ \\
\hline \multirow[t]{2}{*}{ OIF OIML } & a & $\square$ & घ & 口 & 口 & - & $\bullet$ & o & $\bullet$ \\
\hline & घ & $\bullet$ & $\bullet$ & $\square$ & घ & $\bullet$ & O & O & O \\
\hline \multirow[t]{2}{*}{$\begin{array}{c}\text { OIV } \\
\text { OPCW }\end{array}$} & a & $\square$ & $\square$ & $\bullet$ & $\square$ & O & $\mathrm{O}$ & $\bullet$ & $\bullet$ \\
\hline & घ & $\square$ & - & $\square$ & ! & O & $\mathrm{O}$ & O & $\bullet$ \\
\hline \multirow[t]{2}{*}{ OSCE OTIF } & $\bullet$ & - & a & 口 & $\square$ & 0 & O & $\bullet$ & 口 \\
\hline & a & 口 & $\bullet$ & O & घ & O & $\mathrm{O}$ & O & O \\
\hline \multirow[t]{2}{*}{$\begin{array}{l}\text { OZONE } \\
\text { PIC/S }\end{array}$} & a & घ & $\square$ & घ & $\square$ & $\square$ & - & - & - \\
\hline & $\square$ & $\square$ & 0 & 曰 & - & 0 & $\mathrm{O}$ & O & $\bullet$ \\
\hline \multirow[t]{2}{*}{ SAICM UNDP } & - & घ & a & $\bullet$ & $\bullet$ & 口 & O & $\mathrm{O}$ & $\bullet$ \\
\hline & $\bullet$ & $\square$ & 口 & $\square$ & $\bullet$ & 口 & $\mathrm{O}$ & $\bullet$ & o \\
\hline \multirow[t]{2}{*}{ UNECE UNEP } & घ & घ & $\bullet$ & घ & घ & - & $\bullet$ & $\bullet$ & O \\
\hline & घ & घ & $\bullet$ & $\bullet$ & - & - & O & O & O \\
\hline \multirow[t]{2}{*}{$\begin{array}{l}\text { UNIDO } \\
\text { UNODC }\end{array}$} & a & $\square$ & $\square$ & $\square$ & $\square$ & 口 & O & O & व \\
\hline & $\square$ & $\square$ & $\square$ & $\square$ & $\square$ & $\bullet$ & $\mathrm{O}$ & O & O \\
\hline \multirow[t]{2}{*}{ UNWTO UPU } & a & - & - & $\square$ & $\square$ & O & $\mathrm{O}$ & O & 口 \\
\hline & घ & घ & - & $\square$ & $\square$ & $\square$ & O & $\bullet$ & 口 \\
\hline \multirow[t]{2}{*}{$\begin{array}{l}\text { WCO } \\
\text { WHO }\end{array}$} & घ & घ & $\square$ & - & घ & $\square$ & $\mathrm{O}$ & O & O \\
\hline & a & . & $\square$ & $\bullet$ & $\square$ & $\bullet$ & $\mathrm{O}$ & 0 & $\bullet$ \\
\hline \multirow[t]{2}{*}{ WIPO WMO } & 口 & O & $\bullet$ & $\square$ & $\square$ & $\square$ & $\mathrm{O}$ & - & O \\
\hline & 口 & $\square$ & - & a & 口 & $\bullet$ & $\bullet$ & - & $\bullet$ \\
\hline $\begin{array}{c}\text { WTO/OMC } \\
\text { Total OI }\end{array}$ & घ & - & घ & घ & - & घ & - & - & O \\
\hline Sistemáticamente $\square$ & $\begin{array}{l}31 \\
14 \\
\end{array}$ & $\begin{array}{l}28 \\
11 \\
\end{array}$ & $\begin{array}{l}22 \\
16 \\
\end{array}$ & $\begin{array}{l}20 \\
21 \\
\end{array}$ & $\begin{array}{l}28 \\
19 \\
\end{array}$ & $\begin{array}{l}10 \\
10 \\
\end{array}$ & $\begin{array}{l}5 \\
0 \\
\end{array}$ & $\begin{array}{l}5 \\
3 \\
\end{array}$ & $\begin{array}{l}4 \\
8 \\
\end{array}$ \\
\hline $\begin{array}{l}\text { Frecuentemente } \square \\
\text { Ocasionalmente }\end{array}$ & 5 & 9 & 11 & 8 & 3 & 16 & 8 & 12 & 15 \\
\hline Nunca $\bigcirc$ & 0 & 2 & 1 & 1 & 0 & 14 & 37 & 30 & 23 \\
\hline
\end{tabular}

Fuente: OCDE (2016), International regulatory co-operation: The role of international organisations in fostering better rules of globalisation, OECD Publishing, París. 


\section{Gráfico 4.11. Garantía de calidad de los instrumentos de las organizaciones internacionales}

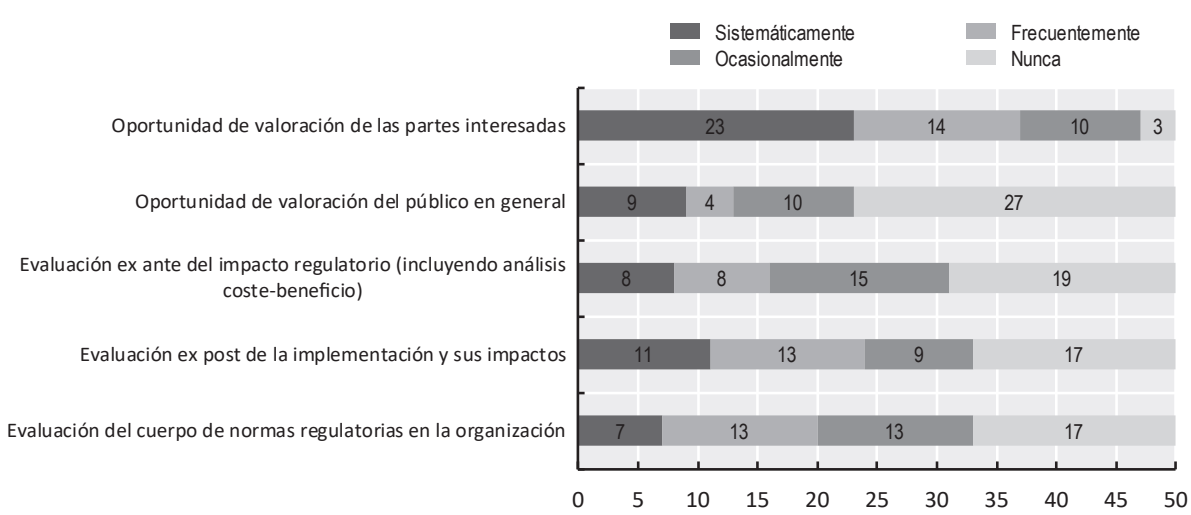

Fuente: OCDE (2016), International regulatory co-operation: The role of international organisations in fostering better rules of globalisation, OECD Publishing, París.

$<$ http://dx.doi.org/10.1787/888933532694> 



\section{CAPÍTULO 5. PRÁCTICAS Y PROCEDIMIENTOS PRESUPUESTARIOS}

\section{PRESUPUESTOS BASADOS EN RESULTADOS}

Los Principios de Gobernanza Presupuestaria de la OCDE instan a los países a «garantizar que los resultados, la evaluación y la rentabilidad sean parte integral del proceso presupuestario». Dentro de los países de la OCDE, la evolución de la práctica de presupuestos basados en resultados abarca décadas, y las Administraciones públicas utilizan la información sobre el desempeño para asignar y priorizar recursos, fomentar la responsabilidad y la transparencia y construir una cultura de rendimiento con el fin de aumentar la eficiencia administrativa y mejorar los servicios públicos.

Los resultados de la Encuesta de la OCDE sobre presupuestos basados en resultados confirman que este marco presupuestario continúa siendo la norma en la OCDE, como declararon 26 países miembros ( 25 de manera obligatoria y uno opcional). Las Administraciones públicas afirman que la práctica de este tipo de presupuestos fomenta la cultura del rendimiento y el progreso en materia de rendición de cuentas y transparencia. En los países que no cuentan con este marco presupuestario, los ministerios competentes pueden desarrollar el suyo propio (Bélgica e Israel) o pueden recibir orientación sobre la estructura y contenidos de los planes estratégicos e informes de rendimiento (los Estados Unidos).

Más de dos tercios de los países con este marco presupuestario utilizan la información sobre el desempeño en las negociaciones presupuestarias (18 países), vinculando así de manera explícita los resultados con las decisiones de asignación de recursos. Dos países sin marco afirman seguir una línea presupuestaria similar. En comparación con las encuestas de 2007 y 2011, los países comunican que el bajo rendimiento tiene mayores consecuencias, en especial a nivel de gestión debido a la publicación de los resultados negativos. Las consecuencias presupuestarias son menos habituales, aunque la congelación y el aumento de los presupuestos son más usuales que su reducción. El alcance de los marcos de desempeño varía del muy amplio (indicadores nacionales clave 
e indicadores/objetivos sistemáticos establecidos para todos los programas) al más específico (indicadores/objetivos establecidos para casi todos los programas o solo los prioritarios). La utilización de información sobre el desempeño en las negociaciones presupuestarias es frecuente en todos los tipos de marcos. Sin embargo, en los países con marcos de actuación más específica y que fueron de los primeros en adoptar las prácticas presupuestarias basadas en resultados, el bajo rendimiento parece tener mayores consecuencias.

El índice de la OCDE de presupuestos basados en resultados de 2016 muestra el grado de existencia de estas prácticas y su utilización a nivel central de la Administración, aunque no mide el éxito de sus resultados. Si bien se ha observado una caída en la especificación general de los marcos de desempeño desde 2011, ha habido un aumento en el uso de información sobre el desempeño en las negociaciones presupuestarias y toma de decisiones y, por tanto, el índice medio de todos los países de la OCDE se ha mantenido similar. Hay grandes disparidades entre los países de la OCDE en materia de prácticas presupuestarias basadas en resultados, que se reflejan en la variación de puntuaciones por país. Se observan cambios considerables en países como Austria, que introdujo los presupuestos basados en resultados en 2013 como parte de su proceso de reforma presupuestaria; en el Reino Unido, donde se introdujo un marco de información sobre el desempeño más integrado en 2015-2016, y en Alemania, donde la documentación presupuestaria se ha complementado con información sobre el desempeño desde 2013.

\section{Metodología y definiciones}

Los datos proceden de la Encuesta de la OCDE sobre presupuestos basados en resultados de 2016. Los encuestados eran predominantemente altos funcionarios encargados de los presupuestos y reflejan las valoraciones de los propios países en cuanto a las prácticas existentes. Los datos se refieren a las Administraciones centrales/federales que no operan a nivel estatal/local.

La Tabla 5.1 refleja las características de los marcos de presupuestos basados en resultados. Los países utilizan los datos de operaciones e información sobre el desempeño en las negociaciones presupuestarias si las Administraciones los han utilizado en sus negociaciones por lo menos ocasionalmente y de manera usual. La tabla muestra las respuestas de gestión al bajo rendimiento si el marco provoca por lo menos ocasionalmente cinco tipos de respuesta de gestión. La tabla muestra las consecuencias presupuestarias del bajo rendimiento si el marco provoca por lo 
menos ocasionalmente dos de las siguientes consecuencias: congelación de los presupuestos, reducción de los presupuestos y aumento de los presupuestos.

El índice compuesto del Gráfico 5.2 contiene 10 variables que incluyen datos sobre la disponibilidad y tipo de la información desarrollada sobre el desempeño, los procesos de seguimiento y comunicación de resultados, y sobre si (y de qué manera) se utiliza la información sobre el desempeño. El índice no mide la calidad global de los sistemas presupuestarios basados en resultados. Debido a diferencias entre las encuestas de 2011 y 2016, se han ajustado algunas ponderaciones a efectos de comparabilidad. El anexo E contiene una descripción de la metodología que se ha seguido para realizar este índice.

\section{Otras publicaciones}

OECD (2017), 2016 OECD performance budgeting survey highlights: Integrating performance and results in budgeting, OECD Publishing, París, $<$ www.oecd.org/gov/budgeting/Performance-Budgeting-SurveyHighlights.pdf $>$.

Shaw, T. (2016), «Performance budgeting practices and procedures», OECD Journal on Budgeting, vol. 15/3, OECD Publishing, París, <http://dx.doi. org/10.1787/budget15-5jlz6rhqdvhh>.

\section{Notas de los gráficos}

5.1: Incluye 24 de los 26 países de la OCDE que confirman utilizar un marco de presupuestos basados en resultados. Islandia tiene un marco obligatorio, pero no se incluye puesto que su respuesta a la encuesta no proporciona los datos necesarios. No se incluye a Japón ya que tiene un marco opcional. Bélgica, los Estados Unidos, Grecia, Hungría, Israel, Luxemburgo y Portugal declaran no tener un marco estándar de presupuestos basados en resultados.

5.2: Los datos de España y la República Eslovaca no están disponibles ya que no completaron la encuesta de 2016. Los datos de Islandia e Israel no están disponibles puesto que no completaron la encuesta de 2011. Letonia no era miembro de la OCDE en 2011. España, Islandia, Israel, Letonia y la República Eslovaca se excluyeron de la media de la OCDE ya que faltan series temporales.

Información sobre los datos de Israel: <http://dx.doi.org/10.1787/888932315602>. 
Tabla 5.1. Características del marco de presupuestos basados en resultados, 2016

\begin{tabular}{|c|c|c|c|c|c|c|}
\hline \multirow[b]{2}{*}{ País } & \multicolumn{3}{|c|}{ Diseño } & \multirow[b]{2}{*}{ 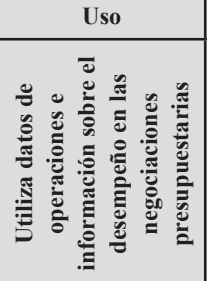 } & \multicolumn{2}{|c|}{ Consecuencias } \\
\hline & 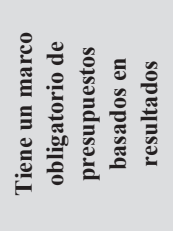 & 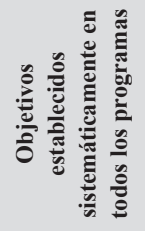 & 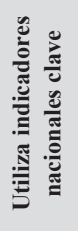 & & 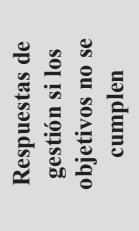 & 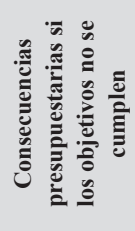 \\
\hline Alemania & $\bullet$ & ○ & - & $\bullet$ & O & - \\
\hline Australia & - & - & O & O & O & - \\
\hline Austria & $\bullet$ & ○ & O & $\bullet$ & $\bullet$ & O \\
\hline Canadá & $\bullet$ & O & O & $\bullet$ & $\bullet$ & O \\
\hline Chile & $\bullet$ & O & O & $\bullet$ & O & O \\
\hline Corea & $\bullet$ & $\bullet$ & $\bullet$ & $\bullet$ & $\bullet$ & O \\
\hline Dinamarca & - & O & - & $\bullet$ & $\bullet$ & - \\
\hline Estonia & - & $\bullet$ & $\bullet$ & O & O & O \\
\hline Finlandia & - & O & O & $\bullet$ & O & O \\
\hline Francia & $\bullet$ & $\bullet$ & $\bullet$ & $\bullet$ & $\bullet$ & O \\
\hline Irlanda & $\bullet$ & O & O & $\bullet$ & O & O \\
\hline Italia & - & - & O & O & O & O \\
\hline Letonia & - & O & $\bullet$ & O & O & O \\
\hline México & $\bullet$ & $\bullet$ & $\bullet$ & ○ & O & O \\
\hline Noruega & - & O & O & O & - & O \\
\hline Nueva Zelanda & - & $\bullet$ & 0 & O & - & O \\
\hline Países Bajos & - & O & 0 & $\bullet$ & - & O \\
\hline Polonia & $\bullet$ & $\bullet$ & - & $\bullet$ & O & O \\
\hline Reino Unido & $\bullet$ & O & - & $\bullet$ & $\bullet$ & O \\
\hline República Checa & $\bullet$ & O & O & $\bullet$ & $\bullet$ & $\bullet$ \\
\hline República de Eslovenia & $\bullet$ & $\bullet$ & O & $\bullet$ & O & O \\
\hline Suecia & $\bullet$ & O & ○ & $\bullet$ & O & $\bullet$ \\
\hline Suiza & $\bullet$ & O & ○ & $\bullet$ & O & O \\
\hline Turquía & $\bullet$ & O & ○ & - & O & O \\
\hline \multicolumn{7}{|l|}{ Total OCDE } \\
\hline - Sí & 24 & 11 & 11 & 18 & 10 & 3 \\
\hline O No & 0 & 13 & 12 & 6 & 14 & 19 \\
\hline - Sin respuesta & 0 & 0 & 1 & 0 & 0 & 2 \\
\hline
\end{tabular}

Fuente: (2016), Encuesta de la OCDE sobre presupuestos basados en resultados, OCDE, París.

$<$ http://dx.doi.org/10.1787/888933534917> 
Gráfico 5.2. Utilización de prácticas presupuestarias basadas en resultados a nivel central de las Administraciones públicas, 2011 y 2016

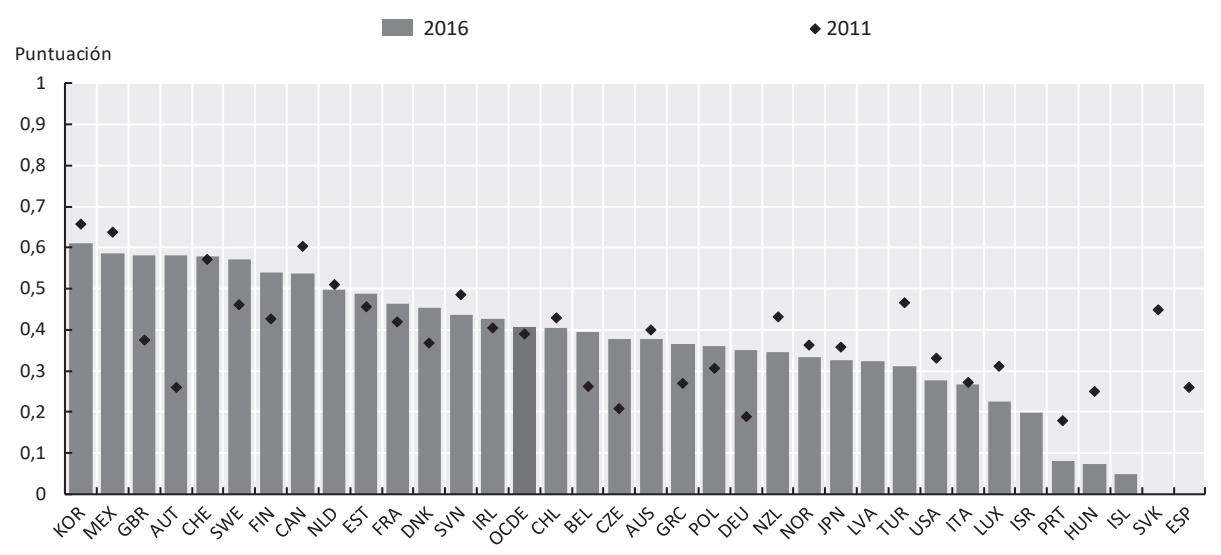

Fuente: (2016), Encuesta de la OCDE sobre presupuestos basados en resultados, OCDE, París.

\section{APARTADO ESPECIAL: PRESUPUESTOS CON PERSPECTIVA DE GÉNERO}

Hoy en día existen muchas disparidades y desigualdades entre los sexos que parecen estar arraigadas en las políticas públicas y en la asignación de recursos. Varias organizaciones internacionales y de otro tipo han sido pioneras en la promoción de la perspectiva de género, es decir, en el diseño y supervisión de políticas públicas que incluyen una evaluación del impacto atendiendo a la diferencia de género con el fin de eliminar gradualmente las desigualdades en el sector público y en la economía en general. Los presupuestos con perspectiva de género integran este principio en el proceso presupuestario, mediante la implementación de procesos específicos y herramientas analíticas que fomentan políticas sensibles a las cuestiones de género con el fin de solventar las desigualdades y disparidades entre los sexos.

Según la Encuesta de la OCDE sobre presupuestos con perspectiva de género de 2016, poco más de un tercio de los países de la OCDE (12 países) confirman haber incorporado la perspectiva de género en su proceso presupuestario. Del resto de los países de la OCDE, Italia prevé la introducción de presupuestos con perspectiva de género y la República Checa y Turquía están considerando activamente su introducción en el futuro. Este tipo de presupuestos se han introducido paulatinamente durante la última década en respuesta a la creciente percepción de desigualdades, factor que se cita con más frecuencia como motivo para su implementación. 
Aunque los presupuestos con perspectiva de género varían entre los países que los han introducido, los distintos sistemas presupuestarios se pueden agrupar en tres grandes bloques: 1) asignación de recursos con información de género, que incorpora las evaluaciones en las decisiones políticas individuales o en destinaciones de fondos; 2) presupuestos con evaluación del impacto en función del género, a nivel global, y 3 ) presupuestos basados en las necesidades de género, donde las evaluaciones forman parte del proceso presupuestario. Estas tres categorías son a grandes rasgos progresivas, en cuanto que los países que tienen presupuestos con evaluación del impacto en función del género suelen llevar cabo también una asignación de recursos con orientación de género, y los países que tienen presupuestos basados en las necesidades de género incorporan también la evaluación del impacto en función del género. Dos tercios de los países de la OCDE (8 países) que realizan presupuestos con perspectiva de género pertenecen a las dos primeras categorías, y solo cuatro llevan a cabo una evaluación de las necesidades de género como parte de su proceso presupuestario (Austria, México, Noruega y los Países Bajos).

La mitad de estos países (6 países) con algún tipo de presupuestos de género podría proporcionar ejemplos específicos de cómo las herramientas presupuestarias han provocado cambios significativos en el diseño de políticas o resultados. En estos casos, los países a menudo citan ejemplos en los que los presupuestos de género han estimulado el desarrollo de políticas que mejoran la igualdad entre los sexos. Por el contrario, los ejemplos que incluyen cambios en la asignación de recursos son más limitados. Puesto que la introducción de presupuestos con perspectiva de género es todavía relativamente reciente en un número de países, el alcance de su impacto podría hacerse más evidente en el futuro.

La gran mayoría de países que no han introducido formalmente los presupuestos con perspectiva de género aplican, en distinta medida, un enfoque de género a su proceso de formulación de políticas, que puede a su vez repercutir en los gastos. La naturaleza y calidad de estos enfoques es bastante variable, y va desde una declaración pro forma del impacto sobre la igualdad de género que debe acompañar a todas las políticas presentadas al Gobierno hasta evaluaciones del impacto en función del género más estructuradas y sistemáticas. 


\section{Metodología y definiciones}

Los datos proceden de la Encuesta de la OCDE sobre presupuestos con perspectiva de género de 2016. Los encuestados eran predominantemente altos funcionarios encargados de los presupuestos en los países de la OCDE. Se recibieron respuestas de todos los países de la OCDE, exceptuando Letonia (que no era miembro de la OCDE en el momento de recogida de datos). Las respuestas reflejan las valoraciones de los propios países en cuanto a las prácticas existentes. En su mayor parte, las respuestas se refieren solo a la Administración central/federal y excluyen las prácticas presupuestarias con perspectiva de género a nivel estatal/ local.

La información de la Encuesta de la OCDE sobre presupuestos con perspectiva de género de 2016 se ha utilizado para desarrollar una tipología de los sistemas presupuestarios de género. Se pidió a los países que han introducido este tipo de presupuestos que indicaran las herramientas y métodos utilizados para su implementación. Las herramientas y métodos usados en cada país proporcionan una indicación de la naturaleza del sistema presupuestario con perspectiva de género del país en cuestión. La OCDE ha utilizado esta información para identificar tres categorías principales de sistemas presupuestarios con perspectiva de género, que se presentan en la Tabla 5.4.

\section{Otras publicaciones}

OECD (2016), Gender budgeting in OECD countries, OECD Publishing, París, $<$ www.oecd.org/gender/Gender-Budgetingin-OECD-countries.pdf $>$.

OECD (2016), 2015 OECD recommendation of the Council on gender equality in public life, OECD Publishing, París, <http://dx.doi. org/10.1787/9789264252820-en>.

\section{Notas de los gráficos}

Los datos de Letonia no están disponibles.

Información sobre los datos de Israel: <http://dx.doi.org/10.1787/888932315602>. 


\section{Gráfico 5.3. Estado de los presupuestos con perspectiva de género, 2016}

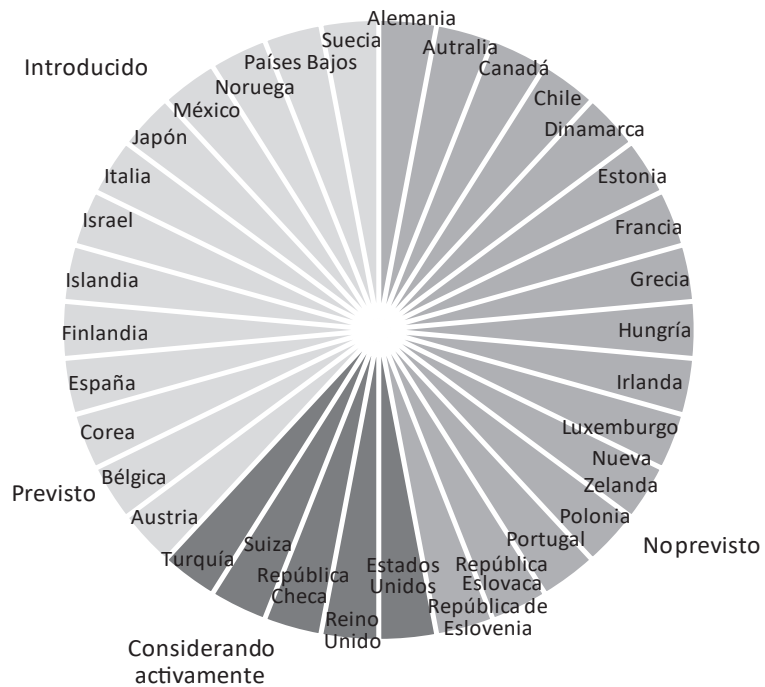

Fuente: OCDE (2016), Encuesta sobre presupuestos con perspectiva de género, OCDE, París.

$<$ http://dx.doi.org/10.1787/888933532732>

Tabla 5.4. Tipología de los sistemas presupuestarios con perspectiva de género, 2016

\begin{tabular}{|c|c|c|c|c|c|c|c|c|c|c|}
\hline \multirow[b]{2}{*}{$\begin{array}{l}\text { Categorías de presupuestos con } \\
\text { perspectiva de género }\end{array}$} & & \multicolumn{9}{|c|}{ Uso de herramientas presupuestarias de género } \\
\hline & & 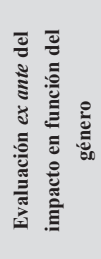 & 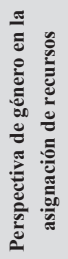 & 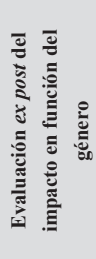 & 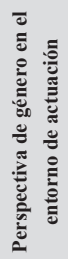 & 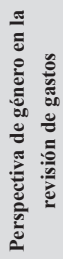 & 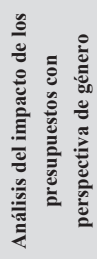 & 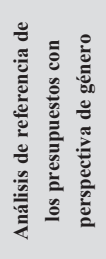 & 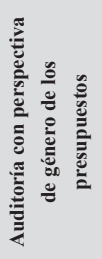 & 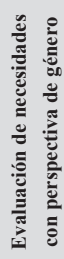 \\
\hline \multirow{3}{*}{$\begin{array}{l}\text { 1) Asignación de recursos con } \\
\text { información de género }\end{array}$} & Bélgica & $\bullet$ & O & 0 & o & o & o & ○ & o & O \\
\hline & Finlandia & O & $\bullet$ & o & $\bullet$ & o & ० & o & o & o \\
\hline & Japón & O & $\bullet$ & ○ & ○ & ○ & ○ & ○ & o & O \\
\hline \multirow{5}{*}{$\begin{array}{l}\text { 2) Presupuestos con evaluación } \\
\text { de género }\end{array}$} & Corea & O & $\bullet$ & O & • & $\bullet$ & o & $\bullet$ & o & O \\
\hline & España & $\bullet$ & $\bullet$ & $\bullet$ & $\bullet$ & o & $\bullet$ & $\bullet$ & $\bullet$ & 0 \\
\hline & Islandia & $\bullet$ & $\bullet$ & $\bullet$ & $\bullet$ & 0 & o & $\bullet$ & 0 & 0 \\
\hline & Israel & $\bullet$ & 0 & $\bullet$ & o & o & $\bullet$ & - & 0 & 0 \\
\hline & Suecia & - & 0 & • & $\bullet$ & $\bullet$ & 0 & 0 & $\bullet$ & 0 \\
\hline
\end{tabular}




\begin{tabular}{|c|c|c|c|c|c|c|c|c|c|c|}
\hline \multirow[b]{2}{*}{$\begin{array}{l}\text { Categorías de presupuestos con } \\
\text { perspectiva de género }\end{array}$} & & \multicolumn{9}{|c|}{ Uso de herramientas presupuestarias de género } \\
\hline & & 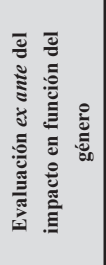 & 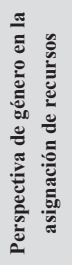 & 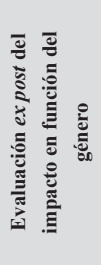 & 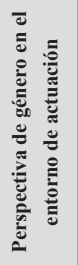 & 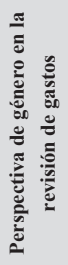 & 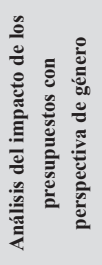 & 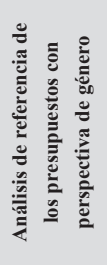 & 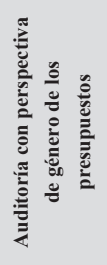 & 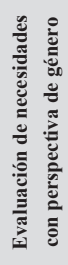 \\
\hline \multirow{4}{*}{$\begin{array}{l}\text { 3) Presupuestos basados en las } \\
\text { necesidades de género }\end{array}$} & Austria & $\bullet$ & O & $\bullet$ & $\bullet$ & o & $\bullet$ & $\bullet$ & O & $\bullet$ \\
\hline & México & $\bullet$ & $\bullet$ & $\bullet$ & $\bullet$ & o & $\bullet$ & - & O & $\bullet$ \\
\hline & Noruega & $\bullet$ & $\bullet$ & o & o & o & $\bullet$ & O & $\bullet$ & $\bullet$ \\
\hline & $\begin{array}{l}\text { Países } \\
\text { Bajos }\end{array}$ & $\bullet$ & $\bullet$ & $\bullet$ & $\bullet$ & O & $\bullet$ & $\bullet$ & $\bullet$ & $\bullet$ \\
\hline \multicolumn{11}{|l|}{ Total OCDE } \\
\hline $\begin{array}{l}\text { Herramienta presupuestaria } \\
\text { de género en uso }\end{array}$ & & 9 & 8 & 7 & 8 & 2 & 6 & 7 & 4 & 4 \\
\hline $\begin{array}{l}\text { O Herramienta presupuestaria } \\
\text { de género no en uso }\end{array}$ & & 3 & 4 & 5 & 4 & 10 & 6 & 5 & 8 & 8 \\
\hline
\end{tabular}

Fuente: OCDE (2016), Encuesta sobre presupuestos con perspectiva de género, OCDE, París.

\section{ANÁLISIS DE GASTOS}

La práctica del análisis de gastos ha aumentado drásticamente desde la crisis financiera mundial. El análisis de gastos tiene dos objetivos fundamentales: dar a las Administraciones públicas mayor control del nivel del gasto agregado y mejorar la priorización de gastos. Los países con más experiencia en el uso del análisis de gastos han demostrado que esta práctica centra a las Administraciones públicas en la mejora de la priorización de gastos y en la búsqueda de espacio fiscal que dé cabida a estas nuevas prioridades. Dado el difícil contexto fiscal al que se enfrentan muchos Gobiernos de la OCDE, esta herramienta podría resultar inestimable, en especial si se integra de manera permanente en el proceso presupuestario.

En 2016, 23 países de la OCDE confirmaron utilizar el análisis de gastos, en comparación con 16 en 2011. Cinco países más están considerando el uso de esta herramienta en el futuro (Austria, Estonia, Israel, Noruega y Turquía). Más del $70 \%$ de los países que utilizan el análisis de gastos están realizando múltiples análisis, lo cual indica que la práctica se está integrando en los procesos presupuestarios y no es solo una respuesta ad hoc a las presiones fiscales. Si se va a institucionalizar el análisis de gastos, su diseño debe ser adecuado y corregido para que deje de ejercer como una herramienta específica de consolidación fiscal y pueda ser incorporado en la elaboración ordinaria 
de presupuestos. Además, puesto que el análisis de gastos es una actividad que requiere gran cantidad de recursos, es esencial que su diseño sea lo más eficiente posible en función de sus costes.

Históricamente existen dos modelos de análisis de gastos: análisis específicos anuales (Dinamarca y los Países Bajos) y análisis globales cíclicos (el Reino Unido). Un análisis específico de gastos se centra en una lista de temas por revisar que se decide al inicio. Por el contrario, un análisis global de gastos no se ve limitado a una lista ex ante de temas que revisar, y tiene como objetivo analizar los gastos en mayor profundidad. Sin embargo, un análisis global de gastos no trata de examinar literalmente todo. Hasta el momento, los países que han introducido recientemente esta práctica parecen ser partidarios del análisis global de gastos y no del análisis limitado.

El modelo de gobernanza del análisis de gastos determina cómo y cuándo cada institución está inmersa en un análisis de gastos. En lo que respecta a los roles y responsabilidades del proceso del análisis de gastos, la supervisión y orientación política resulta imprescindible. La práctica más usual es que la autoridad presupuestaria central dirija el análisis de gastos (Bélgica, Canadá, Finlandia, Francia, Irlanda, Letonia, México, Nueva Zelanda, Reino Unido y Suiza). Un número reducido de países de la OCDE han optado por un análisis dirigido por la Oficina del Presidente o Primer Ministro (Italia y Luxemburgo), con resultados desiguales. Otros países de la OCDE tienden hacía un modelo mixto de gobernanza del análisis de gastos, en el que un número de agentes gubernamentales tiene un nivel de responsabilidad importante. En Japón, sin embargo, los responsables principales de los procedimientos del análisis de gastos son expertos fuera del ámbito de las Administraciones.

A pesar de su popularidad, los resultados del análisis de gastos no siempre son claros. Diez países de la OCDE concluyeron haber alcanzado el 90\% o más de los objetivos fiscales establecidos en análisis de gastos previos (Canadá, Grecia, Irlanda, Italia, Letonia, Luxemburgo, México, el Reino Unido, Suecia y Suiza). Sin embargo, nueve países de la OCDE no tienen información sobre los resultados fiscales de los análisis de gastos (Alemania, Australia, Dinamarca, los Estados Unidos, Finlandia, Francia, Japón, Polonia y Portugal). Más problemático aún, 13 países de la OCDE no tienen información sobre la consecución de los objetivos de desempeño de análisis de gastos previos. El seguimiento adecuado de la implementación y efectividad de los análisis de gastos supone un ámbito de posible mejora.

\section{Metodología y definiciones}

Los datos corresponden a 2016 y se basan en las respuestas a preguntas de la Encuesta de la OCDE sobre presupuestos basados en resultados de 2016. Los encuestados eran predominantemente altos funcionarios 
encargados de los presupuestos en los países de la OCDE. Se recibieron respuestas de 33 de los 35 países de la OCDE, que reflejan las valoraciones de los propios países en cuanto a las prácticas existentes. Las respuestas se refieren solo a la Administración central/federal y excluyen las prácticas presupuestarias basadas en resultados a nivel estatal/local.

Un análisis limitado de gastos comprende entre el $0 \%$ y el $5 \%$ del gasto público total, un análisis amplio de gastos comprende entre el $5 \%$ y el $20 \%$ del gasto público total y un análisis global de gastos comprende entre el $20 \%$ y el $100 \%$ del gasto público.

La autoridad presupuestaria central es una entidad pública, o varias entidades coordinadas, responsables de la custodia y gestión de todos (o la mayoría de) los fondos públicos. A menudo forma parte del Ministerio de Hacienda de la Administración central.

El Gráfico 5.6 muestra el número de procesos de análisis de gastos del que es responsable cada agente gubernamental como porcentaje de los procesos totales de análisis de gastos realizados por agentes gubernamentales. Pondera todos los procesos por igual.

\section{Otras publicaciones}

OECD (2017), 2016 OECD performance budgeting survey highlights: Integrating performance and results in budgeting, OECD Publishing, París, $<$ www.oecd.org/gov/budgeting/Performance-Budgeting-SurveyHighlights.pdf $>$.

OECD (2008), «Performance budgeting: A user's guide», OECD policy brief, OECD Publishing, París, <www.oecd.org/ gov/budgeting/PerformanceBudgeting-Guide.pdf $>$.

\section{Notas de los gráficos}

5.5: Los datos abarcan el periodo 2008 hasta el 4 de marzo de 2016. Solo se muestra a los países de la OCDE que han realizado análisis de gastos. Los Estados Unidos ha realizado análisis de gastos, pero no proporcionó información sobre su frecuencia y alcance.

5.6: Solo se muestra a los países de la OCDE que han realizado análisis de gastos. Australia ha realizado análisis de gastos, pero no proporcionó información sobre su modelo de gobernanza. 


\section{Gráfico 5.5. Frecuencia y alcance de los análisis de gastos, 2000-2007 y 2008-2016}

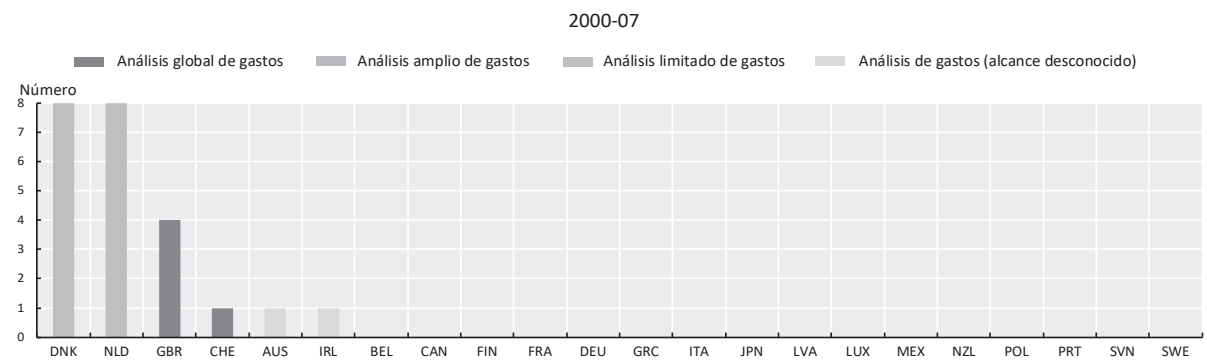

2008-16

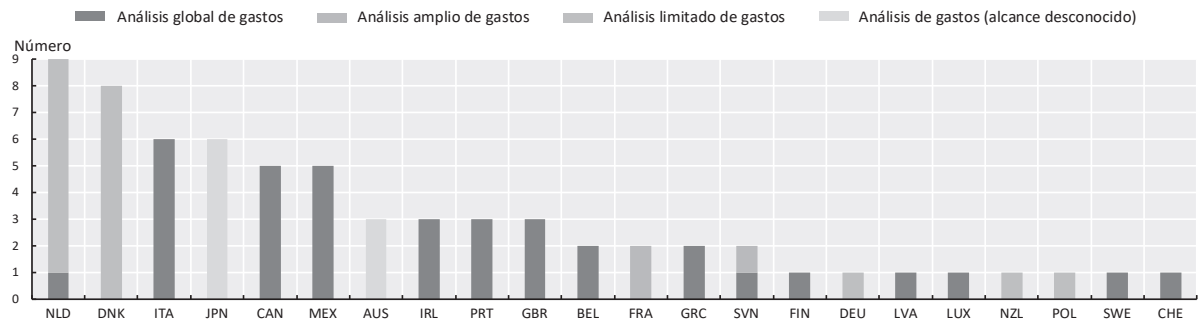

Fuente: (2016), Encuesta de la OCDE sobre presupuestos basados en resultados, OCDE, París.

$<$ http://dx.doi.org/10.1787/888933532751>

Gráfico 5.6. Modelo de gobernanza del análisis de gastos, 2016 y 20082016

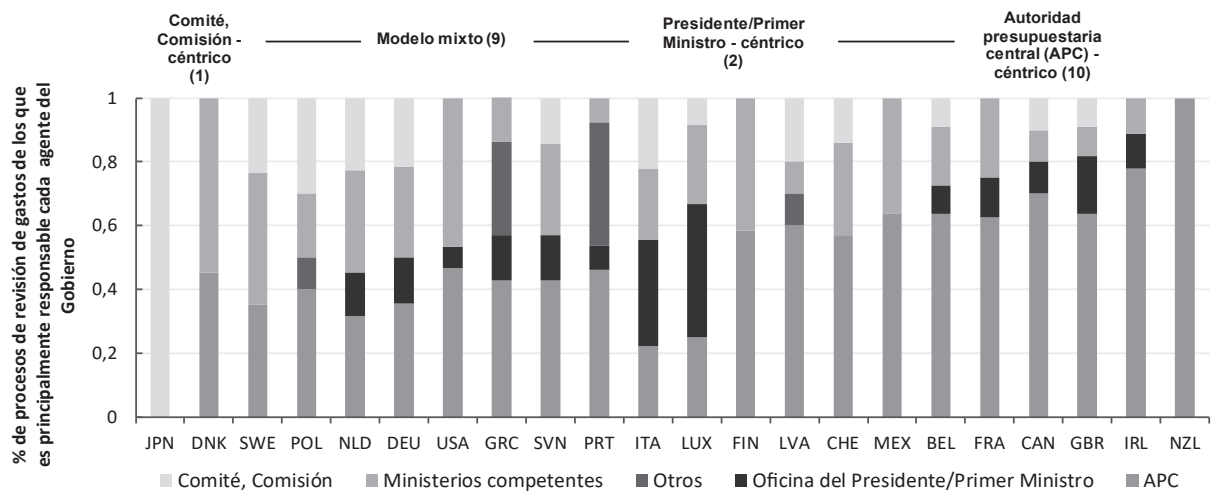

Fuente: (2016), Encuesta de la OCDE sobre presupuestos basados en resultados, OCDE, París.

$<$ http://dx.doi.org/10.1787/888933532770> 


\section{GOBERNANZA DE LAS INFRAESTRUCTURAS}

Las infraestructuras de alta calidad constituyen una piedra angular de las Administraciones públicas para conseguir el desarrollo inclusivo a largo plazo. No obstante, los proyectos de infraestructuras a veces no cumplen su marco temporal, presupuesto y objetivos de la prestación de servicios. Esto a menudo se debe a deficiencias en el marco de gobernanza para infraestructuras del país.

La gobernanza adecuada de las infraestructuras no solo fomenta la rentabilidad y asequibilidad, sino también la realización de proyectos apropiados que cuentan con la confianza de usuarios y ciudadanos. El éxito en la gobernanza de las infraestructuras requiere una marco regulatorio e institucional claro, una coordinación sólida entre los distintos niveles de las Administraciones y el rendimiento sostenible del activo durante su ciclo completo. Además, requiere una fase de preparación integral, que incluya una planificación estratégica, mecanismos de priorización abiertos y transparentes y procesos de toma de decisiones basados en la asequibilidad y el rendimiento (OCDE, 2017). Sin embargo, diseñar una visión estratégica clara y coherente es difícil debido a la naturaleza compleja de la política de infraestructuras, ya que debe abordar objetivos múltiples y potencialmente contradictorios como pueden ser el crecimiento, la productividad, la asequibilidad, el desarrollo inclusivo y aspectos medioambientales.

La planificación estratégica a largo plazo es un elemento clave del éxito en el desarrollo de infraestructuras, pero solo la mitad de los países de la OCDE cuentan con una visión estratégica de infraestructuras a largo plazo que cubra transversalmente todos los sectores. Para suplementar la visión a largo plazo, las Administraciones públicas deberían también identificar una lista reducida de los proyectos prioritarios, teniendo en cuenta objetivos políticos opuestos, las necesidades existentes y las limitaciones presupuestarias. Según datos recogidos en 2016, solo 16 países de la OCDE preparan este tipo de lista. Nueve países (Australia, Austria, Corea, Hungría, Italia, Nueva Zelanda, los Países Bajos, el Reino Unido y Turquía) combinan ambos enfoques. La congestión de los transportes y los objetivos de desarrollo regionales suelen impulsar los planes estratégicos de infraestructuras en los países de la OCDE. Solo cuatro países mencionan el cambio climático como un factor importante.

La priorización, aprobación y financiación deberían estar basadas en unos criterios formales establecidos para garantizar la rentabilidad, asequibilidad, transparencia y rendición de cuentas. La rentabilidad podría ser definida como lo que el gobierno considera una combinación óptima de cantidad, calidad, características y precio (es decir, los costes), a lo largo del ciclo completo del proyecto. Puede ser medida en términos absolutos de costes-beneficios o en términos relativos en comparación con otras modalidades de prestación. La rentabilidad es esencial para garantizar la asequibilidad y sostenibilidad y 
ayuda a los responsables políticos a priorizar proyectos y a generar el máximo valor para la sociedad en general.

Aunque formar parte de un plan estratégico a largo plazo y mostrar un análisis de rendimiento sólido son criterios importantes en la selección y financiación de proyectos, la motivación política es un factor clave de las decisiones de inversión en infraestructuras. Los intereses ciudadanos y empresariales son fundamentales para la priorización de proyectos, aunque resultan menos importantes cuando se trata de las fases de financiación y aprobación. Solo alrededor del 50\% de los países de la OCDE cuentan con un proceso sistemático para garantizar la rentabilidad absoluta de los proyectos de infraestructuras, y las decisiones sobre las modalidades diferentes de prestación no siempre se basan en análisis comparativos y cualitativos.

\section{Metodología y definiciones}

Los datos de todos los gráficos proceden de la Encuesta de la OCDE sobre la Gobernanza de Infraestructuras de 2016. La encuesta se llevó a cabo a principios de 2016 y comprende 26 países de la OCDE. Los encuestados eran predominantemente altos funcionarios del ministerio de hacienda central/federal, y de otros ministerios competentes.

La gobernanza de las infraestructuras engloba una variedad de procesos, herramientas y normas de interacción, toma de decisiones y supervisión, utilizados por las Administraciones públicas y otras entidades que proporcionan servicios de infraestructuras. Está relacionada, por tanto, con las interacciones de las instituciones gubernamentales a nivel interno, y con las interacciones de estas con los usuarios del sector privado y ciudadanos. Los datos sobre los pilares clave de los planes estratégicos de infraestructuras y los criterios de priorización de proyectos están disponibles online (véase el Anexo F). 


\section{Otras publicaciones}

OECD (2017), «Getting Infrastructure Right: A Framework for Better Governance», OECD Publishing, París.

OECD (2017), «Review of Gaps and Governance Standards of Public Infrastructure in Chile», OECD Publishing, París.

OECD (2012), Recommendation of the Council on Principles for Public Governance of Public-Private Partnerships, OECD Publishing, París.

\section{Notas de los gráficos}

Los datos de Canadá, los Estados Unidos, Grecia, Islandia, Israel, Letonia, Polonia, Portugal y la República Eslovaca no están disponibles.

5.7: Irlanda tiene un plan de infraestructuras a medio plazo de seis a siete años, publicado en 2015. En México, el plan se refiere a la Administración central desde una perspectiva sectorial. En Austria, España y Hungría el plan se refiere solo a la Administración central. Se preguntó solo a los países sin un plan estratégico general de infraestructuras a largo plazo sobre su plan sectorial de infraestructuras a largo plazo. En Australia y Bélgica, las regiones y autoridades locales son las principales responsables de la inversión en infraestructuras, y las respuestas dadas se refieren solo a la Administración central/federal.

5.9: Japón no contestó a la pregunta.

Tabla 5.7. Existencia de un enfoque estratégico en la planificación y priorización de los proyectos de infraestructuras, 2016

\begin{tabular}{|c|c|c|c|c|}
\hline País & $\begin{array}{c}\text { Plan estratégico } \\
\text { general de } \\
\text { infraestructuras a } \\
\text { largo plazo }\end{array}$ & $\begin{array}{c}\text { El plan integra a la } \\
\text { Administración } \\
\text { central y a las } \\
\text { Administraciones } \\
\text { subnacionales }\end{array}$ & $\begin{array}{c}\text { Plan sectorial de } \\
\text { infraestructuras a } \\
\text { largo plazo }\end{array}$ & $\begin{array}{c}\text { Lista reducida de } \\
\text { proyectos } \\
\text { prioritarios }\end{array}$ \\
\hline Alemania & $\circ$ & 目 & $\bullet$ & $\bullet$ \\
\hline Australia & $\bullet$ & $\bullet$ & 目 & $\bullet$ \\
\hline Austria & $\bullet$ & 0 & 目 & $\bullet$ \\
\hline Bélgica & $\circ$ & 目 & $\bullet$ & $\bullet$ \\
\hline Chile & $\circ$ & 目 & $\bullet$ & $\bullet$ \\
\hline Corea & $\bullet$ & $\bullet$ & 目 & $\bullet$ \\
\hline Dinamarca & $\circ$ & 目 & 0 & $\bullet$ \\
\hline
\end{tabular}




\begin{tabular}{|c|c|c|c|c|}
\hline España & $\bullet$ & O & 目 & 0 \\
\hline Estonia & 0 & 目 & - & $\bullet$ \\
\hline Finlandia & 0 & 目 & 0 & 0 \\
\hline Francia & 0 & 目 & - & 0 \\
\hline Hungría & $\bullet$ & 0 & ○ & $\bullet$ \\
\hline Irlanda & 0 & 目 & 目 & $\bullet$ \\
\hline Italia & $\bullet$ & $\bullet$ & 国 & $\bullet$ \\
\hline Japón & $\bullet$ & ○ & 国 & 0 \\
\hline Luxemburgo & 0 & 目 & $\mathrm{O}$ & $\bullet$ \\
\hline México & $\bullet$ & 目 & 国 & 0 \\
\hline Noruega & 0 & 目 & - & 0 \\
\hline Nueva Zelanda & $\bullet$ & - & 目 & 0 \\
\hline Países Bajos & $\bullet$ & 目 & 目 & $\bullet$ \\
\hline Reino Unido & $\bullet$ & - & 国 & $\bullet$ \\
\hline República Checa & 0 & 目 & - & 0 \\
\hline $\begin{array}{l}\text { República de } \\
\text { Eslovenia }\end{array}$ & 0 & 目 & $\bullet$ & $\bullet$ \\
\hline Suecia & $\bullet$ & - & 国 & 0 \\
\hline Suiza & 0 & 目 & ○ & $\bullet$ \\
\hline Turquía & $\bullet$ & $\bullet$ & 国 & $\bullet$ \\
\hline \multicolumn{5}{|l|}{ Total OCDE } \\
\hline - Sí & 13 & 8 & 10 & 16 \\
\hline O No & 13 & 3 & 3 & 10 \\
\hline
\end{tabular}

Fuente: OCDE (2016), Encuesta sobre la Gobernanza de Infraestructuras, OCDE, París.

$<$ http://dx.doi.org/10.1787/888933534955> 


\section{Gráfico 5.8. Proceso formal para garantizar el rendimiento absoluto de los proyectos de infraestructuras, 2016}

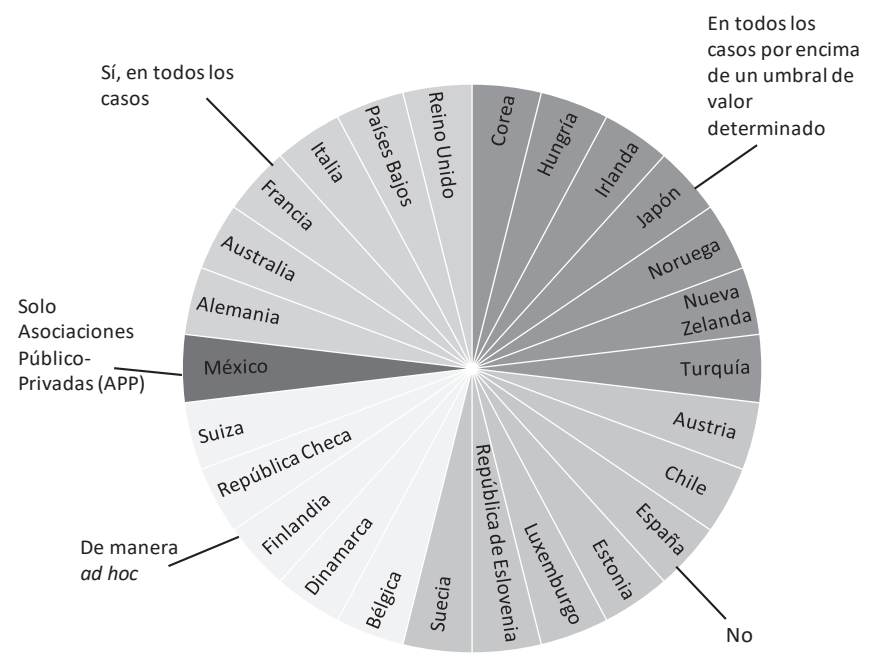

Fuente: OCDE (2016), Encuesta sobre la Gobernanza de Infraestructuras, OCDE, París

<http://dx.doi.org/10.1787/888933532789>

\section{Gráfico 5.9. Proceso para la comparación cualitativa de las modalidades de desempeño, 2016}

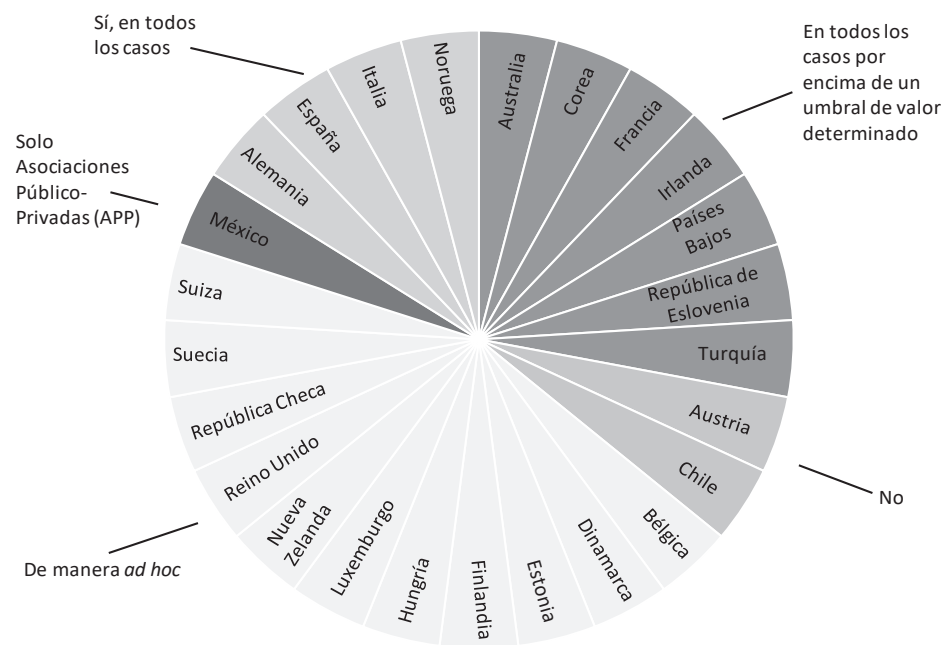

Fuente: OCDE (2016), Encuesta sobre la Gobernanza de Infraestructuras, OCDE, París. 


\section{CALIDAD DE LOS INFORMES FINANCIEROS DE LAS ADMINISTRACIONES PÚBLICAS}

La información financiera es uno de los fundamentos de la buena gestión fiscal. Los informes financieros de alta calidad son esenciales para garantizar que las decisiones fiscales de las Administraciones públicas se basan en una comprensión correcta y actualizada de su situación financiera. Los informes financieros son además el mecanismo mediante el cual los legisladores, auditores y el público en general exigen que las Administraciones rindan cuentas sobre su desempeño financiero. Por último, suponen una fuente de información crítica para que los mercados y otras partes interesadas entiendan las operaciones financieras de las Administraciones públicas y las repercusiones que estas pueden tener en sus propias decisiones económicas.

Los informes financieros de alta calidad siguen tres criterios principales: la exhaustividad, en términos de las operaciones financieras que incluyen; la amplitud, en términos de las entidades que recogen; y la integridad, en términos del grado de validación externa.

En cerca de tres cuartos de los países de la OCDE, las Administraciones públicas han mejorado la exhaustividad de sus informes financieros en cuanto que han sustituido la contabilidad de caja por la contabilidad en valores devengados. Las Administraciones que han adoptado la contabilidad en valores devengados establecen balances generales que: informan sobre los saldos de activos y pasivos; muestran si los pasivos se corresponden con los activos; y miden si las actividades y decisiones generan una carga fiscal. Sin embargo, los países han evolucionado de manera diferente en cuanto a los elementos que incluyen en sus balances generales. Por ejemplo, las pensiones de los funcionarios y los recursos naturales se recogen en los balances de 11 y 3 países de la OCDE respectivamente.

La actividad fiscal se lleva a cabo por niveles distintos de las Administraciones públicas. Los organismos gubernamentales, las entidades de la seguridad social y las Administraciones locales pueden recaudar, gastar y, en algunos casos, obtener préstamos de recursos fiscales. Cuando la información sobre la situación financiera de estas entidades públicas no está centralizada, consolidada y disponible a nivel público, la transparencia de las finanzas públicas se ve limitada. Sin embargo, solo cinco países de la OCDE (14\%) proporcionan una visión general del sector público en sus informes financieros.

Las evaluaciones de la información financiera realizadas por entidades externas e independientes y por organismos públicos son una de las principales garantías de la integridad de este tipo de informes. En todos los países de la OCDE, los informes financieros de cierre del ejercicio están sujetos a un control independiente y externo o a auditorías de instituciones supremas de auditoría. En el caso de las auditorías, 19 países de la OCDE (56\%) aplican las normas internacionales de auditoría, lo cual muestra que las técnicas de audi- 
toría han evolucionado de manera simultánea a la adopción por parte de las Administraciones públicas de la contabilidad en valores devengados.

En términos generales, los progresos en materia de exhaustividad y amplitud de los informes financieros han sido evidentes durante las últimas dos décadas. No obstante, una proporción elevada de los informes de las instituciones supremas de auditoría mencionan problemas y preocupaciones relacionados con los informes financieros, lo cual demuestra que las Administraciones públicas todavía pueden mejorar considerablemente la calidad de sus prácticas de información.

\section{Metodología y definiciones}

Los datos proceden de la Encuesta de la OCDE sobre Valores Devengados de 2016. Los encuestados eran altos funcionarios de los ministerios de hacienda. Las respuestas reflejan las valoraciones de los propios países en cuanto a las prácticas existentes.

La contabilidad en valores devengados es el método por el cual las transacciones financieras se presupuestan o reconocen en los informes financieros en el momento en el que ocurre el evento económico subyacente, independientemente de cuándo se reciban o abonen los fondos de liquidez correspondientes, y los activos y pasivos se detallan en el balance general.

Las instituciones supremas de auditoria son organismos nacionales independientes, como pueden ser las oficinas del auditor general o los tribunales de cuentas, responsables, entre otras funciones, de auditar y controlar el informe financiero anual de las Administraciones públicas.

\section{Otras publicaciones}

OECD/IFAC (2017), «Accrual Practices and Reform Experiences in OECD Countries», OECD Publishing, París, http://dx.doi. org/10.1787/9789264270572-en.

Cavanagh J. (2016), «Implementing Accrual Accounting in the Public Sector, International Monetary Fund», Washington, DC, www.imf.org/external/ pubs/cat/longres.aspx?sk=44121.0. 


\section{Notas de los gráficos}

5.12: Los países que contestaron tener tanto informes financieros de valores devengados como de caja (Hungría y la República Checa) están clasificados bajo «de devengo». Luxemburgo está clasificada bajo «de caja» pero está planificando una transición a la contabilidad en valores devengados.

5.13: Algunos países especificaron en «Administración central» que sus informes financieros incluyen las entidades de la seguridad social (España, Hungría, Noruega, los Países Bajos y Portugal). Todos los países incluyen a las entidades de la seguridad social en «Administración central y Administraciones locales».

5.14: En Australia, los recursos naturales son propiedad de las Administraciones estatales y no se incluyen en los informes financieros de la Administración federal.

Información sobre los datos de Israel: <http://dx.doi.org/10.1787/888932315602>.

\section{Gráfico 5.12. Modelo de contabilidad de los informes financieros anuales, 2015}

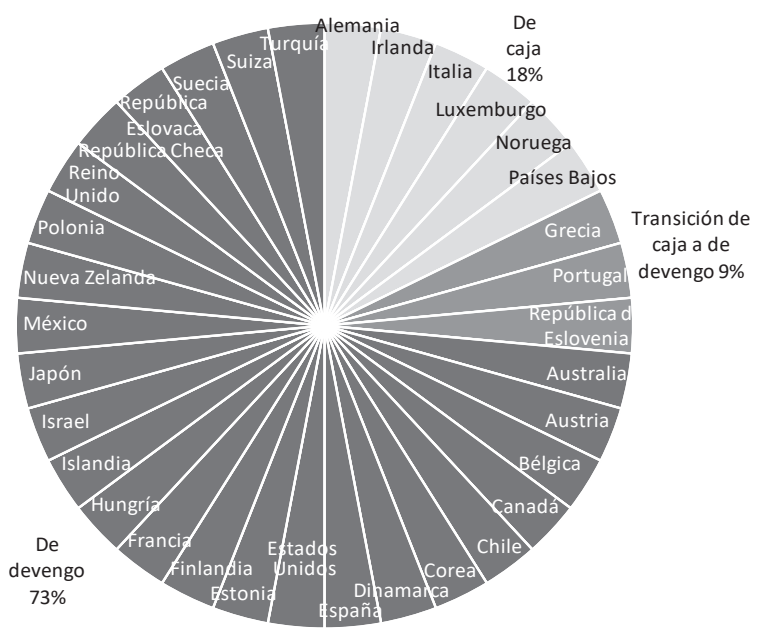

Fuente: OCDE (2016), Encuesta sobre Valores Devengados, OCDE, París.

$<h t t p: / / d x$. doi.org/10.1787/888933532827> 
Gráfico 5.13. Cobertura institucional en el informe financiero anual, 2015

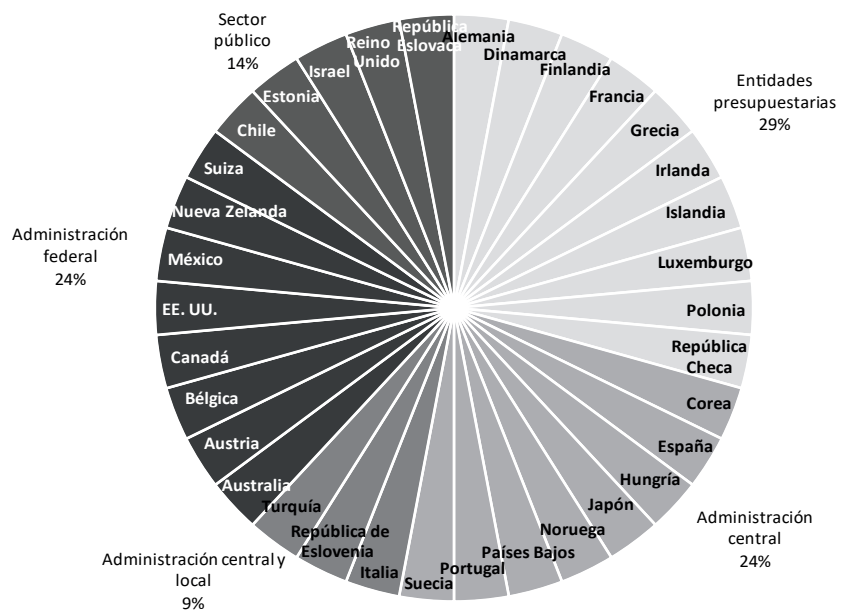

Fuente: OCDE (2016), Encuesta sobre Valores Devengados, OCDE, París.

$<$ http://dx.doi.org/10.1787/888933532846>

Tabla 5.14. Prácticas de información de activos y pasivos seleccionados en los informes financieros anuales de países implementando o en proceso de transición a la contabilidad en valores devengados, 2015

\begin{tabular}{|c|c|c|c|c|c|c|c|c|c|c|c|}
\hline & 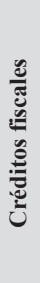 & 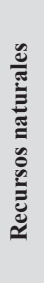 & 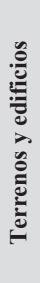 & 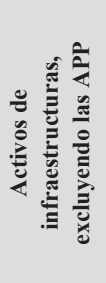 & 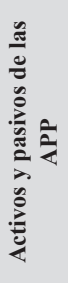 & 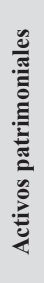 & 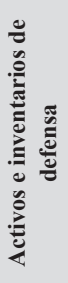 & 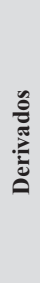 & 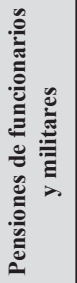 & 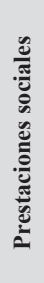 & 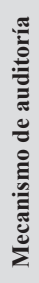 \\
\hline Australia & $\mathbf{\square}$ & - & $\mathbf{\square}$ & $\mathbf{\square}$ & $\mathbf{\square}$ & $\mathbf{\square}$ & $\mathbf{\square}$ & $\mathbf{\square}$ & $\mathbf{\square}$ & - & - \\
\hline Austria & $\mathbf{\square}$ & - & $\mathbf{\square}$ & $\mathbf{\square}$ & $\mathbf{\square}$ & $\mathbf{\square}$ & $\mathbf{\square}$ & $\mathbf{\square}$ & $\Lambda$ & - & - \\
\hline Bélgica & $\Delta$ & $x$ & $\mathbf{\square}$ & $\mathbf{\square}$ & - & - & $\mathbf{\square}$ & 口 & - & - & $\square$ \\
\hline Canadá & $\mathbf{\square}$ & $\boldsymbol{-}$ & $\mathbf{\square}$ & $\mathbf{\square}$ & $\mathbf{\square}$ & $\mathbf{\square}$ & $\mathbf{\square}$ & $\Lambda$ & $\mathbf{\square}$ & 口 & $\bullet$ \\
\hline Chile & $\mathbf{\square}$ & $\boldsymbol{-}$ & $\mathbf{\square}$ & - & - & - & - & $\mathbf{0}$ & - & $\boldsymbol{-}$ & $\square$ \\
\hline Dinamarca & $\mathbf{\square}$ & $x$ & $\mathbf{\square}$ & $\mathbf{\square}$ & $\mathbf{\square}$ & - & $\mathbf{\square}$ & $\mathbf{\square}$ & - & - & $\bullet$ \\
\hline España & $\mathbf{\square}$ & - & $\mathbf{\square}$ & $\square$ & $\Lambda$ & $\mathbf{\square}$ & $\mathbf{\square}$ & 口 & - & - & $\square$ \\
\hline Estados Unidos & $\mathbf{\square}$ & $\Delta$ & $\boldsymbol{\square}$ & $\square$ & $\square$ & $\Lambda$ & $\mathbf{\square}$ & $\mathbf{\square}$ & $\mathbf{\square}$ & $\Delta$ & ○ \\
\hline Estonia & $\mathbf{\square}$ & $\Delta$ & $\boldsymbol{\square}$ & $\square$ & $\square$ & $x$ & $\square$ & $\mathbf{0}$ & $\mathbf{\square}$ & - & 0 \\
\hline Finlandia & - & - & $\boldsymbol{\square}$ & $\square$ & $\mathbf{\square}$ & $\mathbf{\square}$ & - & $\square$ & $\Lambda$ & - & - \\
\hline
\end{tabular}




\begin{tabular}{|c|c|c|c|c|c|c|c|c|c|c|c|}
\hline & 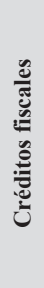 & 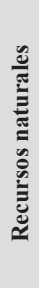 & 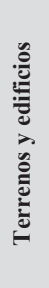 & 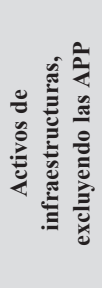 & 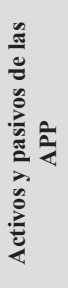 & 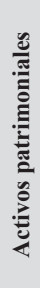 & 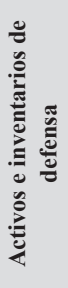 & 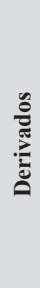 & 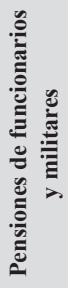 & 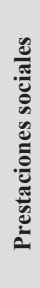 & 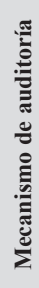 \\
\hline Francia & 口 & $x$ & $\mathbf{\square}$ & $\square$ & $\mathbf{\square}$ & 口 & $\boldsymbol{\square}$ & $\square$ & $\Delta$ & $\mathbf{\square}$ & $\bullet$ \\
\hline Grecia & 口 & - & - & - & - & - & - & $\boldsymbol{c}$ & - & - & $\bullet$ \\
\hline Hungría & - & - & $\mathbf{\square}$ & $\mathbf{\square}$ & $\Delta$ & - & $\mathbf{\square}$ & $\Delta$ & $x$ & $\Delta$ & $\square$ \\
\hline Islandia & 口 & - & - & - & - & - & - & $\boldsymbol{c}$ & $\mathbf{\square}$ & $\boldsymbol{c}$ & $\bullet$ \\
\hline Israel & 口 & $\mathbf{\square}$ & $\mathbf{\square}$ & $\mathbf{\square}$ & $\mathbf{\square}$ & $\Lambda$ & $\mathbf{\square}$ & $\mathbf{\square}$ & $\mathbf{\square}$ & $\mathbf{\square}$ & $\square$ \\
\hline Japón & 口 & $x$ & $\mathbf{\square}$ & $\mathbf{\square}$ & $\mathbf{\square}$ & $x$ & $\mathbf{\square}$ & $\mathbf{\square}$ & $x$ & $\mathbf{\square}$ & $\square$ \\
\hline Corea & 口 & - & $\mathbf{\square}$ & $\mathbf{\square}$ & $\mathbf{\square}$ & $\Lambda$ & - & $\mathbf{\square}$ & $\mathbf{\square}$ & - & $\square$ \\
\hline México & $\Delta$ & - & $\mathbf{\square}$ & $\mathbf{\square}$ & $\Delta$ & - & $\mathbf{\square}$ & $x$ & - & - & $\bullet$ \\
\hline Nueva Zelanda & 口 & - & $\mathbf{\square}$ & $\square$ & $\mathbf{\square}$ & $\mathbf{\square}$ & $\mathbf{\square}$ & $\mathbf{\square}$ & $\mathbf{\square}$ & $\mathbf{\square}$ & $\bullet$ \\
\hline Polonia & 口 & - & $\mathbf{\square}$ & $\mathbf{\square}$ & $\mathbf{\square}$ & $\mathbf{\square}$ & $\mathbf{\square}$ & $x$ & $x$ & $\mathbf{\square}$ & $\square$ \\
\hline Portugal & - & - & $\mathbf{\square}$ & $\boldsymbol{\square}$ & - & - & $\mathbf{\square}$ & - & - & $\mathbf{\square}$ & $\square$ \\
\hline Reino Unido & ם & - & $\mathbf{\square}$ & $\boldsymbol{\square}$ & $\mathbf{\square}$ & $\mathbf{\square}$ & 口 & $\mathbf{\square}$ & $\mathbf{\square}$ & - & $\bullet$ \\
\hline República Checa & $\mathbf{\square}$ & - & $\mathbf{\square}$ & $\mathbf{\square}$ & $\Delta$ & $\mathbf{\square}$ & $\mathbf{\square}$ & $\mathbf{\square}$ & - & $x$ & $\bullet$ \\
\hline República Eslovaca & $\mathbf{\square}$ & $x$ & $\mathbf{\square}$ & $\mathbf{\square}$ & $\mathbf{\square}$ & $x$ & $\mathbf{\square}$ & $\mathbf{\square}$ & $\mathbf{\square}$ & $\mathbf{\square}$ & $\bullet$ \\
\hline República de Eslovenia & $\mathbf{\square}$ & $\mathbf{\square}$ & $\mathbf{\square}$ & $\mathbf{\square}$ & - & $\mathbf{\square}$ & $\mathbf{\square}$ & $\mathbf{\square}$ & - & $x$ & $\bullet$ \\
\hline Suecia & - & $\mathbf{\square}$ & $\mathbf{\square}$ & $\mathbf{\square}$ & $x$ & $\mathbf{\square}$ & $\mathbf{\square}$ & $\mathbf{\square}$ & $\mathbf{\square}$ & $\boldsymbol{-}$ & $\bullet$ \\
\hline Suiza & $\mathbf{\square}$ & - & $\mathbf{\square}$ & $\mathbf{\square}$ & $x$ & - & - & $\mathbf{\square}$ & $\Delta$ & - & $\bullet$ \\
\hline Turquía & $\mathbf{\square}$ & - & $\mathbf{\square}$ & $\mathbf{\square}$ & $\mathbf{\square}$ & - & $\mathbf{\square}$ & $\mathbf{\square}$ & - & - & $\bullet$ \\
\hline \multicolumn{12}{|l|}{ Total OCDE } \\
\hline $\begin{array}{l}\text { Información en el } \\
\text { balance general }\end{array}$ & 24 & 3 & 26 & 25 & 16 & 12 & 22 & 21 & 11 & 9 & \\
\hline $\begin{array}{l}\text { Anformación en } \\
\text { declaraciones }\end{array}$ & 2 & 2 & & & 4 & 3 & & 2 & 4 & 2 & \\
\hline - Sin información & 2 & 18 & 2 & 3 & 6 & 10 & 6 & 3 & 10 & 15 & \\
\hline $\begin{array}{l}\text { Opinión de auditoria de } \\
\text { acuerdo con las normas } \\
\text { internacionales de auditoría } \\
\text { aplicables }\end{array}$ & & & & & & & & & & & 19 \\
\hline $\begin{array}{c}\square \text { Control de cumplimiento } \\
\text { u otro tipo de control }\end{array}$ & & & & & & & & & & & 9 \\
\hline$\times$ No aplicable & & 5 & & & 2 & 3 & & 2 & 3 & 2 & \\
\hline
\end{tabular}

Fuente: OCDE (2016), Encuesta sobre Valores Devengados, OCDE, París. 


\section{CAPÍTULO 6. GESTIÓN DE RECURSOS HUMANOS}

\section{DELEGACIÓN DE COMPETENCIAS EN LA GESTIÓN DE RECURSOS HUMANOS}

La toma de decisiones en la gestión de recursos humanos (GRH), relacionada por ejemplo con la selección, contratación, remuneración, condiciones laborales y despido de empleados, es responsabilidad de las autoridades centrales de GRH, que a su vez pueden delegar en los ministerios, departamentos u organismos competentes. La delegación, en condiciones apropiadas y siguiendo unas normas establecidas, empodera y capacita a los gestores públicos a dirigir mejor a su personal, y les permite tener en cuenta tanto los requisitos específicos de las organizaciones como los méritos de sus empleados a nivel personal. Esto conlleva una mejor alineación de las estrategias de planificación y gestión de RR. HH. Sin embargo, la delegación sin unos criterios similares de gestión y sin la supervisión de la autoridad central a menudo resulta en escalas salariales desiguales, limita las oportunidades de planificación estratégica de la GRH a nivel global de las Administraciones, y abre la puerta al nepotismo y a la interferencia política en la toma de decisiones.

El índice compuesto presentado resume el grado de delegación en las prácticas de gestión de recursos humanos en los ministerios competentes de la Administración central. Los resultados muestran que no existe un modelo único o una normativa común en esta materia en los países de la OCDE, y el grado de delegación varía considerablemente entre los países. En 2016, varios países de la OCDE demostraron un nivel alto de delegación, con la República Eslovaca y Suecia como ejemplos destacados. En la República Eslovaca no existe una unidad central de GRH que supervise unos estándares mínimos, lo cual dificulta la recogida de datos útiles para la planificación de RR. HH. y para establecer procesos comunes de desempeño. En Suecia, la delegación es más eficiente puesto que se acompaña de unas normas efectivas establecidas y gestionadas por la unidad central de RR. HH. En comparación, Israel y Luxemburgo muestran niveles relativamente más bajos de delegación, siendo los 
organismos centrales de GRH los principales responsables de este tipo de decisiones.

Casi todos los países de la OCDE (con la excepción de Alemania y la República Eslovaca) tienen por lo menos una unidad central de GRH a nivel central/nacional/federal. Veintidós países de la OCDE cuentan con una unidad central responsable de al menos algunas funciones clave de la GRH, como la fijación de salarios, el establecimiento de sistemas de evaluación del rendimiento profesional, los códigos de conducta y aspectos éticos. Once países de la OCDE (Australia, Austria, Bélgica, Finlandia, Francia, Irlanda, Islandia, Italia, Portugal, la República de Eslovenia y Suecia) tienen una unidad central de GRH que juega un papel de coordinación entre los ministerios competentes pero que no es formalmente responsable de las funciones de GRH.

Desde la última encuesta de 2010, Alemania, Irlanda, Italia y la República Eslovaca han aumentado su grado de delegación significativamente. Por el contrario, la República Checa ha aumentado su grado de centralización. En los Países Bajos, las políticas de RR. HH. también están más centralizadas, con ejemplos como el sistema de grupos ocupacionales, el sistema de gestión del rendimiento profesional, y un mayor nivel de servicios compartidos que operan a todos los niveles de la Administración. A pesar de los cambios en países específicos, no es posible identificar una tendencia clara en un sentido u otro. Las funciones de RR. HH. que se delegan en los ministerios con mayor frecuencia son la gestión de la parte variable del salario (es decir, las bonificaciones), la formación y la planificación de carreras profesionales a nivel individual. Las unidades centrales de RR. HH. y el ministerio de hacienda suelen estar más involucrados en funciones como la gestión general de los sistemas de pago, los sistemas de evaluación del rendimiento profesional, los códigos de conducta y los aspectos éticos.

\section{Metodología y definiciones}

Los datos corresponden a 2016 y 2010 y se han recogido de la Encuesta de la OCDE sobre gestión estratégica de recursos humanos de 2016 y 2010. Los encuestados eran predominantemente altos funcionarios de los departamentos de GRH de la Administración central, y los datos se refieren a prácticas de GRH a nivel central. Todos los países de la OCDE (exceptuando Letonia y Luxemburgo en 2010) y los países en proceso de adhesión, Colombia, Costa Rica y Letonia, completaron la encuesta. Las definiciones de función pública, así como de las organizaciones gobernadas por la Administración a nivel central, difieren entre los países y esto se debe tener en cuenta al establecer comparaciones. Los términos función pública, servicio público y funcionariado/ funcionarios se utilizan indistintamente en este capítulo.

El índice de delegación de prácticas de GRH se compone de las siguientes variables: la existencia de un organismo central de GRH, y el papel de los mi- 
nisterios competentes a la hora de determinar el número y tipos de puestos dentro de las organizaciones; asignaciones presupuestarias a nóminas y otros gastos; niveles retributivos del personal; clasificación de puestos, contratación y despido; y las condiciones laborales. El índice varía entre 0 (sin delegación) y 1 (grado alto de delegación). En el caso de datos ausentes de países se ha utilizado el método de sustitución por la media.

Véase el Anexo online para más información específica por país y para información sobre la metodología y factores utilizados para elaborar el índice. Las variables que componen el índice y su importancia relativa se basan en juicios expertos. Se presentan con el fin de promover el debate y, por tanto, pueden evolucionar a lo largo del tiempo.

\section{Otras publicaciones}

OECD (2011), Public Servants as Partners for Growth: Toward a Stronger, Leaner and More Equitable Workforce, OECD Publishing, París.

\section{Notas de los gráficos}

Información sobre los datos de Israel: $<$ http://dx.doi.org/10.1787/ 888932315602>.

Gráfico 6.1. Grado de delegación en las prácticas de gestión de recursos humanos de los ministerios competentes de la Administración central, 2016 y 2010

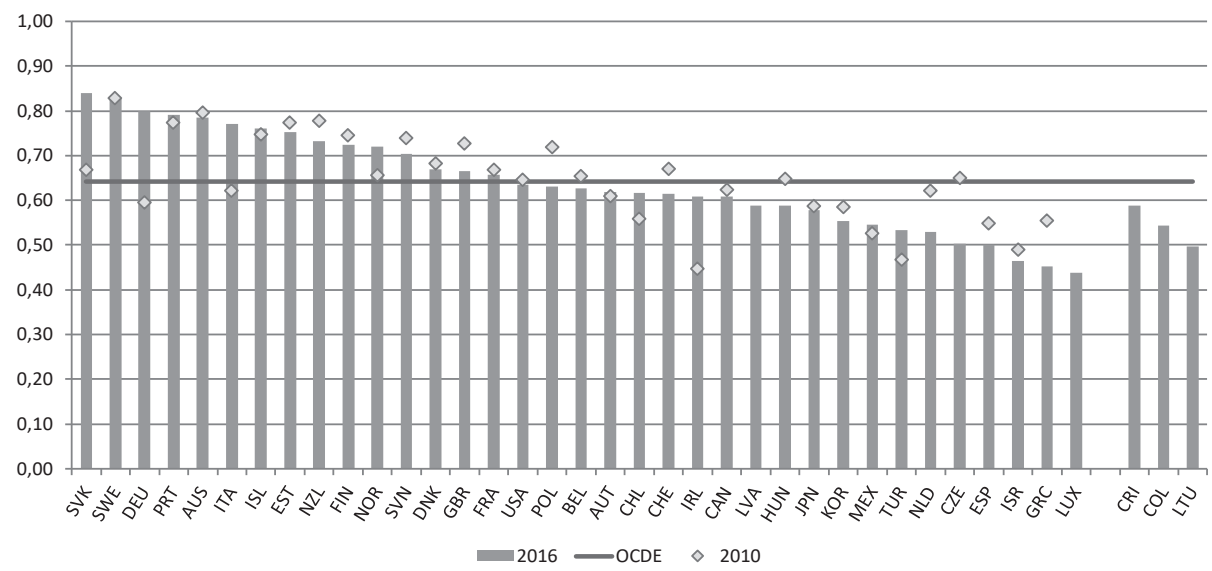

Fuente: OCDE (2016, 2010), Encuesta sobre Gestión Estratégica de Recursos Humanos, OCDE, París. 
Tabla 6.2. Delegación de responsabilidades clave de GRH en ministerios competentes de la Administración central, 2016

\begin{tabular}{|c|c|c|c|c|c|c|c|}
\hline & 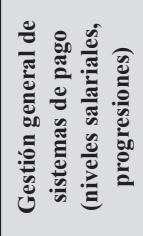 & 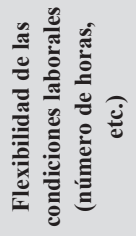 & 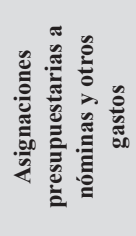 & 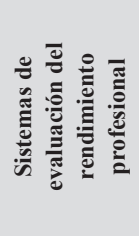 & 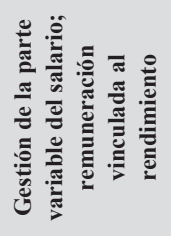 & 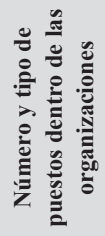 & 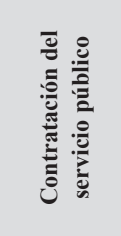 \\
\hline Alemania & $\mathbf{\square}$ & - & $\square$ & $\mathbf{0}$ & $\mathbf{\square}$ & $\mathbf{\square}$ & $\mathbf{\square}$ \\
\hline Australia & $\square$ & 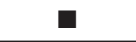 & $\square$ & $\square$ & 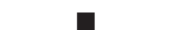 & $\square$ & $\square \Delta$ \\
\hline Austria & $\bullet$ & $\bullet$ & $\square$ & $\bullet$ & 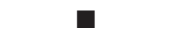 & $\bullet$ & $\square$ \\
\hline Bélgica & $\bullet$ & $\bullet$ & $\mathbf{\square}$ & $\bullet$ & $\uparrow$ & $\square$ & $\bullet$ \\
\hline Canadá & $\bullet$ & $\bullet \leftarrow$ & $\mathbf{\square}$ & $\bullet \square$ & $\bullet \leftarrow$ & $\square$ & - 1 \\
\hline Chile & - $\square$ & 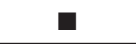 & - $\square$ & $\downarrow \square$ & $-\square \Delta$ & $\bullet$ & $\bullet \square$ \\
\hline Corea & $\bullet$ & $\bullet$ & $\bullet$ & $\downarrow$ & 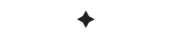 & $x$ & 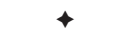 \\
\hline Dinamarca & 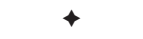 & $\bullet \square$ & $\bullet$ & $\square \Delta$ & 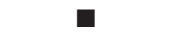 & 口 & 口 1 \\
\hline España & $\bullet$ & $\bullet$ & $\bullet \leftarrow$ & $\bullet \leftarrow$ & 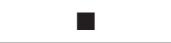 & $\bullet \leftarrow$ & $\bullet 4$ \\
\hline Estados Unidos & $\bullet$ & $\square$ & $\square$ & $\bullet$ & 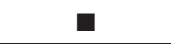 & $\square$ & $\square$ \\
\hline Estonia & $\square$ & 口 1 & $\square$ & $\mathbf{0}$ & 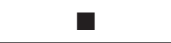 & $\mathbf{0}$ & $\mathbf{0}$ \\
\hline Finlandia & - & $\downarrow$ & $\square$ & $\downarrow$ & 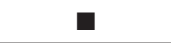 & a & $\mathbf{a}$ \\
\hline Francia & $\bullet$ & $\downarrow \square \wedge$ & $\bullet \square$ & $\downarrow \square \wedge$ & $\uparrow$ & $\bullet$ & $\bullet \square \Delta$ \\
\hline Grecia & $\bullet$ & $\bullet$ & $x$ & $\bullet$ & $x$ & $x$ & $\bullet$ \\
\hline Hungría & $\bullet$ & $\mathbf{0}$ & - $\square$ & $\bullet$ & $\bullet \leftarrow \square$ & $\bullet \quad \square$ & $\mathbf{0}$ \\
\hline Islandia & $\bullet$ & $\square \quad \Delta$ & $\square$ & $x$ & $\uparrow \square$ & $\square$ & $\square \Delta$ \\
\hline Irlanda & $x$ & $\downarrow$ & $\bullet$ & $\bullet$ & $x$ & $\square$ & -4 \\
\hline Israel & $\bullet$ & $\bullet$ & $\bullet$ & $\square$ & $\bullet$ & $\bullet$ & $\bullet$ \\
\hline Italia & $\uparrow \square$ & $\downarrow$ & $\square$ & $\mathbf{\square}$ & $\square$ & $\mathbf{a}$ & $\square$ \\
\hline Japón & $\downarrow$ & 4 & $x$ & $\downarrow$ & $\downarrow$ & 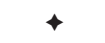 & 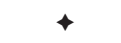 \\
\hline Letonia & $\bullet$ & $\bullet$ & - $\square$ & $\bullet$ & $\square$ & $\bullet \square$ & $\square$ \\
\hline Luxemburgo & $\bullet$ & $\bullet$ & $\bullet$ & $\bullet$ & $x$ & $\bullet$ & $\uparrow$ \\
\hline México & $\bullet$ & $\bullet$ & $\bullet \square$ & $\bullet \square$ & $\bullet \square$ & & \\
\hline Noruega & $\downarrow$ & 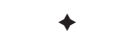 & $\bullet \square$ & $\square \wedge$ & $\square$ & $\mathbf{0}$ & $\Delta$ \\
\hline Nueva Zelanda & $\square$ & $\square$ & $\times$ & $\square$ & $\square$ & $x$ & $\square$ \\
\hline Países Bajos & $\bullet$ & $\mathbf{0}$ & $\bullet$ & $\bullet$ & $\bullet$ & $\square$ & $\square$ \\
\hline Polonia & $\square$ & $\square$ & $\bullet \square$ & $\bullet$ & $\square$ & $\square$ & $\square$ \\
\hline Portugal & $\mathbf{\square}$ & $\mathbf{\square}$ & $\square$ & $\mathbf{\square}$ & $\square$ & $\square$ & $\square$ \\
\hline Reino Unido & $\square$ & $\mathbf{\square}$ & $\bullet$ & $\mathbf{\square}$ & $\square$ & $\square$ & $\square$ \\
\hline República Checa & $\bullet$ & $\bullet \square$ & $\bullet$ & $\bullet$ & $\uparrow \square$ & $\bullet 4$ & $\square$ \\
\hline República Eslovaca & $\square$ & $\mathbf{\square}$ & $\square$ & $\square$ & $\Delta$ & $\square$ & $\square$ \\
\hline República de Eslovenia & 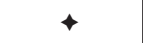 & $\square$ & $\bullet$ & $\square$ & $\square$ & 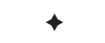 & $\square$ \\
\hline Suecia & $\square$ & 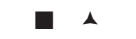 & $\square$ & $\square \Delta$ & $\square \Delta$ & $\square$ & $\square \Delta$ \\
\hline
\end{tabular}




\begin{tabular}{|c|c|c|c|c|c|c|c|}
\hline & 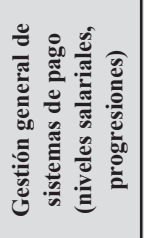 & 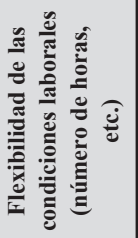 & 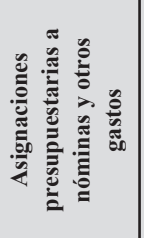 & 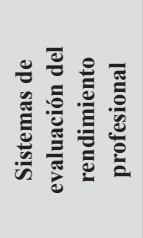 & 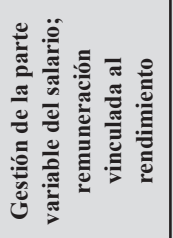 & 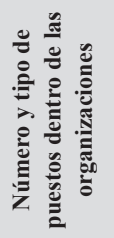 & 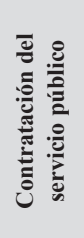 \\
\hline Suiza & + & - $\square$ & + & + & $\square$ & + & D 1 \\
\hline Turquía & 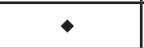 & घ & - & 口 & - & - & + \\
\hline \multicolumn{8}{|l|}{ Total OCDE } \\
\hline $\begin{array}{c}\text { 1) Organismo central de } \\
\text { GRH }\end{array}$ & 19 & 14 & 18 & 15 & 7 & 11 & 8 \\
\hline $\begin{array}{l}\text { 2) Organismo central de } \\
\text { GRH pero con margen } \\
\text { para ministerios/ } \\
\text { organismos } \downarrow\end{array}$ & 6 & 7 & 2 & 6 & 8 & 5 & 6 \\
\hline $\begin{array}{l}\text { 3) Ministerios/ } \\
\text { organismos } \square\end{array}$ & 12 & 23 & 20 & 18 & 23 & 23 & 25 \\
\hline $\begin{array}{l}\text { 4) Nivel de unidad/ } \\
\text { equipo }\end{array}$ & 0 & 4 & 0 & 4 & 4 & 0 & 8 \\
\hline $\begin{array}{c}\mathrm{X}=\text { no aplicable } / \\
\text { nodisponible }\end{array}$ & 1 & 0 & 3 & 1 & 3 & 3 & 0 \\
\hline Colombia & - & ! & $x$ & + & $\rightarrow$ & & $x$ \\
\hline Costa Rica & + & $x$ & + & + & 口 & $\cdot$ & + \\
\hline Lithuania & 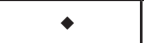 & $\bullet$ & 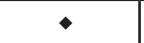 & 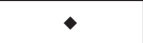 & $\bullet$ & $\square$ & 口 \\
\hline
\end{tabular}

Fuente: OCDE (2016), Encuesta sobre Gestión Estratégica de Recursos Humanos, OCDE, París.

$<$ http://dx.doi.org/10.1787/888933534993>

\section{GESTIÓN DEL RENDIMIENTO LABORAL}

Mejorar la calidad, accesibilidad y capacidad de respuesta de los servicios públicos, a la vez que se administran cuidadosamente los recursos limitados, requiere una gestión efectiva del rendimiento laboral del sector público. La definición adecuada de los itndicadores de rendimiento para políticas y servicios puede determinar los objetivos de desempeño de los empleados. Este tipo de prácticas ayuda a aclarar las metas de las organizaciones, de manera que los trabajadores comprenden mejor su papel dentro de las mismas y cómo contribuir en la consecución de los objetivos estratégicos. Las evaluaciones del rendimiento profesional sirven además de estímulo para mejorar el desempeño ya que permiten el reconocimiento de los esfuerzos individuales y colectivos de manera consistente y transparente. Las evaluaciones del rendimiento ayudan a identificar deficiencias en materia de competencias y habilidades, y proporcionan valiosa información para la planificación y formación estratégica de los RR. HH. 
Hoy en día, casi todos los países de la OCDE realizan evaluaciones del rendimiento laboral a los empleados de la Administración central de manera obligatoria. El indicador compuesto valora el uso de estas evaluaciones en la toma de decisiones de RR. HH., e incluye aspectos como los requisitos formales, las herramientas utilizadas y las implicaciones que tienen las evaluaciones del rendimiento para los empleados. Chile y el Reino Unido integran las evaluaciones del rendimiento en su toma de decisiones de RR. HH. en mayor grado que otros países de la OCDE. Por el contrario, España e Islandia no realizan este tipo de evaluaciones de manera obligatoria y formal, mientras que en Noruega y la República Eslovaca se realizan solo a algunos empleados. 16 países de la OCDE han identificado la gestión del rendimiento laboral como un ámbito de reforma actual. Canadá e Irlanda han implementado recientemente nuevos sistemas de gestión del rendimiento laboral. Canadá ha desarrollado un sistema único para todo el sistema público federal, mientras que Irlanda ha simplificado sus evaluaciones a una escala de dos valores: satisfactorio o no.

Relacionar los resultados de las evaluaciones de rendimiento con recompensas del personal continúa siendo un desafío en muchos países de la OCDE. Los incentivos al rendimiento incluyen oportunidades profesionales (como ascensos) y retribuciones. La práctica de la remuneración por rendimiento (RPR) en forma de bonificaciones (18 países) o de aumentos permanentes basados en el rendimiento (21 países) se ha mantenido relativamente estable desde que la encuesta fue realizada por última vez en 2010. La RPR puede variar en función de la gama de puestos a los que se aplica, de su implementación a nivel individual o grupal, del grado en que se utilizan los rankings, y del tamaño de las recompensas. Dinamarca y Japón utilizan la RPR de manera más extensa que otros países. Ambos países aplican la RPR a la mayoría de los empleados de las Administraciones mediante una combinación de bonificaciones al rendimiento puntuales y aumentos permanentes de salario basados en el rendimiento. En estos casos, la RPR puede suponer más del $40 \%$ del salario base de un empleado. En Polonia, por el contrario, la RPR se utiliza solo en profesiones específicas. Bélgica, Grecia, Islandia, Luxemburgo, México y Turquía declaran no utilizar la RPR a ningún nivel.

\section{Metodología y definiciones}

Los datos corresponden a 2016 y 2010 y se han recogido de la Encuesta de la OCDE sobre gestión estratégica de recursos humanos de 2016 y 2010. Los encuestados eran predominantemente altos funcionarios de los departamentos de GRH de la Administración central, y los datos se refieren a prácticas de GRH a nivel central. Todos los países de la OCDE y los países en proceso de adhesión, Colombia, Costa Rica y Lituania, completaron la encuesta. Las definiciones de función pública, 
así como de las organizaciones gobernadas por la Administración a nivel central, difieren entre los países y esto se debe tener en cuenta al establecer comparaciones. Los términos función pública, servicio público y funcionariado/funcionarios se utilizan indistintamente en este capítulo.

El índice de evaluación del rendimiento se compone de las siguientes variables: existencia de una evaluación del rendimiento formalizada; uso de herramientas de evaluación del rendimiento; criterios de evaluación del rendimiento; y la importancia de la evaluación del rendimiento en la promoción profesional, remuneración y renovación de contrato. El índice de RPR se compone de las siguientes variables: uso de un mecanismo de RPR y categorías del funcionariado en el que se implementa; uso de bonificaciones puntuales y/o aumentos por mérito; y la proporción máxima del salario base que representa el RPR. Los datos ausentes se estimaron mediante el método de sustitución por la media. Los índices proporcionan información sobre el uso formal de evaluaciones del rendimiento y RPR en las Administraciones centrales, pero no informan sobre su implementación o la calidad del trabajo realizado.

Véase el Anexo online para más información específica por país y para información sobre la metodología y factores utilizados para elaborar el índice. Las variables que componen el índice y su importancia relativa se basan en juicios expertos. Se presentan con el fin de promover el debate y, por tanto, pueden evolucionar a lo largo del tiempo. Las comparaciones entre los índices de evaluación del rendimiento de Panorama de las Administraciones Públicas 2011 y 2017 se deben llevar a cabo con cautela, ya que las ponderaciones y número de respuestas de los países varían entre las dos publicaciones.

\section{Otras publicaciones}

OECD (2016), Engaging Public Employees for a High-Performing Civil Service, OECD Publishing, París.

\section{Notas de los gráficos}

6.3 No se incluyen datos de Nueva Zelanda.

6.4 La media de la OCDE incluye los seis países de la OCDE que han declarado no tener un sistema de RPR: Bélgica, Grecia, Islandia, Luxemburgo, México y Turquía.

Información sobre los datos de Israel: <http://dx.doi.org/10.1787/888932315602>. 
Gráfico 6.3. Alcance del uso de las evaluaciones del rendimiento en las decisiones de RR. HH. de la Administración central, 2016

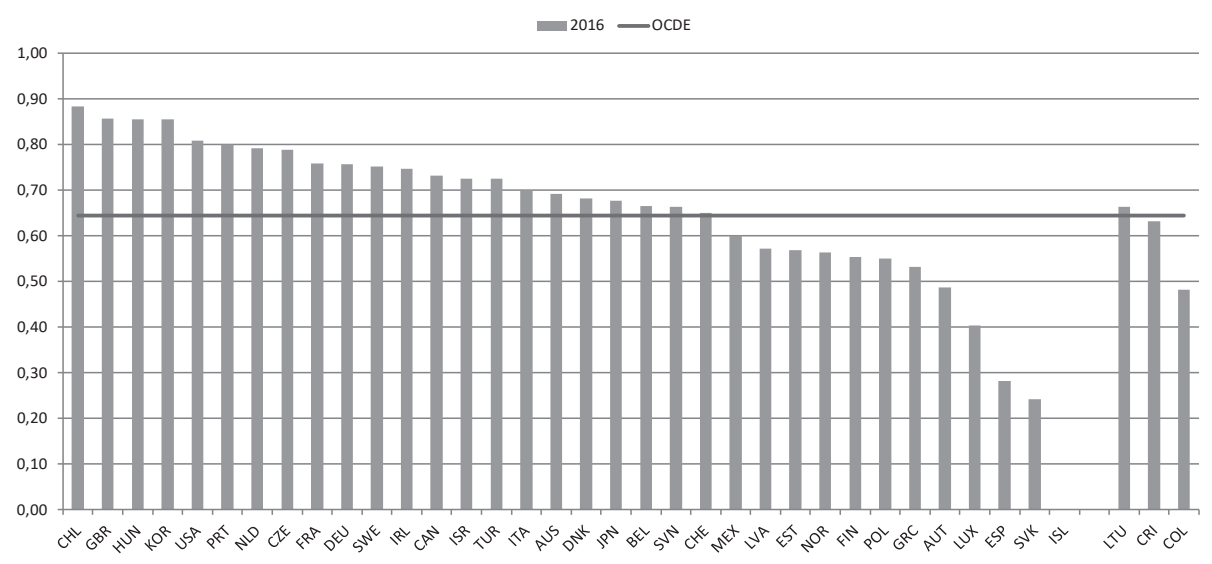

Fuente: OCDE (2016), Encuesta sobre Gestión Estratégica de Recursos Humanos, OCDE, París.

$<$ http://dx.doi.org/10.1787/888933532884>

Gráfico 6.4. Alcance del uso de la remuneración por rendimiento en la Administración central, 2016 y 2010

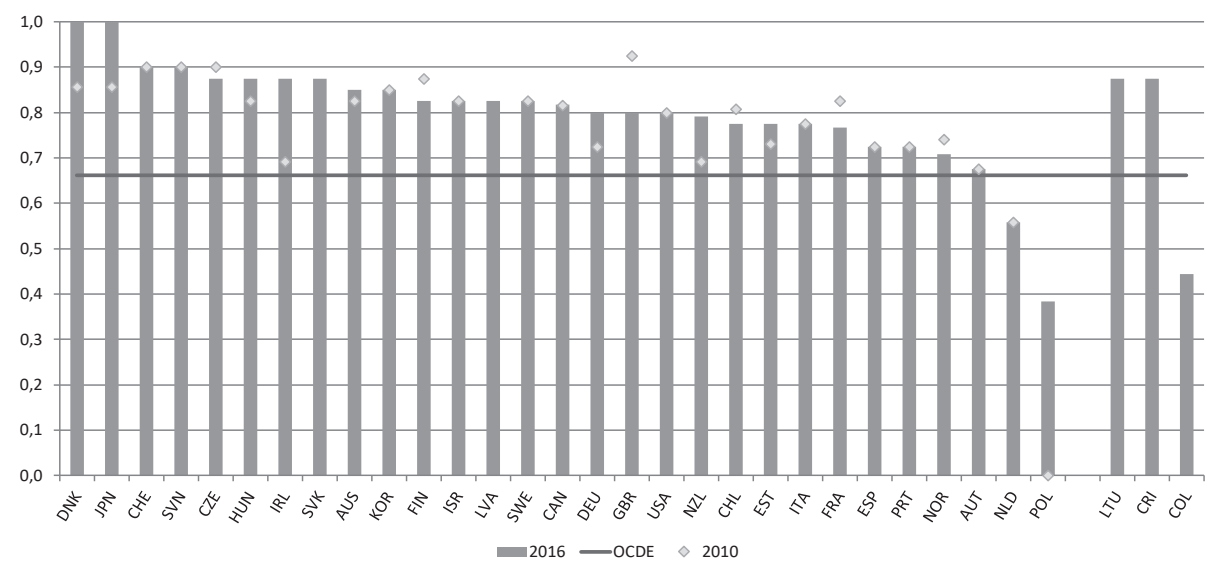

Fuente: OCDE (2016, 2010), Encuesta sobre Gestión Estratégica de Recursos Humanos, OCDE, París.

$<$ http://dx.doi.org/10.1787/888933532903> 


\section{PRÁCTICAS DE GESTIÓN DE RECURSOS HUMANOS ESPECÍFICAS A LOS ALTOS FUNCIONARIOS}

Los altos funcionarios (AF) se encuentran en una posición crítica entre la formulación y la aplicación de políticas. Deben mostrar capacidades de liderazgo para implementar agendas políticas de manera efectiva y aprovechar sus conocimientos de la función pública y experiencia en el sector para contribuir a la formulación de políticas basadas en evidencias. Se espera que los AF tengan capacidad de reacción a nivel político, un conocimiento profundo de los ciudadanos a los que sirven, y que sean administradores competentes de las organizaciones públicas en las que trabajan. Mejorar el desempeño, agilidad y eficacia de las Administraciones públicas, por tanto, depende en parte de la calidad y capacidad del alto funcionariado.

En reconocimiento al papel central que juegan los AF, todos los países de la OCDE, exceptuando la República Checa y Suecia, identifican un grupo específico de AF que se atiene a unas políticas de gestión de recursos humanos (GRH) diferentes. El indicador compuesto muestra el grado en que se aplican estas prácticas y normas distintas a los AF. Analiza si los AF se consideran como un grupo aparte de empleados públicos, si existen políticas para la identificación de líderes y posible talento en el tramo inicial de las carreras profesionales, y si se aplican prácticas de evaluación del rendimiento diferentes a este sector de la función pública. Entre los países de la OCDE, Canadá, Francia y el Reino Unido tienen el nivel más alto de institucionalización de la gestión de los AF.

En la mayoría de los países de la OCDE, se pone más énfasis en el desarrollo de competencias y en incentivar el rendimiento adecuado de los AF que en el del resto de empleados. Un total de 19 países de la OCDE cuentan con un sistema específico de gestión del rendimiento para los AF, mientras que en otros 9 países los AF están sujetos al mismo régimen de rendimiento que el resto de trabajadores. Las características más comunes de los sistemas de gestión del rendimiento de los AF son la remuneración por rendimiento (18 países), el despido como consecuencia del desempeño deficiente (15 países), contratos de duración determinada (15 países), y acuerdos sobre el rendimiento con el ministro (14 países) o el director administrativo del servicio público (10 países). Nueve países de la OCDE declaran realizar una evaluación de 360 grados de la actuación profesional en las categorías superiores de la Administración.

En la actualidad, el desarrollo y selección de líderes altamente cualificados es uno de los ámbitos prioritarios en la reforma de recursos humanos de los países de la OCDE. En 24 países de la OCDE existe un perfil de competencias específico para los AF, que suelen ser contratados mediante un proceso más centralizado que el de los demás funcionarios (22 países). Muchos países han revisado este perfil recientemente, ante los cambios en las expectativas de lo que supone el liderazgo efectivo del sector público. Por ejemplo, la nueva vi- 
sión de liderazgo de los Países Bajos destaca la reflexión, la cooperación y la integridad. A pesar del énfasis en el desarrollo de liderazgo, solo 13 países confirman tener en funcionamiento políticas para la identificación de posibles AF en el tramo inicial de las carreras profesionales, y solo 8 países cuentan con programas de captación y formación de licenciados para puestos del alto funcionariado (por ejemplo, programas intensivos de formación). Ofrecer oportunidades de desarrollo profesional y liderazgo a candidatos cualificados al inicio de su carrera no solo aumentaría el atractivo de la función pública para el joven talento, permitiría también el desarrollo temprano de competencias y programas de mentores.

\section{Metodología y definiciones}

Los datos corresponden a 2016 y se han recogido de la Encuesta de la OCDE sobre gestión estratégica de recursos humanos de 2016. Los encuestados eran predominantemente altos funcionarios de los departamentos de GRH de la Administración central, y los datos se refieren a prácticas de GRH a nivel central. Todos los países de la OCDE y los países en proceso de adhesión, Colombia, Costa Rica y Lituania, completaron la encuesta. Las definiciones de función pública, así como de las organizaciones gobernadas por la Administración a nivel central, difieren entre los países y esto se debe tener en cuenta al establecer comparaciones. Los términos función pública, servicio público y funcionariado/ funcionarios se utilizan indistintamente en este capítulo.

El índice de alto funcionariado se compone de las siguientes variables: la existencia de un grupo separado de AF; la existencia de políticas para la identificación temprana de posibles AF; el uso de perfiles de competencias de AF definidos a nivel central; y el uso de prácticas distintas de contratación, evaluación del rendimiento y remuneración por rendimiento para los AF. El índice varía entre 0 (prácticas de GRH para AF que no son diferentes) y 1 (prácticas de GRH que son muy diferentes). Los datos ausentes se estimaron mediante el método de sustitución por la media. El índice no es un indicador de la buena gestión de los AF o de su desempeño.

Véase el Anexo online para más información específica por país y para información sobre la metodología y factores utilizados para elaborar el índice. Las variables que componen el índice y su importancia relativa 
se basan en juicios expertos. Se presentan con el fin de promover el debate y, por tanto, pueden evolucionar a lo largo del tiempo. Las comparaciones entre los índices de evaluación del rendimiento de Panorama de las Administraciones Públicas 2011 y 2017 se deben llevar a cabo con cautela, ya que las ponderaciones y número de respuestas de los países varían entre las dos publicaciones.

\section{Otras publicaciones}

OECD (2016), Engaging Public Employees for a High-Performing Civil Service, OECD Publishing, París.

\section{Notas de los gráficos}

Información sobre los datos de Israel: <http://dx.doi.org/10.1787/888932315602>.

Gráfico 6.5. Alcance del uso de prácticas específicas de gestión de recursos humanos para los altos funcionarios de la Administración central, 2016

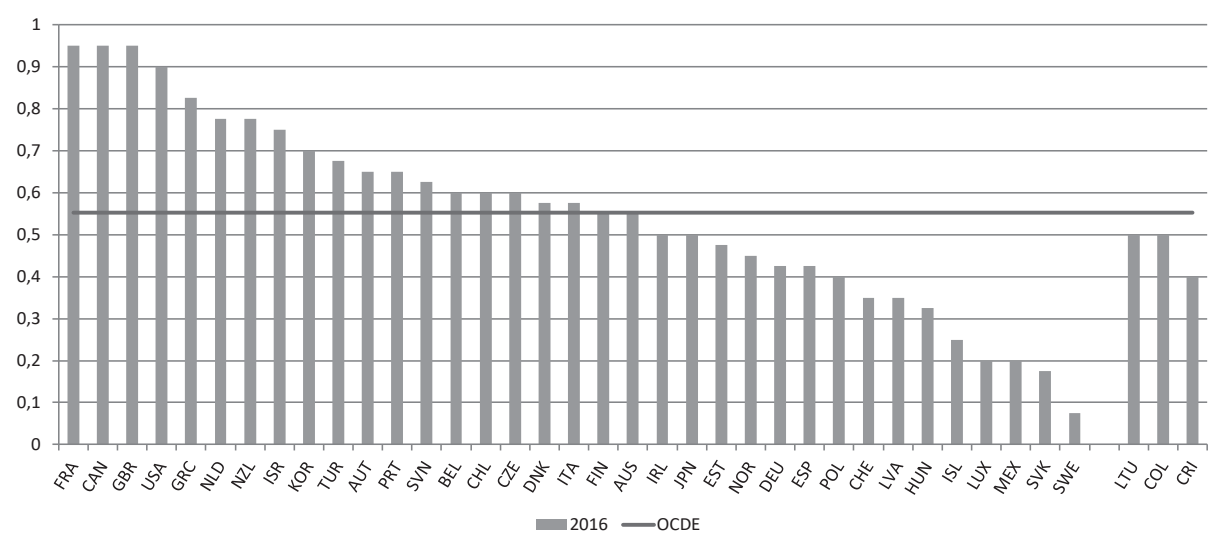

Fuente: OCDE (2016), Encuesta sobre Gestión Estratégica de Recursos Humanos, OCDE, París.

$<$ http://dx.doi.org/10.1787/888933532922> 
Tabla 6.6. Prácticas de gestión de recursos humanos para AF de la Administración central, 2016

\begin{tabular}{|c|c|c|c|c|c|c|c|}
\hline & \multirow{2}{*}{ 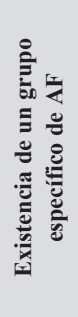 } & \multirow{2}{*}{ 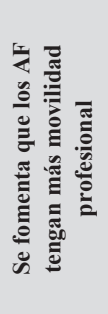 } & \multirow{2}{*}{ 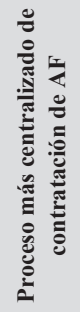 } & \multirow{2}{*}{ 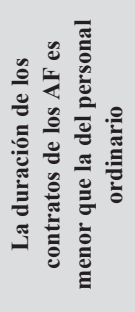 } & \multirow{2}{*}{ 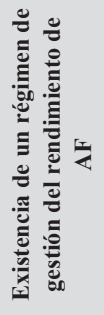 } & \multicolumn{2}{|c|}{$\begin{array}{l}\text { Características relativas } \\
\text { al régimen de gestión del } \\
\text { rendimiento de } \mathrm{AF}\end{array}$} \\
\hline & & & & & & 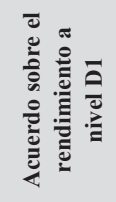 & 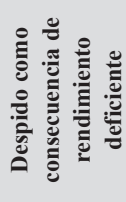 \\
\hline Alemania & - & $\bullet$ & $\bullet$ & O & O & $\mathrm{x}$ & $\mathrm{x}$ \\
\hline Australia & $\bullet$ & $\bullet$ & $\bullet$ & O & $\bullet$ & $\bullet \quad \square$ & $\bullet$ \\
\hline Austria & $\bullet$ & O & O & $\bullet$ & $*$ & O & $\bullet$ \\
\hline Bélgica & $\bullet$ & O & $\bullet$ & $\bullet$ & $\bullet$ & $\bullet$ & $\bullet$ \\
\hline Canadá & $\bullet$ & $\bullet$ & $\bullet$ & O & $\bullet$ & 口 & O \\
\hline Chile & $\bullet$ & O & $\bullet$ & O & - & $\bullet \quad \square$ & $\bullet$ \\
\hline Corea & $\bullet$ & $\bullet$ & O & $\bullet$ & $\bullet$ & 口 & $\bullet$ \\
\hline Dinamarca & $\bullet$ & O & $\bullet$ & $\bullet$ & $\bullet$ & 口 & O \\
\hline España & $\bullet$ & O & O & O & $*$ & $\diamond$ & $\bullet$ \\
\hline Estados Unidos & $\bullet$ & O & $\bullet$ & O & $\bullet$ & 口 & $\bullet$ \\
\hline Estonia & $\bullet$ & O & $\bullet$ & $\bullet$ & $\bullet$ & O & O \\
\hline Finlandia & $\bullet$ & $\bullet$ & $\bullet$ & O & $\bullet$ & O & $\bullet$ \\
\hline Francia & $\bullet$ & $\bullet$ & $\bullet$ & $\bullet$ & $\bullet$ & $\bullet$ & O \\
\hline Grecia & $\bullet$ & O & $\bullet$ & $\bullet$ & $*$ & O & $\bullet$ \\
\hline Hungría & $\bullet$ & $\bullet$ & O & O & O & $\mathrm{x}$ & $\mathrm{x}$ \\
\hline Irlanda & $\bullet$ & $\bullet$ & $\bullet$ & $\bullet$ & $\bullet$ & $\bullet$ & O \\
\hline Islandia & $\bullet$ & O & O & $\bullet$ & O & $\mathrm{x}$ & $\mathrm{x}$ \\
\hline Israel & $\bullet$ & $\bullet$ & O & $\bullet$ & $\bullet$ & O & $\bullet$ \\
\hline Italia & - & O & O & O & $\bullet$ & $\diamond$ & $\bullet$ \\
\hline Japón & $\bullet$ & O & O & O & $\nLeftarrow$ & $\mathrm{x}$ & $\mathrm{x}$ \\
\hline Letonia & $\bullet$ & $\bullet$ & $\bullet$ & O & $\bullet$ & $\diamond$ & \\
\hline Luxemburgo & $\bullet$ & O & O & O & O & $\mathrm{x}$ & $\mathrm{x}$ \\
\hline México & $\bullet$ & O & O & O & $*$ & 0 & $\bullet$ \\
\hline Noruega & $\bullet$ & O & $\bullet$ & O & - & $\bullet \quad \square$ & O \\
\hline Nueva Zelanda & $\bullet$ & $\bullet$ & O & $\bullet$ & $\bullet$ & 口 & O \\
\hline Países Bajos & $\bullet$ & $\bullet$ & $\bullet$ & $\bullet$ & $*$ & $\diamond \quad \square$ & O \\
\hline Polonia & $\bullet$ & O & O & O & O & $\mathrm{x}$ & $\mathrm{x}$ \\
\hline Portugal & $\bullet$ & O & $\bullet$ & $\bullet$ & $\bullet$ & $\diamond$ & $\bullet$ \\
\hline Reino Unido & $\bullet$ & $\bullet$ & $\bullet$ & O & $\bullet$ & 口 & $\bullet$ \\
\hline
\end{tabular}




\begin{tabular}{|c|c|c|c|c|c|c|c|}
\hline & \multirow{2}{*}{ 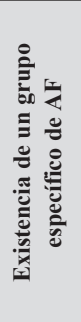 } & \multirow{2}{*}{ 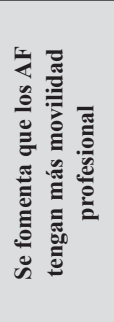 } & \multirow{2}{*}{ 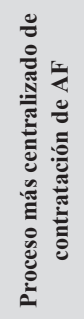 } & \multirow{2}{*}{ 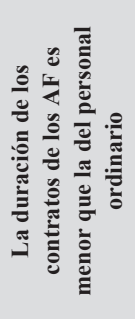 } & \multirow{2}{*}{ 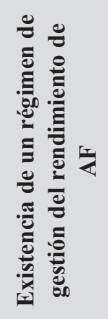 } & \multicolumn{2}{|c|}{$\begin{array}{l}\text { Características relativas } \\
\text { al régimen de gestión del } \\
\text { rendimiento de } \mathrm{AF}\end{array}$} \\
\hline & & & & & & 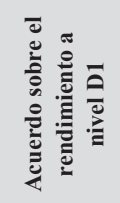 & 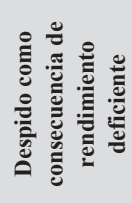 \\
\hline República Checa & $\bullet$ & 0 & $\bullet$ & $\bullet$ & o & $\mathrm{x}$ & $\mathrm{x}$ \\
\hline República de Eslovenia & $\bullet$ & $\mathrm{O}$ & $\bullet$ & $\bullet$ & $\%$ & $\mathrm{x}$ & 0 \\
\hline República Eslovaca & 0 & O & 0 & $\bullet$ & O & $\mathrm{x}$ & $\mathrm{x}$ \\
\hline Suecia & 0 & 0 & $\bullet$ & $\bullet$ & $\bullet$ & $\bullet$ & 0 \\
\hline Suiza & $\bullet$ & O & $\bullet$ & 0 & 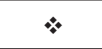 & $\diamond$ & $\bullet$ \\
\hline Turquía & $\bullet$ & $\bullet$ & $\bullet$ & $\bullet$ & 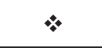 & $\diamond$ & O \\
\hline Total OCDE & 33 & 14 & 22 & 18 & 19 & & 15 \\
\hline \multicolumn{8}{|l|}{ Sí $=\bullet$} \\
\hline \multicolumn{8}{|l|}{$\mathrm{No}=\mathrm{O}$} \\
\hline $\begin{array}{l}\text { No, es igual para todos los } \\
\text { funcionarios }=\$\end{array}$ & & & & & 9 & & \\
\hline $\begin{array}{l}\text { Acuerdo sobre el rendimiento con } \\
\text { el ministro (a nivel D1) }\end{array}$ & & & & & & 14 & \\
\hline $\begin{array}{l}\text { Acuerdo sobre el rendimiento con } \\
\text { el director administrativo del } \\
\text { servicio público (a nivel D1) }\end{array}$ & & & & & & 10 & \\
\hline \multicolumn{8}{|l|}{ No aplicable $=\mathrm{x}$} \\
\hline Costa Rica & $\bullet$ & 0 & 0 & 0 & $\%$ & 0 & $\bullet$ \\
\hline Colombia & $\bullet$ & 0 & $\bullet$ & $\bullet$ & $\bullet$ & $\diamond$ & 0 \\
\hline Lituania & $\bullet$ & $\bullet$ & 0 & 0 & • & $\diamond$ & • \\
\hline
\end{tabular}

Fuente: OCDE (2016), Encuesta sobre Gestión Estratégica de Recursos Humanos, OCDE, París.

$<$ http://dx.doi.org/10.1787/888933535012>

\section{INFLUENCIA POLÍTICA EN EL ALTO FUNCIONARIADO}

Contar con un servicio público profesional e imparcial desde el punto de vista político garantiza un alto nivel de competencia e integridad, así como la continuidad en el desarrollo, asesoramiento e implementación de políticas al servicio del interés público. La presión política que se ejerce para el nombramiento de los cargos superiores suele ser resultado del deseo de las Administraciones públicas de asegurarse un alto grado de respuesta por parte de la función 
pública mediante la contratación de personal directivo que comparte su visión política. Sin embargo, sin niveles apropiados de transparencia y rendición de cuentas (por ejemplo, la confirmación o veto en votación abierta por parte de los cargos oficiales electos), la presión política puede dar lugar a la proliferación de favoritismos y clientelismo perjudiciales para la profesionalización del servicio público. Las influencias políticas también pueden provocar un alto grado de rotación profesional en los niveles superiores de gestión, que contribuye a la falta de estabilidad y continuidad necesarias para la supervisión de mejoras y reformas a largo plazo. Es más, la influencia política en las decisiones de selección del personal funcionario puede llevar a favorecer la contratación de agentes políticos en lugar de administradores públicos con los conocimientos y aptitudes necesarios para ejercer un liderazgo eficaz. En última instancia, dicha presión puede producir la pérdida de confianza en las instituciones públicas si la ciudadanía percibe que los administradores públicos son elegidos más en base a sus afiliaciones políticas que a su capacidad de liderazgo y competencia política.

El nivel de rotación de personal influenciado por motivos políticos en los países de la OCDE constituye una indicación del grado en que la política y/o afiliación política influyen en la selección de personal del servicio público. En las cuatro categorías de altos funcionarios de gestión (siendo D1 el nivel más alto y D4 el nivel más bajo), los niveles inferiores (niveles D3 y D4) tienden a experimentar un grado de rotación bajo o nulo con los cambios de gobierno. En comparación, el nivel de rotación motivado políticamente es más alto en los niveles superiores (niveles D1 y D2). El grupo con mayor rotación es el de los asesores ministeriales, que suelen ser nombrados directamente por el ministro.

En Chile, España y Turquía, los dos niveles superiores del funcionariado cambian por completo con la elección de un nuevo gobierno. El gobierno de Chile ha reconocido los retos derivados de estos índices de rotación tan altos y está tomando medidas para reforzar la Dirección Nacional del Servicio Civil y el Servicio Ejecutivo Sénior. Todos los cargos del nivel superior (D1) cambian con cada nuevo gobierno en Hungría y la República Eslovaca.

En 17 países de la OCDE (Austria, Bélgica, Canadá, Dinamarca, los Estados Unidos, Estonia, Finlandia, Irlanda, Islandia, Japón, Luxemburgo, Noruega, Nueva Zelanda, los Países Bajos, Portugal, el Reino Unido y Suecia), la rotación de personal derivada de los cambios de gobierno en los cuatro niveles de alta gestión es nula o casi nula. Estos países suelen tener sistemas parlamentarios o una larga tradición de estabilidad y profesionalismo del alto funcionariado.

\section{Metodología y definiciones}

Los datos corresponden a 2016 y se han recogido de la Encuesta de la OCDE sobre Gestión Estratégica de Recursos Humanos de 2016. Los encuestados eran predominantemente altos funcionarios de los departa- 
mentos de GRH de la Administración central, y los datos se refieren a prácticas de GRH a nivel central. Todos los países de la OCDE y los países en proceso de adhesión, Colombia, Costa Rica y Lituania, completaron la encuesta. Las definiciones de función pública, así como de las organizaciones gobernadas por la Administración a nivel central, difieren entre los países y esto se debe tener en cuenta al establecer comparaciones. Los términos función pública, servicio público y funcionariado/ funcionarios se utilizan indistintamente en este capítulo.

Las clasificaciones utilizadas para definir los cuatro niveles de altos funcionarios (D1 a D4) de los que se presentan datos son una adaptación de los códigos CIUO-08 desarrollados por la Organización Internacional del Trabajo (OIT). Las definiciones detalladas de cada nivel pueden verse en el Anexo disponible online. Los asesores de los líderes ministeriales son asesores políticos que proporcionan ideas o planes utilizados por el gobierno como base para la toma de decisiones.

\section{Otras publicaciones}

OECD (2016), Engaging Public Employees for a High-Performing Civil Service, OECD Publishing, París.

\section{Notas de los gráficos}

Información sobre los datos de Israel: <http://dx.doi.org/10.1787/888932315602>.

Tabla 6.7. Rotación de personal por cambios de gobierno, 2016

\begin{tabular}{|c|c|c|c|c|c|}
\hline & \multirow{2}{*}{$\begin{array}{c}\text { Asesores } \\
\text { ministeriales }\end{array}$} & \multicolumn{2}{|c|}{ Altos funcionarios } & \multicolumn{2}{|c|}{ Cargos intermedios } \\
\hline & & D1 & D2 & D3 & D4 \\
\hline Alemania & O & $\odot$ & O & O & O \\
\hline Australia & - & $\odot$ & O & 0 & 0 \\
\hline Austria & - & 0 & O & 0 & 0 \\
\hline Bélgica & $\bullet$ & 0 & 0 & 0 & 0 \\
\hline Canadá & O & 0 & O & 0 & O \\
\hline Chile & $\bullet$ & $\bullet$ & $\bullet$ & घ & घ \\
\hline Corea & $\bullet$ & 口 & $\odot$ & 0 & O \\
\hline Dinamarca & $\bullet$ & 0 & O & O & O \\
\hline España & $\bullet$ & - & - & $\odot$ & 0 \\
\hline
\end{tabular}




\begin{tabular}{|c|c|c|c|c|c|}
\hline & \multirow{2}{*}{$\begin{array}{c}\text { Asesores } \\
\text { ministeriales }\end{array}$} & \multicolumn{2}{|c|}{ Altos funcionarios } & \multicolumn{2}{|c|}{ Cargos intermedios } \\
\hline & & D1 & D2 & D3 & D4 \\
\hline Estados Unidos & $\bullet$ & 0 & 0 & 0 & 0 \\
\hline Estonia & a & 0 & O & O & O \\
\hline Finlandia & $\bullet$ & 0 & 0 & O & O \\
\hline Francia & $\bullet$ & $\odot$ & 0 & O & O \\
\hline Grecia & $\bullet$ & $\odot$ & $\odot$ & $\odot$ & $\odot$ \\
\hline Hungría & $\bullet$ & $\bullet$ & घ & $\odot$ & $\odot$ \\
\hline Irlanda & $\bullet$ & 0 & 0 & 0 & 0 \\
\hline Islandia & $\bullet$ & 0 & 0 & 0 & 0 \\
\hline Israel & घ & $\mathbf{\square}$ & $\odot$ & 0 & 0 \\
\hline Italia & $\bullet$ & $\mathbf{\square}$ & 0 & 0 & 0 \\
\hline Japón & ○ & O & 0 & $\mathrm{O}$ & $\mathrm{O}$ \\
\hline Letonia & $\bullet$ & $\odot$ & $\odot$ & 0 & 0 \\
\hline Luxemburgo & O & 0 & 0 & 0 & 0 \\
\hline México & $\odot$ & $\odot$ & $\odot$ & $\odot$ & $\odot$ \\
\hline Noruega & O & 0 & 0 & O & $\mathrm{O}$ \\
\hline Nueva Zelanda & 0 & 0 & 0 & 0 & O \\
\hline Países Bajos & 0 & 0 & 0 & 0 & O \\
\hline Polonia & $\bullet$ & 口 & $\odot$ & $\odot$ & 0 \\
\hline Portugal & $\bullet$ & 0 & 0 & 0 & 0 \\
\hline Reino Unido & $\bullet$ & $\mathrm{O}$ & $\mathrm{O}$ & $\mathrm{O}$ & O \\
\hline República Checa & $\bullet$ & $\odot$ & 0 & $\odot$ & $\odot$ \\
\hline República de Eslovenia & $\square$ & $\odot$ & 0 & 0 & $\mathrm{O}$ \\
\hline República Eslovaca & $\bullet$ & $\bullet$ & 口 & $\odot$ & $\odot$ \\
\hline Suecia & $\bullet$ & 0 & 0 & 0 & 0 \\
\hline Suiza & $\odot$ & $\odot$ & 0 & 0 & O \\
\hline Turquía & $\bullet$ & $\bullet$ & $\bullet$ & 口 & $\odot$ \\
\hline \multicolumn{6}{|l|}{ Total OCDE } \\
\hline Todos $(95-100 \%) \bullet$ & 21 & 6 & 3 & 0 & 0 \\
\hline Muchos (50-94\%) & 5 & 3 & 2 & 2 & 1 \\
\hline Algunos $(5-49 \%) \odot$ & 2 & 9 & 6 & 8 & 6 \\
\hline Ninguno $(0-5 \%) \bigcirc$ & 7 & 17 & 24 & 25 & 28 \\
\hline Colombia & $\bullet$ & $\bullet$ & - & $\odot$ & $\odot$ \\
\hline Costa Rica & $\bullet$ & a & 0 & 0 & 0 \\
\hline Lituania & $\bullet$ & $\odot$ & 0 & 0 & $\odot$ \\
\hline
\end{tabular}

Fuente: OCDE (2016), Encuesta sobre Gestión Estratégica de Recursos Humanos, OCDE, París.

$<$ http://dx.doi.org/10.1787/888933535031> 


\section{GESTIÓN DE RECURSOS HUMANOS BASADA EN EVIDENCIAS}

La transformación digital alcanza todos los aspectos del sector público y la gestión de recursos humanos (GRH) no es una excepción. Los datos facilitan que los responsables políticos tengan una buena comprensión de la situación actual, identifiquen tendencias, planifiquen actuaciones futuras y gestionen los riesgos. Los datos de la fuerza de trabajo del servicio público ofrecen información sobre la composición del personal, y sobre la capacidad de las Administraciones públicas de contratar, retener y gestionar el rendimiento de los funcionarios. Conocer esta información es esencial para una planificación y gestión estratégica efectivas de los recursos humanos. Cuando está centralizada, esta información constituye una herramienta eficaz para el análisis comparativo de organizaciones y para orientar reformas. Es más, los datos de la fuerza de trabajo constituyen un mecanismo potente para garantizar la transparencia y rendición de cuentas con respecto a la diversidad y para llevar a cabo prácticas eficientes de GRH.

Casi todos los países mantienen datos centralizados del número de empleados, género y edad, mientras que 18 países de la OCDE incluyen también datos en cuanto a discapacidad. Solo nueve países de la OCDE recogen datos de pertenencia a minorías. Un total de 21 países de la OCDE recopilan datos sobre el nivel de educación de los trabajadores de forma estandarizada. Corea, la República de Eslovenia y Suiza parecen tener el mayor nivel de estandarización de datos de GRH almacenados en bases de datos centralizadas. En países como Polonia y la República Eslovaca, muchos datos administrativos no están recogidos ni centralizados, por lo que no se encuentran disponibles a efectos comparativos. Algunos países almacenan los datos de GRH de forma descentralizada. Alemania, por ejemplo, recoge diversos datos de empleados, pero no tiene un repositorio central de los mismos.

La recolección de datos es solo el primer paso hacia una GRH basada en el análisis de la información. Es preciso analizar los datos y comunicarlos a los responsables políticos de forma que ofrezcan perspectiva y fomenten la gestión responsable. La mayoría de los países de la OCDE presenta los datos de RR. HH. en informes que se hacen llegar periódicamente al público, a los políticos (por ejemplo, al Parlamento) y a los funcionarios de alto rango. En 25 países de la OCDE, los datos se incorporan sistemáticamente a la planificación de RR. HH. y se comunican a los gestores de forma esquematizada. Sin embargo, menos de la mitad de los países de la OCDE utiliza esta información para diseñar planes de formación (12 países), o para evaluar el rendimiento de la gestión (15 países). En la mayoría de los países de la OCDE (28 países), los datos administrativos de la fuerza de trabajo se comparten activamente online, por ejemplo, en los portales de datos abiertos. 
Disponer de sistemas capaces de relacionar los datos necesarios para gestionar las carreras de los empleados y para mejorar la GRH continúa siendo un reto en muchos países de la OCDE. Por ejemplo, disponer de información de los índices de permanencia de los trabajadores por edad o por sector demográfico es útil para evaluar el carácter inclusivo de la función pública. Sin embargo, son pocos los países capaces de proporcionar indicadores de este tipo. Para hacer un seguimiento de los aspectos relacionados con la inclusión, es necesario diseñar repositorios de datos que proporcionen información sobre grupos minoritarios en el servicio público. Sin embargo, aunque muchos países anglosajones han desarrollado una gama relativamente amplia de categorías, los países europeos tienden a centrarse únicamente en el género.

\section{Metodología y definiciones}

Los datos corresponden a 2016 y se han recogido de la Encuesta de la OCDE sobre gestión estratégica de recursos humanos de 2016. Los encuestados eran predominantemente altos funcionarios de los departamentos de GRH de la Administración central, y los datos se refieren a prácticas de GRH a nivel central. Todos los países de la OCDE y los países en proceso de adhesión, Colombia, Costa Rica y Lituania, completaron la encuesta. Las definiciones de función pública, así como de las organizaciones gobernadas por la Administración a nivel central, difieren entre los países y esto se debe tener en cuenta al establecer comparaciones. Los términos función pública, servicio público y funcionariado/ funcionarios se utilizan indistintamente en este capítulo.

El índice de recogida y disponibilidad de datos administrativos de RR. HH. mide la existencia de los siguientes registros a nivel central/federal: número de empleados, nivel, función, edad, género, discapacidades, pertenencia a otros grupos minoritarios, nivel de estudios, antigüedad, idiomas, tipo de contrato, afiliación sindical, trabajo a tiempo parcial, otros acuerdos de flexibilidad laboral, días de baja por enfermedad, días dedicados a formación, bajas especiales, movilidad en el servicio público, rotación de personal, jubilaciones, dimisiones y despidos. El índice varía entre 0 (bajo nivel de datos recogidos a nivel central) y 1 (alto nivel de datos recogidos a nivel central). Los datos ausentes se estimaron mediante el método de sustitución por la media. 
Véase el Anexo online para más información específica por país y para información sobre la metodología y factores utilizados para elaborar el índice. Las variables que componen el índice y su importancia relativa se basan en juicios expertos. Se presentan con el fin de promover el debate y, por tanto, pueden evolucionar a lo largo del tiempo.

\section{Notas de los gráficos}

Véase el Anexo online para más información específica por país y para información sobre la metodología y factores utilizados para elaborar el índice.

Información sobre los datos de Israel: <http://dx.doi.org/10.1787/888932315602>.

Gráfico 6.8. Recogida y disponibilidad de datos administrativos de recursos humanos (RR. HH.) en la Administración central, 2016

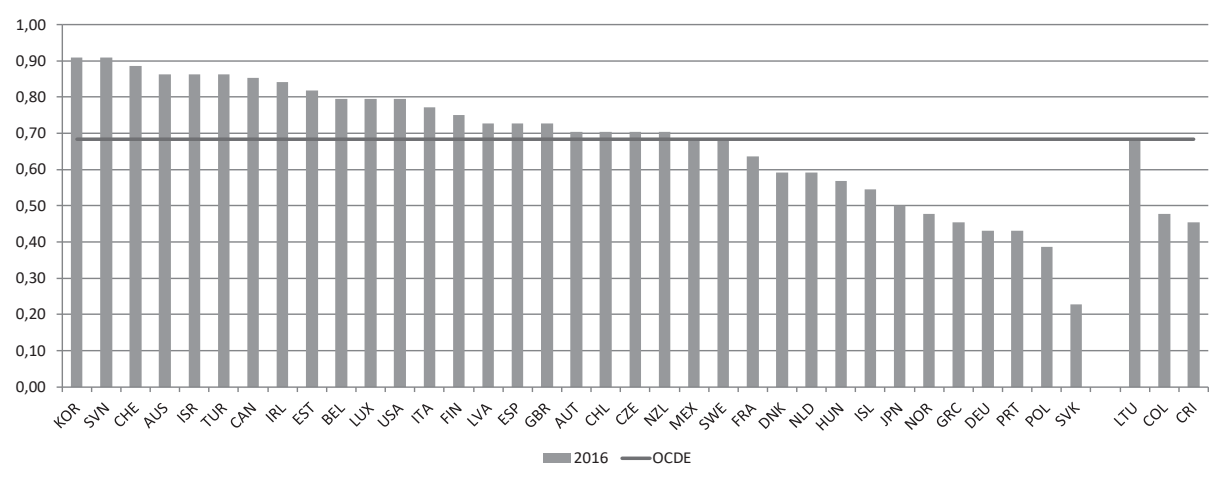

Fuente: OCDE (2016), Encuesta sobre Gestión Estratégica de Recursos Humanos, OCDE, París.

$<$ http://dx.doi.org/10.1787/888933532941> 
Tabla 6.9. Uso de datos administrativos de recursos humanos (RR. HH.) en la Administración central, 2016

\begin{tabular}{|c|c|c|c|c|c|c|c|}
\hline & 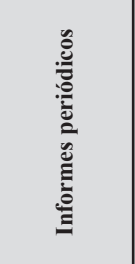 & 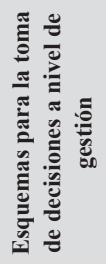 & 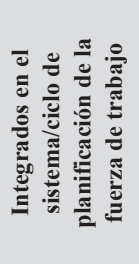 & 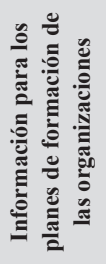 & 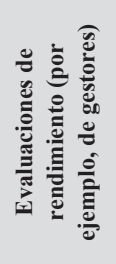 & 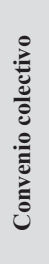 & 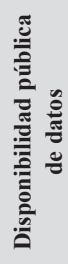 \\
\hline Alemania & घ & $\bullet$ & 0 & 0 & O & 0 & $\odot$ \\
\hline Australia & $\| \bullet \square$ & $\bullet$ & $\bullet$ & $\bullet$ & $\bullet$ & $\bullet$ & $\odot$ \\
\hline Austria & - $\diamond \square$ & $\bullet$ & $\bullet$ & $\bullet$ & O & $\bullet$ & $\odot$ \\
\hline Bélgica & $\diamond \quad \square$ & O & $\bullet$ & O & O & 0 & $\odot$ \\
\hline Canadá & $\square \diamond \square$ & $\bullet$ & $\bullet$ & O & $\bullet$ & $\bullet$ & $\odot$ \\
\hline Chile & $\square$ & O & O & O & O & 0 & $\odot$ \\
\hline Corea & $\square \diamond \square$ & $\bullet$ & $\bullet$ & $\bullet$ & $\bullet$ & 0 & $\odot$ \\
\hline Dinamarca & $\boldsymbol{\square}$ & - & O & $\bullet$ & O & 0 & $\odot$ \\
\hline España & $\boldsymbol{\Delta} \bullet \square$ & $\bullet$ & $\bullet$ & $\bullet$ & 0 & $\bullet$ & $\odot$ \\
\hline Estados Unidos & $\boldsymbol{\Delta} \bullet \square$ & $\bullet$ & $\bullet$ & O & $\bullet$ & 0 & $\odot$ \\
\hline Estonia & $\square \diamond \square$ & - & $\bullet$ & O & O & 0 & $\odot$ \\
\hline Finlandia & O & O & O & O & O & O & ○ \\
\hline Francia & $\diamond \square$ & O & $\bullet$ & O & $\bullet$ & $\bullet$ & $*$ \\
\hline Grecia & O & O & O & O & O & 0 & $\odot$ \\
\hline Hungría & O & O & $\bullet$ & $\bullet$ & O & 0 & O \\
\hline Irlanda & - $\square$ & $\bullet$ & $\bullet$ & $\bullet$ & $\bullet$ & $\bullet$ & $\odot$ \\
\hline Islandia & $\square \diamond \square$ & $\bullet$ & O & O & O & $\bullet$ & $\star$ \\
\hline Israel & $\square \diamond \square$ & O & $\bullet$ & O & O & $\bullet$ & $\odot$ \\
\hline Italia & - $\diamond \square$ & O & $\bullet$ & O & $\bullet$ & 0 & $\odot$ \\
\hline Japón & $\square$ & $\bullet$ & O & O & O & 0 & $\odot$ \\
\hline Letonia & - $\diamond \square$ & $\bullet$ & $\bullet$ & O & 0 & $\bullet$ & $\odot$ \\
\hline Luxemburgo & $\diamond \square$ & O & O & O & O & $\bullet$ & $\odot$ \\
\hline México & $\square \diamond \square$ & O & $\bullet$ & $\bullet$ & $\bullet$ & 0 & 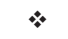 \\
\hline Noruega & O & O & O & O & O & $\bullet$ & O \\
\hline Nueva Zelanda & $\square \diamond \square$ & $\bullet$ & $\bullet$ & $\bullet$ & $\bullet$ & $\bullet$ & $\odot$ \\
\hline Países Bajos & - $\diamond \square$ & $\bullet$ & - & 0 & $\bullet$ & $\bullet$ & $\odot$ \\
\hline
\end{tabular}




\begin{tabular}{|c|c|c|c|c|c|c|c|}
\hline & 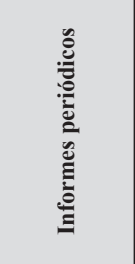 & 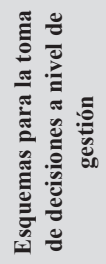 & 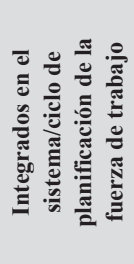 & 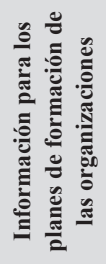 & 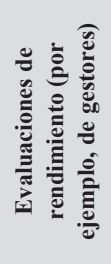 & 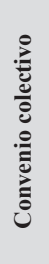 & 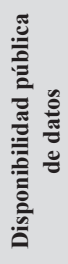 \\
\hline Polonia & $\square \bullet \square$ & $\bullet$ & O & ○ & O & 0 & $\odot$ \\
\hline Portugal & - $\bullet \square$ & $\bullet$ & $\bullet$ & $\bullet$ & $\bullet$ & O & $\odot$ \\
\hline Reino Unido & $\mathbf{\Delta} \bullet \square$ & $\bullet$ & $\bullet$ & O & $\bullet$ & O & $\odot$ \\
\hline República Checa & $\diamond \square$ & $\bullet$ & $\bullet$ & O & O & $\bullet$ & $\odot$ \\
\hline República de Eslovenia & $\mathbf{\Delta} \bullet \square$ & O & $\bullet$ & O & $\bullet$ & $\bullet$ & $\odot$ \\
\hline República Eslovaca & $\bullet$ & O & $\bullet$ & $\bullet$ & O & $\bullet$ & $*$ \\
\hline Suecia & $\mathbf{\Delta} \bullet \square$ & $\bullet$ & $\bullet$ & O & $\bullet$ & $\bullet$ & $\odot$ \\
\hline Suiza & $\diamond \square$ & $\bullet$ & $\bullet$ & O & O & $\bullet$ & $\odot$ \\
\hline Turquía & $\mathbf{\Delta} \bullet \square$ & $\bullet$ & $\bullet$ & $\bullet$ & $\bullet$ & $\bullet$ & $\odot$ \\
\hline \multicolumn{8}{|l|}{ Total OCDE } \\
\hline Sí $=\bullet$ & & 22 & 25 & 12 & 15 & 19 & \\
\hline \multicolumn{8}{|l|}{$\mathrm{No}=\mathrm{O}$} \\
\hline Informes a $\mathrm{AF}$ - & 23 & & & & & & \\
\hline Informes a políticos $\bullet$ & 26 & & & & & & \\
\hline Informes al público $\square$ & 28 & & & & & & \\
\hline $\begin{array}{l}\text { Los datos se comparten } \\
\text { activamente online } \odot\end{array}$ & & & & & & & 28 \\
\hline $\begin{array}{c}\text { Los datos se comparten } \\
\text { bajo petición }\end{array}$ & & & & & & & 4 \\
\hline Colombia & - $\square$ & 0 & $\bullet$ & $\bullet$ & 0 & $\bullet$ & 0 \\
\hline Costa Rica & $\diamond$ & O & O & 0 & O & 0 & $\%$ \\
\hline Lituania & $\boldsymbol{\nabla} \bullet \square$ & $\bullet$ & $\bullet$ & - & $\bullet$ & 0 & 0 \\
\hline
\end{tabular}

Fuente: OCDE (2016), Encuesta sobre Gestión Estratégica de Recursos Humanos, OCDE, París.

$<$ http://dx.doi.org/10.1787/888933535050> 


\section{ENCUESTAS DE EMPLEADOS}

Las encuestas de empleados permiten a las organizaciones públicas medir y monitorizar las percepciones de los empleados relativas a su trabajo y entorno laboral. Esta información aporta datos útiles a los indicadores relacionados con el rendimiento, como pueden ser el compromiso con el trabajo y con los empleadores, el bienestar laboral, y las percepciones con respecto a la gestión y el liderazgo. Las encuestas de empleados también pueden medir y valorar indicadores importantes relacionados con la diversidad, la inclusión, el acoso laboral y la discriminación en el trabajo. Cuando se realiza la misma encuesta en varias entidades públicas, se pueden utilizar los resultados para comparar rendimientos, identificar el grado de implicación de distintas áreas, y llevar a cabo las medidas apropiadas de gestión y reforma de la función pública. Cuando las encuestas se realizan periódicamente, sirven para evaluar los cambios en el tiempo, incluyendo el impacto de las reformas.

En los países de la OCDE está generalizado el uso de encuestas, con solo cinco países que no utilizan esta herramienta. Entre los demás países, el alcance de las encuestas es variado. Diecinueve países realizan encuestas centralizadas en toda la Administración pública central, y el mismo número de países lleva a cabo además encuestas diferentes en ministerios/organismos individuales. La mayoría de los países de la OCDE realiza encuestas periódicas. Catorce países realizan encuestas anuales, 7 países cada dos años y 10 países lo hacen con menos frecuencia. Además, las encuestas de empleados son objeto de reforma en 10 países de la OCDE (incluidos varios países que todavía no utilizan esta herramienta), y un tema relevante en el estudio de reformas en otros 16 países.

El contenido de las encuestas de empleados también varía. La mayoría de los países de la OCDE utiliza las encuestas de empleados para medir el grado de implicación, motivación, satisfacción y compromiso de los trabajadores. Los indicadores de bienestar (por ejemplo, conciliación familiar y laboral, nivel de estrés o carga de trabajo) y las percepciones de los empleados en cuanto a la gestión y liderazgo también destacan entre los factores relevantes. Hay menos países que utilizan las encuestas para medir cuestiones de integridad, como la corrupción o los conflictos de intereses. El grado de idoneidad para el puesto, que puede ser un indicador de la productividad, se mide con menos frecuencia todavía. Sería útil desarrollar este indicador, puesto que los estudios de la OCDE indican que la capacidad de las organizaciones de hacer uso de las habilidades y conocimientos de sus empleados es un motor de la productividad, tanto en el sector público como en el privado. Los datos de los Estados Unidos indican que los empleados de la burocracia federal consideran sus capacidades infrautilizadas a un nivel significativamente mayor que los empleados del sector privado. 
Las encuestas de empleados constituyen una herramienta eficaz para evaluar y abordar cuestiones relacionadas con la diversidad y la inclusión. Solo 10 países de la OCDE utilizan sus encuestas para evaluar la integración en el lugar de trabajo, mientras que 12 países preguntan sobre situaciones de acoso y 15 países sobre discriminación. Segmentar los resultados por indicadores demográficos y estudiar las diferencias de respuesta entre, por ejemplo, hombres y mujeres, distintos grupos de edad, o miembros de grupos minoritarios, también puede proporcionar información útil. Por ejemplo, en los Estados Unidos, el índice de compromiso se analiza en cinco categorías demográficas y para determinados puestos clave que son particularmente difíciles de ocupar y retener. En este caso, las encuestas sirven a los empleadores para desarrollar estrategias corporativas orientadas a atraer la fuerza laboral apropiada, y estrategias de GRH que fomentan la retención de personal.

\section{Metodología y definiciones}

Los datos corresponden a 2016 y se han recogido de la Encuesta de la OCDE sobre gestión estratégica de recursos humanos de 2016. Los encuestados eran predominantemente altos funcionarios de los departamentos de GRH de la Administración central, y los datos se refieren a prácticas de GRH a nivel central. Todos los países de la OCDE y los países en proceso de adhesión, Colombia, Costa Rica y Lituania, completaron la encuesta. Las definiciones de función pública, así como de las organizaciones gobernadas por la Administración a nivel central, difieren entre los países y esto se debe tener en cuenta al establecer comparaciones. Los términos función pública, servicio público y funcionariado/ funcionarios se utilizan indistintamente en este capítulo.

\section{Otras publicaciones}

OECD (2016), Engaging Public Employees for a High-Performing Civil Servi$c e$, OECD Publishing, París.

\section{Notas de los gráficos}

Información sobre los datos de Israel: <http://dx.doi.org/10.1787/888932315602>. 
Tabla 6.10. Alcance y contenido de las encuestas de empleados, 2016

\begin{tabular}{|c|c|c|c|c|c|c|c|c|}
\hline & \multirow[b]{2}{*}{ 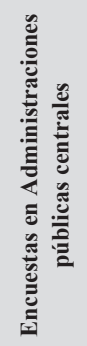 } & \multirow[b]{2}{*}{ 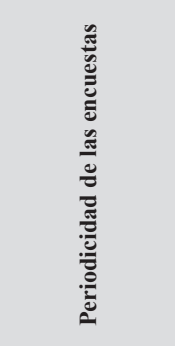 } & \multicolumn{6}{|c|}{ Aspectos evaluados en las encuestas de empleados } \\
\hline & & & 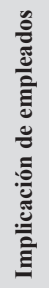 & 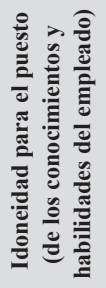 & 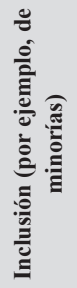 & 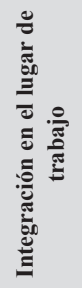 & 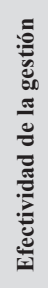 & 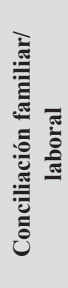 \\
\hline Australia & - $\square$ & $\square \square$ & $\bullet$ & $\bullet$ & $\bullet$ & $\bullet$ & $\bullet$ & $\bullet$ \\
\hline Alemania & $\square$ & 口 & O & O & O & $\bullet$ & $\bullet$ & $\bullet$ \\
\hline Austria & - & $*$ & $\bullet$ & O & O & O & $\bullet$ & $\bullet$ \\
\hline Bélgica & $\square$ & ㄷ & $\bullet$ & $\bullet$ & O & O & O & $\bullet$ \\
\hline Canadá & - $\square$ & 口* & $\bullet$ & $\bullet$ & $\bullet$ & $\bullet$ & $\bullet$ & $\bullet$ \\
\hline Chile & $\underset{\square}{\bullet}$ & $\square \square$ & 0 & $\bullet$ & O & O & $\bullet$ & $\bullet$ \\
\hline Corea & घ & $*$ & - & 0 & 0 & 0 & 0 & $\bullet$ \\
\hline Dinamarca & $\square$ & $\square$ & - & $\bullet$ & 0 & 0 & 0 & $\bullet$ \\
\hline España & O & $\mathrm{x}$ & $\mathrm{x}$ & $\mathrm{x}$ & $\mathrm{x}$ & $\mathrm{x}$ & $\mathrm{x}$ & $\mathrm{x}$ \\
\hline Estados Unidos & $\underset{\square}{\bullet}$ & $\square$ & $\bullet$ & $\bullet$ & $\bullet$ & $\bullet$ & $\bullet$ & $\bullet$ \\
\hline Estonia & - $\square$ & $\square \square \odot *$ & $\bullet$ & O & $\bullet$ & $\bullet$ & 0 & 0 \\
\hline Finlandia & - $\square$ & $\square$ & $\bullet$ & O & 0 & $\bullet$ & $\bullet$ & - \\
\hline Francia & $\underset{\square}{\square}$ & $*$ & 0 & O & O & O & $\bullet$ & O \\
\hline Grecia & O & $\mathrm{x}$ & $\mathrm{x}$ & $\mathrm{x}$ & $\mathrm{x}$ & $\mathrm{x}$ & $\mathrm{x}$ & $\mathrm{x}$ \\
\hline Hungría & O & $\mathrm{x}$ & $\mathrm{x}$ & $\mathrm{x}$ & $\mathrm{x}$ & $\mathrm{x}$ & $\mathrm{x}$ & $\mathrm{x}$ \\
\hline Irlanda & घ & $\odot$ & $\bullet$ & $\bullet$ & 0 & 0 & $\bullet$ & $\bullet$ \\
\hline Islandia & . $\square$ & $\square \square$ & $\bullet$ & $\bullet$ & $\bullet$ & $\bullet$ & $\bullet$ & $\bullet$ \\
\hline Israel & घ & $\square$ & $\bullet$ & $\bullet$ & $\bullet$ & $\bullet$ & $\bullet$ & $\bullet$ \\
\hline Italia & $\square$ & $*$ & 0 & O & O & 0 & - & $\bullet$ \\
\hline Japón & 0 & $\mathrm{x}$ & $\mathrm{x}$ & $\mathrm{x}$ & $\mathrm{x}$ & $\mathrm{x}$ & $\mathrm{x}$ & $\mathrm{x}$ \\
\hline Letonia & - & $\odot$ & 0 & 0 & 0 & $\bullet$ & $\bullet$ & $\bullet$ \\
\hline Luxemburgo & O & $\mathrm{x}$ & $\mathrm{x}$ & $\mathrm{x}$ & $\mathrm{x}$ & $\mathrm{x}$ & $\mathrm{x}$ & $\mathrm{x}$ \\
\hline México & $\square \bullet$ & $\square$ & $\bullet$ & $\bullet$ & O & $\bullet$ & 0 & $\bullet$ \\
\hline Noruega & घ & $*$ & $\bullet$ & $\bullet$ & $\bullet$ & $\bullet$ & $\bullet$ & $\bullet$ \\
\hline Nueva Zelanda & $\square$ & 口 & $\bullet$ & $\bullet$ & $\bullet$ & O & $\bullet$ & $\bullet$ \\
\hline Países Bajos & $\diamond \square$ & $\odot \nLeftarrow$ & $\bullet$ & O & O & $\bullet$ & $\bullet$ & $\bullet$ \\
\hline Polonia & $\square$ & 口 & 0 & O & O & O & ○ & O \\
\hline
\end{tabular}




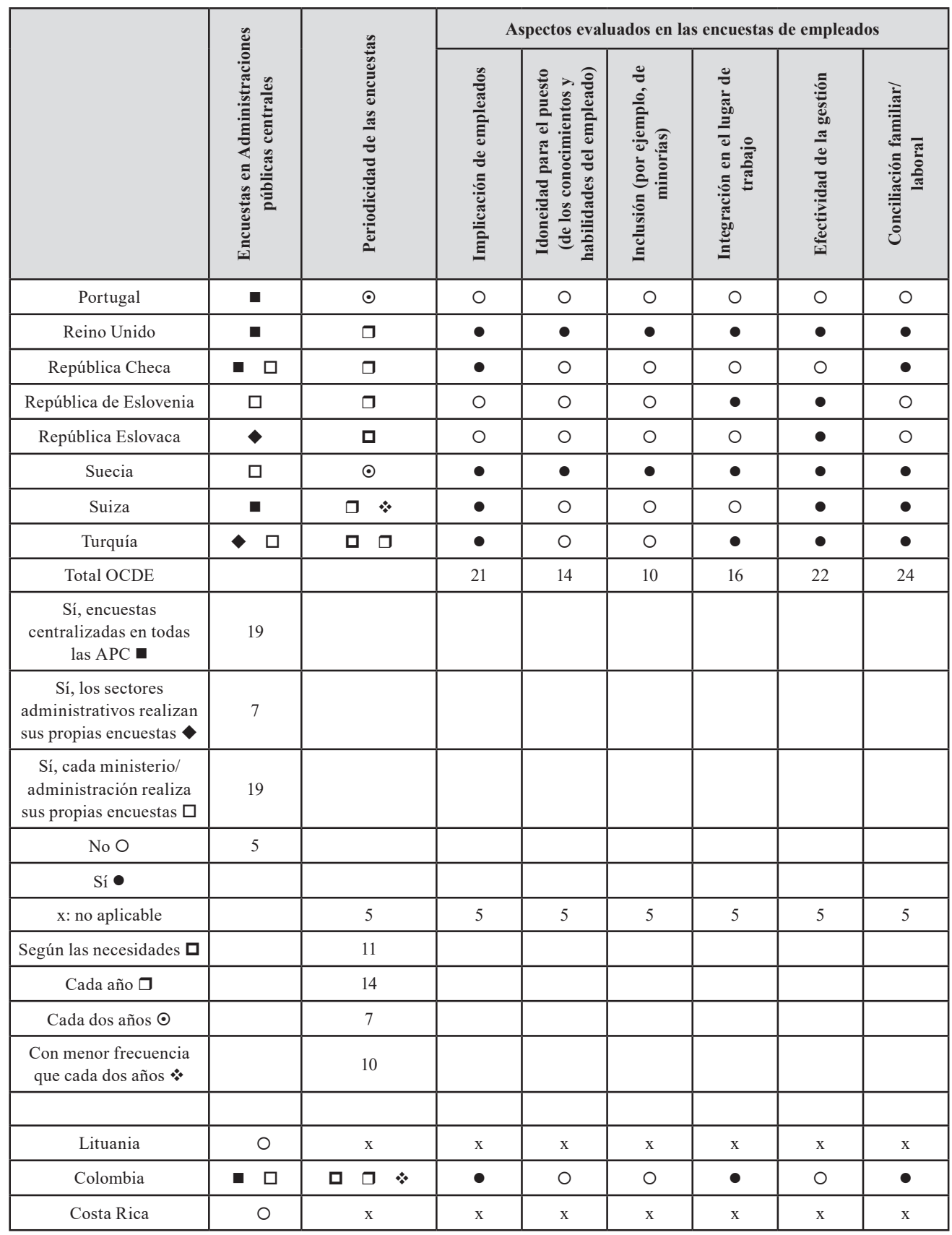

Fuente: OCDE (2016), Encuesta sobre Gestión Estratégica de Recursos Humanos, OCDE, París. 



\title{
CAPÍTULO 7. \\ INTEGRIDAD DEL SECTOR PÚBLICO
}

\author{
MEDIDAS INSTITUCIONALES PARA LOS SISTEMAS DE \\ INTEGRIDAD EN EL SECTOR PÚBLICO
}

Dada la multitud de elementos que componen los sistemas de integridad del sector público, es necesario el establecimiento de medidas institucionales que apoyen el diseño, implementación, supervisión y evaluación de estos. Por tanto, los países deben delimitar claramente los mandatos institucionales además de garantizar que las organizaciones tengan las capacidades y recursos necesarios para cumplir efectivamente con sus responsabilidades.

La variación entre países en cuanto a la organización de sus sistemas de integridad pública es considerable $\mathrm{y}$, en muchos casos, las responsabilidades se comparten entre una o más instituciones. Prevalece, sin embargo, el enfoque descentralizado en el que distintos ministerios competentes del poder ejecutivo son responsables del diseño y de la dirección del grueso de las políticas de integridad: desde las normas y códigos de conducta hasta las políticas para la gestión de conflictos de interés, la transparencia de las actividades de lobbying y el control interno y gestión del riesgo.

Lo mismo cabe decir del diseño de las estrategias anticorrupción o de integridad nacional, aunque en estos casos los centros de gobierno del poder ejecutivo pueden a veces tomar las riendas (8 países). Los centros de gobierno pueden asumir este papel por varios motivos, como por ejemplo para apoyar un enfoque más integral, facilitar la coordinación interinstitucional y/o garantizar una supervisión mayor. En Canadá, por ejemplo, la Secretaría del Consejo del Tesoro lleva a cabo esta función clave. En Reino Unido, la Oficina del Gabinete cumple este rol y dirige la Unidad Conjunta Anticorrupción, un grupo interdepartamental responsable de desarrollar la subsiguiente estrategia anticorrupción.

En algunos países, los organismos autónomos desempeñan un papel más destacado. Se considera que estos organismos son independientes y su mandato puede ir más allá que el del poder ejecutivo. El Sistema Nacional Antico- 
rrupción (SNA) de México, por ejemplo, está consagrado en la Constitución y dirigido por un Comité Coordinador que tiene por presidente a un representante de la sociedad civil. En Letonia, la Oficina de Prevención y Lucha contra la Corrupción (KNAB, por sus siglas originales) es la autoridad anticorrupción por excelencia desde 2002. Entre otras actividades, la KNAB es responsable del desarrollo y coordinación de la implementación del programa nacional anticorrupción. En Japón, la Oficina de Ética del Servicio Público Nacional está encargada de la supervisión de las prácticas éticas asociadas al desempeño laboral de los empleados públicos.

Estas instituciones pueden también ser responsables de recibir quejas de denunciantes, que se benefician de su mayor autonomía y de sus garantías de protección de datos, confidencialidad y anonimato. Sin embargo, algunos países han establecido organismos especializados como el Comisionado de Integridad del Sector Público de Canadá.

Por razones similares, otros tipos de organismos autónomos (como los institutos electorales y las instituciones supremas de auditoría) son conjuntamente responsables de las políticas relativas al financiamiento político (15 países) $\mathrm{y}$, por tanto, su independencia se valora puesto que garantiza una supervisión efectiva.

\section{Metodología y definiciones}

Los datos proceden de la Encuesta de la OCDE sobre la integridad del sector público de 2016 en la que participaron 31 países de la OCDE y 6 países no miembros. Los encuestados eran altos funcionarios responsables de las políticas de integridad de la Administración central/federal correspondiente.

El término sistema de integridad pública se define como un sistema que incluye leyes, regulaciones, políticas y prácticas, así como funcionarios, organismos y unidades que contribuyen de manera específica a la integridad en el sector público. 
El término organismo o unidad central de integridad hace referencia al bloque de la organización (departamento, dirección, sección, división, equipo/grupo de trabajo, comisión, etc.) responsable de las políticas de integridad en la Administración central.

El término centro de gobierno $(\mathrm{CdG})$ se define como la estructura administrativa que sirve al Ejecutivo (presidente o primer ministro, y el gabinete a nivel colectivo). Tiene una gran variedad de nombres dependiendo del país, como Secretaría General, Oficina del Gabinete, Cancillería, Oficina/Ministerio del Presidente, Oficina del Consejo de Ministros, etc.

El término organismos autónomos se define como los organismos que tienen independencia financiera, administrativa y operativa, protegida por la legislación, y que están encargados de una cartera/agenda política específica.

\section{Otras publicaciones}

OECD (2017), Recommendation of the Council on Public Integrity, OECD, París.

OECD (2017), «OECD Integrity Review of Peru», OECD Publishing, París.

OECD (2017), «OECD Integrity Review of Mexico», OECD Publishing, París.

\section{Notas de los gráficos}

Los datos de Argentina, Brasil y Perú se incluyeron de manera ad hoc.

7.1: La gama completa de políticas del sistema de integridad de los Estados Unidos se desarrolla e implementa por entidades y organismos independientes con jurisdicciones específicas por tema o sector. 
Tabla 7.1. Instituciones responsables del diseño de las políticas del sistema de integridad

\begin{tabular}{|c|c|c|c|c|c|c|c|}
\hline & \multirow{2}{*}{ 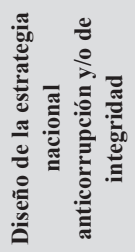 } & \multicolumn{6}{|c|}{ Diseño de políticas públicas relacionadas con } \\
\hline & & 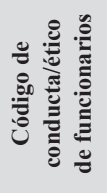 & 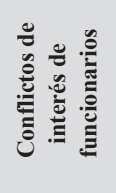 & 苋 & 兰 & 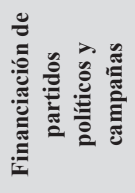 & 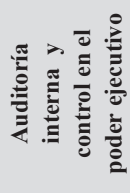 \\
\hline Alemania & $\boldsymbol{\Delta}$ & $\Delta$ & $\Delta$ & $\boldsymbol{\Delta}$ & $\boldsymbol{\Delta}$ & $\boldsymbol{\Delta}$ & $\Delta \boldsymbol{E}$ \\
\hline Australia & $\boldsymbol{\Delta}$ & $\bullet$ & $\bullet$ & $\bullet$ & $\bullet$ & $\bullet$ & $\bullet$ \\
\hline Austria & $\Delta$ & $\bullet \boldsymbol{\Delta}$ & $\Delta$ & $\bullet \boldsymbol{\Delta}$ & $\Delta$ & $\bullet$ & $\Delta \boldsymbol{\theta}$ \\
\hline Bélgica & $\bullet \boldsymbol{\Delta}$ & $\Delta$ & $\Delta$ & $\Delta \boldsymbol{\theta}$ & $\boldsymbol{\Delta}$ & $\boldsymbol{\Delta}$ & $\Delta \boldsymbol{\square}$ \\
\hline Canadá & $\bullet \boldsymbol{\Delta}$ & $\bullet \boldsymbol{\Delta}$ & $\bullet \boldsymbol{\Delta}$ & $\bullet$ & $\bullet$ & - & $\bullet \boldsymbol{\Delta}$ \\
\hline Chile & $\Delta=$ & $\Delta$ & - & $\Delta \mathbf{m}$ & - & - & $\bullet \boldsymbol{A}$ \\
\hline Corea & $\Delta \boldsymbol{m}$ & $\Delta$ & $\Delta$ & $\Delta$ & $\boldsymbol{\Delta}$ & - & ! \\
\hline España & $\bullet \boldsymbol{\Delta}$ & $\bullet \boldsymbol{\Delta}$ & $\bullet \boldsymbol{\Delta}$ & $\square$ & $\bullet \boldsymbol{\Delta}$ & $\bullet \boldsymbol{\Delta}$ & $\bullet \boldsymbol{\Delta}$ \\
\hline Estados Unidos & $\square$ & $\Delta$ & $\Delta$ & $\boldsymbol{\Delta}$ & $\bullet \boldsymbol{\Delta}$ - & $\Delta \boldsymbol{m}$ & $\bullet \Delta \boldsymbol{\Delta}$ \\
\hline Estonia & $\Delta$ & - & $\Delta$ & $\boldsymbol{\Delta}$ & $\Delta-$ & - & - \\
\hline Finlandia & $\boldsymbol{\Delta}$ & $\Delta$ & $\Delta$ & $\Delta$ & $\square$ & $\Delta \cdot$ & $\boldsymbol{\Delta}$ \\
\hline Francia & $\Delta$ & $\Delta \mathbf{m}$ & $\Delta=-$ & $\Delta$ & $\Delta \mathbf{\theta}$ & $\Delta \cdot$ & $\Delta=\triangleleft$ \\
\hline Grecia & $\Delta$ & $\Delta$ & $\Delta$ & $\Delta$ & $\Delta$ & $\Delta$ & $\bullet \boldsymbol{\Delta} \boldsymbol{\square}$ \\
\hline Hungría & $\Delta$ & - & $\bullet \boldsymbol{\Delta}$ & - & $\boldsymbol{\Delta}$ & $\Delta \boldsymbol{n}$ & $\Delta$ \\
\hline Irlanda & $\square$ & - & $\Delta$ & $\boldsymbol{\Delta}$ & $\Delta$ & $\boldsymbol{\Delta}$ & - \\
\hline Islandia & $\bullet \boldsymbol{\Delta}$ & $\bullet$ & $\bullet$ & $\bullet \boldsymbol{\Delta}$ & $\bullet \boldsymbol{\Delta}$ & $\Delta$ & $\Delta$ \\
\hline Italia & - & $\Delta \mathbf{m}$ & - & $\Delta \mathbf{m}$ & - & - & $\Delta \mathbf{m}-$ \\
\hline Japón & $\bullet$ & $\bullet \Delta \boldsymbol{\|}$ & $\bullet$ & - & $\square$ & - & $\Delta$ \\
\hline Letonia & - & $\bullet$ & - & $\bullet$ & - & - & $\Delta$ \\
\hline México & - & $\Delta$ & $\Delta$ & $\Delta$ & - & - & $\Delta \mathbf{n}$ \\
\hline Noruega & $\square$ & $\Delta$ & $\Delta$ & $\boldsymbol{\Delta}$ & $\boldsymbol{\Delta}$ & $\boldsymbol{\Delta}$ & $\Delta$ \\
\hline Nueva Zelanda & $\bullet \boldsymbol{\Delta}$ & $\bullet \Delta \mathbf{E}$ & $\bullet \Delta \square$ & $\bullet \Delta \boldsymbol{\square}$ & $\bullet$ & $\bullet \Delta \boldsymbol{\square}$ & $\bullet \Delta \boldsymbol{\square}$ \\
\hline Países Bajos & $\Delta$ & $\Delta$ & $\Delta$ & - & $\boldsymbol{\Delta}$ & $\Delta$ & $\Delta$ \\
\hline Polonia & $\Delta$ & $\bullet$ & $\square$ & $\boldsymbol{\Delta}$ & $\bullet$ & - & $\Delta$ \\
\hline Portugal & - & - & - & - & $\square$ & - & $\Delta$ \\
\hline Reino Unido & $\bullet$ & $\bullet$ & $\bullet$ & $\bullet$ & $\bullet$ & - & $\bullet$ \\
\hline República Checa & $\Delta$ & $\Delta$ & $\Delta$ & $\Delta$ & $\Delta$ & $\Delta=$ & $\Delta \boldsymbol{\square}$ \\
\hline $\begin{array}{c}\text { República de } \\
\text { Eslovenia }\end{array}$ & $\bullet \Delta \mathbf{m}$ & $\bullet \boldsymbol{\Delta} \boldsymbol{\square}$ & $\bullet \boldsymbol{\Delta} \boldsymbol{\square}$ & $\Delta \boldsymbol{\square}$ & $\Delta \boldsymbol{\theta}$ & $\boldsymbol{\Delta}$ & $\boldsymbol{\Delta}$ \\
\hline
\end{tabular}




\begin{tabular}{|c|c|c|c|c|c|c|c|}
\hline & \multirow{2}{*}{ 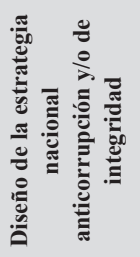 } & \multicolumn{6}{|c|}{ Diseño de políticas públicas relacionadas con } \\
\hline & & 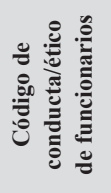 & 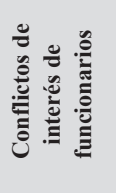 & 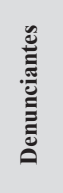 & $\begin{array}{l}\stackrel{60}{0} \\
\frac{0}{0} \\
\frac{0}{0} \\
1\end{array}$ & 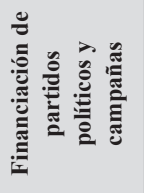 & 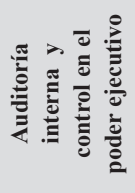 \\
\hline $\begin{array}{l}\text { República } \\
\text { Eslovaca }\end{array}$ & $\boldsymbol{\Delta}$ & $\Delta$ & $\bullet \boldsymbol{\Delta}$ & $\Delta$ & $\square$ & $\Delta$ & $\bullet \Delta \mathbf{\square}$ \\
\hline Suecia & - & - & - & - & $\square$ & - & - \\
\hline Suiza & $\Delta \boldsymbol{\Delta}$ & $\boldsymbol{\Delta}$ & $\Delta$ & $\Delta \mathbf{m}$ & $\bullet$ & $\bullet$ & $\Delta \mathbf{I}$ \\
\hline \multicolumn{8}{|l|}{ Total OCDE } \\
\hline $\begin{array}{l}\text { - Centro de } \\
\text { gobierno }\end{array}$ & 8 & 11 & 10 & 7 & 9 & 5 & 9 \\
\hline $\begin{array}{l}\Delta \text { Ministerio o } \\
\text { unidad dentro de } \\
\text { un ministerio }\end{array}$ & 21 & 21 & 21 & 21 & 16 & 16 & 25 \\
\hline $\begin{array}{l}\text { Organismo } \\
\text { autónomo }\end{array}$ & 10 & 8 & 10 & 12 & 7 & 15 & 15 \\
\hline $\begin{array}{c}\qquad \text { Comité } \\
\text { interinstitucional }\end{array}$ & 3 & 1 & 0 & 0 & 0 & 0 & 1 \\
\hline$\square \mathrm{N} / \mathrm{A}$ & 3 & 0 & 1 & 1 & 5 & 0 & 0 \\
\hline - Otros & 0 & 2 & 1 & 0 & 3 & 4 & 3 \\
\hline Argentina & $\Delta$ & $\Delta$ & $\Delta$ & $\Delta$ & $\Delta$ & $\Delta$ & $\Delta$ \\
\hline Brasil & $\bullet$ & $\Delta$ & $\Delta$ & $\square$ & $\square$ & - & $\Delta$ \\
\hline Colombia & $\bullet \Delta \mathbf{E}$ & - & $\Delta$ & - & $\bullet$ & - & $\bullet \Delta \mathbf{n}$ \\
\hline Costa Rica & - & $\Delta$ & $\Delta$ & $\Delta \mathbf{n}$ & $\square$ & - & 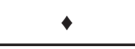 \\
\hline Lituania & $\bullet \bullet$ & $\bullet$ & - & $\square$ & ! & $\| \triangleleft$ & $\Delta-$ \\
\hline Perú & $\bullet$ & $\bullet$ & $\bullet$ & $\bullet \bullet$ & $\bullet$ & at & ! \\
\hline & & & & & & & \\
\hline
\end{tabular}

Fuente: OCDE (2016), Encuesta sobre la integridad del sector público, OCDE, París.

$<$ http://dx.doi.org/10.1787/888933535088> 


\section{MECANISMOS DE COORDINACIÓN PARA LA IMPLEMENTACIÓN DE POLÍTICAS DE INTEGRIDAD}

Los sistemas de integridad pública se componen de numerosos actores responsables de diversos ámbitos políticos específicos que proceden de los niveles central y subcentral (es decir, regional y local) de las Administraciones. Los mecanismos de coordinación interinstitucional vertical y horizontal son, por tanto, esenciales para garantizar la implementación efectiva en todo el conjunto de las Administraciones públicas, así como para prevenir la duplicación o fragmentación y, consecuentemente, el desperdicio de recursos públicos y/o desarrollo de políticas ineficaces.

Muchos sistemas de integridad están descentralizados. En el $72 \%$ de los países (22), las Administraciones estatales y locales funcionan con autonomía y pueden determinar sus propias políticas de integridad. Entre estos países se incluyen muchos (aunque no todos) de los cuasifederales, como Bélgica, España y Suiza. De hecho, el concepto de sistema de integridad local cobra sentido en muchos países, puesto que los riesgos en materia de integridad pueden variar significativamente entre los países y jurisdicciones administrativas, y un enfoque único a nivel global de las Administraciones no sería efectivo. Por ejemplo, las Administraciones estatales y locales pueden tener, comparativamente, mayores competencias en la prestación de servicios públicos $\mathrm{y}$, por tanto, un nivel más elevado de interacción con los ciudadanos y empresas, lo cual puede generar oportunidades de corrupción. Pueden tener además un mayor grado de gastos en riesgo, como los gastos sociales o de contratación pública, que requieren medidas adicionales de control. Por ejemplo, en la OCDE en 2015, el 63\% de los gastos de contratación pública se dieron a nivel subcentral de las Administraciones.

Incluso cuando las Administraciones estatales y locales operan con autonomía en el diseño e implementación de las políticas de integridad, a menudo reciben apoyo a nivel central a través de mecanismos de coordinación. De hecho, solo unos pocos países (3) carecen de mecanismos de coordinación. Las formas más comunes de apoyo son la orientación por parte de un organismo de integridad de la Administración central (9 países), las reuniones periódicas de un comité o comisión específico de integridad (11) y la participación de las Administraciones estatales y locales en el diseño de las propias políticas (7).

Algunos han adoptado enfoques más formales de coordinación. En Estonia, Japón, México y Nueva Zelanda, por ejemplo, existen acuerdos o contratos legales entre las Administraciones centrales y subcentrales. A diferencia de otros métodos, estas alianzas pueden obligar legalmente a que las partes cumplan las iniciativas y objetivos acordados. En general, sin embargo, pocos 
países declararon adoptar varias herramientas de coordinación de manera simultánea. Esto podría ser reflejo de retos frecuentemente citados, como la alta fluctuación de personal, las elevadas cargas administrativas asociadas a la coordinación y el miedo de los niveles subnacionales a que la coordinación invada sus poderes de decisión.

La coordinación es igualmente importante en los ministerios y departamentos competentes para implementar las políticas en los distintos sectores públicos y garantizar su cumplimiento. Los requisitos normativos son, por tanto, la herramienta de uso más habitual (29 países), seguidos de la orientación constante por parte del organismo o unidad de la Administración central (22). Bastantes países (17) también exigen que los ministerios competentes tengan sus propias unidades de integridad en funcionamiento. Esto facilita notablemente la coordinación, puesto que identifica una entidad específica que tiene que rendir cuentas de los resultados. En Alemania, Austria y Canadá, por ejemplo, los responsables de asuntos éticos y puntos de enlace de los ministerios competentes han establecido redes de intercambio de buenas prácticas y búsqueda de asesoramiento.

\section{Metodología y definiciones}

Los datos proceden de la Encuesta de la OCDE sobre la integridad del sector público de 2016, en la que participaron 31 países de la OCDE y 6 países no miembros. Los encuestados eran altos funcionarios responsables de las políticas de integridad de la Administración central/federal correspondiente.

La Administración central a menudo se denomina Administración federal o nacional, dependiendo del país. A efectos de este estudio, la Administración central se compone de las unidades controladas y financiadas a nivel central y de las instituciones sin ánimo de lucro controladas y principalmente financiadas esta. A efectos de este estudio, solo se ha considerado el poder ejecutivo de la Administración central.

Las Administraciones subnacionales se refieren a las Administraciones estatales (regionales) o locales (municipales). A efectos de este estudio, solo se ha considerado el poder ejecutivo. 


\section{Otras publicaciones}

OECD (2017), Recommendation of the Council on Public Integrity, OECD, París.

OECD (2017), «OECD Integrity Review of Peru», OECD Publishing, París.

OECD (2017), «OECD Integrity Review of Mexico», OECD Publishing, París.

\section{Notas de los gráficos}

Los datos de Argentina, Brasil y Perú se incluyeron de manera ad hoc.

7.2: En Francia, los órganos autónomos, en arreglo a la legislación nacional, están encargados de las políticas de integridad tanto a nivel nacional como subnacional. Dentro del marco legal definido, los órganos autónomos son además libres de adoptar de manera independiente su propia implementación de mecanismos.

7.3: En Bélgica, Estados Unidos, Noruega y Países Bajos, los órganos centrales y subnacionales participan en la coordinación informal de muchos de los asuntos específicos de los sistemas de integridad.

\section{Gráfico 7.2. Autonomía de las políticas de integridad a nivel subnacional}

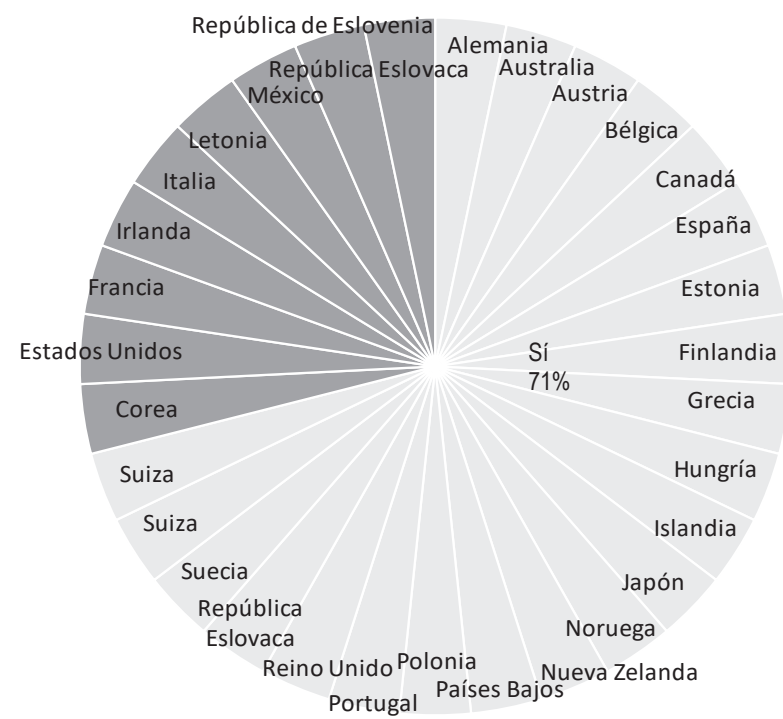

Fuente: OCDE (2016), Encuesta sobre la integridad del sector público, OCDE, París.

$<$ http://dx.doi.org/10.1787/888933532960> 


\section{Tabla 7.3. Mecanismos de coordinación de las políticas de integridad}

\begin{tabular}{|c|c|c|c|c|c|c|c|c|c|}
\hline & \multicolumn{5}{|c|}{$\begin{array}{c}\text { Coordinación entre los organismos de integración a } \\
\text { nivel central y subcentral }\end{array}$} & \multicolumn{4}{|c|}{$\begin{array}{l}\text { Tipos de mecanismos para implementar las } \\
\text { políticas de integridad en los ministerios } \\
\text { competentes }\end{array}$} \\
\hline & 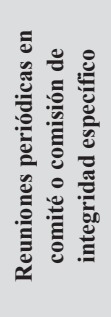 & 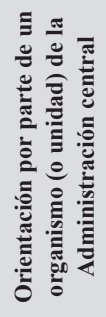 & 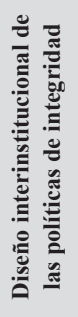 & 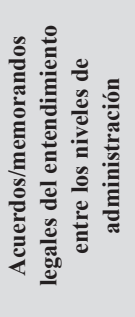 & 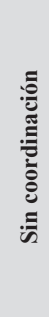 & 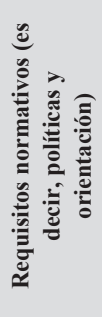 & 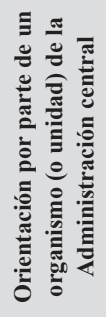 & 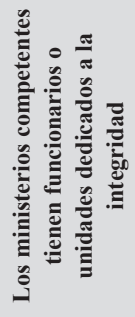 & 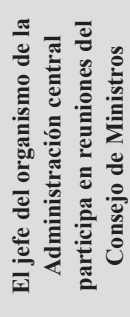 \\
\hline Alemania & & - & & & & - & $\bullet$ & - & \\
\hline Australia & $\bullet$ & & & & & $\bullet$ & & $\bullet$ & \\
\hline Austria & $\bullet$ & & $\bullet$ & & & $\bullet$ & & $\bullet$ & \\
\hline Bélgica & & & & & $\bullet$ & $\bullet$ & $\bullet$ & $\bullet$ & \\
\hline Canadá & & & & & & $\bullet$ & $\bullet$ & $\bullet$ & \\
\hline Chile & & $\bullet$ & & & & & $\bullet$ & & $\bullet$ \\
\hline Corea & & - & $\bullet$ & & & $\bullet$ & $\bullet$ & $\bullet$ & $\bullet$ \\
\hline España & $\bullet$ & & & & & $\bullet$ & $\bullet$ & $\bullet$ & \\
\hline $\begin{array}{l}\text { Estados } \\
\text { Unidos }\end{array}$ & & & & & & $\bullet$ & $\bullet$ & $\bullet$ & \\
\hline Estonia & $\bullet$ & & & $\bullet$ & & $\bullet$ & & & \\
\hline Finlandia & $\bullet$ & & & & & $\bullet$ & $\bullet$ & & $\bullet$ \\
\hline Francia & & & & & • & $\bullet$ & $\bullet$ & $\bullet$ & \\
\hline Grecia & & - & $\bullet$ & & & $\bullet$ & $\bullet$ & & \\
\hline Hungría & & $\bullet$ & $\bullet$ & & & $\bullet$ & $\bullet$ & & \\
\hline Irlanda & & & & & & $\bullet$ & $\bullet$ & & \\
\hline Islandia & & & & & & $\bullet$ & $\bullet$ & & \\
\hline Italia & $\bullet$ & - & $\bullet$ & & & $\bullet$ & $\bullet$ & $\bullet$ & \\
\hline Japón & & & & $\bullet$ & & $\bullet$ & $\bullet$ & $\bullet$ & \\
\hline Letonia & & & $\bullet$ & & & $\bullet$ & & & \\
\hline México & $\bullet$ & $\bullet$ & & $\bullet$ & & $\bullet$ & $\bullet$ & & $\bullet$ \\
\hline Noruega & $\bullet$ & - & & & & - & & & \\
\hline $\begin{array}{l}\text { Nueva } \\
\text { Zelanda }\end{array}$ & $\bullet$ & $\bullet$ & & $\bullet$ & & $\bullet$ & $\bullet$ & $\bullet$ & \\
\hline $\begin{array}{c}\text { Países } \\
\text { Bajos }\end{array}$ & & & & & & $\bullet$ & $\bullet$ & $\bullet$ & \\
\hline Polonia & & & & & $\bullet$ & $\bullet$ & $\bullet$ & & \\
\hline Portugal & & & & & & $\bullet$ & & & \\
\hline $\begin{array}{l}\text { Reino } \\
\text { Unido }\end{array}$ & & & & & & $\bullet$ & $\bullet$ & $\bullet$ & $\bullet$ \\
\hline
\end{tabular}




\begin{tabular}{|c|c|c|c|c|c|c|c|c|c|}
\hline & \multicolumn{5}{|c|}{$\begin{array}{c}\text { Coordinación entre los organismos de integración a } \\
\text { nivel central y subcentral }\end{array}$} & \multicolumn{4}{|c|}{$\begin{array}{l}\text { Tipos de mecanismos para implementar las } \\
\text { políticas de integridad en los ministerios } \\
\text { competentes }\end{array}$} \\
\hline & 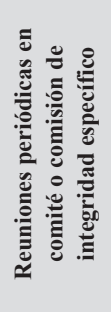 & 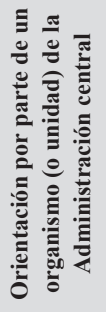 & 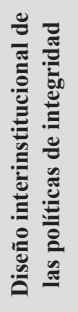 & 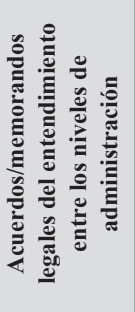 & 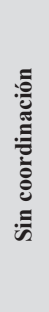 & 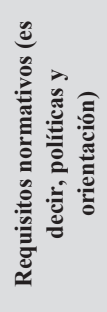 & 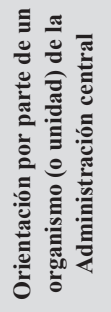 & 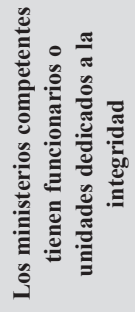 & 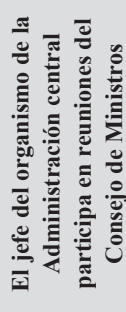 \\
\hline $\begin{array}{l}\text { República } \\
\text { Checa }\end{array}$ & & & & & & $\bullet$ & & $\bullet$ & \\
\hline $\begin{array}{l}\text { República } \\
\text { de } \\
\text { Eslovenia }\end{array}$ & & & $\bullet$ & & & $\bullet$ & $\bullet$ & $\bullet$ & $\bullet$ \\
\hline $\begin{array}{l}\text { República } \\
\text { Eslovaca }\end{array}$ & $\bullet$ & & & & & & & $\bullet$ & \\
\hline Suecia & $\bullet$ & & & & & $\bullet$ & $\bullet$ & & $\bullet$ \\
\hline Suiza & & & & & & $\bullet$ & & & \\
\hline $\begin{array}{l}\text { Estados } \\
\text { Unidos }\end{array}$ & & & & & & $\bullet$ & $\bullet$ & $\bullet$ & \\
\hline $\begin{array}{c}\text { Total } \\
\text { OCDE }\end{array}$ & 11 & 9 & 7 & 4 & 3 & 29 & 22 & 17 & 7 \\
\hline Argentina & & $\bullet$ & & $\bullet$ & & $\bullet$ & $\bullet$ & & $\bullet$ \\
\hline Brasil & $\bullet$ & $\bullet$ & & $\bullet$ & & $\bullet$ & & $\bullet$ & \\
\hline Colombia & & $\bullet$ & & & & $\bullet$ & - & & \\
\hline Costa Rica & & $\bullet$ & & & & $\bullet$ & & & $\bullet$ \\
\hline Lituania & & $\bullet$ & & & & $\bullet$ & $\bullet$ & $\bullet$ & $\bullet$ \\
\hline Perú & $\bullet$ & & & & & $\bullet$ & $\bullet$ & $\bullet$ & \\
\hline & & & & & & & & & \\
\hline
\end{tabular}

Fuente: OCDE (2016), Encuesta sobre la integridad del sector público, OCDE, París.

$<$ http://dx.doi.org/10.1787/888933535107>

\section{SUPERVISIÓN Y EVALUACIÓN DE LOS SISTEMAS DE INTEGRIDAD}

Al igual que en cualquier otro ámbito político, medir el rendimiento genera evidencia para el diseño de políticas de integridad más eficaces. También facilita su implementación, ayudando a los responsables políticos a supervisar el 
cumplimiento de las políticas de integridad, detectar posibles obstáculos e identificar riesgos de integridad sin resolver.

La mayoría de los países de la OCDE y países asociados tienen en marcha estrategias de seguimiento y evaluación de las políticas de integridad del sector público, a excepción de Estonia, Lituania, Portugal y Suiza. Las evaluaciones se llevan a cabo por un organismo central o de manera individual por los ministerios competentes y otras organizaciones del sector público. Los aspectos más estudiados por la Administración central del poder ejecutivo incluyen verificar la existencia y calidad de los códigos de conducta y de los mapas de riesgo de fraude y la existencia y cumplimiento de las políticas de conflictos de interés y de declaración patrimonial.

Los países recopilan información sobre el rendimiento a través de distintos medios, incluyendo las encuestas de personal (14 países), entrevistas y grupos de trabajo (8), encuestas de opinión pública (6) y estudios de casos (7). Sin embargo, la fuente más utilizada son los datos administrativos internos de las organizaciones, con 18 países que confirman su uso. El motivo principal del uso generalizado de los datos administrativos es su disponibilidad, ya que en la mayoría de los casos son un recurso interno de las organizaciones. No obstante, con frecuencia solo reflejan los insumos y productos de las iniciativas de integridad (es decir, datos de presupuestos y personal, formación y reuniones, listas de asistentes, declaraciones recibidas, etc.).

Si bien esta información es útil, la visión que puede ofrecer en cuanto a los resultados de las políticas (es decir, la calidad de los resultados, internalización de los valores de integridad, etc.) es limitada. Un marco analítico adecuado para el seguimiento y evaluación de los sistemas de integridad debe combinar los datos administrativos con otras fuentes adicionales de información externa (ciudadanos, empresas, etc.) y con datos de percepción de la integridad. El Instituto Nacional de Estadística y Geografía (INEGI) de México, por ejemplo, recoge datos detallados de las percepciones y experiencias de los ciudadanos en materia de corrupción en una muestra estándar de los servicios públicos a nivel federal, estatal y municipal. Este instituto también realiza encuestas de opinión pública sobre la percepción de los niveles de corrupción de varias instituciones. La Comisión Anticorrupción y de Derechos Civiles de Corea desarrolló la evaluación de la iniciativa anticorrupción (AIA, por sus siglas en inglés) y la evaluación de integridad (IA, por sus siglas en inglés), que combinan datos administrativos cuantitativos y de percepción recogidos a través de encuestas para supervisar y comparar las prácticas de implementación de las políticas anticorrupción en las organizaciones. En Hungría, la institución suprema de auditoría evalúa las instituciones del sector público periódicamente a través de cuestionarios, que a su vez alimentan el cálculo de sus índices de riesgo de corrupción. 


\section{Metodología y definiciones}

Los datos proceden de la Encuesta de la OCDE sobre la integridad del sector público de 2016, en la que participaron 31 países de la OCDE y 6 países no miembros. Los encuestados eran altos funcionarios responsables de las políticas de integridad de la Administración central/federal correspondiente.

El término sistema de integridad pública se define como un sistema que incluye leyes, regulaciones, políticas y prácticas, así como funcionarios, organismos y unidades que contribuyen de manera específica a la integridad del sector público.

\section{Otras publicaciones}

OECD (2017), Recommendation of the Council on Public Integrity, OECD, París.

OECD (2009), «Integrity in Government: Towards Output and Outcome Measurement», OECD Publishing, París.

OECD (2009), «Measuring Government Activity», OECD Publishing, París.

\section{Notas de los gráficos}

Los datos de Argentina, Brasil y Perú se incluyeron de manera ad hoc.

7.4: En Canadá, la existencia de códigos de conducta se verifica durante las evaluaciones. Sin embargo, la evaluación de la calidad de los códigos de conducta no se contempla o varía de manera significativa. En Polonia, hasta la fecha la evaluación se ha realizado una sola vez, en 2014. En Australia, Austria, Canadá, Estados Unidos, Hungría, Noruega, Nueva Zelanda, República Eslovaca, Reino Unido y Suecia, los elementos del sistema de integridad se supervisan y evalúan por entidades y organismos independientes expertos en la materia. El alcance y métodos pueden variar. 
Tabla 7.4. Evaluación de los sistemas de integridad del sector público: alcance y métodos

\begin{tabular}{|c|c|c|c|c|c|c|c|c|c|c|c|c|}
\hline & \multicolumn{7}{|c|}{ Elementos incluidos en la evaluación } & \multicolumn{5}{|c|}{ Métodos usados para la evaluación } \\
\hline & 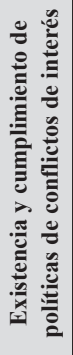 & 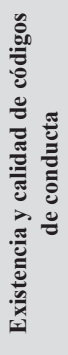 & 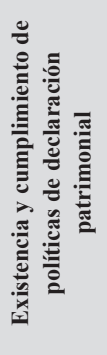 & 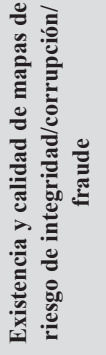 & 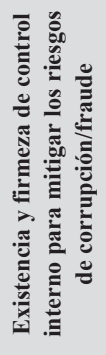 & 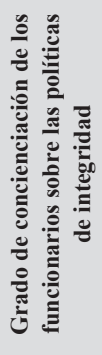 & & 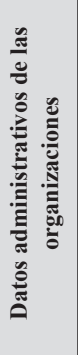 & 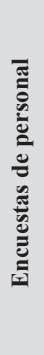 & 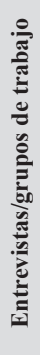 & 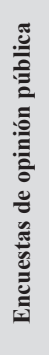 & 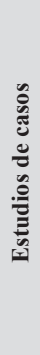 \\
\hline Alemania & $\circ$ & $\circ$ & N/A & $\bullet$ & $\bullet$ & $\circ$ & & $\bullet$ & $\circ$ & $\circ$ & $\circ$ & $\circ$ \\
\hline Australia & • & $\bullet$ & $\circ$ & $\bullet$ & $\bullet$ & $\bullet$ & & $\bullet$ & $\bullet$ & $\circ$ & $\circ$ & $\circ$ \\
\hline Austria & - & - & - & - & - & - & & $\circ$ & $\bullet$ & $\circ$ & $\circ$ & $\bullet$ \\
\hline Bélgica & • & - & $\Delta$ & $\bullet$ & $\Delta$ & $\Delta$ & & $\circ$ & $\bullet$ & $\bullet$ & ० & $\circ$ \\
\hline Canadá & $\Delta$ & - & $\Delta$ & 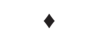 & $\Delta$ & 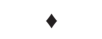 & & $\bullet$ & $\bullet$ & $\circ$ & $\circ$ & $\circ$ \\
\hline Chile & $\bullet$ & - & $\bullet$ & - & $\bullet$ & • & & $\bullet$ & $\bullet$ & $\bullet$ & $\circ$ & $\circ$ \\
\hline Corea & • & - & $\circ$ & • & - & - & & - & $\bullet$ & $\circ$ & • & $\bullet$ \\
\hline España & $\bullet$ & $\bullet$ & $\bullet$ & - & $\Delta$ & - & & - & $\circ$ & $\circ$ & $\bullet$ & $\circ$ \\
\hline $\begin{array}{l}\text { Estados } \\
\text { Unidos }\end{array}$ & - & - & - & - & - & - & & • & $\bullet$ & $\bullet$ & $\bullet$ & $\bullet$ \\
\hline Estonia & & & & & & & $\begin{array}{l}\text { No existe una } \\
\text { evaluación } \\
\text { central del } \\
\text { sistema de } \\
\text { integridad } \\
\text { pública }\end{array}$ & & & & & \\
\hline Finlandia & - & - & - & - & - & - & & $\circ$ & $\circ$ & $\circ$ & ○ & $\circ$ \\
\hline Francia & - & $\bullet$ & $\bullet$ & $\bullet$ & - & - & & - & $\circ$ & $\circ$ & ० & $\circ$ \\
\hline Grecia & $\Delta$ & $\bullet$ & $\bullet$ & $\bullet$ & $\bullet$ & $\bullet$ & & $\bullet$ & $\circ$ & $\circ$ & ○ & $\circ$ \\
\hline Hungría & ० & ० & ० & • & ○ & $\circ$ & & • & $\circ$ & $\bullet$ & o & $\circ$ \\
\hline Irlanda & $\circ$ & $\circ$ & $\circ$ & $\circ$ & $\circ$ & $\circ$ & & $\circ$ & $\circ$ & $\circ$ & $\circ$ & $\circ$ \\
\hline Islandia & $\circ$ & $\circ$ & $\circ$ & $\circ$ & $\circ$ & $\bullet$ & & $\circ$ & $\bullet$ & $\circ$ & ○ & $\circ$ \\
\hline Italia & $\bullet$ & $\bullet$ & $\bullet$ & $\bullet$ & - & - & & $\bullet$ & $\circ$ & $\circ$ & $\circ$ & $\bullet$ \\
\hline Japón & $\boldsymbol{\Delta}$ & $\bullet$ & $\bullet$ & N/A & $\bullet$ & $\bullet$ & & $\bullet$ & $\circ$ & $\bullet$ & ○ & $\circ$ \\
\hline Letonia & & & & & & & $\begin{array}{c}\text { No existe una } \\
\text { evaluación } \\
\text { central del } \\
\text { sistema de } \\
\text { integridad } \\
\text { pública }\end{array}$ & & & & & \\
\hline
\end{tabular}




\begin{tabular}{|c|c|c|c|c|c|c|c|c|c|c|c|c|}
\hline & \multicolumn{7}{|c|}{ Elementos incluidos en la evaluación } & \multicolumn{5}{|c|}{ Métodos usados para la evaluación } \\
\hline & 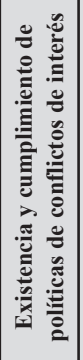 & 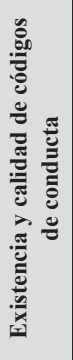 & 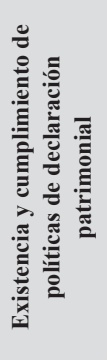 & 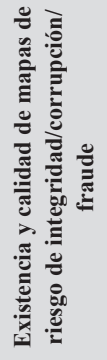 & 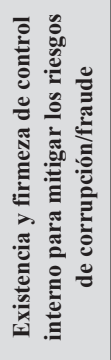 & 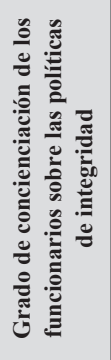 & & 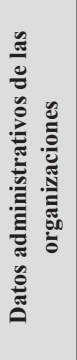 & 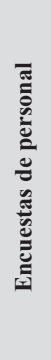 & 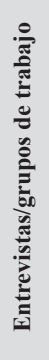 & 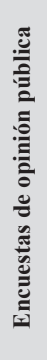 & 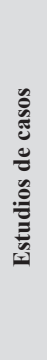 \\
\hline México & $\bullet$ & $\bullet$ & $\bullet$ & - & - & $\boldsymbol{\Delta}$ & & $\bullet$ & $\bullet$ & $\circ$ & $\circ$ & $\circ$ \\
\hline Noruega & - & - & - & - & - & - & & $\bullet$ & $\bullet$ & $\bullet$ & $\bullet$ & $\bullet$ \\
\hline $\begin{array}{l}\text { Nueva } \\
\text { Zelanda }\end{array}$ & $\boldsymbol{\Delta}$ & $\boldsymbol{\Delta}$ & $\Delta$ & $\boldsymbol{\Delta}$ & $\Delta$ & $\boldsymbol{\Delta}$ & & ० & - & $\circ$ & $\bullet$ & $\circ$ \\
\hline Países Bajos & $\bullet$ & $\bullet$ & $\bullet$ & $\bullet$ & $\bullet$ & $\bullet$ & & - & $\bullet$ & $\bullet$ & $\circ$ & $\circ$ \\
\hline Polonia & - & $\bullet *$ & - & - & - & $\bullet *$ & & $\bullet$ & $\circ$ & $\circ$ & $\circ$ & $\circ$ \\
\hline Portugal & & & & & & & $\begin{array}{c}\text { No existe una } \\
\text { evaluación } \\
\text { central del } \\
\text { sistema de } \\
\text { integridad } \\
\text { pública }\end{array}$ & & & & & \\
\hline Reino Unido & $\bullet$ & $\boldsymbol{\Delta}$ & $\bullet$ & $\Delta$ & $\bullet$ & $\boldsymbol{\Delta}$ & & $\bullet$ & $\bullet$ & $\circ$ & $\circ$ & $\circ$ \\
\hline $\begin{array}{l}\text { República } \\
\text { Checa }\end{array}$ & $\bullet$ & $\bullet$ & N/A & $\bullet$ & ० & $\bullet$ & & - & $\circ$ & $\circ$ & $\circ$ & $\circ$ \\
\hline $\begin{array}{l}\text { República de } \\
\text { Eslovenia }\end{array}$ & • & $\bullet$ & $\bullet$ & $\bullet$ & $\bullet$ & $\bullet$ & & ० & $\circ$ & $\circ$ & $\bullet$ & $\bullet$ \\
\hline $\begin{array}{l}\text { República } \\
\text { Eslovaca }\end{array}$ & - & - & - & - & - & - & & $\circ$ & ० & $\circ$ & $\circ$ & $\circ$ \\
\hline Suecia & - & - & - & - & - & - & & $\circ$ & $\bullet$ & $\bullet$ & $\circ$ & $\bullet$ \\
\hline Suiza & & & & & & & $\begin{array}{c}\text { No existe una } \\
\text { evaluación } \\
\text { central del } \\
\text { sistema de } \\
\text { integridad } \\
\text { pública }\end{array}$ & & & & & \\
\hline \multicolumn{13}{|l|}{ Total OCDE } \\
\hline - Siempre & 11 & 12 & 10 & 9 & 8 & 10 & - Sí & 18 & 14 & 8 & 6 & 7 \\
\hline A menudo & 1 & 2 & 0 & 5 & 3 & 3 & $\circ$ No & 9 & 13 & 19 & 21 & 20 \\
\hline$\Delta$ A veces & 4 & 2 & 3 & 2 & 4 & 4 & & & & & & \\
\hline$\circ$ Nunca & 4 & 4 & 5 & 2 & 4 & 3 & & & & & & \\
\hline $\begin{array}{c}\text { - } \\
\text { Desconocido/ } \\
\text { Varía mucho }\end{array}$ & 7 & 7 & 7 & 8 & 8 & 7 & & & & & & \\
\hline
\end{tabular}




\begin{tabular}{|c|c|c|c|c|c|c|c|c|c|c|c|c|}
\hline & \multicolumn{7}{|c|}{ Elementos incluidos en la evaluación } & \multicolumn{5}{|c|}{ Métodos usados para la evaluación } \\
\hline & 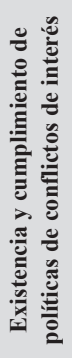 & 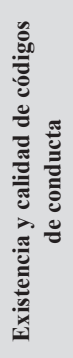 & 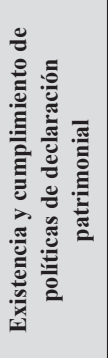 & 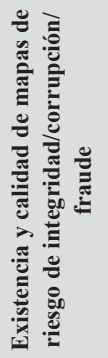 & 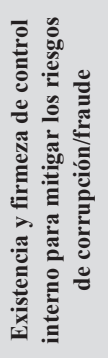 & 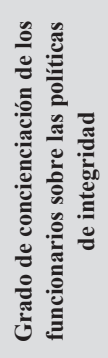 & & 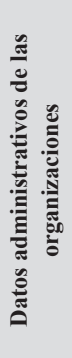 & 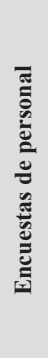 & 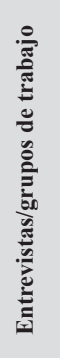 & 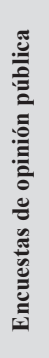 & 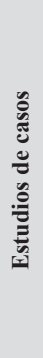 \\
\hline Argentina & & & & & & & $\begin{array}{l}\text { No existe una } \\
\text { evaluación } \\
\text { central del } \\
\text { sistema de } \\
\text { integridad } \\
\text { pública }\end{array}$ & & & & & \\
\hline Brasil & & & & & & & $\begin{array}{l}\text { No existe una } \\
\text { evaluación } \\
\text { central del } \\
\text { sistema de } \\
\text { integridad } \\
\text { pública }\end{array}$ & & & & & \\
\hline Colombia & $\circ$ & $\circ$ & • & • & 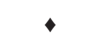 & $\Delta$ & & • & - & $\circ$ & $\circ$ & $\circ$ \\
\hline Costa Rica & & & & & & & $\begin{array}{l}\text { No existe una } \\
\text { evaluación } \\
\text { central del } \\
\text { sistema de } \\
\text { integridad } \\
\text { pública }\end{array}$ & & & & & \\
\hline Lituania & & & & & & & $\begin{array}{l}\text { No existe una } \\
\text { evaluación } \\
\text { central del } \\
\text { sistema de } \\
\text { integridad } \\
\text { pública }\end{array}$ & & & & & \\
\hline Perú & $\circ$ & $\Delta$ & - & - & - & ○ & & - & ○ & o & $\circ$ & $\circ$ \\
\hline
\end{tabular}

Fuente: OCDE (2016), Encuesta sobre la integridad del sector público, OCDE, París.

\section{CONTROL INTERNO Y GESTIÓN DEL RIESGO}

Todas las organizaciones, incluidas las del sector público, son susceptibles a riesgos de integridad externos o internos, como el fraude o la corrupción. La ausencia de mecanismos para identificar, analizar y solventar estos riesgos puede tener consecuencias negativas, como pérdidas económicas, fallos de se- 
guridad y daños a la reputación. A su vez, estas repercusiones pueden erosionar la confianza de la ciudadanía en los servicios públicos y en las Administraciones.

Los sistemas efectivos de control interno y las actividades de gestión del riesgo son críticos para proteger la integridad de las organizaciones del sector público, especialmente en áreas de alto riesgo, como la gestión financiera, las tecnologías de la información y la contratación pública. Un enfoque basado en el riesgo permite que las entidades del sector público apliquen controles eficaces en términos de costes para reforzar la supervisión, sin sobrecargar la organización y dificultar la eficiencia. Al mismo tiempo, se puede reducir la percepción entre el personal de un exceso de control y, por tanto, reforzar su compromiso intrínseco con la integridad.

La responsabilidad de los sistemas de control interno recae, en primer lugar, en los gestores, que constituyen la primera línea de defensa (IIA, 2013). En concreto, los gestores son responsables del diseño, implementación, seguimiento y mejora del sistema de control interno y de la función de gestión del riesgo, tal y como está estipulado en las políticas y normas de muchos países. Disponer de leyes que establezcan esta responsabilidad puede resultar un incentivo para los gestores, así como ayudar a que los países establezcan una cultura basada en el compromiso, la supervisión y la rendición de cuentas. La mayoría de los países manifestaron que los gestores del poder ejecutivo son responsables por ley de la supervisión e implementación del control (26 países) y de las actividades de gestión del riesgo (22). Es más, alrededor de la mitad de los países encuestados (16) tienen leyes específicas que establecen la responsabilidad de los gestores en materia de políticas de gestión del riesgo de la integridad.

Los países se enfrentan también a desafíos relacionados con la implementación e incorporación de las funciones y actividades de control en los sistemas de gestión y funcionamiento diario de las organizaciones. Por ejemplo, once de los países encuestados de la OCDE indicaron que promover los procesos de control como una herramienta para fomentar la integridad y mejorar el rendimiento de las organizaciones, en lugar de utilizar ejercicios puntuales y burocráticos de marcar la casilla, suponía un desafío moderado o severo. Nueve países mencionaron que el escaso apoyo recibido de los líderes políticos y de la jerarquía administrativa superior constituía un desafío moderado o serio.

Tener una función centralizada de auditoría interna, especialmente si pone énfasis en la introducción de la integridad como un objetivo estratégico, puede reforzar la coherencia y armonía de la respuesta política a los riesgos de integridad. La auditoría de múltiples entidades a nivel central puede aprovechar los recursos de auditoría disponibles (por ejemplo, concentración de expertos en auditoría forense o en seguridad cibernética); mejorar la capacidad de las Administraciones públicas de identificar problemas sistémicos e intersectoriales; y apoyar la puesta en marcha de medidas que proporcionen respuestas 
desde una perspectiva global de gobierno. Al mismo tiempo, una función centralizada de auditoría interna se podría percibir como un control externo, ajeno, con conocimientos limitados de los sistemas y operaciones de las entidades individuales. Quince países de la OCDE declararon tener una función de auditoría interna responsable de auditar más de un ministerio del Gobierno. Diez de estos países tienen funciones centrales de auditoría que han adoptado objetivos dedicados a la integridad en sus mandatos o estrategias.

\section{Metodología y definiciones}

Los datos proceden de la Encuesta de la OCDE sobre la integridad del sector público de 2016, en la que participaron 31 países de la OCDE y 6 países no miembros. Los encuestados eran altos funcionarios responsables de las políticas de integridad de la Administración central/federal correspondiente.

El término control interno se define como «el proceso diseñado, implementado y mantenido por los encargados de la gobernanza, gerencia y otro personal para proporcionar seguridad razonable sobre el logro de los objetivos de la entidad, respecto a la confiabilidad de la información financiera, efectividad y eficiencia de las operaciones y el cumplimiento de las leyes y normativas aplicables». Esta definición se ajusta al marco de control interno integrado del Comité de Organizaciones Patrocinadoras de la Comisión Treadway (COSO, por sus siglas en inglés). Más información en $<$ www.coso.org/IC.htm $>$.

La gestión del riesgo es una parte integrada del sistema de gestión de una entidad, efectuada por la alta dirección de esta, los gestores competentes y otro personal. Se diseña para identificar, comprender y evaluar los riesgos y oportunidades potenciales (y su interdependencia) que pueden afectar a la entidad, y para gestionar estos riesgos y oportunidades dentro de su tolerancia al riesgo, con el fin de proporcionar información adecuada y garantías razonables relativas al logro de los objetivos de la entidad. 


\section{Otras publicaciones}

OECD (2017), Recommendation of the Council on Public Integrity, OECD, París.

OECD (2015), Recommendation on Public Procurement, OECD, París.

The Institute of Internal Auditors (2013), «Three Lines of Defense in Effective Risk Management and Control», IIA Position Paper, The Institute of Internal auditors, Altamonte Springs, <www.theiia.org/goto/3Lines $>$.

\section{Notas de los gráficos}

7.5: Los datos de Argentina, Brasil y Perú se incluyeron de manera ad hoc.

7.6: Los datos de Argentina, Brasil y Perú se incluyeron de manera ad hoc.

República Checa y Chile planean desarrollar una función centralizada de auditoría.

La Oficina Nacional de Auditoría de Suecia, una institución de auditoría externa que está a cargo del Parlamento, audita todo el sector público.

Tabla 7.5. Las leyes requieren que los gestores competentes del poder ejecutivo implementen y supervisen las políticas de control interno y de gestión del riesgo

\begin{tabular}{|c|c|c|c|}
\hline & $\begin{array}{c}\text { Sí, las políticas de } \\
\text { control interno }\end{array}$ & $\begin{array}{c}\text { Sí, las políticas de } \\
\text { gestión del riesgo }\end{array}$ & $\begin{array}{c}\text { Sí, en específico la gestión del } \\
\text { riesgo de la integridad/ } \\
\text { corrupción }\end{array}$ \\
\hline Alemania & $\bullet$ & $\bullet$ & $\bullet$ \\
\hline Australia & $\bullet$ & $\bullet$ & $\bullet$ \\
\hline Austria & $\bullet$ & $\bullet$ & $\bullet$ \\
\hline Bélgica & $\bullet$ & $\bullet$ & $\bullet$ \\
\hline Canadá & $\bullet$ & $\bullet$ & $\bullet$ \\
\hline Chile & $\bullet$ & $\bullet$ & $\bullet$ \\
\hline Corea & $\bullet$ & $\bullet$ & $\bullet$ \\
\hline España & $\bullet$ & $\bullet$ & \\
\hline Estados Unidos & $\bullet$ & $\bullet$ & \\
\hline Estonia & $\bullet$ & $\bullet$ & \\
\hline Finlandia & $\bullet$ & $\bullet$ & \\
\hline Francia & $\bullet$ & $\bullet$ & \\
\hline Grecia & $\bullet$ & $\bullet$ & \\
\hline Hungría & & $\bullet$ & \\
\hline
\end{tabular}


INTEGRIDAD DEL SECTOR PÚBLICO

\begin{tabular}{|c|c|c|c|}
\hline & $\begin{array}{l}\text { Sí, las políticas de } \\
\text { control interno }\end{array}$ & $\begin{array}{l}\text { Sí, las políticas de } \\
\text { gestión del riesgo }\end{array}$ & $\begin{array}{l}\text { Sí, en específico la gestión del } \\
\text { riesgo de la integridad/ } \\
\text { corrupción }\end{array}$ \\
\hline \multicolumn{4}{|l|}{ Irlanda } \\
\hline \multicolumn{4}{|l|}{ Islandia } \\
\hline Italia & $\bullet$ & $\bullet$ & $\bullet$ \\
\hline Japón & $\bullet$ & & \\
\hline Letonia & $\bullet$ & & \\
\hline México & $\bullet$ & $\bullet$ & $\bullet$ \\
\hline \multicolumn{4}{|l|}{ Noruega } \\
\hline Nueva Zelanda & $\bullet$ & $\bullet$ & $\bullet$ \\
\hline Países Bajos & $\bullet$ & $\bullet$ & $\bullet$ \\
\hline Polonia & $\bullet$ & $\bullet$ & \\
\hline Portugal & $\bullet$ & & \\
\hline \multicolumn{4}{|l|}{ Reino Unido } \\
\hline República Checa & $\bullet$ & $\bullet$ & \\
\hline República de Eslovenia & $\bullet$ & - & - \\
\hline República Eslovaca & $\bullet$ & $\bullet$ & $\bullet$ \\
\hline \multicolumn{4}{|l|}{ Suecia } \\
\hline Suiza & $\bullet$ & $\bullet$ & $\bullet$ \\
\hline Total OCDE & 26 & 22 & 16 \\
\hline \multicolumn{4}{|l|}{ Argentina } \\
\hline Brasil & $\bullet$ & $\bullet$ & \\
\hline Colombia & $\bullet$ & $\bullet$ & $\bullet$ \\
\hline Costa Rica & $\bullet$ & $\bullet$ & \\
\hline Lituania & $\bullet$ & $\bullet$ & $\bullet$ \\
\hline Perú & $\bullet$ & $\bullet$ & \\
\hline
\end{tabular}

Fuente: OCDE (2016), Encuesta sobre la integridad del sector público, OCDE, París.

$<$ http://dx.doi.org/10.1787/888933535145> 


\section{Gráfico 7.6. Existencia de una función centralizada de auditoría interna con objetivos estratégicos dedicados a la integridad}

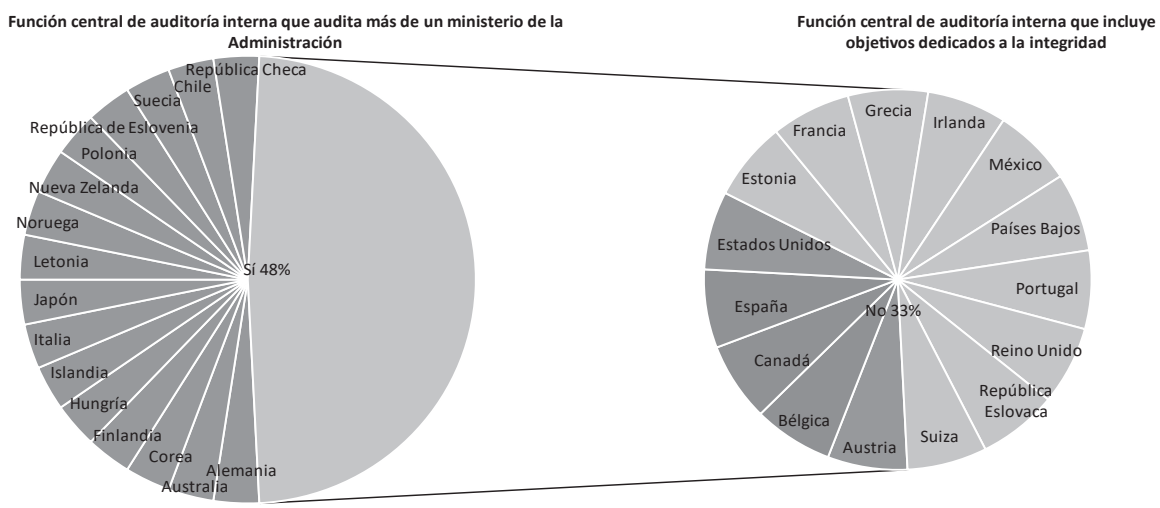

Fuente: OCDE (2016), Encuesta sobre la integridad del sector público, OCDE, París.

<http://dx.doi.org/10.1787/888933532979> 


\section{CAPÍTULO 8. GOBERNANZA REGULATORIA}

\section{COMPROMISO DE LAS PARTES INTERESADAS EN EL DESARROLLO DE LA NORMATIVA}

El compromiso de las partes interesadas es un elemento crucial de la política regulatoria. Ayuda a garantizar que la normativa se elabora en beneficio del interés público mediante la participación de las partes afectadas, incluyendo ciudadanos, empresas, sociedad civil y otros miembros de la comunidad. El compromiso de las partes interesadas mejora la calidad del proceso de elaboración de las normas, puesto que reúne ideas, experiencia y evidencias sobre los problemas políticos y sus posibles soluciones. También garantiza que la normativa se lleva a cabo con un enfoque centrado en los usuarios y que responde a las necesidades de los ciudadanos. La participación de todas las partes interesadas y afectadas aumenta además el carácter inclusivo de las políticas y apoya el desarrollo de un sentido de la propiedad en cuanto a su regulación. Esto a su vez refuerza la confianza en las Administraciones, la cohesión social y el cumplimiento de la normativa.

Los indicadores de la OCDE de política y gobernanza regulatoria (iREG) proporcionan la primera base de evidencia exhaustiva sobre los progresos de los países de la OCDE en la mejora de prácticas regulatorias, tal y como se describen en la Recomendación del Consejo de la OCDE sobre Política y Gobernanza Regulatoria de 2012. Cuantas más prácticas adopten los países, mayor será su indicador. El indicador compuesto incluye cuatro categorías de igual ponderación: Metodología recopila información sobre los métodos y herramientas facilitados para la participación de los interesados; Supervisión y control de la calidad registra información sobre los mecanismos utilizados para supervisar y evaluar las prácticas de participación; Adopción sistemática registra los requisitos formales y la frecuencia con que se llevan a cabo en la práctica; y Transparencia registra información relacionada con los principios de gobierno abierto. La puntuación máxima en cada categoría es 1 y la total del indicador compuesto varía de 0 a 4. Si bien Panorama de las Administraciones Públicas 2015 proporcionó datos subyacentes de los iREG, la presente edición incluye tres 
indicadores compuestos creados sobre una base de datos de encuesta. El indicador compuesto de los iREG sobre la participación de los interesados es también uno de los indicadores centrales utilizados para medir la dimensión del compromiso ciudadano del Î́ndice de la OCDE para una Vida Mejor.

La mayoría de los países de la OCDE han adoptado prácticas para promover el compromiso de las partes interesadas y han desarrollado una metodología para su funcionamiento. Los países de la OCDE utilizan diferentes modelos de participación, que van desde la consulta online hasta la formal con los actores sociales, además de mecanismos de consulta informal. Las puntuaciones más altas las reciben países como Canadá, Estados Unidos, Estonia, México, Reino Unido y República Eslovaca, que han invertido en un marco transparente de participación de interesados y en mecanismos de supervisión y control de la calidad. Por ejemplo, los países con puntuaciones elevadas tienen procesos de participación abiertos al público en general y publican los comentarios de los interesados, así como las respuestas de las Administraciones. Tienen asignada cierta responsabilidad institucional en materia de supervisión del compromiso de las partes interesadas y publican información sobre el funcionamiento del sistema de participación (como la Comisión Federal de Mejora Regulatoria de México [COFEMER]). Los países que no realizan consultas públicas de manera sistemática, que no involucran a las partes interesadas hasta una fase tardía del proceso regulatorio o que no tienen periodos mínimos de presentación de comentarios suelen obtener una puntuación baja, como Irlanda, Israel, Japón y Portugal. En la mayoría de los países de la OCDE, los valores del indicador de participación en el desarrollo de normas secundarias son ligeramente menores que los de participación en el desarrollo de normas primarias, debido a que los procesos del primer tipo de regulación son menos estrictos.

\section{Metodología y definiciones}

Los indicadores de la OCDE de política y gobernanza regulatoria (iREG) se basan en las respuestas proporcionadas por los delegados al Comité de Política Regulatoria de la OCDE y por funcionarios de la Administración central a la Encuesta de la OCDE sobre Indicadores Regulatorios de 2014, en todos los países de la OCDE y la Comisión Europea y en Letonia en 2016. Los datos solo abarcan las normas primarias y secundarias establecidas por iniciativa del Ejecutivo. En la mayoría de los países de la OCDE, las normas primarias son iniciadas por el Ejecutivo, excepto en Corea y México, donde una mayor proporción de normas primarias son iniciativa del poder legislativo (un $84 \%$ y un $90,6 \%$ respectivamente). Todas las preguntas sobre normas primarias no son aplicables a Estados Unidos puesto que en este país el Ejecutivo no inicia normas 
primarias. Para más información sobre los indicadores iREG, véase el Anexo online en $<$ www.oecd.org/gov/regulatory-policy/indicators-regulatory-policy-and-governance.htm>.

\section{Otras publicaciones}

OECD (de próxima publicación), Best Practice Principles on Stakeholder Engagement in Regulatory Policy, OECD Publishing, París.

OECD (2015), OECD Regulatory Policy Outlook 2015, OECD Publishing, París.

OECD (2012), 2012 OECD Recommendation of the Council on Regulatory Policy and Governance, OECD Publishing, París.

\section{Notas de los gráficos}

8.2: Las puntuaciones de los países se presentan en orden según las puntuaciones totales de las normas primarias, con la excepción de Estados Unidos, en donde se toma como base la puntuación de las normas secundarias.

Información sobre los datos de Israel: <http://dx.doi.org/10.1787/888932315602>.

\section{Gráfico 8.1. Compromiso de las partes interesadas en el desarrollo de normativa, 2014}

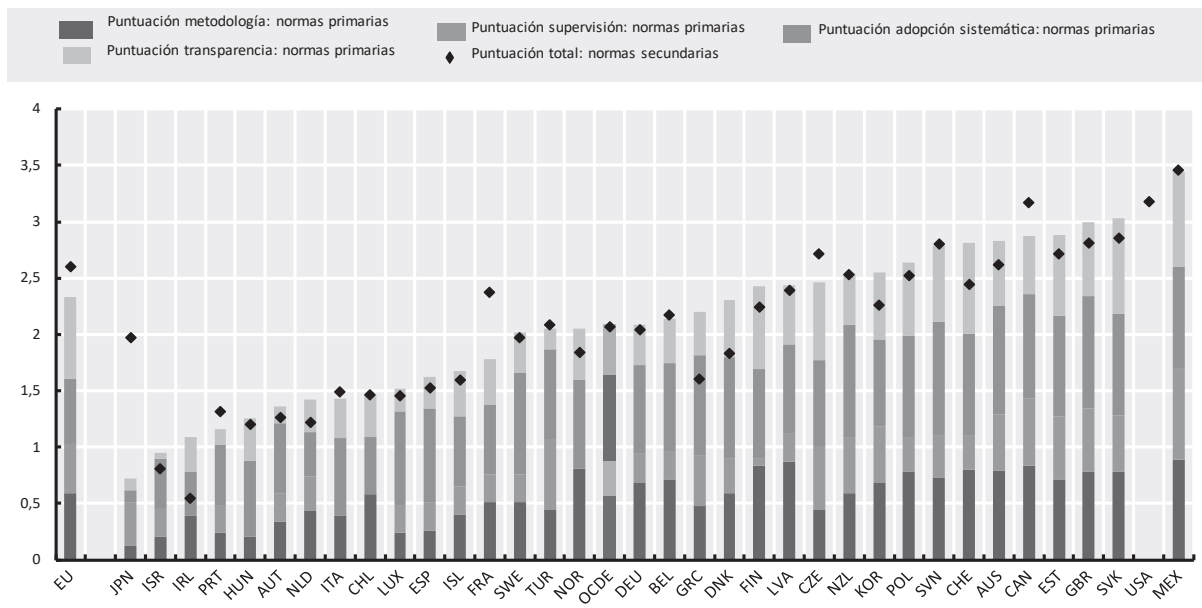

Fuente: OCDE (2015), Indicadores de política y gobernanza regulatoria (iREG), OECD Publishing, París, $<\mathrm{http}$ //www.oecd.org/gov/regulatory-policy/indicatorsregulatory-policy-and-governance.htm>. 
Tabla 8.2. Periodos mínimos, apertura y mecanismos de respuesta para la participación de partes interesadas, 2014

\begin{tabular}{|c|c|c|c|}
\hline & $\begin{array}{l}\text { Requisito formal de un } \\
\text { periodo mínimo de } \\
\text { consulta con el público en } \\
\text { normas primarias }\end{array}$ & $\begin{array}{l}\text { Cualquier miembro del } \\
\text { público puede participar } \\
\text { en una consulta de: }\end{array}$ & $\begin{array}{l}\text { ¿Se requiere que los } \\
\text { reguladores publiquen una } \\
\text { respuesta a los comentarios } \\
\text { de las consultas online? }\end{array}$ \\
\hline Alemania & & + & $\mathrm{O}$ \\
\hline Australia & & $\Delta$ & $\mathrm{O}$ \\
\hline Austria & $\checkmark$ & + & $\mathrm{O}$ \\
\hline Bélgica & $\checkmark$ & $\Delta$ & $\triangle$ \\
\hline Canadá & & 口 & $\mathrm{O}$ \\
\hline Chile & & + & $\mathrm{O}$ \\
\hline Corea & $\checkmark$ & $\square$ & $\mathrm{O}$ \\
\hline Dinamarca & & a & 口 \\
\hline España & $\checkmark$ & + & $\mathrm{O}$ \\
\hline Estonia & $\checkmark$ & 口 & a \\
\hline Finlandia & $\checkmark$ & a & 0 \\
\hline Francia & & + & 0 \\
\hline Grecia & $\checkmark$ & च & 0 \\
\hline Hungría & $\checkmark$ & $\square$ & $\square$ \\
\hline Irlanda & & + & 0 \\
\hline Islandia & & + & 0 \\
\hline Israel & & - & O \\
\hline Italia & & + & 0 \\
\hline Japón & & $\bullet$ & $\mathrm{O}$ \\
\hline Letonia & $\checkmark$ & 口 & 0 \\
\hline Luxemburgo & $\checkmark$ & + & 0 \\
\hline México & $\checkmark$ & 口 & $\square$ \\
\hline Noruega & $\checkmark$ & $\square$ & 0 \\
\hline Nueva Zelanda & & घ & $\diamond$ \\
\hline Países Bajos & & + & $\mathrm{O}$ \\
\hline Polonia & $\checkmark$ & + & $\diamond$ \\
\hline Portugal & & + & O \\
\hline Reino Unido & & a & 口 \\
\hline República Checa & & + & $\triangle$ \\
\hline República de Eslovenia & $\checkmark$ & ! & $\mathrm{O}$ \\
\hline República Eslovaca & $\checkmark$ & a & a \\
\hline Suecia & $\checkmark$ & a & $\mathrm{O}$ \\
\hline Suiza & $\checkmark$ & a & $\diamond$ \\
\hline Turquía & $\checkmark$ & $\bullet$ & 0 \\
\hline
\end{tabular}




\begin{tabular}{|c|c|c|c|}
\hline & $\begin{array}{l}\text { Requisito formal de un } \\
\text { periodo mínimo de } \\
\text { consulta con el público en } \\
\text { normas primarias }\end{array}$ & $\begin{array}{l}\text { Cualquier miembro del } \\
\text { público puede participar } \\
\text { en una consulta de: }\end{array}$ & $\begin{array}{l}\text { ¿Se requiere que los } \\
\text { reguladores publiquen una } \\
\text { respuesta a los comentarios } \\
\text { de las consultas online? }\end{array}$ \\
\hline Unión Europea & $\checkmark$ & + & 口 \\
\hline Total OCDE & 18 & & \\
\hline $\begin{array}{c}\text { Todas las normas } \\
\text { primarias }\end{array}$ & & 16 & \\
\hline $\begin{array}{c}\text { A Principales normas } \\
\text { primarias }\end{array}$ & & 2 & \\
\hline $\begin{array}{c}\text { + Algunas normas } \\
\text { primarias }\end{array}$ & & 13 & \\
\hline - Nunca & & 3 & \\
\hline $\begin{array}{c}\text { En todas las } \\
\text { consultas públicas de } \\
\text { normas primarias }\end{array}$ & & & 6 \\
\hline $\begin{array}{c}\triangle \text { En las consultas } \\
\text { relativas a las } \\
\text { principales normas } \\
\text { primarias }\end{array}$ & & & 2 \\
\hline $\begin{array}{c}\diamond \text { En algunas } \\
\text { consultas públicas de } \\
\text { normas primarias }\end{array}$ & & & 3 \\
\hline O Nunca & & & 23 \\
\hline
\end{tabular}

Fuente: OCDE (2015), Indicadores de política y gobernanza regulatoria (iREG), OECD Publishing, París, $<\mathrm{http}$ ://www.oecd.org/gov/regulatory-policy/indicatorsregulatory-policy-and-governance.htm >.

\section{EVALUACIÓN DEL IMPACTO REGULATORIO}

La Evaluación del Impacto Regulatorio (EIR) es tanto un documento como un proceso que sirve de apoyo a los responsables políticos para decidir cómo y cuándo regular con el fin de alcanzar los objetivos establecidos. La EIR ayuda a mejorar el diseño de la normativa proporcionando información que permite identificar la mejor solución a cada problema político. Analiza los costes y beneficios de las alternativas posibles, regulatorias y no regulatorias, para alcanzar los objetivos políticos, determinando el enfoque con más probabilidad de conseguir el mayor beneficio neto para la sociedad. La EIR puede fomentar la coherencia política indicando las ventajas inherentes a las propuestas regulatorias e identificando a los posibles beneficiarios y a quienes sufragarán los costes de cada norma. Este tipo de evaluación puede además fomentar y mejorar el uso de la evidencia en la formulación de políticas y ayudar a evitar fallos 
en la regulación debidos a la adopción de normas prescindibles o a su carencia en momentos de necesidad. Por último, la EIR documenta la evidencia y aumenta la rendición de cuentas de las decisiones políticas.

El indicador presentado forma parte de los iREG y resulta clave para medir la implementación de procesos de elaboración de políticas basadas en evidencias. Se basa en la Recomendación del Consejo de la OCDE sobre Política y Gobernanza Regulatoria de 2012. Cuantas más prácticas adopten los países, mayor será su indicador. El indicador compuesto incluye cuatro categorías de igual ponderación: Metodología recopila información sobre las distintas evaluaciones que incluye la EIR; Supervisión y control de la calidad registra los mecanismos que supervisan y garantizan la calidad de la EIR; Adopción sistemática registra los requisitos formales y la frecuencia con que se lleva a cabo la EIR en la práctica; y Transparencia evalúa el carácter abierto de la EIR. La puntuación máxima en cada categoría es 1 y la total del indicador compuesto varía de 0 a 4 .

Prácticamente todos los países de la OCDE han introducido requisitos formales y una metodología para la realización de EIR. Los países con puntuaciones elevadas en la metodología, como Canadá y Reino Unido, han ido más allá de la mera evaluación de los costes potenciales de la regulación. Evalúan además una amplia gama de los impactos de las propuestas regulatorias, establecen la exhaustividad de la EIR en relación con la importancia de la norma y consideran aspectos como el cumplimiento y la aplicación. La mayoría de los países con puntuaciones elevadas en este indicador han invertido en la trasparencia y en la supervisión de sus sistemas de EIR, como Alemania, Estonia, México, Reino Unido y República Checa. Sus sistemas incluyen medidas como la publicación online de las EIR en un registro central, el establecimiento de un organismo de supervisión que puede exigir la revisión de evaluaciones de impacto inadecuadas o la publicación de informes sobre el desempeño del sistema de EIR. La media de la OCDE en el indicador de normativa secundaria es ligeramente inferior que el de normativa primaria. La brecha es más pronunciada en Dinamarca, Grecia e Islandia, que obtienen puntuaciones significativamente más elevadas en las normas primarias.

La EIR es una parte integral de la gobernanza regulatoria y debe ser incorporada como una herramienta más de su gestión. La disponibilidad pública de los documentos de las EIR otorga transparencia al proceso de formulación de políticas y la oportunidad de analizar la información y datos obtenidos. Sin embargo, solo el $18 \%$ de los países de la OCDE tienen como requisito obligatorio realizar consultas públicas de las EIR relativas a nuevas normas primarias. La EIR puede además allanar el camino para las evaluaciones ex post de las regulaciones, estableciendo criterios para la evaluación de normas después de su implementación, como por ejemplo si se han alcanzado los objetivos políticos. Vincular la EIR con la evaluación ex post es un proceso en curso: solo alrededor del $40 \%$ de los países de la OCDE establecen un mecanismo que evalúe el progreso en la consecución de los objetivos políticos cuando desarrollan nuevas normas primarias. 


\section{Metodología y definiciones}

Los indicadores de la OCDE de política y gobernanza regulatoria (iREG) se basan en las respuestas proporcionadas por los delegados al Comité de Política Regulatoria de la OCDE y por funcionarios de la Administración central a la Encuesta de la OCDE sobre Indicadores Regulatorios de 2014 en todos los países de la OCDE y la Comisión Europea. Los datos solo abarcan las normas primarias y secundarias establecidas por iniciativa del Ejecutivo. En la mayoría de los países de la OCDE, las normas primarias son iniciadas por el Ejecutivo, excepto en Corea y México, donde una mayor proporción de normas primarias son iniciativa del poder legislativo (un $84 \%$ y un $90,6 \%$ respectivamente). Todas las preguntas sobre normas primarias no son aplicables a Estados Unidos, puesto que en este país el Ejecutivo no inicia normas primarias. Para más información sobre los indicadores iREG, véase el Anexo online en $<$ www.oecd.org/gov/regulatory-policy/indicators-regulatory-policy-andgovernance.htm>.

Las normas primarias deben ser aprobadas por el poder legislativo, mientras que las secundarias pueden ser aprobadas por el jefe del Gobierno, por un ministro o por el gabinete.

\section{Otras publicaciones}

Arndt, C. et al. (2016), «Building regulatory policy systems in OECD countries», OECD Regulatory Policy Working Papers, n. . 5, OECD Publishing, París.

OECD (2015), OECD Regulatory Policy Outlook 2015, OECD Publishing, París.

OECD (2012), 2012 OECD Recommendation of the Council on Regulatory Policy and Governance, OECD Publishing, París.

\section{Notas de los gráficos}

Los datos de Letonia no están disponibles.

8.3: Las puntuaciones de los países se presentan en orden según las puntuaciones totales de las normas primarias, con la excepción de Estados Unidos, en donde se toma como base la puntuación de las normas secundarias.

Información sobre los datos de Israel: <http://dx.doi.org/10.1787/888932315602>. 


\section{Gráfico 8.3. Evaluación del impacto regulatorio para el desarrollo de normativa, 2014}

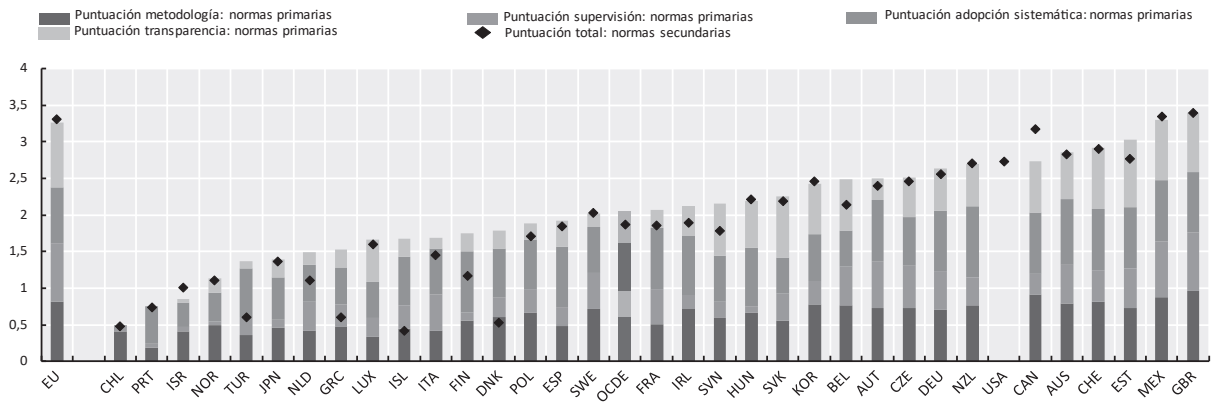

Fuente: OCDE (2015), Indicadores de política y gobernanza regulatoria (iREG), OECD Publishing, París, $<$ http://www.oecd.org/gov/regulatory-policy/indicatorsregulatory-policy-and-governance.htm>.

\section{Gráfico 8.4. ¿Se requiere la publicación de las EIR de normas primarias para su consulta con el público en general? 2014}

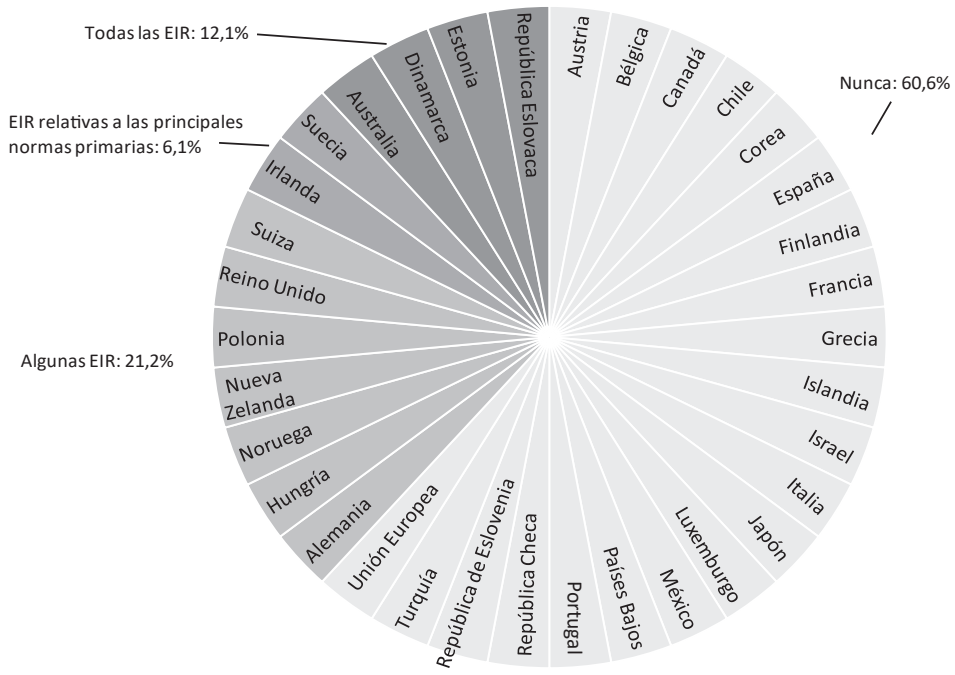

Fuente: OCDE (2015), Indicadores de política y gobernanza regulatoria (iREG), OECD Publishing, París, $<$ http://www.oecd.org/gov/regulatory-policy/indicatorsregulatory-policy-and-governance.htm>. 


\section{Gráfico 8.5 . ¿Se requiere que los reguladores identifiquen un proceso de evaluación del progreso en el logro de los objetivos de las normas primarias cuando las desarrollan?}

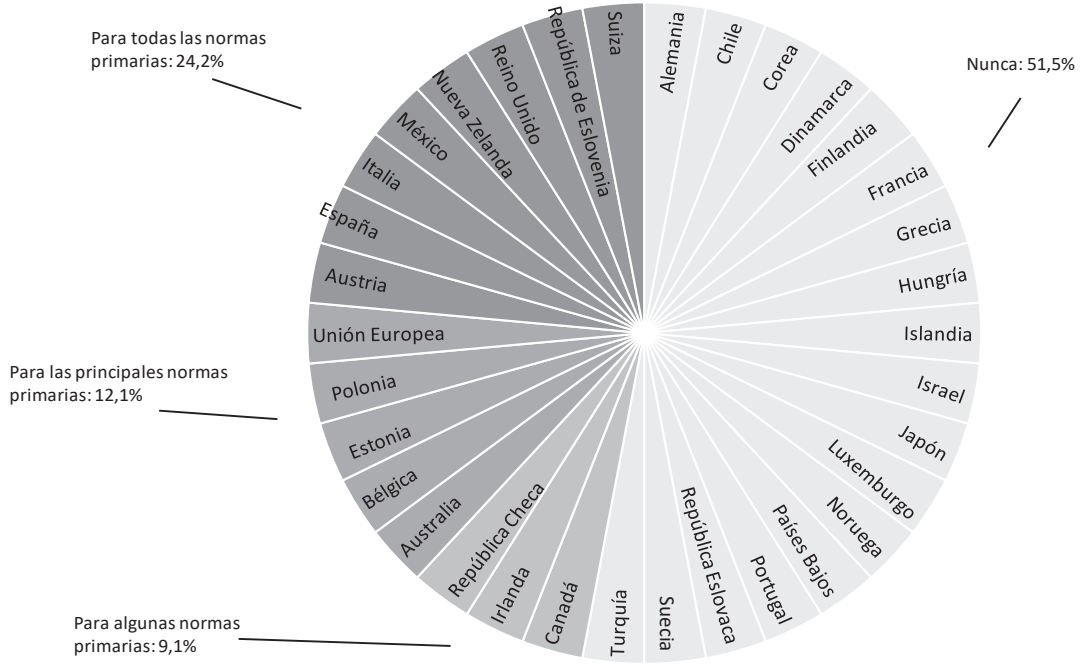

Fuente: OCDE (2015), Indicadores de política y gobernanza regulatoria (iREG), OECD Publishing, París, $<$ http://www.oecd.org/gov/regulatory-policy/indicatorsregulatory-policy-and-governance.htm>.

$<$ http://dx.doi.org/10.1787/888933533055>

\section{EVALUACIÓN EX POST DE LA NORMATIVA}

La evaluación de las normas es esencial para garantizar que son relevantes y que cumplen su propósito. Solo se pueden evaluar los efectos e impactos de las normas tras su implementación, incluyendo las consecuencias directas, indirectas e imprevistas. Las normas podrían quedar obsoletas debido a cambios, como las preferencias sociales y los avances tecnológicos. Sin procesos de revisión y evaluación, los trámites burocráticos y costes regulatorios tienden a crecer orgánicamente en el tiempo. Esto complica la vida diaria de los ciudadanos y obstaculiza el funcionamiento eficiente del sector empresarial. La evaluación ex post no se debería considerar la etapa final del ciclo completo de las normas, sino más bien un retroceso deliberado y responsable en el ciclo que proporciona una comprensión de las áreas de posible mejora y una herramienta de planificación regulatoria. La evaluación ex post es además un instrumento que mejora la transparencia y rendición de cuentas de la actividad regulatoria y, consecuentemente, aumenta la confianza pública en las Administraciones. 
El indicador iREG de evaluación ex post se basa en las prácticas descritas en la Recomendación del Consejo de la OCDE sobre política y gobernanza regulatoria de 2012. Cuantas más prácticas adopten los países, mayor será su indicador. El indicador compuesto incluye cuatro categorías de igual ponderación: Metodología recopila información sobre las distintas evaluaciones que se utilizan; Supervisión y control de la calidad registra los mecanismos que supervisan y garantizan la calidad de las evaluaciones ex post; Adopción sistemática registra los requisitos formales y el uso de diferentes tipos de evaluaciones ex post; y Transparencia evalúa el carácter abierto de las evaluaciones ex post. La puntuación máxima en cada categoría es 1 y la total del indicador compuesto varía de 0 a 4 .

La puntuación media del indicador iREG de evaluación ex post en las normas primarias es menor $(1,48)$ que la de los indicadores de participación de los interesados y de procesos de evaluación del impacto regulatorio para el desarrollo de nueva normativa. Esto sugiere que la implementación de evaluaciones ex post tiene menor prioridad que las herramientas ex ante de gobernanza regulatoria en muchos países de la OCDE. El planteamiento sistemático de las evaluaciones ex post no está generalizado en los países de la OCDE y las metodologías que se aplican varían considerablemente. Muchos países todavía carecen de técnicas de evaluación normalizadas, y solo un tercio de los países de la OCDE valora de manera sistemática, como parte de las evaluaciones ex post, si los objetivos políticos subyacentes han sido alcanzados. Por el contrario, los países que realizan evaluaciones ex post a menudo involucran a las partes interesadas y ponen a disposición del público los resultados. Solo algunos países de la OCDE han puesto en funcionamiento mecanismos de supervisión y control de las evaluaciones ex post, incluyendo Australia y Reino Unido.

En muchos países de la OCDE, las puntuaciones en las prácticas de evaluación ex post de normas primarias y secundarias difieren solo ligeramente. Canadá y Estados Unidos obtienen puntuaciones significativamente mayores en el indicador de normas secundarias, lo cual puede reflejar el hecho de que las normas secundarias juegan un papel importante en los marcos regulatorios de estos países. Por otra parte, Chile y Polonia tienen mayores puntuaciones en el indicador de normas primarias que en el de secundarias.

La mayoría de los países de la OCDE (27) han realizado análisis ex post basados en principios, es decir, se centran en un aspecto específico de las normas como filtro inicial para identificar cuáles precisan revisión o reforma. La mayoría de los países se centran en reducir la carga administrativa y los gastos de cumplimiento o en estimular la competencia. Los países deberían dejar atrás la evaluación individualizada de normas e implementar mecanismos de evaluación más estratégicos y sistemáticos. Esto se podría conseguir mediante la realización de análisis exhaustivos e integrales que evalúen el impacto acumulativo del marco regulatorio en su totalidad, con especial atención en los 
resultados de las políticas. Hasta el momento, solo 9 países de la OCDE llevan a cabo este tipo de análisis. Al mismo tiempo, es necesario desarrollar capacidades para realizar evaluaciones. También sería beneficioso para los países establecer un organismo permanente que lleve a cabo evaluaciones exhaustivas e integrales en distintos sectores o ámbitos políticos, con el fin de proporcionar información para las reformas a gran escala.

\section{Metodología y definiciones}

Los indicadores de la OCDE de política y gobernanza regulatoria (iREG) se basan en las respuestas proporcionadas por los delegados al Comité de Política Regulatoria de la OCDE y por funcionarios de la Administración central a la Encuesta de la OCDE sobre Indicadores Regulatorios de 2014 en todos los países de la OCDE y la Comisión Europea. Para más información sobre los indicadores iREG, véase el Anexo online en <www.oecd.org/gov/regulatory-policy/indicators-regulatory-policyand-governance.htm>.

Las normas primarias deben ser aprobadas por el poder legislativo, mientras que las secundarias pueden ser aprobadas por el jefe del Gobierno, por un ministro o por el gabinete.

\section{Otras publicaciones}

Arndt, C. et al. (2016), «Building regulatory policy systems in OECD countries». OECD Regulatory Policy Working Papers, n. . 5, OECD Publishing, París.

OECD (2015), OECD Regulatory Policy Outlook 2015, OECD Publishing, París.

OECD (2012), OECD 2012 Recommendation of the Council on Regulatory Policy and Governance, OECD, París.

\section{Notas de los gráficos}

8.7: Los datos de Letonia no están disponibles.

Información sobre los datos de Israel: <http://dx.doi.org/10.1787/888932315602>. 


\section{Gráfico 8.6. Evaluación ex post de la normativa, 2014}

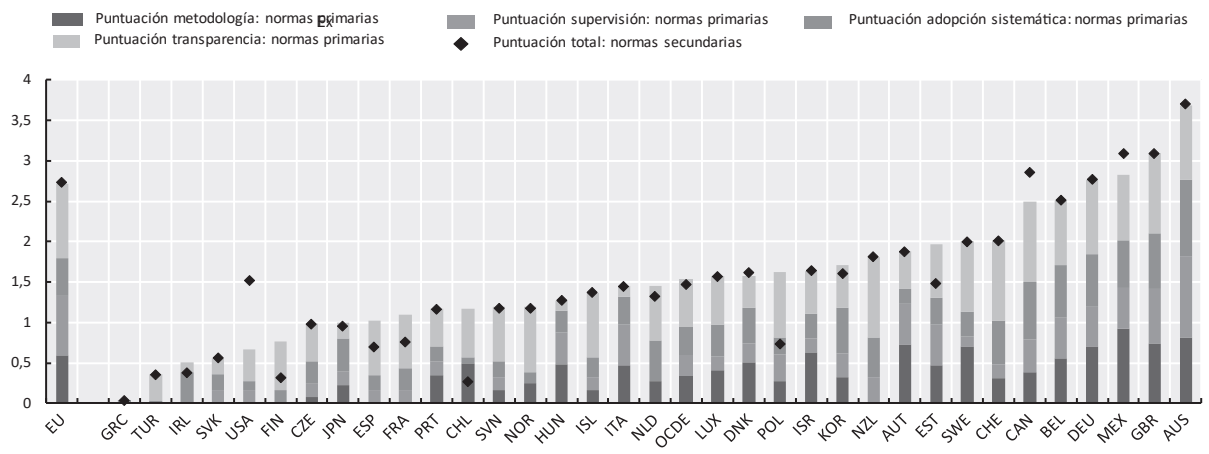

Fuente: OCDE (2015), Indicadores de política y gobernanza regulatoria (iREG), OECD Publishing, París, $<$ http://www.oecd.org/gov/regulatory-policy/indicatorsregulatory-policy-and-governance.htm>.

\section{Tabla 8.7. Análisis ad hoc del ordenamiento jurídico realizados en los} últimos 12 años, 2014

\begin{tabular}{|c|c|c|c|c|}
\hline & $\begin{array}{c}\text { Análisis } \\
\text { basados en } \\
\text { principios }\end{array}$ & $\begin{array}{l}\text { Evaluación pública que invita } \\
\text { a las empresas y ciudadanos a } \\
\text { proporcionar información } \\
\text { sobre la efectividad, eficiencia } \\
\text { y cargas impuestas por la } \\
\text { normativa }\end{array}$ & $\begin{array}{l}\text { Análisis que comparan la } \\
\text { normativa, los procesos } \\
\text { regulatorios y/o los resultados } \\
\text { de la normativa de los distintos } \\
\text { países, regiones o jurisdicciones }\end{array}$ & $\begin{array}{c}\text { Análisis } \\
\text { exhaustivos }\end{array}$ \\
\hline Alemania & $\checkmark$ & & $\checkmark$ & \\
\hline Australia & $\checkmark$ & $\checkmark$ & $\checkmark$ & $\checkmark$ \\
\hline \multicolumn{5}{|l|}{ Austria } \\
\hline Bélgica & $\checkmark$ & $\checkmark$ & & $\checkmark$ \\
\hline Canadá & $\checkmark$ & $\checkmark$ & $\checkmark$ & $\checkmark$ \\
\hline \multicolumn{5}{|l|}{ Chile } \\
\hline Corea & & & $\checkmark$ & \\
\hline Dinamarca & $\checkmark$ & $\checkmark$ & & \\
\hline España & $\checkmark$ & & & \\
\hline Estados Unidos & $\checkmark$ & $\checkmark$ & & \\
\hline Estonia & $\checkmark$ & & & \\
\hline Finlandia & $\checkmark$ & $\checkmark$ & & \\
\hline Francia & $\checkmark$ & & & $\checkmark$ \\
\hline \multicolumn{5}{|l|}{ Grecia } \\
\hline Hungría & $\checkmark$ & & & \\
\hline
\end{tabular}




\begin{tabular}{|c|c|c|c|c|}
\hline & $\begin{array}{c}\text { Análisis } \\
\text { basados en } \\
\text { principios }\end{array}$ & $\begin{array}{c}\text { Evaluación pública que invita } \\
\text { a las empresas y ciudadanos a } \\
\text { proporcionar información } \\
\text { sobre la efectividad, eficiencia } \\
\text { y cargas impuestas por la } \\
\text { normativa }\end{array}$ & $\begin{array}{c}\text { Análisis que comparan la } \\
\text { normativa, los procesos } \\
\text { regulatorios y/o los resultados } \\
\text { de la normativa de los distintos } \\
\text { países, regiones o jurisdicciones }\end{array}$ & $\begin{array}{c}\text { Análisis } \\
\text { exhaustivos }\end{array}$ \\
\hline Irlanda & $\checkmark$ & & & \\
\hline Islandia & $\checkmark$ & & & $\checkmark$ \\
\hline Israel & $\checkmark$ & & & \\
\hline Italia & $\checkmark$ & & & \\
\hline Japón & & & & $\checkmark$ \\
\hline Luxemburgo & $\checkmark$ & $\checkmark$ & & \\
\hline México & $\checkmark$ & $\checkmark$ & $\checkmark$ & $\checkmark$ \\
\hline Noruega & $\checkmark$ & & & \\
\hline Nueva Zelanda & $\checkmark$ & & & $\checkmark$ \\
\hline Países Bajos & $\checkmark$ & $\checkmark$ & & \\
\hline Polonia & $\checkmark$ & $\checkmark$ & & \\
\hline \multicolumn{5}{|l|}{ Portugal } \\
\hline Reino Unido & $\checkmark$ & $\checkmark$ & & $\checkmark$ \\
\hline República Checa & $\checkmark$ & & & \\
\hline República de Eslovenia & $\checkmark$ & & & \\
\hline República Eslovaca & $\checkmark$ & $\checkmark$ & & \\
\hline Suecia & $\checkmark$ & & & \\
\hline Suiza & $\checkmark$ & $\checkmark$ & $\checkmark$ & \\
\hline \multicolumn{5}{|l|}{ Turquía } \\
\hline Unión Europea & $\checkmark$ & $\checkmark$ & $\checkmark$ & $\checkmark$ \\
\hline Total OCDE & 27 & 13 & 6 & 9 \\
\hline
\end{tabular}

Fuente: OCDE (2015), Indicadores de política y gobernanza regulatoria (iREG), OECD Publishing, París, $<\mathrm{http}$ ://www.oecd.org/gov/regulatory-policy/indicatorsregulatory-policy-and-governance.htm>. 


\section{APARTADO ESPECIAL: IMPLEMENTACIÓN DE PERCEPCIONES DEL COMPORTAMIENTO EN EL DISEÑO Y APLICACIÓN DE POLÍTICAS}

Las percepciones del comportamiento tienen como objetivo mejorar el bienestar de los ciudadanos y consumidores a través de políticas y normas basadas en estudios derivados de experimentos y de la observación. Las percepciones del comportamiento utilizan un enfoque basado en evidencias para la formulación de políticas y comprueban empíricamente los diferentes planteamientos propuestos para la resolución de asuntos y problemas antes de su implementación. Combinan estrategias tradicionales de economía y conocimientos de psicología, ciencia cognitiva y otras ciencias sociales, e identifican patrones de conducta que reemplazan y cuestionan los supuestos tradicionales de lo que supone el comportamiento racional.

Las percepciones del comportamiento están creciendo en popularidad entre los Gobiernos como una herramienta útil para la creación de soluciones nuevas, relativamente sencillas y especialmente efectivas. Enfrentan de manera directa los sesgos de comportamiento que a menudo impiden que las intervenciones del Gobierno logren los resultados deseados. El alcance de este método impulsa la formulación de políticas más allá del nivel individual y busca influir en el comportamiento de las organizaciones, permitiendo que los Gobiernos tengan un impacto efectivo en, por ejemplo, sectores regulados y en entidades públicas y privadas.

En una encuesta única, la OCDE (2017) estableció la aplicación de las percepciones del comportamiento a nivel global y en numerosos sectores, incluyendo la protección del consumidor, la educación, la energía, el medioambiente, las finanzas, la salud y seguridad, el mercado laboral, la prestación de servicios públicos, los impuestos y las telecomunicaciones. Los resultados muestran que las percepciones del comportamiento ya no se consideran una tendencia de moda a corto plazo, sino más bien que están arraigadas en muchos países. Además, su potencial de aplicaciones es mucho mayor que su práctica actual, limitada y principalmente centrada en las últimas fases de diseño e implementación de las nuevas políticas, en lugar de en las fases iniciales de investigación y diagnóstico. Esto significa que se aplican cuando la política en cuestión ya está en marcha, para ajustar y mejorar su implementación y cumplimiento. El siguiente paso sería aplicar las percepciones del comportamiento en la evaluación y diseño de las políticas.

La evaluación de los resultados experimentales es otra área de crecimiento futuro. Los métodos científicos correctos requieren la evaluación de resultados e impactos, en especial para formular hipótesis sobre lo que podría funcionar o no. Sin embargo, los resultados muestran que solo el $36 \%$ de los casos fue evaluado, comparado con un $30 \%$ que no lo fue. Incluso sin tener en cuenta el 34\% de casos que no proporcionó una respuesta (probablemente de- 
bido a la falta de evaluación), los resultados sugieren que la evaluación de resultados es un área que requiere desarrollo, puesto que puede debilitar la efectividad de la aplicación de las percepciones del comportamiento.

En cuanto a la transparencia, los resultados de los experimentos muestran un panorama desigual. El 50\% de los estudios de casos fueron publicados, la mayoría en forma de informe institucional o gubernamental y el resto online - a menudo por una empresa de consultoría, institución internacional o socio no gubernamental - o en publicaciones o artículos académicos. El resto se publicaron a través de documentos privados internos ( $9 \%$ ) o no proporcionaron información (41\%), lo cual, en algunos casos, puede ser indicativo de que los resultados están todavía pendientes de publicación.

A medida que las Administraciones públicas avanzan en el uso de las percepciones del comportamiento, aumenta la importancia de compartir lo que funciona y no en este ámbito. Por ejemplo, el Equipo de Ciencias Sociales y del Comportamiento (SBST, por sus siglas en inglés) de Estados Unidos y el Equipo de Percepciones del Comportamiento (BIT, por sus siglas en inglés) de Reino Unido publican informes anuales. La información periódica de resultados tiene la doble ventaja de abordar los aspectos éticos relacionados con la implementación por parte de los organismos públicos de las percepciones del comportamiento, manteniendo a la vez los estándares de calidad de su aplicación.

\section{Metodología y definiciones}

Los datos presentados proceden de la Encuesta de la OCDE sobre estudios de casos de percepciones del comportamiento, que se distribuyó a delegados de la OCDE, así como a redes académicas y profesionales de los distintos países y sectores. Un total de 59 instituciones (Anexo onli$n e$ ) en representación de 22 países de la OCDE y países asociados, el Programa de las Naciones Unidas para el Desarrollo (PNUD) y el Banco Mundial completaron la encuesta. El 82\% de los encuestados eran departamentos de la Administración central y autoridades reguladoras y fiscales (en partes iguales). El resto se compuso de Administraciones subnacionales y locales, bancos centrales, organizaciones internacionales y programas y entidades gubernamentales establecidas para un propósito altamente especializado. Se puede encontrar más información de la encuesta y el trabajo sobre percepciones del comportamiento en <www. oecd.org/gov/regulatory-policy/behavioural-insights.htm>. 


\section{Otras publicaciones}

OECD (2017), Behavioural Insights and Public Policy: Lessons from around the World, OECD Publishing, París, <http://dx.doi.org/10.1787/9789264270480-en>.

OECD (2016), Protecting Consumers through Behavioural Insights: Regulating the Communications Market in Colombia, OECD Publishing, París, $<$ http://dx.doi.org/10.1787/9789264255463-en>.

Lunn, P. (2014), Regulatory Policy and Behavioural Economics, OECD Publishing, París, <http://dx.doi.org/10.1787/9789264207851-en>.

\section{Notas de los gráficos}

8.8: Los datos representan las instituciones encuestadas que contestaron que sí aplicaban las percepciones del comportamiento «por lo menos algunas veces».

Los datos de Austria, Bélgica, República Checa, Estonia, Grecia, Islandia, Japón, Corea, Letonia, Luxemburgo, México, Noruega, Polonia, República Eslovaca, Eslovenia y Turquía no están disponibles.

Información sobre los datos de Israel: <http://dx.doi.org/10.1787/888932315602>.

8.9 y 8.10: Los 59 encuestados proporcionaron 158 estudios de casos. Los datos de Austria, Bélgica, Corea, Islandia, Japón, Letonia, Luxemburgo, México, Noruega, Polonia, República Eslovaca, República de Eslovenia y Turquía no están disponibles. Los datos de Singapur, el PNUD y el Banco Mundial se incluyeron de manera ad hoc, puesto que tienen unidades muy avanzadas de percepciones del comportamiento.

Tabla 8.8. Proporción de organismos públicos en los países que utilizan las percepciones del comportamiento «por lo menos algunas veces» por fase política, 2016

\begin{tabular}{|c|c|c|c|}
\hline & Investigación/Diagnóstico & Diseño & Implementación \\
\hline Alemania & $\bullet$ & $\bullet$ & $\bullet$ \\
\hline Australia & $\bullet$ & $\bullet$ & $\bullet$ \\
\hline Canadá & $\bullet$ & $\bullet$ & $\bullet$ \\
\hline Dinamarca & $\bullet$ & $\bullet$ & $\bullet$ \\
\hline España & $\bullet$ & $\bullet$ & $\bullet$ \\
\hline Estados Unidos & $\bullet$ & $\bullet$ & $\bullet$ \\
\hline Finlandia & $\bullet$ & $\bullet$ & $\bullet$ \\
\hline Francia & $\bullet$ & $\bullet$ & $\bullet$ \\
\hline Hungría & $\bullet$ & & $\bullet$ \\
\hline
\end{tabular}


GOBERNANZA REGULATORIA

\begin{tabular}{|c|c|c|c|}
\hline & Investigación/Diagnóstico & Diseño & Implementación \\
\hline Irlanda & $\bullet$ & $\bullet$ & $\bullet$ \\
\hline Israel & $\bullet$ & $\bullet$ & $\bullet$ \\
\hline Italia & $\bullet$ & $\bullet$ & घ \\
\hline Nueva Zelanda & $\bullet$ & $\bullet$ & $\bullet$ \\
\hline Países Bajos & $\bullet$ & $\bullet$ & $\bullet$ \\
\hline Portugal & घ & $\bullet$ & घ \\
\hline Reino Unido & $\bullet$ & $\bullet$ & $\bullet$ \\
\hline Suecia & $\mathbf{\square}$ & - & घ \\
\hline Suiza & $\mathbf{\square}$ & - & $\bullet$ \\
\hline \multicolumn{4}{|l|}{ Total OCDE } \\
\hline $1>66 \%$ & 9 & 11 & 10 \\
\hline t $33,1 \%-65,9 \%$ & 5 & 2 & 2 \\
\hline $\mathrm{n}<33 \%$ & 4 & 5 & 6 \\
\hline Colombia & $\diamond$ & $\bullet$ & $\bullet$ \\
\hline Brasil & घ & $\bullet$ & घ \\
\hline Singapur & $\bullet$ & $\bullet$ & $\bullet$ \\
\hline Sudáfrica & $\mathrm{X}$ & $\mathrm{X}$ & $\mathrm{X}$ \\
\hline PNUD & $\bullet$ & $\bullet$ & $\bullet$ \\
\hline Banco Mundial & घ & $\bullet$ & $\bullet$ \\
\hline $\mathrm{X}$ Sin respuesta & & & \\
\hline & & & \\
\hline
\end{tabular}

Fuente: OCDE (2016), Encuesta sobre estudios de casos de percepciones del comportamiento, OCDE, París.

$<$ http://dx.doi.org/10.1787/888933535202> 
Gráfico 8.9. Porcentaje de estudios de casos en los que se evalúan los resultados experimentales, 2016

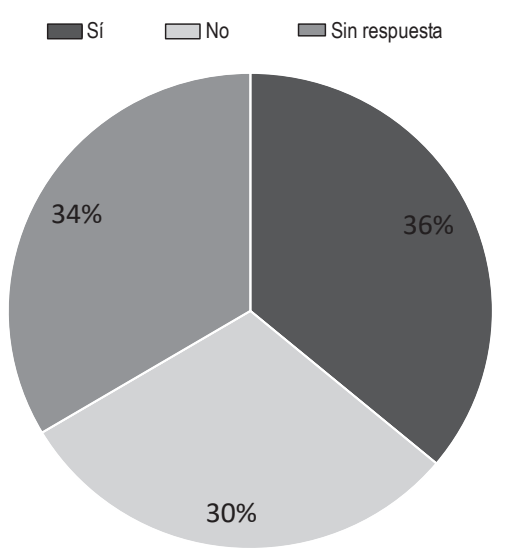

Fuente: OCDE (2016), Encuesta sobre estudios de casos de percepciones del comportamiento, OCDE, París. $<$ http://dx.doi.org/10.1787/888933533093>

Gráfico 8.10. Método para la publicación de los estudios de casos de percepciones del comportamiento, 2016

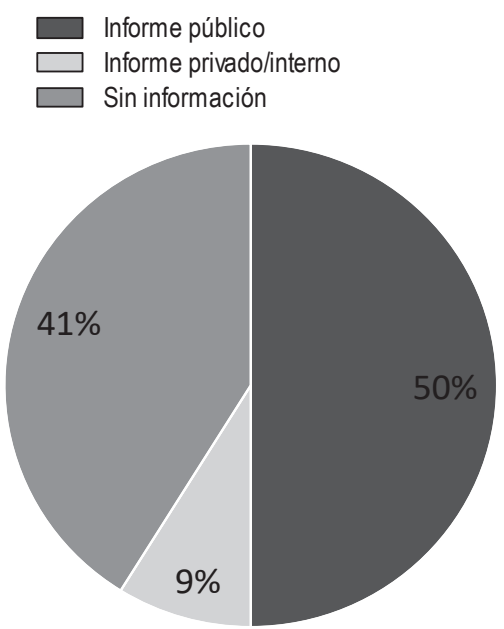

Fuente: OCDE (2016), Encuesta sobre estudios de casos de percepciones del comportamiento, OCDE, París. $<$ http://dx.doi.org/10.1787/888933533112> 


\section{CAPÍTULO 9. CONTRATACIÓN PÚBLICA}

\section{VOLUMEN DE LA CONTRATACIÓN PÚBLICA}

La contratación pública — es decir, la adquisición pública de bienes, servicios y obras por parte de las Administraciones públicas y empresas estatales- se utiliza cada vez más como una herramienta estratégica para cumplir con el mandato y alcanzar objetivos políticos más amplios. Además de ajustarse a los principios y normas en vigor, las Administraciones públicas se esfuerzan en aumentar la eficiencia y efectividad de esta función clave. La contratación pública repercute de manera directa en el desempeño del sector público y en la satisfacción de los ciudadanos, ya que incluye aspectos que van desde la identificación de necesidades y de la persona u organización que las puede solventar hasta la garantía de entrega, dentro del plazo acordado y con el nivel de calidad adecuado. De hecho, es relevante no solo para la Administración central, sino también para las Administraciones subcentrales, puesto que la mayoría de los gastos de contratación pública en los países de la OCDE (63\%) tuvieron lugar en este segundo nivel.

La mera magnitud de la contratación pública la convierte en una actividad económica clave que supone una media del $12 \%$ del PIB en los países de la OCDE, y oscila entre el 5,1\% en México y el 20,2\% en Países Bajos. El alto volumen de la contratación pública, junto con la interacción estrecha y compleja entre los sectores público y privado, hace que esté expuesta a riesgos relacionados con el desaprovechamiento, la gestión inadecuada y la corrupción en todos sus ámbitos de ejercicio. El elevado poder adquisitivo de las Administraciones públicas tiene a su vez el potencial de influir en la economía general del país. Mientras que el nivel medio de gasto en contratación pública en los países de la OCDE permanece relativamente estable en el tiempo, es bastante volátil en algunos países. La capacidad económica de la contratación pública es más pronunciada en los momentos de recesión económica y, por tanto, su gasto en relación con el PIB experimentó un incremento entre 2007 y 2009 (+1,5 p.p.). Al estar bajo presión fiscal, las Administraciones públicas promueven reformas en sus sistemas de contratación pública, desarrollando y adap- 
tando nuevas tecnologías y herramientas con el fin de gestionar mejor estos gastos en recursos públicos. Algunos ejemplos incluyen estrategias del desarrollo de la capacidad, la digitalización y la automatización de los procesos de contratación pública y la agregación estratégica de la demanda principalmente mediante centrales de compras.

La contratación pública ayuda a los Gobiernos a cumplir con su mandato de proporcionar servicios públicos a los ciudadanos. Los gastos en sanidad son los más elevados, pues contabilizan casi un tercio de los gastos totales en contratación pública en los países de la OCDE $(29,8 \%)$, con países que despuntan como Bélgica (47\%), Italia (44,8\%), Japón (44,5\%) y Alemania (42\%). Las diferencias en la estructura de gastos de la contratación pública reflejan el enfoque político de cada país en materia de servicios públicos. Los asuntos económicos $(17 \%)$, educación $(11,9 \%)$, defensa $(10,1 \%)$ y protección social (9,8\%) suponen cuotas importantes de los gastos en contratación pública en todos los países de la OCDE. Estas áreas de gasto elevado, estrechamente relacionadas con el bienestar de la población, se perciben a menudo como ámbitos de alto riesgo. La contratación pública eficiente y efectiva es, por tanto, esencial para responder adecuadamente a las necesidades de los ciudadanos y constituye un pilar cada vez más importante de la buena gobernanza, capaz quizá de restaurar la confianza ciudadana en el sector público.

\section{Metodología y definiciones}

El importe del gasto público destinado a contratación se estima a partir de los datos de las Estadísticas de Contabilidad Nacional (base de datos), que se basan en el Sistema de Contabilidad Nacional (SCN). La contratación pública se define como la suma del consumo intermedio (bienes y servicios adquiridos por las Administraciones para su propio uso, tales como servicios de contabilidad o de tecnologías de la información), la formación bruta de capital fijo (adquisición de capital excluyendo la venta de activos fijos, como la construcción de nuevas carreteras) y las transferencias sociales en especie a través de productores del mercado (compras por las Administraciones públicas de bienes y servicios producidos por productores del mercado y suministrados a los hogares). Las corporaciones públicas se han excluido de la estimación de los gastos en contratación. 
En el Gráfico 9.2 el gasto público en contratación se desglosa de acuerdo con la clasificación de las funciones del gobierno (CFG). Véase el Anexo C para más información sobre los tipos de gastos incluidos en cada categoría.

Los datos de los cambios en la estructura del gasto público en contratación por función, de 2012 a 2015, y de la contratación pública por nivel de Administración, 2007, 2009 y 2015, están disponibles online (véase el Anexo F).

\section{Otras publicaciones}

OECD (2016), Public Governance Reviews; Improving ISSSTE's Public Procurement for Better Results, OECD Publishing, París.

OECD (2015), «Recommendation of the Council on Public Procurement», OECD, París, <www.oecd.org/gov/ethics/OECD-Recommendation-on-Public-Procurement.pdf $>$.

OECD (2015), Government at a Glance 2015, OECD, París.

\section{Notas de los gráficos}

Los datos de Chile no están disponibles. Los de Costa Rica, Rusia y Sudáfrica corresponden a 2014 en lugar de 2015.

Una gran proporción de la contratación de Países Bajos se gasta en transferencias sociales en especie. Este nivel tan elevado se puede deber, en parte, al sistema de becas escolares del país, así como al sistema de seguro de salud obligatorio por el cual la Administración subsidia la adquisición de coberturas individuales a través de entidades privadas.

9.1: Los datos de Turquía no se incluyen en la media de la OCDE, ya que faltan series temporales.

9.2: Los datos de Australia, Canadá, México, Nueva Zelanda y Turquía no están disponibles. Los datos de Islandia no se incluyen en la media de la OCDE, puesto que faltan series temporales. Los datos de Corea corresponden a 2014 en lugar de 2015. 


\section{Gráfico 9.1. Gasto público en contratación como porcentaje del PIB y del gasto público total, 2007, 2009 y 2015}
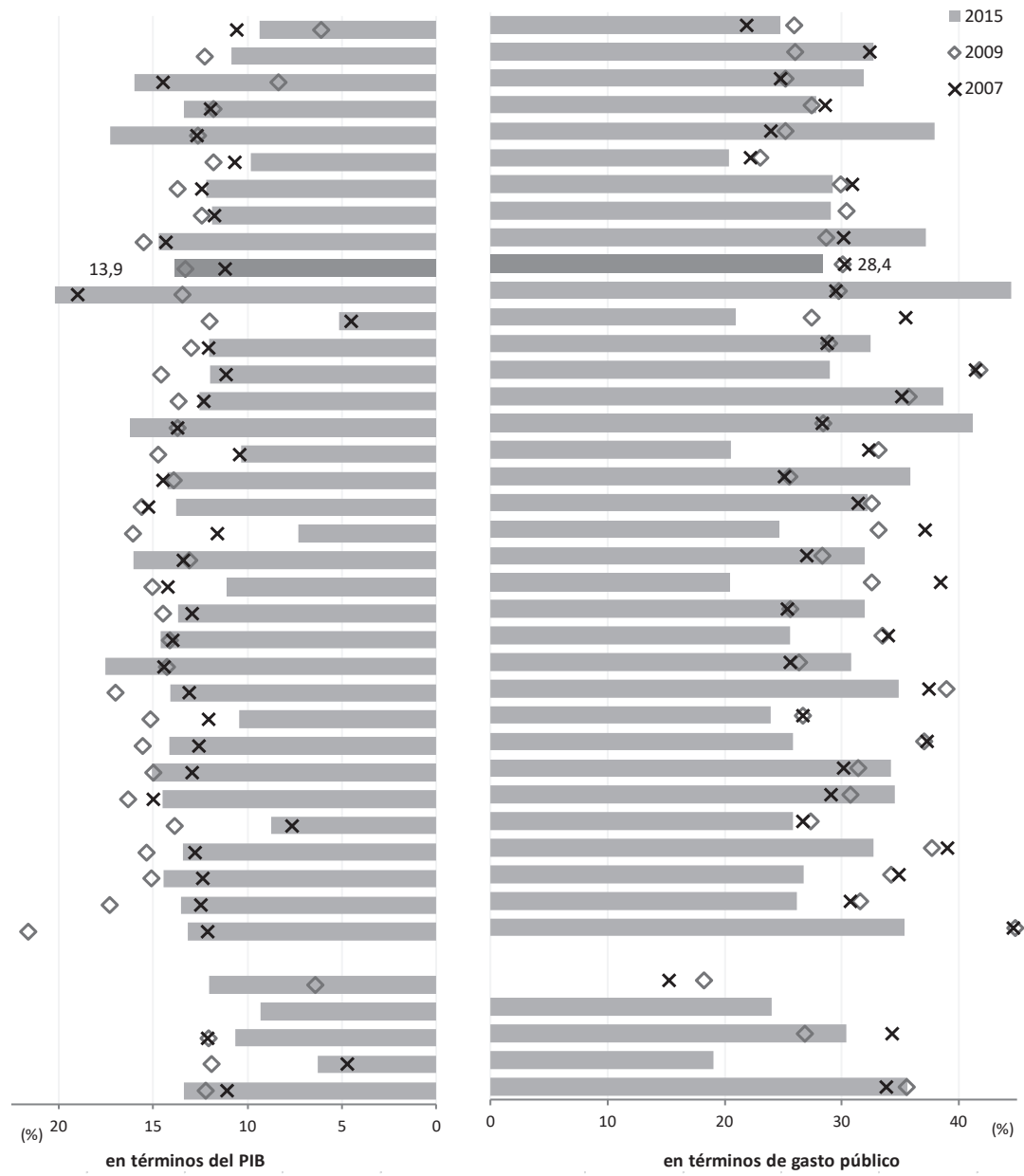

Fuentes: Estadísticas de Contabilidad Nacional de la OCDE (base de datos). Los datos de Australia se basan en las Estadísticas Financieras Públicas proporcionadas por la Oficina de Estadísticas de Australia.

$<$ http://dx.doi.org/10.1787/888933533131> 
Tabla 9.2. Estructura del gasto público en contratación por función, 2015

\begin{tabular}{|c|c|c|c|c|c|c|c|c|c|c|}
\hline & 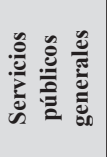 & 冚 & ప & 递 & 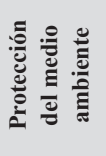 & 总 & : & 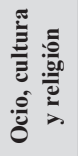 & & 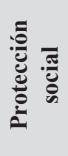 \\
\hline Alemania & 9,5 & 3,8 & 3,4 & 9,6 & 2,6 & 1,2 & 42,0 & 2,5 & 7,1 & 18,4 \\
\hline Austria & 11,6 & 1,4 & 3,0 & 22,0 & 1,3 & 0,7 & 35,7 & 4,1 & 9,1 & 11,0 \\
\hline Bélgica & 11,1 & 1,4 & 1,9 & 9,7 & 3,1 & 1,1 & 47,0 & 2,9 & 8,6 & 13,1 \\
\hline Corea & 10,8 & 11,4 & 3,0 & 19,2 & 4,5 & 4,8 & 30,3 & 2,9 & 10,7 & 2,5 \\
\hline Dinamarca & 14,8 & 4,3 & 2,6 & 11,7 & 1,4 & 0,6 & 30,6 & 5,5 & 12,9 & 15,6 \\
\hline España & 11,0 & 3,5 & 3,8 & 16,9 & 6,3 & 2,9 & 31,5 & 5,5 & 10,7 & 8,0 \\
\hline Estados Unidos & 9,8 & 21,3 & 6,4 & 23,4 & 0,0 & 2,6 & 13,5 & 1,4 & 18,3 & 3,3 \\
\hline Estonia & 11,8 & 8,7 & 3,0 & 20,6 & 3,2 & 2,0 & 25,4 & 6,3 & 15,9 & 3,2 \\
\hline Finlandia & 21,9 & 4,7 & 2,3 & 14,0 & 0,7 & 0,9 & 21,9 & 3,6 & 12,2 & 17,7 \\
\hline Francia & 8,0 & 5,8 & 2,4 & 12,5 & 4,3 & 2,7 & 38,3 & 3,9 & 6,7 & 15,6 \\
\hline Grecia & 22,6 & 8,0 & 1,1 & 18,6 & 5,6 & 1,9 & 29,3 & 2,6 & 8,1 & 2,2 \\
\hline Hungría & 15,4 & 1,4 & 3,2 & 26,0 & 6,4 & 4,3 & 23,2 & 5,7 & 9,4 & 5,1 \\
\hline Irlanda & 6,3 & 1,2 & 4,6 & 15,3 & 3,2 & 5,5 & 33,2 & 4,2 & 9,3 & 17,1 \\
\hline Islandia & 10,8 & 0,0 & 5,3 & 12,0 & 2,4 & 1,6 & 31,1 & 11,0 & 16,8 & 9,1 \\
\hline Israel & 7,4 & 28,4 & 3,3 & 2,7 & 2,5 & 1,5 & 30,1 & 4,2 & 10,0 & 10,0 \\
\hline Italia & 11,3 & 3,0 & 3,2 & 10,5 & 8,1 & 3,3 & 44,8 & 4,2 & 5,7 & 5,8 \\
\hline Japón & 6,5 & 3,2 & 2,1 & 14,1 & 5,8 & 1,9 & 44,5 & 1,5 & 7,0 & 13,4 \\
\hline Letonia & 11,6 & 3,8 & 6,1 & 21,5 & 3,1 & 5,9 & 15,3 & 6,2 & 19,5 & 6,8 \\
\hline Luxemburgo & 9,7 & 0,6 & 2,0 & 22,1 & 3,7 & 2,8 & 30,9 & 4,9 & 11,0 & 12,4 \\
\hline Noruega & 10,9 & 6,6 & 2,5 & 20,4 & 4,2 & 4,3 & 25,6 & 4,4 & 10,9 & 10,2 \\
\hline Países Bajos & 6,6 & 2,2 & 3,3 & 12,6 & 5,0 & 1,6 & 36,0 & 3,2 & 8,7 & 20,9 \\
\hline Polonia & 6,5 & 5,9 & 4,1 & 27,5 & 3,8 & 4,6 & 27,0 & 5,1 & 11,1 & 4,4 \\
\hline Portugal & 9,9 & 3,1 & 5,9 & 22,2 & 2,0 & 2,2 & 32,2 & 3,1 & 16,8 & 2,5 \\
\hline Reino Unido & 3,1 & 10,7 & 6,0 & 13,0 & 4,4 & 1,3 & 31,8 & 2,9 & 13,4 & 13,4 \\
\hline República Checa & 5,5 & 3,3 & 4,0 & 21,5 & 6,5 & 3,1 & 31,4 & 4,9 & 14,9 & 4,9 \\
\hline República de Eslovenia & 9,3 & 1,5 & 2,8 & 24,2 & 6,3 & 3,8 & 30,0 & 6,1 & 12,2 & 3,7 \\
\hline República Eslovaca & 9,4 & 2,6 & 5,6 & 28,3 & 4,2 & 3,6 & 34,9 & 3,1 & 6,4 & 2,0 \\
\hline Suecia & 19,0 & 4,2 & 2,9 & 13,4 & 1,0 & 3,4 & 21,8 & 3,0 & 15,1 & 16,1 \\
\hline Suiza & 21,8 & 5,7 & 5,7 & 16,4 & 4,4 & 1,5 & 2,2 & 3,1 & 18,1 & 21,1 \\
\hline OCDE & 9,1 & 10,1 & 4,2 & 17,0 & 3,1 & 2,4 & 29,8 & 2,6 & 11,9 & 9,8 \\
\hline Costa Rica & 5,5 & 0,0 & 8,1 & 13,2 & 3,9 & 4,5 & 36,0 & 1,9 & 21,3 & 5,6 \\
\hline Lituania & 6,8 & 5,0 & 5,0 & 23,0 & 3,6 & 2,1 & 25,1 & 3,5 & 16,5 & 9,5 \\
\hline
\end{tabular}

Fuentes: Estadísticas de Contabilidad Nacional de la OCDE (base de datos); Estadísticas de Finanzas Públicas de Eurostat (base de datos). 


\section{CONTRATACIÓN PÚBLICA ESTRATÉGICA}

Las Administraciones públicas continúan utilizando la contratación pública para alcanzar objetivos políticos secundarios al mismo tiempo que proporcionan los bienes y servicios necesarios para cumplir su cometido de manera oportuna, económica y eficiente. Dada la significativa relevancia de la contratación pública en los resultados económicos y en la gobernanza pública coherente, como sugiere su elevado volumen, las Administraciones la utilizan como instrumento para lograr objetivos políticos adicionales, relacionados con retos medioambientales, económicos y sociales según las prioridades de cada país.

Los aspectos medioambientales continúan siendo los objetivos políticos clave que se abordan a través de la contratación pública. Casi todos los países de la OCDE encuestados (29) apoyan la contratación ecológica mediante diversas políticas y estrategias que se desarrollan a nivel central y por entidades específicas de contratación. En comparación con 2014, dos países más (Estonia y República Eslovaca) han desarrollado políticas que apoyan la contratación ecológica. Las políticas centrales a menudo se acompañan de orientación detallada sobre su implementación, como la desarrollada por el Ministerio de Medio Ambiente en Estonia y la Agencia de Protección Medioambiental en Irlanda. Las disposiciones legislativas específicas también exigen que los países tengan en consideración la eficiencia energética, las consideraciones medioambientales y los costes del ciclo completo de la contratación.

Las políticas y estrategias de contratación pública se utilizan cada vez más en los países de la OCDE para incorporar políticas económicas, especialmente las que fomenten la participación y el desarrollo de la pequeña y mediana empresa (pyme). Aunque en la mayoría de los países de la OCDE (21) la división del contrato en lotes es el enfoque más utilizado para apoyar a las pymes, más de la mitad de los países, como Australia, Corea e Israel, utilizan además directrices (20 países) y formación y talleres (17). En especial, los países miembros de la Unión Europea (UE) reforzaron el uso estratégico de la contratación pública mediante la transposición de las directivas de la UE de contratación pública de 2014. La transposición de estas directivas facilitó que las pymes tuvieran acceso a la contratación pública a través de la implementación de procesos más sencillos y flexibles y fomentando la división en lotes.

La contratación pública es una de las principales políticas de innovación basadas en la demanda y se utiliza en la mayoría de los países de la OCDE (24) para promover los bienes y servicios innovadores, exceptuando en Chile, Grecia, Islandia, Israel, Japón y República Eslovaca. Existe una amplia gama de medidas que apoyan la contratación estratégica centrada en la innovación, incluyendo instrumentos legales y programas más integrales de las Administraciones, e instrumentos no legales como la orientación, que es el enfoque más utilizado (16 países). Con menor frecuencia, las disposiciones legislativas 
y políticas específicas estipulan la preferencia de bienes y servicios innovadores a través de procesos de reserva y licitación, como en el caso de Austria, Letonia y Turquía, e incluso del trato preferencial, que incluye la exención de tasas y cuotas para las empresas innovadoras, como en España y México. También existen programas gubernamentales que apoyan la contratación precomercial y facilitan la entrada en el mercado de productos y servicios en fase avanzada, como por ejemplo el Build in Canada Innovation Program (en español: Programa de Innovación Construir en Canadá) y el Market Development Fund (en español: Fondo de Desarrollo del Mercado) de Dinamarca.

\section{Metodología y definiciones}

Los datos se recogieron mediante la Encuesta de la OCDE sobre contratación pública de 2016, que se centró en la contratación pública estratégica, la contratación electrónica, las centrales de compras, la contratación pública a nivel subcentral y los proyectos de infraestructuras. Un total de 30 países de la OCDE completaron la encuesta, así como tres en proceso de adhesión (Colombia, Costa Rica y Lituania) y un socio clave, India. Los encuestados eran delegados nacionales, responsables de las políticas de contratación a nivel central y altos funcionarios de las centrales de compras.

La contratación pública ecológica se define por la Comisión Europea como «un proceso por el cual las autoridades públicas tratan de adquirir bienes, servicios y obras con un impacto ambiental reducido durante todo su ciclo completo en comparación con los bienes, servicios y obras con la misma función primaria que serían adquiridos de otra manera».

El uso estratégico de la contratación pública en la innovación se define como cualquier práctica de contratación pública destinada a estimular la innovación mediante la investigación y el desarrollo y la implantación en el mercado de productos y servicios innovadores.

\section{Otras publicaciones}

OECD (2017), Public Procurement for Innovation: Good Practices and Strategies, OECD Publishing, París.

OECD (2015a), «Recommendation of the Council on Public Procurement», OECD, París, <www.oecd.org/gov/ethics/OECD-Recommendation-on-Public-Procurement.pdf>.

OECD (2015b), «Procurement - Green procurement», OECD, París, <www. oecd.org/gov/public-procurement/green/>. 


\section{Notas de los gráficos}

9.5: El ICT Sustainability Plan (en español: Plan de Sostenibilidad TIC) de Australia expiró en junio de 2015, pero las Reglas de Contratación Pública de la Commonwealth requieren que los funcionarios consideren los costes financieros y no financieros de cada contratación incluyendo, pero sin limitarse a, la sostenibilidad medioambiental de los bienes y servicios propuestos. En Noruega, el primer plan nacional de Responsabilidad Social y Medioambiental en la Contratación Pública se adoptó en 2007 y luego se rescindió.

9.6: Las disposiciones legales específicas incluyen procesos de reserva y licitación.

Tabla 9.5. Desarrollo de estrategias/políticas de contratación pública que apoyan objetivos políticos secundarios

\begin{tabular}{|c|c|c|c|c|c|c|}
\hline & \multicolumn{2}{|c|}{$\begin{array}{c}\text { Contratación pública } \\
\text { ecológica }\end{array}$} & \multicolumn{2}{|c|}{ Pymes } & \multicolumn{2}{|c|}{$\begin{array}{l}\text { Bienes y servicios } \\
\text { innovadores }\end{array}$} \\
\hline & 2016 & 2014 & 2016 & 2014 & 2016 & 2014 \\
\hline Alemania & $\bullet$ & $\bullet$ & • & $\bullet$ & $\bullet$ & • \\
\hline Australia & - & $\bullet$ & - & $\bullet$ & $\bullet$ & - \\
\hline Austria & $\bullet$ & $\bullet$ & $\bullet$ & $\rightarrow$ & $\bullet$ & - \\
\hline Bélgica & $\bullet$ & $\bullet$ & $\bullet$ & $\bullet$ & $\bullet$ & $\bullet$ \\
\hline Canadá & $\bullet$ & $\bullet$ & $\bullet$ & - & 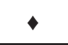 & $\bullet$ \\
\hline Chile & $\bullet$ & $\bullet$ & $\bullet$ & $\bullet$ & $\circ$ & $\bullet$ \\
\hline Corea & $\bullet$ & $\bullet$ & $\bullet$ & $\bullet$ & $\bullet$ & $\bullet$ \\
\hline Dinamarca & $\bullet$ & $\bullet$ & - & $\bullet$ & $\bullet$ & - \\
\hline España & $\bullet$ & $\bullet$ & $\bullet$ & $\bullet$ & $\bullet$ & $\bullet$ \\
\hline Estados Unidos & ".." & - & ".." & $\bullet$ & ".." & $\bullet$ \\
\hline Estonia & $\bullet$ & $\circ$ & $\bullet$ & $\circ$ & $\bullet$ & $\circ$ \\
\hline Finlandia & $\bullet$ & $\bullet$ & 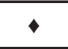 & 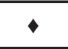 & $\bullet$ & 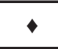 \\
\hline Francia & ".." & $\bullet$ & ".." & $\bullet$ & ".." & $\bullet$ \\
\hline Grecia & 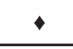 & $\bullet$ & 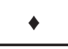 & $\bullet$ & $\circ$ & $\circ$ \\
\hline Hungría & - & 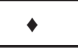 & $\bullet$ & $\bullet$ & - & $\bullet$ \\
\hline Irlanda & $\bullet$ & $\bullet$ & $\bullet$ & $\bullet$ & $\bullet$ & $\bullet$ \\
\hline Islandia & - & - & 0 & $\circ$ & $\circ$ & $\circ$ \\
\hline Israel & $\bullet$ & ".." & - & ".." & $\circ$ & ".." \\
\hline Italia & $\bullet$ & $\bullet$ & 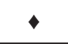 & $\bullet$ & $\bullet$ & 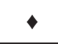 \\
\hline
\end{tabular}




\begin{tabular}{|c|c|c|c|c|c|c|}
\hline & \multicolumn{2}{|c|}{$\begin{array}{c}\text { Contratación pública } \\
\text { ecológica }\end{array}$} & \multicolumn{2}{|c|}{ Pymes } & \multicolumn{2}{|c|}{$\begin{array}{l}\text { Bienes y servicios } \\
\text { innovadores }\end{array}$} \\
\hline & 2016 & 2014 & 2016 & 2014 & 2016 & 2014 \\
\hline Japón & $\bullet$ & $\bullet$ & $\bullet$ & $\bullet$ & o & $\bullet$ \\
\hline Letonia & $\bullet$ & ".." & $\bullet$ & ".." & $\checkmark$ & ".." \\
\hline Luxemburgo & ".." & $\bullet$ & ".." & $\bullet$ & ".." & 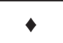 \\
\hline México & $\bullet$ & $\bullet$ & $\bullet$ & $\bullet$ & $\bullet$ & $\bullet$ \\
\hline Noruega & 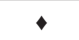 & घ & 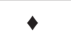 & $\bullet$ & $\bullet$ & $\bullet$ \\
\hline Nueva Zelanda & $\bullet$ & $\bullet$ & $\bullet$ & $\bullet$ & $\bullet$ & $\bullet$ \\
\hline Países Bajos & 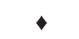 & 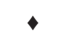 & $\bullet$ & 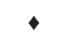 & 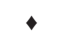 & $\bullet$ \\
\hline Polonia & $\bullet$ & $\bullet$ & $\bullet$ & $\bullet$ & $\bullet$ & $\bullet$ \\
\hline Portugal & $\bullet$ & $\bullet$ & $\bullet$ & 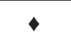 & $\checkmark$ & $\checkmark$ \\
\hline Reino Unido & $\bullet$ & $\bullet$ & $\bullet$ & $\bullet$ & $\bullet$ & $\bullet$ \\
\hline República Checa & ".." & ".." & ".." & ".." & ".." & ".." \\
\hline República de Eslovenia & $\bullet$ & $\bullet$ & $\bullet$ & $\bullet$ & $\bullet$ & $\bullet$ \\
\hline República Eslovaca & $\bullet$ & $\circ$ & $\bullet$ & $\circ$ & $\circ$ & $\circ$ \\
\hline Suecia & $\bullet$ & $\bullet$ & $\bullet$ & $\bullet$ & $\bullet$ & $\bullet$ \\
\hline Suiza & ".." & $\bullet$ & ".." & $\bullet$ & ".." & $\bullet$ \\
\hline Turquía & $\bullet$ & $\bullet$ & $\bullet$ & $\bullet$ & $\bullet$ & $\bullet$ \\
\hline \multicolumn{7}{|l|}{ Total OCDE } \\
\hline $\begin{array}{c}\text { - Estrategias/políticas } \\
\text { desarrolladas a nivel } \\
\text { central }\end{array}$ & 25 & 26 & 24 & 24 & 19 & 22 \\
\hline $\begin{array}{l}\text { Estrategias/políticas } \\
\text { internas desarrolladas } \\
\text { por entidades de } \\
\text { contratación }\end{array}$ & 11 & 14 & 8 & 12 & 9 & 11 \\
\hline Rescindido & 1 & 1 & 0 & 0 & 0 & 0 \\
\hline - Nunca desarrollado & 0 & 2 & 1 & 3 & 6 & 4 \\
\hline $\begin{array}{l}\text { ".." Sin información } \\
\text { disponible }\end{array}$ & 6 & 3 & 6 & 3 & 6 & 3 \\
\hline Colombia & $\bullet$ & $\bullet$ & $\bullet$ & $\bullet$ & $\bullet$ & $\bullet$ \\
\hline Costa Rica & • & $\bullet$ & $\bullet$ & $\bullet$ & $\circ$ & $\circ$ \\
\hline India & $\circ$ & ".." & $\bullet$ & ".." & 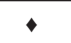 & ".." \\
\hline Lituania & $\bullet$ & ".." & $\bullet$ & ".." & $\bullet$ & ".." \\
\hline Rusia & ".." & o & ".." & $\bullet$ & ".." & 0 \\
\hline
\end{tabular}

Fuente: $\operatorname{OCDE}(2016,2014)$, Encuesta sobre contratación pública, OCDE, París. 


\section{Gráfico 9.6. Enfoques para apoyar la participación de las pymes en la contratación pública}

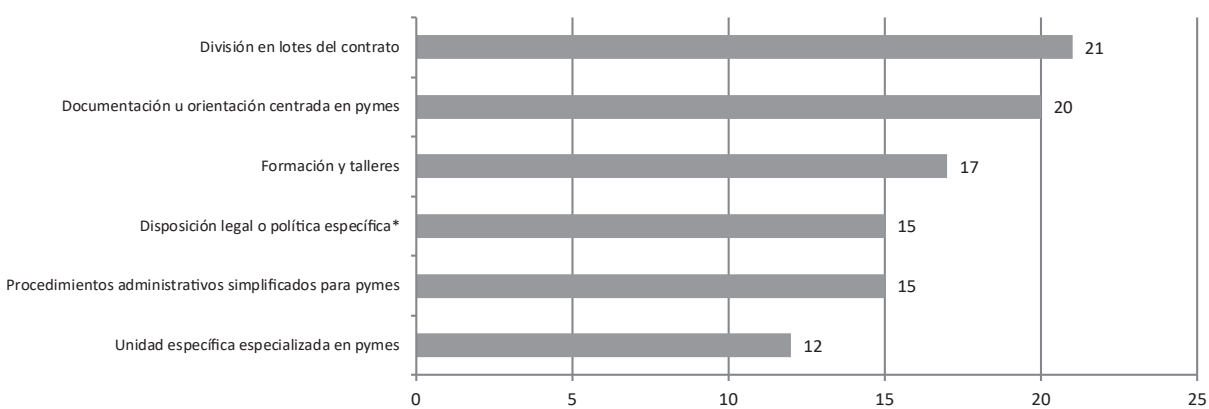

Fuente: OCDE (2016, 2014), Encuesta sobre contratación pública, OCDE, París.

$<$ http://dx.doi.org/10.1787/888933533150>

\section{CONTRATACIÓN ELECTRÓNICA}

El uso de las tecnologías digitales en el sector público impulsa la eficiencia y apoya la implementación efectiva y seguimiento de las políticas, fomentando Administraciones más abiertas, innovadoras y dignas de confianza. En concreto, la contratación electrónica permite ahorrar tiempo y dinero mediante la automatización y estandarización de los procesos, y mejora la transparencia y rendición de cuentas del sistema de contratación pública.

La digitalización de los procesos de contratación pública aumenta a medida que los países toman conciencia de sus beneficios. Todos los países de la OCDE encuestados han implementado sistemas electrónicos, a menudo en forma de una plataforma central acompañada de entidades específicas de contratación. Sin embargo, las funcionalidades que desempeñan estos sistemas varían notablemente entre los países. Los sistemas de contratación electrónica se utilizan normalmente para publicar y almacenar información sobre la contratación. Con la excepción de Suecia, todos los países encuestados (29) publican licitaciones y adjudicaciones de contratos en sus sistemas centrales de contratación electrónica. Los documentos de licitación también se proporcionan en los sistemas centrales de contratación electrónica de la mayoría de los países (26), exceptuando Dinamarca, Polonia, Reino Unido y Suecia, donde se distribuyen por los sistemas electrónicos o páginas web de las entidades específicas de contratación. En alrededor de la mitad de los países de la OCDE (15), las centrales de compras a nivel subcentral también utilizan sistemas de contratación electrónica.

Las funcionalidades relacionadas con los aspectos transaccionales de los sistemas de contratación electrónica se proporcionan en menos países de la 
OCDE. En 21 países, las plataformas centrales de contratación electrónica facilitan la presentación electrónica de ofertas, y un número mucho menor de países habilita subastas electrónicas (11), la presentación electrónica de facturas (10) y catálogos online (11). Varios países tienen en marcha proyectos para implementar funcionalidades transaccionales adicionales. Por ejemplo, Canadá, Israel y República de Eslovenia proyectan implementar la presentación electrónica de ofertas en los próximos años. La Comisión Europea ha desarrollado iniciativas que apoyan la transición hacia sistemas electrónicos que incorporan el ciclo completo de la contratación pública, incluyendo habilitar obligatoriamente la presentación electrónica de ofertas en los países miembros de la UE antes de 2018.

La integración de los sistemas de contratación electrónica en otros sistemas de gobierno electrónico no es todavía una práctica común en los países de la OCDE. La integración de la contratación pública en los procesos globales de gestión de las finanzas, presupuestos y prestación de servicios tiene el potencial de aprovechar los recursos públicos mediante una mejor transmisión de la información y aumentar la rendición de cuentas. Los sistemas de contratación electrónica también apoyan y facilitan el contacto con otros sistemas informáticos del gobierno electrónico. En los países de la OCDE, los sistemas de contratación electrónica suelen estar integrados en los registros mercantiles (8 países), registros tributarios (7), sistemas presupuestarios (6) y bases de datos de la seguridad social (6). En varios países, la integración de la contratación electrónica en otros sistemas del gobierno electrónico es parte de la agenda política, como en Finlandia y Polonia.

Los países están aumentando sus sistemas de contratación electrónica mediante la implementación de funcionalidades adicionales en las plataformas y la integración de otras tecnologías del gobierno electrónico, con el fin de disfrutar de los beneficios de la digitalización de la contratación pública. Sin embargo, solo una decena de países de la OCDE (33\%), incluyendo Corea, Estonia, Finlandia y Portugal, miden la eficiencia generada por los sistemas de contratación electrónica, centrándose en distintas fuentes de rendimiento como el ahorro de tiempo y la reducción de los costes transaccionales.

\section{Metodología y definiciones}

Los datos se recogieron mediante la Encuesta de la OCDE sobre contratación pública de 2016, que se centró en la contratación pública estratégica, la contratación electrónica, las centrales de compras, la contratación pública a nivel subcentral y los proyectos de infraestructuras. Un total de 30 países de la OCDE completaron la encuesta, así como tres países en proceso de adhesión (Colombia, Costa Rica y Lituania) y 
un socio clave, India. Los encuestados eran delegados nacionales, responsables de las políticas de contratación a nivel central y altos funcionarios de las centrales de compras.

La contratación electrónica se refiere a la integración de las tecnologías digitales en el reemplazo o rediseño de los procedimientos basados en papel a lo largo del ciclo de la contratación.

El ciclo de la contratación pública se refiere a la secuencia de actividades relacionadas, desde la evaluación de las necesidades hasta el pago y gestión de los contratos, pasando por la licitación y la adjudicación, así como a cualquier actividad posterior de seguimiento o auditoría.

\section{Otras publicaciones}

OECD (2016), The Korean Public Procurement Service: Innovating for Effectiveness, OECD Publishing, París. $\quad<\mathrm{http} / / \mathrm{dx}$.doi. org/10.1787/9789264249431-en>.

OECD (2015), «Recommendation of the Council on Public Procurement», OECD, París, <www.oecd.org/gov/ethics/OECD-Recommendation-on-Public-Procurement.pdf $>$.

\section{Notas de los gráficos}

9.7: En Polonia, los documentos de licitación se proporcionan en los sitios web de las entidades de contratación o en los sistemas de contratación electrónica de algunas entidades sectoriales de contratación.

Los datos de Estados Unidos, Francia, Luxemburgo, República Checa y Suiza no están disponibles.

9.8 y 9.9: Los datos de Estados Unidos, Francia, Luxemburgo, República Checa y Suiza no están disponibles. 
Tabla 9.7. Provisión de funcionalidades de contratación electrónica

\begin{tabular}{|c|c|c|c|c|c|c|c|}
\hline & 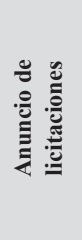 & 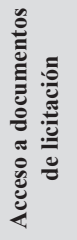 & 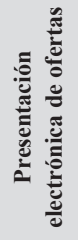 & 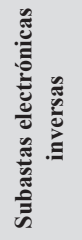 & 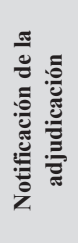 & 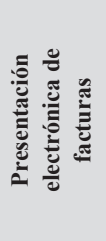 & 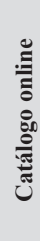 \\
\hline Alemania & $\bullet$ & $\bullet$ & $\bullet$ & $\circ$ & $\bullet$ & $\circ$ & $\circ$ \\
\hline Australia & $\bullet$ & $\bullet$ & $\bullet$ & $\circ$ & $\bullet$ & $\circ$ & $\circ$ \\
\hline Austria & $\bullet$ & $\bullet$ & $\bullet$ & $\bullet$ & $\bullet$ & $\bullet$ & $\bullet$ \\
\hline Bélgica & $\bullet$ & • & $\bullet$ & $\bullet$ & $\bullet$ & 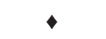 & $\bullet$ \\
\hline Canadá & $\bullet$ & $\bullet$ & $\circ$ & $\circ$ & $\bullet$ & $\bullet$ & $\bullet$ \\
\hline Chile & $\bullet$ & $\bullet$ & $\bullet$ & $\circ$ & $\bullet$ & $\circ$ & $\bullet$ \\
\hline Corea & $\bullet$ & • & $\bullet$ & $\circ$ & $\bullet$ & $\bullet$ & $\bullet$ \\
\hline Dinamarca & $\bullet$ & $\bullet$ & $\bullet$ & $\bullet$ & $\bullet$ & $\bullet$ & $\circ$ \\
\hline España & $\bullet$ & $\bullet$ & $\bullet$ & $\circ$ & $\bullet$ & $\bullet$ & $\bullet$ \\
\hline Estonia & $\bullet$ & $\bullet$ & $\bullet$ & $\bullet$ & $\bullet$ & $\bullet$ & $\circ$ \\
\hline Finlandia & $\bullet$ & $\bullet$ & $\bullet$ & $\bullet$ & $\bullet$ & $\bullet$ & $\bullet$ \\
\hline Grecia & $\bullet$ & $\bullet$ & $\bullet$ & $\bullet$ & $\bullet$ & $\circ$ & $\circ$ \\
\hline Hungría & $\bullet$ & $\bullet$ & $\circ$ & $\circ$ & $\bullet$ & $\circ$ & $\circ$ \\
\hline Irlanda & $\bullet$ & • & $\bullet$ & $\circ$ & $\bullet$ & $\circ$ & $\circ$ \\
\hline Islandia & $\bullet$ & $\bullet$ & $\circ$ & $\circ$ & $\bullet$ & $\bullet$ & $\circ$ \\
\hline Israel & $\bullet$ & $\bullet$ & $\circ$ & $\bullet$ & $\bullet$ & $\bullet$ & $\circ$ \\
\hline Italia & $\bullet$ & $\bullet$ & $\bullet$ & $\bullet$ & $\bullet$ & $\bullet$ & $\bullet$ \\
\hline Japón & $\bullet$ & $\bullet$ & $\bullet$ & $\circ$ & $\bullet$ & $\bullet$ & $\bullet$ \\
\hline Letonia & $\bullet$ & $\bullet$ & $\bullet$ & $\circ$ & $\bullet$ & $\circ$ & $\circ$ \\
\hline México & $\bullet$ & $\bullet$ & $\bullet$ & $\bullet$ & $\bullet$ & $\circ$ & $\circ$ \\
\hline Noruega & $\bullet$ & $\bullet$ & 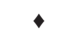 & $\circ$ & $\bullet$ & $\bullet$ & 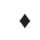 \\
\hline Nueva Zelanda & $\bullet$ & $\bullet$ & $\bullet$ & $\bullet$ & $\bullet$ & $\bullet$ & $\bullet$ \\
\hline Países Bajos & $\bullet$ & $\bullet$ & $\bullet$ & $\circ$ & $\bullet$ & $\circ$ & $\bullet$ \\
\hline Polonia & $\bullet$ & 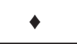 & $\circ$ & $\bullet$ & $\bullet$ & $\circ$ & $\bullet$ \\
\hline Portugal & $\bullet$ & $\bullet$ & $\bullet$ & $\bullet$ & $\bullet$ & $\circ$ & $\bullet$ \\
\hline Reino Unido & $\bullet$ & $\bullet$ & $\bullet$ & $\bullet$ & $\bullet$ & $\bullet$ & 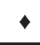 \\
\hline República de Eslovenia & $\bullet$ & $\bullet$ & $\circ$ & $\bullet$ & $\bullet$ & $\bullet$ & $\bullet$ \\
\hline República Eslovaca & $\bullet$ & $\bullet$ & $\bullet$ & $\bullet$ & $\bullet$ & $\circ$ & $\circ$ \\
\hline Suecia & $\bullet$ & $\bullet$ & $\bullet$ & $\bullet$ & - & 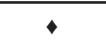 & 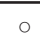 \\
\hline Turquía & $\bullet$ & $\bullet$ & $\bullet$ & $\circ$ & $\bullet$ & $\circ$ & $\circ$ \\
\hline
\end{tabular}




\begin{tabular}{|c|c|c|c|c|c|c|c|}
\hline & 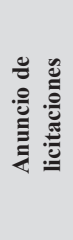 & 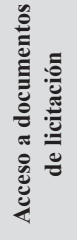 & 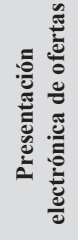 & 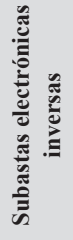 & 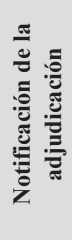 & 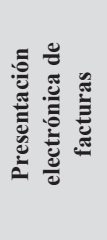 & 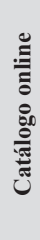 \\
\hline \multicolumn{8}{|l|}{ Total OCDE } \\
\hline $\begin{array}{l}\text { - En un sistema central de } \\
\text { contratación electrónica }\end{array}$ & 29 & 26 & 21 & 11 & 29 & 10 & 11 \\
\hline $\begin{array}{l}\text { Solo en sistemas de } \\
\text { contratación electrónica de } \\
\text { algunas entidades de } \\
\text { contratación específicas }\end{array}$ & 1 & 4 & 3 & 5 & 1 & 7 & 5 \\
\hline$\circ$ No & 0 & 0 & 6 & 14 & 0 & 13 & 14 \\
\hline Colombia & $\bullet$ & $\bullet$ & $\bullet$ & $\circ$ & $\bullet$ & $\bullet$ & $\bullet$ \\
\hline Costa Rica & $\bullet$ & $\bullet$ & $\bullet$ & $\bullet$ & $\bullet$ & $\bullet$ & $\bullet$ \\
\hline India & $\bullet$ & $\bullet$ & $\bullet$ & $\bullet$ & $\bullet$ & $\circ$ & $\bullet$ \\
\hline Lituania & $\bullet$ & $\bullet$ & - & $\bullet$ & $\bullet$ & $\bullet$ & 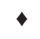 \\
\hline
\end{tabular}

Fuente: OCDE $(2016,2014)$, Encuesta sobre contratación pública, OCDE, París.

$<$ http://dx.doi.org/10.1787/888933535259>

\section{Gráfico 9.8. Integración del sistema(s) de contratación electrónica con otro(s) sistema(s) de gobierno electrónico}

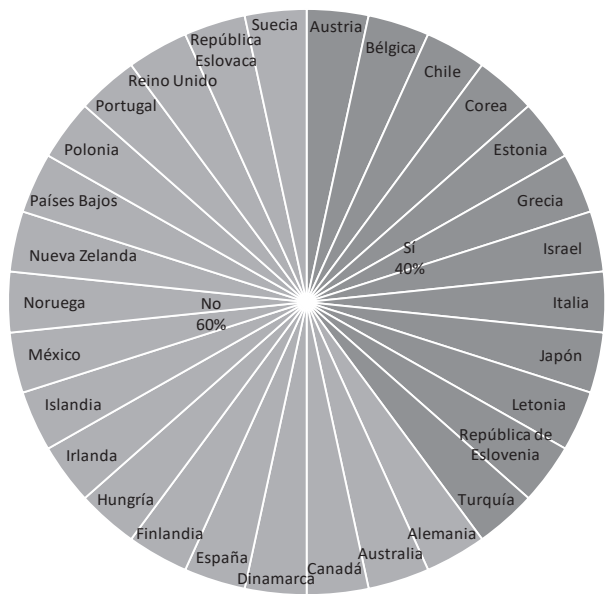

Fuente: OCDE (2016, 2014), Encuesta sobre contratación pública, OCDE, París.

$<$ http://dx.doi.org/10.1787/888933533169> 


\section{Gráfico 9.9. Medición de la eficiencia generada por el uso de sistema(s) de contratación electrónica}

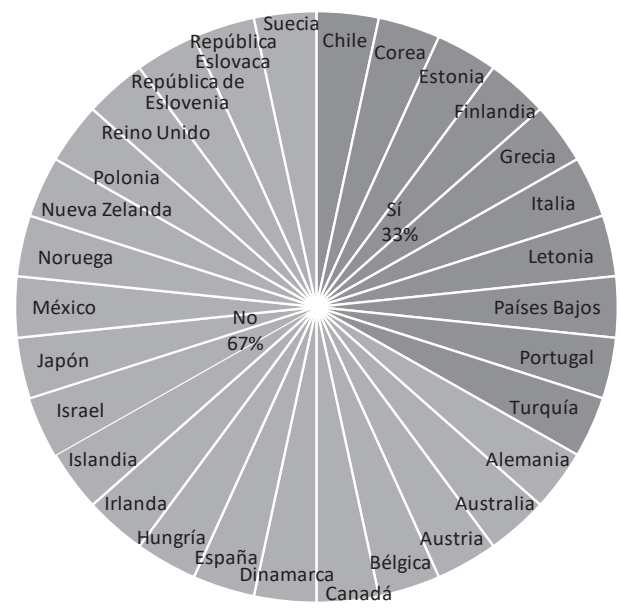

Fuente: OCDE $(2016,2014)$, Encuesta sobre contratación pública, OCDE, París.

$<$ http://dx.doi.org/10.1787/888933533188>

\section{CENTRALES DE COMPRAS}

Las actividades centralizadas de compras generan importantes beneficios, como mejores precios resultantes de las economías de escala, costes transaccionales menores y el aumento de capacidades y conocimientos. Los países de la OCDE aprovechan los beneficios de agregar las demandas y productos de las actividades de contratación en centrales de compras (CPB, por sus siglas en inglés), que se definen como autoridades contratantes (AC) que proporcionan actividades centralizadas de compras $\mathrm{y}$, posiblemente, actividades auxiliares.

Un papel clave de la mayoría de las CPB en los países de la OCDE (28) es el establecimiento de acuerdos marco y otros instrumentos consolidados de contratación. Los acuerdos marco buscan alcanzar mayor eficiencia y relación coste-beneficio en el proceso de contratación pública mediante la competencia y poder adquisitivo agregado de las $\mathrm{CPB}$, que crean economías de escala tanto en la oferta como en la demanda. Sin embargo, no todos los bienes y servicios se pueden contratar a través de este instrumento. Los países de la OCDE seleccionan cuidadosamente los bienes y servicios que están sujetos a este tipo de contratación, basándose en criterios asociados con la competitividad del mercado de proveedores, el impacto en las AC y la recurrencia de la adquisición. 
Los cambios recientes en las funciones que desempeñan las CPB en los países de la OCDE confirman su papel estratégico en el impulso de la eficiencia. Desde 2014, en un número cada vez mayor de países las CPB adoptan el papel de establecer los acuerdos marco, como en Alemania, Noruega, Polonia y República Eslovaca. Al mismo tiempo, comparado con 2014, en 2016 las CPB compraron en nombre de otras AC en un número menor de países (19). Las CPB en los países de la OCDE se centran cada vez más en la agregación estratégica de demandas mediante el desarrollo y uso de herramientas de contratación, incluyendo acuerdos marco y sistemas dinámicos de adquisición, con el fin de alcanzar mejor relación coste-beneficio. Otras funciones comunes de las CPB consisten en coordinar la formación de los funcionarios encargados de la contratación pública (10 países) y establecer políticas para las $\mathrm{AC}()$.

El uso de acuerdos marco establecidos por las CPB es obligatorio para las AC a nivel central de la Administración en 21 países de la OCDE (77\%) y para todas las AC del sector público en Corea y República Eslovaca. Cuando el uso es obligatorio para las $\mathrm{AC}$ a nivel central, a menudo las que funcionan a nivel subcentral pueden unirse de manera voluntaria, como es el caso de Austria, España y Portugal. Este tipo de funcionamiento garantiza el uso de acuerdos marco tanto a las CPB como a los proveedores. A pesar de las ventajas del uso obligatorio de acuerdos marco, seis países de la OCDE permiten que las AC los apliquen de manera voluntaria. Este último tipo de funcionamiento podría ser resultado de varios obstáculos en la centralización, como la heterogeneidad regulatoria, y supone que las CPB se ven presionadas a mantener competitivas las condiciones de sus instrumentos en relación con el mercado. No obstante, en general, se espera que las CPB de los países de la OCDE desarrollen instrumentos competitivos como parte de sus objetivos.

\section{Metodología y definiciones}

Los datos se recogieron mediante la Encuesta de la OCDE sobre contratación pública de 2016, que se centró en la contratación pública estratégica, la contratación electrónica, las centrales de compras, la contratación pública a nivel subcentral y los proyectos de infraestructuras. Un total de 30 países de la OCDE completaron la encuesta, así como tres países en proceso de adhesión (Colombia, Costa Rica y Lituania) y un socio clave, India. Los encuestados eran delegados nacionales, responsables de las políticas de contratación a nivel central y altos funcionarios de las centrales de compras. 
Las actividades centralizadas de compras son actividades realizadas de forma permanente, de una de las siguientes maneras: la adquisición de suministros y/o servicios destinados a AC, y/o la adjudicación de contratos públicos o la conclusión de acuerdos marco relativos a obras, suministros o servicios destinados a AC.

Una autoridad contratante es cualquier autoridad estatal, regional o local que realice actividades de contratación.

Un acuerdo marco es cualquier acuerdo con uno o más operadores económicos para el suministro de bienes, servicios y, en algunos casos, obras, que tiene como propósito establecer las condiciones que deberán regir los contratos adjudicados por una o más autoridades contratantes durante un periodo determinado, en relación con el precio máximo, las especificaciones técnicas mínimas y, en su caso, las cantidades previstas.

\section{Otras publicaciones}

OECD (2017), Public Procurement in Chile: Policy Options for Efficient and Inclusive Framework Agreements, OECD Publishing, París.

OECD (2015), «Recommendation of the council on Public Procurement», OECD, París, <www.oecd.org/gov/ethics/OECD-Recommendation-on-Public-Procurement.pdf $>$.

\section{Notas de los gráficos}

9.10: El gráfico se refiere a las $\mathrm{CPB}$ a nivel central donde existen infinidad de ellas. N/A representa casos en los que no existen CPB.

9.11: Los datos de Bélgica, Estados Unidos, Irlanda, Luxemburgo, República Checa, Suecia y Suiza no están disponibles. Japón y Países Bajos no tienen centrales de compras. 
Tabla 9.10. Función de las centrales de compras

\begin{tabular}{|c|c|c|c|c|c|c|c|c|}
\hline & \multicolumn{2}{|c|}{$\begin{array}{c}\text { Las CPB establecen } \\
\text { acuerdos marco u otros } \\
\text { instrumentos consolidados, } \\
\text { de los cuales se encargan } \\
\text { las AC }\end{array}$} & \multicolumn{2}{|c|}{$\begin{array}{c}\text { Las CPB actúan } \\
\text { como AC agregando } \\
\text { la demanda y } \\
\text { comprando }\end{array}$} & \multicolumn{2}{|c|}{$\begin{array}{l}\text { Las CPB coordinan la } \\
\text { formación de los } \\
\text { funcionarios } \\
\text { encargados de la } \\
\text { contratación pública }\end{array}$} & \multicolumn{2}{|c|}{$\begin{array}{c}\text { Las CPB establecen } \\
\text { las políticas de las } \\
\text { AC }\end{array}$} \\
\hline & 2016 & 2014 & 2016 & 2014 & 2016 & 2014 & 2016 & 2014 \\
\hline Alemania & $\bullet$ & $\circ$ & $\bullet$ & $\bullet$ & $\circ$ & $\circ$ & $\circ$ & $\circ$ \\
\hline Australia & $\bullet$ & N/A & $\bullet$ & $\mathrm{N} / \mathrm{A}$ & $\circ$ & $\mathrm{N} / \mathrm{A}$ & $\circ$ & $\mathrm{N} / \mathrm{A}$ \\
\hline Austria & $\bullet$ & $\bullet$ & $\bullet$ & $\bullet$ & $\bullet$ & $\circ$ & $\circ$ & $\circ$ \\
\hline Bélgica & $\bullet$ & $\bullet$ & $\bullet$ & $\circ$ & $\circ$ & $\circ$ & $\circ$ & $\circ$ \\
\hline Canadá & - & $\bullet$ & $\bullet$ & - & $\bullet$ & $\circ$ & $\circ$ & $\circ$ \\
\hline Chile & $\bullet$ & $\bullet$ & $\circ$ & $\circ$ & $\bullet$ & $\bullet$ & $\bullet$ & $\bullet$ \\
\hline Corea & $\bullet$ & $\bullet$ & $\bullet$ & $\bullet$ & $\bullet$ & $\bullet$ & $\circ$ & $\circ$ \\
\hline Dinamarca & $\bullet$ & $\bullet$ & $\bullet$ & $\circ$ & $\bullet$ & $\circ$ & $\bullet$ & $\bullet$ \\
\hline España & $\bullet$ & $\bullet$ & $\bullet$ & $\bullet$ & $\circ$ & $\circ$ & $\bullet$ & $\bullet$ \\
\hline Estados Unidos & ".." & $\bullet$ & ".." & $\bullet$ & ".." & $\bullet$ & ".." & $\bullet$ \\
\hline Estonia & $\bullet$ & $\bullet$ & $\bullet$ & $\circ$ & $\circ$ & $\circ$ & $\circ$ & $\circ$ \\
\hline Finlandia & $\bullet$ & $\bullet$ & $\bullet$ & - & $\circ$ & $\circ$ & $\circ$ & $\circ$ \\
\hline Francia & $\bullet$ & $\bullet$ & $\bullet$ & $\bullet$ & $\circ$ & $\bullet$ & $\circ$ & $\circ$ \\
\hline Grecia & $\bullet$ & $\bullet$ & $\bullet$ & $\bullet$ & $\circ$ & $\bullet$ & $\bullet$ & $\bullet$ \\
\hline Hungría & $\bullet$ & $\bullet$ & $\bullet$ & $\bullet$ & $\circ$ & $\circ$ & $\circ$ & $\circ$ \\
\hline Irlanda & $\bullet$ & $\bullet$ & $\circ$ & $\bullet$ & $\bullet$ & $\bullet$ & $\bullet$ & $\bullet$ \\
\hline Islandia & $\bullet$ & $\bullet$ & $\circ$ & $\circ$ & $\bullet$ & $\bullet$ & $\circ$ & $\circ$ \\
\hline Israel & - & ".." & $\circ$ & ".." & $\bullet$ & ".." & - & ".." \\
\hline Italia & $\bullet$ & $\bullet$ & $\circ$ & $\circ$ & $\circ$ & $\circ$ & $\circ$ & $\circ$ \\
\hline Japón & N/A & N/A & N/A & $\mathrm{N} / \mathrm{A}$ & N/A & $\mathrm{N} / \mathrm{A}$ & N/A & N/A \\
\hline Letonia & $\bullet$ & ".." & $\bullet$ & ".." & $\circ$ & ".." & $\circ$ & ".." \\
\hline Luxemburgo & ".." & $\circ$ & ".." & $\bullet$ & ".." & $\circ$ & ".." & $\circ$ \\
\hline México & $\bullet$ & $\bullet$ & $\circ$ & $\bullet$ & $\bullet$ & $\bullet$ & $\bullet$ & $\bullet$ \\
\hline Noruega & $\bullet$ & $\circ$ & $\bullet$ & $\bullet$ & $\circ$ & $\circ$ & $\circ$ & $\circ$ \\
\hline Nueva Zelanda & $\bullet$ & $\bullet$ & $\bullet$ & $\bullet$ & $\bullet$ & $\bullet$ & $\bullet$ & $\bullet$ \\
\hline Países Bajos & N/A & N/A & N/A & N/A & $\mathrm{N} / \mathrm{A}$ & $\mathrm{N} / \mathrm{A}$ & N/A & $\mathrm{N} / \mathrm{A}$ \\
\hline Polonia & $\bullet$ & $\circ$ & $\bullet$ & $\bullet$ & $\circ$ & $\circ$ & $\circ$ & $\circ$ \\
\hline Portugal & $\bullet$ & - & $\circ$ & - & $\circ$ & $\circ$ & $\circ$ & $\circ$ \\
\hline Reino Unido & $\bullet$ & $\bullet$ & $\bullet$ & $\bullet$ & $\circ$ & $\bullet$ & $\bullet$ & $\bullet$ \\
\hline República Checa & ".." & ".." & ".." & ".." & ".." & ".." & ".." & ".." \\
\hline $\begin{array}{l}\text { República de } \\
\text { Eslovenia }\end{array}$ & $\bullet$ & $\bullet$ & $\bullet$ & $\bullet$ & $\circ$ & $\circ$ & $\circ$ & $\circ$ \\
\hline República Eslovaca & $\bullet$ & $\circ$ & $\circ$ & $\bullet$ & $\circ$ & $\circ$ & $\circ$ & $\circ$ \\
\hline Suecia & $\bullet$ & $\bullet$ & ० & ० & $\circ$ & $\circ$ & o & ० \\
\hline
\end{tabular}




\begin{tabular}{|c|c|c|c|c|c|c|c|c|}
\hline & \multicolumn{2}{|c|}{$\begin{array}{c}\text { Las CPB establecen } \\
\text { acuerdos marco u otros } \\
\text { instrumentos consolidados, } \\
\text { de los cuales se encargan } \\
\text { las AC }\end{array}$} & \multicolumn{2}{|c|}{$\begin{array}{c}\text { Las CPB actúan } \\
\text { como AC agregando } \\
\text { la demanda y } \\
\text { comprando }\end{array}$} & \multicolumn{2}{|c|}{$\begin{array}{l}\text { Las CPB coordinan la } \\
\text { formación de los } \\
\text { funcionarios } \\
\text { encargados de la } \\
\text { contratación pública }\end{array}$} & \multicolumn{2}{|c|}{$\begin{array}{c}\text { Las CPB establecen } \\
\text { las políticas de las } \\
\text { AC }\end{array}$} \\
\hline & 2016 & 2014 & 2016 & 2014 & 2016 & 2014 & 2016 & 2014 \\
\hline Suiza & ".." & • & ".." & - & ".." & - & ".." & - \\
\hline Turquía & $\circ$ & $\circ$ & $\circ$ & • & $\circ$ & $\circ$ & $\circ$ & $\circ$ \\
\hline \multicolumn{9}{|l|}{ Total OCDE } \\
\hline - Sí & 28 & 23 & 19 & 22 & 10 & 11 & 9 & 10 \\
\hline$\circ \mathrm{No}$ & 1 & 6 & 10 & 7 & 19 & 18 & 20 & 19 \\
\hline ".." Sin información & 4 & 3 & 4 & 3 & 4 & 3 & 4 & 3 \\
\hline Brasil & ".." & $\circ$ & ".." & $\bullet$ & ".." & $\bullet$ & ".." & $\bullet$ \\
\hline Colombia & $\bullet$ & • & $\circ$ & $\circ$ & $\circ$ & $\bullet$ & $\circ$ & $\bullet$ \\
\hline Costa Rica & $\bullet$ & • & $\bullet$ & $\circ$ & $\circ$ & $\bullet$ & $\circ$ & $\bullet$ \\
\hline India & $\bullet$ & ".." & $\circ$ & ".." & $\circ$ & ".." & $\circ$ & ".." \\
\hline Lituania & • & ".." & $\circ$ & ".." & $\circ$ & ".." & ० & ".." \\
\hline Rusia & ".." & $\mathrm{N} / \mathrm{A}$ & ".." & $\mathrm{N} / \mathrm{A}$ & ".." & N/A & ".." & N/A \\
\hline
\end{tabular}

Fuente: OCDE (2016, 2014), Encuesta sobre contratación pública, OCDE, París.

\section{Gráfico 9.11. Uso obligatorio vs. voluntario de los acuerdos marco establecidos por las CPB}

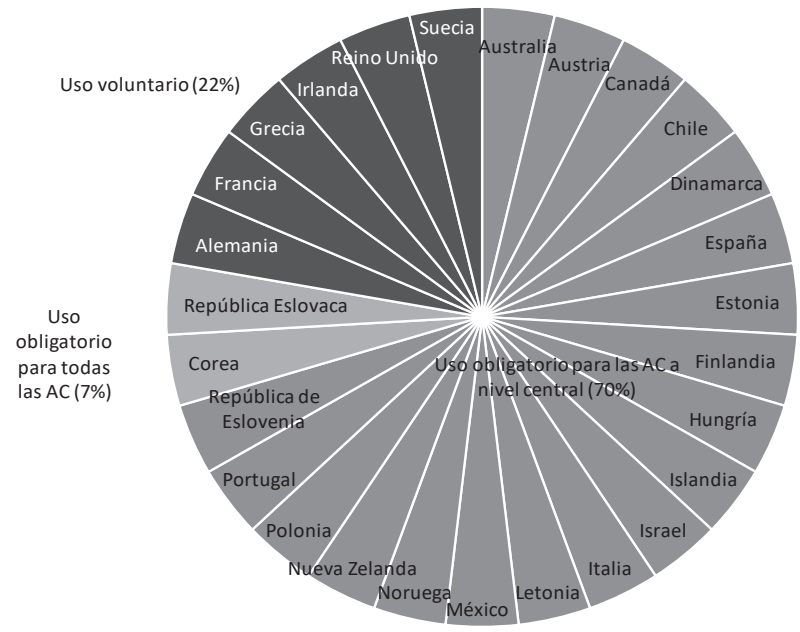

Fuente: OCDE (2016, 2014), Encuesta sobre contratación pública, OCDE, París.

$<$ http://dx.doi.org/10.1787/888933533207> 


\section{CONTRATACIÓN Y REALIZACIÓN DE PROYECTOS DE INFRAESTRUCTURAS}

Los proyectos de infraestructuras constituyen un mandato importante de los Gobiernos en la prestación de servicios públicos clave y tienen repercusiones elevadas y directas en ámbitos trascendentales de los países, como el desarrollo humano, la inclusión social y la sostenibilidad medioambiental. Una vez que se han definido las fases de planificación y financiación, resulta esencial que las Administraciones públicas lleven a cabo los proyectos de una manera rentable, que asegure la confianza de usuarios y ciudadanos.

Las decisiones sobre cómo realizar los proyectos de infraestructuras conllevan una estrecha evaluación y el equilibrio adecuado entre la distribución del riesgo y la rentabilidad. A menudo se critica la modalidad de ejecución por estar basada más en la costumbre que en las características del proyecto y mercado. Los 15 países de la OCDE que completaron la encuesta (54\%) no cuentan con una entidad encargada del desarrollo de políticas para los proyectos de infraestructuras, incluyendo la selección de las modalidades de ejecución. Esto podría dificultar la aplicación de una metodología coherente para la selección de las modalidades de ejecución de proyectos. Trece países (46\%), por el contrario, cuentan con una entidad (o entidades) dedicada al desarrollo de políticas para los proyectos de infraestructuras. Estas entidades suelen ser unidades especializadas de la Administración central. Grecia ha puesto en funcionamiento una unidad sectorial especializada. En Dinamarca, la central de compras es la encargada de desarrollar las políticas para los proyectos de infraestructuras.

Utilizar la contratación pública como una herramienta de la gobernanza estratégica de las infraestructuras ayuda a configurar su realización efectiva. Independientemente de la modalidad de ejecución, las normas y regulaciones de la contratación pública se aplican a los proyectos de infraestructuras en 19 países de la OCDE, y por lo menos de manera parcial en el resto de países encuestados de la OCDE, con la excepción de Turquía. El marco de contratación pública puede ayudar a enfrentar riesgos relacionados con la ineficiencia y la corrupción, a menudo asociados a los proyectos de infraestructuras de gran envergadura y complejidad. Mientras que los principios fundamentales que gobiernan la contratación pública, incluyendo la transparencia, imparcialidad y la competitividad, se aplican de manera consistente, algunos países han desarrollado marcos nacionales adicionales y proporcionan orientación sobre la realización de infraestructuras para reducir aún más los riesgos. La orientación a menudo se proporciona dependiendo de las modalidades específicas de ejecución. Por ejemplo, en Alemania, Letonia y Noruega existen directrices para las asociaciones público-privadas y en Australia, para la alianza nacional de contratación. 


\section{Metodología y definiciones}

Los datos se recogieron mediante la Encuesta de la OCDE sobre contratación pública de 2016, que se centró en la contratación pública estratégica, la contratación electrónica, las centrales de compras, la contratación pública a nivel subcentral y los proyectos de infraestructuras. Un total de 30 países de la OCDE completaron la encuesta, así como tres países en proceso de adhesión (Colombia, Costa Rica y Lituania) y un socio clave, India. Los encuestados eran delegados nacionales, responsables de las políticas de contratación a nivel central y altos funcionarios de las centrales de compras.

Las infraestructuras públicas se definen como instalaciones, estructuras, redes, sistemas, plantas, propiedades, equipamientos y activos físicos y las empresas que los emplean, que proporcionan bienes públicos o que cumplen un mandato político o una necesidad fundamental que el mercado no es capaz de proveer por sí solo.

Existen grandes diferencias entre los modelos de ejecución de las infraestructuras (por ejemplo, diseño-construcción, diseño-licitaciónconstrucción, contratación en alianza, asociación público-privada, concesión y provisión privada) en cuanto a la distribución de riesgos y el control público de la construcción de las infraestructuras. Véase la página 91 de OCDE (2015a) para información más detallada.

\section{Otras publicaciones}

OECD (2016), «High-level Principles for Integrity, Transparency and Effective Control of Major Events and Related Infrastructures», OECD, París, $<$ www.oecd.org/gov/ethics/High-Level_Principles_Integrity_Transparency_Control_Events_Infrastructures.pdf $>$.

OECD (2015a), Effective Delivery of Large Infrastructure Projects: The Case of the New International Airport of Mexico City, OECD Public Governance Reviews, OECD Publishing, París, <http://dx.doi. org $/ 10.1787 / 9789264248335$-en>.

OECD (2015b), «Recommendation of the Council on Public Procurement», OECD, París, <www.oecd.org/gov/ethics/OECD-Recommendation-on-Public-Procurement.pdf $>$. 


\section{Notas de los gráficos}

9.12: Los datos de Bélgica, Estados Unidos, Francia, Luxemburgo, República Checa y Suecia no están disponibles.

9.13: «Parcialmente $(*) »$ significa que las normas y regulaciones de contratación pública se aplican de manera parcial y existen regulaciones y normas específicas para algunos o todos los proyectos de infraestructuras.

Los datos de Bélgica, Estados Unidos, Francia, Luxemburgo, República Checa y Suecia no están disponibles.

\section{Gráfico 9.12. Entidad (o entidades) a cargo del desarrollo de políticas para los proyectos de infraestructuras}

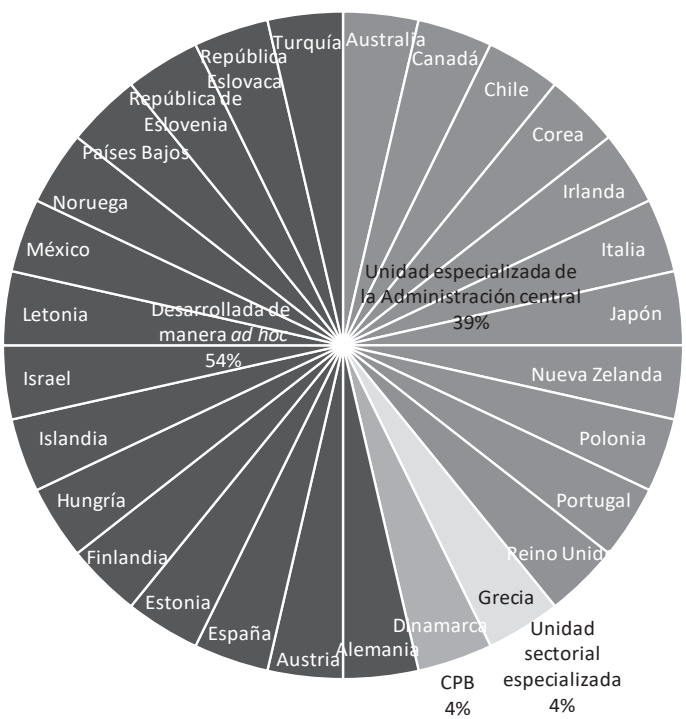

Fuente: OCDE $(2016,2014)$, Encuesta sobre contratación pública, OCDE, París.

$<$ http://dx.doi.org/10.1787/888933533226> 


\section{CONTRATACIÓN PÚBLICA}

\section{Gráfico 9.13. Aplicación de normas y regulaciones de contratación pública a los proyectos de infraestructuras}

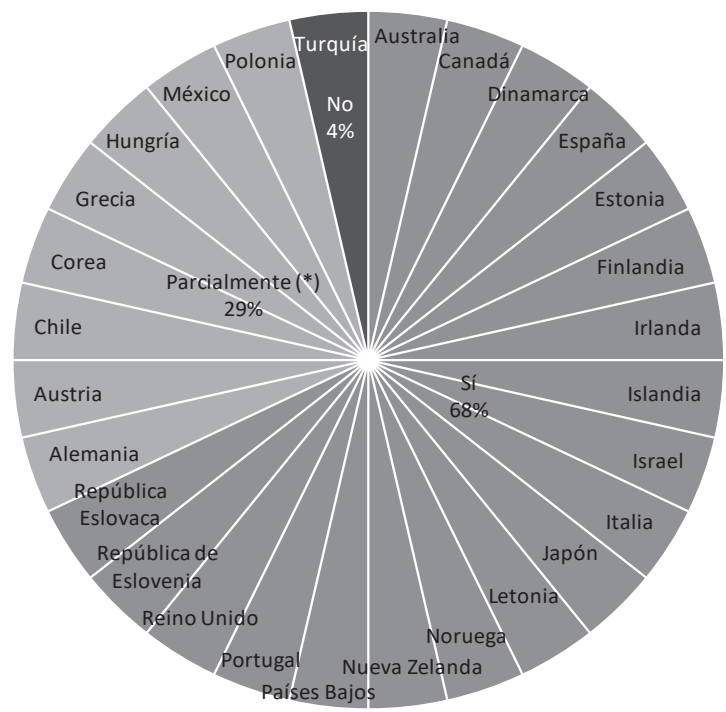

Fuente: OCDE (2016, 2014), Encuesta sobre contratación pública, OCDE, París.

$<$ http://dx.doi.org/10.1787/888933533245> 



\section{CAPÍTULO 10. GOBIERNO ABIERTO}

\section{OBJETIVOS Y ESTRATEGIAS DE GOBIERNO ABIERTO}

Los países reconocen el papel de las reformas de gobierno abierto como un catalizador de la democracia, el crecimiento inclusivo y la gobernanza pública eficiente. Los principios de gobierno abierto de transparencia, rendición de cuentas y participación tienen el potencial de cambiar la relación entre funcionarios y ciudadanos, haciéndola más dinámica y basada en el beneficio mutuo y en la confianza recíproca. Si se implementan de manera coordinada, las reformas de gobierno abierto, más que ser un fin en sí mismas, pueden proporcionar una herramienta para alcanzar objetivos políticos más amplios. En el informe Open Government: The Global Context and the Way Forward (Gobierno abierto: el contexto global y camino a seguir), la OCDE ha actualizado su definición de gobierno abierto a «una cultura de gobierno basada en políticas públicas innovadoras y sostenibles y en prácticas inspiradas en los principios de transparencia, rendición de cuentas y participación que fomentan la democracia y el crecimiento inclusivo». La variedad de objetivos políticos que los países de la OCDE tratan de alcanzar a través de iniciativas de gobierno abierto reflejan la diversidad y naturaleza horizontal de las reformas. Por ejemplo, el principal objetivo en Alemania, Bélgica y República Checa es mejorar la transparencia del sector público. Otros países, como Australia y Canadá, van más allá del enfoque tradicional y reconocen el impacto potencial del gobierno abierto sobre el crecimiento económico. Grecia implementa iniciativas de gobierno abierto con el objetivo primordial de prevenir y luchar contra la corrupción, y Corea busca aumentar la confianza de los ciudadanos en las instituciones.

En este contexto multidimensional, una definición compartida de gobierno abierto a nivel nacional y una estrategia nacional integral permiten a los países aprovechar las contribuciones positivas que las reformas pueden aportar a los objetivos políticos nacionales, evitando al mismo tiempo las metas poco definidas. Por tanto, el acuerdo sobre una definición única por parte de todas las partes involucradas es fundamental para el éxito en la implementación. De 
todos los países de la OCDE, 17 (49\%) tienen una definición única de gobierno abierto. De ellos, $10(29 \%)$ han creado su propia definición adaptada a sus necesidades específicas, como es el caso de Canadá, Chile, Francia, Luxemburgo y Países Bajos. Por ejemplo, estos últimos describen el gobierno abierto como «transparente, facilitador y accesible», mientras que para Canadá es «una cultura de gobierno que sostiene que el público tiene el derecho de acceder a los documentos y procedimientos del gobierno para permitir mayor apertura, rendición de cuentas y compromiso». Aunque disponer de una definición única es crucial, su pleno reconocimiento por parte de todo el sector público y partes relevantes también es fundamental para alcanzar el resultado deseado, es decir, proporcionar una base sólida para una estrategia integral de gobierno abierto que permita a los países beneficiarse de estas reformas.

Se necesita una estrategia nacional coherente e integral, a medio o largo plazo, que proporcione orientación clara al Ejecutivo a nivel central y a todas las instituciones interesadas a nivel local. En la OCDE, 17 de los países (49\%) tienen un documento estratégico único (es decir, una estrategia nacional, plan de acción nacional, etc.) a su disposición. De ellos, 13 (76\%) utilizan los planes de acción bianuales de las alianzas de gobierno abierto como una base estratégica para las iniciativas. Aunque estas acciones tienen la ventaja de una implementación centrada y orientada en el impacto, solo una estrategia de gobierno abierto garantiza la alineación de las diversas iniciativas dispersas incluidas en estos planes con los objetivos políticos nacionales y resulta, por tanto, esencial para la coordinación de las Administraciones en su conjunto.

\section{Metodología y definiciones}

En 2015, la OCDE efectuó la Encuesta sobre coordinación de gobierno abierto y participación ciudadana en el ciclo político, que completaron 54 países. Todos los de la OCDE contestaron la encuesta, junto con 13 países de América Latina y el Caribe, Indonesia, Lituania, Marruecos, Filipinas, Rumanía y Túnez. Altos funcionarios de la Administración encargados de la agenda nacional de gobierno abierto contestaron la encuesta. Esta se dividió en dos partes: la primera, centrada en el enfoque existente de gobierno abierto a nivel nacional, fue contestada por la institución principal encargada de gobierno abierto; la segunda, dirigida a la detección de los enfoques existentes de participación ciudadana en el ciclo político, fue completada por los ministros de sanidad y hacienda. 


\section{Otras publicaciones}

OCDE (2016), Open Government: The Global Context and the Way Forward, OECD Publishing, París, DOI: <http://dx.doi.org/10.1787/9789264268104-en>.

\section{Notas de los gráficos}

10.1 y 10.2: Información sobre los datos de Israel: <http://dx.doi. org $/ 10.1787 / 888932315602>$.

10.3: El Gobierno de Nueva Zelanda no ha efectuado un ejercicio de priorización de las prioridades listadas. Existen elementos de todas estas prioridades en distintos programas del Gobierno, incluyendo el Programa para Mejores Resultados de los Servicios Públicos y el Plan de Acción de la Alianza para el Gobierno Abierto (los grandes retos de la AGA en el Plan de Acción de Nueva Zelanda son mejorar los servicios públicos, desarrollar la integridad pública y gestionar de manera más efectiva los recursos públicos).

Información sobre los datos de Israel: <http:/dx.doi.org/10.1787/888932315602>.

\section{Gráfico 10.1. Existencia de una única definición de gobierno abierto en el país, 2015}

No se utiliza una única definición oficial: $51 \%$

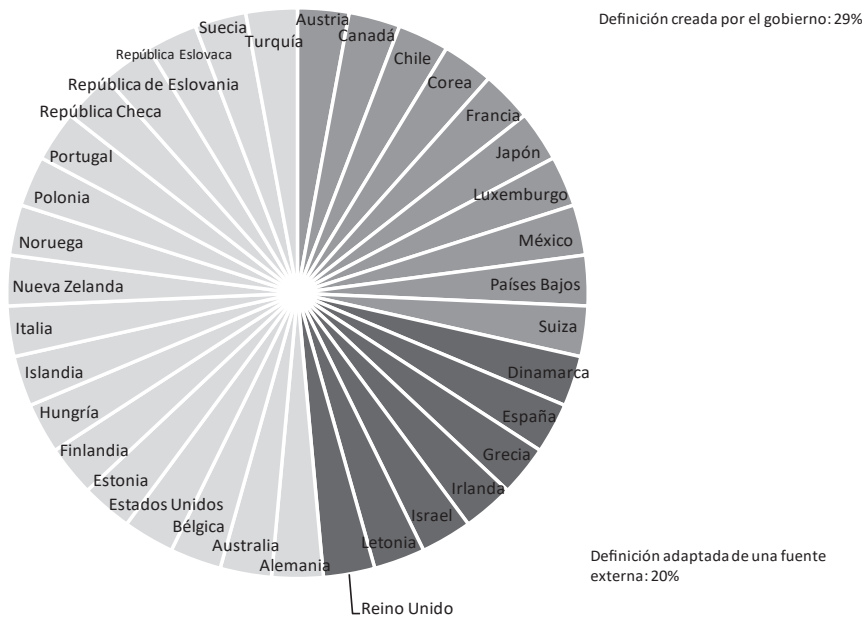

Fuente: OCDE (2015), Encuesta sobre coordinación de gobierno abierto y participación ciudadana en el ciclo político, OCDE, París. 


\section{Gráfico 10.2. Existencia de una estrategia de gobierno abierto en el país, 2015}

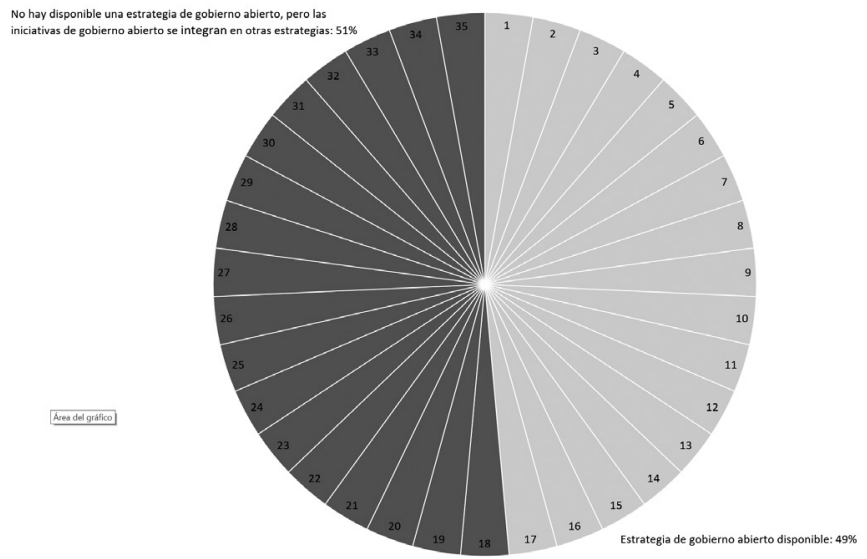

Fuente: OCDE (2015), Encuesta sobre coordinación de gobierno abierto y participación ciudadana en el ciclo político, OCDE, París.

\section{Tabla 10.3. Principales objetivos políticos de las reformas de gobierno abierto, 2015}

\begin{tabular}{|c|c|c|}
\hline $\begin{array}{c}\text { Objetivo principal en la implementación de } \\
\text { iniciativas de gobierno abierto }\end{array}$ & País & $\begin{array}{c}\text { Total } \\
\text { OCDE }\end{array}$ \\
\hline Mejorar la transparencia del sector público & $\begin{array}{c}\text { Alemania, Bélgica, Chile, Dinamarca, España, } \\
\text { Hungría, Italia, Japón, Letonia, Países Bajos, Polonia, } \\
\text { República Checa, República Eslovaca, Suiza, Turquía }\end{array}$ & 15 \\
\hline Mejorar la rendición de cuentas del sector público & Francia, Islandia, Israel & 3 \\
\hline $\begin{array}{c}\text { Mejorar la capacidad de respuesta del sector público a las } \\
\text { necesidades de ciudadanos y empresas }\end{array}$ & Luxemburgo, Suecia, Reino Unido & 3 \\
\hline $\begin{array}{c}\text { Aumentar la confianza de los ciudadanos en las instituciones } \\
\text { públicas }\end{array}$ & Corea, Irlanda, República de Eslovenia & 3 \\
\hline Mejorar la participación ciudadana en la formulación de políticas & Estonia, Finlandia & 2 \\
\hline Mejorar la efectividad del sector público & Austria, Noruega & 2 \\
\hline Mejorar la eficiencia del sector público & Estados Unidos, Portugal & 2 \\
\hline Generar crecimiento económico & Australia, Canadá & 2 \\
\hline Prevenir y luchar contra la corrupción & Grecia & 1 \\
\hline $\begin{array}{c}\text { Contribuir a superar los retos públicos, influir positivamente en } \\
\text { la calidad de vida de los ciudadanos y generar beneficios sociales }\end{array}$ & México & 1 \\
\hline Otros & Nueva Zelanda & 1 \\
\hline
\end{tabular}

Fuente: OCDE (2015), Encuesta sobre coordinación de gobierno abierto y participación ciudadana en el ciclo político, OCDE, París. 


\section{COORDINACIÓN DE GOBIERNO ABIERTO Y GESTIÓN DE RECURSOS HUMANOS}

La implementación efectiva de una estrategia de gobierno abierto depende en gran medida del contexto facilitador en el que se integran las reformas. La naturaleza transversal de dicha estrategia requiere la coordinación y liderazgo sólidos del Centro de Gobierno (CdG), junto con recursos humanos y financieros adecuados. La gobernanza efectiva de las reformas de gobierno abierto precisa además la competencia de los funcionarios para diseñar y realizar consultas públicas; responder a los ciudadanos, periodistas y sociedad civil que solicitan acceso a la información pública; y para implementar las políticas relacionadas con el gobierno abierto como, por ejemplo, la política de datos abiertos.

La mayoría de los 35 países de la OCDE (27, el 77\%) tienen una oficina dedicada a la coordinación horizontal de su estrategia e iniciativas de gobierno abierto. Aunque la existencia de dicha oficina es un elemento esencial de la coordinación eficiente, su capacidad de orientar y dirigir la implementación de la estrategia de gobierno abierto e iniciativas relacionadas depende en gran medida de un número de factores, incluyendo la ubicación de la oficina. De los 26 países de la OCDE que tienen esta oficina en funcionamiento, 16 (62\%) la sitúan en la Oficina del Jefe de Gobierno, como es el caso de Islandia e Israel, o en la Oficina del Gabinete/Cancillería/Consejo de Ministros, como Austria y Bélgica. Los 10 países restantes de la OCDE (38\%) sitúan la oficina en otros ministerios, como, por ejemplo, Finlandia, que la ubica en el Ministerio de Hacienda, o Eslovenia que la ubica en el Ministerio de Administraciones Públicas. Mientras que la OCDE no recomienda que una institución determinada esté a cargo de la agenda de gobierno abierto, la capacidad de la oficina de movilizar el apoyo político de las altas esferas y a todos los agentes relevantes de la Administración es fundamental para el éxito en la implementación de las reformas de gobierno abierto.

Las estrategias e iniciativas de gobierno abierto generan mejores resultados tangibles cuando los funcionarios que participan en su diseño e implementación son conscientes de sus beneficios. La gran mayoría de los países de la OCDE (32 de 35) reconocen la necesidad de llevar a cabo esfuerzos para conseguir cambios en el funcionamiento de las Administraciones públicas y adopta medidas para desarrollar las capacidades de los funcionarios a fin de apoyar las reformas de gobierno abierto. Un total de 18 países de la OCDE (51\%) han llevado a cabo iniciativas que van más allá de aumentar la concienciación pasiva e incorporan cursos sobre principios y prácticas de gobierno abierto en el currículum de las escuelas nacionales de formación de las Administraciones públicas. Asimismo, la mayoría de los países de la OCDE (20 de 35 , el 57\%) incluyen principios de gobierno abierto en un marco común de valores del sector público y el 66\% (23 de 35) han desarrollado manuales ad hoc y códigos de conducta. 
Además, los países promueven la implementación de las iniciativas de gobierno abierto de diversas maneras. Por ejemplo, entre otras, en Canadá, España, Estonia, Italia, Noruega y Polonia, los principios y prácticas de gobierno abierto se incluyen en los marcos de competencia de recursos humanos. Austria, Bélgica, Canadá, Corea, Finlandia, México, Noruega y República Checa incluyen los principios y prácticas de gobierno abierto en sus acuerdos sobre el rendimiento de funcionarios y en los marcos de rendición de cuentas. Exigir que los funcionarios informen públicamente (en 11 de los 35 países de la OCDE) o internamente (en 9) sobre los avances en materia de la implementación de los principios y prácticas de gobierno abierto puede proporcionar enfoques que mejoren la rendición de cuentas de los funcionarios y evitar la gestión ineficiente de los recursos humanos. Con el tiempo, todos estos enfoques pueden facilitar y fomentar que las reformas de gobierno abierto se implementen de manera oportuna, sostenible y efectiva. Sin embargo, un tercio de los países no ha tomado medidas específicas para promover la implementación de iniciativas de gobierno abierto a nivel central.

\section{Metodología y definiciones}

En 2015, la OCDE realizó la Encuesta sobre coordinación de gobierno abierto y participación ciudadana en el ciclo político, que completaron 54 países. Todos los países de la OCDE contestaron la encuesta, junto con 13 países de América Latina y el Caribe, Indonesia, Lituania, Marruecos, Filipinas, Rumania y Túnez. Altos funcionarios de la Administración encargados de la agenda nacional de gobierno abierto contestaron la encuesta.

El CdG se define por la OCDE como las instituciones y oficinas que proporcionan apoyo directo y asesoramiento al Jefe de Gobierno y al Consejo de Ministros. En la mayoría de los países, el CdG tiene tres funciones principales: apoyar al Jefe de Gobierno en la toma de decisiones de calidad, coordinar los distintos niveles de gobierno y supervisar la implementación de la estrategia de gobierno.

\section{Otras publicaciones}

OECD (2016), Open Government: The Global Context and the Way Forward, OECD Publishing, París. DOI: <http://dx.doi.org/10.1787/9789264268104-en>. 


\section{Notas de los gráficos}

10.4: En Canadá y Grecia ha habido nuevos avances en las políticas de gobierno abierto desde 2015 que no se reflejan en esta edición de Panorama de las Administraciones Públicas.

10.5: En el caso de Canadá, «otros» se refiere a materiales de formación que se están desarrollando para ayudar a los departamentos a implementar la directiva de gobierno abierto. En Grecia, en lo que respecta a la motivación, la ley establece un concurso anual para todas las personas físicas y jurídicas sobre el uso de datos públicos abiertos (desarrollo de aplicaciones basadas en el uso efectivo de estos), así como premios a la excelencia para entidades públicas que han implementado procedimientos efectivos e innovadores de datos abiertos y políticas de reutilización.

En Dinamarca ha habido nuevos avances en las políticas de gobierno abierto desde 2015 que no se reflejan en esta edición de Panorama de las Administraciones Públicas.

Información sobre los datos de Israel: <http://dx.doi.org/10.1787/888932315602>.

\section{Gráfico 10.4. Existencia de una oficina responsable de la coordinación horizontal de las iniciativas de gobierno abierto, 2015}

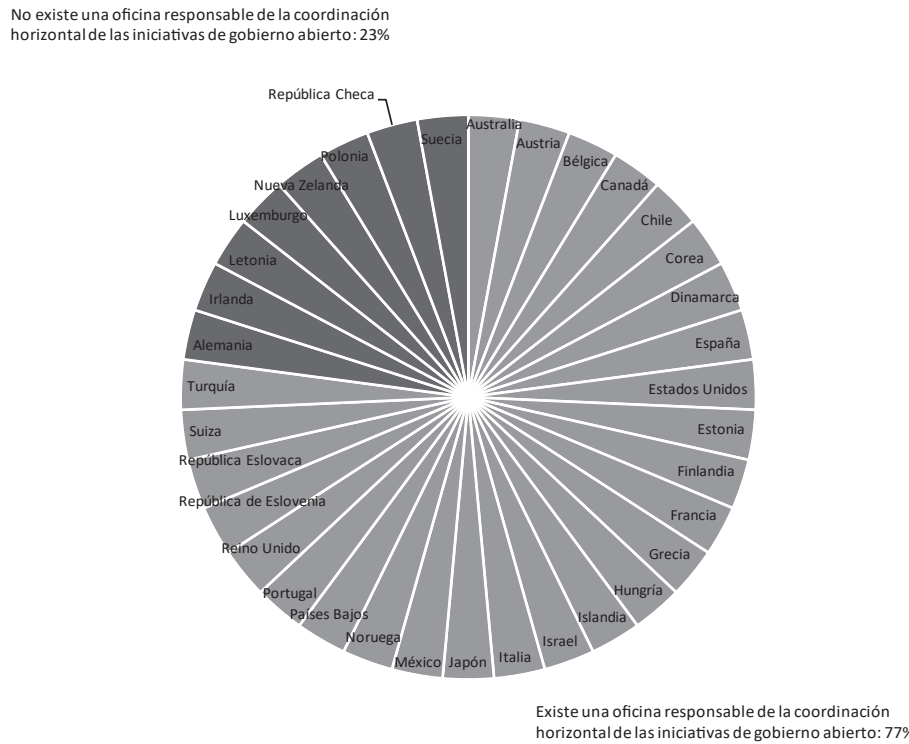

Fuente: OCDE (2015), Encuesta sobre coordinación de gobierno abierto y participación ciudadana en el ciclo político, OCDE, París. 
Tabla 10.5. Principales iniciativas para desarrollar capacidades y fomentar la implementación del gobierno abierto, 2015

\begin{tabular}{|c|c|c|c|c|c|c|c|c|c|}
\hline \multirow{2}{*}{\begin{tabular}{|c|} 
\\
País
\end{tabular}} & \multirow[b]{2}{*}{ 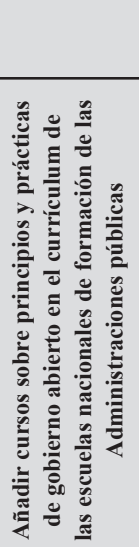 } & \multicolumn{4}{|c|}{$\begin{array}{c}\text { Desarrollar las capacidades de los } \\
\text { funcionarios }\end{array}$} & \multicolumn{4}{|c|}{$\begin{array}{c}\text { Fomentar la implementación de iniciativas de } \\
\text { gobierno abierto }\end{array}$} \\
\hline & & 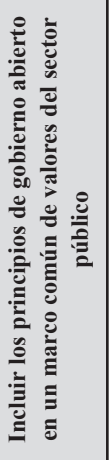 & 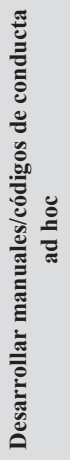 & 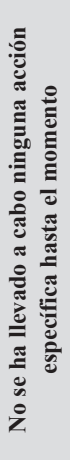 & 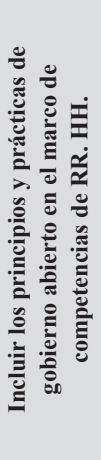 & 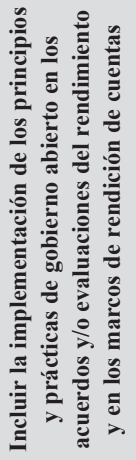 & 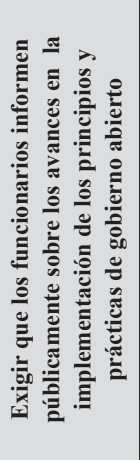 & 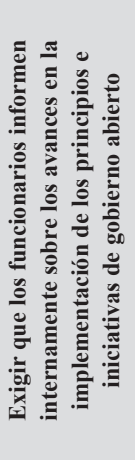 & 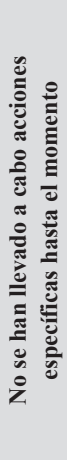 \\
\hline Alemania & $\bullet$ & ० & $\bullet$ & 0 & $\circ$ & 0 & $\bullet$ & $\bullet$ & o \\
\hline Australia & ० & $\bullet$ & $\bullet$ & 0 & 0 & o & $\bullet$ & $\circ$ & O \\
\hline Austria & $\bullet$ & 0 & $\bullet$ & $\circ$ & o & $\bullet$ & o & $\circ$ & 0 \\
\hline Bélgica & o & o & o & - & 0 & - & o & o & - \\
\hline Canadá & $\circ$ & ० & $\circ$ & 0 & $\bullet$ & - & - & $\bullet$ & o \\
\hline Chile & $\circ$ & $\bullet$ & $\bullet$ & ० & o & $\circ$ & - & o & o \\
\hline Corea & $\bullet$ & o & $\bullet$ & o & ○ & $\bullet$ & o & $\bullet$ & o \\
\hline Dinamarca & o & o & - & $\bullet$ & 0 & $\circ$ & o & $\circ$ & - \\
\hline España & $\bullet$ & $\bullet$ & $\bullet$ & $\circ$ & $\bullet$ & 0 & $\bullet$ & - & ० \\
\hline $\begin{array}{l}\text { Estados } \\
\text { Unidos }\end{array}$ & - & - & - & - & - & - & - & - & - \\
\hline Estonia & ० & $\bullet$ & - & ० & - & $\circ$ & o & 0 & 0 \\
\hline Finlandia & - & $\bullet$ & $\bullet$ & 0 & 0 & $\bullet$ & - & - & 0 \\
\hline Francia & - & $\bullet$ & o & ० & o & 0 & - & ० & o \\
\hline Grecia & $\bullet$ & $\bullet$ & - & 0 & $\circ$ & $\circ$ & o & $\circ$ & $\circ$ \\
\hline Hungría & $\bullet$ & $\bullet$ & $\bullet$ & o & $\bullet$ & $\circ$ & ० & ० & ० \\
\hline Irlanda & 0 & $\bullet$ & $\bullet$ & $\circ$ & $\circ$ & $\circ$ & $\bullet$ & - & 0 \\
\hline Islandia & - & 0 & - & 0 & 0 & 0 & o & o & - \\
\hline Israel & $\circ$ & $\bullet$ & - & o & $\circ$ & 0 & 0 & $\circ$ & - \\
\hline Italia & $\bullet$ & o & $\bullet$ & 0 & $\bullet$ & $\circ$ & $\bullet$ & o & o \\
\hline Japón & $\circ$ & o & • & o & $\circ$ & $\circ$ & o & $\bullet$ & o \\
\hline Letonia & - & $\bullet$ & - & $\circ$ & o & $\circ$ & o & $\bullet$ & o \\
\hline Luxemburgo & $\circ$ & $\bullet$ & - & $\circ$ & o & o & o & $\circ$ & $\bullet$ \\
\hline México & - & $\bullet$ & $\bullet$ & ० & o & - & - & - & o \\
\hline Noruega & $\bullet$ & $\bullet$ & o & o & $\bullet$ & $\bullet$ & o & ० & o \\
\hline
\end{tabular}




\begin{tabular}{|c|c|c|c|c|c|c|c|c|c|}
\hline \multirow[b]{2}{*}{ País } & \multirow[b]{2}{*}{ 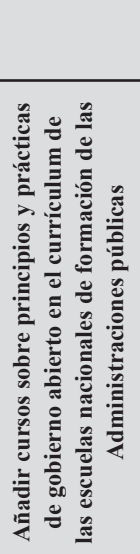 } & \multicolumn{4}{|c|}{$\begin{array}{l}\text { Desarrollar las capacidades de los } \\
\text { funcionarios }\end{array}$} & \multicolumn{4}{|c|}{$\begin{array}{c}\text { Fomentar la implementación de iniciativas de } \\
\text { gobierno abierto }\end{array}$} \\
\hline & & 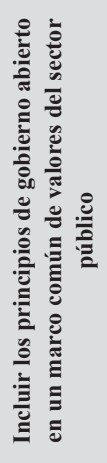 & 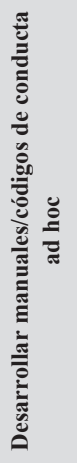 & 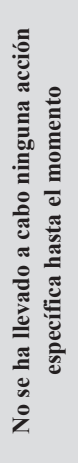 & 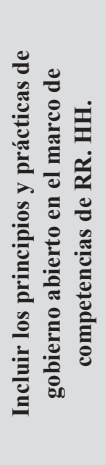 & 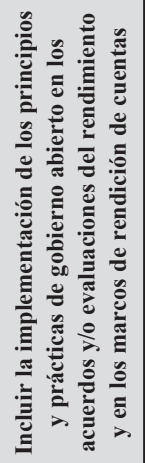 & 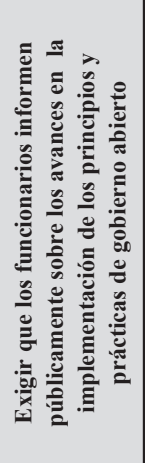 & 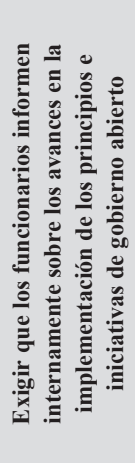 & 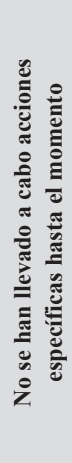 \\
\hline $\begin{array}{c}\text { Nueva } \\
\text { Zelanda }\end{array}$ & $\circ$ & $\circ$ & $\bullet$ & $\circ$ & $\circ$ & $\circ$ & $\circ$ & $\circ$ & $\bullet$ \\
\hline Países Bajos & $\bullet$ & - & $\bullet$ & $\circ$ & $\circ$ & $\circ$ & $\circ$ & $\circ$ & $\bullet$ \\
\hline Polonia & $\bullet$ & $\bullet$ & $\circ$ & $\circ$ & $\bullet$ & $\circ$ & $\circ$ & $\circ$ & $\circ$ \\
\hline Portugal & $\circ$ & $\bullet$ & $\circ$ & $\circ$ & $\circ$ & $\circ$ & $\circ$ & $\circ$ & $\bullet$ \\
\hline Reino Unido & $\bullet$ & $\circ$ & $\bullet$ & $\circ$ & $\circ$ & $\circ$ & $\bullet$ & $\circ$ & $\circ$ \\
\hline $\begin{array}{l}\text { República } \\
\text { Checa }\end{array}$ & $\circ$ & $\bullet$ & $\circ$ & $\circ$ & $\circ$ & $\bullet$ & $\circ$ & $\circ$ & $\circ$ \\
\hline $\begin{array}{l}\text { República de } \\
\text { Eslovenia }\end{array}$ & $\bullet$ & $\circ$ & ○ & $\circ$ & $\circ$ & $\circ$ & $\circ$ & $\circ$ & $\bullet$ \\
\hline $\begin{array}{l}\text { República } \\
\text { Eslovaca }\end{array}$ & $\circ$ & $\circ$ & $\circ$ & $\bullet$ & $\circ$ & $\circ$ & $\circ$ & $\bullet$ & ○ \\
\hline Suecia & $\bullet$ & $\bullet$ & $\bullet$ & $\circ$ & $\circ$ & $\circ$ & $\circ$ & $\circ$ & $\bullet$ \\
\hline Suiza & $\circ$ & $\circ$ & $\bullet$ & $\circ$ & $\circ$ & $\circ$ & $\circ$ & $\circ$ & $\bullet$ \\
\hline Turquía & $\circ$ & $\bullet$ & $\circ$ & $\circ$ & $\circ$ & $\circ$ & $\circ$ & $\circ$ & $\bullet$ \\
\hline Total OCDE & 18 & 20 & 24 & 3 & 7 & 8 & 11 & 10 & 12 \\
\hline Sí & $\bullet$ & & & & & & & & \\
\hline No & $\circ$ & & & & & & & & \\
\hline No sabe & - & & & & & & & & \\
\hline
\end{tabular}

Fuente: OCDE (2015), Encuesta sobre coordinación de gobierno abierto y participación ciudadana en el ciclo político, OCDE, París. 


\section{SEGUIMIENTO Y EVALUACIÓN DE LAS ESTRATEGIAS DE GOBIERNO ABIERTO}

Los mecanismos de seguimiento y evaluación que las Administraciones públicas tienen a su disposición son cruciales para mejorar el diseño e implementación de las políticas en materia de transparencia, rendición de cuentas y participación ciudadana. La OCDE define el seguimiento como «una función continua que consiste en la recopilación sistemática de datos de indicadores específicos a fin de suministrar a la Administración y principales partes interesadas de una intervención [...] en marcha con indicaciones sobre el grado de avance y logro de los objetivos e información sobre la utilización de los fondos asignados» (OCDE, 2009). La evaluación se define como «la evaluación sistemática y objetiva de un proyecto, programa o política en marcha o finalizado, de su diseño, implementación y resultados. Tiene como objetivo determinar la relevancia y cumplimiento de los objetivos, [...] la eficacia, efectividad, impacto y sostenibilidad. Una evaluación debe proporcionar información que sea creíble y útil, facilitando la incorporación de las lecciones aprendidas en el proceso de decisión de los receptores y donantes» (OCDE, 2009).

Sin sistemas sólidos de seguimiento y evaluación, las estrategias e iniciativas de gobierno abierto no podrán cumplir sus promesas de mejorar la democracia y promover el crecimiento inclusivo. El carácter intersectorial de la estrategia de gobierno abierto implica un alto grado de complejidad para desarrollar una visión consolidada de sus impactos en todos los sectores. Requiere además un entendimiento sólido sobre cómo las iniciativas políticas propias de cada sector están relacionadas con las metas comunes de la estrategia. Los países se enfrentan, por tanto, al reto de diseñar enfoques apropiados de seguimiento y evaluación que desenreden esta complejidad.

La mayoría de los países de la OCDE (30 de 35, el 86\%) supervisan las iniciativas de gobierno abierto. En muchos casos (77\%), los países dependen de las actividades normales de seguimiento que realiza cada institución pública involucrada en las iniciativas de gobierno abierto. Además, los miembros de la Alianza para el Gobierno Abierto (AGA) utilizan el Mecanismo de Revisión Independiente (MRI) de esta o llevan a cabo la autoevaluación anual que esta alianza requiere. Varios países utilizan otros tipos de mecanismos de seguimiento que incluyen el establecimiento de una institución específica, un mecanismo ad hoc o una oficina encargada de todas las iniciativas de gobierno abierto. Por ejemplo, 9 de los 30 países de la OCDE contestaron que tenían en marcha mecanismos de seguimiento ad hoc para las iniciativas de gobierno abierto. En Finlandia consiste en un Grupo de Apoyo a la Implementación de Gobierno Abierto y en el Reino Unido en una Red de Gobierno Abierto. Normalmente, las actividades de estos comités apoyan el trabajo de la oficina encargada del gobierno abierto, garantizando que todas las partes interesadas del sector público, sociedad civil y sector privado contribuyen al desarrollo e 
implementación de políticas e iniciativas de gobierno abierto. Aunque el seguimiento es esencial para garantizar una implementación adecuada, solo una evaluación exhaustiva de los impactos positivos y negativos de la estrategia e iniciativas de gobierno abierto ofrece a los responsables políticos la oportunidad de mejorar los resultados actuales a través del diseño e implementación de planes futuros.

Sin embargo, aunque la mayoría de los países de la OCDE recogen datos sobre el progreso de las iniciativas de gobierno abierto, solo cerca de la mitad (20 países, el 59\%) utilizan los datos para evaluar su impacto. De estos países, 16 de los 19 (84\%) con datos disponibles utilizan las actividades de evaluación de cada institución pública. Las ONG participan en el proceso evaluativo de 5 de los 19 países de la OCDE que especificaron el enfoque usado para la evaluación del impacto (Canadá, España, Estados Unidos, México y República Checa). En línea con los enfoques de seguimiento, los países miembros de la OCDE-AGA que evalúan el impacto de las iniciativas de gobierno abierto utilizan el Mecanismo de Revisión Independiente y los informes de autoevaluación de la AGA. La falta de evidencia sobre el impacto de las estrategias e iniciativas de gobierno abierto dificulta el progreso de los países en el diseño e implementación de planteamientos que se ajusten mejor a las necesidades tanto de las partes interesadas como de los ciudadanos.

\section{Metodología y definiciones}

En 2015, la OCDE realizó la Encuesta sobre coordinación de gobierno abierto y participación ciudadana en el ciclo político, que completaron 54 países.

Los mecanismos ad hoc pueden adoptar diferentes formas en los países de la OCDE. Dependiendo de la base y mandato institucional del mecanismo ad hoc, sus funciones pueden incluir el seguimiento, la evaluación y la coordinación. Pueden consistir en un Comité Directivo del Gobierno, un Grupo de Apoyo a la Implementación de Gobierno Abierto o una Red de Gobierno Abierto.

\section{Otras publicaciones}

OECD (2016), Open Government: The Global Context and the Way Forward, OECD Publishing, París. DOI: <http://dx.doi.org/10.1787/9789264268104-en>. 


\section{Notas de los gráficos}

10.6: Información sobre los datos de Israel: <http://dx.doi. org $/ 10.1787 / 888932315602>$.

10.7: Luxemburgo no proporcionó una respuesta a esta pregunta.

Información sobre los datos de Israel: <http://dx.doi.org/10.1787/888932315602>.

10.8: Se preguntaron estas cuestiones sobre el enfoque de evaluación del impacto solo a los países que contestaron que evaluaban las iniciativas de gobierno abierto. Turquía sí evalúa las iniciativas de gobierno abierto, pero no contestó las preguntas.

Información sobre los datos de Israel: <http://dx.doi.org/10.1787/888932315602>.

\section{Gráfico 10.6. Seguimiento de las iniciativas de gobierno abierto, 2015}

No: $14 \%$

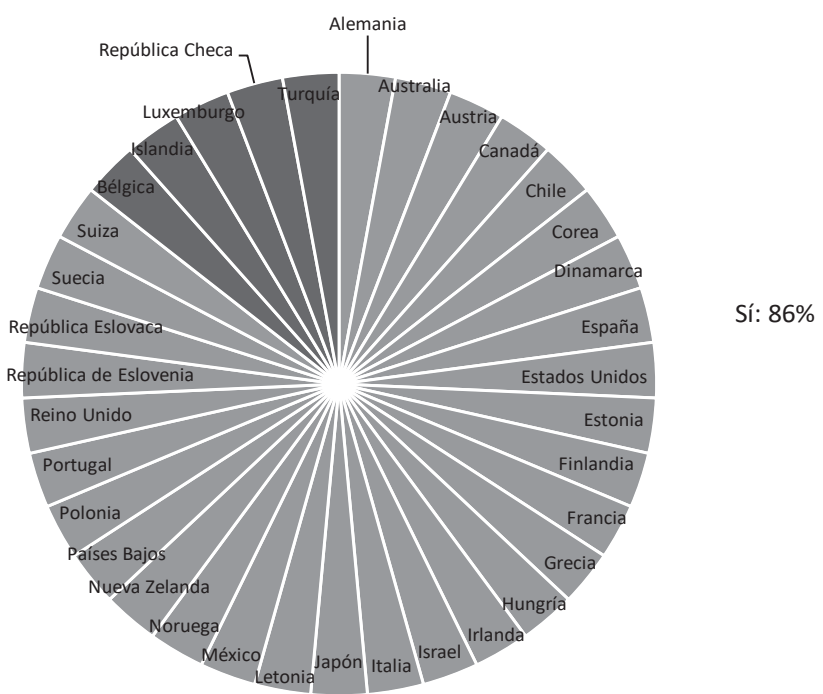

Fuente: OCDE (2015), Encuesta sobre coordinación de gobierno abierto y participación ciudadana en el ciclo político, OCDE, París. 


\section{Gráfico 10.7. Evaluación del impacto de las iniciativas de gobierno abierto, 2015}

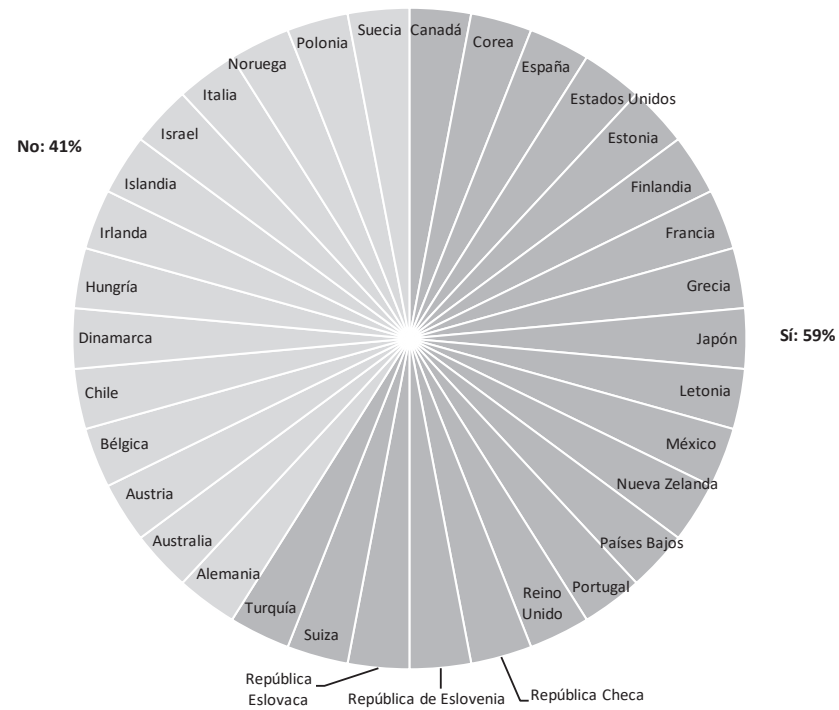

Fuente: OCDE (2015), Encuesta sobre coordinación de gobierno abierto y participación ciudadana en el ciclo político, OCDE, París.

$<$ http://dx.doi.org/10.1787/888933533340>

Tabla 10.8. Enfoques de evaluación del impacto de las iniciativas de gobierno abierto, 2015

\begin{tabular}{|c|c|c|c|c|c|c|c|c|}
\hline & \multicolumn{8}{|c|}{ Evaluación del impacto de las iniciativas de gobierno abierto mediante... } \\
\hline País & 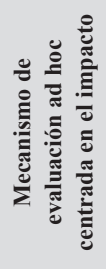 & 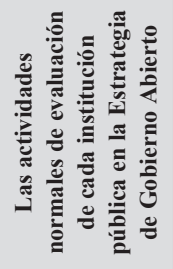 & 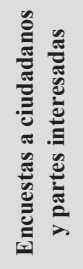 & 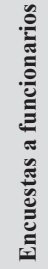 & 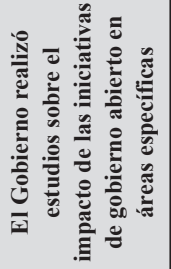 & 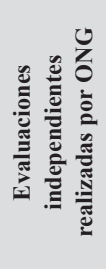 & 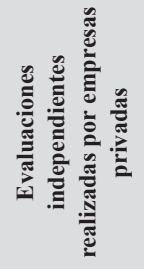 & 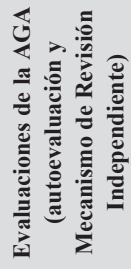 \\
\hline Canadá & $\circ$ & $\circ$ & $\circ$ & $\circ$ & $\circ$ & $\bullet$ & $\circ$ & $\bullet$ \\
\hline Corea & $\circ$ & $\bullet$ & $\circ$ & $\circ$ & $\circ$ & $\circ$ & $\circ$ & $\bullet$ \\
\hline España & ० & $\bullet$ & $\bullet$ & $\circ$ & $\bullet$ & $\bullet$ & $\bullet$ & $\bullet$ \\
\hline $\begin{array}{c}\text { Estados } \\
\text { Unidos }\end{array}$ & $\circ$ & $\bullet$ & $\circ$ & $\circ$ & $\circ$ & $\bullet$ & $\circ$ & $\bullet$ \\
\hline Estonia & ० & $\bullet$ & $\bullet$ & $\circ$ & $\circ$ & $\circ$ & $\circ$ & $\bullet$ \\
\hline Finlandia & $\circ$ & $\bullet$ & $\circ$ & $\bullet$ & $\circ$ & $\circ$ & ० & $\bullet$ \\
\hline
\end{tabular}




\begin{tabular}{|c|c|c|c|c|c|c|c|c|}
\hline & \multicolumn{8}{|c|}{ Evaluación del impacto de las iniciativas de gobierno abierto mediante... } \\
\hline País & 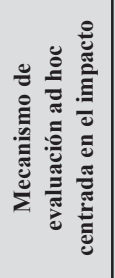 & 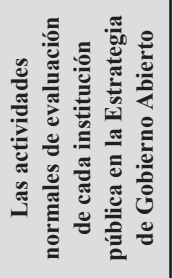 & 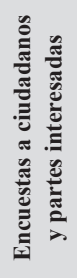 & 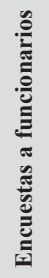 & 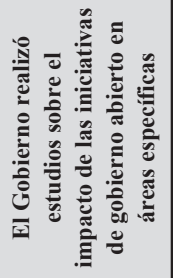 & 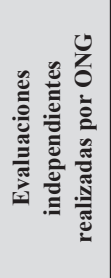 & 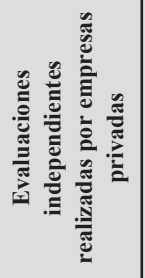 & 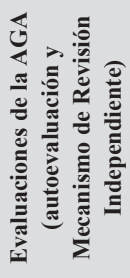 \\
\hline Francia & $\bullet$ & $\bullet$ & $\circ$ & $\circ$ & $\circ$ & $\circ$ & $\circ$ & $\bullet$ \\
\hline Grecia & $\bullet$ & $\bullet$ & $\bullet$ & $\bullet$ & $\bullet$ & $\circ$ & $\circ$ & $\bullet$ \\
\hline Japón & ○ & $\circ$ & $\bullet$ & $\circ$ & $\circ$ & $\circ$ & $\circ$ & $\circ$ \\
\hline Letonia & $\circ$ & $\bullet$ & $\circ$ & $\circ$ & $\circ$ & $\circ$ & $\circ$ & $\bullet$ \\
\hline México & $\bullet$ & $\bullet$ & $\circ$ & $\bullet$ & $\circ$ & • & $\circ$ & $\bullet$ \\
\hline $\begin{array}{l}\text { Nueva } \\
\text { Zelanda }\end{array}$ & $\circ$ & $\bullet$ & $\circ$ & $\circ$ & ० & $\circ$ & ० & $\bullet$ \\
\hline Países Bajos & $\circ$ & $\bullet$ & $\circ$ & $\circ$ & $\circ$ & $\circ$ & $\circ$ & $\bullet$ \\
\hline Portugal & $\circ$ & - & $\circ$ & $\circ$ & $\circ$ & $\circ$ & $\circ$ & $\circ$ \\
\hline Reino Unido & $\circ$ & $\bullet$ & $\circ$ & $\circ$ & $\circ$ & $\circ$ & $\circ$ & $\bullet$ \\
\hline $\begin{array}{l}\text { República } \\
\text { Checa }\end{array}$ & ० & $\bullet$ & $\bullet$ & $\circ$ & ० & $\bullet$ & $\circ$ & $\bullet$ \\
\hline $\begin{array}{c}\text { República de } \\
\text { Eslovenia }\end{array}$ & $\circ$ & $\bullet$ & $\circ$ & $\circ$ & ० & $\circ$ & $\circ$ & $\circ$ \\
\hline $\begin{array}{l}\text { República } \\
\text { Eslovaca }\end{array}$ & $\circ$ & $\bullet$ & $\circ$ & $\circ$ & ० & $\circ$ & $\circ$ & $\bullet$ \\
\hline Suiza & $\bullet$ & $\circ$ & $\circ$ & $\circ$ & $\circ$ & $\circ$ & $\circ$ & $\circ$ \\
\hline Total OCDE & 4 & 16 & 5 & 3 & 2 & 5 & 1 & 15 \\
\hline Sí & $\bullet$ & & & & & & & \\
\hline No & $\circ$ & & & & & & & \\
\hline
\end{tabular}

Fuente: OCDE (2015), Encuesta sobre coordinación de gobierno abierto y participación ciudadana en el ciclo político, OCDE, París. 


\section{PARTICIPACIÓN CIUDADANA EN LA FORMULACIÓN DE POLÍTICAS}

La participación efectiva de los ciudadanos en la formulación de políticas es un aspecto esencial de las reformas de gobierno abierto y tiene el potencial de renovar las relaciones existentes entre los responsables políticos y los ciudadanos. Ante el declive en los niveles de participación electoral, pertenencia a partidos políticos y confianza en las instituciones públicas, los gobiernos reconocen la necesidad de complementar su función de proveedor de servicios mediante alianzas estrechas con las partes interesadas relevantes.

Un documento general sobre la participación ciudadana en la elaboración de políticas, es decir, un manual, guía o estrategia común, proporciona un paso importante en el desarrollo de un enfoque más global. Los funcionarios y ciudadanos posiblemente abordan los procesos participativos desde distintas perspectivas conceptuales y un documento de estrategia integral ayudaría a aunar las posturas. Para garantizar su coherencia, las estrategias de participación ciudadana deben ser integradas en los esfuerzos nacionales de gobierno abierto. Sin embargo, menos de la mitad de los países de la OCDE (16, el 46\%) han desarrollado este tipo de documento.

Que las políticas se traduzcan en mejoras tangibles para los ciudadanos depende en gran medida del alcance y tiempos de su participación en las distintas fases del ciclo político. La mayoría de los ministerios de hacienda encuestados $(22$, el $73 \%)$ dan a los ciudadanos la oportunidad de proporcionar retroalimentación sobre el funcionamiento de los servicios. En los ministerios de sanidad de Israel, Japón y Luxemburgo, la participación ciudadana es más prominente, y en 18 de los 24 ministerios $(75 \%)$ intervienen en la fase inicial de formulación de las políticas. Sin embargo, en estos ministerios la participación ciudadana en la evaluación del impacto de las políticas permanece por debajo del $50 \%$.

Si se comparan los diferentes niveles de participación ciudadana en la formulación de políticas, la encuesta muestra que los ministerios que proporcionan servicios, como los de sanidad, consultan a los ciudadanos de manera más activa. Esto es especialmente cierto en la fase inicial de identificación de prioridades políticas, así como en la fase de implementación. La fase de retroalimentación es la única en la que la participación ciudadana en iniciativas de los ministerios de hacienda excede los resultados de los ministerios de sanidad. Además de consultar a los ciudadanos, el Ministerio de Sanidad de Suecia utiliza la retroalimentación de organizaciones no gubernamentales, otros grupos de apoyo a pacientes y mayores, y de representantes de distintas regiones. En 28 de los 30 ministerios de hacienda (93\%) y en todos los ministerios de sanidad, los ciudadanos están involucrados en alguna/s fase/s del ciclo político. Sin embargo, los países no hacen todavía un uso óptimo de la retroalimentación de los ciudadanos para evaluar si su participación en la formulación de políticas tiene un impacto positivo en estas y, por tanto, en su calidad de vida. 


\section{Metodología y definiciones}

En 2015, la OCDE realizó la Encuesta sobre coordinación de gobierno abierto y participación ciudadana en el ciclo político, que completaron 54 países. Todos los países de la OCDE contestaron la encuesta, junto con 13 países de América Latina y el Caribe, Indonesia, Lituania, Marruecos, Filipinas, Rumania y Túnez. Altos funcionarios de la Administración encargados de la agenda nacional de gobierno abierto contestaron la encuesta. Esta se dividió en dos partes: la primera, centrada en el enfoque existente de gobierno abierto a nivel nacional, fue contestada por la institución principal encargada de gobierno abierto; la segunda, centrada en la detección de los enfoques existentes de participación ciudadana en el ciclo político, fue completada por los ministros de sanidad y hacienda. En total, 32 ministerios de hacienda y 25 de sanidad contestaron la encuesta. No todos los ministerios proporcionaron respuestas a todas las preguntas, lo cual explica los huecos en el Gráfico 10.10.

\section{Otras publicaciones}

OECD (2016), Open Government: The Global Context and the Way Forward, OECD Publishing, París. DOI: <http://dx.doi.org/10.1787/9789264268104-en>.

OECD (2009), Measuring Government Activity, OECD Publishing, París, $<\mathrm{http} / / / \mathrm{dx}$.doi.org/10.1787/9789264060784-en>.

Involve (2009), Open Government: beyond static measures, <http://www.oecd. org/gov/46560184.pdf>.

\section{Notas de los gráficos}

10.9: Esta pregunta la contestaron las principales instituciones responsables de la coordinación de gobierno abierto.

Información sobre los datos de Israel: <http://dx.doi. org $/ 10.1787 / 888932315602>$.

10.10: MH: Ministerio de Hacienda; MS: Ministerio de Sanidad; N/A: El ministerio no contestó la encuesta o a esta pregunta. Los ministerios de Corea, Estados Unidos y Letonia no contestaron a la encuesta o a esta pregunta en particular.

Información sobre los datos de Israel: <http://dx.doi.org/10.1787/888932315602>. 
Gráfico 10.9. Existencia de un documento general sobre la participación ciudadana, 2015

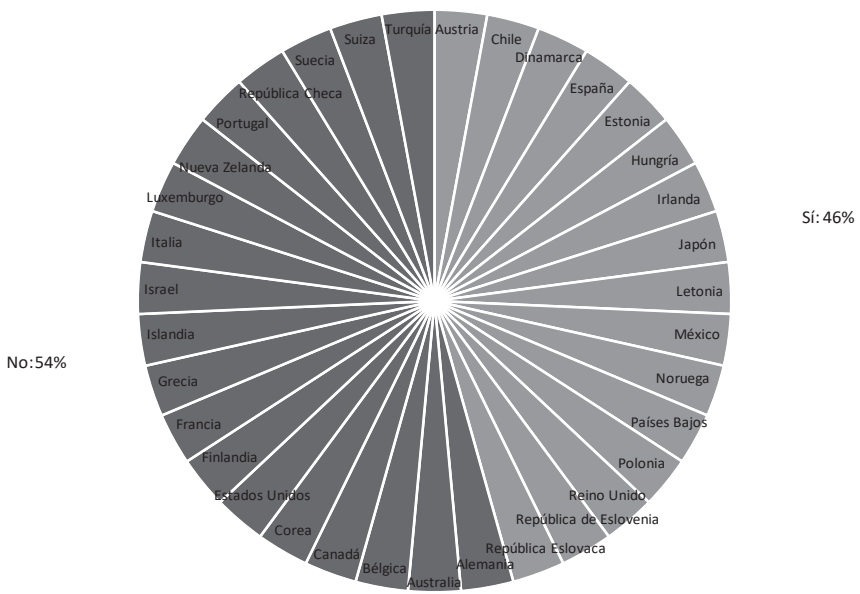

Fuente: OCDE (2015), Encuesta sobre coordinación de gobierno abierto y participación ciudadana en el ciclo político, OCDE, París.

$<$ http://dx.doi.org/10.1787/888933533359>

Tabla 10.10. Involucración de los ciudadanos en el ciclo político en los ministerios centrales/federales de hacienda y sanidad, 2015

\begin{tabular}{|c|c|c|c|c|c|c|c|c|c|c|c|c|}
\hline \multirow[t]{2}{*}{ País } & \multicolumn{2}{|c|}{ 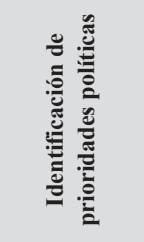 } & \multicolumn{2}{|c|}{ 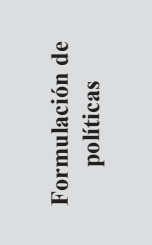 } & \multicolumn{2}{|c|}{ 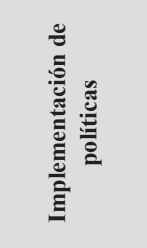 } & \multicolumn{2}{|c|}{ 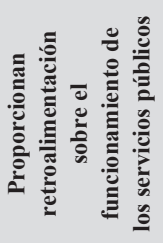 } & \multicolumn{2}{|c|}{ 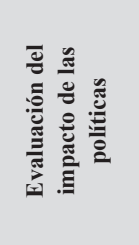 } & \multicolumn{2}{|c|}{ 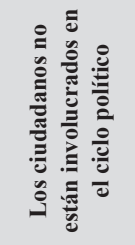 } \\
\hline & МH & MS & MH & MS & МH & MS & МH & MS & МH & MS & MH & MS \\
\hline Alemania & ○ & $\bullet$ & ० & $\bullet$ & $\circ$ & $\bullet$ & $\circ$ & $\circ$ & $\circ$ & $\circ$ & $\circ$ & \\
\hline Australia & $\circ$ & $\circ$ & ० & $\circ$ & $\circ$ & $\bullet$ & $\bullet$ & $\bullet$ & $\circ$ & $\bullet$ & $\circ$ & \\
\hline Austria & $\circ$ & $\bullet$ & ० & $\bullet$ & $\bullet$ & $\bullet$ & - & $\bullet$ & ० & $\circ$ & $\circ$ & \\
\hline Bélgica & $\circ$ & $\bullet$ & $\circ$ & $\bullet$ & $\circ$ & ० & ० & $\bullet$ & $\bullet$ & - & $\circ$ & \\
\hline Canadá & ○ & $\circ$ & $\bullet$ & $\circ$ & ○ & $\bullet$ & $\circ$ & $\bullet$ & $\circ$ & $\bullet$ & $\circ$ & \\
\hline Chile & $\circ$ & N.A. & $\circ$ & N.A. & $\circ$ & N.A. & • & N.A. & $\circ$ & N.A. & $\circ$ & \\
\hline Dinamarca & $\circ$ & N.A. & $\bullet$ & N.A. & $\bullet$ & N.A. & $\bullet$ & N.A. & ० & N.A. & ० & \\
\hline Estonia & $\circ$ & $\bullet$ & • & $\bullet$ & ० & $\bullet$ & $\bullet$ & $\bullet$ & ० & $\bullet$ & $\circ$ & \\
\hline Finlandia & $\bullet$ & $\bullet$ & $\bullet$ & $\bullet$ & $\bullet$ & $\bullet$ & $\bullet$ & $\bullet$ & ० & • & ० & \\
\hline Francia & o & $\bullet$ & • & $\bullet$ & $\bullet$ & • & $\bullet$ & $\circ$ & $\circ$ & $\bullet$ & $\circ$ & \\
\hline
\end{tabular}




\begin{tabular}{|c|c|c|c|c|c|c|c|c|c|c|c|c|}
\hline \multirow[t]{2}{*}{ País } & \multicolumn{2}{|c|}{ 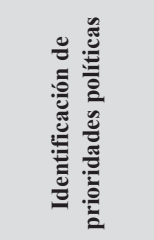 } & \multicolumn{2}{|c|}{ 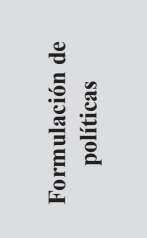 } & \multicolumn{2}{|c|}{ 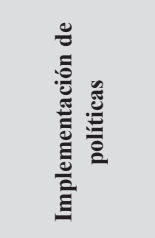 } & \multicolumn{2}{|c|}{ 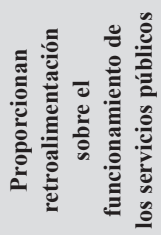 } & \multicolumn{2}{|c|}{ 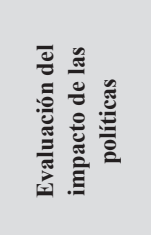 } & \multicolumn{2}{|c|}{ 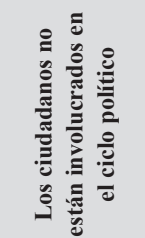 } \\
\hline & Мн & MS & Мн & MS & Мн & MS & MH & MS & Мн & MS & Мн & MS \\
\hline Grecia & $\circ$ & $\circ$ & $\bullet$ & $\bullet$ & $\circ$ & $\circ$ & • & • & $\circ$ & $\circ$ & $\circ$ & \\
\hline Hungría & $\bullet$ & $\circ$ & $\circ$ & $\bullet$ & $\circ$ & $\circ$ & $\bullet$ & $\bullet$ & $\circ$ & $\bullet$ & $\circ$ & \\
\hline Irlanda & $\circ$ & N.A. & $\bullet$ & N.A. & $\circ$ & N.A. & 0 & N.A. & $\bullet$ & N.A. & ० & \\
\hline Islandia & $\circ$ & $\circ$ & $\circ$ & $\bullet$ & $\circ$ & $\bullet$ & $\bullet$ & $\bullet$ & $\circ$ & $\circ$ & $\circ$ & \\
\hline Israel & $\circ$ & $\circ$ & $\bullet$ & $\bullet$ & $\circ$ & $\circ$ & $\circ$ & $\bullet$ & $\circ$ & $\bullet$ & $\circ$ & \\
\hline Italia & $\circ$ & N.A. & $\circ$ & N.A. & $\circ$ & N.A. & $\circ$ & N.A. & $\circ$ & N.A. & $\bullet$ & \\
\hline Japón & $\circ$ & $\circ$ & $\circ$ & $\bullet$ & $\circ$ & $\circ$ & $\circ$ & $\circ$ & $\circ$ & $\circ$ & $\bullet$ & \\
\hline Luxemburgo & - & - & $\circ$ & - & $\circ$ & - & - & - & - & $\circ$ & $\circ$ & \\
\hline México & $\bullet$ & $\circ$ & $\circ$ & $\circ$ & $\bullet$ & $\circ$ & $\bullet$ & $\bullet$ & $\bullet$ & $\circ$ & $\circ$ & $\circ$ \\
\hline Noruega & $\circ$ & N.A. & $\bullet$ & N.A. & $\circ$ & N.A. & - & N.A. & - & N.A. & $\circ$ & N.A. \\
\hline $\begin{array}{c}\text { Nueva } \\
\text { Zelanda }\end{array}$ & $\bullet$ & $\bullet$ & $\bullet$ & $\circ$ & $\bullet$ & ○ & $\bullet$ & ० & $\bullet$ & ○ & $\circ$ & $\circ$ \\
\hline Países Bajos & ० & N.A. & - & N.A. & $\circ$ & N.A. & - & N.A. & • & N.A. & $\circ$ & N.A. \\
\hline Polonia & N.A. & $\bullet$ & N.A. & $\bullet$ & N.A. & $\bullet$ & N.A. & $\bullet$ & N.A. & $\bullet$ & N.A. & $\circ$ \\
\hline Portugal & $\bullet$ & $\bullet$ & $\bullet$ & $\bullet$ & $\circ$ & $\bullet$ & $\bullet$ & $\bullet$ & $\circ$ & $\circ$ & $\circ$ & $\circ$ \\
\hline Reino Unido & $\bullet$ & $\bullet$ & $\circ$ & $\bullet$ & $\bullet$ & $\bullet$ & $\bullet$ & $\bullet$ & $\bullet$ & $\bullet$ & $\circ$ & $\circ$ \\
\hline $\begin{array}{l}\text { República } \\
\text { Checa }\end{array}$ & - & - & $\bullet$ & $\bullet$ & $\bullet$ & $\circ$ & $\bullet$ & $\circ$ & $\bullet$ & $\bullet$ & $\circ$ & \\
\hline $\begin{array}{l}\text { República } \\
\text { Eslovaca }\end{array}$ & N.A. & $\circ$ & N.A. & $\bullet$ & N.A. & $\bullet$ & N.A. & - & N.A. & $\circ$ & N.A. & $\circ$ \\
\hline $\begin{array}{l}\text { República de } \\
\text { Eslovenia }\end{array}$ & $\bullet$ & N.A. & $\bullet$ & N.A. & $\circ$ & N.A. & $\bullet$ & N.A. & $\circ$ & N.A. & $\circ$ & N.A. \\
\hline España & $\bullet$ & $\circ$ & $\bullet$ & $\bullet$ & $\bullet$ & $\circ$ & $\bullet$ & $\circ$ & $\bullet$ & $\circ$ & $\circ$ & $\circ$ \\
\hline Suecia & $\circ$ & $\bullet$ & $\bullet$ & $\circ$ & - & $\circ$ & $\circ$ & $\bullet$ & $\circ$ & o & $\circ$ & $\circ$ \\
\hline Suiza & ० & $\bullet$ & $\bullet$ & $\circ$ & $\bullet$ & $\circ$ & $\bullet$ & $\circ$ & $\bullet$ & $\circ$ & $\circ$ & $\circ$ \\
\hline Turquía & $\circ$ & N.A. & $\bullet$ & N.A. & $\bullet$ & N.A. & $\bullet$ & N.A. & $\bullet$ & N.A. & $\circ$ & N.A. \\
\hline Total OCDE & 10 & 14 & 18 & 18 & 12 & 13 & 22 & 17 & 12 & 11 & 2 & 0 \\
\hline Sí & $\bullet$ & & & & & & & & & & & \\
\hline No & o & & & & & & & & & & & \\
\hline
\end{tabular}

Fuente: OCDE (2015), Encuesta sobre coordinación de gobierno abierto y participación ciudadana en el ciclo político, OCDE, París. 


\section{DATOS DE GOBIERNO ABIERTO}

Los datos de gobierno abierto (DGA) constituyen un instrumento potente para el desarrollo económico y social. Se pueden utilizar para reforzar la gobernanza pública, mejorando el diseño y eficiencia de los servicios públicos con un enfoque centrado en los ciudadanos y estimulando la integridad y rendición de cuentas del sector público. La accesibilidad, disponibilidad y reutilización de los DGA por parte de los agentes públicos, privados y civiles permite a las Administraciones públicas diseñar políticas más inclusivas y basadas en evidencias, estimular la innovación dentro y fuera del sector público y empoderar a los ciudadanos a tomar decisiones mejor fundamentadas.

En reconocimiento a los beneficios de los DGA, en los últimos cinco años se han desarrollado varios instrumentos internacionales para promover la adopción de políticas que fomentan la accesibilidad de los datos de gobierno. Por ejemplo, la Carta de Datos Abiertos del G8 se adoptó en 2013, seguida de la Carta Internacional de Datos Abiertos en 2015 y de los Principios Anticorrupción de Datos Abiertos, también en 2015.

El OURdata Index (índice de datos abiertos, útiles y reutilizables) es una de las herramientas desarrolladas por la OCDE (junto con las revisiones y análisis de políticas nacionales de DGA) para apoyar los esfuerzos de los países miembros relativos a DGA. Tiene como objetivo resumir algunos de los puntos fuertes y débiles de los países en un conjunto de indicadores seleccionados y ayudar a identificar posibles áreas de acción. Mide el nivel de implementación de los principios de la Carta Internacional de Datos Abiertos a nivel central/federal basándose en un marco desarrollado por la OCDE.

La edición de 2017 del OURdata Index de la OCDE presenta tres conclusiones clave.

- En primer lugar, las Administraciones públicas han realizado esfuerzos importantes para apoyar la provisión de una gran cantidad de datos en un formato abierto, libre y accesible, aunque se podrían realizar esfuerzos adicionales para promover su reutilización. Por ejemplo, la mayoría de los países han adoptado una política de abrir por defecto, mediante la cual todos los datos del gobierno son abiertos, a no ser que haya una causa justificada para lo contrario. Sin embargo, a nivel central/federal, el grado en que los países llevan a cabo iniciativas para promover la reutilización de datos tanto fuera del sector público (por ejemplo, en hackathones y eventos de cocreación) como dentro (mediante sesiones informativas y formativas de funcionarios) varía considerablemente. Es más, son pocos los países que realizan un seguimiento del impacto económico y social de los datos abiertos, así como de su impacto en el rendimiento del sector público. 
- En segundo lugar, la información reunida por la OCDE sugiere la existencia de deficiencias en la implementación de algunos países que han introducido esta política hace poco, notablemente en países de Europa del Este como Letonia, República Checa, República Eslovaca y República de Eslovenia. Por el contrario, Corea, Estados Unidos, Francia y Reino Unido, que están entre los países que primero adoptaron los DGA, han podido introducir e implementar una gama amplia de políticas que promueven la disponibilidad, accesibilidad y reutilización de los datos.

- En tercer lugar, en la mayoría de los países de la OCDE los ministerios y organismos competentes consultan a las partes interesadas periódicamente para identificar los conjuntos de datos de más utilidad para los usuarios, aunque pocos países han desarrollado un portal de datos a nivel central/federal que se conciba como una plataforma de intercambio, colaboración y crowdsourcing en la que los usuarios puedan presentar información y proporcionar retroalimentación sobre la calidad y limitaciones de los datos para garantizar la mejora continua. Empoderar a los usuarios y apoyar las plataformas de intercambio entre empresas, organizaciones civiles y entidades públicas es un aspecto fundamental para promover la reutilización e impacto de los datos y un componente importante de los principios de la Carta Internacional de Datos Abiertos.

\section{Metodología y definiciones}

Los datos proceden de la Encuesta de la OCDE sobre datos de gobierno abierto que se efectuó en noviembre y diciembre de 2016. Los encuestados eran principalmente funcionarios superiores de información en países de la OCDE. Las respuestas reflejan las valoraciones de los propios países en cuanto a las prácticas y procedimientos existentes de datos de gobierno abierto. Las respuestas se refieren solo a la Administración central/federal y excluyen las prácticas de DGA a nivel estatal/local. Debido a cambios en el marco básico (en la Carta de Datos Abiertos del G8 y en la Carta Internacional de Datos Abiertos, por ejemplo) y por tanto en los datos, la edición de 2017 no es comparable con la de 2014.

El indicador compuesto se basa en los principios de la Carta Internacional de Datos Abiertos y en la metodología descrita en trabajos de la OCDE (Ubaldi, 2013). El OURdata Index contiene 140 puntos de datos. Para más información sobre la metodología y datos básicos, por favor, véase el anexo online. 


\section{Otras publicaciones}

OECD (2017), G20 Compendium on the use of open data for anti-corruption across G20 countries (de próxima publicación).

OECD (2016), Open Government Data Review of Mexico: Data Reuse for Public Sector Impact and Innovation, OECD Publishing, París. DOI: <http:// dx.doi.org/10.1787/9789264259270-en>.

Ubaldi, B. (2013), «Open Government Data: Towards Empirical Analysis of Open Government Data Initiatives», OECD Working Papers on Public Governance, n. ${ }^{o}$ 22, OECD, París, <http://dx.doi.org/10.1787/5k46bj4f03s7-en>.

\section{Notas de los gráficos}

10.12: Los datos de Hungría, Islandia y Luxemburgo no están disponibles. Dinamarca no tiene un portal de datos central/federal $y$, por tanto, no se muestran en el índice.

La información detallada de la metodología y datos básicos están disponibles en el anexo online.

Información sobre los datos de Israel: <http:/dx.doi.org/10.1787/888932315602>.

\section{Gráfico 10.11. Índice de datos de gobierno abierto, útiles y reutilizables (OURdata Index), 2017}

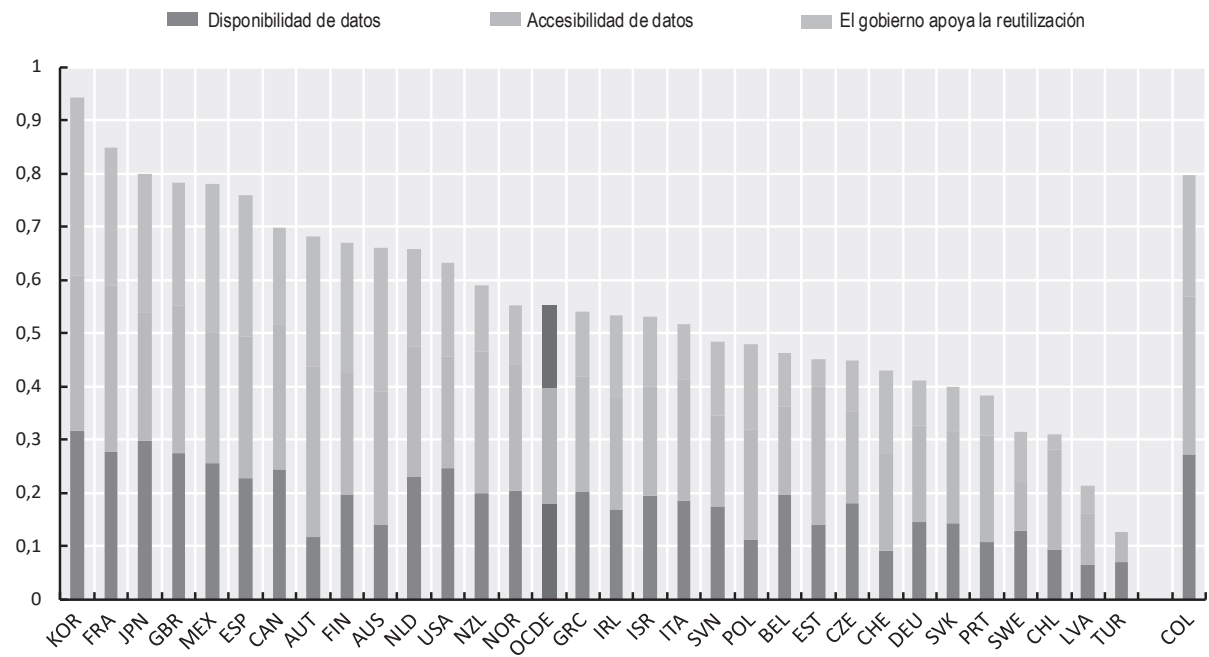

Fuente: OCDE (2016), Encuesta de la OCDE sobre datos de gobierno abierto, OCDE, París. 


\section{Gráfico 10.12. OURdata Index, apoyo del gobierno a la reutilización de} datos (pilar 3), 2017

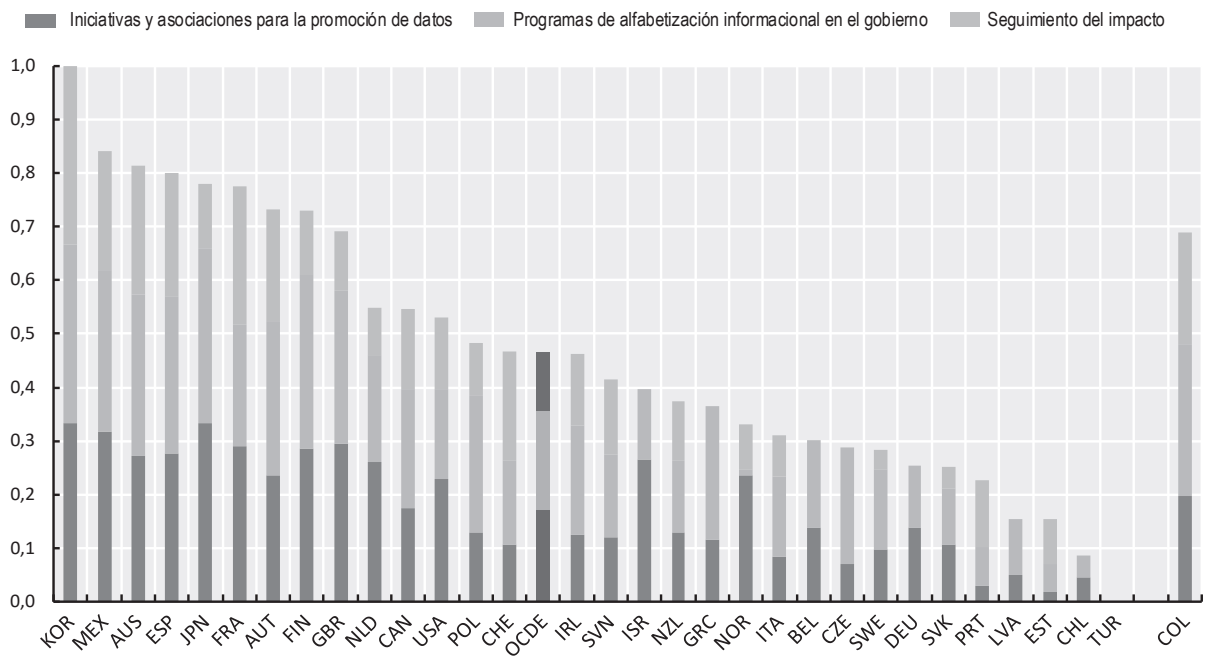

Fuente: OCDE (2016), Encuesta de la OCDE sobre datos de gobierno abierto, OCDE, París.

$<$ http://dx.doi.org/10.1787/888933533397> 


\title{
CAPÍTULO 11. INNOVACIÓN EN EL SECTOR PÚBLICO Y GOBIERNO DIGITAL
}

\author{
INNOVACIÓN DE LAS ESTRATEGIAS Y PROGRAMAS DE \\ GESTIÓN DE RECURSOS HUMANOS
}

Los Gobiernos se enfrentan a restricciones fiscales, cambios tecnológicos y demográficos y a las crecientes expectativas de los ciudadanos, que requieren respuestas innovadoras del sector público. Como resultado, muchos Gobiernos están experimentando con diversas formas de promover la innovación. Los funcionarios necesitan la capacidad, motivación y oportunidad de contribuir al desarrollo y, por tanto, la gestión de recursos humanos (GRH) supone un instrumento importante de apoyo a la innovación en el sector público, capacitando a gestores y personal de primera línea a formular ideas que se traduzcan en una mejor prestación de los servicios. La GRH que fomenta la capacidad de innovación incluye estructuras de incentivos y recompensas; enfoques de gestión y liderazgo; prácticas organizativas relacionadas con la contratación, formación, movilidad y remuneración de los empleados; y factores sobre el diseño laboral, como la autonomía y distintas maneras de trabajar.

En los países de la OCDE el concepto de innovación está penetrando en todas las funciones centrales de la GRH. Esto se hace más evidente en la formación y desarrollo, puesto que el $60 \%$ de los países pone a disposición de sus empleados algún tipo de formación en innovación. La formación puede ser el primer paso para garantizar que el concepto de innovación se extienda en todos los ámbitos del sector público y no se limite a un grupo reducido de expertos. Muchos países ponen un énfasis especial en el desarrollo del liderazgo. Los líderes y gestores con capacidades de dirección, planificación estratégica y gestión del personal son fundamentales para fomentar un sector público más innovador. Países como Bélgica, Canadá y Corea van más allá e incluyen la innovación en sus procesos básicos de gestión del personal. La innovación se incluye en el marco de competencias del $46 \%$ de los países de la OCDE, mientras que el $40 \%$ la incluye en sus debates sobre la gestión del rendimiento. Un número menor de países incluye la innovación en sus directrices de contratación (31\%) y en los criterios de promoción (23\%). La contratación y promoción 
son decisiones difíciles de tomar que repercuten considerablemente en las carreras profesionales y en las organizaciones, mientras que la participación en formación, los perfiles de competencia y los análisis del rendimiento proporcionan una base para los debates sobre innovación y exploran su contribución al desarrollo de los empleados. Estos aspectos pueden reflejar el nivel de maduración del concepto de innovación en el sector público, ya que los países consideran el concepto antes de incorporarlo activamente en sus prácticas de GRH.

Existen también medidas de GRH que influyen e incentivan directamente la innovación en el sector público. Los programas de movilidad no solo introducen nuevas capacidades, también promueven el intercambio de información, ideas y diversidad de perspectivas, que sirven de impulso para innovar. Vincular la innovación con los programas de movilidad, sin embargo, no es una práctica extendida. Los premios a la innovación proporcionan la plataforma para compartir iniciativas que, de otro modo, podrían pasar desapercibidas y para recoger estudios de casos que pueden ofrecer información, inspirar e, incluso, reproducir el éxito alcanzado. El 63\% de los países de la OCDE tienen en marcha premios a la innovación a nivel central de las Administraciones. Esto ayuda a desarrollar una cultura que celebra la innovación. Los resultados sugieren que muchos países de la OCDE reconocen y premian el resultado final de la innovación; sin embargo, identificar los incentivos y procesos de GRH adecuados continúa suponiendo un reto en la mayoría de las Administraciones públicas centrales.

\section{Metodología y definiciones}

Los datos de esta sección proceden de la Encuesta de la OCDE sobre la gestión estratégica de recursos humanos (GERH) en las Administraciones centrales/federales de los países de la OCDE 2016. Los encuestados eran predominantemente funcionarios directivos de departamentos de GRH en la Administración central. Todos los países de la OCDE completaron la encuesta.

Los datos que se presentan reflejan el grado en que se incluye el concepto de innovación en los marcos, estrategias y programas de GRH a nivel central/federal en los países de la OCDE. La magnitud y alcance de las Administraciones públicas centrales varía notablemente entre los países y se debe tener en cuenta al establecer comparaciones. Además, el grado de centralización/descentralización de la GRH y las funciones de innovación también pueden influir en las comparaciones entre países. 
La innovación en el sector público se definió, a efectos de esta encuesta, como nuevas ideas que trabajan en la creación de valor público, con las siguientes características: 1) novedad: las innovaciones introducen enfoques nuevos, relativos al contexto en el que se introducen; 2) implementación: las innovaciones, no solo las ideas, se deben implementar; y 3) impacto: las innovaciones tienen como objetivo mejorar los resultados públicos, incluyendo la eficiencia, la efectividad y la satisfacción de los empleados o usuarios.

La medida de los programas de movilidad indica situaciones en las que la innovación se mencionó de manera explícita en los objetivos de promoción de la movilidad en la función pública. No todos los países tienen programas de movilidad a nivel central/federal de la Administración.

\section{Otras publicaciones}

OECD (de próxima publicación), «Core skills for public sector innovation: a beta model of skills to promote and enable innovation in public sector organisations», OECD, París.

OECD (2017), «Innovation Skills in the Public Sector: Building Capability in Chile», OECD, París.

\section{Notas de los gráficos}

11.1: Para los programas de movilidad se formuló la pregunta «¿Existen programas específicos de movilidad para fomentar la movilidad en la función pública?», puesto que, en general, los programas de movilidad afectan positivamente a la innovación.

Información sobre los datos de Israel: <http://dx.doi.org/10.1787/888932315602>. 
Tabla 11.1. La innovación en los marcos, estrategias y programas de GRH en la Administración central/federal, 2016

\begin{tabular}{|c|c|c|c|c|c|c|c|c|}
\hline & 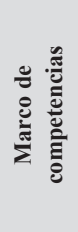 & 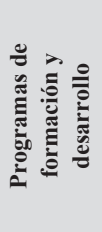 & 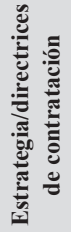 & 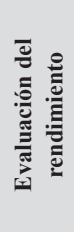 & 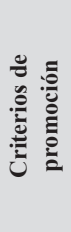 & 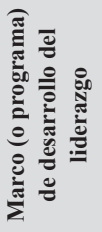 & 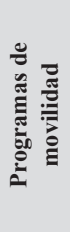 & 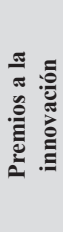 \\
\hline Alemania & O & - & O & $\mathrm{O}$ & $\mathrm{O}$ & $\mathrm{O}$ & $\mathrm{O}$ & - \\
\hline Australia & $\mathrm{O}$ & O & O & $\bigcirc$ & $\mathrm{O}$ & O & - & - \\
\hline Austria & $\mathrm{O}$ & - & - & $\bigcirc$ & $\mathrm{O}$ & - & - & - \\
\hline Bélgica & • & - & - & - & $\mathrm{O}$ & - & - & $\mathrm{O}$ \\
\hline Canadá & $\bullet$ & - & - & - & - & - & - & - \\
\hline Chile & $\bullet$ & - & O & O & O & O & O & - \\
\hline Corea & • & - & - & - & - & - & - & - \\
\hline Dinamarca & - & - & O & $\mathrm{O}$ & $\mathrm{O}$ & $\bigcirc$ & O & $\mathrm{O}$ \\
\hline España & - & - & - & - & - & $\mathrm{O}$ & $\bigcirc$ & - \\
\hline Estados Unidos & O & O & - & ○ & O & - & O & - \\
\hline Estonia & - & - & O & $\mathrm{O}$ & $\mathrm{O}$ & - & O & $\mathrm{O}$ \\
\hline Finlandia & ○ & - & $O$ & $\mathrm{O}$ & $\mathrm{O}$ & - & $\bigcirc$ & - \\
\hline Francia & O & - & O & O & O & - & O & - \\
\hline Grecia & • & - & - & - & • & - & O & O \\
\hline Hungría & $\mathrm{O}$ & $\mathrm{O}$ & $\mathrm{O}$ & $\mathrm{O}$ & $\mathrm{O}$ & $\bigcirc$ & $\mathrm{O}$ & $\mathrm{O}$ \\
\hline Irlanda & $\mathrm{O}$ & $\mathrm{O}$ & $\mathrm{O}$ & $\mathrm{O}$ & $\mathrm{O}$ & $\mathrm{O}$ & 0 & - \\
\hline Islandia & O & O & O & O & $\mathrm{O}$ & O & O & $\mathrm{O}$ \\
\hline Israel & • & - & O & - & $\mathrm{O}$ & $\bullet$ & - & - \\
\hline Italia & $\mathrm{O}$ & - & - & $\mathrm{O}$ & $\mathrm{O}$ & $\mathrm{O}$ & - & - \\
\hline Japón & $\mathrm{O}$ & - & $\mathrm{O}$ & - & - & - & $\mathrm{O}$ & - \\
\hline Letonia & • & $\mathrm{O}$ & O & $\mathrm{O}$ & O & $\bullet$ & O & O \\
\hline Luxemburgo & O & O & O & $\mathrm{O}$ & O & O & O & $\mathrm{O}$ \\
\hline México & - & - & $\mathrm{O}$ & $\mathrm{O}$ & $\mathrm{O}$ & $\mathrm{O}$ & - & - \\
\hline Noruega & $\mathrm{O}$ & O & O & O & O & - & $\mathrm{O}$ & O \\
\hline Nueva Zelanda & O & O & O & O & O & O & O & - \\
\hline Países Bajos & $\mathrm{O}$ & O & O & O & O & O & O & - \\
\hline Polonia & $\mathrm{O}$ & - & $\mathrm{O}$ & - & 0 & $\mathrm{O}$ & $\mathrm{O}$ & - \\
\hline Portugal & - & - & $\mathrm{O}$ & - & $\mathrm{O}$ & - & $\mathrm{O}$ & $\mathrm{O}$ \\
\hline Reino Unido & • & - & $\bullet$ & - & $\mathrm{O}$ & - & - & - \\
\hline República Checa & $\bigcirc$ & - & - & - & - & - & $\mathrm{O}$ & $\mathrm{O}$ \\
\hline
\end{tabular}




\begin{tabular}{|c|c|c|c|c|c|c|c|c|}
\hline & 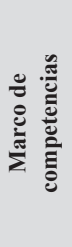 & 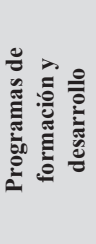 & 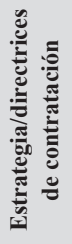 & 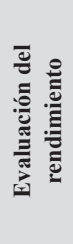 & 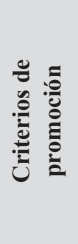 & 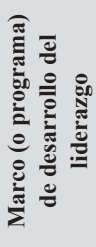 & 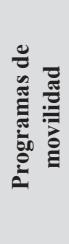 & 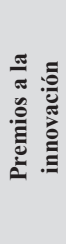 \\
\hline $\begin{array}{l}\text { República de } \\
\text { Eslovenia }\end{array}$ & - & 0 & 0 & - & - & - & 0 & - \\
\hline República Eslovaca & O & $\bullet$ & $\mathrm{O}$ & $\bullet$ & $\mathrm{O}$ & O & $\mathrm{O}$ & $\bullet$ \\
\hline Suecia & O & O & 0 & 0 & O & O & O & $\bullet$ \\
\hline Suiza & O & O & O & O & O & $\bullet$ & O & O \\
\hline Turquía & $\bullet$ & $\bullet$ & $\bullet$ & $\bullet$ & $\bullet$ & $\bullet$ & O & O \\
\hline \multicolumn{9}{|l|}{ Total OCDE } \\
\hline - Incluido & 16 & 21 & 11 & 14 & 8 & 19 & 9 & 22 \\
\hline O No incluido & 19 & 14 & 24 & 21 & 27 & 16 & 26 & 13 \\
\hline
\end{tabular}

Fuente: OCDE (2016), Encuesta sobre la gestión estratégica de recursos humanos en las Administraciones centrales/federales de los países de la OCDE, OCDE, París.

\section{ESTRUCTURAS DE APOYO PARA LA INNOVACIÓN EN EL SECTOR PÚBLICO}

Innovar en el sector público puede ser difícil y requiere apoyo y recursos adicionales y específicos. En los últimos años ha crecido notablemente el tipo y número de organizaciones y estructuras que sirven de apoyo para la innovación en el sector público (OCDE, 2017). Se conocen como equipos, unidades, laboratorios o redes. Entre ellos, las redes centradas en la innovación y los laboratorios de innovación han suscitado especial interés. Las redes pueden apoyar y motivar la innovación en el sector público proporcionando un espacio donde los participantes pueden compartir ideas, prácticas y los desafíos de la implementación. Las unidades/laboratorios dedicados a la innovación pueden ayudar a abordar algunas de las barreras impuestas; por ejemplo, compensando la falta de líderes y promotores de la innovación y contribuyendo a superar la rigidez de los sistemas de premios e incentivos que a menudo dificultan el desempeño del sector público en este ámbito. Pueden ayudar a compartir el conocimiento organizativo sobre las maneras de aplicar los procesos y métodos de innovación y apoyar enfoques más colaborativos y consensuados para resolver problemas. Esto, a su vez, enfrenta el problema del pensamiento aislado adoptando planteamientos trasversales e interdisciplinares que conjugan capacidades, herramientas y métodos nuevos o distintos. 
Los países de la OCDE presentan una amplia gama de redes y laboratorios que apoyan la innovación de diferentes maneras. Los datos de la Tabla 11.2 muestran que la mayoría de los países de la OCDE (22) tienen redes centradas en la innovación a nivel central de la Administración. Aunque el objetivo principal de las redes es fomentar que sus miembros compartan experiencias, también se utilizan para desarrollar las capacidades de sus miembros mediante la formación, proporcionar apoyo para la realización de proyectos específicos y para ofrecer asesoramiento y orientación a las instituciones públicas. Por ejemplo, en Estonia, Finlandia, Reino Unido y República Checa, las redes incluyen todas las funciones mencionadas.

Un elevado número de los países encuestados de la OCDE (21 de 25) tienen además en funcionamiento uno o varios laboratorios de innovación a nivel central/federal de la Administración. Aumentar la toma de conciencia, proporcionar asesoramiento y formación y fomentar el contacto son las funciones más comunes de los laboratorios de innovación. En 17 países de la OCDE, estos laboratorios además ofrecen apoyo directo a los proyectos de innovación, y en 15 países proporcionan espacio para la experimentación, creando así un entorno seguro para la toma de riesgos. A pesar de la gran variedad de organizaciones dedicadas a la innovación a nivel central/federal de la Administración, los estudios recientes muestran coincidencias: están predominantemente orientadas a los resultados y su trabajo se basa en proyectos (OCDE, 2017). Este es el caso, por ejemplo, de Mindlab en Dinamarca y de Lab para la Ciudad en México. Debido a la relativa novedad de los laboratorios y redes de innovación, este es un campo en constante desarrollo, con nuevas organizaciones emergentes y otras que evolucionan y maduran. Pese a este constante estado de flujo, el panorama global de las redes y laboratorios, de lo que hacen y cómo funcionan, proporciona información sobre el apoyo de los países a la innovación en el sector público. Esto permite que los países se sitúen y comparen, identifiquen los modelos existentes y sus contextos organizativos y aprendan de la experiencia de los demás.

\section{Metodología y definiciones}

Los datos de esta sección proceden de la Encuesta de la OCDE sobre la gestión estratégica de recursos humanos (GERH) en las Administraciones centrales/federales de los países de la OCDE 2016 y de la Encuesta sobre facilitadores de la innovación en el sector público (SPSIE, por sus siglas en inglés) de 2017. La encuesta de GERH la completaron predominantemente funcionarios directivos de departamentos de GRH 
de la Administración central. Los encuestados de la SPSIE eran funcionarios de la Administración central que se ocupan, en mayor o menor medida, de la innovación en diversos ámbitos del sector público. La encuesta fue completada por 25 países de la OCDE.

La innovación en el sector público se definió, en ambas encuestas, como nuevas ideas que trabajan en la creación de valor público, con las siguientes características: 1) novedad: las innovaciones introducen enfoques nuevos, relativos al contexto en el que se introducen; 2) implementación: las innovaciones, no solo las ideas, se deben implementar; y 3) impacto: las innovaciones tienen como objetivo mejorar los resultados públicos, incluyendo la eficiencia, la efectividad y la satisfacción de los empleados o usuarios.

Los laboratorios de innovación se definieron en la SPSIE como organizaciones (por ejemplo, instituciones, agencias, laboratorios, centros) dedicadas a la innovación en el sector público y a apoyar a las Administraciones en la búsqueda e implementación de nuevas maneras de hacer las cosas con el fin de mejorar el rendimiento del sector público (por ejemplo, creando mejores servicios públicos y resultados, mayor eficiencia o políticas públicas más efectivas).

La encuesta de GERH midió las redes centradas en innovación en toda la función pública.

\section{Otras publicaciones}

OECD (2017), «Fostering Innovation in the Public Sector», OECD, París.

\section{Notas de los gráficos}

11.2: Información sobre los datos de Israel: <http://dx.doi. org $/ 10.1787 / 888932315602>$. 


\section{Tabla 11.2. Estructuras de apoyo para la innovación en el sector público en la Administración central/federal, 2016/2017}

\begin{tabular}{|c|c|c|c|c|}
\hline & \multicolumn{2}{|r|}{ Redes centradas en la innovación } & \multicolumn{2}{|r|}{ Laboratorios de innovación } \\
\hline & n. ${ }^{\circ}$ & Actividades & n. ${ }^{\circ}$ & Actividades \\
\hline Alemania & $\Delta$ & Formación, compartir experiencias & $\Delta$ & Formación \\
\hline Australia & $\boldsymbol{\Delta}$ & $\begin{array}{l}\text { Compartir experiencias, proyectos } \\
\text { específicos de innovación, asesoramiento y } \\
\text { orientación, creación de comunidades online }\end{array}$ & $\Delta$ & $\begin{array}{l}\text { Concienciación, asesoramiento, formación, apoyo } \\
\text { a proyectos de innovación, experimentación, } \\
\text { desarrollo de innovación, redes de contactos }\end{array}$ \\
\hline Austria & $\bullet$ & $\begin{array}{l}\text { Formación, compartir experiencias, } \\
\text { proyectos específicos de innovación }\end{array}$ & $\Delta$ & $\begin{array}{l}\text { Concienciación, asesoramiento, formación, apoyo } \\
\text { a proyectos de innovación, experimentación, } \\
\text { desarrollo de innovación, inversión, redes de } \\
\text { contactos }\end{array}$ \\
\hline Bélgica & 0 & - & $\Delta$ & $\begin{array}{l}\text { Concienciación, asesoramiento, formación, apoyo } \\
\text { a proyectos de innovación, experimentación, } \\
\text { desarrollo de innovación, inversión, redes de } \\
\text { contactos }\end{array}$ \\
\hline Canadá & $\bullet$ & $\begin{array}{l}\text { Formación, compartir experiencias, } \\
\text { proyectos específicos de innovación }\end{array}$ & $\bullet$ & $\begin{array}{c}\text { Asesoramiento, formación, apoyo a proyectos de } \\
\text { innovación, experimentación, desarrollo de } \\
\text { innovación, redes de contactos }\end{array}$ \\
\hline Chile & 0 & $\begin{array}{l}\text { Formación, compartir experiencias, } \\
\text { proyectos específicos de innovación }\end{array}$ & $\bullet$ & $\begin{array}{l}\text { Concienciación, asesoramiento, formación, apoyo } \\
\text { a proyectos de innovación, experimentación, } \\
\text { desarrollo de innovación, inversión, redes de } \\
\text { contactos }\end{array}$ \\
\hline Corea & $\bullet$ & Formación & $\mathbf{\Delta}$ & $\begin{array}{l}\text { Concienciación, asesoramiento, formación, apoyo } \\
\text { a proyectos de innovación, experimentación, } \\
\text { desarrollo de innovación, inversión, redes de } \\
\text { contactos }\end{array}$ \\
\hline Dinamarca & $\boldsymbol{\Delta}$ & $\begin{array}{l}\text { Compartir experiencias, creación de } \\
\text { comunidades online }\end{array}$ & $\Delta$ & $\begin{array}{c}\text { Concienciación, asesoramiento, formación, apoyo } \\
\text { a proyectos de innovación, desarrollo de } \\
\text { innovación, redes de contactos }\end{array}$ \\
\hline España & $\bullet$ & $\begin{array}{l}\text { Formación, compartir experiencias, } \\
\text { proyectos específicos de innovación }\end{array}$ & $\bullet$ & $\begin{array}{c}\text { Concienciación, asesoramiento, formación, apoyo } \\
\text { a proyectos de innovación, desarrollo de } \\
\text { innovación, redes de contactos }\end{array}$ \\
\hline Estados Unidos & $\boldsymbol{\Delta}$ & $\begin{array}{l}\text { Compartir experiencias, proyectos } \\
\text { específicos de innovación }\end{array}$ & SR & SR \\
\hline Estonia & $\boldsymbol{\Delta}$ & $\begin{array}{l}\text { Formación, compartir experiencias, } \\
\text { proyectos específicos de innovación, } \\
\text { asesoramiento y orientación }\end{array}$ & $\boldsymbol{\Delta}$ & $\begin{array}{l}\text { Concienciación, asesoramiento, formación, apoyo } \\
\text { a proyectos de innovación, experimentación, } \\
\text { desarrollo de innovación, inversión, redes de } \\
\text { contactos }\end{array}$ \\
\hline Finlandia & $\bullet$ & $\begin{array}{l}\text { Formación, compartir experiencias, } \\
\text { proyectos específicos de innovación, } \\
\text { asesoramiento y orientación, creación de } \\
\text { comunidades online }\end{array}$ & $\boldsymbol{\Delta}$ & $\begin{array}{l}\text { Concienciación, asesoramiento, formación, apoyo } \\
\text { a proyectos de innovación, experimentación, } \\
\text { desarrollo de innovación, inversión, redes de } \\
\text { contactos }\end{array}$ \\
\hline Francia & $\bullet$ & $\begin{array}{l}\text { Formación, compartir experiencias, } \\
\text { proyectos específicos de innovación }\end{array}$ & $\boldsymbol{\Delta}$ & $\begin{array}{l}\text { Concienciación, asesoramiento, formación, } \\
\text { experimentación, desarrollo de innovación, } \\
\text { inversión, redes de contactos }\end{array}$ \\
\hline Grecia & 0 & - & SR & SR \\
\hline Hungría & 0 & - & 0 & - \\
\hline Irlanda & $\bullet$ & $\begin{array}{l}\text { Asesoramiento y orientación, compartir } \\
\text { experiencias }\end{array}$ & 0 & - \\
\hline Islandia & 0 & - & 0 & - \\
\hline
\end{tabular}




\begin{tabular}{|c|c|c|c|c|}
\hline & \multicolumn{2}{|r|}{ Redes centradas en la innovación } & \multicolumn{2}{|r|}{ Laboratorios de innovación } \\
\hline & n. ${ }^{\circ}$ & Actividades & n. ${ }^{0}$ & Actividades \\
\hline Israel & $\bullet$ & $\begin{array}{l}\text { Compartir experiencias, proyectos } \\
\text { específicos de innovación }\end{array}$ & SR & SR \\
\hline Italia & $\boldsymbol{\Delta}$ & $\begin{array}{l}\text { Formación, compartir experiencias, } \\
\text { proyectos específicos de innovación, } \\
\text { creación de comunidades online }\end{array}$ & $\bullet$ & $\begin{array}{l}\text { Concienciación, asesoramiento, formación, apoyo } \\
\text { a proyectos de innovación, experimentación, } \\
\text { desarrollo de innovación, redes de contactos }\end{array}$ \\
\hline Japón & $\boldsymbol{\Delta}$ & - & $\bullet$ & $\begin{array}{c}\text { Apoyo a proyectos de innovación, desarrollo de } \\
\text { innovación, redes de contactos }\end{array}$ \\
\hline Letonia & O & - & O & - \\
\hline Luxemburgo & O & - & SR & SR \\
\hline México & $\Delta$ & - & $\bullet$ & $\begin{array}{c}\text { Asesoramiento, apoyo a proyectos de innovación, } \\
\text { experimentación, desarrollo de innovación, redes } \\
\text { de contactos }\end{array}$ \\
\hline Noruega & $\boldsymbol{\Delta}$ & Compartir experiencias & SR & SR \\
\hline Nueva Zelanda & $\boldsymbol{\Delta}$ & $\begin{array}{l}\text { Compartir experiencias, proyectos } \\
\text { específicos de innovación }\end{array}$ & SR & SR \\
\hline Países Bajos & $\boldsymbol{\Delta}$ & $\begin{array}{c}\text { Formación, compartir experiencias, creación } \\
\text { de comunidades online }\end{array}$ & $\bullet$ & $\begin{array}{c}\text { Concienciación, asesoramiento, formación, apoyo } \\
\text { a proyectos de innovación, experimentación, } \\
\text { desarrollo de innovación }\end{array}$ \\
\hline Polonia & $\boldsymbol{\Delta}$ & Formación, Compartir experiencias & O & - \\
\hline Portugal & 0 & - & $\bullet$ & $\begin{array}{c}\text { Concienciación, asesoramiento, formación, apoyo } \\
\text { a proyectos de innovación, experimentación, } \\
\text { desarrollo de innovación, inversión, redes de } \\
\text { contactos }\end{array}$ \\
\hline Reino Unido & $\boldsymbol{\Delta}$ & $\begin{array}{l}\text { Formación, compartir experiencias, } \\
\text { proyectos específicos de innovación, } \\
\text { asesoramiento y orientación, creación de } \\
\text { comunidades online }\end{array}$ & $\Delta$ & $\begin{array}{c}\text { Concienciación, asesoramiento, formación, apoyo } \\
\text { a proyectos de innovación, experimentación, } \\
\text { desarrollo de innovación, inversión, redes de } \\
\text { contactos }\end{array}$ \\
\hline República Checa & $\boldsymbol{\Delta}$ & $\begin{array}{l}\text { Formación, compartir experiencias, } \\
\text { proyectos específicos de innovación, } \\
\text { asesoramiento y orientación }\end{array}$ & SR & SR \\
\hline $\begin{array}{l}\text { República de } \\
\text { Eslovenia }\end{array}$ & O & - & $\bullet$ & Concienciación, asesoramiento, formación \\
\hline República Eslovaca & 0 & - & $\Delta$ & Asesoramiento, desarrollo de innovación \\
\hline Suecia & O & - & $\bullet$ & $\begin{array}{l}\text { Concienciación, formación, apoyo a proyectos de } \\
\text { innovación, experimentación, redes de contactos }\end{array}$ \\
\hline Suiza & O & - & SR & SR \\
\hline Turquía & O & - & O & - \\
\hline \multicolumn{5}{|l|}{ Total OCDE } \\
\hline & 13 & Ninguna & 6 & Ninguna \\
\hline & 8 & - Una & 10 & - Una \\
\hline & 14 & $\boldsymbol{\Delta}$ Varias & 11 & $\Delta$ Varias \\
\hline & SR & Sin respuesta & SR & Sin respuesta \\
\hline & 35 & n. ${ }^{\circ}$ de encuestados & 27 & n. ${ }^{\circ}$ de encuestados \\
\hline
\end{tabular}

Fuentes: OCDE (2016), Encuesta sobre la gestión estratégica de recursos humanos en las Administraciones centrales/federales de los países de la OCDE, OCDE, París; OCDE (2017), Encuesta sobre facilitadores de la innovación en el sector público en las Administraciones centrales/federales de los países de la OCDE, OCDE, París. 


\section{MECANISMOS DE FINANCIACIÓN PARA LA INNOVACIÓN EN EL SECTOR PÚBLICO}

Los incentivos financieros pueden jugar un papel importante en la promoción de la innovación en el sector público. Incluso en un contexto de fuertes restricciones económicas, el uso estratégico de herramientas presupuestarias y la flexibilidad combinada con las metas en resultados pueden apoyar la innovación en el sector público. Los incentivos financieros, como los fondos centrales de innovación o los dividendos de eficiencia, pueden estimular la innovación y aumentar la capacidad de las organizaciones públicas para respaldar la innovación en su ciclo completo, en especial en aspectos como la obtención de ideas y la reproducción de resultados a gran escala.

Los fondos de innovación se imponen como una práctica emergente en los países de la OCDE. Estos fondos pueden cumplir una función formativa determinando cuándo y cómo los países específicos llevan a cabo la innovación en el sector público, aunque su éxito depende de varios factores importantes como la flexibilidad en la utilización de nuevos recursos; la eliminación de la financiación fragmentada a fin de facilitar respuestas estratégicas; y presupuestos previsibles para varios años, que permiten a los organismos realizar inversiones estratégicas para mejorar el rendimiento a través de la innovación (OCDE, 2014, 2017). Además, la introducción de fuentes presupuestarias horizontales puede fomentar la innovación que está fuera del alcance de los organismos individuales (OCDE, 2017).

Los datos de la Tabla 11.3 muestran que 14 de los 25 países encuestados de la OCDE tienen por lo menos un fondo dedicado a la innovación a nivel central/federal de la Administración y 9 países tienen más de uno. Mientras que en la mayoría de los países encuestados de la OCDE (12) la financiación procede del presupuesto central, hay algunos países (Bélgica, Canadá, Italia y Reino Unido) en los que proviene de los ministerios/organismos. La introducción de mayor flexibilidad presupuestaria para los administradores y la relajación del control de los insumos son características de las reformas presupuestarias en muchos países de la OCDE (OCDE, 2014). La mayoría de los países miembros destinan créditos globales a los costes operativos, aunque muchos lo hacen con limitaciones. Además, la mayoría de los países miembros de la OCDE permiten el traspaso de fondos no utilizados y que los gestores reasignen los fondos entre las partidas presupuestarias. Esto es de vital importancia para la innovación, exista o no un fondo específico, ya que hay mucha incertidumbre relativa a la implementación de proyectos de este ámbito. Adicionalmente, algunos países de la OCDE (por ejemplo, Italia, Polonia y Portugal) combinan diferentes fuentes de financiación, como fondos del presupuesto central con contribuciones de la Unión Europea.

Aunque los fondos están localizados a nivel central/federal de la Administración, en parte se destinan a organizaciones públicas subnacionales y a enti- 
dades del sector privado. Cabe destacar que muchas organizaciones tienen distintos grupos destinatarios. Esto es indicativo de la naturaleza transversal de la innovación y de la necesidad de planteamientos de financiación más flexibles.

Los principales objetivos de los fondos dedicados a la innovación en los países de la OCDE son la realización de proyectos, el apoyo a soluciones innovadoras implementadas en otros lugares y la creación de prototipos, seguidos muy de cerca por la ampliación de proyectos, la experimentación y la evaluación del éxito de los proyectos en marcha. Aunque los fondos dedicados a la innovación son relativamente nuevos en el sector público, la naturaleza de estos es diversa y a menudo apoyan la transformación digital de proyectos en ámbitos políticos específicos (por ejemplo, la asistencia sanitaria y el envejecimiento). De la misma manera, el importe de los fondos varía considerablemente. En la mayoría de los casos, es difícil estimar su cuantía, ya que se incluyen en grandes partidas presupuestarias o definen como un porcentaje de los gastos generales.

\section{Metodología y definiciones}

Los datos de esta sección proceden de la Encuesta de la OCDE sobre facilitadores de la innovación en el sector público (SPSIE, por sus siglas en inglés) de 2017. Los encuestados de la SPSIE eran funcionarios de la Administración central que se ocupan, en mayor o menor medida, de la innovación en diversos ámbitos del sector público. La encuesta fue completada por 25 países de la OCDE.

La innovación en el sector público se definió en esta encuesta como nuevas ideas que trabajan en la creación de valor público, con las siguientes características: 1) novedad: las innovaciones introducen enfoques nuevos, relativos al contexto en el que se introducen; 2) implementación: las innovaciones, no solo las ideas, se deben implementar; y 3) impacto: las innovaciones tienen como objetivo mejorar los resultados públicos, incluyendo la eficiencia, la efectividad y la satisfacción de los empleados o usuarios.

Los fondos de innovación se definieron en la encuesta como cualquier financiación destinada al inicio, realización o ampliación de proyectos/ programas de innovación en el sector público (incluyendo, pero sin limitarse a, becas de innovación, bonos de innovación social y dividendos de eficiencia que han sido utilizados para la innovación). La falta de fondos destinados a la innovación no conlleva la falta de financiación de la innovación en el sector público, puesto que pueden existir otros marcos de financiación. 


\section{Otras publicaciones}

OECD (2017), «Fostering Innovation in the Public Sector», OECD, París.

OECD (2014), «Budgeting Practices and Procedures in OECD countries», OECD, París.

\section{Notas de los gráficos}

11.3: Los datos de Australia, Chile, Estados Unidos, Grecia, Israel, Luxemburgo, Noruega, Nueva Zelanda, República Checa y Suiza no están disponibles.

Tabla 11.3. Características de los fondos destinados a la innovación en el sector público en la Administración central/federal, 2017

\begin{tabular}{|c|c|c|c|c|c|c|c|c|c|c|c|c|}
\hline & \multirow[b]{2}{*}{ 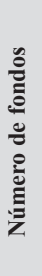 } & \multicolumn{3}{|c|}{ Fuente de la financiación } & \multicolumn{8}{|c|}{ Objetivos de los fondos } \\
\hline & & 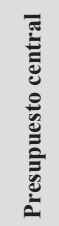 & 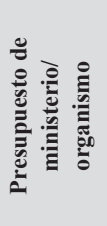 & 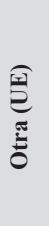 & 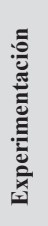 & 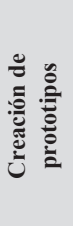 & 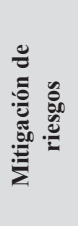 & 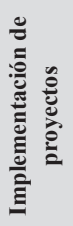 & 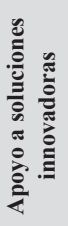 & 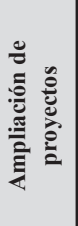 & 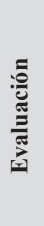 & 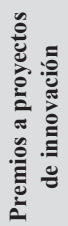 \\
\hline Alemania & O & - & - & - & - & - & - & - & - & - & - & - \\
\hline Austria & O & - & - & - & - & - & - & - & - & - & - & - \\
\hline Bélgica & $\Delta$ & - & $\checkmark$ & - & - & - & - & $\checkmark$ & - & - & - & - \\
\hline Canadá & $\bullet$ & - & $\checkmark$ & - & $\checkmark$ & $\checkmark$ & - & $\checkmark$ & - & $\checkmark$ & $\checkmark$ & - \\
\hline Corea & $\Delta$ & $\checkmark$ & - & - & $\checkmark$ & $\checkmark$ & $\checkmark$ & - & $\checkmark$ & $\checkmark$ & $\checkmark$ & $\checkmark$ \\
\hline Dinamarca & $\mathrm{O}$ & - & - & - & - & - & - & - & - & - & - & - \\
\hline España & $\mathrm{O}$ & - & - & - & - & - & - & - & - & - & - & - \\
\hline Estonia & $\Delta$ & $\checkmark$ & - & - & $\checkmark$ & $\checkmark$ & $\checkmark$ & - & $\checkmark$ & $\checkmark$ & $\checkmark$ & - \\
\hline Finlandia & $\Delta$ & $\checkmark$ & - & - & $\checkmark$ & - & - & $\checkmark$ & $\checkmark$ & $\checkmark$ & - & - \\
\hline Francia & $\Delta$ & $\checkmark$ & - & - & $\checkmark$ & $\checkmark$ & $\checkmark$ & $\checkmark$ & - & - & - & - \\
\hline Hungría & O & - & - & - & - & - & - & - & - & - & - & - \\
\hline Irlanda & $\bullet$ & $\checkmark$ & - & - & - & $\checkmark$ & - & - & $\checkmark$ & - & $\checkmark$ & $\checkmark$ \\
\hline Islandia & O & - & - & - & - & - & - & - & - & - & - & - \\
\hline Italia & $\bullet$ & $\checkmark$ & $\checkmark$ & $\checkmark$ & - & $\checkmark$ & - & $\checkmark$ & $\checkmark$ & $\checkmark$ & $\checkmark$ & - \\
\hline Japón & O & - & - & - & - & - & - & - & - & - & - & - \\
\hline Letonia & O & - & - & - & - & - & - & - & - & - & - & - \\
\hline México & $\Delta$ & $\checkmark$ & - & - & $\checkmark$ & - & $\checkmark$ & $\checkmark$ & $\checkmark$ & $\checkmark$ & $\checkmark$ & - \\
\hline Países Bajos & $\Delta$ & $\checkmark$ & - & - & $\checkmark$ & $\checkmark$ & $\checkmark$ & $\checkmark$ & $\checkmark$ & $\checkmark$ & $\checkmark$ & $\checkmark$ \\
\hline Polonia & $\Delta$ & $\checkmark$ & - & $\checkmark$ & - & $\checkmark$ & - & $\checkmark$ & $\checkmark$ & - & - & - \\
\hline Portugal & $\bullet$ & $\checkmark$ & - & $\checkmark$ & - & - & - & $\checkmark$ & - & - & - & - \\
\hline
\end{tabular}




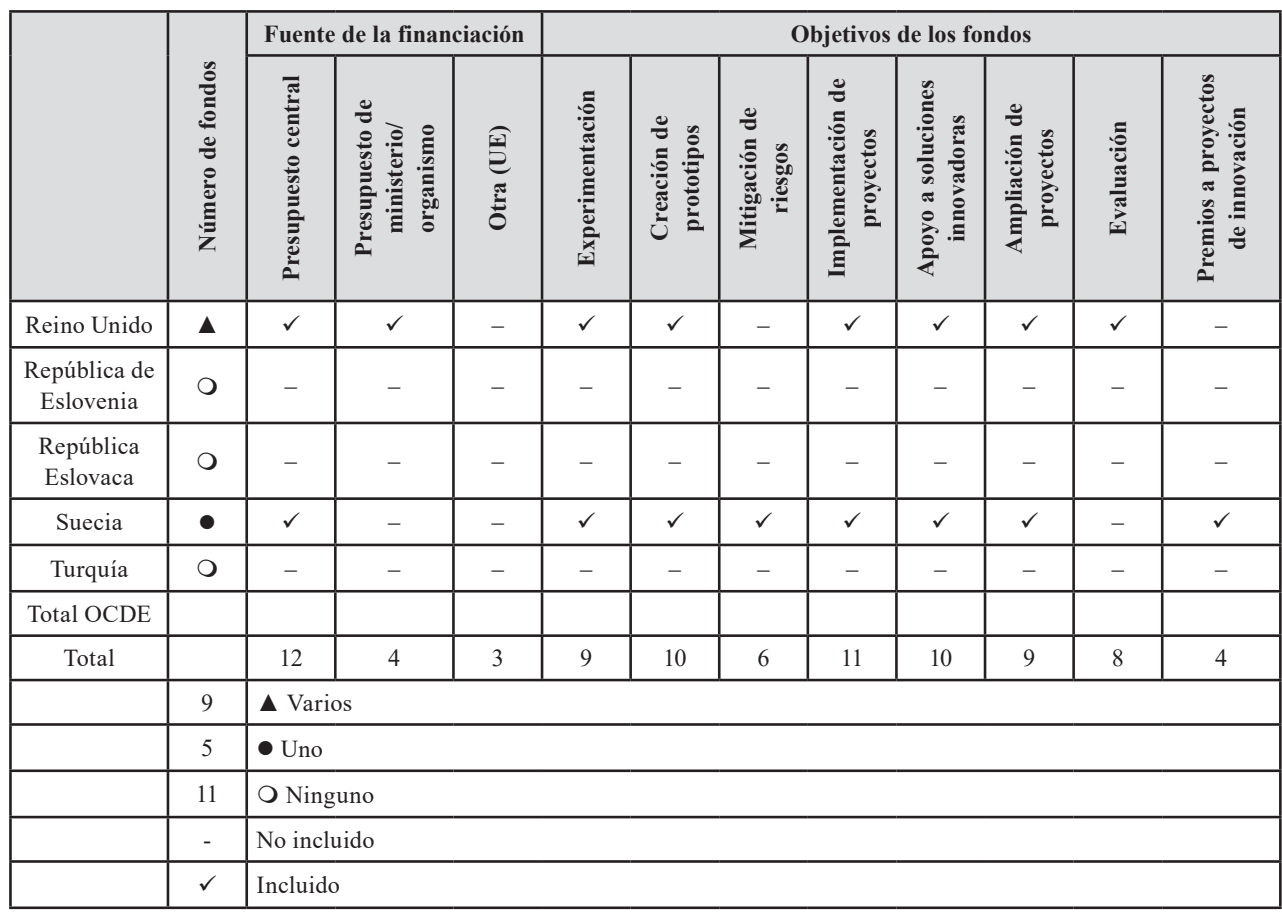

Fuente: OCDE (2017), Encuesta sobre facilitadores de la innovación en el sector público en las Administraciones centrales/federales de los países de la OCDE, OCDE, París.

$<$ http://dx.doi.org/10.1787/888933535373>

Tabla 11.4. Destinatarios previstos de los fondos de innovación, 2017

\begin{tabular}{|c|c|c|}
\hline & $\begin{array}{c}\text { Países (número de fondos con destinatarios } \\
\text { previstos) }\end{array}$ & $\begin{array}{l}\text { Número de } \\
\text { fondos }\end{array}$ \\
\hline Todas las organizaciones del sector público & $\begin{array}{c}\text { BEL (1), EST (2), FIN (2), ITA (1) NDL (2), POL } \\
\text { (1), SWE (1) }\end{array}$ & 10 \\
\hline Organizaciones a nivel nacional/federal & $\begin{array}{c}\text { CAN (1), FIN (2), FRA (2), GBR (1), IRL (1), } \\
\text { KOR (1) MEX (2), NDL } \\
\text { (1), POL (1) }\end{array}$ & 12 \\
\hline Organizaciones públicas subnacionales & $\begin{array}{l}\text { FIN (2), FRA (2), GBR (3), KOR (1), MEX (2), } \\
\text { NLD (1), POL (1) }\end{array}$ & 12 \\
\hline $\begin{array}{l}\text { Organizaciones del sector público que desempeñan } \\
\text { funciones específicas (por ejemplo, hospitales, centros } \\
\text { educativos) }\end{array}$ & BEL (3), GBR (3), MEX (2), NDL (3), POL (1) & 12 \\
\hline Organizaciones privadas con ánimo de lucro & EST (1), FIN (1), GBR (4), NDL (1), POL (2) & 9 \\
\hline Organizaciones privadas sin ánimo de lucro & $\begin{array}{l}\operatorname{EST}(1), \operatorname{FIN}(1), \operatorname{GBR}(3), \operatorname{NDL}(1), \operatorname{POL}(2), \\
\text { PRT (1) }\end{array}$ & 9 \\
\hline
\end{tabular}

Fuente: OCDE (2017), Encuesta sobre facilitadores de la innovación en el sector público en las Administraciones centrales/federales de los países de la OCDE, OCDE, París. 


\section{TRANSFORMACIÓN DIGITAL DE LA PRESTACIÓN DE SERVICIOS PÚBLICOS}

La transformación digital de la sociedad y la economía está cambiando radicalmente las prácticas de la prestación de servicios. El sector privado ha introducido nuevas formas de ofrecer servicios $\mathrm{y}$, en consecuencia, las expectativas de los ciudadanos relativas a los servicios públicos han aumentado. El cambio de mecanismos de prestación de servicios reactivos a servicios proactivos, posible gracias a la transición de gobierno electrónico a gobierno digital, donde el uso de las tecnologías digitales se considera como una parte integrada de las estrategias de modernización e innovación de las Administraciones públicas, crea valor público mediante la participación de un ecosistema amplio de partes interesadas y ofrece la oportunidad de proporcionar mejores respuestas a las demandas de los usuarios. Sin embargo, para lograrlo, las Administraciones públicas deben determinar, entender e integrar las demandas y necesidades de los ciudadanos en las estrategias de diseño y prestación de los servicios públicos. Los datos públicos constituyen un recurso potente para pasar de un enfoque centrado en los ciudadanos a uno impulsado por ellos, permitiendo a las Administraciones diseñar procesos de prestación de servicios públicos adaptados a las necesidades de los usuarios.

En 2016, cerca del 36\% de las personas de los países miembros de la OCDE presentaron formularios a través de los sitios web de las Administraciones públicas. En la última década se ha experimentado un aumento marcado en el uso de los servicios digitales de las Administraciones, que de media se ha triplicado entre los países de la OCDE desde 2006. Esto refleja el impacto positivo de los esfuerzos de digitalización de las Administraciones públicas y la adopción progresiva por parte de los ciudadanos de estos nuevos canales de prestación de servicios. Sin embargo, existen diferencias persistentes en el uso de los servicios digitales de la Administración entre distintos grupos de población. Las Administraciones públicas deben tener en cuentas estas diferencias a fin de desarrollar enfoques adaptados de prestación de servicios públicos y evitar así nuevas formas de exclusión digital a medida que avanza la digitalización del sector.

Al comparar los niveles de estudios de los usuarios de los servicios digitales de las Administraciones públicas, se encuentran diferencias considerables. De media, entre los países de la OCDE en 2016 alrededor del 54\% de las personas con estudios superiores completaron formularios a través de los sitios web de las autoridades públicas, frente a un $17 \%$ de personas con niveles bajos de formación. Esta diferencia en el uso de los servicios digitales por nivel de formación es menor en los países nórdicos (como Dinamarca, Finlandia y Noruega) y mayor en Estonia, Grecia, Hungría, Irlanda, Letonia y Portugal. El nivel de ingresos y la edad de las personas también parecen influir en el grado de interacción digital con las autoridades públicas. En los países de la OCDE, un promedio del $49 \%$ de las personas en el cuartil superior de ingresos (es de- 
cir, los más ricos) utilizaron Internet para presentar formularios a través de los sitios web de las autoridades públicas, frente a un $25 \%$ de personas en el cuarto cuartil de ingresos (los más pobres). Además, cerca del $42 \%$ de las personas entre 25 y 54 años rellenaron formularios online a través de los sitios web del sector público, frente a solo el $24 \%$ de personas con edades comprendidas entre 55 y 74 años. Estas diferencias en la interacción digital con los servicios públicos se pueden deber a las distintas necesidades de la población y también a los distintos niveles de destreza digital como consecuencia de las desigualdades socioeconómicas.

Con el fin de promover la transformación digital como modo de reforzar y fomentar la interacción digital, un número de países han adoptado el principio de solo una vez, que supone que los ciudadanos y empresas deben proporcionar la misma información de manera única a la Administración. Para lograr este objetivo, las Administraciones públicas han tenido que reorganizar su modus operandi administrativo, de manera que las entidades públicas pueden intercambiar y reutilizar los datos e información de los ciudadanos y empresas, al mismo tiempo que garantizan los estándares nacionales e internacionales de seguridad y protección de la privacidad. La adopción generalizada del principio de solo una vez y el intercambio progresivo de datos entre las instituciones del sector público, junto con la introducción extensiva del uso informático y de las técnicas de inteligencia artificial, permiten a las Administraciones públicas tener una mejor comprensión de las necesidades de los ciudadanos y facilitan la transformación digital de la prestación de los servicios públicos.

\section{Metodología y definiciones}

Los datos proceden de la base de datos sobre la Sociedad de la Información de Eurostat y de la base de datos sobre TIC de la OCDE. Las autoridades públicas se refieren a servicios públicos y administrativos (por ejemplo, impuestos, aduanas, registro mercantil y seguridad social). Los datos abarcan los niveles local, regional y nacional.

Los ingresos altos corresponden a las personas con niveles en el $25 \%$ superior (el cuartil más alto de ingresos). Los bajos corresponden a personas con ingresos en el 25\% inferior (el cuartil más bajo). Los niveles de formación se basan en la Clasificación Internacional Normalizada de la Educación (CINE). Para más información, véase $<$ http://ec.europa.eu/eurostat $/>$. 


\section{Otras publicaciones}

OECD (2016), «Digital Government Toolkit», OECD, París, <http://www. oecd.org/governance/digital-government/toolkit/>.

OECD (2014), Recommendation of the Council on Digital Government Strategies, OECD Publishing, París, <http://www.oecd.org/gov/digitalgovernment/recommendation-on-digitalgovernment-strategies.htm $>$.

\section{Notas de los gráficos}

Los datos de Australia, Corea, Estados Unidos, Israel y Japón no están disponibles.

11.5: Los datos de Canadá, Polonia, Reino Unido, Suecia y Turquía corresponden a 2007 en lugar de 2006. Los datos de México corresponden a 2015 en lugar de 2016. La media de la OCDE excluye Canadá, Chile, Islandia y Nueva Zelanda, ya que faltan series temporales.

11.6: Los datos de los países miembros de la OCDE no europeos no están disponibles. Los datos de México corresponden a 2015 en lugar de 2016.

11.7: Los datos de los países miembros de la OCDE no europeos y de Islandia, Italia, Reino Unido y Suecia no están disponibles.

Gráfico 11.5. Personas que han utilizado Internet para completar formularios a través de los sitios web de las autoridades públicas en los últimos 12 meses, 2006 y 2016

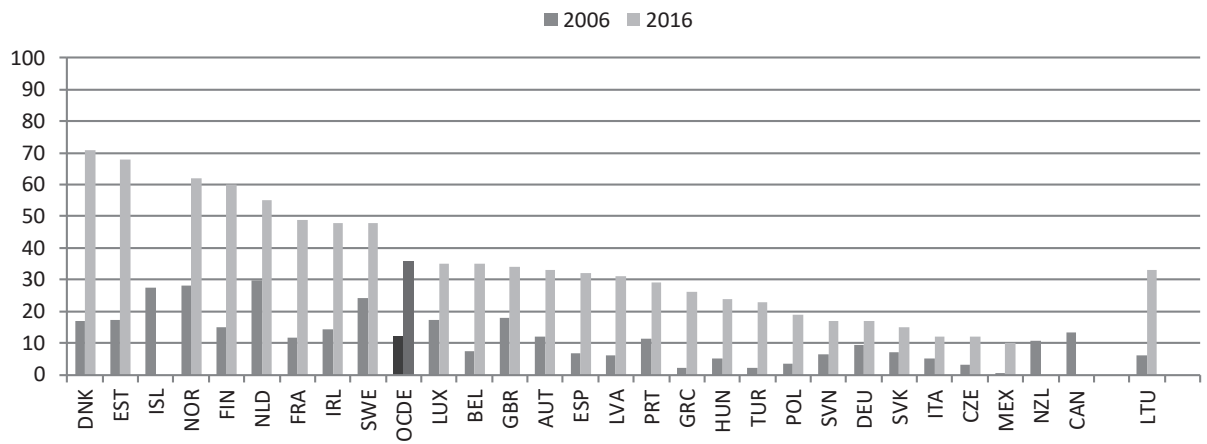

Fuentes: OCDE, Base de datos sobre TIC, OCDE, París; Eurostat, Base de datos sobre la Sociedad de la Información, Eurostat, Luxemburgo. 
Gráfico 11.6. Personas que han utilizado Internet para completar formularios a través de los sitios web de las autoridades públicas en los últimos 12 meses, por nivel de formación, 2016

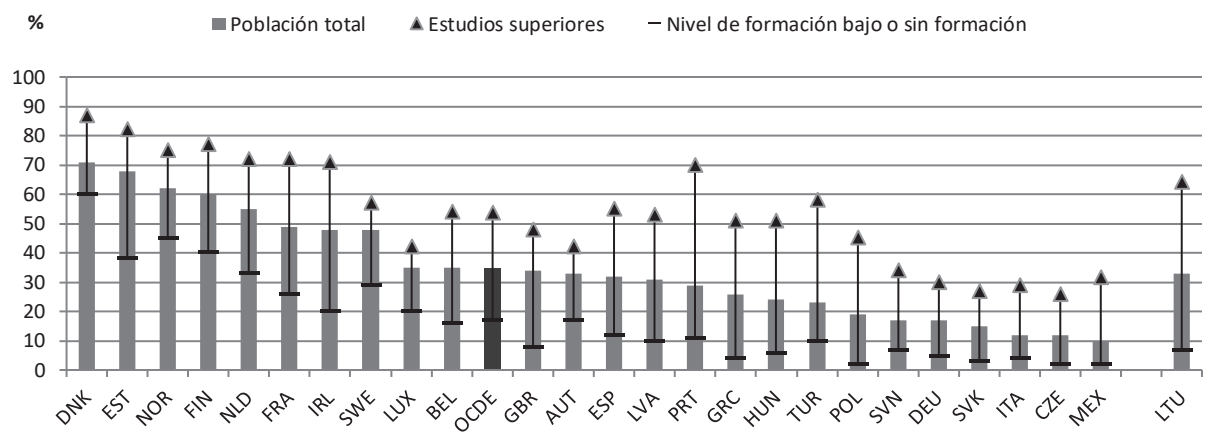

Fuentes: OCDE, Base de datos sobre TIC, OCDE, París; Eurostat, Base de datos sobre la Sociedad de la Información, Eurostat, Luxemburgo.

Gráfico 11.7. Personas que han utilizado Internet para completar formularios a través de los sitios web de las autoridades públicas en los últimos 12 meses, por nivel de ingresos, 2016

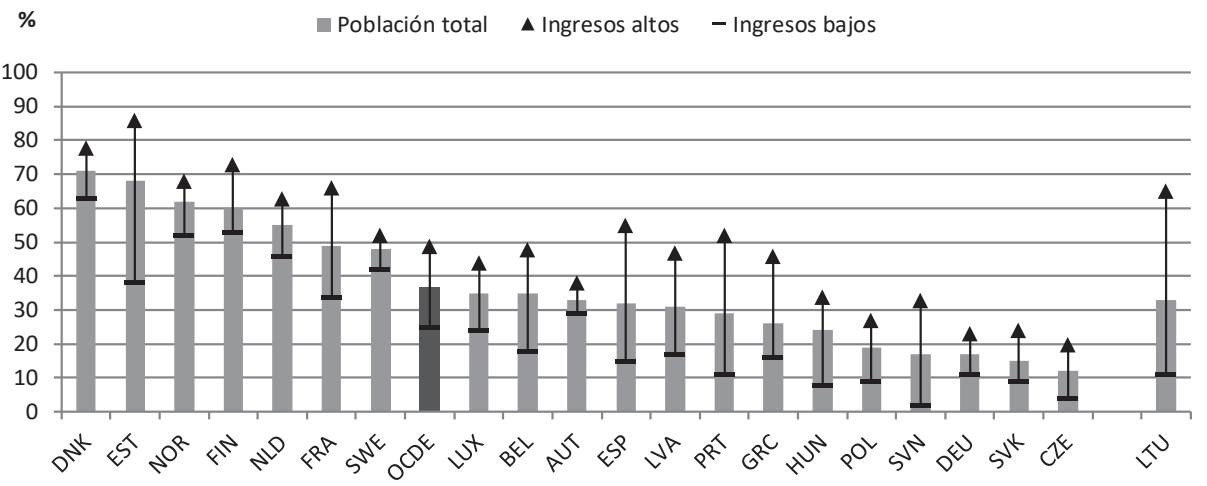

Fuentes: OCDE, Base de datos sobre TIC, OCDE, París; Eurostat, Base de datos sobre la Sociedad de la Información, Eurostat, Luxemburgo. 



\section{CAPÍTULO 12. GESTIÓN DEL RIESGO Y COMUNICACIÓN}

\section{IMPACTO SOCIOECONÓMICO DE LOS DESASTRES EN LOS PAÍSES DE LA OCDE}

Los países de la OCDE se han visto significativamente afectados por los desastres durante las últimas décadas, con consecuentes impactos económicos que van en aumento. Los desastres pueden derivarse de fenómenos naturales, pandemias, accidentes industriales o tecnológicos graves y de actos malintencionados. En los últimos 30 años, el número de desastres ha aumentado de alrededor de 100 a más de 300 al año en los países miembros de la OCDE, causando pérdidas anuales de cientos de miles de millones de dólares. Las consecuencias inmediatas son visibles en términos de vidas humanas y destrucción de capital, y los impactos a largo plazo se acumulan debido a los trastornos en los flujos económicos. Las grandes estructuras críticas también están en riesgo, con repercusiones devastadoras como se pudo observar tras el terremoto que sacudió el este de Japón en 2011. Estos desastres a gran escala han llevado a los países a reforzar sus políticas en materia de gobernanza del riesgo mediante la inclusión de un mayor número de partes interesadas y comunidades para identificar y evaluar los riesgos, así como mediante la implementación de medidas que aumentan la resiliencia a nivel nacional y subnacional.

Los riesgos de desastres se distribuyen de manera desigual en los países de la OCDE, con mayor incidencia en los países más grandes y densamente poblados. Los países con el promedio anual más elevado de desastres son Australia, Estados Unidos, Japón, México y Turquía (Gráfico 12.1). En cuanto a la media anual de daños económicos durante el periodo 1980-2016, los países con mayores pérdidas debidas a desastres fueron Estados Unidos, Italia y Japón. Sin embargo, el escenario cambia al relacionar el impacto de los desastres con los ingresos durante el periodo 1995-2015. Los países con actividad sísmica notable como Chile y Nueva Zelanda, en donde los centros urbanos han sido sacudidos recientemente por terremotos, tienen el mayor índice de daños en relación con los ingresos. En los países más ricos, como Estados 
Unidos y Japón, el impacto agregado es proporcionalmente menor, lo cual ayuda a estas economías a amortiguar el golpe. El análisis de un grupo más amplio de países, no solo los de la OCDE, revela una correlación entre un menor PIB per cápita y más pérdidas humanas debido a desastres, mientras que los países con un mayor PIB per cápita han experimentado un impacto económico más elevado pero menores pérdidas humanas (OCDE, 2014).

Aunque en promedio en los países de la OCDE las pérdidas económicas debidas a desastres han sido relativamente modestas en relación con el PIB total, grandes catástrofes específicas han tenido consecuencias a gran escala en algunos países, especialmente en las pequeñas economías. Los daños de los terremotos en Chile en 2010 y en Christchurch (Nueva Zelanda) en 2011 supusieron el equivalente al 20\% del PIB anual. Desde una perspectiva nacional, los huracanes como el Katrina quizá solo conllevaron daños económicos del $0,1 \%$ del PIB anual, pero las pérdidas estimadas en 125.000 millones de dólares fueron sufridas de forma desproporcional en la zona geográfica y en la población directamente afectada. El impacto económico local puede tener como consecuencia una caída considerable en la producción económica regional, con repercusiones negativas en las finanzas públicas de la zona, además de desequilibrios sectoriales y otras pérdidas resultantes de la erosión en la confianza de consumidores y empresas.

Los grandes riesgos pueden desarrollarse con rapidez y tener itinerarios imprevistos, causando impactos transfronterizos que se extienden a lo largo de distintas comunidades, sectores económicos y que traspasan límites nacionales. Por ejemplo, las erupciones del volcán Eyjafjallajökull en Islandia en 2010 produjeron una nube de cenizas sobre gran parte del espacio aéreo europeo, con la consecuente cancelación de numerosos vuelos en todo el mundo debido a las condiciones peligrosas. Estas cancelaciones no solo produjeron grandes pérdidas económicas a la industria del transporte aéreo, también interrumpieron la cadena de suministro de múltiples industrias que dependen de ella, incluyendo la de productos perecederos.

Puesto que los desastres han tenido impactos tan extensos y transfronterizos, a menudo con un efecto dominó, es importante extraer las lecciones de eventos pasados y predecir las tendencias futuras de vulnerabilidades con el fin de estar mejor preparados. Por esta razón, es necesario que los Gobiernos y el sector privado piensen en maneras innovadoras de abordar este problema $\mathrm{y}$ formen alianzas de trabajo conjunto para articular estrategias adecuadas de gobernanza del riesgo que mitiguen los futuros impactos. 


\section{Metodología y definiciones}

Los datos de desastres se basan en la EM-DAT, la Base de Datos Internacional sobre Desastres de OFDA/CRED ( $<w w w . e m d a t . b e>)$ desarrollada por la Universidad Católica de Lovaina, Bruselas (Bélgica). Para que un desastre se registre en la base de datos tiene que cumplir por lo menos uno de los siguientes criterios: que hayan muerto 10 o más personas, que haya habido 100 o más personas afectadas, que se produzca una declaración de estado de emergencia o que se realice una llamada de asistencia internacional. En cada desastre, la cifra registrada corresponde al valor de los daños en el momento del evento, es decir, las cantidades corresponden al año del desastre. Los datos del PIB anual proceden de las Estadísticas de Contabilidad Nacional (base de datos).

Los riesgos críticos se refieren a amenazas y peligros que plantean el riesgo más estratégicamente significativo, como resultado de (i) su probabilidad o posibilidad y (ii) de la importancia nacional de sus consecuencias negativas, incluidos fenómenos imprevistos y repentinos (por ejemplo, terremotos, accidentes industriales y ataques terroristas), fenómenos imprevistos de desarrollo gradual (por ejemplo, pandemias), y riesgos constantes (sobre todo los relacionados con el comercio ilegal o el crimen organizado).

\section{Otras publicaciones}

OECD (2014), «Boosting Resilience through Innovative Risk Governance», OECD Publishing, París, <http://dx.doi.org/10.1787/9789264209114-en>.

\section{Notas de los gráficos}

Las notas detalladas de los gráficos se proporcionan en el Statslinks.

Información sobre los datos de Israel: <http://dx.doi.org/10.1787/888932315602>. 


\section{Gráfico 12.1. Promedio anual de desastres en los países de la OCDE, 1980-2016}

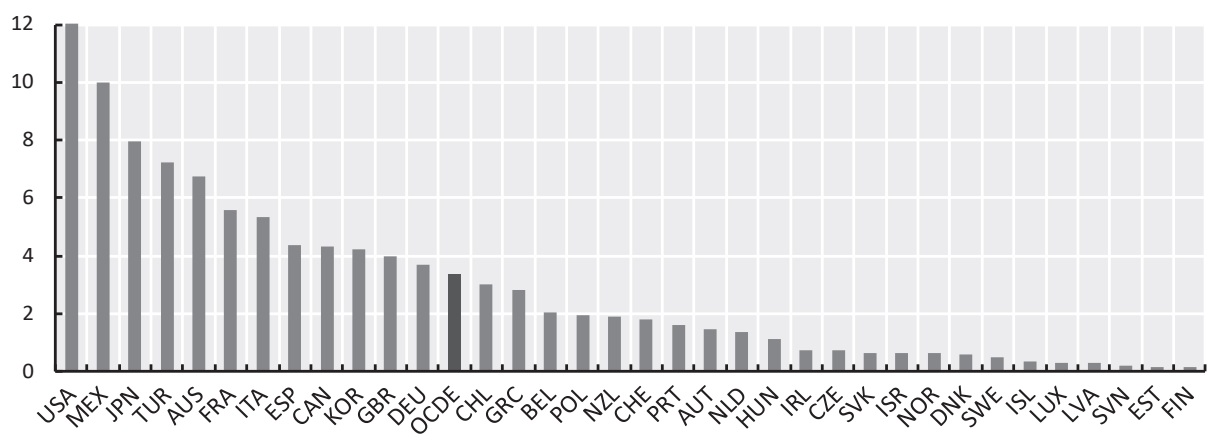

Fuente: Guha-Sapir, EM-DAT: Base de Datos Internacional sobre Desastres de OFDA/CRED, Universidad Católica de Lovaina, Bruselas, Bélgica, <www.emdat.be>, consultado en marzo de 2017.

$<$ http://dx.doi.org/10.1787/888933533473>

\section{Gráfico 12.2. Promedio de daños causados por desastres en los países de la OCDE, 1980-2016}

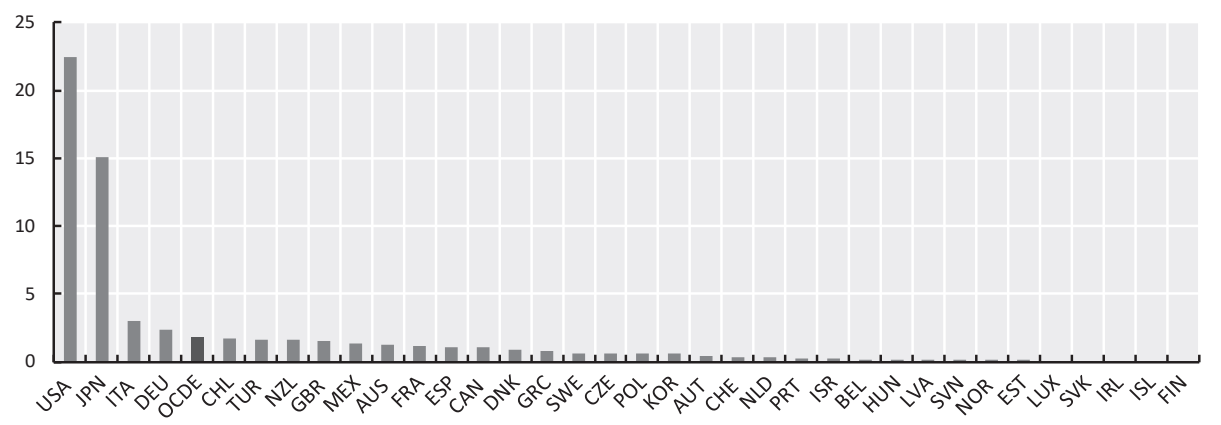

Fuente: Guha-Sapir, EM-DAT: Base de Datos Internacional sobre Desastres de OFDA/CRED, Universidad Católica de Lovaina, Bruselas, Bélgica, <www.emdat.be>, consultado en marzo de 2017. 


\section{Gráfico 12.3. Promedio de daños causados por desastres como porcentaje del PIB en los países de la OCDE, 1995-2015}

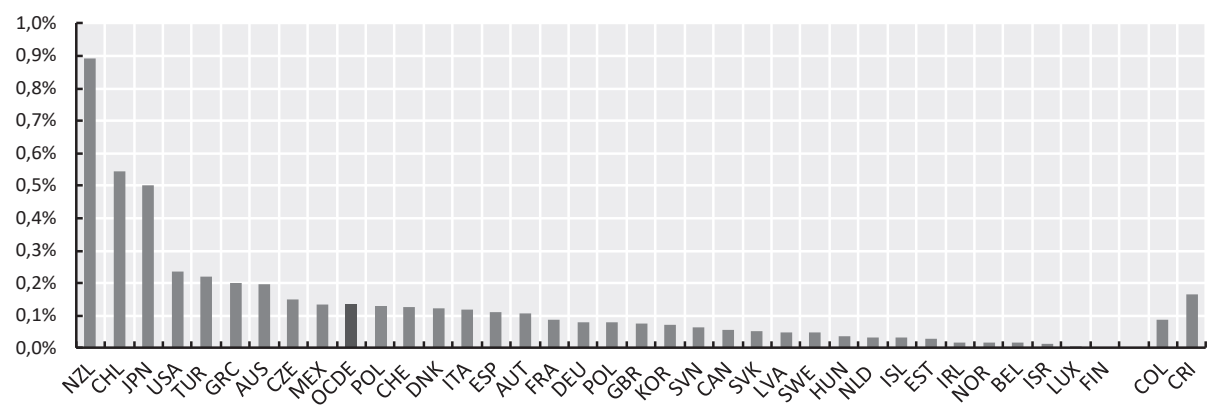

Fuente: Guha-Sapir, EM-DAT: Base de Datos Internacional sobre Desastres de OFDA/CRED, Universidad Católica de Lovaina, Bruselas, Bélgica, <www.emdat.be>, consultado en marzo de 2017.

$<$ http://dx.doi.org/10.1787/888933533511>

\section{GOBERNANZA DE RIESGOS CRÍTICOS}

La Recomendación del Consejo de la OCDE sobre la Gobernanza de Riesgos Críticos de 2014 propone que los países «involucren a todos los actores a nivel nacional y subnacional, para coordinar a un amplio abanico de partes interesadas en una formulación de políticas inclusivas» en materia de gobernanza de riesgos críticos. Este enfoque busca implicar a toda la sociedad en la seguridad y protección de los ciudadanos y su propiedad, y tiene como objetivo defender la integridad territorial y ayudar a mantener las infraestructuras críticas y el buen funcionamiento de los mercados. Los países de la OCDE han mostrado su compromiso en lograr la alta calidad de la gobernanza del riesgo, que se apoya en la implementación de políticas de gestión del riesgo. Los ciudadanos y empresas esperan que los Gobiernos estén preparados para una amplia gama de posibles crisis y conmociones mundiales, y que se enfrenten a ellos de manera efectiva en el caso de que surjan.

La OCDE también recomienda que los países miembros desarrollen una estrategia nacional para todo tipo de peligros que proporcione una visión conjunta en todas las fases del ciclo de gestión del riesgo: identificación y evaluación del riesgo, prevención y mitigación, preparación y respuesta, y recuperación y reconstrucción. En 2016, la OCDE realizó una encuesta de seguimiento de la implementación de la Recomendación sobre la Gobernanza de Riesgos Críticos, que muestra que la mayoría de los países (29) han establecido una estrategia nacional para gestionar los riesgos críticos, y que la mayoría de estos (24) siguen un enfoque que abarca todos los peligros. Casi todos los países de la OCDE han reconocido que se necesita una fuerte capacidad institucional, recursos y el compromiso constante del liderazgo del centro de gobierno. Como 
resultado, la mayoría de los países (28) asignaron el liderazgo, o la función de coordinar la gestión de los riesgos críticos, a una institución de la Administración central. Solo cuatro países no cuentan con una unidad de organización o coordinación que lidere la gestión de riesgos críticos.

La gestión de riesgos críticos abarca las competencias de muchos departamentos y organismos de las Administraciones públicas a distintos niveles. La gobernanza efectiva de políticas requiere por tanto mecanismos que coordinen este escenario complejo. La encuesta mostró que las instituciones líderes consultan una variedad de partes interesadas a nivel nacional y subnacional durante el proceso de formulación de políticas. La mayoría de los países (26) realizan conferencias ad hoc para interactuar con expertos en análisis del riesgo. Más de la mitad de los encuestados (23) llevan a cabo seminarios nacionales en los que los funcionarios públicos participan en diálogos políticos sobre la protección de las infraestructuras críticas, y alrededor de la mitad de los países (20) consultan a las ONG y grupos interesados mediante conferencias. Una pequeña minoría de países han puesto en marcha mecanismos que fomentan la participación ciudadana, como plataformas de redes sociales (6 países), consultas online (6) y reuniones municipales abiertas a todo el público (2). De cara al futuro, existe la necesidad de interactuar más directamente con los ciudadanos, por ejemplo, mediante redes sociales y plataformas virtuales que lleguen a mayores grupos de usuarios. La formulación de políticas de carácter más inclusivo fomenta un enfoque que integra a toda la sociedad y conlleva una tasa de cumplimiento de la normativa más alta, claridad en la rendición de cuentas $\mathrm{y}$, en última instancia, comunidades más resilientes.

\section{Metodología y datos}

Los datos se basan en la Encuesta sobre la gobernanza de riesgos críticos de 2016 que completaron 32 países de la OCDE y países en proceso de adhesión (Colombia, Costa Rica y Lituania). El cuestionario se centró en temas de gobernanza del riesgo y seleccionados de la gestión del riesgo. Se pidió a los encuestados que proporcionaran información sobre las políticas y prácticas de gestión del riesgo en funcionamiento a nivel central de la Administración. La Administración central incluye todos los ministerios/departamentos competentes del poder ejecutivo del Gobierno, e incluye también al gabinete u oficinas y órganos ejecutivos. No incluye los ministerios y departamentos subnacionales ni las empresas estatales y corporaciones públicas.

Un enfoque que integra a toda la sociedad conlleva la involucración de todas las partes interesadas, desde las personas hasta los organismos gubernamentales, empresas, organizaciones no gubernamentales y el tercer sector. 


\section{Otras publicaciones}

OECD (de próxima publicación), «Implementing the Recommendation on the Governance of Critical Risks: Overview of Country Progress», OECD Publishing, París.

OECD (2014), «OECD Recommendation on the Governance of Critical Risks», OECD Publishing, París, <www.oecd.org/gov/risk/Critical-RisksRecommendation.pdf>.

\section{Notas de los gráficos}

12.5: Incluye solo a países que contestaron «Sí» a la pregunta «¿Su gobierno tiene una institución (es decir, una organización principal o unidad de coordinación) a la que se le asigne el liderazgo en la gestión de riesgos críticos a nivel nacional?».

Información sobre los datos de Israel: <http://dx.doi.org/10.1787/888932315602>

12.6: Información sobre los datos de Israel: <http://dx.doi. org $/ 10.1787 / 888932315602>$.

\section{Gráfico 12.4. Estrategia nacional para la gobernanza de riesgos críticos,} 2016

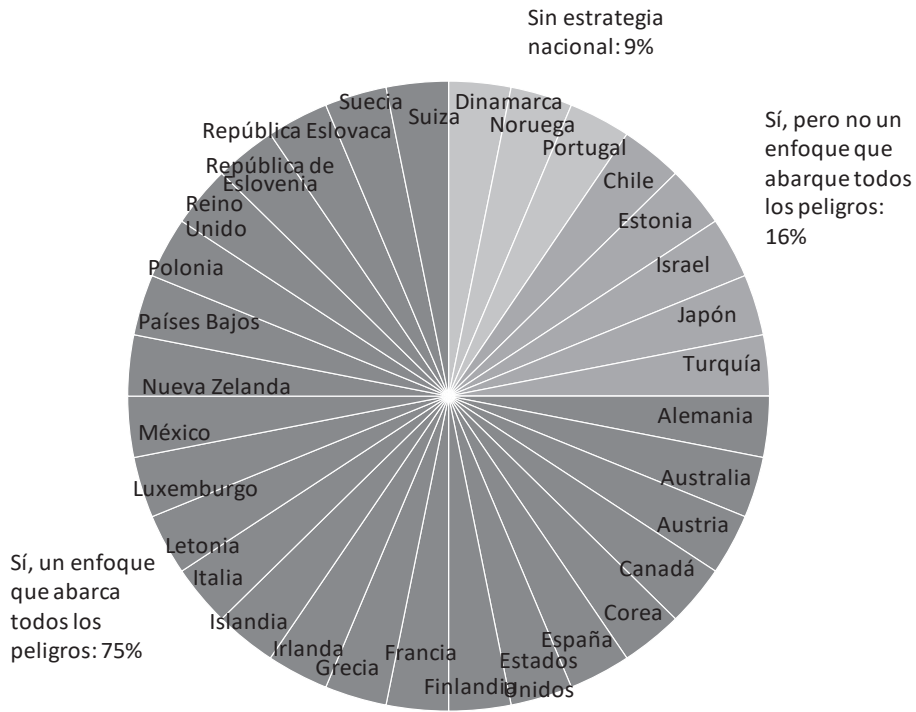

Fuente: OCDE (2016), Encuesta sobre la gobernanza de riesgos críticos, OCDE, París. 
Gráfico 12.5. Institución principal para la gobernanza de riesgos críticos, 2016

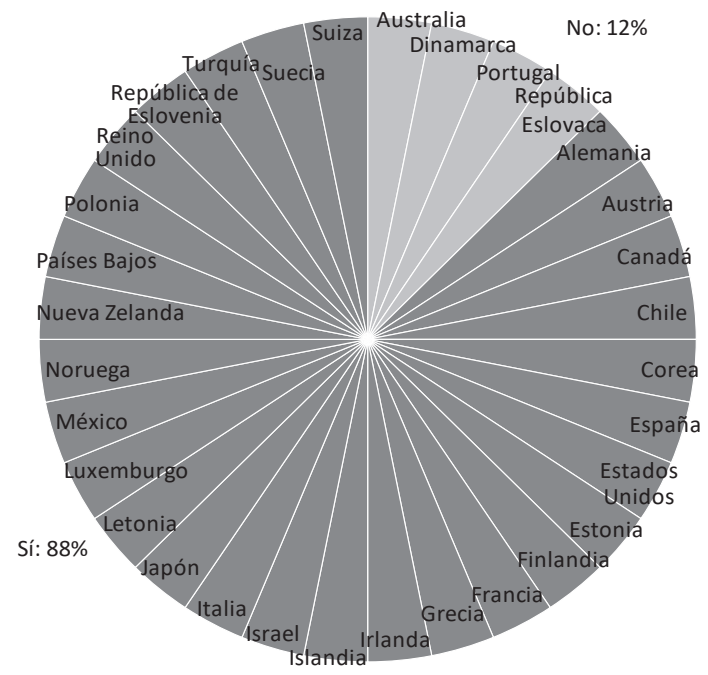

Fuente: OCDE (2016), Encuesta sobre la gobernanza de riesgos críticos, OCDE, París.

$<$ http://dx.doi.org/10.1787/888933533549>

Tabla 12.6. Función de gobernanza del riesgo de la organización responsable de la gestión de riesgos críticos a nivel central/federal, 2016

\begin{tabular}{|c|c|c|c|c|c|c|c|c|c|c|c|}
\hline & 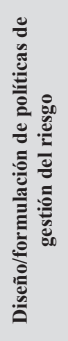 & 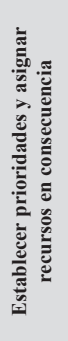 & 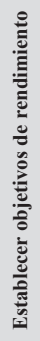 & 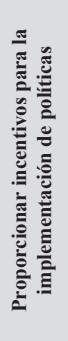 & 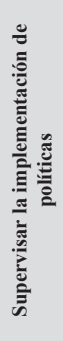 & 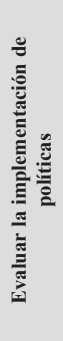 & 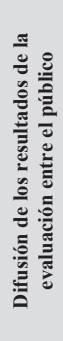 & 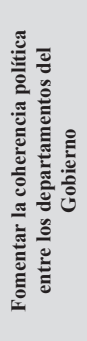 & 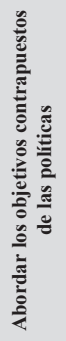 & 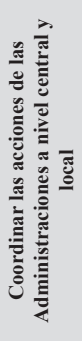 & 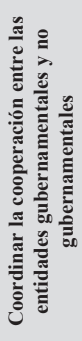 \\
\hline Alemania & 0 & O & 0 & 0 & O & O & O & $\bullet$ & O & 0 & $\bullet$ \\
\hline Australia & O & O & $\mathrm{X}$ & 0 & 0 & 0 & $\theta$ & 0 & O & o & 0 \\
\hline Austria & 0 & 0 & 0 & 0 & 0 & 0 & $\bullet$ & $\bullet$ & 0 & $\bullet$ & $\bullet$ \\
\hline Canadá & $\bullet$ & $\bullet$ & $\bullet$ & $\bullet$ & $\bullet$ & $\bullet$ & $\bullet$ & $\bullet$ & $\bullet$ & $\bullet$ & $\bullet$ \\
\hline Chile & $\bullet$ & O & 0 & $\bullet$ & 0 & 0 & 0 & $\bullet$ & $\bullet$ & $\bullet$ & $\bullet$ \\
\hline Corea & $\bullet$ & - & $\bullet$ & $\bullet$ & $\bullet$ & $\bullet$ & $\bullet$ & $\bullet$ & - & $\bullet$ & $\bullet$ \\
\hline Dinamarca & $\mathrm{X}$ & $\mathrm{X}$ & $\mathrm{X}$ & $\mathrm{x}$ & $\mathrm{x}$ & $\mathrm{x}$ & $\mathrm{x}$ & $\mathrm{X}$ & $\mathrm{X}$ & $\mathrm{X}$ & $\mathrm{x}$ \\
\hline España & $\bullet$ & $\bullet$ & $\bullet$ & $\bullet$ & $\bullet$ & $\bullet$ & $\bullet$ & $\bullet$ & $\bullet$ & $\bullet$ & $\bullet$ \\
\hline
\end{tabular}




\begin{tabular}{|c|c|c|c|c|c|c|c|c|c|c|c|}
\hline & 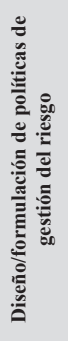 & 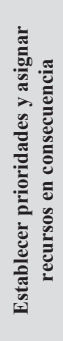 & 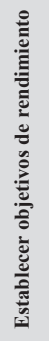 & 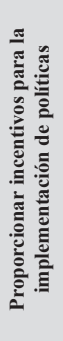 & 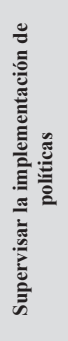 & 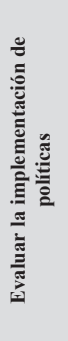 & 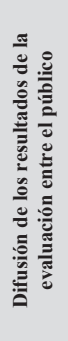 & 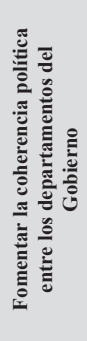 & 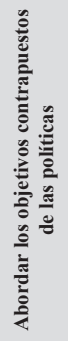 & 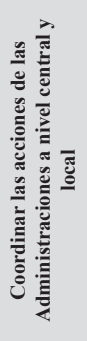 & 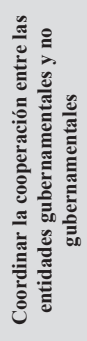 \\
\hline Estados Unidos & $\bullet$ & $\bullet$ & - & $\bullet$ & $\bullet$ & $\bullet$ & $\bullet$ & $\bullet$ & $\bullet$ & $\bullet$ & $\bullet$ \\
\hline Estonia & $\bullet$ & 0 & 0 & 0 & $\bullet$ & $\bullet$ & $\bullet$ & $\bullet$ & 0 & $\bullet$ & $\bullet$ \\
\hline Finlandia & 0 & 0 & 0 & 0 & $\bullet$ & $\bullet$ & 0 & $\bullet$ & 0 & 0 & $\bullet$ \\
\hline Francia & $\bullet$ & 0 & 0 & 0 & O & O & 0 & $\bullet$ & 0 & O & O \\
\hline Grecia & $\bullet$ & 0 & 0 & $\bullet$ & $\bullet$ & $\bullet$ & 0 & $\bullet$ & 0 & o & $\bullet$ \\
\hline Irlanda & 0 & 0 & 0 & 0 & 0 & 0 & 0 & 0 & 0 & 0 & O \\
\hline Islandia & 0 & $\bullet$ & $\bullet$ & $\bullet$ & 0 & 0 & $\bullet$ & $\bullet$ & $\bullet$ & $\bullet$ & - \\
\hline Israel & $\bullet$ & $\bullet$ & $\bullet$ & 0 & $\bullet$ & $\bullet$ & 0 & $\bullet$ & 0 & $\bullet$ & - \\
\hline Italia & $\bullet$ & 0 & 0 & 0 & $\bullet$ & $\bullet$ & $\bullet$ & $\bullet$ & $\bullet$ & $\bullet$ & - \\
\hline Japón & $\bullet$ & 0 & 0 & 0 & 0 & 0 & 0 & $\bullet$ & 0 & $\bullet$ & O \\
\hline Letonia & O & O & 0 & 0 & $\bullet$ & $\bullet$ & 0 & 0 & $\bullet$ & $\bullet$ & $\bullet$ \\
\hline Luxemburgo & $\bullet$ & $\bullet$ & $\bullet$ & - & $\bullet$ & $\bullet$ & $\bullet$ & $\bullet$ & $\bullet$ & $\bullet$ & - \\
\hline México & $\bullet$ & $\bullet$ & $\bullet$ & $\bullet$ & $\bullet$ & $\bullet$ & $\bullet$ & $\bullet$ & $\bullet$ & $\bullet$ & $\bullet$ \\
\hline Noruega & $\bullet$ & 0 & 0 & $\bullet$ & $\bullet$ & $\bullet$ & $\bullet$ & $\bullet$ & 0 & $\bullet$ & $\bullet$ \\
\hline Nueva Zelanda & $\bullet$ & $\bullet$ & 0 & 0 & 0 & 0 & 0 & $\bullet$ & $\bullet$ & $\bullet$ & O \\
\hline Países Bajos & $\bullet$ & O & $\bullet$ & $\bullet$ & $\bullet$ & $\bullet$ & $\bullet$ & $\bullet$ & $\bullet$ & $\bullet$ & $\bullet$ \\
\hline Polonia & $\bullet$ & 0 & 0 & O & $\bullet$ & $\bullet$ & $\bullet$ & $\bullet$ & 0 & 0 & O \\
\hline Portugal & $\mathrm{x}$ & $\mathrm{X}$ & $\mathrm{X}$ & $\mathrm{X}$ & $\mathrm{X}$ & $\mathrm{X}$ & $\mathrm{X}$ & $\mathrm{X}$ & $\mathrm{X}$ & $\mathrm{X}$ & $\mathrm{X}$ \\
\hline Reino Unido & $\bullet$ & $\bullet$ & $\bullet$ & $\bullet$ & $\bullet$ & $\bullet$ & $\bullet$ & $\bullet$ & $\bullet$ & $\bullet$ & $\bullet$ \\
\hline $\begin{array}{l}\text { República de } \\
\text { Eslovenia }\end{array}$ & O & 0 & 0 & $\bullet$ & 0 & $\bullet$ & $\bullet$ & $\bullet$ & O & $\bullet$ & $\bullet$ \\
\hline $\begin{array}{c}\text { República } \\
\text { Eslovaca }\end{array}$ & $\mathrm{x}$ & $\mathrm{X}$ & $\mathrm{X}$ & $\mathrm{X}$ & $\mathrm{X}$ & $\mathrm{X}$ & $\mathrm{X}$ & $\mathrm{X}$ & $\mathrm{X}$ & $\mathrm{X}$ & $\mathrm{X}$ \\
\hline Suecia & $\bullet$ & 0 & $\bullet$ & $\bullet$ & $\bullet$ & $\bullet$ & $\bullet$ & $\bullet$ & $\bullet$ & $\bullet$ & $\bullet$ \\
\hline Suiza & $\bullet$ & $\bullet$ & 0 & 0 & $\bullet$ & $\bullet$ & 0 & $\bullet$ & 0 & $\bullet$ & $\bullet$ \\
\hline Turquía & O & $\bullet$ & $\bullet$ & O & $\bullet$ & $\bullet$ & 0 & O & O & $\bullet$ & $\bullet$ \\
\hline \multicolumn{12}{|l|}{ Total OCDE } \\
\hline - Sí & 20 & 12 & 12 & 14 & 19 & 20 & 16 & 25 & 14 & 22 & 23 \\
\hline O No & 9 & 17 & 16 & 15 & 10 & 9 & 12 & 4 & 15 & 7 & 6 \\
\hline x No aplicable & 3 & 3 & 4 & 3 & 3 & 3 & 4 & 3 & 3 & 3 & 3 \\
\hline Costa Rica & $\bullet$ & - & - & $\bullet$ & $\bullet$ & $\bullet$ & $\bullet$ & - & - & $\bullet$ & $\bullet$ \\
\hline Colombia & $\bullet$ & $\bullet$ & $\bullet$ & $\bullet$ & $\bullet$ & $\bullet$ & $\bullet$ & $\bullet$ & $\bullet$ & $\bullet$ & $\bullet$ \\
\hline Lituania & $\bullet$ & $\bullet$ & - & $\bullet$ & $\bullet$ & $\bullet$ & $\bullet$ & $\bullet$ & $\bullet$ & $\bullet$ & $\bullet$ \\
\hline
\end{tabular}

Fuente: OCDE (2016), Encuesta sobre la gobernanza de riesgos críticos, OCDE, París.

$<$ http://dx.doi.org/10.1787/888933535392> 


\section{TENDENCIAS EN LA COMUNICACIÓN DEL RIESGO}

La comunicación es un aspecto fundamental de las estrategias de gestión del riesgo que tratan de reducir las pérdidas y daños futuros de los desastres. Aumenta la sensibilización en los hogares, empresas y comunidades relativa a los peligros y vulnerabilidades específicas, e informa sobre las medidas de prevención, mitigación y preparación que hay que tomar. Los debates públicos sobre la inversión en estas medidas se hallan, de esta manera, mejor fundamentados.

La Encuesta de la OCDE sobre las políticas y prácticas de la comunicación del riesgo (2015) muestra que las Administraciones centrales lideran la comunicación del riesgo, aunque en 15 países de la OCDE (y Colombia) esta función se comparte con las Administraciones subnacionales. El sector privado juega también un papel importante en algunos países, proporcionando información científica para los análisis subyacentes y transmitiendo y publicando los riesgos al público. El sector privado también comparte información con las autoridades públicas y la población cuando los accidentes relacionados con sus actividades suponen un peligro, como los accidentes industriales o de plantas nucleares. Esta encuesta muestra que el sector privado asume un rol oficial en la comunicación del riesgo en solo 9 de los países encuestados de la OCDE.

La responsabilidad básica de los gobiernos de proporcionar seguridad y protección públicas se fomenta mediante la comunicación efectiva de los riesgos que involucra a toda la sociedad. La Encuesta de la OCDE sobre la Gobernanza de Riesgos Críticos (2016) muestra que 31 países de la OCDE siguen este enfoque; indica que 29 países proporcionan información al público sobre las medidas que han de tomar antes de la llegada inminente del peligro, y que 27 países tratan de estimular la inversión en medidas de autoprotección y de desarrollo de la resiliencia comunicando información sobre los riesgos.

La utilización de canales de comunicación en los dos sentidos entre los proveedores y receptores de los mensajes se ha demostrado que promueve la comunicación eficaz en las situaciones de riesgo. Permite que las personas puedan proporcionar a las Administraciones públicas información más detallada sobre los riesgos a los que están expuestas distintas comunidades y partes interesadas para que puedan recalibrar sus decisiones de gestión en consecuencia. Esto a su vez promueve la confianza en las Administraciones y la credibilidad de sus políticas. Los datos de la encuesta de 2016 muestran que, en los países de la OCDE, las líneas de comunicación del riesgo en los dos sentidos están bien establecidas, con 20 países encuestados que proporcionan plataformas con este fin. Adicionalmente, la encuesta de 2015 muestra que 12 de los países encuestados han puesto en funcionamiento mecanismos de retroalimentación o interacción entre los ciudadanos y sus Administraciones públicas. Las redes sociales proporcionan un canal potente que fomenta el 
diálogo sobre riesgos, por ejemplo, con la creación de plataformas electrónicas interactivas.

La comunicación efectiva de riesgos se adapta a grupos específicos de población y se ajusta a las necesidades de gestión del riesgo de las diferentes situaciones demográficas y contextos sociales. Por ejemplo, las personas mayores pueden tener limitaciones físicas que les impidan reaccionar y cambiar su comportamiento cuando se enfrentan a una situación de peligro inminente. La comunicación del riesgo dirigida a niños en edad escolar debe ser diferente que la dirigida a adultos. Los países han realizado considerables esfuerzos para ajustar sus prácticas de comunicación del riesgo a las necesidades de grupos específicos de la población, y la encuesta de 2016 muestra que más de la mitad de los encuestados (24 países) realizan comunicación dirigida a grupos vulnerables.

La evaluación política de la influencia que la comunicación del riesgo tiene en el comportamiento es importante para discernir si los objetivos deseados han sido alcanzados y para aprender lecciones que mejoren el diseño de futuras políticas. Aunque 11 países de la OCDE han intentado evaluar el impacto de sus esfuerzos en la comunicación del riesgo, son pocos los que han informado de resultados concretos.

\section{Metodología y definiciones}

Los datos se basan en la Encuesta de la OCDE sobre la gobernanza de riesgos críticos (2016) y en la Encuesta de la OCDE sobre las politicas y prácticas de comunicación del riesgo (2015), las cuales se realizaron a países de la OCDE y países en proceso de adhesión (Colombia, Costa Rica y Lituania). Los encuestados eran principalmente funcionarios en departamentos de la Administración central.

La comunicación del riesgo es el intercambio de información sobre la exposición de poblaciones y bienes a un peligro. El objetivo es mantener o mejorar la comprensión del riesgo, influir en la percepción del riesgo y/o dotar a las personas o grupos para que actúen de manera apropiada en respuesta a un riesgo detectado.

La comunicación en los dos sentidos es una forma de comunicar información en la que las dos partes involucradas transmiten información la una a la otra.

Hay información más detallada sobre los actores con responsabilidad legal u oficial disponible online (véase el Anexo F). 


\section{Otras publicaciones}

OECD (2016), «Trends in Risk Communication Policies and Practices», OECD Publishing, París, http://dx.doi. org/10.1787/9789264260467-en.

OECD (2014), «OECD Recommendation on the Governance of Critical Risks», OECD, Paris, http://www.oecd.org/gov/risk/Critical-Risks-Recommendation.pdf.

\section{Notas de los gráficos}

12.8: «No aplicable» se refiere a países que contestaron «Sí» a la pregunta « $i \mathrm{Su}$ gobierno fomenta un enfoque que integra a toda la sociedad en la comunicación del riesgo?».

12.9: «No aplicable» se refiere a países que no proporcionaron una respuesta a la pregunta «¿Existen mecanismos de retroalimentación e interacción entre los ciudadanos y el gobierno?» o que contestaron «No sabe».

12.10: «No aplicable» se refiere a países que no proporcionaron una respuesta a la pregunta «¿Existen estudios en su país que evalúen el impacto de la comunicación del riesgo?» o que contestaron «No sabe».

Información sobre los datos de Israel: <http://dx.doi.org/10.1787/888932315602>.

Tabla 12.8. Objetivos de las estrategias de comunicación del riesgo a nivel central/federal que fomentan un enfoque en la comunicación del riesgo que integra a toda la sociedad, 2016

\begin{tabular}{|c|c|c|c|c|c|c|}
\hline & \multicolumn{2}{|c|}{ Fomentar la inclusión } & \multicolumn{2}{|c|}{$\begin{array}{l}\text { Fomentar medidas de } \\
\text { autoprotección }\end{array}$} & \multicolumn{2}{|c|}{$\begin{array}{c}\text { Fomentar la comunicación en los } \\
\text { dos sentidos }\end{array}$} \\
\hline & $\begin{array}{l}\text { Comunicación } \\
\text { dirigida a } \\
\text { grupos } \\
\text { vulnerables de } \\
\text { la población }\end{array}$ & $\begin{array}{c}\text { Promover } \\
\text { medidas de } \\
\text { resiliencia en } \\
\text { los hogares a } \\
\text { través del } \\
\text { sistema de } \\
\text { educación } \\
\text { pública }\end{array}$ & $\begin{array}{c}\text { Información } \\
\text { para estimular } \\
\text { la inversión en } \\
\text { medidas de } \\
\text { autoprotección } \\
\text { y desarrollo de } \\
\text { la resiliencia }\end{array}$ & $\begin{array}{c}\text { Información al } \\
\text { público sobre } \\
\text { qué medidas } \\
\text { adoptar antes } \\
\text { de la llegada } \\
\text { inminente del } \\
\text { peligro }\end{array}$ & $\begin{array}{c}\text { Foros de } \\
\text { debate sobre } \\
\text { la necesidad } \\
\text { de prevención }\end{array}$ & $\begin{array}{c}\text { Plataformas } \\
\text { para la } \\
\text { comunicación } \\
\text { del riesgo en los } \\
\text { dos sentidos } \\
\text { con las partes } \\
\text { interesadas }\end{array}$ \\
\hline Alemania & $\bullet$ & $\bullet$ & - & O & O & O \\
\hline Australia & 0 & 0 & - & 0 & 0 & 0 \\
\hline Austria & 0 & 0 & 0 & - & - & - \\
\hline Canadá & $\bullet$ & 0 & - & ○ & - & - \\
\hline Chile & - & ○ & - & - & 0 & 0 \\
\hline Corea & $\bullet$ & ○ & 0 & - & 0 & ? \\
\hline Dinamarca & O & 0 & - & O & 0 & - \\
\hline España & $\bullet$ & 0 & 0 & 0 & 0 & 0 \\
\hline
\end{tabular}




\begin{tabular}{|c|c|c|c|c|c|c|}
\hline & \multicolumn{2}{|c|}{ Fomentar la inclusión } & \multicolumn{2}{|c|}{$\begin{array}{c}\text { Fomentar medidas de } \\
\text { autoprotección }\end{array}$} & \multicolumn{2}{|c|}{$\begin{array}{c}\text { Fomentar la comunicación en los } \\
\text { dos sentidos }\end{array}$} \\
\hline & $\begin{array}{l}\text { Comunicación } \\
\text { dirigida a } \\
\text { grupos } \\
\text { vulnerables de } \\
\text { la población }\end{array}$ & $\begin{array}{c}\text { Promover } \\
\text { medidas de } \\
\text { resiliencia en } \\
\text { los hogares a } \\
\text { través del } \\
\text { sistema de } \\
\text { educación } \\
\text { pública }\end{array}$ & $\begin{array}{c}\text { Información } \\
\text { para estimular } \\
\text { la inversión en } \\
\text { medidas de } \\
\text { autoprotección } \\
\text { y desarrollo de } \\
\text { la resiliencia }\end{array}$ & $\begin{array}{l}\text { Información al } \\
\text { público sobre } \\
\text { qué medidas } \\
\text { adoptar antes } \\
\text { de la llegada } \\
\text { inminente del } \\
\text { peligro }\end{array}$ & $\begin{array}{c}\text { Foros de } \\
\text { debate sobre } \\
\text { la necesidad } \\
\text { de prevención }\end{array}$ & $\begin{array}{c}\text { Plataformas } \\
\text { para la } \\
\text { comunicación } \\
\text { del riesgo en los } \\
\text { dos sentidos } \\
\text { con las partes } \\
\text { interesadas }\end{array}$ \\
\hline Estados Unidos & $\bullet$ & $\bullet$ & $\bullet$ & $\bullet$ & $\bullet$ & $\bullet$ \\
\hline Estonia & O & O & O & $\bullet$ & $\bullet$ & O \\
\hline Finlandia & $\bullet$ & $\bullet$ & $\bullet$ & $\bullet$ & $\bullet$ & $\bullet$ \\
\hline Francia & 0 & 0 & 0 & 0 & 0 & 0 \\
\hline Grecia & 0 & 0 & $\bullet$ & $\bullet$ & O & $\bullet$ \\
\hline Irlanda & $\bullet$ & $\bullet$ & $\bullet$ & $\bullet$ & O & O \\
\hline Islandia & $\bullet$ & 0 & $\bullet$ & $\bullet$ & 0 & $\bullet$ \\
\hline Israel & 0 & 0 & 0 & 0 & $\mathrm{O}$ & 0 \\
\hline Italia & 0 & 0 & 0 & 0 & 0 & 0 \\
\hline Japón & 0 & 0 & - & 0 & 0 & 0 \\
\hline Letonia & $\bullet$ & $\bullet$ & O & $\bullet$ & O & $\bullet$ \\
\hline Luxemburgo & 0 & $\bigcirc$ & 0 & 0 & 0 & 0 \\
\hline México & 0 & 0 & 0 & 0 & 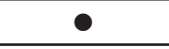 & 0 \\
\hline Noruega & 0 & 0 & 0 & 0 & 0 & 0 \\
\hline Nueva Zelanda & 0 & 0 & 0 & 0 & 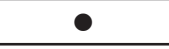 & 0 \\
\hline Países Bajos & 0 & 0 & 0 & 0 & 0 & 0 \\
\hline Polonia & 4 & 4 & 4 & 4 & 4 & 4 \\
\hline Portugal & 0 & 0 & 0 & 0 & 0 & 0 \\
\hline Reino Unido & 0 & 0 & 0 & $\bullet$ & $\bullet$ & 0 \\
\hline $\begin{array}{c}\text { República de } \\
\text { Eslovenia }\end{array}$ & $\bullet$ & $\bullet$ & $\bullet$ & ○ & O & O \\
\hline República Eslovaca & $\bigcirc$ & 0 & 0 & 0 & 0 & 0 \\
\hline Suecia & 0 & 0 & 0 & 0 & 0 & 0 \\
\hline Suiza & 0 & 0 & - & 0 & $\bullet$ & 0 \\
\hline Turquía & 0 & 0 & - & $\bullet$ & $\bigcirc$ & 0 \\
\hline \multicolumn{7}{|l|}{ Total OCDE } \\
\hline - Sí & 24 & 22 & 27 & 29 & 16 & 20 \\
\hline No & 7 & 9 & 4 & 2 & 16 & 12 \\
\hline x No aplicable & 1 & 1 & 1 & 1 & 1 & 1 \\
\hline Colombia & 0 & 0 & 0 & 0 & 0 & 0 \\
\hline Costa Rica & 0 & 0 & - & 0 & 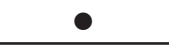 & 0 \\
\hline Lituania & $\bullet$ & $\bullet$ & $\bullet$ & $\bullet$ & O & $\bullet$ \\
\hline
\end{tabular}

Fuente: OCDE (2016), Encuesta sobre la gobernanza de riesgos críticos, OCDE, París. 


\section{Gráfico 12.9. Mecanismos de retroalimentación e interacción entre los ciudadanos y el Gobierno}

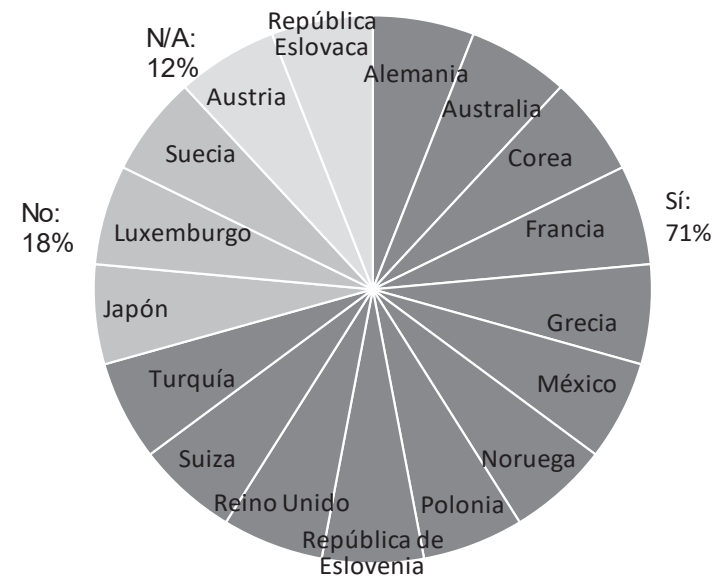

Fuente: OCDE (2016), Encuesta sobre la gobernanza de riesgos críticos, OCDE, París.

$<$ http://dx.doi.org/10.1787/888933533568>

\section{Gráfico 12.10. Estudios para evaluar el impacto de la comunicación del riesgo, 2015}

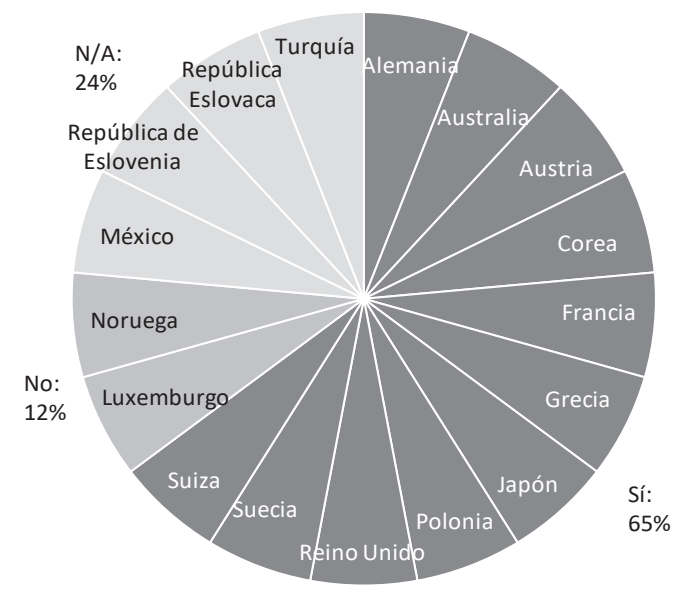

Fuente: OCDE (2016), Encuesta sobre la gobernanza de riesgos críticos, OCDE, París.

$<$ http://dx.doi.org/10.1787/888933533587> 


\section{CAPÍTULO 13. RESULTADOS BÁSICOS DE LAS ADMINISTRACIONES PÚBLICAS}

\section{CONFIANZA EN EL GOBIERNO}

La confianza se puede entender como una percepción positiva sobre las acciones de una persona u organización. Esta percepción positiva puede estar fundamentada en la experiencia real, pero se determina en gran medida por las evaluaciones subjetivas de las personas. La confianza en las Administraciones públicas supone un motor de la efectividad de la Administración y del desarrollo económico y una medida de los resultados para la acción de gobierno. La confianza en las Administraciones conlleva un mayor cumplimiento de la normativa y del sistema fiscal, facilita el consenso social y político, fomenta la aceptación de políticas que requieren el sacrificio a corto plazo de la población y moviliza el compromiso ciudadano para facilitar los procesos abiertos e inclusivos. La confianza en las Administraciones también apoya el crecimiento económico estimulando la inversión y el consumo. Los niveles de confianza dependen en parte de las valoraciones de los ciudadanos sobre su Gobierno; si lo consideran fiable, receptivo e imparcial, capaz de proteger a la población de riesgos y de proporcionar servicios públicos de manera efectiva.

Los niveles de confianza en el Gobierno nacional varían significativamente entre los países de la OCDE y a lo largo del tiempo. Los factores sociales, económicos y culturales influyen en las diferencias de confianza entre los países. Consecuentemente, el análisis se centra en los cambios en los niveles de confianza a lo largo del tiempo, en lugar de en los niveles absolutos de confianza. Los datos más recientes se comparan con los valores de 2007, el año anterior al comienzo de la crisis financiera y económica. En promedio, menos de la mitad de los ciudadanos de los países de la OCDE (42\%) tienen confianza en su Gobierno nacional, lo que supone un descenso de tres puntos porcentuales desde 2007. Las mayores pérdidas de confianza en este, de más de 20 puntos porcentuales, se han dado en Chile, Eslovenia, Finlandia y Grecia. En el otro extremo, se han observado cambios positivos a nivel similar en Alemania, Israel y República Eslovaca. Sin embargo, los cambios en los niveles de confianza a lo largo del tiempo deben ser interpretados con cautela, ya que 
pueden estar influidos por muchos factores, incluyendo la situación económica, los cambios políticos (por ejemplo, las elecciones) y otros eventos importantes como los desastres y grandes escándalos (por ejemplo, los casos de corrupción). Además, las expectativas de los ciudadanos podrían aumentar a un ritmo mayor que las respuestas de las Administraciones, erosionando la confianza de los ciudadanos en la capacidad de sus Gobiernos de reaccionar a las nuevas circunstancias.

En los países de la OCDE, la confianza en el Gobierno está correlacionada con la aprobación ciudadana del liderazgo político y con la percepción del alcance de la corrupción en las Administraciones públicas. En los países donde los ciudadanos consideran que sus Gobiernos tienen una alta integridad moral, hay mayores niveles de confianza. De manera similar, las acciones de los líderes políticos y la opinión pública resultante pueden repercutir en la percepción ciudadana de las instituciones gubernamentales que representan.

\section{Metodología y definiciones}

Las medidas de confianza en el Gobierno a menudo se basan en las evidencias de las encuestas de percepción. Los datos proceden de la Encuesta Mundial Gallup (EMG), que es el instrumento más usado para calibrar la medida de confianza en el Gobierno. Es la única que recoge datos de los niveles de confianza en el Gobierno de manera anual en los países de la OCDE y otras economías importantes. La EMG recopila datos basándose en el muestreo probabilístico estratificado proporcional y utiliza una muestra de alrededor de 1.000 ciudadanos para la mayoría de los países.

La metodología de la EMG tiene algunas limitaciones: mide la confianza en el Gobierno mediante una única pregunta acerca de si la gente tiene confianza en su Gobierno nacional; no especifica ningún ámbito determinado de este ni diferencia entre los políticos y la burocracia gubernamental en su pregunta. La EMG no permite identificar las acciones públicas que provocan la confianza o desconfianza de los ciudadanos en su Gobierno.

Más información sobre la EMG está disponible en <www.gallup.com/ services/170945/world-poll.aspx>. 


\section{Otras publicaciones}

OECD (2016), «Trust in government», OECD, París, <www.oecd.org/gov/ trust-in-government.htm>.

OECD (de próxima publicación), «Trust in government: Towards actionable policy insights». Background paper, OECD, París.

\section{Notas de los gráficos}

13.1: Los datos sobre confianza en el Gobierno nacional de Canadá, Estados Unidos e Islandia están basados en una muestra de alrededor de 500 ciudadanos.

Los datos se refieren al porcentaje que contesto «Sí» a la pregunta «¿Tiene confianza en su Gobierno nacional?». Los datos de Australia, Finlandia, Irlanda, Noruega, Portugal, República Eslovaca, República de Eslovenia y Suiza corresponden a 2006 en lugar de 2007. Los datos de Islandia y Luxemburgo corresponden a 2008 en lugar de 2007.

Información sobre los datos de Israel: <http://dx.doi.org/10.1787/888932315602>.

\section{Gráfico 13.1. Confianza en el gobierno nacional en 2016 y cambios desde 2007}

— en 2016 - Cambio en puntos porcentuales desde 2007

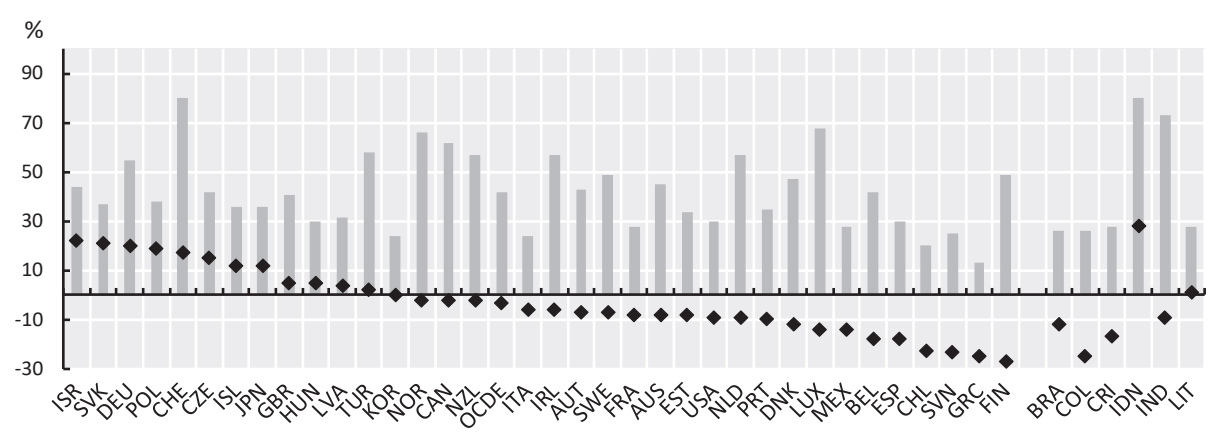

Fuente: Encuesta Mundial Gallup. 


\section{REDISTRIBUCIÓN DE LOS INGRESOS}

La desigualdad de ingresos ha crecido durante las últimas décadas en muchos países de la OCDE y registra un récord histórico en un número de economías. La redistribución de los ingresos a través de los impuestos y transferencias públicas ayuda a reducir la pobreza y desigualdad, reforzando así la economía y fomentando el bienestar social. La desigualdad de ingresos tiene repercusiones profundas no solo en las condiciones de vida de las personas y familias, sino también en sus estados de salud, en la igualdad de oportunidades, cohesión social y confianza en las instituciones. Dificulta además el crecimiento económico a largo plazo, puesto que los hogares de bajos ingresos ven limitadas sus oportunidades de invertir en educación y formación. Esto a su vez dificulta la empleabilidad de las personas, en menor medida durante los auges económicos, pero de manera importante en los periodos posteriores a las crisis económicas (OCDE, 2015).

El coeficiente Gini es la medida estándar para calibrar la desigualdad y representa la distribución de ingresos de la población en un país determinado. Tiene valor 0 cuando todas las personas tienen los mismos ingresos y valor 1 cuando una persona tiene todos los ingresos. Los efectos de las políticas de redistribución de ingresos se pueden medir comparando el coeficiente Gini antes y después de aplicar los impuestos y transferencias. En los países de la OCDE, las desigualdades de ingresos se reducen mediante impuestos y transferencias, con un nivel medio de redistribución del 16\% del promedio de ingresos antes de impuestos y transferencias. En alrededor de un tercio de las economías de la OCDE, la desigualdad se reduce en más de un $20 \%$ mediante las transferencias públicas y sistemas fiscales. Los niveles de redistribución son más elevados en Finlandia e Irlanda. En algunos países de la OCDE, la redistribución de ingresos supone cambios en la desigualdad por debajo del $5 \%$, incluyendo Chile, Corea, México y Turquía.

En promedio, el nivel de desigualdad de ingresos en los países de la OCDE era principalmente el mismo en 2013 que en 2007, antes del comienzo de la crisis. El mayor descenso en la desigualdad de los ingresos disponibles por hogar entre 2007 y 2013 se dio en Islandia y Letonia, mientras que el mayor crecimiento se observó en España, Estonia, República Eslovaca y Suecia. En estos países, los ingresos laborales, que suelen suponer la mayor proporción de los ingresos del mercado, cayeron de manera marcada en el $10 \%$ de la población trabajadora con ingresos más bajos. Los ingresos laborales del 10\% con ingresos superiores sufrieron pérdidas mínimas o incluso crecieron. Esto refleja la evolución de los países miembros de la OCDE, donde los ingresos laborales descendieron especialmente en el $10 \%$ de rango de población con ingresos más bajos, mientras que los ingresos laborales medios o del $10 \%$ con ingresos mayores permanecieron estables o crecieron. Chile lidera el crecimiento de los ingresos laborales, que en este país también incluye a los hogares de bajos ingresos. La media de ingresos laborales descendió de manera 
más notable en los países que se vieron más afectados por la crisis y que, por tanto, experimentaron altos índices de desempleo y reducciones salariales, como España y Grecia (OCDE, 2016).

\section{Metodología y definiciones}

La redistribución se mide comparando los coeficientes Gini para los ingresos de los hogares (es decir, ingresos totales de fuentes del mercado como salarios, dividendos, etc., no ajustados por las transferencias públicas en metálico y los impuestos a los hogares) con los ingresos disponibles (es decir, netos tras transferencias públicas directas e impuestos directos) de la población total. Se ajusta a las diferencias en las necesidades de hogares de distinto tamaño con una escala de equivalencia que divide los ingresos familiares por la raíz cuadrada del tamaño del hogar. Los ingresos laborales reales corresponden a los ingresos por salarios y por autoempleo ajustados a la inflación.

Los datos proceden de la -' (IDD, por sus siglas en inglés) de la OCDE, que se basa en fuentes nacionales (encuestas de hogares y registros administrativos) y en definiciones, clasificaciones y tratamiento de datos comunes. El método de recopilación de datos utilizado por la IDD de la OCDE pretende maximizar la comparabilidad internacional, así como la coherencia temporal de los datos. Esto se logra mediante un conjunto común de protocolos y convenciones estadísticas para derivar estimaciones comparables.

\section{Otras publicaciones}

OECD (2016), «Income inequality remains high in the face of weak recovery», Inequality Update, noviembre 2016, OECD, París.

OECD (2015), «In It together: Why less Inequality Benefits All», OECD Publishing, París.

\section{Notas de los gráficos}

13.2: Los datos de Australia, Estados Unidos, Finlandia, Hungría, Israel, México y Países Bajos corresponden a 2014 en lugar de 2013. Los datos de Japón y Nueva Zelanda corresponden a 2012 en lugar de 2013. En el caso de Hungría, México y Turquía, los ingresos de los hogares se presentan después de impuestos y antes de transferencias y, por tanto, los datos no son estrictamente comparables. 
13.3: Los datos de Alemania, Australia, Estados Unidos, Francia, Israel, México, Noruega, Nueva Zelanda y Suecia corresponden a 2008 en lugar de 2007. Los datos de Chile y Suiza corresponden a 2009 en lugar de 2007. Hay una ruptura en las series de Suiza y los resultados no son estrictamente comparables. Los valores de la media de la OCDE no incluyen Suiza.

13.4: Los datos de Suiza no están disponibles. Los datos de Alemania, Australia, Estados Unidos, Francia, Israel, México, Noruega, Nueva Zelanda y Suecia corresponden a 2008 en lugar de 2007. Los datos de Chile y Japón corresponden a 2006 en lugar de 2007. Los datos de Australia, Corea, Estados Unidos, Finlandia, Hungría, Israel, México y Países Bajos corresponden a 2014 en lugar de 2013. Los datos de Japón y Nueva Zelanda corresponden a 2012 en lugar de 2013.

Información sobre los datos de Israel: <http://dx.doi.org/10.1787/888932315602>.

\section{Gráfico 13.2. Diferencias en la desigualdad de ingresos antes y después de impuestos y transferencias públicas, 2013}

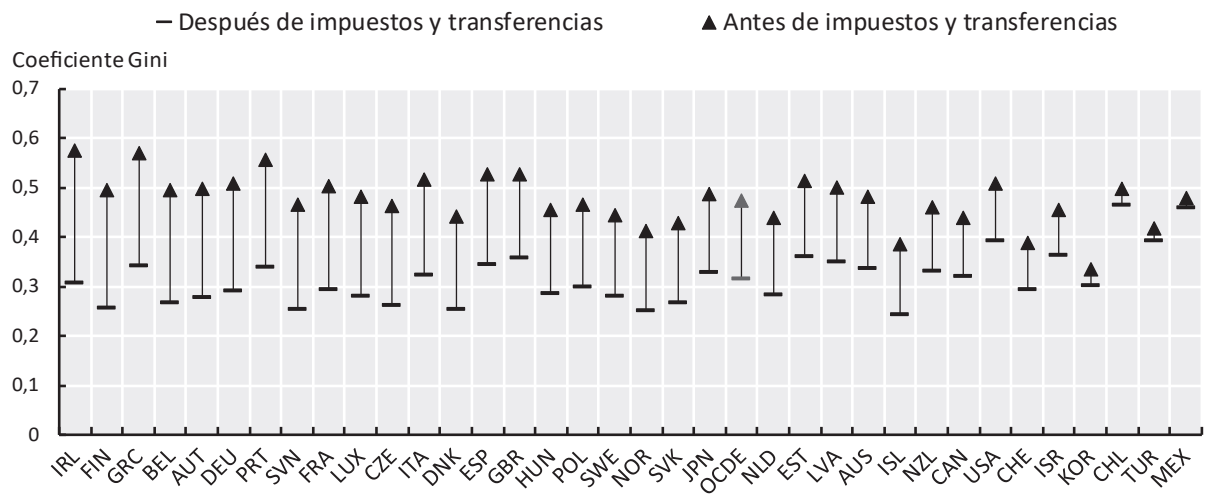

Fuente: OCDE, Base de Datos de Distribución de Ingresos. 
Gráfico 13.3. Diferencias en la desigualdad de ingresos después de impuestos y transferencias públicas entre 2007 y 2013

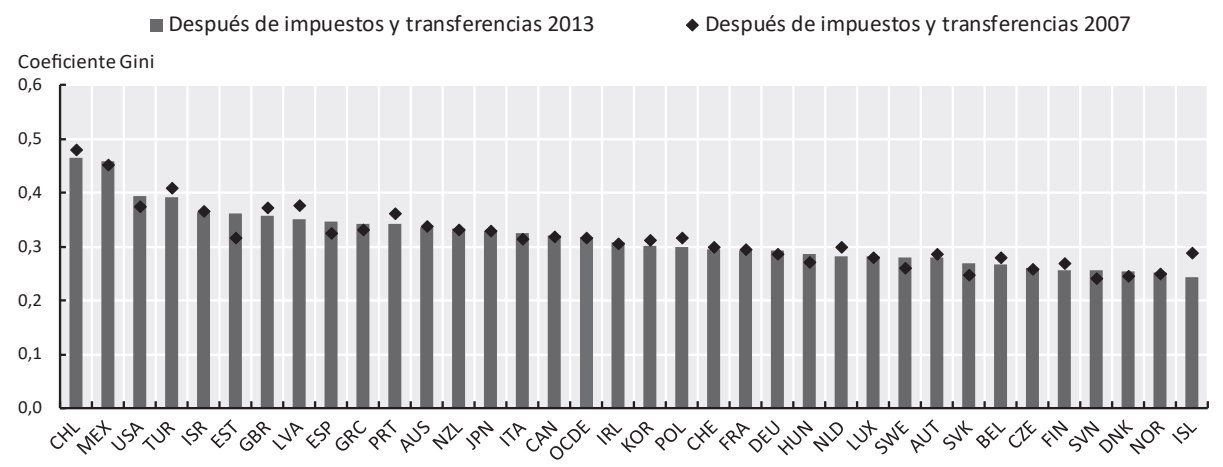

Fuente: OCDE, Base de Datos de Distribución de Ingresos.

<http://dx.doi.org/10.1787/888933533644>

Gráfico 13.4. Cambios en el crecimiento de ingresos laborales reales entre 2007 y 2013 por grupo de ingresos, población en edad de trabajar

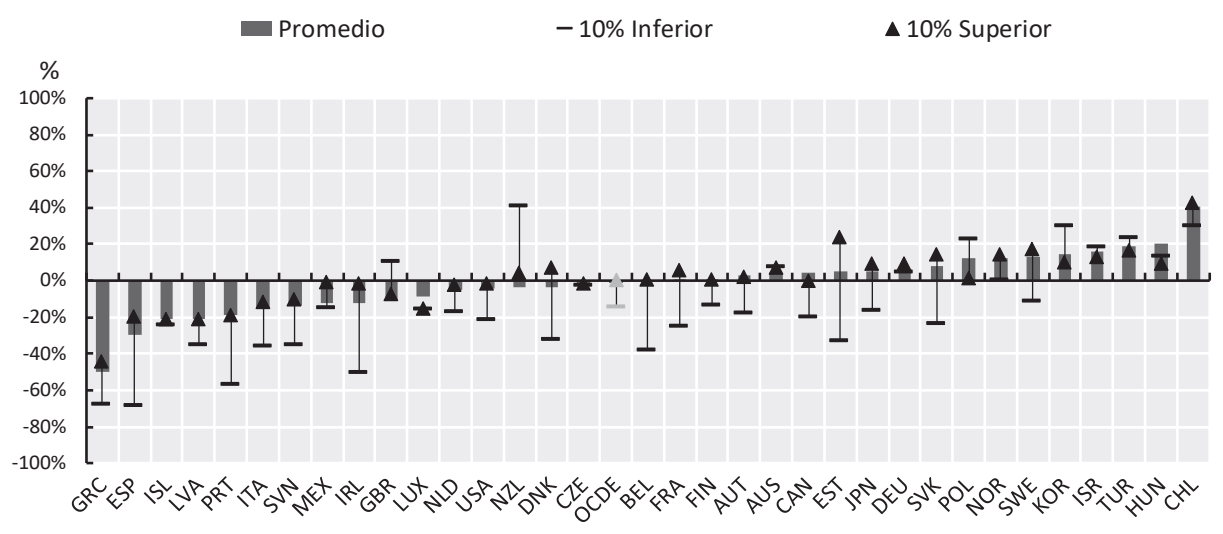

Fuente: OCDE, Base de Datos de Distribución de Ingresos. 


\section{ESTADO DE DERECHO}

El Estado de Derecho se refiere a la idea de que se deben aplicar las mismas reglas, normas y principios a todas las personas y organizaciones, incluyendo el Gobierno. El concepto se implementa en la práctica mediante un abanico de leyes, códigos y procedimientos que proporcionan igualdad de acceso a la ley y justicia, y que garantizan la predictibilidad, fiabilidad y responsabilidad del sistema legal. Se considera un elemento clave de la buena gobernanza pública y es un prerrequisito esencial para mantener la paz y el orden, para la provisión de los bienes y servicios públicos, el control efectivo de la corrupción y el desarrollo económico.

Las definiciones existentes de Estado de Derecho son diversas. Esta publicación se basa en el modelo desarrollado por el Proyecto Justicia Mundial (WJP, por sus siglas en inglés), que emplea uno de los enfoques más sistemáticos para conceptualizar y medir el Estado de Derecho. De acuerdo con su metodología, los sistemas que lo respetan incluyen cuatro principios universales: 1) el Gobierno y sus funcionarios y agentes, así como las personas y entidades privadas, son responsables ante la ley; 2) las leyes son claras, públicas, estables y justas, se aplican de manera uniforme y protegen los derechos fundamentales, incluyendo la seguridad de las personas y de la propiedad; 3.) el proceso por el cual las leyes se promulgan, administran y aplican es accesible, justo y eficiente; 4) la justicia se administra de manera oportuna por representantes competentes y éticos que actúan de forma independiente y neutral, en un número suficiente y con recursos adecuados, y reflejan la composición de las comunidades a las que sirven.

El WJP mide el Estado de Derecho a través de ocho factores que valoran distintos aspectos del concepto. Esta publicación se centra en los resultados de los siguientes dos factores: limitaciones a los poderes del Gobierno y derechos fundamentales. Las puntuaciones de los factores varían entre 0 y 1 , siendo el 1 la puntuación máxima y 0 la mínima.

El factor que mide las limitaciones a los poderes del Gobierno evalúa «el grado en que aquellos que gobiernan están sujetos a la ley. Comprende los medios, tanto constitucionales como institucionales, mediante los cuales los poderes del Gobierno y sus funcionarios y agentes se ven limitados y son responsables ante la ley. También incluye el control no gubernamental de los poderes del Gobierno, como el de una prensa libre e independiente». La media de la OCDE en este factor es de 0,75 , y casi la mitad de los países miembros de la OCDE alcanzan una puntuación por encima de 0,8 . Algunos países nórdicos como Dinamarca, Finlandia, Noruega y Suecia, así como Austria, Nueva Zelanda y Países Bajos, muestran valores especialmente elevados. Hungría, México y Turquía, por el contrario, obtienen valores por debajo de 0,5. Entre los países en proceso de adhesión y otras economías importantes, solo Costa Rica puntúa sobre la media de la OCDE. 
El factor que mide la protección de los derechos fundamentales incluye información sobre la aplicación efectiva de la ley y el debido proceso legal, así como sobre el respeto a una gama de derechos humanos fundamentales y derechos laborales que establece la legislación internacional. En la mayoría de los países de la OCDE, países en proceso de adhesión y en otras economías importantes, las puntuaciones en este factor son muy similares a las obtenidas en las limitaciones a los poderes del Gobierno. La media de la OCDE es solo ligeramente mayor con un valor de 0,77. Las excepciones son Eslovenia y Hungría, que obtienen puntuaciones significativamente más altas en los derechos fundamentales que en las limitaciones a los poderes del Gobierno, así como India y Ucrania, que obtienen mayores puntuaciones en las limitaciones a los poderes del Gobierno que en los derechos fundamentales. Por consiguiente, existe una fuerte correlación positiva entre estos dos factores. Este resultado apunta a que los países que han establecido el control y equilibrio de los poderes del Gobierno también garantizan los derechos fundamentales.

\section{Metodología y definiciones}

Los datos se recogen por el Proyecto Justicia Mundial mediante una serie de cuestionarios basados en el marco conceptual del índice del Estado de Derecho. Los cuestionarios se remiten a una muestra representativa del público en general y de expertos legales. En el caso del público en general, se seleccionó una muestra probabilística de 1.000 encuestados en las tres ciudades más grandes de cada país. En el caso de los expertos legales, se encuestó a una media de 24 expertos por país. Se utilizaron los servicios de empresas demoscópicas locales para administrar la encuesta al público. Se dispone de datos de 28 países de la OCDE, así como de 9 países en proceso de adhesión o que son economías importantes. Todas las variables que se utilizan para puntuar cada uno de los factores están codificadas y normalizadas en un rango entre 0 y 1 , donde 1 significa la puntuación más alta y 0 la más baja.

Información más detallada sobre los factores seleccionados en limitaciones a los poderes públicos y en protección de los derechos fundamentales se encuentra disponible online en $<\mathrm{http}$ ://worldjusticeproject.org/ factors/constraints-government-powers $>$ y en $<$ http://worldjusticeproject. org/factors/fundamental-rights $>$. 


\section{Otras publicaciones}

World Justice Project (2016), «Rule of law Index 2016», World Justice Project,

Washington, DC, <http://worldjusticeproject.org/sites/default/files/media/ wjp_rule_of_law_index_2016.pdf $>$.

\section{Notas de los gráficos}

13.5, 13.6 y 13.7: Los datos de Irlanda, Islandia, Israel, Letonia, Luxemburgo, República Eslovaca y Suiza no están disponibles.

Información sobre los datos de Israel: $<$ http://dx.doi.org/10.1787/888932315602>.

\section{Gráfico 13.5. Limitaciones a los poderes del Gobierno, 2016}

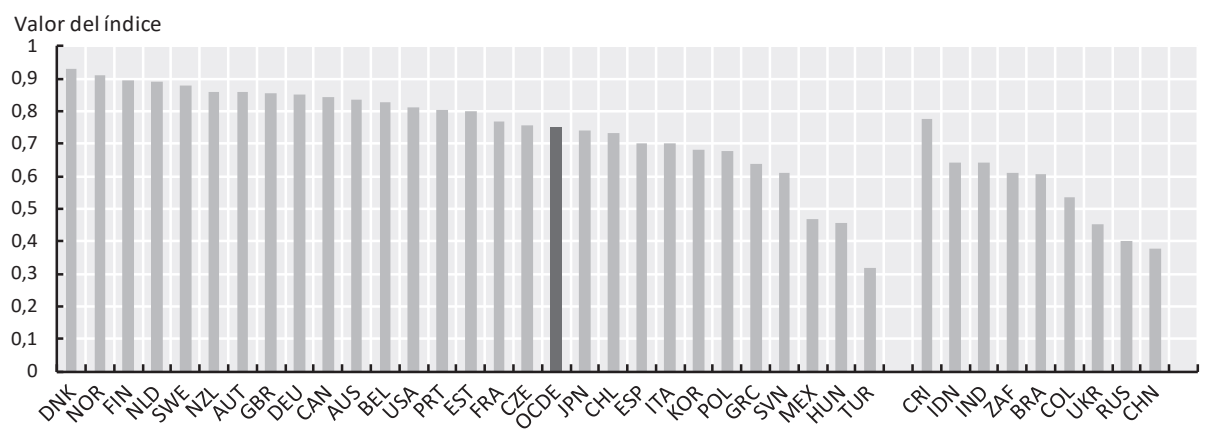

Fuente: Proyecto Justicia Mundial.

$<$ http://dx.doi.org/10.1787/888933533682>

Gráfico 13.6. Derechos fundamentales, 2016

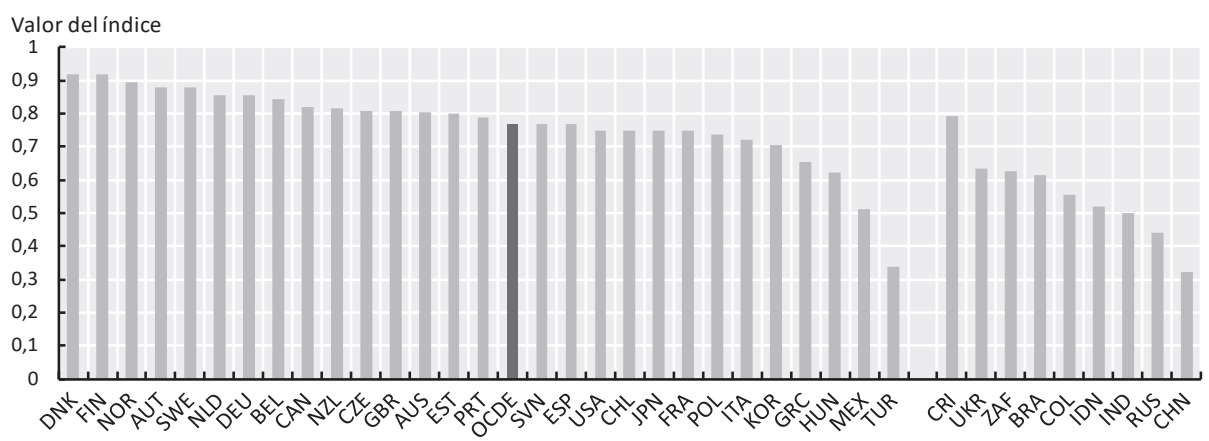

Fuente: Proyecto Justicia Mundial. 


\section{Gráfico 13.7. Limitaciones a los poderes del Gobierno vs. los derechos fundamentales, 2016}

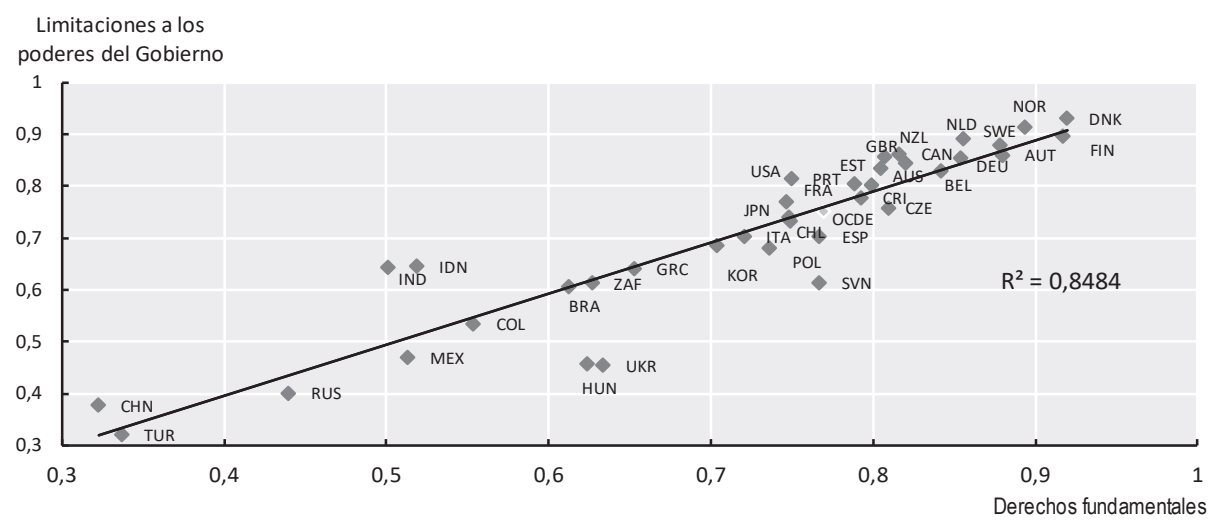

Fuente: Proyecto Justicia Mundial.

\section{EFICIENCIA DEL SECTOR PÚBLICO}

Las limitaciones presupuestarias han aumentado la presión sobre las Administraciones en materia de eficiencia. Desde un punto de vista económico, la eficiencia es la relación entre uno o más insumos (o factores de producción) y uno o más productos.

La noción de eficiencia y de otros conceptos relacionados, como la relación calidad-precio, son dimensiones que suscitan mucho debate en el ámbito de la sanidad. En un número de países de la OCDE, el envejecimiento de la población y el creciente coste de las tecnologías médicas conllevan un aumento pronunciado de los gastos en salud. Como consecuencia, los países están implementando una combinación de políticas para mejorar la coordinación de la atención sanitaria con el fin de contener este aumento de gastos y garantizar, al mismo tiempo, la alta calidad de los servicios.

Una serie de problemas crónicos de salud, como la diabetes, el asma y la enfermedad pulmonar obstructiva crónica (EPOC), se pueden tratar en el sistema de atención primaria para evitar el uso hospitalario innecesario y costoso. La tasa de admisiones hospitalarias evitables (pacientes admitidos por enfermedades crónicas que podrían ser tratados fuera del hospital) supone, por tanto, un buen indicador de la eficiencia del sistema de atención primaria. En 2013, la tasa de admisiones hospitalarias evitables fue especialmente elevada en Austria, Corea y Nueva Zelanda, mientras que fue más baja en Italia, Portugal y Suiza. Proporcionar atención ambulatoria consistente a largo plazo, 
ajustar y coordinar la atención para aquellos con múltiples necesidades de salud y apoyar al paciente en el autocuidado y automanejo son varias opciones políticas que han sido implementadas en los países de la OCDE para reducir las admisiones hospitalarias evitables y mejorar la eficiencia en la gestión del tratamiento de pacientes. Una tasa muy baja de admisiones hospitalarias por tratamiento de estas enfermedades crónicas no significa, sin embargo, que los pacientes reciban buenos cuidados fuera de los hospitales.

Cuando los pacientes deben ser admitidos en hospitales, reducir el promedio de la duración de la estancia se ha convertido en una apuesta política importante para disminuir costes. En condiciones normales, una estancia más corta reducirá las necesidades de recursos y el coste por alta hospitalaria, permitiendo así el tratamiento de un número mayor de pacientes con unos insumos determinados. No obstante, las estancias cortas tienden a necesitar servicios más intensivos y a tener un mayor coste por día. Una estancia demasiado corta puede tener efectos adversos en los resultados de salud o reducir la comodidad y recuperación del paciente.

En la mayoría de los países, la duración de las estancias hospitalarias ha descendido durante la última década de un promedio de poco más de 8 días en 2004 a uno de poco más de 7 en 2014. Los países han utilizado diferentes estrategias para reducir la duración de las estancias, manteniendo o mejorando al mismo tiempo la calidad de la atención. Estas estrategias incluyen reducir el número de camas de hospital junto con el desarrollo de programas de alta temprana que permiten a los pacientes volver a casa para recibir tratamiento de seguimiento, así como promover el uso de procedimientos quirúrgicos menos invasivos (OCDE, 2013).

\section{Metodología y definiciones}

Los indicadores se definen como el número de admisiones hospitalarias por diagnóstico primario de asma, EPOC y diabetes entre personas de 15 o más años por 100.000 habitantes. Las tasas se normalizaron por edad y género con arreglo a los habitantes de 15 o más años de la OCDE en 2010 .

La duración media de estancia se refiere al promedio de días que los pacientes pasan en el hospital. Normalmente se mide dividiendo el número total de días de estancia hospitalaria de todos los pacientes en un año entre el número de altas (por la causa que sea). Se excluyen los casos de hospital de día. 


\section{Otras publicaciones}

OECD (2015), «Health at a Glance 2015: OECD Indicators», OECD Publishing, París, <http://dx.doi.org/10.1787/health_glance-2015-en>.

\section{Notas de los gráficos}

13.8: Se proporciona la media de tres años en el caso de Islandia y Luxemburgo.

13.9: Los datos de Corea y Polonia corresponden a 2005 en lugar de 2004. Los datos de China corresponden a 2000 en lugar de 2004. Los datos de Colombia corresponden a 2009 en lugar de 2014. Los datos de Australia, Bélgica, Canadá, Chile, Dinamarca, Estados Unidos, Francia, Nueva Zelanda y Colombia corresponden a 2013 en lugar de 2014. Los datos de Japón corresponden a 2012 en lugar de 2014. Los datos de Grecia corresponden a 2011 en lugar de 2014. Los datos de Canadá, Japón y Países Bajos se refieren a atención curativa y excluyen los cuidados hospitalarios a largo plazo.

Información sobre los datos de Israel: <http://dx.doi.org/10.1787/888932315602>.

\section{Gráfico 13.8. Admisiones hospitalarias de adultos por asma, diabetes y EPOC, 2013 (o año más próximo)}

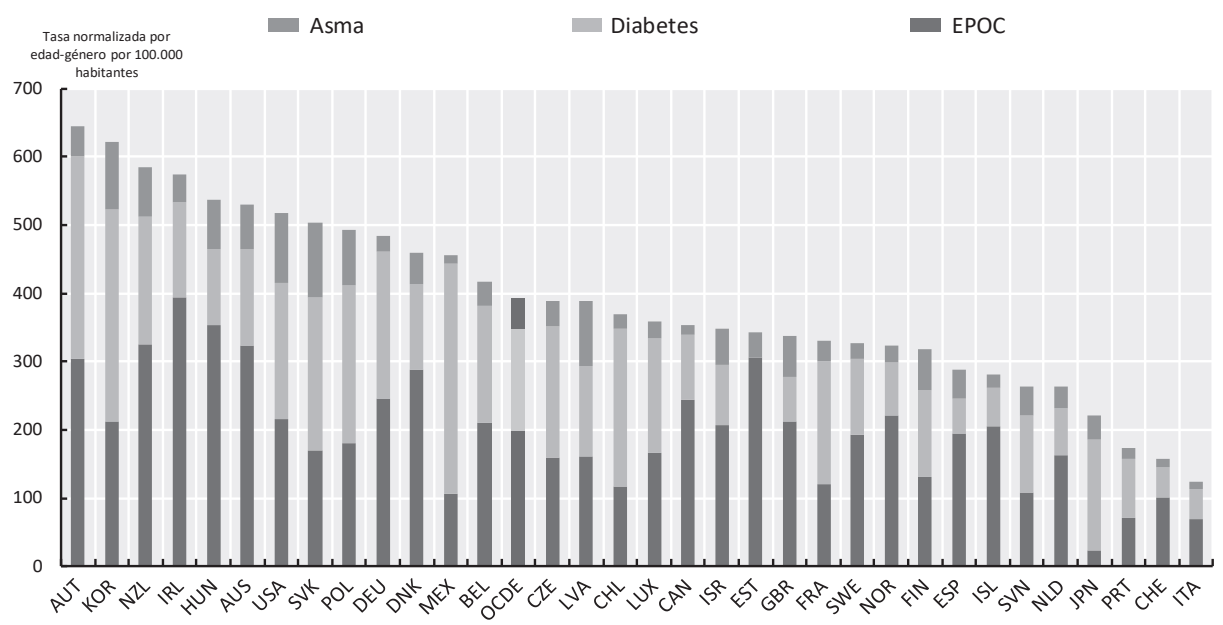

Fuente: OCDE, Estadísticas de Salud. 
Gráfico 13.9. Duración media de estancia hospitalaria bajo cualquier condición, 2004 y 2014

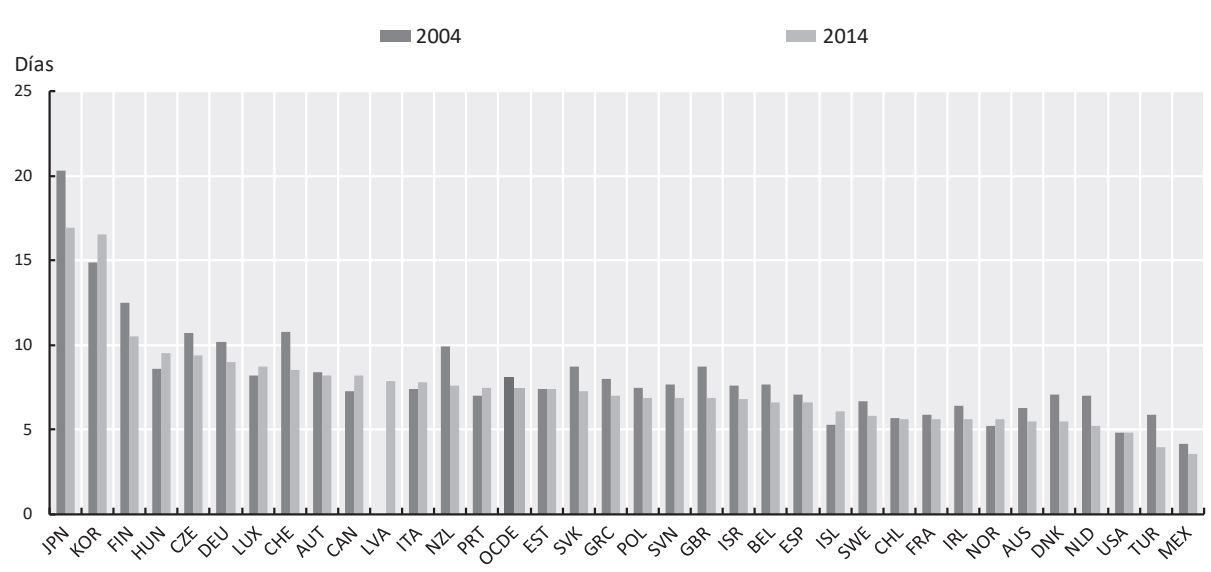

Fuente: OCDE, Estadísticas de Salud.

\section{RELACIÓN COSTE-EFECTIVIDAD EN EL SECTOR PÚBLICO}

La rentabilidad del sector público se puede medir observando la relación entre los insumos (humanos o financieros) y algunos de los resultados importantes de cada sector. En general, los resultados se refieren a los efectos de los programas y servicios públicos en términos de beneficios para la salud, avances educativos, ganancias en satisfacción y en confianza. En un contexto de fuertes limitaciones presupuestarias, mejorar la relación coste-efectividad de los servicios públicos es importante, ya que, en última instancia, los ciudadanos valoran los resultados y las Administraciones públicas deben demostrar que se hace un buen uso de los gastos. Sin embargo, aunque parte de los resultados finales se pueden atribuir a los servicios públicos, esta atribución a menudo conlleva dificultades puesto que hay muchos factores que repercuten en la salud, la educación y en otros aspectos de las vidas de las personas.

\section{Sanidad}

La relación coste-efectividad en la asistencia sanitaria se puede medir observando la relación entre los gastos actuales en sanidad (o solo los gastos públicos en esta, que contabilizan alrededor del $75 \%$ de los totales) y la esperanza de vida al nacer. Aunque esta es uno de los parámetros más utilizados para medir los resultados de sanidad, su valor como indicador de la efectividad de los servicios públicos es limitado, ya que solo mide la duración de vida y no la 
calidad de salud de la vida de las personas. Además, se ve afectada por muchos otros factores que van más allá de las actividades relacionadas con la asistencia sanitaria y sus gastos derivados, como pueden ser las condiciones laborales y de vida de las personas (nivel de estudios e ingresos), el entorno físico (por ejemplo, la contaminación del aire), factores conductuales (como el tabaquismo, la consumición de alcohol y la nutrición), entre muchos otros.

Un mayor gasto en sanidad se suele asociar con vidas más longevas, aunque esta relación generalmente se debilita a medida que aumenta el gasto. Esto sugiere que, por encima de cierto umbral de gasto, la mayoría de las diferencias de esperanza de vida entre los países pueden ser debidas a la calidad del gasto y a otros factores medioambientales y conductuales. Corea, España, Israel, Italia y Japón tienen una esperanza de vida relativamente alta en comparación con su nivel de gasto en sanidad. Por el contrario, Estados Unidos, Hungría, Letonia y México tienen una esperanza de vida menor de lo que sus gastos en sanidad podrían prever. En Estados Unidos y México, cerca de la mitad de los gastos en sanidad provienen de fuentes privadas. El grado en que estos dos países tienen una esperanza de vida relativamente baja en comparación con la media de la OCDE se reduce cuando se tienen en consideración solo los gastos públicos en sanidad (Gráfico online).

\section{Educación}

Cada tres años, el Programa Internacional para la Evaluación de Estudiantes (PISA, por sus siglas en inglés) de la OCDE mide el rendimiento de los estudiantes de 15 años en tres dominios: matemáticas, lectura y ciencias. La evaluación PISA de 2015 se centró de manera especial en las ciencias. La comparación entre los resultados del aprendizaje de los estudiantes de acuerdo con las puntuaciones PISA y los gastos en educación acumulados por estudiantes entre los 6 y los 15 años proporciona una medida global de la relación coste-efectividad de los sistemas educativos. Sin embargo, la variable de gastos excluye las horas extra de clases pagadas por los padres, que pueden contabilizar una partida considerable de gastos en educación en un número de países de la OCDE.

Existe una relación positiva entre las puntuaciones PISA en ciencias y lectura y los gastos acumulados por estudiante. No obstante, la correlación es especialmente firme en los niveles bajos de gastos acumulados por estudiante, puesto que por encima de cierto umbral (alrededor de 80.000 USD PPA) el rendimiento de los estudiantes parece depender de otros factores como la calidad de los profesores, su entorno socioeconómico y las prácticas de gestión de los centros, entre otros. Países como Canadá, Corea, Estonia, Finlandia, Japón y Polonia gastan casi lo mismo o menos que la media de la OCDE por estudiante, pero logran mejores rendimientos. Por el contrario, los gastos por estudiante en Islandia y Luxemburgo son mayores que la media de la OCDE, pero sus puntuaciones en ciencias y lectura están por debajo del promedio. 


\section{Metodología}

La esperanza de vida mide la duración media de la vida de las personas sobre la base de un conjunto dado de tasas de mortalidad específicas por edad. El gasto total en sanidad mide el consumo final de bienes y servicios sanitarios (es decir, gastos corrientes) y excluye la inversión de capital en infraestructuras sanitarias. Incluye el gasto tanto de fuentes públicas como privadas en bienes y servicios médicos, en salud pública y programas de prevención y en administración.

Los datos de gasto por estudiante se refieren al ejercicio 2013. Dicho gasto equivale al total realizado por los centros de enseñanza (públicos y privados), dividido por el número correspondiente de estudiantes matriculados a tiempo completo e incluye tanto los servicios principales como los auxiliares. Debido a las diferencias en la duración de los cursos escolares entre países, el gasto anual por estudiante puede no reflejar plenamente el total gastado por estudiante. Las puntuaciones de rendimiento están basadas en las evaluaciones PISA de 2015 para jóvenes de 15 años en ciencias y lectura.

El Gráfico 13.12, que muestra la relación entre la esperanza de vida al nacer y el gasto público corriente en sanidad per cápita (2014), está disponible online (véase el Anexo F).

\section{Otras publicaciones}

OECD (2015), «Health at a Glance 2015: OECD Indicators», OECD Publishing, París, <http://dx.doi.org/10.1787/health_glance-2015-en>.

OECD (2016), «Education at a Glance 2016: OECD Indicators», OECD Publishing, París, <http://dx.doi.org/10.187/eag-2016-en>.

OECD (2016), «PISA 2015 Results (Volume I): Excellence and Equity in Education», PISA, OECD Publishing, París, <http://dx.doi. org/10.1787/9789264266490-en>. 


\section{Notas de los gráficos}

13.10: Información sobre los datos de Israel: <http://dx.doi. org $/ 10.1787 / 888932315602>$.

13.11: En el caso de Grecia, los datos de gastos acumulados no están disponibles.

Información sobre los datos de Israel: <http://dx.doi.org/10.1787/888932315602>.

\section{Gráfico 13.10. Esperanza de vida al nacer y gasto público corriente en sanidad per cápita, 2014}

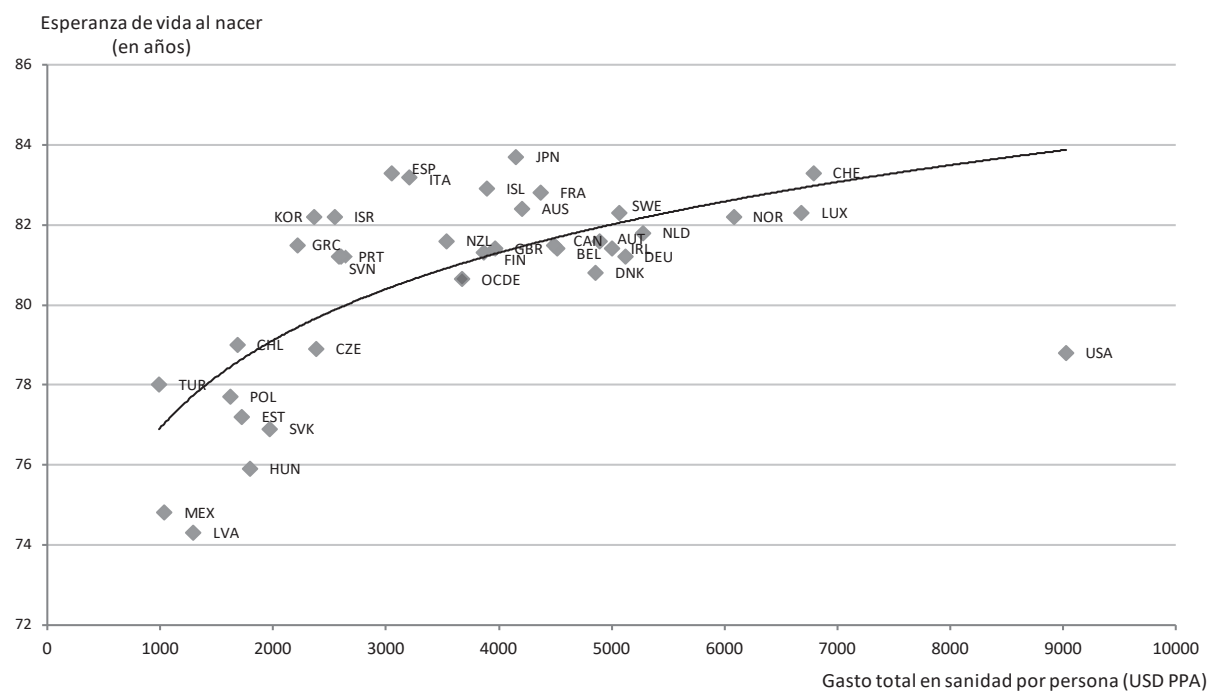

Fuente: OCDE (2016), Estadísticas de Salud, OCDE, París. 
Gráfico 13.11. Rendimiento en PISA 2015, puntuaciones de estudiantes de 15 años y gastos acumulados en educación por estudiante entre 6 y 15 años, 2013

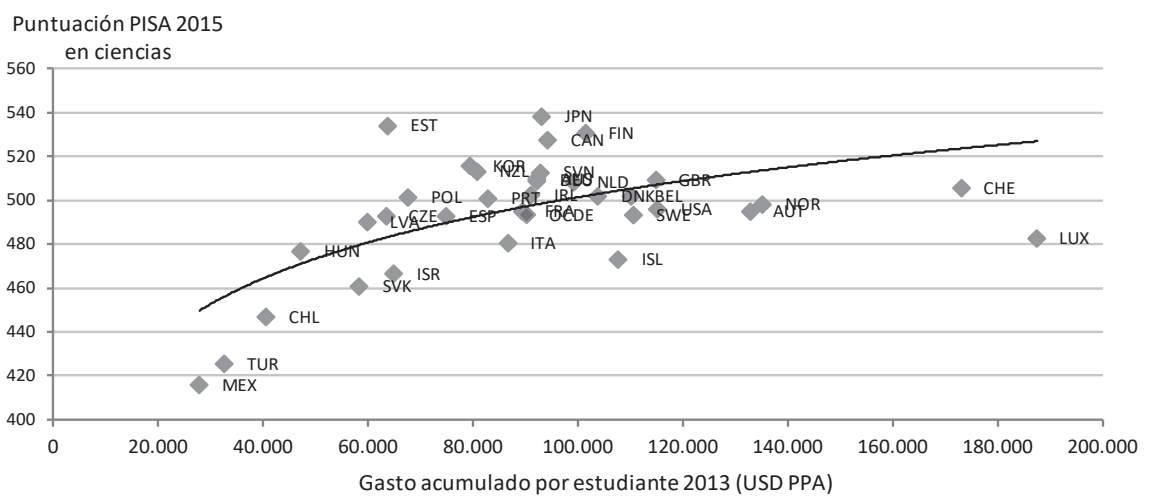

Puntuación PISA 2015

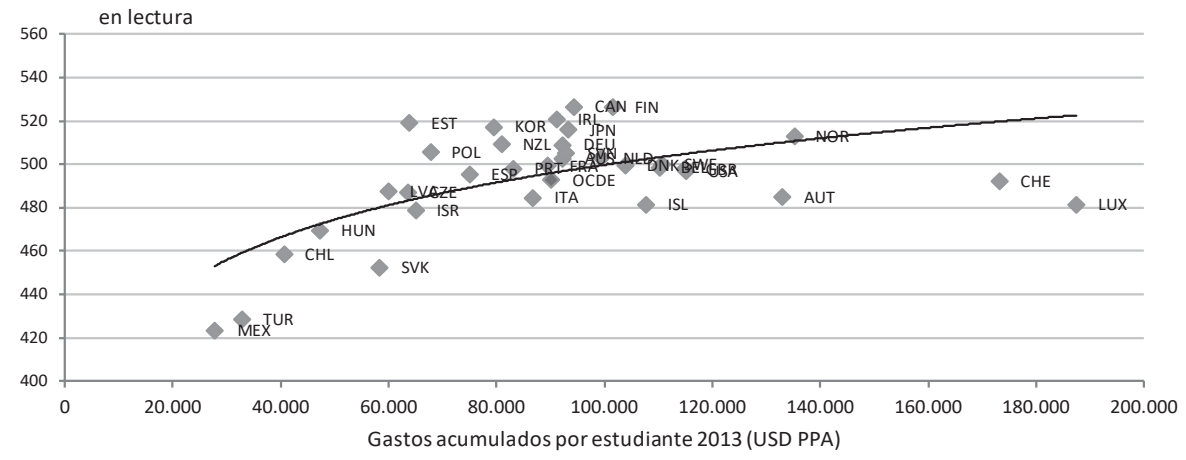

Fuente: OCDE (2016), Base de Datos PISA, OCDE, París. 


\section{CAPÍTULO 14. AL SERVICIO DE LOS CIUDADANOS}

\section{TABLAS DE PUNTUACIÓN DE SERVICIOS A LOS CIUDADANOS}

Este capítulo presenta, por primera vez, un conjunto de tablas de puntuación diseñadas para arrojar luz sobre el desempeño de los países de la OCDE en cuanto a la promoción de la accesibilidad, capacidad de respuesta y calidad de los servicios para los ciudadanos. Estas tablas de puntuación no identifican qué países tienen los mejores servicios públicos globales. Resumen aspectos clave de los sistemas de los países en un conjunto de indicadores seleccionados según el Marco de la OCDE de Servicios a los Ciudadanos para ayudar a identificar posibles áreas de acción prioritaria. Estas tablas de puntuación se centran en tres sectores: sanidad, educación y justicia. Se presenta un conjunto de indicadores seleccionados para cada una de estas tres dimensiones. La selección de los indicadores se basa en tres criterios principales: 1) la relevancia política; 2) la disponibilidad de datos; y 3) la interpretabilidad de los datos (es decir, que no haya ambigüedad sobre si un valor mayor/menor significa un desempeño mejor/peor).

\begin{tabular}{|c|c|c|}
\hline \multicolumn{3}{|c|}{ Marco de la OCDE de Servicios a los Ciudadanos } \\
\hline Acceso & Capacidad de respuesta & Calidad \\
\hline Asequibilidad & Cortesía y trato & $\begin{array}{c}\text { Prestación efectiva de los servicios y } \\
\text { resultados }\end{array}$ \\
\hline Proximidad geográfica & $\begin{array}{c}\text { Adaptación de los servicios a las } \\
\text { necesidades especiales }\end{array}$ & $\begin{array}{c}\text { Coherencia en la prestación de } \\
\text { servicios y resultados }\end{array}$ \\
\hline Acceso a información & Puntualidad & Seguridad/Protección \\
\hline
\end{tabular}

En la mayoría de las tablas, los países se clasifican en tres grupos: 1) grupo del tercio superior; 2) grupo del tercio medio; y 3) grupo del tercio inferior. Además, el ranking específico de los países se indica en cada celda para proporcionar información adicional sobre su posición con respecto al resto de países y grupos. El ranking se basa en el número de países de los que hay da- 
tos disponibles para cada indicador (con un máximo de 35 cuando se incluyen todos los países), y se clasifican en los grupos ya mencionados. Cuando hay datos de tendencia, las flechas indican si la puntuación absoluta de los países en el indicador (no necesariamente en el ranking global) es ascendente $(\uparrow)$, descendente $(\downarrow)$ o permanece igual $(\rightarrow)$. Se puede encontrar información más detallada sobre los indicadores y metodologías más adelante en el capítulo 14 «Al servicio de los ciudadanos».

En muchos países, los servicios de sanidad y educación se proporcionan mediante una combinación de proveedores públicos y privados, aunque a menudo gran parte de los servicios prestados en los hospitales y colegios privados reciben financiación pública para garantizar cierto nivel de acceso. La disponibilidad actual de datos en muchos países no siempre diferencia con claridad los hospitales y colegios públicos de los privados, lo cual limita la posibilidad de evaluar comparativamente el rendimiento de las instituciones públicas y privadas. Este es un aspecto importante de la agenda de datos e investigación que se debe mejorar en los próximos años. Además, la disponibilidad de datos comparables es más limitada en los indicadores de acceso y respuesta de la asistencia sanitaria y procedimientos judiciales, bien por la falta de coordinación de los instrumentos de encuesta o por limitaciones en la disponibilidad de datos administrativos comparables.

\section{Acceso a los servicios}

El acceso a los servicios de sanidad, educación y justicia puede depender de la capacidad de pago de las personas (cuando los servicios no se incluyen en el sector público), su proximidad geográfica y el grado en que tienen información suficiente y correcta para obtener los servicios.

La mayoría de los países de la OCDE han alcanzado la cobertura universal (o casi universal) de los costes de atención sanitaria en un conjunto básico de servicios, con la excepción de Estados Unidos, Grecia y Polonia, donde una parte considerable de la población todavía no tiene cobertura. La protección financiera de las personas frente a los costes por enfermedad depende no solo de si tienen seguro médico, sino también de la gama de bienes y servicios que cubre y el grado en que se cubren. Existen variaciones importantes entre los sistemas de salud de los países de la OCDE en cuanto al grado de cobertura de los bienes y servicios sanitarios. En países como Francia y Reino Unido, la cantidad que tienen que pagar directamente los hogares para los bienes y servicios sanitarios como proporción de su consumo total es relativamente baja. Otros países, como Corea y México, han alcanzado la cobertura universal (o casi universal), pero se cubre una parte relativamente pequeña de los costes de los diferentes bienes y servicios sanitarios, lo que conlleva que una parte significativa de los gastos tiene que ser abonada por los hogares. 
Las necesidades sanitarias insatisfechas, como indican las encuestas basadas en la población, constituyen una buena manera de evaluar los problemas de acceso en determinados grupos de población. Los datos de necesidades sanitarias insatisfechas de este capítulo proceden de dos fuentes principales: 1) la Encuesta de 2015 de las Estadísticas de la Unión Europea sobre la Renta y las Condiciones de Vida (EU-SILC, por sus siglas en inglés), que abarca 25 países de la OCDE en Europa, y 2) la Encuesta de Política Sanitaria Internacional del Commonwealth Fund de 2016, que incluye 11 países de la OCDE en Europa y fuera de Europa (no se muestran en las tablas de puntuación, pero están disponibles en el capítulo 14, «Al servicio de los ciudadanos»). La gente de países como Austria y Eslovenia registra un índice más bajo de necesidades sanitarias insatisfechas que la gente de países que no tienen cobertura sanitaria universal como Estados Unidos, Grecia y Polonia.

En todos los países de la OCDE, los sistemas educativos proporcionan el acceso universal a centros de primaria y secundaria para menores de edades comprendidas entre los 5 y los 14 años. Los gastos privados (incluyendo los pagos directos de los hogares) de la educación preescolar y superior son relativamente bajos en países como Bélgica, Dinamarca y Noruega, mientras que son más altos en Australia y Estados Unidos. La mayoría de los países tienen en funcionamiento programas de préstamos, becas y subvenciones para apoyar el acceso a la educación superior. El número de estudiantes que ingresa en la universidad por primera vez es más elevado en Nueva Zelanda (impulsado en gran medida por la gran proporción de estudiantes internacionales), mientras que es menor en Luxemburgo y México. En Luxemburgo, gran parte de los ciudadanos estudia en el extranjero, lo cual reduce la tasa de nuevos ingresos en la universidad, en especial a nivel de grado.

El acceso a la justicia depende principalmente de la capacidad de pago de las personas, aunque también de su grado de comprensión de los procedimientos y pasos necesarios para abordar cualquier cuestión legal. Los datos recogidos por el Proyecto Justicia Mundial (WJP, por sus siglas en inglés) sugieren que las barreras financieras de acceso a la justicia son menores en Alemania, Nueva Zelanda y Países Bajos, mientras que son mayores en Estados Unidos, México y Turquía. El acceso a la Resolución Alternativa de Disputas (ADR, por sus siglas en inglés) también resulta clave para que las personas solucionen sus diferencias de manera extrajudicial. Basándose en el conjunto de indicadores del WJP, los mecanismos de ADR son más accesibles y efectivos en Corea, Dinamarca y Noruega, mientras que en Italia y México se necesita realizar mayores esfuerzos para resolver los conflictos de manera extrajudicial. El capítulo 14 «Al servicio de los ciudadanos» presenta, por primera vez en esta edición, datos de encuesta más detallados, notablemente sobre las barreras financieras para resolver conflictos y sobre los conocimientos de las personas y el acceso a la información para emprender acciones legales y obtener asistencia legal. 


\section{Capacidad de respuesta de los servicios}

Los parámetros clave para evaluar la capacidad de respuesta varían entre los servicios. En sanidad y justicia, la puntualidad de las intervenciones y procedimientos es especialmente importante. Por el contrario, en educación, la capacidad de respuesta se evalúa observando el grado en que los estudiantes se benefician del material y métodos pedagógicos adecuados.

Basándose en los datos recogidos en 11 países de la OCDE, el tiempo de espera para obtener una cita médica (médico de cabecera) y con un especialista es relativamente bajo en Países Bajos, mientras que es más elevado en Canadá y Noruega. En Alemania y Francia, el tiempo de espera para obtener una cita médica (médico de cabecera) es relativamente alto, mientras que es muy bajo para obtener una cita con un especialista, con menos del $5 \%$ de personas que indicaron esperar dos o más meses para ver a su especialista, comparado con la media del $14 \%$ en los países encuestados de la OCDE y con el $25 \%$ marcado en Canadá y México.

El tiempo que se necesita para resolver casos civiles, mercantiles y administrativos de primera instancia depende del número de casos tratados en un año determinado, de la tradición del sistema legal, del grado en que se utilizan las tecnologías digitales en los tribunales y de otros factores. Basándose en los datos disponibles, el tiempo necesario para resolver casos de primera instancia fue más elevado en Grecia e Italia. La duración estimada de los procedimientos para resolver un caso administrativo es equivalente a más de cuatro años en Grecia y a más de dos y medio en Italia. En cambio, en Eslovenia y Suecia supone menos de cuatro meses. El tiempo necesitado para resolver casos de primera instancia ha mejorado considerablemente desde 2012 en Dinamarca, Eslovenia, Estonia, Hungría y Suecia, mientras que ha empeorado en Finlandia, República Checa y República Eslovaca.

En todos los países de la OCDE, los sistemas educativos se esfuerzan en satisfacer las necesidades de estudiantes con entornos socioeconómicos diferentes. La capacidad de respuesta de los sistemas educativos se puede evaluar a tres niveles distintos: de sistema educativo, de centro y de profesores. En general, Australia, Canadá, Estados Unidos y Suecia puntúan alto en los indicadores de disponibilidad de material escolar, apoyo y ayuda al estudio en los centros, y del uso de métodos de enseñanza adaptada. En Australia, Canadá y Estados Unidos, alrededor del $60 \%$ de los estudiantes manifiestan que su maestro o profesor proporciona ayuda individualizada cuando un estudiante tiene dificultades para comprender un tema o lección, comparado con el promedio del $48 \%$ en los países de la OCDE. 


\section{Calidad de los servicios}

Mejorar la calidad de los servicios y resultados en materia de sanidad, educación y justicia en todos los grupos de población es una prioridad política clave en los países de la OCDE.

En sanidad, la calidad de los servicios se puede evaluar, por lo menos de manera parcial, observando las tasas de mortalidad de las tres principales causas de muerte en los países de la OCDE: ataque al corazón, accidente cerebrovascular y cáncer. Aunque las variaciones entre países y a lo largo del tiempo en las tasas de mortalidad relacionadas con estas tres causas de muerte se deben en gran medida a factores de salud que no son médicos (como aspectos conductuales de estilo de vida, por ejemplo, el tabaquismo y los hábitos alimenticios), la calidad de las intervenciones de la asistencia sanitaria también juega un papel importante en el diagnóstico de problemas en fases tempranas de las enfermedades y en el tratamiento efectivo de estas. Desde 2010, la mayoría de los países han mejorado considerablemente en aspectos como la prevención, el diagnóstico precoz y el tratamiento de estas tres importantes causas de muerte. En Grecia, Hungría y Turquía, las tasas de mortalidad debidas a ataques al corazón y accidentes cerebrovasculares continúan siendo altas pero están descendiendo. En Francia, las tasas de mortalidad por ataques al corazón y accidentes cerebrovasculares son las más bajas entre los países de la OCDE, pero la tasa de mortalidad por cáncer de mama (y otros tipos de cáncer) continúa siendo alta y va en aumento.

Cada tres años, el Programa Internacional para la Evaluación de Estudiantes (PISA, por sus siglas en inglés) de la OCDE evalúa el rendimiento de los estudiantes de 15 años en ciencias, matemáticas y lectura (la última edición de 2015 se centró de manera especial en ciencias). Los estudiantes de Alemania, Canadá, Corea, Eslovenia, Estonia, Finlandia, Japón y Países Bajos obtienen resultados de rendimiento relativamente altos en las tres destrezas. Por el contrario, los estudiantes de Chile, Grecia, Hungría, Islandia, Luxemburgo, México, República Eslovaca y Turquía tienen puntuaciones bajas en las tres áreas de conocimiento. Durante la última década, la media de puntuación PISA en ciencias ha aumentado significativamente en Israel, Noruega y Portugal (más de 10 puntos) mientras que ha descendido en Finlandia, Hungría y República Eslovaca (más de 25 puntos).

Todos los años, el Proyecto Justicia Mundial publica su Índice del Estado de Derecho (RuLI, por sus siglas en inglés), que proporciona un conjunto de parámetros sobre el grado de efectividad e imparcialidad de la implementación del Estado de Derecho, basándose en una combinación de encuestas de población y de expertos en la materia. Entre su conjunto de parámetros, el RuLI incluye indicadores sobre la aplicación efectiva de la justicia civil, el grado en que esta se ve libre de la influencia indebida del Gobierno y el grado en que las personas evitan utilizar la violencia para reparar agravios persona- 
les. Los países nórdicos (Dinamarca, Finlandia, Noruega y Suecia) y Austria obtienen las mayores puntuaciones en los tres indicadores, mientras que países como México y Turquía podrían mejorar.

\section{Tabla de puntuación 1. Acceso a los servicios}

\begin{tabular}{|l|l|}
\hline & Grupo del tercio superior \\
\hline & Grupo del tercio medio \\
\hline & Grupo del tercio inferior \\
\hline $\begin{array}{l}\text { Los países se listan en orden alfabético. El número en la celda indica la posición de cada país entre todos los países } \\
\text { con datos disponibles. La flecha indica si la situación está mejorando }(\uparrow) \text {, permanece igual }(\rightarrow) \text { o está empeorando }(\downarrow) . \\
\text { Los años de referencia de los datos de tendencia se especifican en las notas de los gráficos. La falta de símbolo } \\
\text { significa que no hay datos de tendencia disponibles. } \\
\text { Para una descripción detallada de los indicadores, véase el capítulo } 14 \text { «Al servicio de los ciudadanos». }\end{array}$ \\
\hline
\end{tabular}

\begin{tabular}{|c|c|c|c|c|c|c|c|c|}
\hline \multirow[b]{3}{*}{ Indicador } & \multicolumn{3}{|c|}{ Sanidad } & \multicolumn{3}{|c|}{ Educación } & \multicolumn{2}{|r|}{ Justicia } \\
\hline & \multicolumn{3}{|c|}{$\begin{array}{l}\text { Acceso a la atención (motivos } \\
\text { financieros y otros) }\end{array}$} & \multicolumn{3}{|c|}{ Acceso a la educación } & \multicolumn{2}{|c|}{$\begin{array}{l}\text { Acceso a los servicios } \\
\text { jurídicos y de justicia }\end{array}$} \\
\hline & 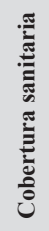 & 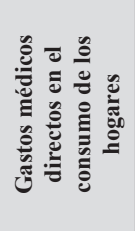 & 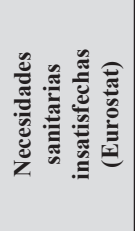 & 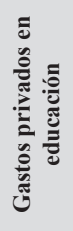 & 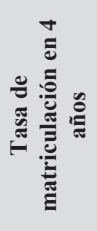 & 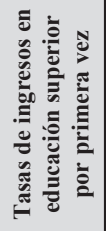 & 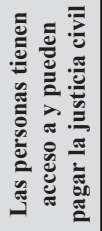 & 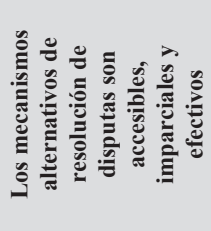 \\
\hline Alemania & 1 & 5 & 3 & 18 & 5 & 18 & 2 & 6 \\
\hline Australia & 1 & 25 & n.a. & $32 *$ & 23 & n.a. & 20 & 4 \\
\hline Austria & 1 & 18 & 1 & 5 & 18 & 14 & 12 & 25 \\
\hline Bélgica & 1 & 24 & 14 & 3 & 4 & 16 & 5 & 8 \\
\hline Canadá & 1 & 10 & n.a. & 23 & n.a. & n.a. & 24 & 10 \\
\hline Chile & 1 & 31 & n.a. & 28 & 25 & 4 & 7 & 22 \\
\hline Corea & 1 & 35 & n.a. & 30 & 15 & n.a. & 6 & 1 \\
\hline Dinamarca & 1 & 15 & 12 & 9 & 7 & 3 & 4 & 3 \\
\hline España & 1 & 29 & 5 & 22 & 8 & 10 & 8 & 18 \\
\hline Estados Unidos & 3 & 13 & n.a. & $29^{*}$ & 29 & 23 & 28 & 12 \\
\hline Estonia & 2 & 14 & 25 & 6 & n.a. & n.a. & 15 & 11 \\
\hline Finlandia & 1 & 19 & 19 & 1 & 26 & 22 & 17 & 21 \\
\hline Francia & 1 & 3 & 11 & 11 & 1 & n.a. & 19 & 7 \\
\hline Grecia & 3 & 33 & 24 & n.a. & 30 & n.a. & 21 & 23 \\
\hline
\end{tabular}




\begin{tabular}{|c|c|c|c|c|c|c|c|c|}
\hline \multirow[b]{3}{*}{ Indicador } & \multicolumn{3}{|c|}{ Sanidad } & \multicolumn{3}{|c|}{ Educación } & \multicolumn{2}{|r|}{ Justicia } \\
\hline & \multicolumn{3}{|c|}{$\begin{array}{l}\text { Acceso a la atención (motivos } \\
\text { financieros y otros) }\end{array}$} & \multicolumn{3}{|c|}{ Acceso a la educación } & \multicolumn{2}{|c|}{$\begin{array}{l}\text { Acceso a los servicios } \\
\text { jurídicos y de justicia }\end{array}$} \\
\hline & 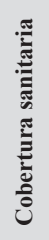 & 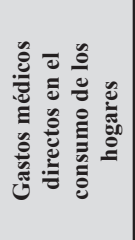 & 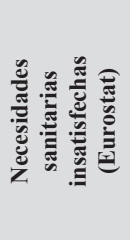 & 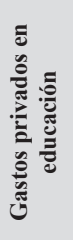 & 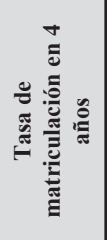 & 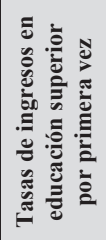 & 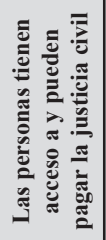 & 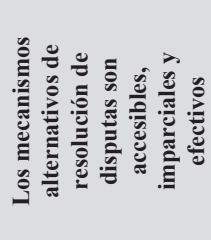 \\
\hline Hungría & 1 & 32 & 15 & 21 & 14 & 25 & 25 & 26 \\
\hline Irlanda & 1 & 16 & 16 & 7 & 16 & n.a. & n.a. & n.a. \\
\hline Islandia & 1 & 22 & 20 & 8 & n.a. & 5 & n.a. & n.a. \\
\hline Israel & 1 & 21 & n.a. & 25 & 3 & 13 & n.a. & n.a. \\
\hline Italia & 1 & 20 & 21 & 13 & 11 & 24 & 23 & 27 \\
\hline Japón & 1 & 9 & n.a. & 31 & 12 & 8 & 10 & 5 \\
\hline Letonia & 1 & 28 & 23 & 10 & 20 & n.a. & n.a. & n.a. \\
\hline Luxemburgo & 1 & 2 & 7 & n.a. & 6 & 27 & n.a. & n.a. \\
\hline México & 1 & 27 & n.a. & 20 & 21 & 26 & 27 & 28 \\
\hline Noruega & 1 & 17 & 9 & 2 & 9 & 6 & 13 & 2 \\
\hline Nueva Zelanda & 1 & 8 & n.a. & $24 *$ & 17 & 1 & 3 & 17 \\
\hline Países Bajos & 1 & 23 & 4 & 19 & 10 & 12 & 1 & 9 \\
\hline Polonia & 2 & 12 & 22 & 16 & 28 & 9 & 18 & 15 \\
\hline Portugal & 1 & 30 & 18 & 26 & 19 & 17 & 11 & 14 \\
\hline Reino Unido & 1 & 4 & 17 & $27^{*}$ & 2 & 20 & 22 & 19 \\
\hline Rep. Checa & 1 & 7 & 6 & 12 & 24 & 15 & 14 & 13 \\
\hline Rep. de Eslovenia & 1 & 6 & 2 & 14 & 22 & 11 & 16 & 20 \\
\hline Rep. Eslovaca & 2 & 11 & 13 & 17 & 27 & 21 & n.a. & n.a. \\
\hline Suecia & 1 & 26 & 8 & 4 & 13 & 19 & 9 & 16 \\
\hline Suiza & 1 & 34 & 10 & n.a. & 31 & 7 & n.a. & n.a. \\
\hline Turquía & 1 & 1 & n.a. & 15 & 32 & 2 & 26 & 24 \\
\hline
\end{tabular}

* En Australia, Estados Unidos, Nueva Zelanda y Reino Unido, el alto nivel de gastos privados en educación se asocia con una gran proporción de estudiantes que reciben becas y subvenciones. Más del $80 \%$ de los estudiantes de enseñanza superior en estos países recibe préstamos públicos, subvenciones y becas (véase el Gráfico 14.2).

Nota: Para la cobertura sanitaria, la agrupación se llevó a cabo de la siguiente manera: grupo del tercio superior (entre el 95\% y el 100\% de cobertura sanitaria); grupo del tercio medio (entre el 90\% y el 95\% de cobertura sanitaria); grupo del tercio inferior (menos del $90 \%$ de cobertura sanitaria). Francia ha expresado su preocupación con respecto al uso de una fuente única, el Proyecto Justicia Mundial, que se basa en un número limitado de observaciones y que puede no reflejar la situación objetiva en términos de acceso y calidad de los sistemas judiciales.

Fuentes: OCDE (2016), Estadísticas de Salud; OCDE (2016), Panorama de la Educación; Proyecto Justicia Mundial (Índice de Estado de Derecho, 2016). 


\section{Tabla de puntuación 2. Capacidad de respuesta en la prestación de servicios}

\begin{tabular}{|l|l|}
\hline & Grupo del tercio superior \\
\hline & Grupo del tercio medio \\
\hline & Grupo del tercio inferior \\
\hline $\begin{array}{l}\text { Los países se listan en orden alfabético. El número en la celda indica la posición de cada país entre todos los países } \\
\text { con datos disponibles. La flecha indica si la situación está mejorando }(\uparrow) \text {, permanece igual }(\rightarrow) \text { o está empeorando }(\downarrow) . \\
\text { Los años de referencia de los datos de tendencia se especifican en las notas de los gráficos. La falta de símbolo } \\
\text { significa que no hay datos de tendencia disponibles. } \\
\text { Para una descripción detallada de los indicadores, véase el capítulo } 14 \text { «Al servicio de los ciudadanos». }\end{array}$ \\
\hline
\end{tabular}

\begin{tabular}{|c|c|c|c|c|c|c|c|c|c|}
\hline \multirow[b]{3}{*}{ Indicador } & \multicolumn{3}{|c|}{ Sanidad } & \multicolumn{3}{|c|}{ Educación } & \multicolumn{3}{|c|}{ Justicia } \\
\hline & \multicolumn{3}{|c|}{$\begin{array}{c}\text { Puntualidad en la prestación de } \\
\text { servicios sanitarios }\end{array}$} & \multicolumn{3}{|c|}{$\begin{array}{c}\text { Capacidad de respuesta de los } \\
\text { centros a las necesidades de } \\
\text { los estudiantes }\end{array}$} & \multicolumn{3}{|c|}{$\begin{array}{c}\text { Puntualidad en las resoluciones } \\
\text { de los tribunales de primera } \\
\text { instancia }\end{array}$} \\
\hline & 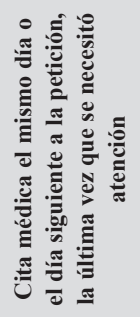 & 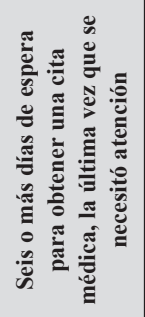 & 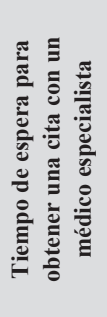 & 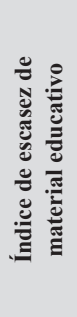 & 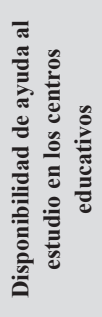 & 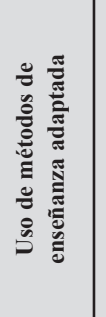 & 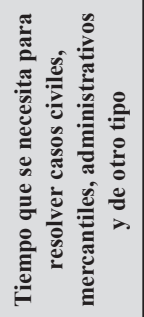 & 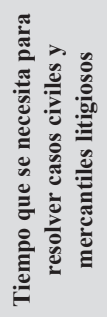 & 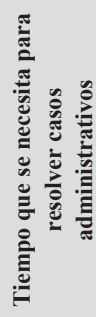 \\
\hline Alemania & 9 & 11 & 1 & 22 & 24 & 32 & n.a. & $9 \uparrow$ & $12 \uparrow$ \\
\hline Australia & 3 & 3 & 6 & 3 & 6 & 4 & n.a. & n.a. & n.a. \\
\hline Austria & n.a. & n.a. & n.a. & 10 & 35 & 33 & $3 \rightarrow$ & $3 \rightarrow$ & \\
\hline Bélgica & n.a. & n.a. & n.a. & 25 & 25 & 26 & n.a. & n.a. & 16 \\
\hline Canadá & 11 & 10 & 11 & 1 & 7 & 2 & n.a. & n.a. & n.a. \\
\hline Chile & n.a. & n.a. & n.a. & 7 & 32 & 8 & n.a. & n.a. & n.a. \\
\hline Corea & n.a. & n.a. & n.a. & 30 & 28 & 23 & n.a. & n.a. & n.a. \\
\hline Dinamarca & n.a. & n.a. & n.a. & 11 & 1 & 7 & $1 \uparrow$ & $8 \uparrow$ & n.a. \\
\hline España & n.a. & n.a. & n.a. & 27 & 31 & 15 & $13 \uparrow$ & $14 \downarrow$ & $13 \uparrow$ \\
\hline Estados Unidos & 6 & 7 & 3 & 6 & 4 & 5 & n.a. & n.a. & n.a. \\
\hline Estonia & n.a. & n.a. & n.a. & 20 & 20 & 22 & $2 \uparrow$ & $2 \uparrow$ & $4 \uparrow$ \\
\hline Finlandia & n.a. & n.a. & n.a. & 23 & 14 & 14 & $8 \downarrow$ & $13 \downarrow$ & $10 \downarrow$ \\
\hline Francia & 8 & 6 & 2 & 14 & 15 & 27 & $14 \downarrow$ & $16 \downarrow$ & 11 \\
\hline Grecia & n.a. & n.a. & n.a. & 29 & 26 & 24 & 16 & $15 \downarrow$ & $18 \uparrow$ \\
\hline Hungría & n.a. & n.a. & n.a. & 33 & 18 & 25 & $5 \uparrow$ & $5 \uparrow$ & $5 \uparrow$ \\
\hline Irlanda & n.a. & n.a. & n.a. & 28 & 27 & 18 & n.a. & n.a. & n.a. \\
\hline Islandia & n.a. & n.a. & n.a. & 2 & 10 & 13 & n.a. & n.a. & n.a. \\
\hline
\end{tabular}




\begin{tabular}{|c|c|c|c|c|c|c|c|c|c|}
\hline \multirow[b]{3}{*}{ Indicador } & \multicolumn{3}{|c|}{ Sanidad } & \multicolumn{3}{|c|}{ Educación } & \multicolumn{3}{|c|}{ Justicia } \\
\hline & \multicolumn{3}{|c|}{$\begin{array}{l}\text { Puntualidad en la prestación de } \\
\text { servicios sanitarios }\end{array}$} & \multicolumn{3}{|c|}{$\begin{array}{l}\text { Capacidad de respuesta de los } \\
\text { centros a las necesidades de } \\
\text { los estudiantes }\end{array}$} & \multicolumn{3}{|c|}{$\begin{array}{c}\text { Puntualidad en las resoluciones } \\
\text { de los tribunales de primera } \\
\text { instancia }\end{array}$} \\
\hline & 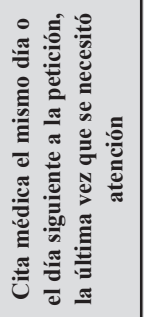 & 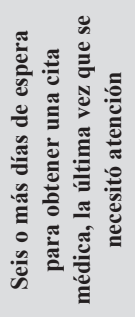 & 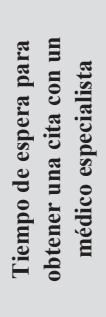 & 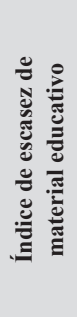 & 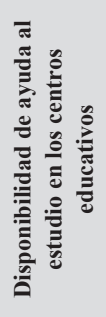 & 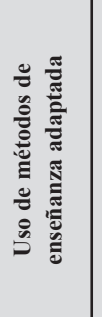 & 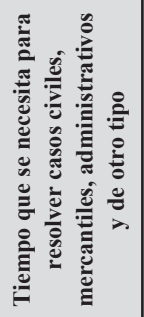 & 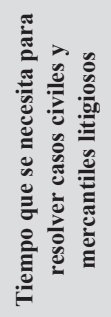 & 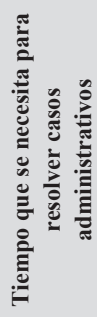 \\
\hline Israel & n.a. & n.a. & n.a. & 31 & 16 & 20 & n.a. & n.a. & n.a. \\
\hline Italia & n.a. & n.a. & n.a. & 34 & 34 & 28 & $15 \uparrow$ & $19 \downarrow$ & $17 \uparrow$ \\
\hline Japón & n.a. & n.a. & n.a. & 35 & 9 & 34 & n.a. & n.a. & n.a. \\
\hline Letonia & n.a. & n.a. & n.a. & 13 & 13 & 9 & $11 \downarrow$ & $12 \uparrow$ & $6 \uparrow$ \\
\hline Luxemburgo & n.a. & n.a. & n.a. & 15 & 2 & 30 & n.a. & $1 \uparrow$ & 9 \\
\hline México & n.a. & n.a. & n.a. & 32 & 33 & 6 & n.a. & n.a. & n.a. \\
\hline Noruega & 10 & 9 & 10 & 18 & 29 & 11 & n.a. & n.a. & n.a. \\
\hline Nueva Zelanda & 2 & 1 & 9 & 17 & 8 & 3 & n.a. & n.a. & n.a. \\
\hline Países Bajos & 1 & 2 & 4 & 12 & 21 & 16 & $6 \downarrow$ & 4 & $8 \downarrow$ \\
\hline Polonia & n.a. & n.a. & n.a. & 5 & 12 & 21 & $4 \downarrow$ & $10 \downarrow$ & $3 \downarrow$ \\
\hline Portugal & n.a. & n.a. & n.a. & 24 & 11 & 1 & $17 \uparrow$ & $17 \uparrow$ & n.a. \\
\hline Reino Unido & 5 & 5 & 8 & 19 & 3 & 10 & n.a. & n.a. & $7 \uparrow$ \\
\hline Rep. Checa & n.a. & n.a. & n.a. & 16 & 17 & 29 & $10 \downarrow$ & $7 \downarrow$ & 15 \\
\hline Rep. de Eslovenia & n.a. & n.a. & n.a. & 8 & 23 & n.a. & $7 \uparrow$ & $11 \uparrow$ & $1 \uparrow$ \\
\hline Rep. Eslovaca & n.a. & n.a. & n.a. & 21 & 19 & 31 & $12 \downarrow$ & $18 \downarrow$ & $14 \downarrow$ \\
\hline Suecia & 4 & 8 & 7 & 9 & 5 & 12 & $9 \uparrow$ & $6 \uparrow$ & $2 \uparrow$ \\
\hline Suiza & 7 & 4 & 5 & 4 & 22 & 19 & n.a. & n.a. & n.a. \\
\hline Turquía & n.a. & n.a. & n.a. & 26 & 30 & 17 & n.a. & n.a. & n.a. \\
\hline
\end{tabular}

Nota: En los indicadores de puntualidad en las resoluciones de justicia, el marco de comparación temporal es 2010-2014. Los datos de Portugal corresponden a 2012 en lugar de 2014. Los datos de los procedimientos administrativos de Luxemburgo corresponden a 2010 en lugar de 2014. Los datos del tiempo que se necesita para resolver casos civiles, mercantiles, administrativos y de otro tipo (en primera instancia) de Austria, Grecia e Italia corresponden a 2012 en lugar de 2014. No hay datos de tendencia disponibles en Bélgica, Países Bajos (casos civiles y mercantiles litigiosos), Luxemburgo y República Checa (solo casos administrativos). El indicador de métodos de enseñanza adaptada comprende la proporción de estudiantes que manifestaron que sus profesores proporcionan ayuda individualizada cuando un alumno tiene dificultades para entender un tema o tarea en «muchas clases» o «todas o casi todas las clases».

Fuentes: Encuesta de Política Sanitaria Internacional del Commonwealth Fund (2016); OCDE, PISA 2015 (base de datos); CEPEJ 2016 (base de datos). 


\section{Tabla de puntuación 3. Calidad en la prestación de servicios}

\begin{tabular}{|l|l|}
\hline & Grupo del tercio superior \\
\hline & Grupo del tercio medio \\
\hline & Grupo del tercio inferior \\
\hline $\begin{array}{l}\text { Los países se listan en orden alfabético. El número en la celda indica la posición de cada país entre todos los países } \\
\text { con datos disponibles. La flecha indica si la situación está mejorando }(\uparrow) \text {, permanece igual }(\rightarrow) \text { o está empeorando }(\downarrow) . \\
\text { Los años de referencia de los datos de tendencia se especifican en las notas de los gráficos. La falta de símbolo } \\
\text { significa que no hay datos de tendencia disponibles. } \\
\text { Para una descripción detallada de los indicadores, véase el capítulo } 14 \text { «Al servicio de los ciudadanos». }\end{array}$ \\
\hline
\end{tabular}

\begin{tabular}{|c|c|c|c|c|c|c|c|c|c|}
\hline \multirow[b]{2}{*}{ Indicador } & \multicolumn{3}{|c|}{$\begin{array}{l}\text { Sanidad (incluyendo } \\
\text { prevención y atención) }\end{array}$} & \multicolumn{3}{|c|}{ Educación } & \multicolumn{3}{|c|}{ Justicia } \\
\hline & 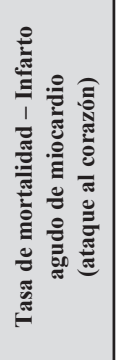 & 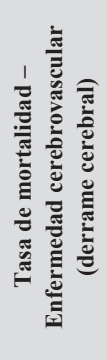 & 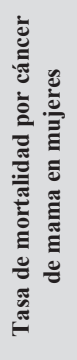 & 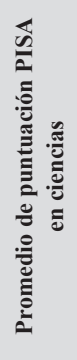 & 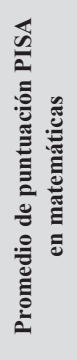 & 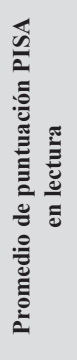 & 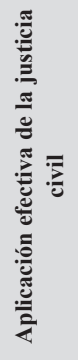 & 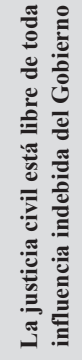 & 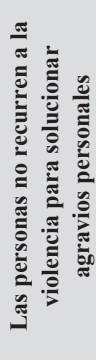 \\
\hline Alemania & $21 \uparrow$ & $10 \uparrow$ & $25 \uparrow$ & 10 & 11 & 9 & 3 & 4 & 11 \\
\hline Australia & $15 \uparrow$ & $8 \uparrow$ & $10 \uparrow$ & $8 \downarrow$ & $18 \downarrow$ & 13 & 10 & 5 & 12 \\
\hline Austria & $20 \uparrow$ & $9 \uparrow$ & $19 \uparrow$ & $20 \downarrow$ & 15 & 25 & 5 & 10 & 6 \\
\hline Bélgica & $14 \uparrow$ & $12 \uparrow$ & $31 \uparrow$ & 14 & $10 \downarrow$ & 17 & 11 & 12 & 13 \\
\hline Canadá & $18 \uparrow$ & $3 \uparrow$ & $15 \uparrow$ & 4 & $5 \downarrow$ & 1 & 13 & 6 & 5 \\
\hline Chile & $27 \uparrow$ & $26 \uparrow$ & $5 \rightarrow$ & 33 & 33 & 32 & 18 & 22 & 28 \\
\hline Corea & $5 \uparrow$ & $25 \uparrow$ & $1 \rightarrow$ & 5 & $2 \downarrow$ & $5 \downarrow$ & 9 & 17 & 19 \\
\hline Dinamarca & $10 \uparrow$ & $18 \uparrow$ & $35 \uparrow$ & 15 & 7 & 15 & 8 & 3 & 3 \\
\hline España & $6 \uparrow$ & $7 \uparrow$ & $6 \uparrow$ & 24 & 25 & $21 \uparrow$ & 22 & 23 & 21 \\
\hline Estados Unidos & $16 \uparrow$ & $5 \uparrow$ & $13 \uparrow$ & 19 & 31 & 20 & 17 & 18 & 18 \\
\hline Estonia & $7 \uparrow$ & $20 \uparrow$ & $17 \rightarrow$ & 2 & 4 & $4 \uparrow$ & 19 & 13 & 14 \\
\hline Finlandia & $29 \uparrow$ & $22 \uparrow$ & $7 \uparrow$ & $3 \downarrow$ & $8 \downarrow$ & $2 \downarrow$ & 6 & 7 & 2 \\
\hline Francia & $1 \uparrow$ & $1 \uparrow$ & $23 \uparrow$ & 21 & 19 & 16 & 15 & 19 & 22 \\
\hline Grecia & $30 \uparrow$ & $32 \uparrow$ & $18 \uparrow$ & $32 \downarrow$ & $32 \downarrow$ & 31 & 26 & 25 & 25 \\
\hline Hungría & $31 \uparrow$ & $33 \uparrow$ & $30 \uparrow$ & $28 \downarrow$ & $28 \downarrow$ & 30 & 25 & 26 & 10 \\
\hline Irlanda & $32 \uparrow$ & $16 \uparrow$ & $34 \uparrow$ & 13 & 13 & 3 & n.a. & n.a. & n.a. \\
\hline Islandia & $28 \uparrow$ & $21 \uparrow$ & $29 \rightarrow$ & $29 \downarrow$ & 24 & 27 & n.a. & n.a. & n.a. \\
\hline
\end{tabular}




\begin{tabular}{|c|c|c|c|c|c|c|c|c|c|}
\hline \multirow[b]{2}{*}{ Indicador } & \multicolumn{3}{|c|}{$\begin{array}{c}\text { Sanidad (incluyendo } \\
\text { prevención y atención) }\end{array}$} & \multicolumn{3}{|c|}{ Educación } & \multicolumn{3}{|c|}{ Justicia } \\
\hline & 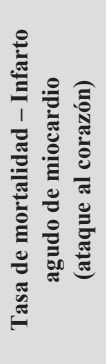 & 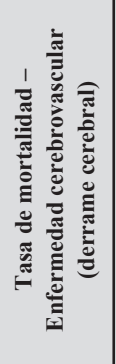 & 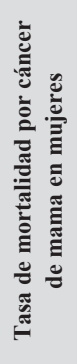 & 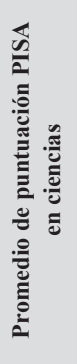 & 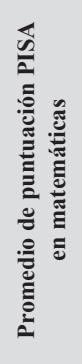 & 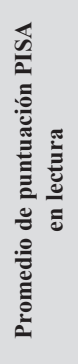 & 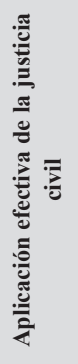 & 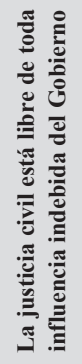 & 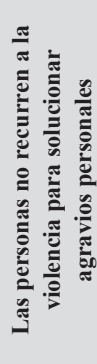 \\
\hline Israel & $3 \uparrow$ & $4 \uparrow$ & $33 \uparrow$ & 30 & $30 \uparrow$ & $29 \uparrow$ & n.a. & n.a. & n.a. \\
\hline Italia & $11 \uparrow$ & $24 \uparrow$ & $20 \uparrow$ & 27 & $23 \uparrow$ & $26 \uparrow$ & 27 & 20 & 26 \\
\hline Japón & $2 \uparrow$ & $17 \uparrow$ & $4 \rightarrow$ & 1 & 1 & $6 \uparrow$ & 4 & 15 & 7 \\
\hline Letonia & $24 \uparrow$ & $35 \uparrow$ & $21 \uparrow$ & 25 & 27 & 23 & n.a. & n.a. & n.a. \\
\hline Luxemburgo & $8 \uparrow$ & $6 \uparrow$ & $24 \rightarrow$ & 26 & 26 & 28 & n.a. & n.a. & n.a. \\
\hline México & $35 \downarrow$ & $19 \uparrow$ & $3 \rightarrow$ & 35 & 35 & 35 & 28 & 27 & 27 \\
\hline Noruega & $23 \uparrow$ & $11 \uparrow$ & $9 \uparrow$ & $18 \uparrow$ & $14 \uparrow$ & $7 \uparrow$ & 1 & 2 & 8 \\
\hline Nueva Zelanda & $33 \uparrow$ & $23 \uparrow$ & $22 \uparrow$ & $6 \downarrow$ & $16 \downarrow$ & 8 & 14 & 11 & 9 \\
\hline Países Bajos & $9 \uparrow$ & $13 \uparrow$ & $28 \uparrow$ & $11 \downarrow$ & $6 \downarrow$ & 12 & 7 & 1 & 16 \\
\hline Polonia & $12 \uparrow$ & $27 \uparrow$ & $16 \rightarrow$ & 16 & 12 & 10 & 20 & 21 & 17 \\
\hline Portugal & $13 \uparrow$ & $28 \uparrow$ & $11 \uparrow$ & $17 \uparrow$ & $22 \uparrow$ & $18 \uparrow$ & 23 & 16 & 24 \\
\hline Reino Unido & $17 \uparrow$ & $15 \uparrow$ & $26 \uparrow$ & 9 & 20 & 19 & 12 & 9 & 15 \\
\hline Rep. Checa & $26 \uparrow$ & $29 \uparrow$ & $12 \uparrow$ & $23 \downarrow$ & $21 \downarrow$ & 24 & 16 & 14 & 4 \\
\hline Rep. de Eslovenia & $19 \uparrow$ & $30 \uparrow$ & $32 \rightarrow$ & 7 & 9 & 11 & 21 & 24 & 20 \\
\hline Rep. Eslovaca & $22 \uparrow$ & $34 \uparrow$ & $27 \rightarrow$ & $31 \downarrow$ & $29 \downarrow$ & 33 & & & \\
\hline Suecia & $25 \uparrow$ & $14 \uparrow$ & $8 \uparrow$ & 22 & 17 & 14 & 2 & 8 & 1 \\
\hline Suiza & $4 \uparrow$ & $2 \uparrow$ & $14 \uparrow$ & 12 & 3 & 22 & n.a. & n.a. & n.a. \\
\hline Turquía & $34 \uparrow$ & $31 \rightarrow$ & 2 & 34 & 34 & $34 \downarrow$ & 24 & 28 & 23 \\
\hline
\end{tabular}

Notas: Sanidad: comparación temporal 2004-2014 (o mejor aproximación disponible). Las flechas reflejan un cambio positivo o negativo de $\geq 2$ p.p. Educación: comparación temporal 2006-2015. Solo se indican los cambios que son estadísticamente significativos. Justicia: no hay comparación de tendencia disponible. Francia ha expresado su preocupación con respecto al uso de una fuente única, el Proyecto Justicia Mundial, que se basa en un número limitado de observaciones y que puede no reflejar la situación objetiva en términos de acceso y calidad de los sistemas judiciales.

Fuentes: OCDE (2016), Estadísticas de Salud; OCDE, PISA 2015 (base de datos); Proyecto Justicia Mundial (Índice de Estado de Derecho, 2016). 


\section{SATISFACCIÓN CIUDADANA CON LOS SERVICIOS E INSTITUCIONES PÚBLICOS}

En un entorno de limitaciones presupuestarias, las organizaciones de los servicios públicos dependen cada vez más de la retroalimentación de sus clientes para tomar decisiones sólidas y efectivas. En la mayoría de los países de la OCDE, las organizaciones, departamentos y organismos del sector público hacen un seguimiento periódico de la satisfacción de usuarios y ciudadanos para evaluar el impacto de las reformas e identificar áreas de acción futura. Las comparaciones entre los niveles de satisfacción ciudadana con los servicios públicos son actualmente de valor limitado, debido a la ausencia de instrumentos y metodologías de encuesta estandarizados tanto a nivel nacional (entre los ministerios y organismos de un mismo país) como entre los países.

Los datos recopilados regularmente mediante la Encuesta Mundial Gallup (Gallup World Poll) permiten un análisis comparativo del nivel de satisfacción de los ciudadanos con una serie de servicios públicos, especialmente en los ámbitos de sanidad, educación y justicia, en los países de la OCDE y asociados. Las comparaciones entre países se deben realizar con cautela, puesto que las percepciones de satisfacción ciudadana pueden estar influenciadas por muchos factores que van más allá del acceso y calidad de los servicios, como son los factores culturales y las campañas de los medios, entre otros.

En 2016, en promedio, el 70\% de los ciudadanos de los países de la OCDE indicaron estar satisfechos con la disponibilidad de asistencia sanitaria de calidad en la ciudad o zona donde viven. Esto es comparable con el porcentaje de ciudadanos satisfechos antes de la crisis financiera y económica (71\%). La satisfacción ciudadana es mayor en Bélgica, Noruega y Suiza y menor en Chile y Grecia, donde menos de 4 ciudadanos de cada 10 muestran satisfacción con los servicios de atención sanitaria. Durante la última década, la satisfacción con los servicios sanitarios aumentó más en Turquía, mientras que disminuyó especialmente en Grecia, Islandia y Japón. En Grecia, esto ha coincidido con drásticos recortes en los gastos de sanidad como consecuencia de la crisis económica y consecuentes programas de austeridad para reducir el déficit y endeudamiento públicos (OCDE, 2014).

Una mayoría de los ciudadanos de los países de la OCDE también manifiesta estar satisfecha con los sistemas educativos y los centros de enseñanza. En 2016, el 67\% de los ciudadanos declararon estar satisfechos con el sistema y centros educativos en la ciudad o zona donde viven, también comparable con el nivel de satisfacción observado antes de la crisis financiera y económica. La satisfacción ciudadana con el sistema educativo es mayor en Irlanda, Noruega y Suiza, mientras que es menor en Chile y Grecia.

Durante la última década, la satisfacción con el sistema educativo ha aumentado más en Israel, mientras que ha descendido notablemente en Chile, España, Hungría y México. El aumento del nivel de satisfacción en Israel se 
asocia con una mejora acentuada de las puntuaciones de los estudiantes en el Programa Internacional para la Evaluación de Estudiantes (PISA, por sus siglas en inglés) de la OCDE durante el mismo periodo, en especial en matemáticas y ciencias.

El nivel de confianza manifestado en el sistema judicial y en los tribunales está generalmente por debajo de los niveles de satisfacción con los sistemas de sanidad y educación. En 2016, en promedio, el 55\% de los ciudadanos en los países de la OCDE manifestaron tener confianza en el sistema judicial y en los tribunales, que supone un pequeño aumento de 2 p.p. desde 2007. En comparación con otros servicios, como sanidad y educación, el nivel de confianza percibido en el sistema judicial y en los tribunales puede estar menos basado en la experiencia, ya que menos personas tienen un trato directo con los tribunales.

En 2016, la confianza en el sistema judicial y en los tribunales fue mayor en Dinamarca, Noruega y Suiza, con 8 personas de cada 10 que manifestaron tener confianza en estas instituciones. En cambio, fue menor en Chile e Italia, donde menos de un cuarto de la población declaró tener confianza en estas instituciones. Durante la última década, la confianza en el sistema judicial y en los tribunales ha aumentado en Alemania, Irlanda, Japón y República Checa, mientras que ha descendido más en Turquía.

\section{Metodología y definiciones}

Los datos proceden de la Encuesta Mundial Gallup (EMG), que generalmente se basa en una muestra representativa de 1.000 ciudadanos de cada país. Aquí se puede encontrar más información sobre esta encuesta: $<$ www.gallup.com/home.aspx>.

Los datos del nivel de satisfacción con la asistencia sanitaria se refieren al porcentaje de personas que contestaron «Satisfecho» a la pregunta «¿Está satisfecho o insatisfecho con la disponibilidad de asistencia sanitaria de calidad en la ciudad o zona donde vive?».

En cuando a la educación, los datos se refieren al porcentaje de personas que contestaron «Satisfecho» a la pregunta «¿Está satisfecho o insatisfecho con el sistema educativo o centros de enseñanza de la ciudad o zona donde vive?».

En el caso de la justicia, los datos se refieren al porcentaje de personas que contestaron «Sí»» a la pregunta «¿Tiene confianza en los siguientes aspectos de su país o no? ¿Y en el sistema judicial y los tribunales?».

Los datos de la satisfacción ciudadana con la policía local están disponibles online (véase el Anexo F). 


\section{Notas de los gráficos}

14-1 Los datos de China corresponden a 2013 en lugar de 2016.

Los datos se refieren al porcentaje que contestó «Sí» a la pregunta «En la ciudad o área donde usted vive, ¿está satisfecho o insatisfecho con la disponibilidad de atención médica de calidad?».

14:2: Los datos de China corresponden a 2013 en lugar de 2016.

Los datos se refieren al porcentaje que contestó «Sí» a la pregunta «En la ciudad o área donde usted vive, ¿está satisfecho o insatisfecho con el sistema educativo o las escuelas?».

14.3: Los datos de China no están disponibles. No se muestran los datos de Corea por cuestiones de fiabilidad. La OCDE está trabajando en mejorar la calidad de los datos del sistema judicial y tribunales.

Los datos se refieren al porcentaje que contestó «Sí» a la pregunta «En este país, ¿tiene usted confianza en cada uno de los siguientes, o no? ¿Qué tal el sistema judicial y los tribunales?».

Información sobre los datos de Israel: $<$ http://dx.doi.org/10.1787/888932315602>.

\section{Gráfico 14.1 Satisfacción ciudadana con la asistencia sanitaria, 2007 y 2016}

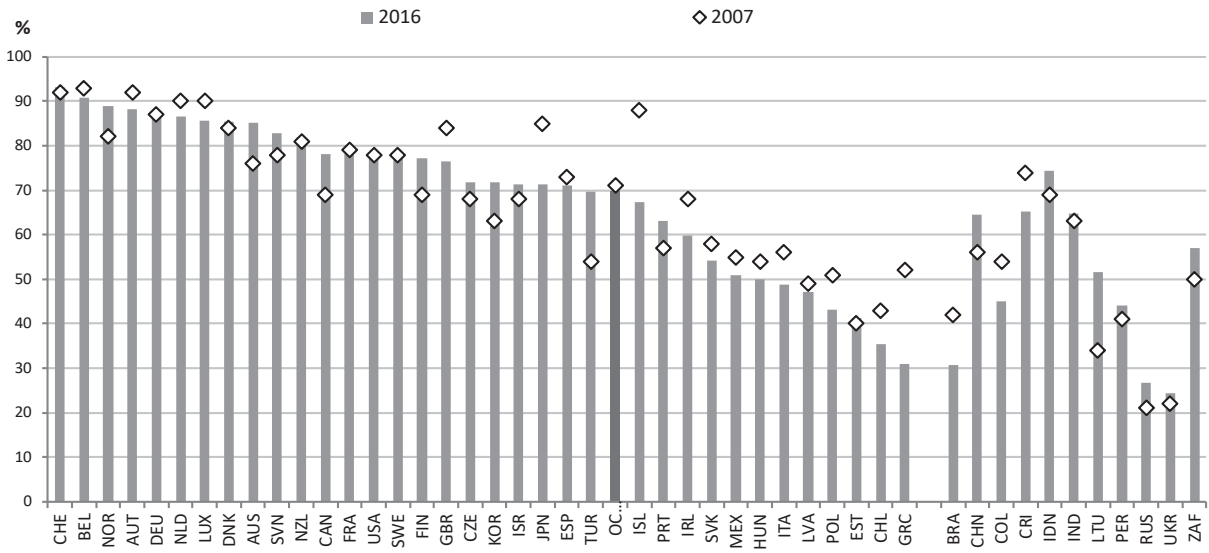

Fuente: Encuesta Mundial Gallup (base de datos). 
Gráfico 14.2 Satisfacción ciudadana con el sistema educativo y centros de enseñanza, 2007 y 2016

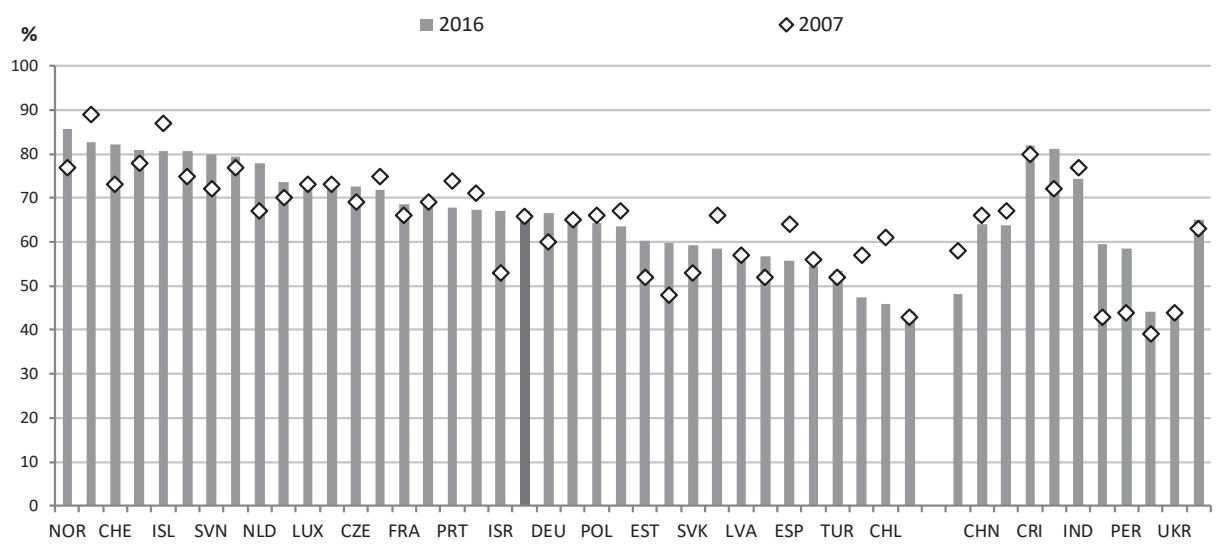

Fuente: Encuesta Mundial Gallup (base de datos).

Gráfico 14.3 Confianza de los ciudadanos en el sistema judicial y en los tribunales, 2007 y 2016

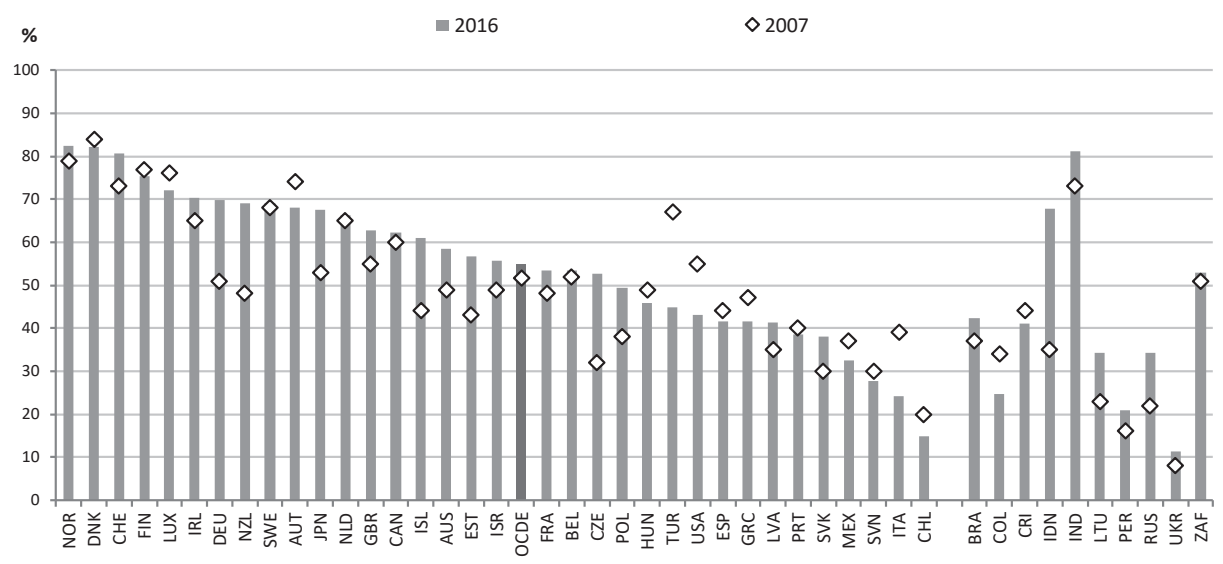

Fuente: Encuesta Mundial Gallup (base de datos). 


\section{ACCESO FINANCIERO Y GEOGRÁFICO A LA ASISTENCIA SANITARIA}

Existen variaciones importantes entre los sistemas sanitarios de los países de la OCDE relativos al grado de cobertura de los bienes y servicios de salud. En la mayoría de los países, la cobertura pública es mayor en hospitales y consultas médicas, mientras que los pagos directos de los usuarios son más elevados para productos farmacéuticos, atención dental y oftalmológica (gafas), lo que arroja una proporción relativamente más elevada de personas que manifiestan necesidades sanitarias insatisfechas en estos ámbitos de salud.

Al contrario que la atención sanitaria financiada con fondos públicos que, teóricamente, está basada en la necesidad, los gastos que asumen de manera directa los hogares dependen de su capacidad de pago. En 2014, en los países de la OCDE, alrededor de una media del 2,8\% del consumo total de los hogares se dedicó a gastos médicos. Esta proporción fue superior al 4\% en Corea, Grecia, Hungría y Suiza e inferior al 2\% en Alemania, Francia, Luxemburgo, Reino Unido y Turquía.

Las necesidades sanitarias insatisfechas, como indican las encuestas basadas en la población, constituyen una buena manera de evaluar los problemas de acceso de determinados grupos de población. Los datos de necesidades sanitarias insatisfechas que se presentan proceden de dos fuentes principales: 1) la Encuesta de 2015 de las Estadísticas de la Unión Europea sobre la Renta y las Condiciones de Vida (EU-SILC, por sus siglas en inglés), que pregunta a los encuestados si en el último año han experimentado alguna vez la necesidad de un reconocimiento médico y no lo han recibido por un número de razones, incluyendo que la asistencia era demasiado cara, el tiempo de espera demasiado largo y la distancia del trayecto demasiado elevada; y 2) la Encuesta de Política Sanitaria Internacional del Commonwealth Fund de 2016 que pregunta a los encuestados si en el último año no acudieron al médico ante un problema de salud, evitaron realizar una prueba médica o tratamiento recomendado por su médico o si no consumieron las recetas médicas o se saltaron dosis debido a los costes.

En 2015, en todos los países incluidos en la encuesta EU-SILC, las personas de bajos ingresos eran más propensas a manifestar necesidades sanitarias insatisfechas que las personas de ingresos altos. Esta brecha fue especialmente importante en Grecia, Italia y Letonia. Las personas de bajos ingresos manifestaron que el coste era el motivo más común de necesidades insatisfechas de reconocimiento médico. Basándose en la encuesta EU-SILC, de media en los países de la OCDE en 2015 la proporción de personas que declaró necesidades insatisfechas de atención dental fue un 50\% mayor que la que manifestó necesidades insatisfechas de reconocimiento médico.

De manera similar, los resultados de la Encuesta Internacional de Políticas Sanitarias del Commonwealth Fund de 2016, que se realizó en 11 países de la 
OCDE, muestran que las personas en hogares de bajos ingresos son más propensas a manifestar necesidades sanitarias insatisfechas debido al coste que aquellas con ingresos por encima de la media. En Estados Unidos, el país de los 11 encuestados donde el porcentaje de población que declara necesidades sanitarias insatisfechas debido al coste es mayor, el $43 \%$ de los adultos de hogares de bajos ingresos manifestaron prescindir de algún cuidado médico debido a los gastos, en comparación con el 32\% de adultos de hogares con ingresos por encima de la media. La proporción de la población que manifestó prescindir de asistencia sanitaria debido a los costes también fue relativamente elevada en Suiza, mientras que fue menor en Reino Unido.

El acceso a la atención médica también requiere un número y distribución adecuados de médicos en todas las partes del país. La escasez de facultativos en algunas regiones puede aumentar el tiempo de viaje necesario para acceder a la atención médica y, por tanto, dar lugar a mayores necesidades sanitarias insatisfechas. La distribución desigual de los médicos es un motivo de preocupación creciente en los países de la OCDE, en especial en los países con zonas remotas y escasamente pobladas.

Los países utilizan una gama de instrumentos políticos para influir en las decisiones de los médicos relativas a la situación geográfica de su práctica profesional, que incluye: 1) proporcionar incentivos financieros para que los médicos trabajen en zonas desatendidas; 2) aumentar la inscripción en programas de educación médica de estudiantes que provienen de regiones geográficas específicas; 3) regular la selección de la ubicación geográfica de la consulta de los médicos (para todos los nuevos graduados o, específicamente, para los graduados médicos internacionales); y 4) reorganizar la prestación de servicios sanitarios para mejorar las condiciones laborales de los médicos en zonas desatendidas y promover la medicina a distancia (OCDE, 2016).

\section{Metodología y definiciones}

Los pagos directos de los usuarios son los gastos que son sufragados directamente por un paciente cuando los seguros públicos o privados no cubren los gastos totales de los bienes y servicios sanitarios. Incluyen el copago y otros gastos pagados directamente por los hogares y las estimaciones de los pagos informales a los proveedores sanitarios en algunos países. Solo se presenta en los indicadores el importe de los gastos médicos (es decir, se excluyen los gastos dedicados a cuidados a largo plazo). Los datos de las necesidades sanitarias insatisfechas proceden de la encuesta EU-SILC. Se pregunta a los encuestados si en el último año han experimentado alguna vez la necesidad de un reconocimiento médico y no lo han recibido, y también sobre la razón por la cual la necesidad que- 
dó insatisfecha. Los datos que se presentan incluyen necesidades sanitarias insatisfechas por motivos financieros, geográficos y relativos a listas de espera. Los ingresos bajos representan a la quinta parte de la población que es más pobre. Los ingresos altos, a la quinta parte de la población que es más rica.

El número de médicos incluye a los médicos de cabecera y especialistas que, en el año analizado, ejercían activamente su profesión tanto en instituciones públicas como privadas. La densidad de médicos se define como el número de médicos en activo por cada 1.000 habitantes.

Los datos del Commonwealth Fund relativos a necesidades sanitarias insatisfechas, incluyendo reconocimiento y tratamiento médicos, debido al coste, por nivel de ingresos, están disponibles online (véase el Anexo F).

\section{Otras publicaciones}

OECD (2016), «Health Workforce Policies in OECD Countries: Right Jobs, Right Skills, Right Places», OECD Publishing.

\section{Notas de los gráficos}

14.6: Los países se clasifican en orden decreciente según la media nacional. Los datos de Países Bajos y Suiza corresponden a 2014 en lugar de 2015.

\section{Gráfico 14.5 Gastos médicos directos como proporción de los gastos finales de los hogares, 2014}

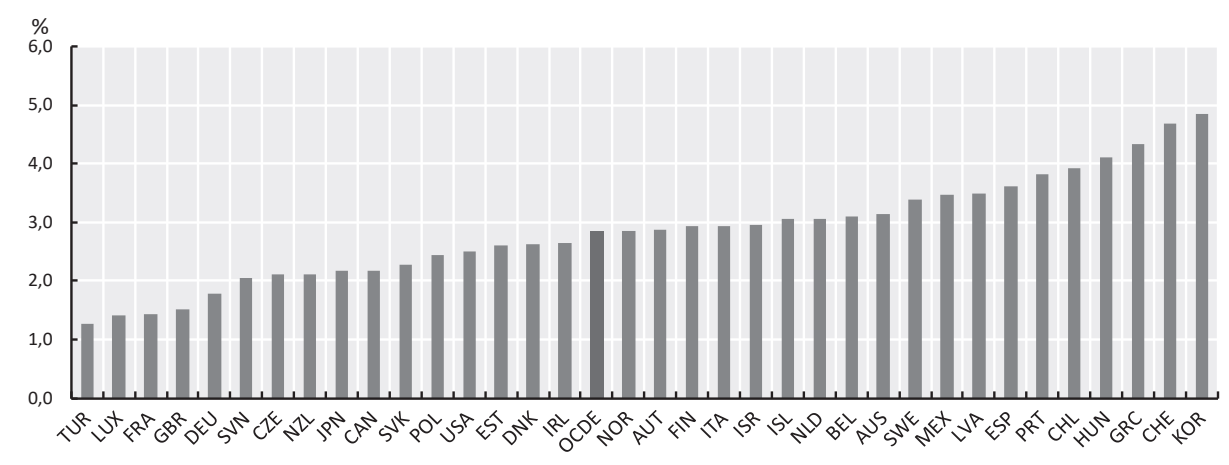

Fuente: OCDE, Estadísticas de Salud. 


\section{Gráfico 14.6 Necesidades sanitarias insatisfechas de reconocimiento médico por nivel de ingresos, 2015}

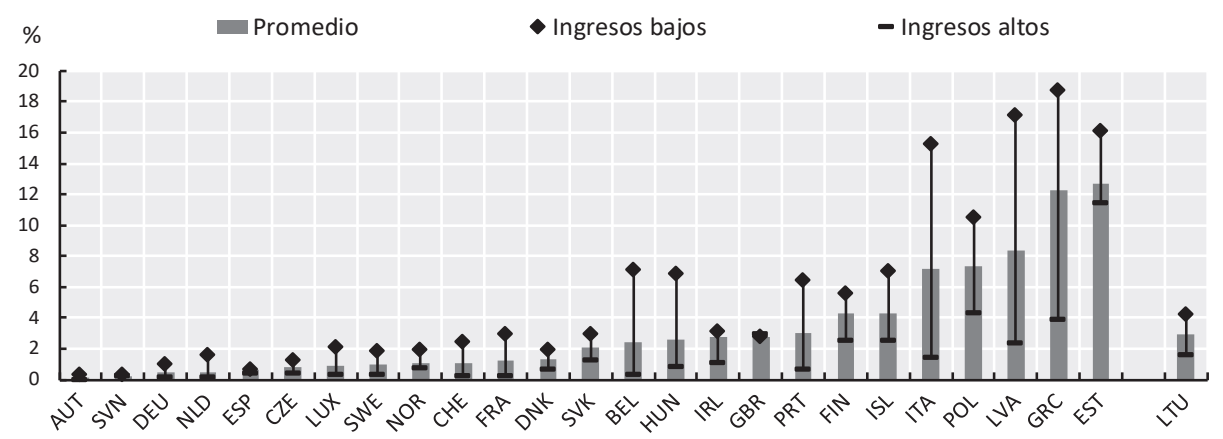

Fuente: Estadísticas de la Unión Europea sobre la Renta y las Condiciones de Vida (EU-SILC).

\section{Gráfico 14.7 Densidad de médicos por regiones (Nivel Territorial 2), 2013}

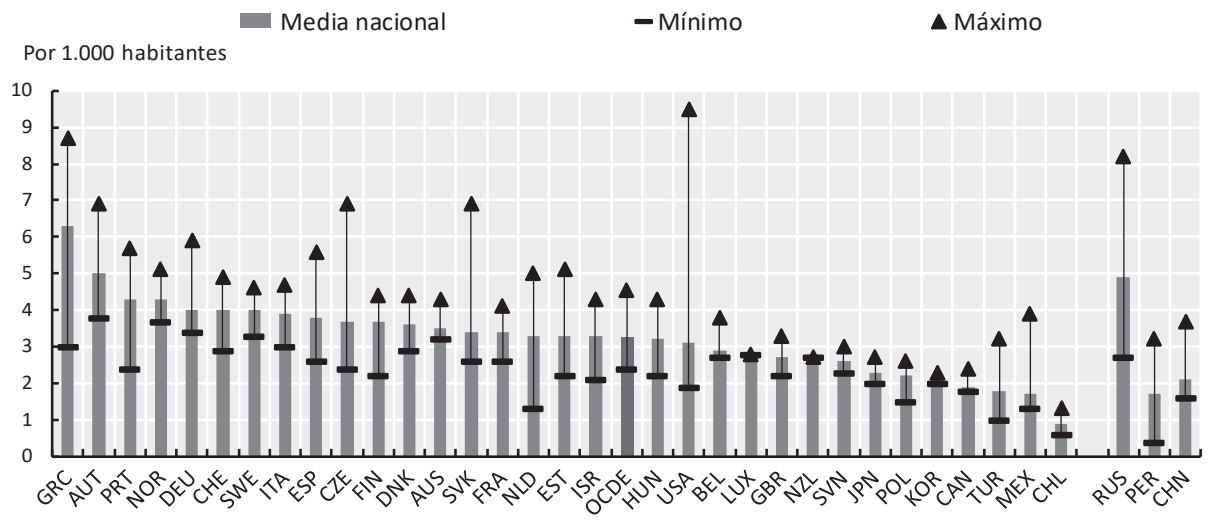

Fuente: Panorama de las Regiones, 2016.

\section{ACCESO FINANCIERO A LA EDUCACIÓN}

En los países de la OCDE, los sistemas educativos proporcionan acceso universal a centros de primaria y secundaria para menores de edades comprendidas entre los 5 y los 14 años, aunque algunos padres pueden decidir mandar a sus hijos a colegios privados por varias razones. El acceso a la edu- 
cación preescolar y superior depende en mayor medida de la capacidad de los hogares para pagar los gastos educativos a estos niveles, de la terminación con éxito de la educación secundaria en el caso de los estudios superiores y de otras razones.

El sector público paga el grueso de la educación primaria y secundaria para garantizar el acceso universal a la educación básica. De media en 2013, casi el $91 \%$ de los fondos de las instituciones de enseñanza primaria, secundaria y postsecundaria no superior provenían de fuentes públicas, y el $9 \%$ restante de fuentes privadas (principalmente en forma de gastos directos de los hogares). Los gastos privados en instituciones de educación primaria, secundaria y postsecundaria (no superior) son relativamente más altos en Chile (21\%), Australia (18\%), México (17\%) y Nueva Zelanda (17\%), mientras que los gastos privados representaron menos del $2 \%$ de los gastos totales en estos niveles en Estonia y Finlandia. Los hogares de algunos países anglosajones (Australia, Nueva Zelanda y Reino Unido) tienden a gastar más en estas instituciones educativas porque hay más estudiantes matriculados en colegios privados (una media de alrededor del 10\%).

Los gastos privados en educación preescolar y superior son relativamente altos. En promedio, los gastos privados en el desarrollo educativo de la primera infancia y en programas preescolares representaron cerca del 19\% de los gastos totales a este nivel en los países de la OCDE en 2013, que supone dos veces más que en los niveles de primaria y secundaria. Existen evidencias abundantes que respaldan que la educación preescolar tiene un impacto positivo en los resultados de aprendizaje a corto y medio plazo y que es especialmente beneficiosa para los estudiantes de entornos socioeconómicos menos privilegiados.

Las tasas de matriculación en enseñanza preescolar para niños de 3 y 4 años han aumentado significativamente durante la última década, pero continúa habiendo variaciones importantes entre países. Aunque las tasas de matriculación en educación preescolar son prácticamente universales en Bélgica o Francia, menos de la mitad de los niños están inscritos en estos programas en otros países como Grecia, Suiza y Turquía. En Grecia y Suiza los niños ingresan en la enseñanza preescolar a una edad posterior y más del $90 \%$ de los niños de 5 años están matriculados. A medida que los países aumentan sus programas de educación preescolar, será importante tener en cuenta las necesidades y expectativas de los padres en relación con la accesibilidad, coste, calidad del programa y personal, y la rendición de cuentas.

A nivel superior, los altos beneficios privados en relación con los costes justifican la mayor contribución de las personas (o sus familias), siempre y cuando haya maneras de garantizar que existen fondos suficientes para que todos los estudiantes tengan acceso a la educación, independientemente de su entorno socioeconómico. Más del 50\% de los gastos de la enseñanza superior son sufragados por los hogares u otras fuentes privadas en varios países de la 
OCDE, incluyendo Australia, Chile, Corea, Estados Unidos y Japón. Por el contrario, la proporción de gastos privados en educación superior permanece relativamente baja en los países nórdicos, donde las tasas de matriculación de las instituciones de enseñanza superior son mínimas o insignificantes.

La OCDE estima que si se mantienen las tendencias actuales, el $68 \%$ de los adultos jóvenes en los países de la OCDE ingresarán en la educación superior por lo menos una vez en la vida. Esta media cae al $61 \%$ cuando se excluye a los estudiantes internacionales y al $51 \%$ cuando se considera solo a los estudiantes nacionales menores de 25 años. Existen, sin embargo, diferencias significativas entre los países, aunque en la mayoría la proporción de estudiantes de enseñanza superior que accede a programas de estudios de grado es más elevada.

La mayoría de los países tiene en funcionamiento programas de préstamos, becas y subvenciones para apoyar el acceso a la educación superior y también para proteger a los estudiantes de la incertidumbre del mercado laboral después de graduarse. En 2013, la OCDE estima que más del 75\% de los estudiantes de enseñanza superior en Australia, Estados Unidos, Nueva Zelanda y Reino Unido se beneficiaban de estos programas. Algunos países de la OCDE tienen dificultades para cuantificar el apoyo que se proporciona a los estudiantes de educación superior y, por tanto, los datos de préstamos deben ser tratados con cautela. Un número de países también ha aplicado otras condiciones especiales a los préstamos públicos o garantizados por el Estado para estudiantes, por ejemplo, en los tipos de interés, el sistema de amortización o mecanismos de exoneración/cancelación.

\section{Metodología y definiciones}

Los datos de todos los gráficos proceden de recopilaciones sobre estadísticas de educación elaboradas por la UNESCO-OCDE-Eurostat (UOE). Los datos de subvenciones/becas proceden de una encuesta $a d$ hoc de la OCDE.

Los gastos privados incluyen todos los directos a instituciones educativas, parcialmente subvencionados con fondos públicos o no. Los países se clasifican en orden decreciente según la proporción de gastos privados a instituciones de educación superior. La enseñanza preescolar (CINE 0) incluye dos tipos de programas: desarrollo educativo de la primera infancia (CINE 01) y educación preescolar (CINE 02). La enseñanza preescolar tiene un componente educativo intencional y está dirigida a niños con edades por debajo de la edad establecida para la educación primaria. 
La tasa neta de ingresos para una edad específica se obtiene dividiendo el número de nuevos ingresos de esa edad por el total de la población de la edad correspondiente. La suma de las tasas netas de ingresos se calcula sumando las tasas de cada edad.

Para más información, véase $<$ www.oecd.org/edu/eag.html $>$.

\section{Otras publicaciones}

OECD (2016), «Education at a Glance 2016: OECD Indicators», OECD Publishing, París, <http://dx.doi.org/10.187/eag-2016-en>.

\section{Notas de los gráficos}

14.9: El año de referencia de Chile es 2014 en lugar de 2013. El año de referencia de Canadá es 2012 en lugar de 2013.

14.11: El año de referencia de Islandia es 2013 en lugar 2014.

\section{Gráfico 14.9. Proporción de gastos privados en educación, 2013}

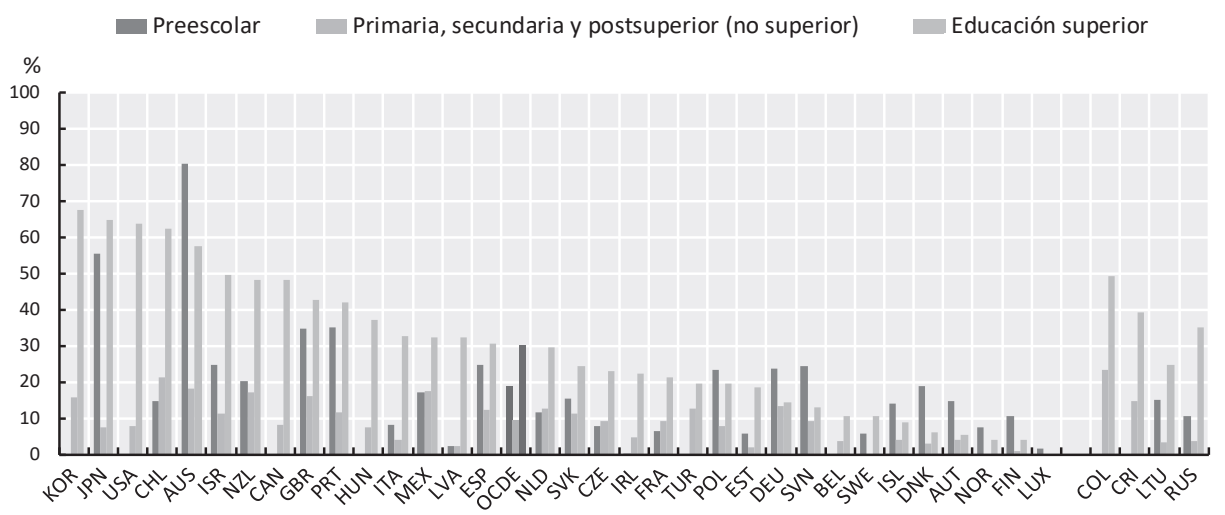

Fuente: Panorama de la Educación 2016, Tablas B3.1 y C2.3, OCDE, París. 


\section{Gráfico 14.10. Tasas de matriculación de niños de 3 y 4 años en educación preescolar y primaria, 2014}

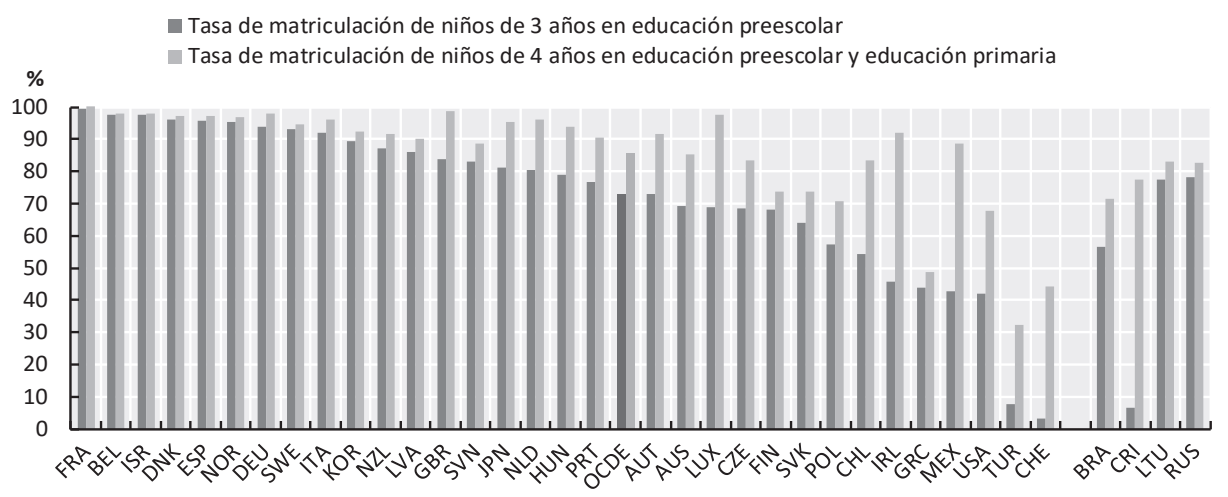

Fuente: Panorama de la Educación 2016, Tabla C2.1, OCDE, París.

$<$ http://dx.doi.org/10.1787/888933533967>

\section{Gráfico 14.11. Tasas de nuevos ingresos en educación superior, 2014}

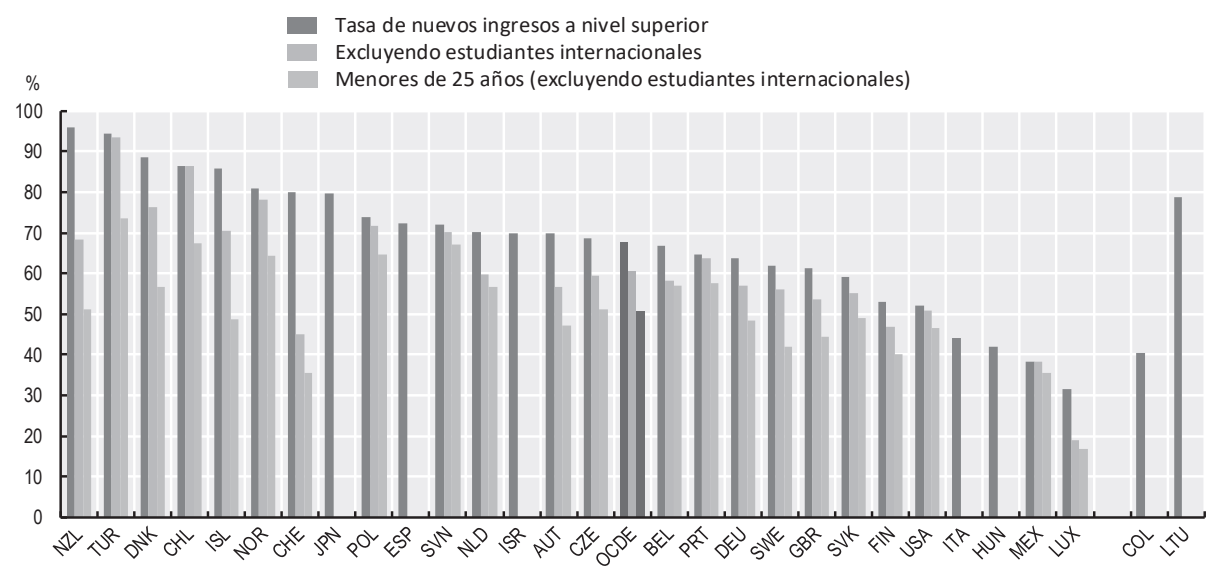

Fuente: Panorama de la Educación 2016, Tabla C3.1, OCDE, París.

$<$ http://dx.doi.org/10.1787/888933533986> 


\section{ACCESO A LOS SERVICIOS JURÍDICOS Y DE JUSTICIA}

La igualdad de acceso para todos a los servicios jurídicos y de justicia es un componente esencial del correcto funcionamiento del Estado de Derecho. También está incluido en el listado de Objetivos de Desarrollo Sostenible (ODS, Objetivo 16) que se deben lograr antes de 2030. Los servicios legales efectivos, eficientes y centrados en las personas, que incluyen acceso a la asistencia jurídica gratuita, a la información sobre las leyes y procedimientos legales, y que fomentan la comprensión de los procesos legales y administrativos resultan clave para garantizar la igualdad de trato ante la ley de todos los ciudadanos y para reforzar la equidad en los países de la OCDE.

Las encuestas de población proporcionan información útil para evaluar las barreras que dificultan el acceso a la acción y asistencia legal necesarias. Sin embargo, estos datos se deben interpretar con cautela, ya que se basan en un número limitado de encuestados, pueden estar influenciados por prejuicios culturales y se recopilaron solo en áreas urbanas de población. Mejorar la calidad de la evidencia sobre el acceso a los servicios de justicia de las encuestas de población y de las fuentes de datos administrativos es importante para promover estos servicios desde una perspectiva ciudadana. Las evidencias sugieren que las necesidades legales insatisfechas pueden ser costosas para las personas, comunidades y economías. Basándose en los datos de la Encuesta General de la Población realizada por el Proyecto Justicia Mundial en 2016, un tercio de las personas experimentaron un conflicto durante los últimos 12 meses. De estas personas, alrededor del $38 \%$ tomaron medidas oportunas para resolver el conflicto. Este porcentaje es mayor en Australia, Estados Unidos y Países Bajos, mientras que es menor en Corea, Japón y Turquía. Las medidas pueden incluir contactar con la policía, reclamar ante un organismo gubernamental, recurrir a los tribunales u otro tipo de acciones.

Los encuestados manifestaron que la causa más común para no adoptar ningún tipo de medidas fue que encontraron una solución rápida y pacífica o que no sintieron la necesidad de emprender acciones. Alrededor del $26 \%$ de las personas de los países miembros de la OCDE indicaron que no adoptaron medidas porque su confianza en los mecanismos de resolución de disputas de sus países es limitada. Las barreras de acceso, incluyendo las financieras y la falta de información y conocimientos sobre los procedimientos, se mencionaron por cerca del $23 \%$ de las personas de los países miembros de la OCDE como motivo para no emprender acciones.

Según la misma Encuesta General de la Población, alrededor del 31\% de las personas de los países miembros de la OCDE recibieron algún tipo de asistencia o asesoramiento legal para resolver sus disputas. La asistencia legal la puede proporcionar una amplia gama de partes interesadas, incluyendo abogados y oficinas gubernamentales, entre otras. Recibir asistencia legal no significa necesariamente que se tomaran medidas para resolver los conflictos. 
En la mayoría de los países de la OCDE, los encuestados manifestaron que la principal razón para no obtener asistencia legal fue que consideraban que el consejo o asesoramiento legal no era necesario. Las barreras financieras para acceder al asesoramiento legal fueron mencionadas por alrededor del $16 \%$ de las personas como uno de los motivos para no pedir asistencia legal en los países miembros de la OCDE. Este porcentaje fue menor en Alemania y Turquía y mayor en Corea. Cerca del $12 \%$ de las personas de los países miembros de la OCDE indicaron que la falta de conocimientos sobre a quién contactar para obtener asistencia legal fue un motivo para no obtenerla. Algunos encuestados también manifestaron que no trataron de obtener asistencia legal porque desconfiaban de los abogados, pensaban que eran poco efectivos o por otros motivos.

\section{Metodología y definiciones}

Los datos proceden de la Encuesta General de la Población realizada por el Proyecto Justicia Mundial (2016). Los datos se basan en una muestra de 1.000 encuestados en las tres ciudades más grandes de cada país. La muestra es probabilística y las entrevistas se realizaron en persona (utilizando una cuota de género 50/50) y a través de Internet. Intervalos de confianza del $95 \%$ representado por $\mathrm{H}$.

Las disputas abarcan conflictos que han tenido lugar en los últimos 12 meses entre un hogar o persona y familia, personas, otros hogares o el Gobierno. Incluyen, por ejemplo, controversias sobre tierras, disputas administrativas y laborales, divorcios/separaciones, violencia doméstica y herencias, entre otros. La asistencia legal se refiere a asesoramiento o ayuda legal por parte de otra persona o grupo, por ejemplo, un líder local, un abogado o un asistente jurídico.

Las barreras de acceso corresponden a la proporción de personas que contestaron que no adoptaron medidas puesto que «no sabían qué hacer o dónde ir», «la persona que podía prestar asistencia estaba demasiado lejos», «costaría demasiado» y «los tribunales son demasiados lentos».

Las opciones exactas de respuesta eran: «No creía que necesitara asesoramiento», «No creía que me pudiera permitir los costes de la ayuda legal» $\mathrm{y}$ «No sabía a quién contactar».

Los datos de «Acceso a la justicia y a la resolución alternativa de disputas (indicadores compuestos)» están disponibles online (véase el Anexo F).

Aquí se puede encontrar más información sobre la metodología utilizada: $<$ http://worldjusticeproject.org/rule-of-law-index $>$. 


\section{Otras publicaciones}

World Justice Project (2016), The Rule of Law Index 2016, World Justice Project, Washington, DC.

\section{Notas de los gráficos}

14.13: Los datos de Austria, Canadá, Chile, Dinamarca, Estonia, Finlandia, Grecia, Hungría, Irlanda, Islandia, Israel, Italia, Letonia, Luxemburgo, México, Noruega, Nueva Zelanda, Portugal, República Checa, República Eslovaca, República de Eslovenia y Suiza no están disponibles en ninguno de los tres gráficos. 14.15: Los datos de Polonia se basan en un número muy limitado de observaciones $(<100)$.

\section{Gráfico 14.13. Porcentaje de personas que adoptaron medidas y recibieron asistencia legal para resolver disputas en los últimos 12 meses, 2016}

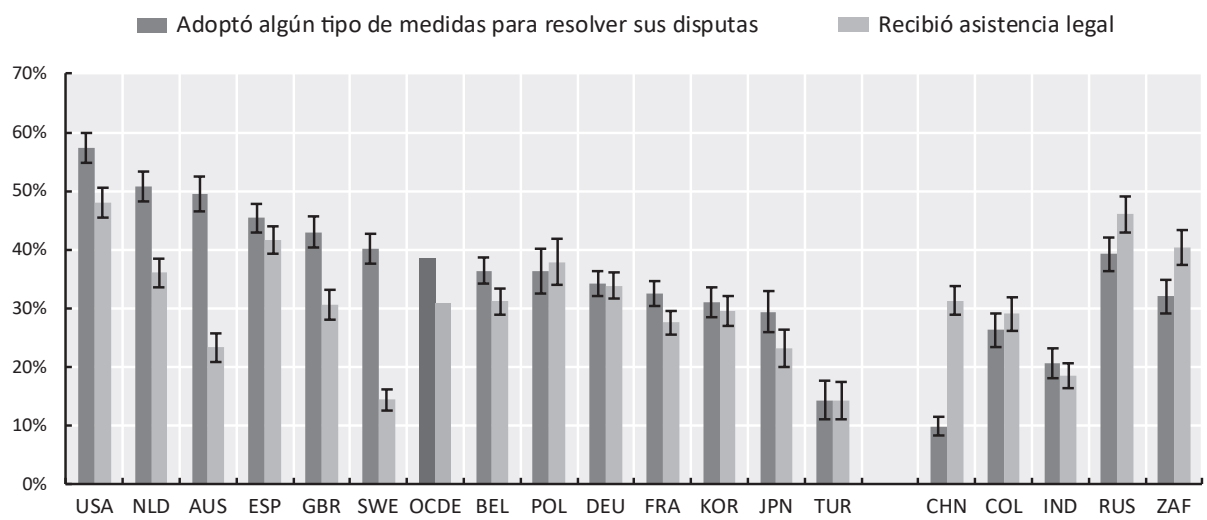

Fuente: Proyecto Justicia Mundial, Encuesta General de la Población (2016).

$<$ http://dx.doi.org/10.1787/888933534005> 
Gráfico 14.14. Motivos para no adoptar medidas en la resolución de una disputa, 2016

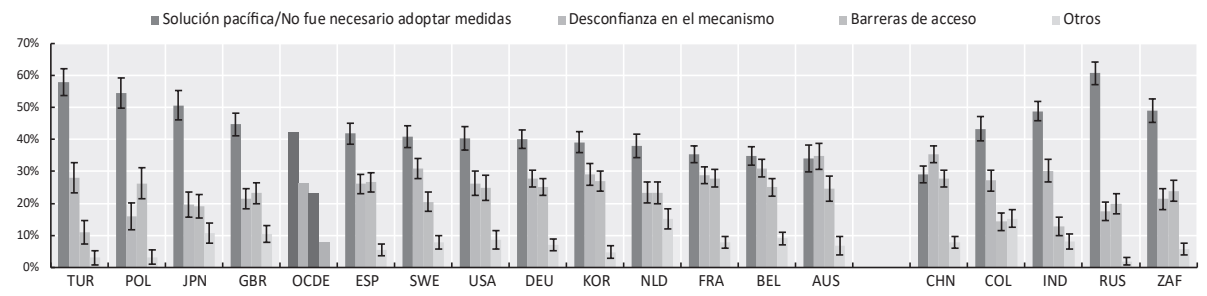

Fuente: Proyecto Justicia Mundial, Encuesta General de la Población (2016).

$<$ http://dx.doi.org/10.1787/888933534024>

\section{Gráfico 14.15. Principales tres motivos por los que no se trata de obtener asistencia legal para resolver una disputa, 2016}

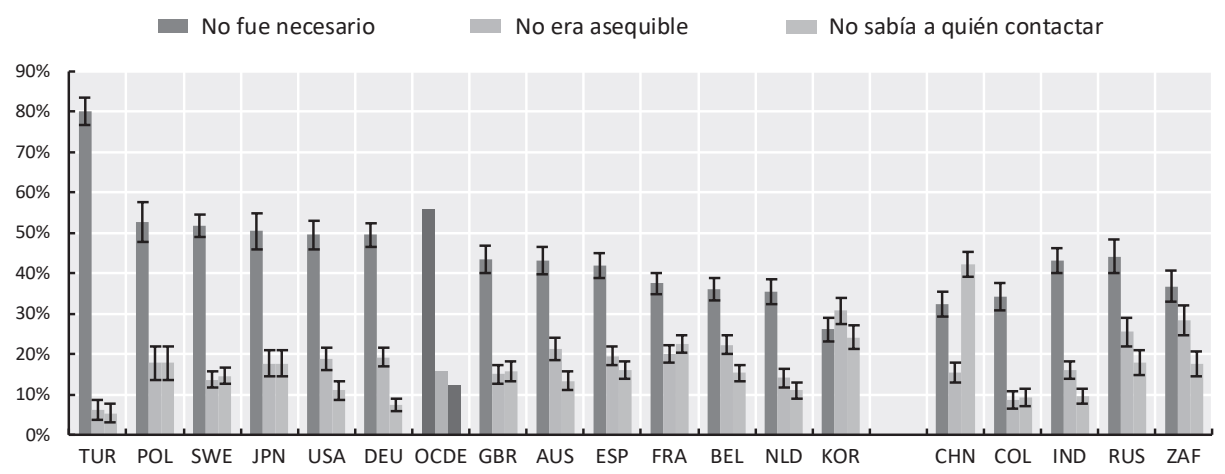

Fuente: Proyecto Justicia Mundial, Encuesta General de la Población (2016).

$<$ http://dx.doi.org/10.1787/888933534043> 


\section{CAPACIDAD DE RESPUESTA DE LOS SISTEMAS SANITARIOS A LAS NECESIDADES DE LOS PACIENTES}

La prestación de asistencia sanitaria que responde y se centra en las necesidades de los pacientes juega un papel cada vez más determinante en las políticas de salud de los países de la OCDE. Un creciente número de países recoge medidas de la experiencia reportada por los pacientes (Patient-Reported Experience Measures, PREM) y medidas de los resultados reportados por los pacientes (Patient-Reported Outcome Measures, PROM) para facilitar la transición de un modelo basado en el volumen a uno centrado en la calidad en materia de gestión de recursos de los servicios sanitarios (Canadian Institute for Health Information, 2015).

Los tiempos de espera largos pueden generar insatisfacción en los pacientes, puesto que posponen los beneficios que se espera conseguir de los tratamientos, mientras que el dolor y la discapacidad continúan. Además, pueden ocasionar resultados de salud adversos cuando la atención necesaria se retrasa. Los tiempos de espera son el resultado de una compleja interacción entre la oferta y la demanda de los servicios sanitarios. La demanda de servicios sanitarios es determinada por el estado de salud de la población, las preferencias de los pacientes y el grado de copago. Los tiempos de espera largos se pueden deber a una escasez de médicos y enfermeras a nivel general o en zonas específicas del país, aunque también pueden derivar de una mala organización del trabajo para responder a las demandas de atención sanitaria (Siciliani et al., 2013).

Basándose en la Encuesta Internacional de Políticas Sanitarias del Commonwealth Fund de 2016 que se realizó en once países de la OCDE, menos de un tercio de la población en Australia, Nueva Zelanda y Países Bajos manifestó no haber recibido una cita médica con su médico de cabecera u otro médico el mismo día o al día siguiente de la petición la última vez que necesitó atención. Esta proporción aumenta a la mitad de la población en Canadá y Noruega. Una consecuencia de los mayores tiempos de espera es que los problemas de salud pueden empeorar y las personas recurren entonces a los servicios de urgencias en hospitales, lo que supone unos costes más elevados. En Canadá, más del $40 \%$ de la población manifestó haber usado los servicios de urgencias en hospitales durante los últimos dos años, el porcentaje más elevado entre los 11 países encuestados.

Existen además importantes diferencias entre los tiempos de espera en relación con los ingresos. En todos los países de la OCDE (exceptuando Países Bajos), las personas de ingresos bajos indicaron mayores tiempos de espera para acceder a la atención necesitada. Más del 35\% de las personas de ingresos bajos en Alemania y Canadá manifestaron que esperaron 6 o más días 
para obtener una cita médica la última vez que necesitaron atención, en comparación con el $27 \%$ de las personas de ingresos más altos. Otros países como Países Bajos, y también más grandes como Australia y Nueva Zelanda, han logrado que el porcentaje de población - pobre o rica- que tiene que esperar tanto para obtener una cita médica sea mucho menor.

Los tiempos de espera para obtener una cita con un médico especialista también varían considerablemente entre países. En promedio, el 14\% de la población de los países de la OCDE declararon que tenían que esperar más de dos meses para obtener una cita con un especialista. Esta proporción oscila entre menos del 10\% en Alemania, Estados Unidos, Francia, Países Bajos y Suiza, y cerca del $30 \%$ en Canadá y Noruega. Estos tiempos de espera pueden dar lugar a retrasos en el establecimiento de un diagnóstico claro y en el comienzo de cualquier tratamiento necesario.

En general, los pacientes manifestaron una opinión positiva sobre la comunicación e interacción con su médico de cabecera. Menos del $20 \%$ de la población en Australia, Nueva Zelanda, Países Bajos, Reino Unido y Suiza declaró que su médico de cabecera no le dedica suficiente tiempo durante la consulta o no proporciona explicaciones en un lenguaje claro y comprensible. La proporción es ligeramente mayor en Francia y Suecia, y ha aumentado desde 2013. Varias características y políticas del sistema sanitario pueden influir en la actitud de los médicos hacia sus pacientes, incluyendo la organización de la asistencia sanitaria, los métodos de remuneración, el seguimiento y comunicación sistemáticos de las experiencias de los pacientes y las políticas médicolegales de protección de los intereses de los pacientes.

\section{Metodología y definiciones}

Los datos proceden de la Encuesta Internacional de Políticas Sanitarias del Commonwealth Fund de 2016, que se realizó en 11 países de la OCDE. Los datos se recopilaron mediante encuestas telefónicas efectuadas a una muestra representativa a nivel nacional de adultos de 18 o más años, entre marzo y junio de 2016. Las muestras finales de población nacional varían entre 1.000 y 1.714 . Los datos se ponderaron para garantizar que el resultado final era representativo de la población adulta de cada país. Más información disponible en $<w w w . c o m m o n w e a l t h f u n d . o r g>$. 


\section{Otras publicaciones}

CIHI - Canadian Institute for Health Information (2015), Wait Times for Priority Procedures in Canada, Ottawa.

Commonwealth Fund (2016), «2016 International Health Policy Survey in Eleven Eountries», noviembre 2016.

Siciliani, L., Borowitz, M. y Moran, V. (2013), «Waiting Time Policies in the Health Sector: What Works?», OECD Health Policy Studies, OECD, París.

\section{Notas de los gráficos}

14.17: Excluye a adultos que no tuvieron que concertar una cita para ver a un médico o enfermera.

14.18: Los países se clasifican en orden decreciente según la proporción de adultos que esperaron 6 o más días la última vez que necesitaron atención médica. Los ingresos bajos se definen como ingresos de hogar de menos del $50 \%$ de la media nacional. El tamaño de las muestras es pequeño $(<100)$ en Países Bajos y Reino Unido. Las diferencias promedio no son estadísticamente significativas en Australia, Noruega, Nueva Zelanda, Países Bajos y Suiza.

14.19: Solo personas que vieron o necesitaron ver a un especialista en los últimos dos años.

\section{Gráfico 14.17. No obtuvo cita con su médico de cabecera u otro médico el mismo día o el día siguiente a la petición la última vez que necesitó atención, 2016}

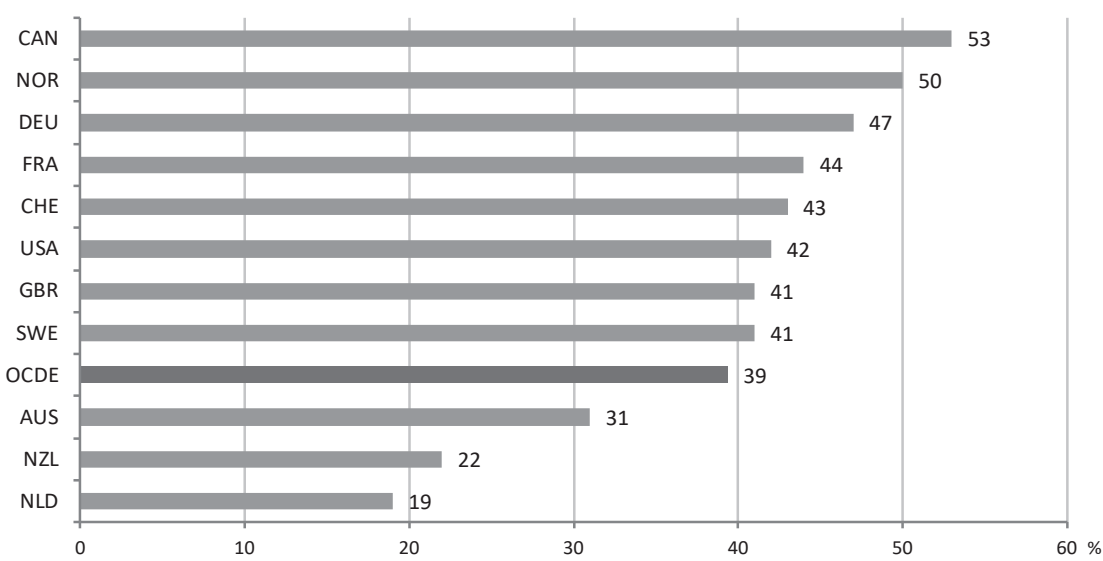

Fuente: Encuesta Internacional de Políticas Sanitarias del Commonwealth Fund (2016). 
Gráfico 14.18. Esperó 6 o más días para obtener una cita médica la última vez que necesitó atención, por nivel de ingresos, 2016

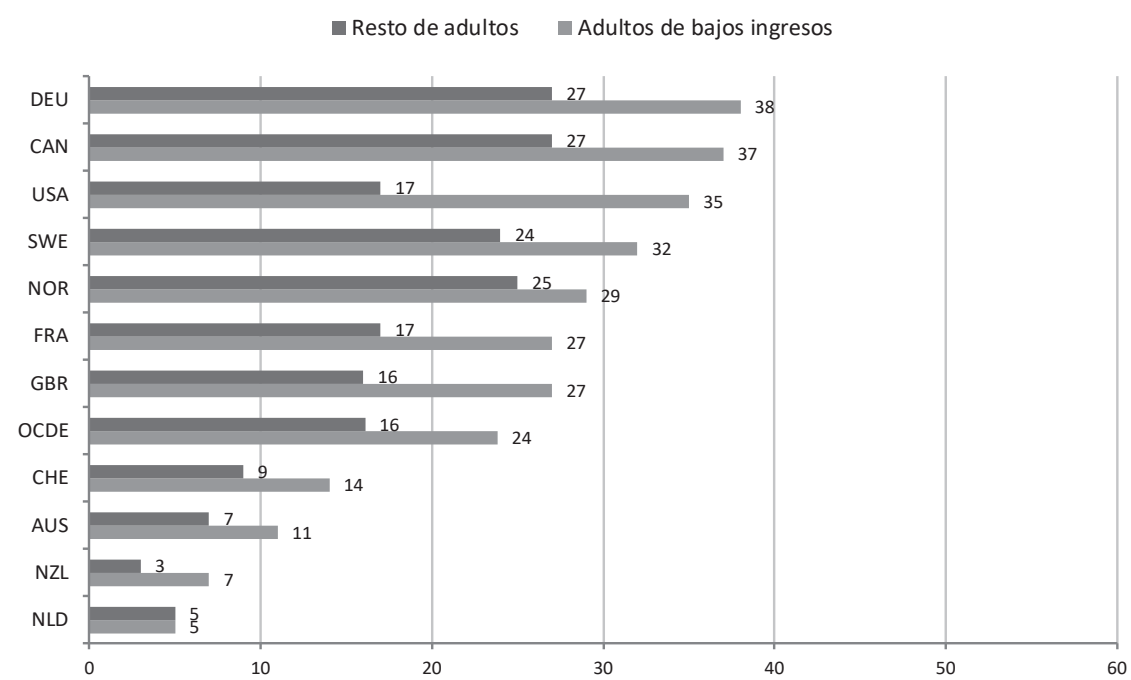

Fuente: Encuesta Internacional de Políticas Sanitarias del Commonwealth Fund (2016).

\section{Gráfico 14.19. Esperó 2 o más meses para obtener una cita con un especialista, 2016}

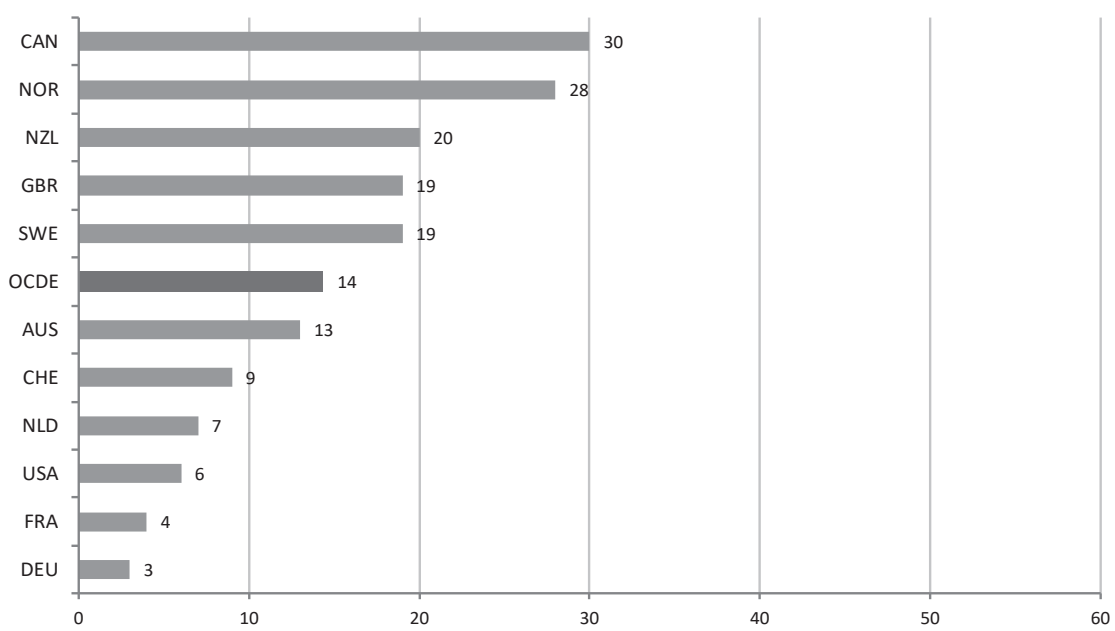

Fuente: Encuesta Internacional de Políticas Sanitarias del Commonwealth Fund (2016). 


\section{Gráfico 14.20. Su médico de cabecera a menudo no pasa suficiente tiempo con usted o no se explica con claridad, 2016}

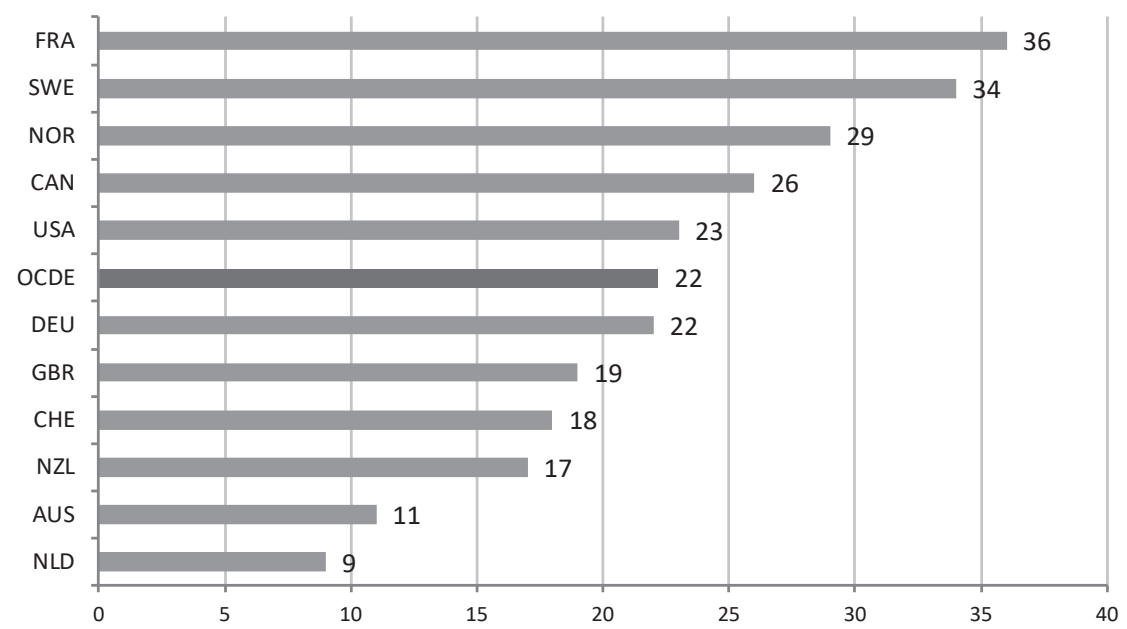

Fuente: Encuesta Internacional de Políticas Sanitarias de la Commonwealth Fund (2016).

\section{CAPACIDAD DE RESPUESTA DE LOS SISTEMAS EDUCATIVOS A LAS NECESIDADES DE LOS ESTUDIANTES}

En todos los países de la OCDE, los sistemas educativos se esfuerzan en satisfacer las necesidades de estudiantes de entornos, ingresos y condiciones de vida diferentes. La capacidad de respuesta de los sistemas educativos se puede evaluar en tres niveles distintos: sistema educativo, centro y profesores.

En el sistema educativo, el índice de escasez de material es un buen indicador para evaluar el grado en que los directores de los centros manifiestan que la falta o mala calidad de los recursos e infraestructuras dificulta la capacidad de enseñanza de sus centros. Las evidencias del informe PISA 2015 muestran que la falta de material escolar y la mala calidad de este repercuten negativamente en el rendimiento de los estudiantes. Entre los países de la OCDE, la escasez de material escolar es especialmente elevada en Hungría, Italia y Japón, mientras que es menor en Australia, Canadá e Islandia. Sin embargo, estos datos se basan en la percepción y, por tanto, el criterio de lo que constituye la escasez de material probablemente varíe entre los países.

En general, la escasez de material educativo dificulta la capacidad de enseñanza en centros con situaciones socioeconómicas desfavorables y en centros rurales en mayor medida que en centros con condiciones más favorables y colegios urbanos (PISA, 2016). 
Con respecto al centro, los programas de asistencia con los deberes organizados por los centros pueden crear las condiciones idóneas para que los estudiantes completen sus tareas escolares y ganen confianza, en especial para alumnos que, de otra manera, no participarían en actividades extraescolares (Beck, 1999; Cosden et al., 2001). Por primera vez, PISA 2015 preguntó a los directores si los centros proporcionan un aula donde los estudiantes puedan hacer sus deberes con la asistencia de personal docente.

En los países de la OCDE, cerca de tres de cada cuatro estudiantes están matriculados en centros que proporcionan un aula para que los alumnos puedan hacer sus deberes, y tres de cada cinco estudiantes van a un centro donde hay personal docente disponible para ayudar con las tareas escolares. En Japón, Luxemburgo y Reino Unido, al menos el 95\% de los estudiantes de 15 años tienen acceso a un aula en el centro para hacer sus deberes, mientras que el porcentaje baja a menos del 50\% de alumnos en Grecia, México y República Eslovaca. En Dinamarca, Estados Unidos, Luxemburgo, Reino Unido y Suecia más del $90 \%$ de los estudiantes asisten a centros donde el personal docente está disponible para ayudar con los deberes; pero en Austria e Italia solo el $30 \%$ de los alumnos asisten a este tipo de centros.

En lo que se refiere a los profesores, los métodos pedagógicos y de enseñanza adecuados son clave para fomentar el interés de los estudiantes en diversos temas, mejorar el rendimiento y aumentar los resultados de aprendizaje de los alumnos. De media en los países de la OCDE, el 45\% de los estudiantes afirmaron que sus profesores adaptan «muchas clases» o «todas o casi todas las clases» a las necesidades y conocimientos del grupo y el $48 \%$ de los alumnos manifestaron que los profesores proporcionan ayuda individualizada cuando un estudiante tiene dificultades para entender un tema o tarea.

Los métodos de enseñanza adaptada están correlacionados positivamente con el rendimiento en ciencias (PISA, 2016). En promedio en los países de la OCDE, y tras tener en cuenta los perfiles socioeconómicos de los estudiantes y centros, los alumnos que indicaron que sus profesores adaptan las clases a las necesidades del grupo en «muchas clases» o en «todas las clases» obtuvieron 20 puntos más en ciencias que los estudiantes que manifestaron que esto ocurría en «algunas clases» o «nunca». Los estudiantes también obtuvieron 13 puntos más de media cuanto indicaron que el profesor proporciona ayuda individualizada cuando un alumno tiene dificultades para entender un tema o tarea, y 8 puntos más de media cuando el profesor cambia la estructura de la clase para enseñar un tema que la mayoría de los estudiantes encuentra difícil de entender. 


\section{Metodología y definiciones}

Los datos de todos los gráficos proceden del Programa Internacional para la Evaluación de Estudiantes (PISA, por sus siglas en inglés) de 2015, que evaluó la competencia de los estudiantes de 15 años en lectura, matemáticas y ciencias (con especial énfasis en ciencias) en 72 países y economías. Más información sobre los datos básicos en $<\mathrm{http}$ ://www. oecd.org/pisa/>.

El índice de escasez de material educativo se calculó según las respuestas de los directores sobre el grado en que la capacidad de enseñanza de sus centros se vio mermada («En absoluto», «Muy poco», «Hasta cierto punto» o «Mucho») por la escasez o insuficiencia de las infraestructuras físicas, tales como edificios, sistemas de calefacción y aire acondicionado y espacio educativo; y del material escolar, como libros de texto, equipos de laboratorio, materiales de enseñanza y ordenadores. La media del índice es 0 y la desviación estándar es 1 en los países de la OCDE. Los valores positivos reflejan las percepciones de los directores de que la escasez de material escolar dificulta la capacidad de enseñanza en mayor medida que la media de la OCDE; los valores negativos indican que los directores creen que la escasez merma la capacidad de enseñanza en menor medida.

El perfil socioeconómico se basa en el índice PISA de estatus económico, social y cultural (ESCS, por sus siglas en inglés).

Los métodos de enseñanza adaptada se midieron basándose en las respuestas de los estudiantes que manifestaron que los profesores los utilizaban en «muchas clases» o en «todas o casi todas las clases».

\section{Otras publicaciones}

OECD (2016), PISA 2015 Results (Volume II): Policies and Practices for Successful Schools, PISA, OECD Publishing, París, <http://dx.doi. org/10.1787/9789264267510-en>.

\section{Notas de los gráficos}

14.21: Los valores más elevados en el indicador reflejan mayor escasez de material educativo. Los países y economías se clasifican en orden decreciente según el índice de escasez de material educativo. 


\section{Gráfico 14.21. Índice de escasez de material educativo, 2015}

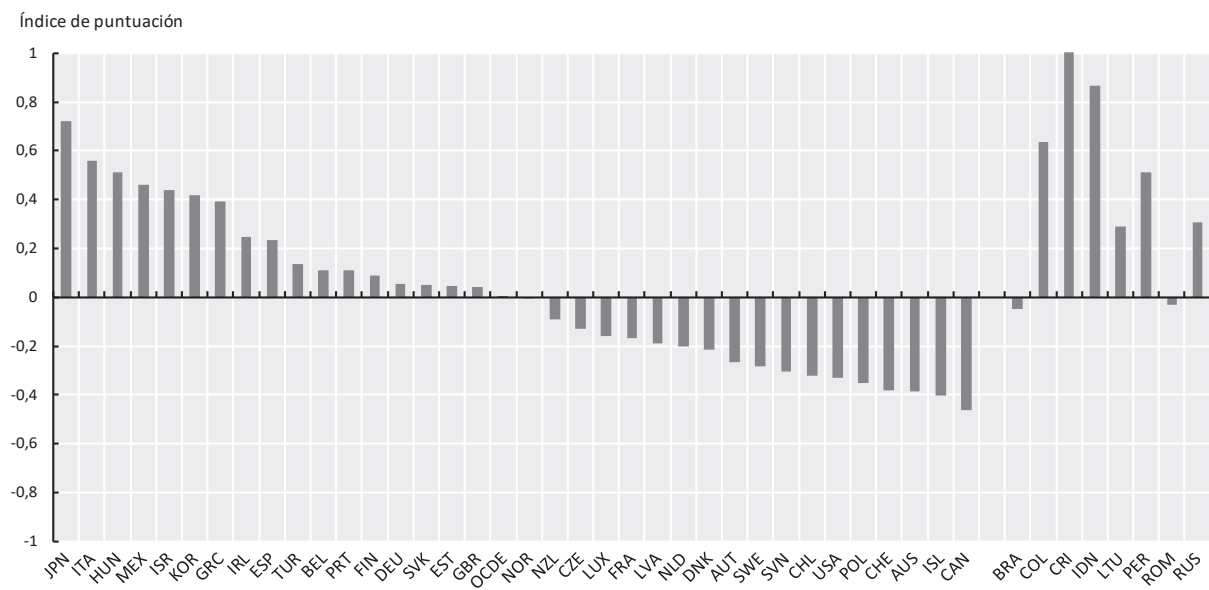

Fuente: OCDE, Base de Datos PISA 2015, Tabla II.6.2.

Gráfico 14.22. Porcentaje de estudiantes en centros que proporcionan ayuda, 2015

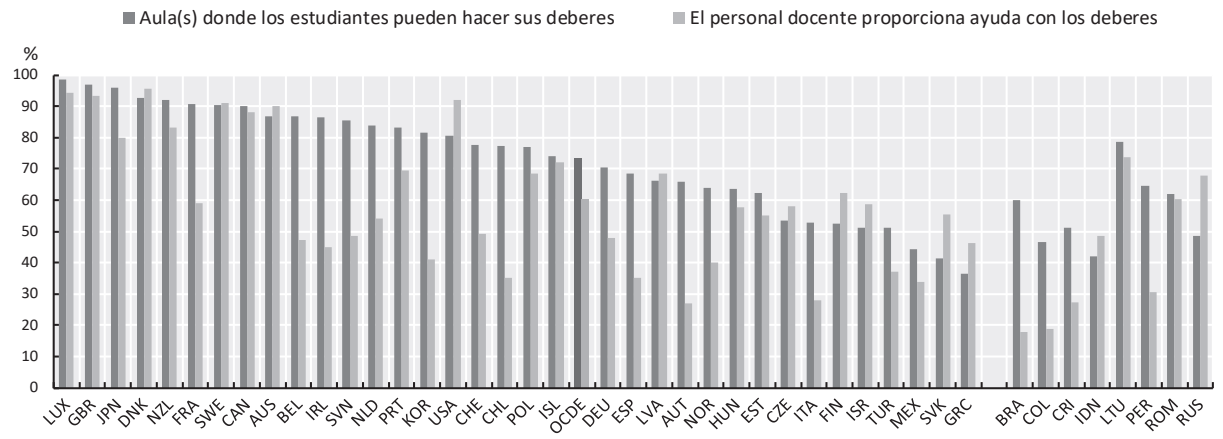

Fuente: OCDE, Base de Datos PISA 2015, Tabla II.2.46 


\section{Gráfico 14.23. Porcentaje de estudiantes que manifestaron que sus profesores utilizan prácticas de enseñanza adaptada en «muchas clases» 0 en «todas o casi todas las clases», 2015}

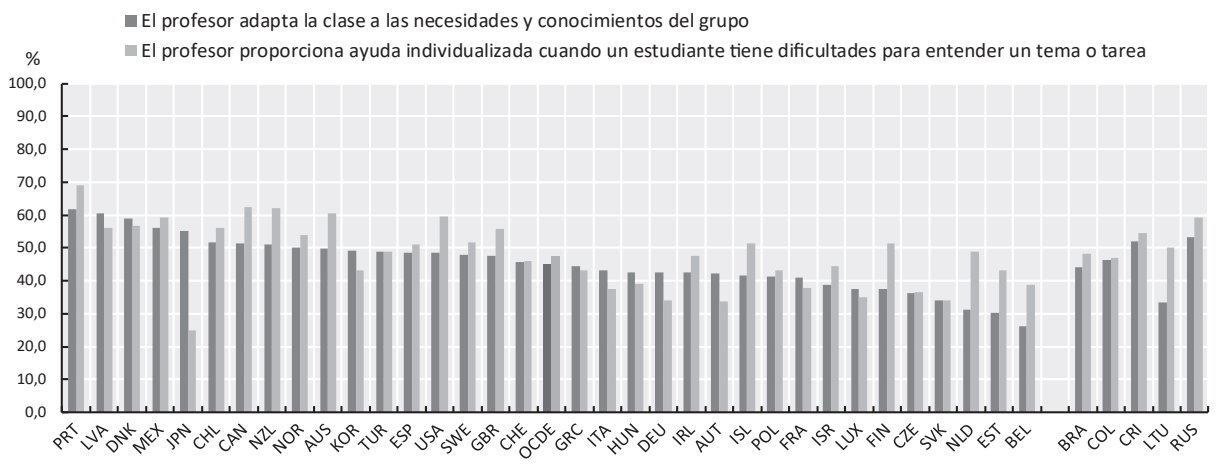

Fuente: OCDE, Base de Datos PISA 2015, Tabla II.2.22

\section{SERVICIOS DE JUSTICIA CIVIL SIN DILACIONES}

La incapacidad de resolver las necesidades legales de manera efectiva y sin dilaciones puede disminuir el acceso a oportunidades económicas, agravar las situaciones de pobreza y minar el potencial humano. Reducir la duración de los procedimientos de justicia civil es una cuestión clave en muchos países de la OCDE y asociados. Los retrasos en el dictamen de resoluciones judiciales pueden disuadir a los ciudadanos, especialmente a aquellos de grupos más vulnerables, con problemas legales legítimos, de recurrir al sistema legal y esto puede conllevar costes elevados para la sociedad.

Cada dos años, la Comisión Europea para la Eficacia de la Justicia (CEPEJ) recoge datos sobre la duración estimada —o tiempo de resolución- de los casos civiles, mercantiles, administrativos y de otro tipo (no penales). El tiempo de resolución (TR) es un indicador que se utiliza de manera habitual para estimar el marco temporal de un sistema judicial para resolver un caso (CEPEJ, 2016). A partir de la capacidad potencial de los tribunales de un país de resolver un caso (medida como el número de casos resueltos en un año), el TR estima el número máximo de días necesarios para que un tribunal de una jurisdicción determinada resuelva un asunto pendiente.

Basándose en los últimos datos disponibles, la duración estimada de los casos civiles, mercantiles, administrativos y de otro tipo (no penales) mejoró entre 2010 y 2014 en los países de la OCDE-UE incluidos en la encuesta de la CEPEJ. Sin embargo, existen variaciones importantes entre jurisdicciones. En 
2014, el tiempo estimado necesario se situó por debajo de 40 días en Dinamarca y Estonia, mientras que en Portugal fue de más de dos años y en Grecia de más de un año y medio en 2012 (último año con datos disponibles de estos dos países).

Centrándose solo en los asuntos civiles y mercantiles litigiosos, que incluyen por ejemplo los casos de divorcio contencioso o controversias relativas a contratos, la duración de los procedimientos también mejoró, aunque las diferencias entre países persisten. En 2014, la duración estimada de los procedimientos fue menor de 6 meses en Austria, Dinamarca, Estonia, Hungría, Luxemburgo, Países Bajos, República Checa y Suecia, mientras que en Italia y República Eslovaca se situó por encima de un año. La duración estimada de los procedimientos ha disminuido más en Estonia, Luxemburgo y República de Eslovenia, mientras que aumentó en Países Bajos.

En comparación con los asuntos civiles y mercantiles litigiosos, la duración estimada de los procedimientos de casos administrativos es generalmente mayor. Varía entre menos de cuatro meses en República de Eslovenia y Suecia a más de cuatro años en Grecia y más de dos años y medio en Italia para el último año con datos disponibles. La duración de los procedimientos de casos administrativos ha mejorado significativamente en Letonia y Reino Unido, mientras que ha empeorado en República Eslovaca.

Además de procedimientos rápidos, los sistemas de justicia civil responsables también implican una gama de servicios adaptados a las necesidades y capacidades de las personas, incluyendo el uso en los tribunales de mecanismos específicos para sectores poblacionales más vulnerables y también la disponibilidad de mecanismos de resolución de disputas.

\section{Metodología y definiciones}

Las figuras proceden del Cuadro de Indicadores de la Justicia en la Unión Europea (EU Justice Scoreboard) de 2016. Los datos se basan en la evaluación de 2016 de los sistemas judiciales de la CEPEJ. Los países se clasifican en orden creciente según el tiempo necesitado en días para el último año disponible.

La duración de los procedimientos indica el tiempo estimado que se necesita para resolver un caso en los tribunales, es decir, el tiempo que tarda un tribunal en emitir una resolución en primera instancia. Se obtiene dividiendo el número de casos pendientes al final del periodo observado por el número de casos resueltos durante el mismo periodo, multiplicado por 365. Este indicador no es una estimación del tiempo promedio que se necesita para procesar un caso, sino una media teórica de la duración de un caso en un sistema específico. 
Las comparaciones entre países relativas a la duración estimada de los procedimientos se deben realizar con cautela, ya que puede haber diferencias en los tipos de casos y tribunales que se recogen por país, así como métodos distintos de recopilación y categorización de datos (UE, 2016). Para capturar con precisión la duración promedio de los procedimientos se necesitaría acceder a los tiempos reales de resolución de cada tipo de casos en los sistemas TIC. Las notas detalladas de los gráficos están disponibles en <http://ec.europa.eu/justice/effective-justice/scoreboard/index_en.htm $>$.

Según la metodología de la CEPEJ, esta categoría incluye todos los casos civiles y mercantiles litigiosos y no litigiosos, casos no litigiosos de registro mercantil y de tierras, otros casos no litigiosos, casos de Derecho administrativo y otros casos no penales.

Los casos civiles (y mercantiles) litigiosos se refieren a disputas entre partes, por ejemplo, relativas a contratos. Por el contrario, los casos civiles (y mercantiles) no litigiosos se refieren a procedimientos no contenciosos, por ejemplo, requerimientos de pago extrajudiciales. Los casos mercantiles son competencia de tribunales mercantiles específicos en algunos países y competencia de tribunales ordinarios (civiles) en otros. Los casos de Derecho administrativo se refieren a disputas entre ciudadanos y las autoridades locales, regionales o nacionales. Son competencia de tribunales administrativos específicos en algunos países $\mathrm{y}$ competencia de tribunales ordinarios (civiles) en otros.

\section{Otras publicaciones}

CEPEJ (2016), European judicial systems Efficiency and quality of justice, Estudios CEPEJ n. ${ }^{\text {o } 23,<h t t p: / / w w w . c o e . i n t / t / d g h l / c o o p e r a t i o n / c e p e j / e v a-~}$ luation/default_en.asp>.

\section{Notas de los gráficos}

14.24, 14.25 y 14.26: Los datos se clasifican en orden creciente según el tiempo necesitado en días para el último año disponible. 
Gráfico 14.24. Tiempo necesitado para resolver casos civiles, mercantiles, administrativos y de otro tipo (primera instancia, en días)

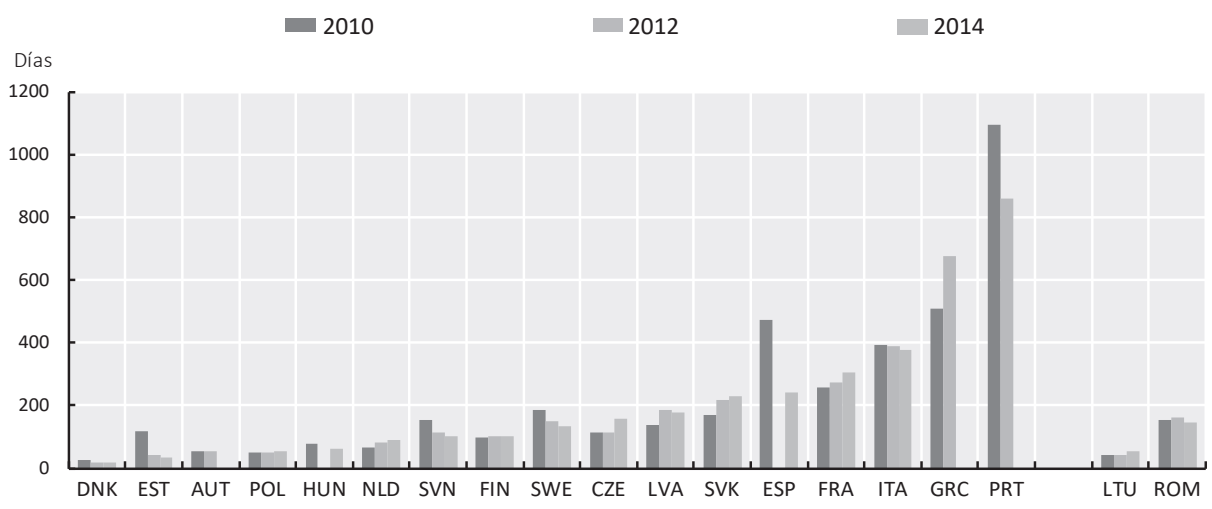

Fuente: Cuadro de Indicadores de la Justicia en la Unión Europea (EU Justice Scoreboard), basado en el Estudio n. ${ }^{\circ} 23$ (2016) de la Comisión Europea para la Eficacia de la Justicia (CEPEJ).

$<$ http://dx.doi.org/10.1787/888933534195>

\section{Gráfico 14.25. Tiempo necesitado para resolver casos civiles y mercantiles litigiosos, 2010-2014}

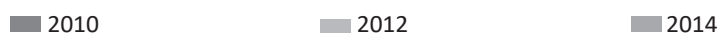

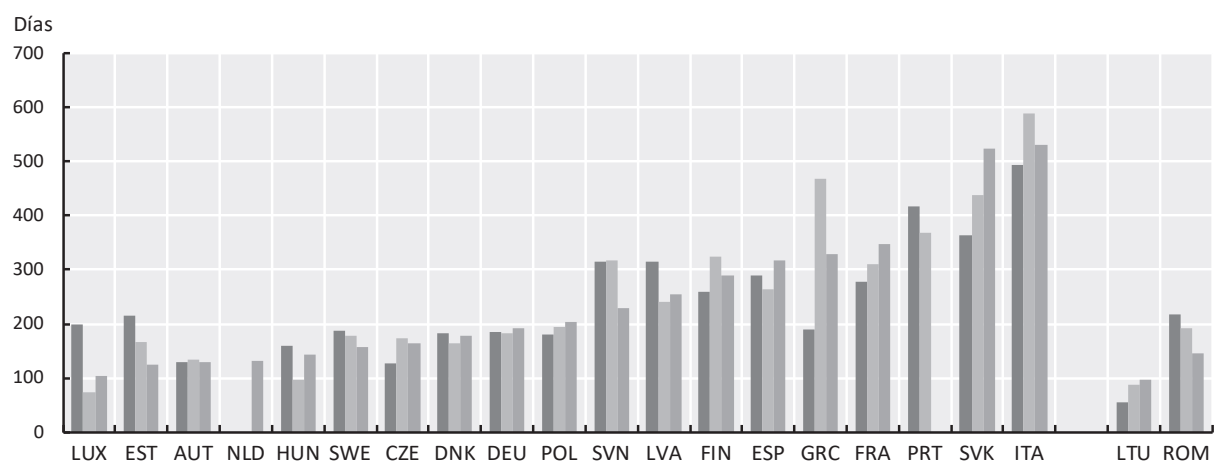

Fuente: Cuadro de Indicadores de la Justicia en la Unión Europea (EU Justice Scoreboard), basado en el Estudio n. ${ }^{\circ} 23$ (2016) de la Comisión Europea para la Eficacia de la Justicia (CEPEJ). 


\section{Gráfico 14.26. Tiempo necesitado para resolver casos administrativos (primera instancia, en días), 2010-2014}

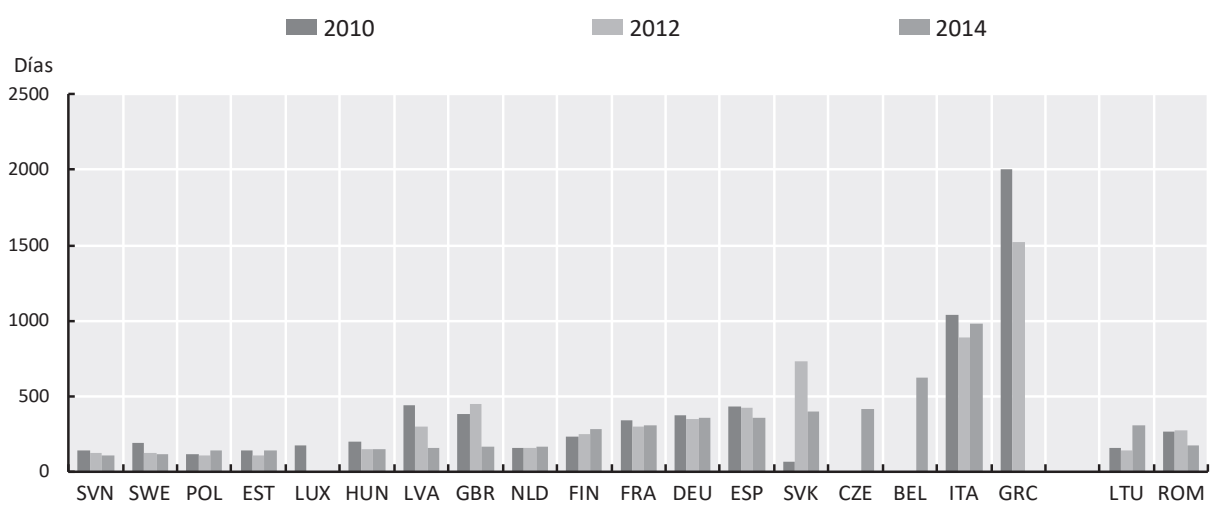

Fuente: Cuadro de Indicadores de la Justicia en la Unión Europea (EU Justice Scoreboard), basado en el Estudio n. ${ }^{\circ} 23$ (2016) de la Comisión Europea para la Eficacia de la Justicia (CEPEJ).

$<$ http://dx.doi.org/10.1787/888933534233>

\section{CALIDAD DE LA ASISTENCIA SANITARIA}

Todos los días, los profesionales sanitarios tienen que enfrentarse a un abanico de problemas de salud, que incluye enfermedades infecciosas y crónicas, así como enfermedades y lesiones potencialmente mortales. Las enfermedades cardiovasculares (ataques al corazón, accidentes cerebrovasculares...) y los diferentes tipos de cáncer son algunas de las enfermedades más graves y frecuentes en los países de la OCDE. Suponen, con diferencia, las dos principales causas de muerte. Las enfermedades cardiovasculares contabilizan cerca de un tercio de todas las muertes y los distintos tipos de cáncer alrededor de un cuarto. Aunque la incidencia de los problemas cardiovasculares y del cáncer se puede reducir con mayores esfuerzos de prevención (por ejemplo, disminuyendo el consumo de tabaco), los sistemas sanitarios juegan un papel importante en la detección temprana, diagnóstico y tratamiento oportuno de estas afecciones.

Un buen indicador de la calidad de los cuidados intensivos de personas que sufren un infarto agudo de miocardio (IAM o ataque al corazón) es la tasa de letalidad en los 30 días posteriores a la admisión hospitalaria. Esta medida refleja los procesos del cuidado, como el transporte a tiempo de pacientes al hospital y las intervenciones médicas efectivas, y oscila entre el mínimo de alrededor del 4\% marcado en Australia y Suecia, al máximo del 28\% en México. En la mayoría de los países (con la excepción de México), las tasas de letalidad por IAM han disminuido durante la última década, lo cual refleja mejoras en la calidad de los servicios de emergencia que se proporcionan 
antes de que los pacientes lleguen al hospital e inmediatamente después de su admisión. De media en los países de la OCDE, la tasa de letalidad ha disminuido más de un $25 \%$ durante la última década.

Después del cáncer de pulmón, el cáncer de mama supone la segunda causa de muerte por cáncer en las mujeres. Su mortalidad se pude reducir mediante el diagnóstico precoz y tratamientos más efectivos. La mayoría de los países de la OCDE han organizado programas de cribado del cáncer de mama dirigidos a mujeres por encima de cierta edad (a menudo de más de 50 años) para promover el diagnóstico precoz. La proporción de mujeres con edades comprendidas entre los 50 y 69 años cribadas durante los últimos dos o tres años ha aumentado en la mayoría de los países de la OCDE en la última década, aunque continúa siendo baja en varios países. En 2014, más del 80\% de las mujeres de 50-69 años habían sido cribadas de manera reciente en Dinamarca, Estados Unidos, Finlandia y República de Eslovenia, mientras que en México y República Eslovaca la proporción disminuye a menos del 30\%, que, aun así, supone una mejora sustancial con respecto a la década anterior. En Corea y Japón también ha habido un aumento significativo en la proporción de mujeres que participa en estos programas de cribado del cáncer de mama.

Durante el mismo periodo, las tasas de mortalidad por cáncer de mama también han disminuido cerca de 3,5 p.p. de media en los países de la OCDE. Esta reducción refleja las mejoras en la detección precoz y en el tratamiento del cáncer de mama. Las disminuciones en mortalidad han sido sustanciales en Nueva Zelanda, Países Bajos y República Checa, con un descenso de más de 6 p.p. en una década. Dinamarca también marcó un descenso considerable, aunque su tasa de mortalidad continuó siendo la más alta en 2014. Por otro lado, en Corea, Japón y Turquía la tasa de mortalidad por cáncer de mama aumentó durante la última década, a pesar de que continúa entre las más bajas de los países de la OCDE.

\section{Metodología y definiciones}

La tasa de letalidad por IAM mide el porcentaje de personas de 45 años o más que mueren en los 30 días posteriores a la admisión hospitalaria. Las tasas que se basan en los datos de admisión se refieren a las muertes que ocurrieron en el mismo hospital de la admisión inicial. Las que derivaron en un traslado se excluyeron en los datos de todos los países, excepto Australia, Bélgica, Dinamarca, Hungría, Irlanda, Israel, Japón, Luxemburgo, México, Países Bajos, República Eslovaca y Suecia. Esta exclusión generalmente aumenta la tasa en comparación con los países que no excluyeron los traslados. Las tasas se normalizaron por edad y género con arreglo a la población de la OCDE mayor de 45 años admitida por IAM en 2010. 
Las tasas de cribado se basan en datos de encuesta o de programas, lo cual puede influir en los resultados. Los basados en datos de encuesta se pueden ver afectados por el sesgo de recuerdo. Los datos de programas a menudo se calculan según los programas nacionales de control y cribado, y las diferencias en la población objetivo y la frecuencia del cribado también pueden producir variaciones de cobertura entre los países. Los datos de mortalidad proceden de datos brutos extraídos de la Base de Datos de Mortalidad de la OMS en junio de 2016 y se han normalizado por edad a las estructuras de población de la OCDE para eliminar variaciones debidas a diferencias en las estructuras de población de los países de la OCDE y a lo largo del tiempo.

Se puede encontrar más información sobre las tasas de mortalidad por infarto agudo de miocardio y enfermedad cerebrovascular online (véase Anexo F).

\section{Otras publicaciones}

OECD (2013), Cancer Care: Assuring Quality to Improve Survival, OECD Publishing, París, <http://dx.doi.org/10.1787/9789264181052-en>.

\section{Notas de los gráficos}

14.27: Se incluyen las admisiones que derivan en traslados. Intervalos de confianza del $95 \%$ representado por $\mathrm{H}$. Se proporciona la media de tres años en el caso de Islandia y Luxemburgo.

14.28 y 14.29: Las notas detalladas del gráfico están disponibles en Statslinks. 


\section{Gráfico 14.27. Mortalidad en los 30 días posteriores a la admisión hospitalaria por IAM, de 2008 a 2013 (o años más próximos)}

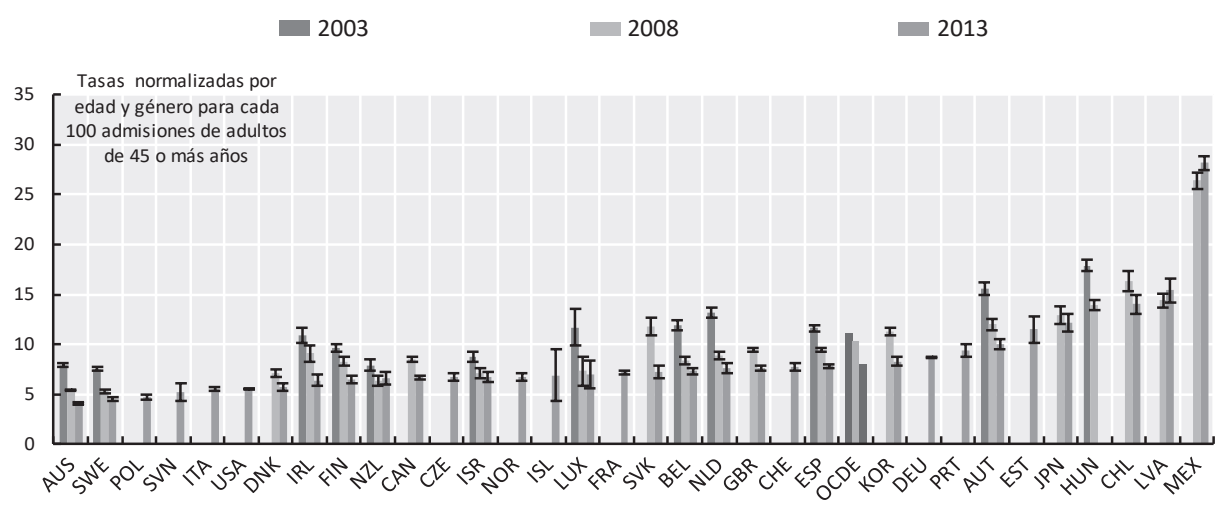

Fuente: OCDE, Estadísticas de Salud 2015, < http://dx.doi.org/10.1787/health-data-en>.

$<$ http://dx.doi.org/10.1787/888933534252>

\section{Gráfico 14.28. Mamografía de cribado en mujeres de 50-69 años, de 2004 a 2014 (o años más próximos)}

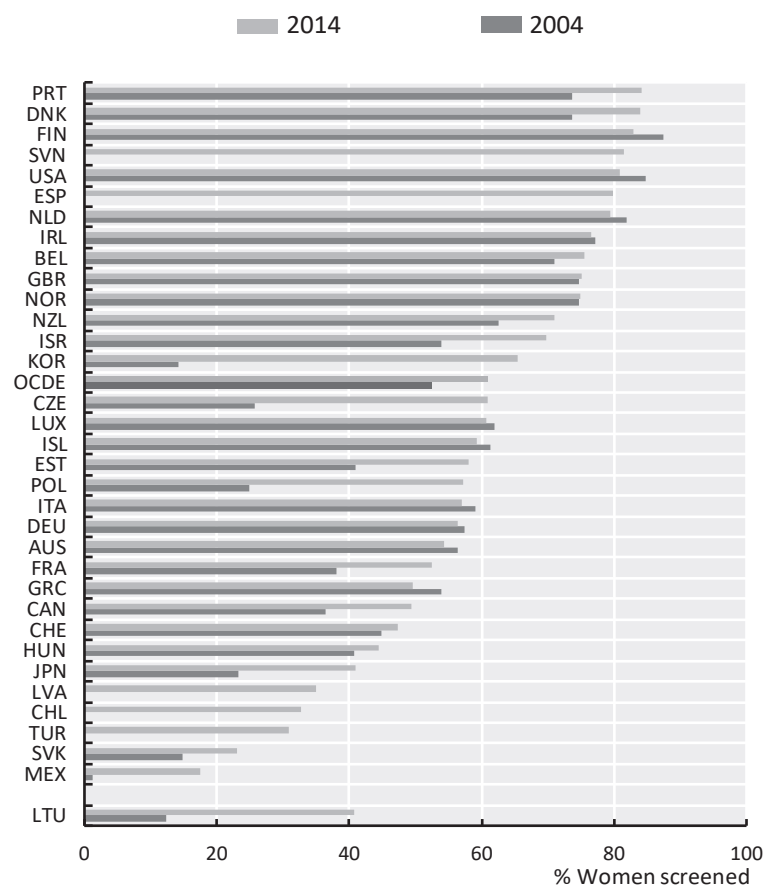

Fuente: OCDE, Estadísticas de Salud 2016 (base de datos). 


\section{Gráfico 14.29. Mortalidad por cáncer de mama en mujeres, de 2004 a 2014 (o años más próximos)}

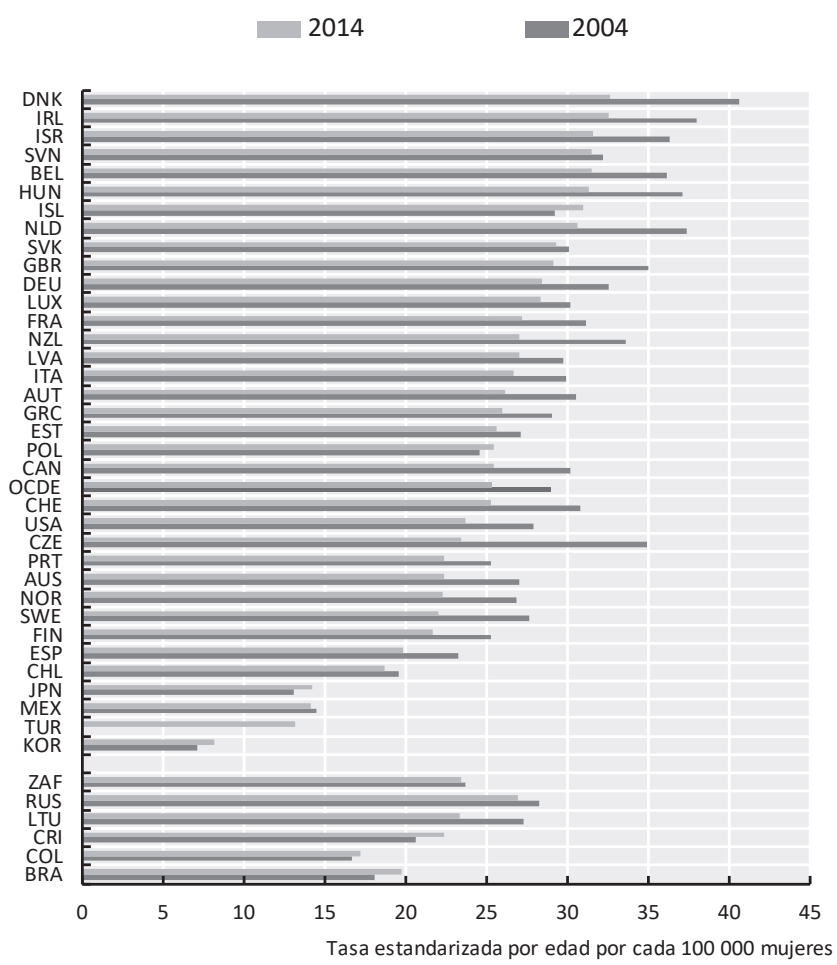

Fuentes: OCDE, Estadísticas de Salud 2015; Organización Mundial de la Salud 2016 (base de datos).

$<$ http://dx.doi.org/10.1787/888933534290>

\section{RENDIMIENTO DE LOS ESTUDIANTES Y EQUIDAD EN LA EDUCACIÓN}

El objetivo principal de los sistemas educativos en los países de la OCDE y asociados es dotar a los estudiantes y adultos de los conocimientos y capacidades necesarios para desarrollar todo su potencial. La encuesta PISA, realizada cada tres años, mide los resultados de aprendizaje de los estudiantes de 15 años en lectura, matemáticas y ciencias. Permite una comparación no solo de las medias nacionales, sino también de las diferencias de puntuación entre los distintos grupos de alumnos y centros educativos. PISA 2015 se centró en el ámbito de las ciencias y la evaluación midió tres habilidades clave: explicar los fenómenos científicos, diseñar y evaluar investigaciones científicas e interpretar datos y evidencias científicamente. En 2015, de los países miembros 
de la OCDE, los mejores resultados en ciencias los obtuvieron Canadá, Estonia, Finlandia y Japón, con una puntuación media por estudiante de más de 525 puntos en comparación con la media de la OCDE de 493 puntos. Por el contrario, Chile, México y Turquía obtuvieron las puntuaciones medias más bajas por estudiante de los países de la OCDE. Durante la última década, la media de puntuación PISA en ciencias ha aumentado significativamente en Israel, Noruega y Portugal, en más de 10 puntos, mientras que ha disminuido más en Finlandia, Hungría y República Eslovaca, por encima de 25 puntos.

Dejando de lado los promedios nacionales, el porcentaje de estudiantes que alcanza cada nivel de competencia indica la capacidad de los países para enfrentarse al rendimiento bajo al mismo tiempo que apoyan la excelencia. Alcanzar por lo menos el nivel 2 es de especial importancia, puesto que supone el nivel básico de competencia que todos los adultos jóvenes deben conseguir para aprovechar nuevas oportunidades de aprendizaje y participar activamente en la vida social, económica y ciudadana de las sociedades modernas en un mundo globalizado (OCDE, 2016). En el ámbito de las ciencias, los estudiantes que alcanzan el nivel 2 pueden utilizar sus conocimientos de contenidos y procedimientos básicos de ciencias para identificar una explicación apropiada, interpretar datos y establecer la cuestión que tratar en un experimento sencillo.

En Canadá, Estonia, Finlandia y Japón hay más estudiantes de alto rendimiento (niveles 5 y 6 ) que de bajo rendimiento (por debajo del 2). En los niveles 5 y 6 , los alumnos utilizan ideas o conceptos científicos abstractos para explicar fenómenos, eventos o procesos desconocidos y más complejos que involucran vínculos causales múltiples. En México y Turquía hay pocos estudiantes de alto rendimiento, mientras que la proporción de alumnos de bajo rendimiento es muy alta, con más del $40 \%$ del total de estudiantes que rinde por debajo del nivel 2.

Los estudiantes de entornos socioeconómicos desfavorables son casi tres veces más propensos a no alcanzar el nivel básico de competencia en ciencias que los alumnos más favorecidos (OCDE, 2016). En promedio, el 13\% de la variación en el rendimiento de los estudiantes en ciencias en los países de la OCDE se puede explicar por la situación socioeconómica de los alumnos. Esta explica menos del 10\% de la variación en el rendimiento en ciencias en países como Canadá, Estonia, Islandia, Italia, Letonia, Noruega y Turquía, mientras que en Francia, Hungría y Luxemburgo explica más del 18\% de la variación en rendimiento.

Durante la última década, la proporción de la variación en el rendimiento en ciencias que se explica por el entorno socioeconómico de los estudiantes disminuyó significativamente en Chile, Estados Unidos y Turquía, mientras que aumentó más en Corea y República Checa. Además de la situación socioeconómica, en algunos países de la OCDE existe una variación sustancial de la puntuación entre alumnos inmigrantes y no inmigrantes. 
En el caso de los estudiantes más desfavorecidos y, en general, para los alumnos que tienen dificultades en ciencias, los recursos adicionales dirigidos a estudiantes o centros con mayores necesidades pueden ayudar a que los alumnos adquieran el nivel básico de competencia y desarrollen un interés permanente en la asignatura. La aplicación más limitada de prácticas que agrupan a los estudiantes en diferentes programas o centros y el uso limitado y estratégico de la repetición de curso serían de beneficio para todos los estudiantes (OCDE, 2016).

\section{Metodología y definiciones}

Los datos de todos los gráficos proceden del Programa Internacional para la Evaluación de Estudiantes (PISA, por sus siglas en inglés) de 2015, que evaluó la competencia de los estudiantes de 15 años en 72 países y economías. Más información sobre los datos básicos en $<\mathrm{http}$ :// www.oecd.org/pisa/>.

En el PISA, el perfil socioeconómico de los estudiantes se basa en el índice de estatus económico, social y cultural (ESCS, por sus siglas en inglés), derivado de varios factores relacionados con el entorno familiar de los alumnos: nivel de formación y ocupación de los padres, un número de posesiones que pueden ser representativas del bienestar material y el número de libros y otros recursos educativos disponibles en el hogar. Los estudiantes favorecidos y desfavorecidos se definen como aquellos que pertenecen al 25\% superior/inferior de la distribución del índice ESCS en su país.

El gráfico «Diferencia de rendimiento en ciencias entre estudiantes inmigrantes y no inmigrantes, 2015» está disponible online (véase Anexo F). Solo se muestran los países donde el porcentaje de estudiantes inmigrantes es mayor al $6,25 \%$.

\section{Otras publicaciones}

OECD (2016), PISA 2015 Results (Volume I): Excellence and Equity in Education, PISA, OECD Publishing, París, $<$ http://dx.doi. org $/ 10.1787 / 9789264266490-$ en $>$. 


\section{Notas de los gráficos}

14.32: Las variaciones de las puntuaciones medias son solo estadísticamente significativas en Australia, Austria, Finlandia, Hungría, Islandia, Nueva Zelanda, Países Bajos, Portugal, República Checa y República Eslovaca.

14.33. Los países se clasifican en orden creciente según la proporción de estudiantes de bajo rendimiento.

\section{Gráfico 14.32. Evolución de la puntuación PISA en ciencias, de 2006 a 2015}

๑ 2015 • 2006

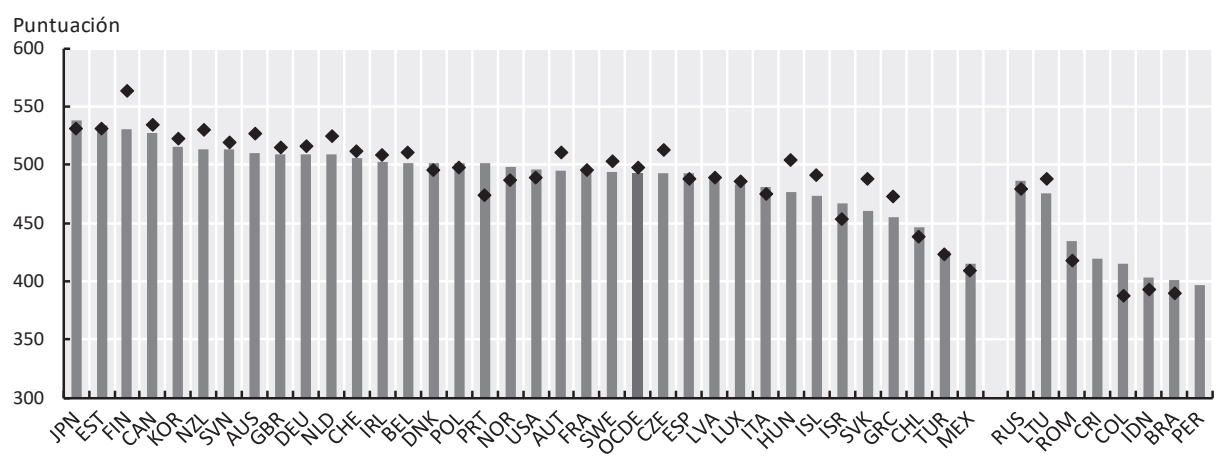

Fuente: Resultados PISA 2015 (Volumen I): Excelencia y Equidad en Educación.

$<$ http://dx.doi.org/10.1787/888933534309>

\section{Gráfico 14.33. Proporción PISA de estudiantes de alto y bajo rendimiento en ciencias, 2015}

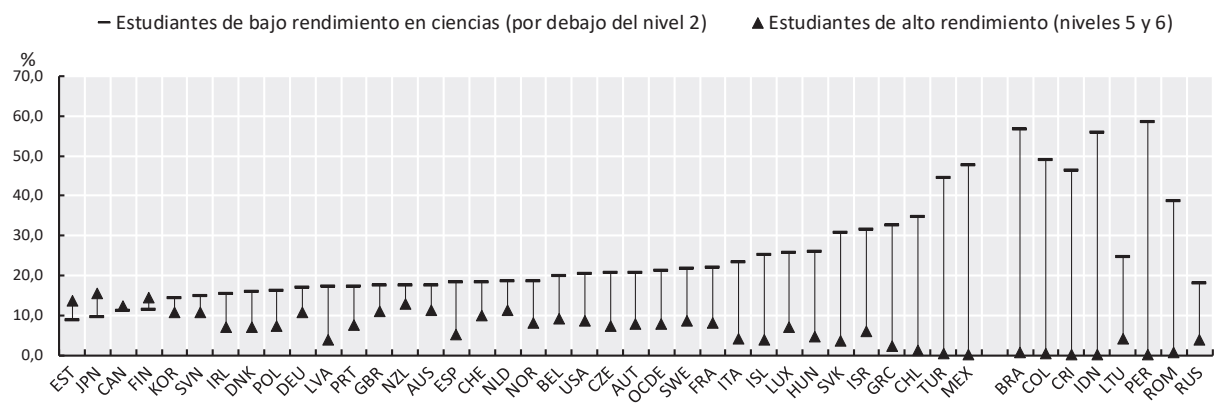

Fuente: Resultados PISA 2015 (Volumen I): Excelencia y Equidad en Educación. 


\section{Gráfico 14.34. Porcentaje de variación en el rendimiento en ciencias} que se explica por el estatus socioeconómico de los estudiantes, 2015

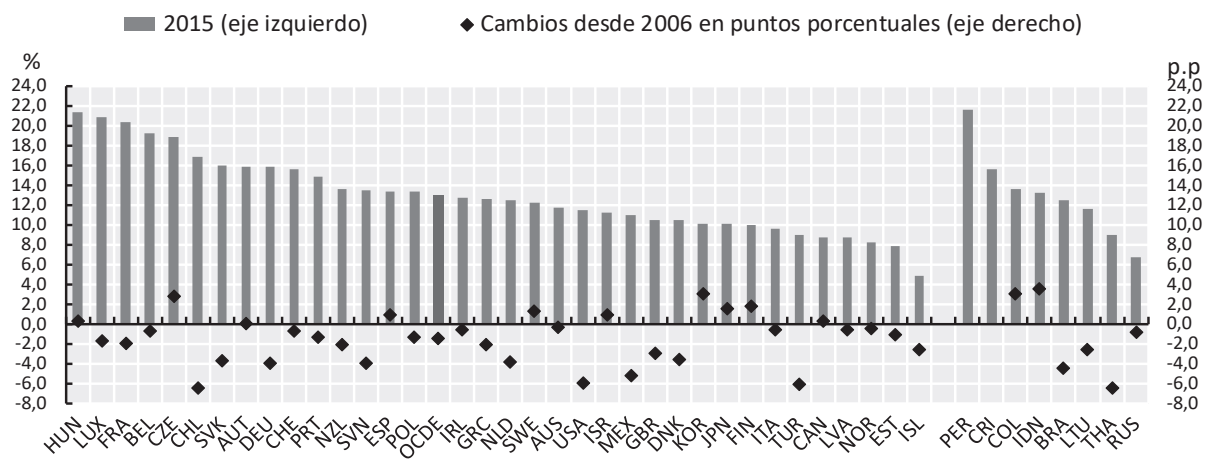

Fuente: OCDE, Base de Datos PISA 2015, Tablas I.2.3, I.6.1, I.6.3a, I.6.7, I.6.17, I.7.1 y I.7.15a.

<http://dx.doi.org/10.1787/888933534347>

\section{EFECTIVIDAD E IMPARCIALIDAD DE LOS SISTEMAS JUDICIALES}

Un componente esencial del Estado de Derecho se basa en sistemas judiciales efectivos e imparciales que garanticen que las leyes se respetan, las necesidades legales se atiendan y que impongan las sanciones adecuadas cuando se vulnere la normativa. Los sistemas de justicia efectivos protegen los derechos de todos los ciudadanos frente a toda infracción de la ley por cualquier persona, incluyendo miembros de partidos políticos y de las Administraciones públicas. El impacto de los sistemas y servicios de justicia que funcionan bien sobre un amplio abanico de factores que influyen en el bienestar de las personas es, sin embargo, difícil de aislar de la intervención de otras partes interesadas como pueden ser la policía, el sistema penitenciario y otros agentes sociales y de justicia.

\section{Efectividad e independencia en la ejecución de resoluciones en el ámbito civil}

En una democracia, los jueces individuales y el sistema judicial en su conjunto deben ser imparciales e independientes de toda presión externa. Esto es clave para garantizar que aquellos que acuden a los tribunales y el público en general tengan confianza en que sus casos serán resueltos con imparcialidad y en concordancia con la ley. Todos los años, un número de ciudadanos confía en los tribunales de justicia civil para resolver una amplia gama de disputas legales, como casos de violencia doméstica, de ruptura familiar/relación, de 
tratamientos médicos y asuntos de vivienda o empleo. La influencia indebida puede surgir de una diversidad de partes interesadas, como pueden ser el poder ejecutivo o legislativo, litigantes individuales, grupos de presión, medios de comunicación, grupos de interés u otros jueces.

El Proyecto Justicia Mundial recoge anualmente datos sobre la percepción que tienen las personas y expertos de la efectividad de los servicios de justicia civil y de su independencia frente a la influencia indebida del Gobierno. Basándose en los últimos datos publicados, existe una fuerte correlación entre la percepción de que los tribunales son efectivos y la de su independencia frente a la influencia indebida del Gobierno. Los servicios de justicia civil implican la ejecución efectiva de las resoluciones judiciales. En 2016, los ciudadanos y expertos de Alemania, Dinamarca, Finlandia, Noruega, Países Bajos y Suecia percibieron que sus sistemas de justicia civil eran tanto efectivos como independientes de la influencia de los Gobiernos.

\section{Efectividad del sistema de justicia penal y protección contra el crimen}

Los sistemas de justicia penal efectivos son capaces de investigar y juzgar los delitos criminales de manera eficiente e imparcial, garantizando al mismo tiempo la protección de los derechos de los sospechosos y víctimas. Las tasas de criminalidad y reincidencia son parámetros que se utilizan de manera habitual para evaluar el rendimiento del sistema de justicia penal. No obstante, la evaluación de dichos sistemas debe tener en consideración el sistema en su conjunto, incluyendo la policía, abogados, fiscales, jueces y funcionarios de prisiones (Botero y Ponce, 2012).

Sin embargo, según los datos recogidos por el Proyecto Justicia Mundial, existe una elevada correlación positiva entre la percepción de un sistema de enjuiciamiento criminal efectivo y sin dilaciones y el grado en que las personas no recurren a la violencia para solucionar disputas y agravios. Esto sugiere que cuando el sistema de enjuiciamiento criminal se percibe como efectivo, los ciudadanos tienden a utilizarlo y a adoptar sus resoluciones en lugar de tomarse la justicia por su mano.

En 2016, el grado en que se percibió que el crimen era controlado efectivamente fue alto en casi todos los países de la OCDE, con la excepción de México y en comparación con otras grandes economías. No obstante, en cuanto a los demás indicadores que se presentan en esta sección, los datos son únicamente relativos a las tres grandes zonas urbanas de cada país. Estos se basan en la percepción y pueden ser sensibles a eventos específicos que ocurrieron en el momento de recogida. Se necesitan datos y análisis adicionales para establecer empíricamente la relación entre los tribunales, la policía y el sistema penitenciario, así como sus consecuencias en el contexto social. 


\section{Metodología y definiciones}

Los datos de los tres gráficos proceden del Índice del Estado de Derecho del Proyecto Justicia Mundial. El índice se basa en las respuestas de una encuesta del público en general realizada por empresas demoscópicas a una muestra de 1.000 encuestados en las tres ciudades más grandes de cada país, y de una encuesta de encuestados cualificados completada por profesionales jurídicos y académicos expertos en Derecho civil. Las puntuaciones a lo largo del tiempo no son perfectamente comparables debido a cambios en la metodología básica y en los instrumentos de encuesta. Más información en $<\mathrm{http}$ ://worldjusticeproject.org $>$.

El «Sistema de enjuiciamiento criminal efectivo y sin dilaciones» mide si los autores de delitos son enjuiciados y sancionados. También mide el grado en que los jueces penales y otros funcionarios judiciales son competentes y proporcionan resoluciones sin dilaciones y sin abusar de la detención preventiva.

«Las personas no recurren a la violencia para solucionar agravios personales» mide el grado en que las personas recurren a la intimidación y violencia para resolver disputas civiles o reclaman al Gobierno, y el grado en que las personas viven libres de disturbios y violencia colectiva.

«El crimen se controla de manera efectiva» mide la prevalencia de delitos comunes, incluyendo el homicidio, el secuestro, el hurto y el robo, el robo armado y la extorsión, y la percepción general de las personas relativa a la seguridad en sus comunidades.

\section{Otras publicaciones}

Botero, J. y Ponce, A. (2012), «Measuring the Rule of Law», WJP Working Paper $n^{\circ}$ 2, World Justice Project, Washington, DC.

World Justice Project (2016), The Rule of Law Index 2016, World Justice Project, Washington, DC. 


\section{Gráfico 14.36. Aplicación efectiva de la justicia civil e independencia de la influencia indebida del Gobierno, 2016}

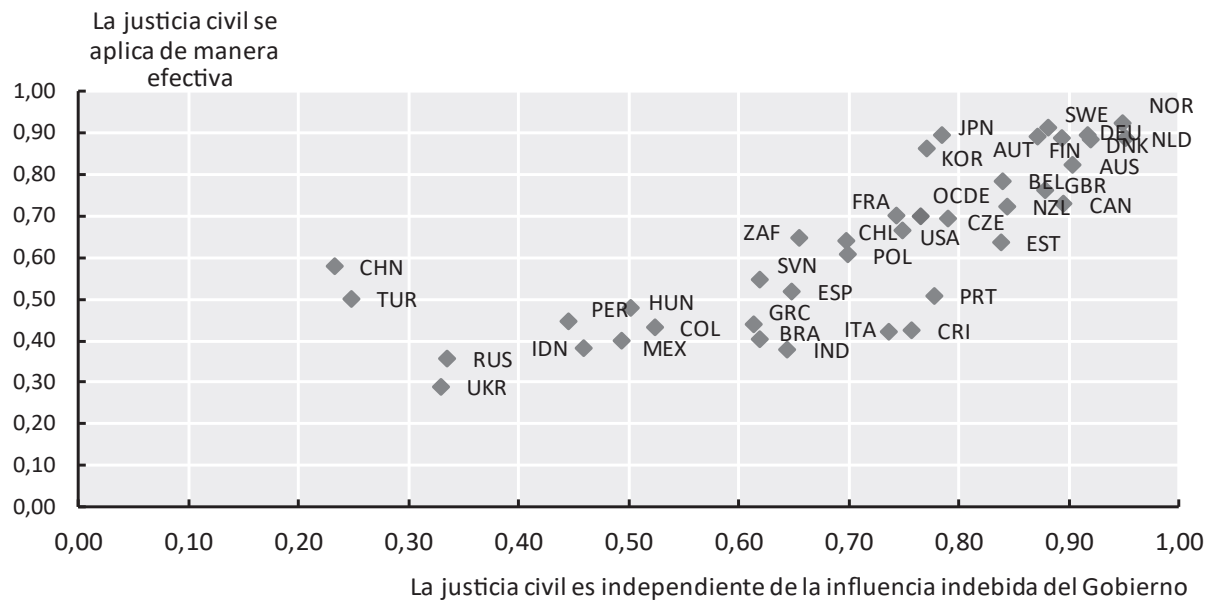

Fuente: Proyecto Justicia Mundial.

\section{Gráfico 14.37. Efectividad/puntualidad del sistema de enjuiciamiento criminal y alcance del uso de violencia para solucionar agravios personales, 2016}

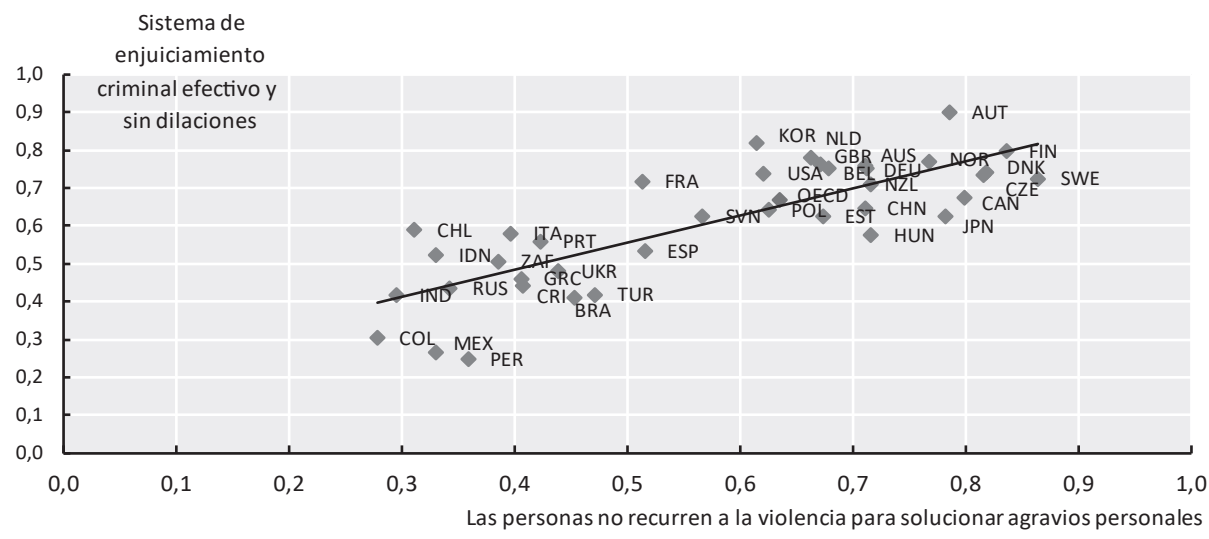

Fuente: Proyecto Justicia Mundial. 
Gráfico 14.38. El crimen se controla de manera efectiva, 2016

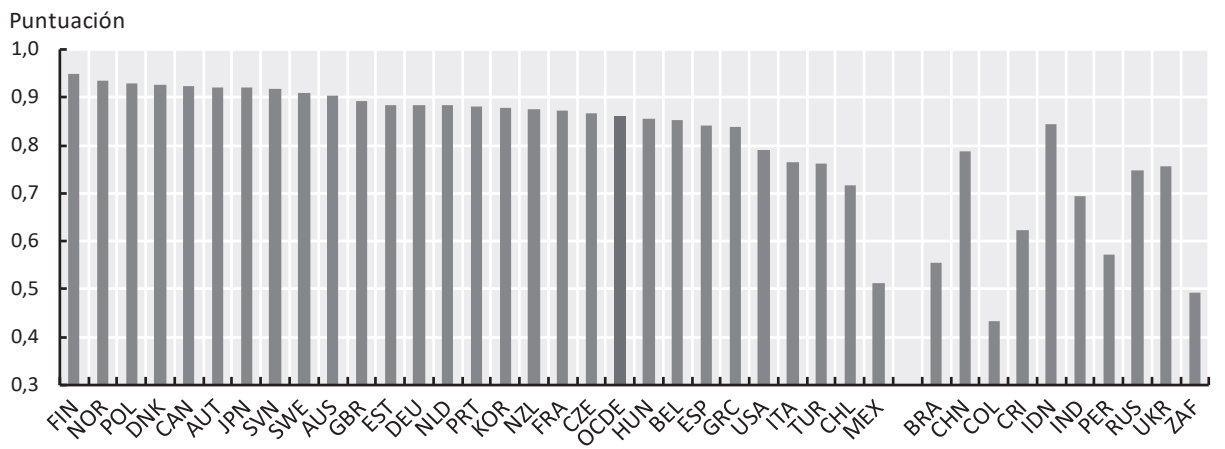

Fuente: Proyecto Justicia Mundial.

<http://dx.doi.org/10.1787/888933534404> 


\section{ANEXO A SISTEMAS Y FUENTES DE INFORMACIÓN DE LOS PAÍSES EN LAS ESTADÍSTICAS DE CONTABILIDAD NACIONAL}

\section{Tabla A.1. Sistemas y fuentes de información de los países}

\begin{tabular}{|c|c|c|}
\hline País & $\begin{array}{l}\text { Cuentas no financieras de las } \\
\text { Administraciones públicas }\end{array}$ & $\begin{array}{c}\text { Cuentas financieras de las Administraciones } \\
\text { públicas }\end{array}$ \\
\hline \multicolumn{3}{|c|}{ Países miembros de la OCDE } \\
\hline Alemania & $\begin{array}{c}\text { SEC2010; Contabilidad Nacional Anual } \\
\text { OCDE, Cuentas de la Administración general }\end{array}$ & $\begin{array}{l}\text { SEC2010; Estadísticas de Finanzas Públicas } \\
\text { Eurostat, Cuentas financieras anuales de la } \\
\text { Administración general, consolidadas* }\end{array}$ \\
\hline Australia & $\begin{array}{c}\text { SCN2008; Contabilidad Nacional Anual } \\
\text { OCDE, Cuentas de la Administración general }\end{array}$ & $\begin{array}{l}\text { SCN2008; Contabilidad Nacional Anual } \\
\text { OCDE, Balance financiero, consolidado }\end{array}$ \\
\hline Austria & $\begin{array}{c}\text { SEC2010; Contabilidad Nacional Anual } \\
\text { OCDE, Cuentas de la Administración general }\end{array}$ & $\begin{array}{l}\text { SEC2010; Contabilidad Nacional Anual } \\
\text { OCDE, Balance financiero, consolidado }\end{array}$ \\
\hline Bélgica & $\begin{array}{c}\text { SEC2010; Contabilidad Nacional Anual } \\
\text { OCDE, Cuentas de la Administración general }\end{array}$ & $\begin{array}{l}\text { SEC2010; Estadísticas de Finanzas Públicas } \\
\text { Eurostat, Cuentas financieras anuales de la } \\
\text { Administración general, consolidadas* }\end{array}$ \\
\hline Canadá & $\begin{array}{c}\text { SCN2008; Contabilidad Nacional Anual } \\
\text { OCDE, Cuentas de la Administración general }\end{array}$ & $\begin{array}{l}\text { SCN2008; Contabilidad Nacional Anual } \\
\text { OCDE, Balance financiero, consolidado }\end{array}$ \\
\hline Chile & $\begin{array}{c}\text { SCN2008; Contabilidad Nacional Anual } \\
\text { OCDE, Cuentas de la Administración general }\end{array}$ & $\begin{array}{l}\text { SCN2008; Contabilidad Nacional Anual } \\
\text { OCDE, Balance financiero, no consolidado }\end{array}$ \\
\hline Corea & $\begin{array}{c}\text { SCN2008; Contabilidad Nacional Anual } \\
\text { OCDE, Cuentas de la Administración general }\end{array}$ & $\begin{array}{l}\text { SCN2008; Contabilidad Nacional Anual } \\
\text { OCDE, Balance financiero, consolidado }\end{array}$ \\
\hline Dinamarca & $\begin{array}{c}\text { SEC2010; Contabilidad Nacional Anual } \\
\text { OCDE, Cuentas de la Administración general }\end{array}$ & $\begin{array}{l}\text { SEC2010; Contabilidad Nacional Anual } \\
\text { OCDE, Balance financiero, consolidado }\end{array}$ \\
\hline España & $\begin{array}{c}\text { SEC2010; Contabilidad Nacional Anual } \\
\text { OCDE, Cuentas de la Administración general }\end{array}$ & $\begin{array}{l}\text { SEC2010; Contabilidad Nacional Anual } \\
\text { OCDE, Balance financiero, consolidado }\end{array}$ \\
\hline Estados Unidos & $\begin{array}{c}\text { SCN2008; Contabilidad Nacional Anual } \\
\text { OCDE, Cuentas de la Administración general }\end{array}$ & $\begin{array}{l}\text { SCN2008; Contabilidad Nacional Anual } \\
\text { OCDE, Balance financiero, consolidado }\end{array}$ \\
\hline Estonia & $\begin{array}{c}\text { SEC2010; Contabilidad Nacional Anual } \\
\text { OCDE, Cuentas de la Administración general }\end{array}$ & $\begin{array}{l}\text { SEC2010; Estadísticas de Finanzas Públicas } \\
\text { Eurostat, Cuentas financieras anuales de la } \\
\text { Administración general, consolidadas* }\end{array}$ \\
\hline Finlandia & $\begin{array}{c}\text { SEC2010; Contabilidad Nacional Anual } \\
\text { OCDE, Cuentas de la Administración general }\end{array}$ & $\begin{array}{l}\text { SEC2010; Contabilidad Nacional Anual } \\
\text { OCDE, Balance financiero, consolidado }\end{array}$ \\
\hline
\end{tabular}




\begin{tabular}{|c|c|c|}
\hline País & $\begin{array}{l}\text { Cuentas no financieras de las } \\
\text { Administraciones públicas }\end{array}$ & $\begin{array}{c}\text { Cuentas financieras de las Administraciones } \\
\text { públicas }\end{array}$ \\
\hline Francia & $\begin{array}{l}\text { SEC2010; Contabilidad Nacional Anual } \\
\text { OCDE, Cuentas de la Administración general }\end{array}$ & $\begin{array}{l}\text { SEC2010; Estadísticas de Finanzas Públicas } \\
\text { Eurostat, Cuentas financieras anuales de la } \\
\text { Administración general, consolidadas* }\end{array}$ \\
\hline Grecia & $\begin{array}{l}\text { SEC2010; Contabilidad Nacional Anual } \\
\text { OCDE, Cuentas de la Administración general }\end{array}$ & $\begin{array}{l}\text { SEC2010; Contabilidad Nacional Anual } \\
\text { OCDE, Balance financiero, consolidado }\end{array}$ \\
\hline Hungría & $\begin{array}{l}\text { SEC2010; Contabilidad Nacional Anual } \\
\text { OCDE, Cuentas de la Administración general }\end{array}$ & $\begin{array}{l}\text { SEC2010; Contabilidad Nacional Anual } \\
\text { OCDE, Balance financiero, consolidado }\end{array}$ \\
\hline Irlanda & $\begin{array}{l}\text { SEC2010; Contabilidad Nacional Anual } \\
\text { OCDE, Cuentas de la Administración general }\end{array}$ & $\begin{array}{l}\text { SEC2010; Contabilidad Nacional Anual } \\
\text { OCDE, Balance financiero, consolidado }\end{array}$ \\
\hline Islandia & $\begin{array}{l}\text { SCN2008; Contabilidad Nacional Anual } \\
\text { OCDE, Cuentas de la Administración general }\end{array}$ & $\begin{array}{l}\text { SCN2008; Contabilidad Nacional Anual } \\
\text { OCDE, Balance financiero, consolidado }\end{array}$ \\
\hline Israel & $\begin{array}{l}\text { SCN2008; Contabilidad Nacional Anual } \\
\text { OCDE, Cuentas de la Administración general }\end{array}$ & $\begin{array}{l}\text { SCN2008; Contabilidad Nacional Anual } \\
\text { OCDE, Balance financiero, consolidado }\end{array}$ \\
\hline Italia & $\begin{array}{l}\text { SEC2010; Contabilidad Nacional Anual } \\
\text { OCDE, Cuentas de la Administración general }\end{array}$ & $\begin{array}{l}\text { SEC2010; Estadísticas de Finanzas Públicas } \\
\text { Eurostat, Cuentas financieras anuales de la } \\
\text { Administración general, consolidadas* }\end{array}$ \\
\hline Japón & $\begin{array}{l}\text { SCN2008; Contabilidad Nacional Anual } \\
\text { OCDE, Cuentas de la Administración general }\end{array}$ & $\begin{array}{l}\text { SCN2008; Contabilidad Nacional Anual } \\
\text { OCDE, Balance financiero, consolidado }\end{array}$ \\
\hline Letonia & $\begin{array}{c}\text { SEC2010; Contabilidad Nacional Anual } \\
\text { OCDE, Cuentas de la Administración general }\end{array}$ & $\begin{array}{l}\text { SEC2010; Estadísticas de Finanzas Públicas } \\
\text { Eurostat, Cuentas financieras anuales de la } \\
\text { Administración general, consolidadas* }\end{array}$ \\
\hline Luxemburgo & $\begin{array}{c}\text { SEC2010; Contabilidad Nacional Anual } \\
\text { OCDE, Cuentas de la Administración general }\end{array}$ & $\begin{array}{l}\text { SEC2010; Contabilidad Nacional Anual } \\
\text { OCDE, Balance financiero, consolidado }\end{array}$ \\
\hline México & $\begin{array}{l}\text { SCN2008; Contabilidad Nacional Anual } \\
\text { OCDE, Cuentas de la Administración general }\end{array}$ & $\begin{array}{l}\text { SCN2008; Contabilidad Nacional Anual } \\
\text { OCDE, Balance financiero, no consolidado }\end{array}$ \\
\hline Noruega & $\begin{array}{l}\text { SCN2008; Contabilidad Nacional Anual } \\
\text { OCDE, Cuentas de la Administración general }\end{array}$ & $\begin{array}{l}\text { SCN2008; Contabilidad Nacional Anual } \\
\text { OCDE, Balance financiero, consolidado }\end{array}$ \\
\hline Nueva Zelanda & $\begin{array}{l}\text { SCN2008; Contabilidad Nacional Anual } \\
\text { OCDE, Cuentas de la Administración general }\end{array}$ & - \\
\hline Países Bajos & $\begin{array}{c}\text { SEC2010; Contabilidad Nacional Anual } \\
\text { OCDE, Cuentas de la Administración general }\end{array}$ & $\begin{array}{l}\text { SEC2010; Estadísticas de Finanzas Públicas } \\
\text { Eurostat, Cuentas financieras anuales de la } \\
\text { Administración general, consolidadas* }\end{array}$ \\
\hline Polonia & $\begin{array}{c}\text { SEC2010; Contabilidad Nacional Anual } \\
\text { OCDE, Cuentas de la Administración general }\end{array}$ & $\begin{array}{l}\text { SEC2010; Contabilidad Nacional Anual } \\
\text { OCDE, Balance financiero, consolidado }\end{array}$ \\
\hline Portugal & $\begin{array}{l}\text { SEC2010; Contabilidad Nacional Anual } \\
\text { OCDE, Cuentas de la Administración general }\end{array}$ & $\begin{array}{l}\text { SEC2010; Contabilidad Nacional Anual } \\
\text { OCDE, Balance financiero, consolidado }\end{array}$ \\
\hline Reino Unido & $\begin{array}{c}\text { SEC2010; Contabilidad Nacional Anual } \\
\text { OCDE, Cuentas de la Administración general }\end{array}$ & $\begin{array}{l}\text { SEC2010; Contabilidad Nacional Anual } \\
\text { OCDE, Balance financiero, consolidado }\end{array}$ \\
\hline República Checa & $\begin{array}{l}\text { SEC2010; Contabilidad Nacional Anual } \\
\text { OCDE, Cuentas de la Administración general }\end{array}$ & $\begin{array}{l}\text { SEC2010; Estadísticas de Finanzas Públicas } \\
\text { Eurostat, Cuentas financieras anuales de la } \\
\text { Administración general, consolidadas* }\end{array}$ \\
\hline $\begin{array}{l}\text { República de } \\
\text { Eslovenia }\end{array}$ & $\begin{array}{l}\text { SEC2010; Contabilidad Nacional Anual } \\
\text { OCDE, Cuentas de la Administración general }\end{array}$ & $\begin{array}{l}\text { SEC2010; Estadísticas de Finanzas Públicas } \\
\text { Eurostat, Cuentas financieras anuales de la } \\
\text { Administración general, consolidadas* }\end{array}$ \\
\hline República Eslovaca & $\begin{array}{c}\text { SEC2010; Contabilidad Nacional Anual } \\
\text { OCDE, Cuentas de la Administración general }\end{array}$ & $\begin{array}{l}\text { SEC2010; Estadísticas de Finanzas Públicas } \\
\text { Eurostat, Cuentas financieras anuales de la } \\
\text { Administración general, consolidadas* }\end{array}$ \\
\hline
\end{tabular}




\begin{tabular}{|c|c|c|}
\hline País & $\begin{array}{c}\text { Cuentas no financieras de las } \\
\text { Administraciones públicas }\end{array}$ & $\begin{array}{c}\text { Cuentas financieras de las Administraciones } \\
\text { públicas }\end{array}$ \\
\hline Suecia & $\begin{array}{c}\text { SEC2010; Contabilidad Nacional Anual } \\
\text { OCDE, Cuentas de la Administración general }\end{array}$ & $\begin{array}{c}\text { SEC2010; Contabilidad Nacional Anual } \\
\text { OCDE, Balance financiero, consolidado }\end{array}$ \\
\hline Suiza & $\begin{array}{c}\text { SCN2008; Contabilidad Nacional Anual } \\
\text { OCDE, Cuentas de la Administración general }\end{array}$ & $\begin{array}{c}\text { SCN2008; Contabilidad Nacional Anual } \\
\text { OCDE, Balance financiero, consolidado }\end{array}$ \\
\hline Turquía & $\begin{array}{c}\text { SCN2008; Contabilidad Nacional Anual } \\
\text { OCDE, Cuentas de la Administración general }\end{array}$ & $\begin{array}{c}\text { SCN2008; Contabilidad Nacional Anual } \\
\text { OCDE, Balance financiero, consolidado }\end{array}$ \\
\hline \multirow{2}{*}{ Colombia } & \multicolumn{2}{|c|}{ Países en proceso de adhesión a la OCDE } \\
\hline Costa Rica & $\begin{array}{c}\text { SCN1993; Contabilidad Nacional Anual } \\
\text { OCDE, Cuentas de la Administración general }\end{array}$ & $\begin{array}{c}\text { SCN2008; Contabilidad Nacional Anual } \\
\text { OCDE, Balance financiero, consolidado }\end{array}$ \\
\hline OCDE, Cuentas de la Administración general
\end{tabular}

* En estos países, la fuente que proporciona las cuentas financieras de las Administraciones públicas es Eurostat, ya que refleja las actualizaciones validadas de datos (que se transmiten dos veces al año). En el resto de países, las actualizaciones validadas de datos se transmiten a y proceden de las Estadísticas de Contabilidad Nacional de la OCDE (base de datos). 



\section{ANEXO B \\ METODOLOGÍA DE LOS INGRESOS AGREGADOS}

La siguiente tabla proporciona información detallada acerca de cómo se elaboraron los agregados de impuestos, cotizaciones sociales netas, ventas y subvenciones y otros ingresos que se presentan en el Capítulo 3, «Economía y finanzas públicas», y que se basan en los datos de la Contabilidad Nacional de la OCDE.

Tabla B.1. Ingresos agregados

\begin{tabular}{|c|c|c|}
\hline $\begin{array}{c}\text { Etiqueta en Panorama de } \\
\text { las Administraciones } \\
\text { Públicas }\end{array}$ & Etiqueta en el Sistema de Contabilidad Nacional & $\begin{array}{l}\text { Código en los datos de la } \\
\text { Contabilidad Nacional de la } \\
\text { OCDE (principales agregados de } \\
\text { la Administración general) }\end{array}$ \\
\hline \multicolumn{3}{|l|}{ Impuestos } \\
\hline Indirectos & $\begin{array}{l}\text { Impuestos sobre la producción e importaciones, a } \\
\text { cobrar }\end{array}$ & GD2R \\
\hline Directos & Impuestos sobre la renta y el patrimonio, a cobrar & GD5R \\
\hline Sobre el capital & Impuestos sobre el capital & GD91R \\
\hline Cotizaciones sociales netas & Cotizaciones sociales netas & GD61R \\
\hline \multirow[t]{2}{*}{ Ventas } & $\begin{array}{c}\text { Producción para el mercado y para consumo final } \\
\text { interno }\end{array}$ & GP11_P12R \\
\hline & Pagos por otros productos fuera del mercado & GP131R \\
\hline \multicolumn{3}{|l|}{$\begin{array}{c}\text { Subvenciones y otros } \\
\text { ingresos } \\
\end{array}$} \\
\hline \multirow[t]{2}{*}{$\begin{array}{c}\text { Subvenciones corrientes y } \\
\text { de capital }\end{array}$} & Otras transferencias corrientes, a cobrar & GD7R \\
\hline & $\begin{array}{c}\text { Otras transferencias de capital y ayudas a la } \\
\text { inversión, a cobrar }\end{array}$ & GD92R_D99R \\
\hline Subsidios & Otros subsidios a la producción, a cobrar & GD39R \\
\hline Ingresos sobre la propiedad & Ingresos sobre la propiedad, a cobrar & GD4R \\
\hline Total ingresos & Total ingresos & GTR \\
\hline
\end{tabular}





\title{
ANEXO C \\ CLASIFICACIÓN DE LAS FUNCIONES DEL GOBIERNO (CFG)
}

\begin{abstract}
Desarrollado por la OCDE, la Clasificación de las Funciones del Gobierno (CFG) ordena los datos de gastos públicos del Sistema de Contabilidad Nacional según la finalidad a la que se destinan los fondos. Como ilustra la Tabla C.1, el primer nivel de la CFG divide los datos de gastos en diez grupos funcionales o subsectores de gastos (como asuntos económicos, educación y protección social) y el segundo nivel divide cada grupo del primer nivel en hasta nueve subgrupos. Si bien hay datos disponibles en 32 de los 35 países miembros de la OCDE en el primer nivel (de acuerdo con la disponibilidad de series temporales), los datos del segundo nivel están actualmente disponibles solo en 25 países europeos de la OCDE, además de Israel1․
\end{abstract}

\footnotetext{
${ }^{1}$ Los datos de primer nivel de la CFG no están disponibles en lo que respecta a Canadá, Chile y México. Hasta hace poco, los datos del segundo nivel estaban disponibles en algunas oficinas estadísticas nacionales, pero no eran recopilados por las organizaciones internacionales. Además, los datos del segundo nivel de la CFG no eran comparables entre países porque la guía del SCN/NU y el Manual del Fondo Monetario Internacional sobre Estadísticas de Finanzas Públicas no proporcionaban mucha información práctica sobre la aplicación de los conceptos de la CFG. Sin embargo, en el año 2005, Eurostat estableció un grupo de trabajo para orientar sobre la aplicación de la CFG a los datos de gastos de la contabilidad nacional y para analizar la recopilación de datos de la CFG de segundo nivel en los países europeos. Los datos de segundo nivel no están disponibles en Turquía y en ninguno de los países miembros no europeos de la OCDE, con la excepción de Israel. Además, estos datos solo están disponibles para ciertas divisiones de la CFG en algunos países de la UE. En estos momentos se están realizando esfuerzos para alcanzar un acuerdo con estos países para la remisión de estos datos a la OCDE.
} 


\section{Tabla C.1. Primer y segundo nivel de la CFG}

\begin{tabular}{|c|c|}
\hline Primer nivel & Segundo nivel \\
\hline Servicios públicos generales & $\begin{array}{l}\text { - Órganos ejecutivos y legislativos, asuntos financieros y fiscales, asuntos exteriores } \\
\text { - Ayuda económica extranjera } \\
\text { - Servicios generales } \\
\text { - Investigación básica } \\
\text { - Servicios públicos generales I+D } \\
\text { - Servicios públicos generales n.c.o.p. } \\
\text { - Transacción de deuda pública } \\
\text { - Transferencias de carácter general entre diferentes niveles de la Administración }\end{array}$ \\
\hline Defensa & $\begin{array}{l}\text { - Defensa militar } \\
\text { - Defensa civil } \\
\text { - Ayuda militar extranjera } \\
\text { - I+D en defensa } \\
\text { - Defensa n.c.o.p. }\end{array}$ \\
\hline Orden público y seguridad & $\begin{array}{l}\text { - Servicios policiales } \\
\text { - Servicios de bomberos } \\
\text { - Servicios judiciales } \\
\text { - Prisiones } \\
\text { - I+D en orden público y seguridad } \\
\text { - Orden público y seguridad n.c.o.p. }\end{array}$ \\
\hline Asuntos económicos & $\begin{array}{l}\text { - Asuntos económicos generales, comerciales y de trabajo } \\
\text { - Agricultura, bosques, pesca y caza } \\
\text { - Combustibles y energía } \\
\text { - Minas, manufacturas y construcción } \\
\text { - Transporte } \\
\text { - Comunicación } \\
\text { - Otras industrias } \\
\text { - I+D en asuntos económicos } \\
\text { - Asuntos económicos n.c.o.p. }\end{array}$ \\
\hline Protección medioambiental & $\begin{array}{l}\text { - Gestión de residuos } \\
\text { - Gestión de aguas residuales } \\
\text { - Control de la polución } \\
\text { - Protección de la biodiversidad y el territorio } \\
\text { - I+D en protección medioambiental } \\
\text { - Protección medioambiental n.c.o.p. }\end{array}$ \\
\hline $\begin{array}{l}\text { Vivienda y servicios } \\
\text { comunitarios }\end{array}$ & $\begin{array}{l}\text { - Desarrollo de viviendas } \\
\text { - Desarrollo comunitario } \\
\text { - Suministro de agua } \\
\text { - Alumbrado público } \\
\text { - I+D en vivienda y servicios comunitarios } \\
\text { - Vivienda y servicios comunitarios n.c.o.p. }\end{array}$ \\
\hline
\end{tabular}


ANEXO C

\begin{tabular}{|c|c|}
\hline Primer nivel & Segundo nivel \\
\hline Sanidad & $\begin{array}{l}\text { - Productos, instrumentos y equipos médicos } \\
\text { - Servicios ambulatorios } \\
\text { - Servicios hospitalarios } \\
\text { - Servicios de salud pública } \\
\text { - I+D en sanidad } \\
\text { - Sanidad n.c.o.p. }\end{array}$ \\
\hline Ocio, cultura y religión & $\begin{array}{l}\text { - Servicios de ocio y deportivos } \\
\text { - Servicios culturales } \\
\text { - Servicios de radiodifusión y publicaciones } \\
\text { - Servicios religiosos y otros servicios comunitarios } \\
\text { - I+D en ocio, cultura y religión } \\
\text { - Ocio, cultura y religión n.c.o.p. }\end{array}$ \\
\hline Educación & $\begin{array}{l}\text { - Educación primaria e infantil } \\
\text { - Educación secundaria } \\
\text { - Educación postsecundaria no superior } \\
\text { - Educación superior } \\
\text { - Educación no definible por nivel } \\
\text { - Servicios auxiliares a la educación } \\
\text { - I+D en educación } \\
\text { - Educación n.c.o.p. }\end{array}$ \\
\hline Protección social & $\begin{array}{l}\text { - Enfermedad y discapacidad } \\
\text { - Tercera edad } \\
\text { - Supervivientes } \\
\text { - Familia y menores } \\
\text { - Desempleo } \\
\text { - Vivienda } \\
\text { - Exclusión social n.c.o.p. } \\
\text { - I+D en protección social } \\
\text { - Protección social n.c.o.p. }\end{array}$ \\
\hline
\end{tabular}

n.c.o.p.: no comprendidos en otras partes. 



\section{ANEXO D \\ METODOLOGÍA Y NOTAS ADICIONALES SOBRE LA REMUNERACIÓN DE LOS EMPLEADOS DE LA ADMINISTRACIÓN}

En 2010, la OCDE lanzó una base de datos, actualizada por primera vez en 2012 y más adelante en 2016, sobre los niveles de remuneración de las ocupaciones típicas de la Administración central en los ministerios principales, que contribuye a una mejor comprensión de las estructuras y niveles salariales en el sector público. Puesto que no existe una definición común de los puestos de gestión y el número de niveles de gestión varía entre los países y ministerios, esta encuesta sobre la remuneración ofrece una tipología común para ocupaciones específicas de la Administración central. Comparar la remuneración promedio en el sector público puede inducir a error, ya que los distintos países incluyen ocupaciones diversas y heterogéneas. Sin embargo, esta encuesta proporciona datos comparables sobre la remuneración de ocupaciones y, por tanto, mejora nuestra comprensión del sector público.

La comparación de niveles de remuneración de altos funcionarios, cargos intermedios, profesionales y puestos de secretariado muestra su retribución total relativa en los países de la OCDE, que incluye no solo sueldos y salarios, sino también cotizaciones para pensiones y sanidad. De esta manera, al comparar los niveles de remuneración, tenemos un enfoque del coste total relativo que permite realizar comparaciones coherentes entre países.

Las comparaciones también deben tener en cuenta los niveles de desarrollo de los países; la remuneración se ha calculado, por tanto, en términos de PIB per cápita. No obstante, las comparaciones entre países deben realizarse con cautela debido a los diferentes mercados laborales, el consenso cultural y político y las posibles diferencias en las características de los sueldos, incluso para los mismos grupos ocupacionales, que no han sido corregidos en este análisis.

Los datos recopilados mediante esta encuesta permiten el análisis comparativo y continuar trabajando en las prácticas y políticas de remuneración de los países de la OCDE y países en proceso de adhesión. La encuesta tiene como objetivo recoger información sobre la remuneración anual de los empleados para una muestra de ocupaciones en la Administración central/fede$\mathrm{ral} /$ nacional. El propósito es construir una base de datos sobre los niveles de 
remuneración para puestos típicos de la Administración central en ministerios principales y sectoriales, lo cual contribuye a una mejor comprensión de las estructuras y niveles salariales en el sector público de los países de la OCDE. Los niveles salariales no solo muestran lo que se paga a los funcionarios, también proporcionan información sobre la capacidad de la Administración central de atraer y retener una fuerza de trabajo competente.

Esta base de datos proporciona información para que la secretaría de la OCDE continúe trabajando en el empleo público, posibilita realizar comparaciones internacionales de la remuneración de funcionarios y facilita la toma de decisiones relativas a las políticas de retribución en el sector público. En concreto, esta encuesta reúne datos que permiten el análisis de: i) el atractivo de las Administraciones públicas como empleador que ofrece salarios competitivos y su capacidad de contratar y retener personal cualificado; ii) las diferencias entre las categorías de empleados y la relación de compresión entre los mejor y peor pagados; y iii) la estructura de los costes de remuneración que la fuerza de empleo público representa para las Administraciones. Conviene señalar que estos ámbitos de investigación no se pueden entender plenamente sin considerar otros aspectos aparte de la retribución.

\section{Ocupaciones}

A fin de crear una base de datos comparables, esta encuesta se basa en una clasificación de ocupaciones típicas en la mayoría de los ministerios de los países de la OCDE y de funcionarios que prestan servicios al público de manera directa.

Esta encuesta recopila datos de los niveles de remuneración de funcionarios en la Administración central/federal y excluye los niveles estatales, regionales y locales, así como las instituciones de la seguridad social. Tampoco incluye todas las corporaciones públicas o casi públicas en todos los niveles de la Administración ni las organizaciones/oficinas subordinadas de los ministerios de la Administración central, también denominadas organismos u organismos ejecutivos, exceptuando los casos de los puestos D1 y D2 (Cuadro D.2) y los funcionarios que trabajan en la prestación directa de servicios (Cuadro D.3).

El cuestionario se centra en información relativa a un número de ocupaciones en la Administración central/federal/central agrupadas bajo cuatro epígrafes básicos: altos funcionarios, cargos intermedios, profesionales y puestos de secretariado. Las ocupaciones seleccionadas se consideran representativas y relativamente comparables entre países. La información sobre estos puestos se recopila de tres ministerios clave (interior, hacienda y justicia) y tres ministerios sectoriales (educación, sanidad y medio ambiente) (Cuadro D.1). 
Además, se pide a los países que proporcionen información sobre funcionarios que trabajan en primera línea de la prestación de servicios, como detectives/investigadores, agentes de policía, funcionarios de inmigración, inspectores de aduana y de hacienda.

La clasificación y la definición de las ocupaciones son una adaptación de la Clasificación Internacional Uniforme de Ocupaciones (CIUO-08) desarrollada por la Organización Internacional del Trabajo (OIT). Pocos países siguen el modelo de la CIUO para clasificar sus ocupaciones en la Administración. En el cuestionario se pidió a los países que identificaran y describieran los puestos que podrían corresponder a las ocupaciones especificadas, incluyendo la presentación de una descripción y ejemplos de las responsabilidades clave de los puestos más sénior y júnior de cada ocupación. La encuesta se centra en los empleados siguiendo el marco de empleo general o estatutario, excluyendo a los asesores.

El Cuadro D. 2 contiene la clasificación y definiciones de las ocupaciones incluidas en esta encuesta y que son consideradas puestos relativamente típicos en todas las Administraciones. Se presta especial atención a los gestores en general, puesto que el criterio para definir un funcionario como tal es que supervise y lidere el trabajo de al menos tres personas. Puesto que es extremadamente difícil proporcionar descripciones más detalladas de las responsabilidades que diferencian los distintos niveles de gestión, se ha optado por centrarse en las diferencias jerárquicas en lugar de en las descripciones detalladas de las funciones. Ya que no existe una definición común de los puestos de gestión y el número de niveles varía entre países y ministerios, a efectos de esta encuesta D1 supone el nivel más alto de gestión por debajo del ministro o secretario de Estado (que es designado por el presidente/primer ministro) y designado por el ministro (a veces nombrado por el presidente o primer ministro). Esta encuesta cubre hasta los puestos de nivel de gestión D4, pero se han incluido los niveles D5 y D6 cuando los países participantes informan de su existencia. En el caso específico de los puestos de gestión, se solicita permiso a los países para publicar los datos teniendo en cuenta la confidencialidad de la información.

La categoría de profesionales se ha dividido en puestos sénior y júnior. Este grupo corresponde al colectivo menos identificable e incluye personal con una amplia variedad de experiencia. 


\section{Cuadro D.1. Responsabilidades típicas de los ministerios analizados en esta encuesta}

\section{Ministerio del Interior/Asuntos Internos}

- Garantiza la representación del Estado en todo el territorio.

- Garantiza el respeto de los derechos de los ciudadanos generalmente a través del sufragio universal.

- Define la política de inmigración.

- Establece y coordina la política de seguridad nacional.

- Garantiza el mantenimiento de una sociedad pacífica y segura.

- Garantiza la preservación de la seguridad interior y la protección del orden constitucional.

\section{Ministerio de Hacienda}

- Planifica y prepara el presupuesto de la Administración.

- Analiza y diseña las políticas fiscales.

- Desarrolla e implementa normativa para las instituciones financieras.

- Supervisa la evolución económica y financiera.

- Administra la transferencia de fondos desde la Administración nacional/central/federal a las Administraciones subnacionales.

\section{Ministerio de Justicia}

- Asegura el funcionamiento del sistema judicial.

- Elabora los proyectos de ley y de normativa en algunos campos específicos.

- Define las principales orientaciones de la política pública en materia de justicia y vela por su aplicación.

- Proporciona apoyo a las víctimas de delitos.

- Procura una aplicación justa, coherente y eficaz de los castigos y de otras sanciones. 


\section{Ministerio de Educación}

- Regula, coordina y organiza el sistema educativo nacional, en general desde la educación primaria hasta la secundaria.

- Asegura la igualdad de acceso a la educación pública.

- Controla y evalúa los colegios e instituciones de educación superior, tanto públicos como privados.

- Asegura una gestión eficaz de los docentes y del personal administrativo de la educación.

\section{Ministerio de Sanidad}

- Diseña e implementa la política de salud pública (prevención, organización sanitaria y formación de los profesionales).

- Define la política en relación con el deporte y con la lucha contra la adicción a las drogas.

- En colaboración con otros ministerios, define las normas de seguridad industrial y de seguridad social.

\section{Cuadro D.2. Clasificación y definición de las ocupaciones}

\section{Altos funcionarios}

Gestores D1 (CIUO-08 1112): son los funcionarios públicos de mayor rango, justo por debajo del ministro o secretario de Estado/viceministro. Pueden ser miembros de la función pública de alto nivel y/o designados por el Gobierno o por el jefe de Gobierno. Asesoran al Gobierno sobre políticas públicas, supervisan la interpretación y aplicación de las políticas públicas y, en algunos países, tienen poderes ejecutivos. Los gestores D1 pueden tener derecho a asistir a algunas reuniones del Gabinete/Consejo de Ministros, pero no son parte de ellos. Asumen la dirección y gestión general en el ministerio/secretaría de Estado o en un ámbito administrativo determinado. En países con un sistema de organismos autónomos, poderes descentralizados, organizaciones más planas y gestores empoderados, el cargo D1 corresponde al de director general. 
Gestores D2 (CIUO-08 11 y 112): se sitúan justo por debajo de los gestores D1. Formulan y revisan las políticas y planifican, dirigen, coordinan y evalúan las actividades generales del ministerio o de una dirección/unidad especial con el apoyo de otros gestores. Pueden formar parte de la función pública de alto nivel. Proporcionan orientación en la coordinación y gestión de programas de trabajo y liderazgo a los equipos de profesionales en diferentes ámbitos administrativos. Determinan los objetivos, estrategias y programas para la unidad/departamento administrativo bajo su supervisión.

\section{Cargos intermedios (asumen responsabilidades de gestión de al menos tres empleados)}

Gestores D3 (CIUO-08 12): se sitúan justo por debajo de los gestores D2. Planifican, dirigen y coordinan el funcionamiento general de una unidad administrativa/de dirección específica dentro de un ministerio con el apoyo de otros gestores, por lo general bajo las directrices establecidas por un comité directivo o un órgano rector. Asumen el liderazgo y la gestión de equipos de profesionales dentro de su área particular. Estos funcionarios desarrollan y gestionan el programa de trabajo y el personal de las unidades, divisiones o áreas políticas. Establecen y gestionan los presupuestos, controlan los gastos y aseguran la utilización eficiente de los recursos. Monitorizan y evalúan el rendimiento de los diferentes equipos profesionales.

Gestores D4 (parte de la CIUO-08 121): se sitúan justo por debajo de los gestores D3. Asesoran y administran las políticas y la planificación estratégica y financiera. Establecen y dirigen los procedimientos operativos y administrativos, $\mathrm{y}$ ofrecen asesoramiento a los altos funcionarios. Controlan la selección, formación y rendimiento del personal; preparan los presupuestos y supervisan las operaciones financieras, controlan el gasto y garantizan el uso eficiente de los recursos. Asumen el liderazgo de equipos profesionales específicos dentro de una unidad.

Gestores D5 (opcional) (CIUO-08 1211, 1212 y 1213): se sitúan justo por debajo de los gestores D4. Pueden ser profesionales sénior cuya responsabilidad principal resida en dirigir la realización del programa de trabajo y supervisar el de otros profesionales, incluidos aquellos más jóvenes.

Gestores D6 (opcional) (CIUO-08 1211, 1212 y 1213): pueden ser profesionales cuya responsabilidad principal resida en dirigir la realización del programa de trabajo y supervisar el trabajo de otros profesionales, incluido el de aquellos más jóvenes. 


\section{Profesionales}

Economistas/analistas políticos sénior (CIUO-08 242 y 2422): no tienen responsabilidades de gestión (más allá de la gestión de un máximo de 3 empleados) y están por encima de los analistas júnior y del personal administrativo/de secretaría. Por lo general, están obligados a tener un título universitario. Tienen algunas responsabilidades de liderazgo sobre un campo de trabajo o varios proyectos; desarrollan y analizan las políticas orientando en el diseño, implementación y modificación de las operaciones y programas de las Administraciones. Estos profesionales revisan las políticas y la legislación existentes con el fin de identificar anomalías y disposiciones desfasadas. Analizan y formulan opciones políticas y preparan documentos y recomendaciones para los cambios en las políticas. Además, evalúan el impacto, las consecuencias financieras y la viabilidad política y administrativa de las políticas públicas. El personal de este grupo tiene la posibilidad de promoción a gestor en el desarrollo de su carrera profesional. Sus áreas de especialización son variadas e incluyen el derecho, la economía, la política, la Administración pública, las relaciones internacionales, la ingeniería, el medio ambiente, la pedagogía, la economía sanitaria, etc. Los economistas/analistas políticos sénior deben tener al menos cinco años de experiencia profesional.

Economistas/analistas políticos sénior (CIUO-08 242 y 2422): están por encima del personal administrativo/de secretariado. Por lo general, están obligados a tener un título universitario. No tienen responsabilidades de liderazgo. Desarrollan y analizan las políticas orientando en el diseño, implementación y modificación de las operaciones y programas administrativos. Estos profesionales revisan las políticas y la legislación a fin de identificar las anomalías y disposiciones desfasadas. Analizan y formulan opciones políticas y preparan documentos y recomendaciones para los cambios en las políticas. Además, evalúan el impacto, las consecuencias financieras y la viabilidad política y administrativa de las políticas públicas. Sus áreas de especialización son variadas e incluyen el derecho, la economía, la política, la Administración pública, las relaciones internacionales, la ingeniería, el medioambiente, la pedagogía, la economía sanitaria, etc. Los economistas/analistas políticos júnior tienen menos de cinco años de experiencia profesional. 


\section{Puestos de secretariado}

Secretarios (personal administrativo general) (CIUO-08 411 y 4110): por lo general, no están obligados a tener un título universitario, aunque muchos lo tienen. Llevan a cabo una amplia gama de tareas de oficina y administrativas en relación con operaciones de caja, reservas de viajes y dietas, y solicitudes de información y citas. Registran, preparan, ordenan, clasifican y completan la información; clasifican, abren y envían el correo, preparan informes y correspondencia; inventarían el equipo para el personal; responden al teléfono o a las consultas electrónicas, o redirigen las comunicaciones a la persona adecuada; verifican las cifras, preparan facturas y registran los detalles de las transacciones financieras realizadas; transcriben información en los ordenadores y la revisan y corrigen. Algunos ayudan en la preparación de los presupuestos, el seguimiento de los gastos y la redacción de contratos y órdenes de compra o adquisición. El personal administrativo de mayor rango que supervisa el trabajo del personal de apoyo administrativo está excluido de esta categoría.

Esta encuesta también incluye una sección sobre la remuneración de los funcionarios que trabajan en la prestación directa de servicios, incluyendo inspectores e investigadores, agentes de policía, funcionarios de inmigración, inspectores de aduanas e inspectores de hacienda. Estas ocupaciones se definen y adaptan de acuerdo con las descripciones de la CIUO-08 (Cuadro D.3). El objetivo es tener una mejor comprensión de la remuneración de funcionarios que prestan servicios relacionados con funciones habitualmente proporcionadas por los Gobiernos nacionales, como pueden ser la administración fiscal, los servicios de inmigración y el mantenimiento del orden, que no se suelen incluir en otras encuestas (como las relativas a los servicios de sanidad y educación que usualmente se centran en las Administraciones subnacionales).

Estas funciones se organizan en la Administración central y pueden ser competencia de ministerios y organismos. Debe señalarse que en algunos países los funcionarios de inmigración no existen y sus actividades las realiza la policía. En otros países, algunas de las funciones mencionadas son efectuadas por las Administraciones estatales y/o locales. 


\section{Cuadro D.3. Funcionarios en la prestación de servicios: descripción de las ocupaciones}

Inspectores e investigadores de policía (CIUO-08 3355): investigan hechos y circunstancias relacionados con delitos con el fin de identificar a los presuntos delincuentes y obtener información que no es evidente o fácilmente disponible sobre establecimientos o las circunstancias y comportamiento de personas, principalmente con el fin de prevenir crímenes. Sus tareas incluyen establecer contactos y fuentes de información relacionados con delitos planeados o cometidos, a fin de prevenir crímenes o identificar a los presuntos delincuentes; obtener, verificar y analizar evidencia para resolver los delitos; realizar arrestos; y testificar en los tribunales de justicia, entre otros. Por lo general tienen responsabilidades de gestión. Los inspectores e investigadores de policía habitualmente están obligados a tener un diploma universitario y/o son contratados a través de la promoción interna después de un cierto número de años de experiencia como agentes de policía (generalmente más de cinco años).

Agentes de policía (CIUO-08 5412): mantienen el orden público, patrullando las vías públicas, aplicando las leyes y normas y arrestando a presuntos delincuentes. Otras funciones incluyen dirigir el tráfico y asumir la autoridad en caso de accidentes, así como proporcionar asistencia de emergencia a las víctimas de accidentes, crímenes y desastres naturales, entre otras. Los agentes de policía no suelen asumir responsabilidades de gestión sobre más de tres personas ni estar obligados a tener un diploma universitario.

Funcionarios de inmigración (CIUO-08 3351): comprueban la identidad de las personas que cruzan las fronteras nacionales para administrar y aplicar las normas y regulaciones existentes. Sus funciones incluyen patrullar las fronteras nacionales y aguas costeras para prevenir que las personas entren o salgan del país de manera ilegal; comprobar los documentos de viaje de las personas que cruzan las fronteras nacionales para garantizar que cuentan con los certificados y autorizaciones necesarios, y coordinar y cooperar con otros organismos involucrados en la aplicación de la ley, la deportación y persecución, entre otras. Los funcionarios de inmigración no suelen asumir responsabilidades de gestión sobre más de tres personas, en caso de asumirlas.

Inspectores de aduanas (CIUO-08 3351): comprueban los vehículos que cruzan las fronteras nacionales para administrar y aplicar las normas y regulaciones existentes. Sus funciones incluyen inspeccionar el equipaje de las personas que cruzan las fronteras nacionales para garantizar que se ajusta a las normas y regulaciones del Gobierno relativas a 
la importación y exportación de mercancías y divisas; verificar los documentos de viaje y el transporte de vehículos que cruzan las fronteras nacionales para garantizar la conformidad con las normas y regulaciones del Gobierno; y detener a personas e incautar mercancías prohibidas y no declaradas que infringen la legislación en materia de inmigración y aduanas, entre otras. Los inspectores de aduanas no suelen asumir responsabilidades de gestión sobre más de tres personas, en caso de asumirlas.

Inspectores de hacienda (CIUO-08 3352): examinan las declaraciones de impuestos, las facturas de venta y otros documentos para determinar el tipo y cuantía de los impuestos, tasas $u$ otro tipo de cargos que deben pagar las personas o empresas, derivando los casos excepcionales o importantes a contables o funcionarios superiores de las Administraciones. Asesoran a las organizaciones, empresas y al público sobre las leyes, normas y regulaciones del Gobierno relativas al pago de impuestos, tasas y otros cargos gubernamentales, y sobre sus derechos y obligaciones; examinan las declaraciones de impuestos, las facturas de venta y otros documentos pertinentes; investigan las declaraciones de impuestos presentadas, así como los registros contables y los sistemas y controles internos de las organizaciones para garantizar el cumplimiento de las leyes y normas fiscales, entre otras funciones. Los inspectores de hacienda no suelen asumir responsabilidades de gestión sobre más de tres personas, en caso de asumirlas.

\section{Remuneración}

La encuesta se centra en la remuneración total, que tiene dos componentes principales: 1) los sueldos y salarios, y 2) las cotizaciones sociales de los empleadores. Se solicitaron datos sobre los niveles de remuneración de los trabajos a tiempo completo.

1. Los sueldos y salarios brutos incluyen los importes de todas las cotizaciones sociales, impuestos sobre la renta, etc., a cargo del empleado aun cuando sean retenidos por el empleador por conveniencia administrativa o por otras razones y pagados directamente a los sistemas de seguros sociales, a las autoridades fiscales, etc., en nombre del empleado. Las cotizaciones sociales del empleador no se incluyen en los sueldos y salarios brutos. Las retribuciones en especie se excluyen de la encuesta. Los sueldos y salarios brutos incluyen:

- Los sueldos y salarios básicos (como se establecen en las escalas salariales): se definen como los pagos regulares anuales a los empleados por su tiempo de trabajo y servicios prestados a la Administración. Aunque 
los sueldos y salarios se pagan a intervalos semanales, mensuales o regulares, a efectos de esta encuesta se pidió el salario anual. El pago de horas extraordinarias se excluye de los datos.

- Pagos adicionales: a causa de las dificultades para obtener datos exhaustivos y asegurar la comparabilidad entre los países, los pagos adicionales se han limitado a sus categorías más importantes.

- Las remuneraciones por el tiempo no trabajado hacen referencia solo a las vacaciones anuales y a los días festivos.

- Las bonificaciones y gratificaciones abonadas regularmente se refieren a los bonos pagados a fin de año y de temporada; a los bonos de participación en beneficios; y a las retribuciones adicionales relativas a las vacaciones y otras primas y gratificaciones.

- Las bonificaciones y gratificaciones no abonadas de forma regular (remuneración por desempeño) se refieren a las primas especiales u otros pagos excepcionales vinculados al rendimiento global del empleado a los que pueda tener derecho.

2. Las cotizaciones sociales del empleador son las efectuadas por este a los fondos de la seguridad social u otros regímenes de seguridad social relacionados con el empleo para asegurar prestaciones sociales (seguro de salud, pensiones...). Las cotizaciones sociales del empleador se pueden dividir en:

- Cotización patronal a los regímenes legales de seguridad social o a regímenes de seguros sociales privados para la cobertura de vejez, pensiones, asistencia sanitaria... Las cotizaciones sociales de los empleadores representan las cotizaciones sociales que pagan los empleadores a los fondos de la seguridad social u otros sistemas de seguros sociales relacionados con el empleo para asegurar las prestaciones sociales (seguro de salud, pensiones...) de sus empleados. En algunos países, estas cotizaciones se abonan a regímenes públicos, mientras que en otros se abonan a sistemas privados. A veces también incluyen fondos específicos establecidos, por ejemplo, en acuerdos sociales. Los datos recogidos sobre cotizaciones sociales de los empleadores se han limitado a los planes de salud y de pensiones, que representan la mayor parte de las cotizaciones sociales de los empleadores.

- Las prestaciones sociales no financiadas pagadas por los empleadores se limitan a beneficios sanitarios y de pensiones. Representan el equivalente a las prestaciones sociales abonadas directamente por las instituciones de la Administración general para las que no existe una aportación o el establecimiento de un fondo, reserva u otro tipo de plan específico a este fin. Puesto que estas cotizaciones no suponen flujos reales de efectivo, tienen que ser imputadas. Estos planes de salud y de pensiones no financiados existen en muchos países. 
No todos los países han sido capaces de incluir el elemento de las cotizaciones sociales en sus respuestas a la encuesta (en especial para los planes de pensiones no financiados). Como consecuencia, ha sido necesario estimar este componente utilizando otras fuentes de datos para estos países. En la Contabilidad Nacional, las imputaciones de los regímenes de pensiones no financiados se hacen de forma que resulten conceptualmente coherentes para los países de la OCDE. Por tanto, fue posible estimar a través de los datos de la Contabilidad Nacional la tasa global de las cotizaciones sociales de los empleadores que se presenta en las diversas bases de datos existentes sobre las retribuciones de los empleados públicos. La tasa seleccionada para calcular los costes de la remuneración en los datos de esta publicación ha sido elegida después de una investigación y un debate con los países incluidos. La Contabilidad Nacional se ha utilizado como fuente de datos de las cotizaciones sociales del empleador en los siguientes países: Alemania, España, Grecia, Japón, Lituania, Noruega y Portugal. Además, en el caso de Bélgica estas participaciones se estimaron mediante una combinación de la información de la encuesta y los datos de la Contabilidad Nacional.

Cabe destacar que, al contrario de la encuesta de remuneración, que solo computa las cotizaciones por asistencia sanitaria y pensiones, los datos en el marco de Contabilidad Nacional consideran el total de las cotizaciones sociales de los empleadores. En consecuencia, el resultado obtenido cuando se tuvo en cuenta esta fuente es, hasta cierto punto, una sobreestimación. Por otra parte, los datos de la Contabilidad Nacional ofrecen las ratios de las cotizaciones sociales de los empleadores para todos los empleados públicos. El uso de esta ratio, por tanto, no permite calcular las diferencias que puedan existir, por ejemplo, en los importes de las cotizaciones sociales de las distintas ocupaciones. Para los países que han proporcionado datos sobre las cotizaciones sociales de los empleadores en la encuesta, se han utilizado los datos exactos de las cotizaciones sociales (que pueden variar según la ocupación).

El nivel de las cotizaciones sociales es solo una aproximación. La cantidad y calidad de las prestaciones recibidas por los empleados a través de las cotizaciones sociales de los empleadores y de los empleados dependen de muchas variables como la calidad y la eficiencia de la gestión de los fondos y servicios en cada país.

\section{Utilización de los comparadores}

Los cálculos se han realizado mediante la conversión de los datos de la remuneración a USD utilizando la metodología de las PPA. Esto compensa las diferencias en los tipos de cambio y en los niveles de precios relativos. Las PPA no tienen en cuenta las diferencias relativas del coste de vida entre las principales ciudades dentro de un país y entre los países. En muchos de estos, la mayoría de los empleados públicos de la Administración central están empleados en las capitales. Los salarios en estos casos pueden tender a compen- 
sar la diferencia relativa del coste de vida en las grandes ciudades. Las PPA se calculan en varios niveles de agregación e incluyen el PIB. Las PPA del PIB cubren tanto el gasto en consumo final como la formación bruta de capital. Las PPA del consumo individual efectivo cubren el gasto en consumo de los hogares - que representa el componente de consumo privado- y la parte del gasto final de las Administraciones públicas que se dedica a los hogares individuales (sanidad, educación, etc.).

Las PPA del consumo privado se utilizaron para la conversión de la remuneración en divisa nacional de los empleados públicos en los distintos puestos. Las ediciones previas a 2013 de Panorama de las Administraciones Públicas convertían la remuneración de los empleados mediante las PPA del PIB. En consecuencia, las retribuciones medias por puesto en USD presentadas en esta edición no son comparables con los valores mostrados en ediciones previas a 2013.

La OCDE también comparó los países mediante datos normalizados relativos al PIB per cápita disponibles en la base de datos de las Estadísticas de Contabilidad Nacional. Esta normalización es una forma de eliminar las diferencias en los niveles de riqueza promedio en el país.

La ratio de remuneración de los empleados en relación con el PIB no se ha corregido por el tiempo trabajado. Se ha seguido este enfoque para mantener la coherencia entre las medidas comparadas.

\section{Cálculos para comparar la remuneración anual incluyendo el ajuste por el tiempo de trabajo}

La retribución anual promedio comparativa se calcula mediante:

$$
W_{c o} a^{*}=H_{-} c_{a^{*}}
$$

donde:

$W_{c o}^{a^{*}}=$ Remuneración anual media de los empleados en el país $c$ en el grupo ocupacional $o$ en PPA corregida por el tiempo de trabajo.

$W_{c o}{ }^{a}=$ Remuneración anual media en divisa nacional en el país $c$ dentro del grupo ocupacional $o$ en divisa nacional.

$P_{c}=$ Paridad de poder adquisitivo del país $c$.

$H_{c}^{a^{*}}=$ Ratio de tiempo de trabajo promedio en el país $c$. Esto se corresponde con la media anual de horas de trabajo en el país c (a partir de datos de encuesta) dividido por 2.088. El número 2.088 es igual a las horas de trabajo teóricas durante un año con un horario de 40 horas de trabajo por semana, sin vacaciones o permisos de ningún tipo. Esto también se traduce en un promedio de 261 días de trabajo al año a razón de 8 horas de trabajo diarias. 
Las diferencias del tiempo efectivo de trabajo de las personas y la remuneración anual promedio (salario bruto anual medio más cotizaciones sociales del empleador) se calculan con el fin de obtener una remuneración anual media ajustada. De hecho, para comparar la remuneración de los empleados entre los países, las diferencias del tiempo de trabajo (número de horas de trabajo a la semana en la función pública, derecho a vacaciones promedio o legal establecido en el contrato laboral y el número de días festivos nacionales al año que corresponden al funcionariado) se utilizan para calcular la remuneración anual media ajustada. En el caso de los gestores (es decir, cargos D1, D2, D3 y D4), puesto que los tiempos de trabajo semanal son muy variables en esta categoría de empleados, los datos se ajustaron solo al número de días de vacaciones.

Las correcciones por el tiempo de trabajo se muestran en la Tabla D.1.

Tabla D.1. Corrección del tiempo de trabajo

\begin{tabular}{|c|c|c|c|c|c|c|c|c|}
\hline & 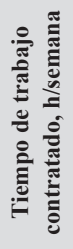 & 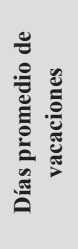 & 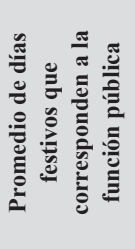 & 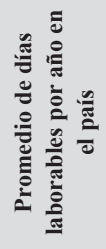 & 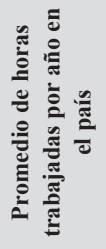 & 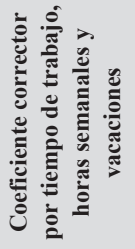 & 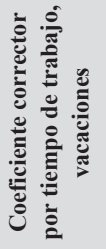 & 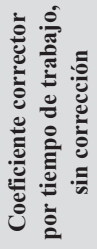 \\
\hline Alemania & 41 & 30 & 9 & 222 & 1.818 & 0,872 & 0,850 & 1,000 \\
\hline Australia & 38 & 20 & 12 & 229 & 1.715 & 0,822 & 0,877 & 1,000 \\
\hline Austria & 40 & 25 & 10 & 226 & 1.806 & 0,866 & 0,866 & 1,000 \\
\hline Bélgica & 38 & 26 & 13 & 222 & 1.685 & 0,808 & 0,850 & 1,000 \\
\hline Canadá & 38 & 20 & 11 & 230 & 1.723 & 0,826 & 0,881 & 1,000 \\
\hline Chile & 44 & 15 & 10 & 236 & 2.074 & 0,995 & 0,904 & 1,000 \\
\hline Corea & 40 & 20 & 15 & 226 & 1.806 & 0,866 & 0,866 & 1,000 \\
\hline Dinamarca & 37 & 30 & 10 & 221 & 1.633 & 0,783 & 0,847 & 1,000 \\
\hline España & 38 & 22 & 14 & 225 & 1.685 & 0,808 & 0,862 & 1,000 \\
\hline Estados Unidos & 40 & 20 & 10 & 231 & 1.846 & 0,885 & 0,885 & 1,000 \\
\hline Estonia & 40 & 35 & 9 & 217 & 1.734 & 0,831 & 0,831 & 1,000 \\
\hline Finlandia & 36 & 34 & 9 & 218 & 1.581 & 0,758 & 0,837 & 1,000 \\
\hline Francia & 35 & 25 & 8 & 228 & 1.594 & 0,764 & 0,873 & 1,000 \\
\hline Grecia & 40 & 25 & 12 & 224 & 1.790 & 0,858 & 0,858 & 1,000 \\
\hline Islandia & 40 & 30 & 14 & 217 & 1.734 & 0,831 & 0,831 & 1,000 \\
\hline Israel & 43 & 24 & 9 & 228 & 1.936 & 0,928 & 0,873 & 1,000 \\
\hline Italia & 36 & 32 & 8 & 221 & 1.589 & 0,762 & 0,847 & 1,000 \\
\hline Japón & 39 & 20 & 19 & 222 & 1.718 & 0,824 & 0,850 & 1,000 \\
\hline
\end{tabular}




\begin{tabular}{|c|c|c|c|c|c|c|c|c|}
\hline & 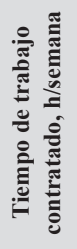 & 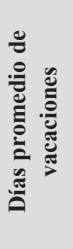 & 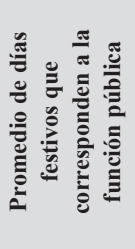 & 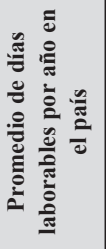 & 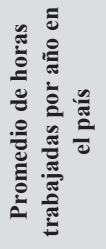 & 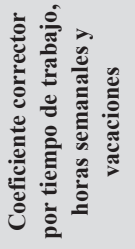 & 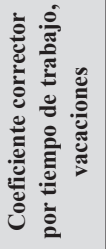 & 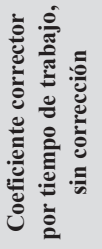 \\
\hline Letonia & 40 & 24 & 14 & 223 & 1.782 & 0,854 & 0,854 & 1,000 \\
\hline México & 40 & 20 & 10 & 231 & 1.846 & 0,885 & 0,885 & 1,000 \\
\hline Noruega & 38 & 25 & 10 & 226 & 1.693 & 0,812 & 0,866 & 1,000 \\
\hline Países Bajos & 36 & 23 & 8 & 230 & 1.654 & 0,793 & 0,881 & 1,000 \\
\hline Portugal & 40 & 22 & 9 & 230 & 1.838 & 0,881 & 0,881 & 1,000 \\
\hline Reino Unido & 37 & 25 & 8 & 228 & 1.685 & 0,808 & 0,873 & 1,000 \\
\hline $\begin{array}{c}\text { República de } \\
\text { Eslovenia }\end{array}$ & 40 & 29 & 14 & 218 & 1.742 & 0,835 & 0,835 & 1,000 \\
\hline Suecia & 40 & 33 & 11 & 217 & 1.723 & 0,826 & 0,831 & 1,000 \\
\hline Colombia & 44 & 15 & 18 & 228 & 2.004 & 0,961 & 0,873 & 1,000 \\
\hline Lituania & 40 & 20 & 15 & 226 & 1.806 & 0,866 & 0,866 & 1,000 \\
\hline
\end{tabular}

Fuentes: OCDE (2016), Encuesta sobre la remuneración de los empleados en las Administraciones centrales/ federales.

Notas: Las cifras de la tabla están redondeadas. Número máximo de días de trabajo al año si se trabajan 5 de los 7 días de la semana: 261. Número máximo de horas de trabajo al año si se trabajan 8 horas al día: 2.088.

Alemania: El horario laboral de los empleados públicos (39 horas por semana) y los funcionarios (41 horas por semana) es diferente.

Italia: El número de días de vacaciones varía. 30 días durante los primeros tres años de trabajo, 32 días a partir del cuarto año. Para la policía, hay dos bandas basadas en la antigüedad: 36 días de 15 a 25 años de servicio, 45 días para los que tengan más de 25 años de servicio.

Austria: Desde el 1 de enero de 2011, el número de días de vacaciones depende de la edad: un trabajador a tiempo completo tiene derecho a 240 horas (30 días/ 6 semanas) a partir de su $43 .^{\circ}$ cumpleaños, en el caso de que sea antes del 1 de julio. Si su $43 .^{\circ}$ cumpleaños es posterior al 30 de junio, tendrá derecho a las 240 horas el año siguiente.

España: El número de días de vacaciones es de 22 días a los que se añaden otros según la antigüedad hasta un máximo de 26.

República de Eslovenia: El número medio de días de licencia anual es una estimación. El trabajador tendrá derecho a unas vacaciones anuales que no podrán ser inferiores a cuatro semanas. Además, tiene derecho a un día adicional de vacaciones anuales por cada hijo menor de 15 años. En relación con el desempeño laboral, los funcionarios también tienen derecho a no más de tres días de permiso anuales. Los permisos anuales podrán ser prorrogados por un máximo de tres días en caso de malas condiciones de trabajo (ruido, calor, etc.) o de mala condición sanitaria o para dirigir una unidad organizativa.

Suecia: El número de días de trabajo varía según la edad, de acuerdo con el convenio colectivo central. Los empleados menores de 30 años tienen 28 días de vacaciones; los de edades comprendidas entre 30 y 39 años, 31 días, y los empleados de 40 años o más tienen 35 días. 


\section{Notas}

Las instituciones sin ánimo de lucro también se excluyen de la encuesta.

El término no financiado se refiere a prestaciones sociales para las que no existen fondos de la seguridad social ni un registro oficial de las aportaciones. Los planes de salud y de pensiones no financiados existen en muchos países; en estos casos, los presupuestos de la Administración general pagan las pensiones y prestaciones sanitarias de los empleados, y a menudo existen líneas presupuestarias que cubren esta parte no financiada de las prestaciones sociales. 


\section{ANEXO E METODOLOGÍA DE LOS ÍNDICES COMPUESTOS DE PRÁCTICAS Y PROCEDIMIENTOS PÚBLICOS}

Los índices compuestos estrictamente definidos y presentados en Panorama de las Administraciones Públicas representan la mejor manera de resumir la información discreta y cualitativa. «Los índices compuestos son mucho más fáciles de interpretar que tratar de encontrar una tendencia común en muchos indicadores separados» (Nardo et al., 2004). Sin embargo, su desarrollo y uso pueden ser controvertidos. Estos índices son a menudo y fácilmente mal interpretados por los usuarios debido a la falta de transparencia en cuanto a la forma en que se generan y a la dificultad resultante de revelar lo que realmente están midiendo.

La OCDE ha tomado varias medidas para evitar o resolver los problemas comunes asociados a los índices compuestos. Los que se presentan en esta publicación se ajustan a las medidas identificadas en el Handbook on Constructing Composite Indicators (Nardo et al., 2008) como necesarias para la elaboración con sentido de los índices compuestos o sintéticos.

Cada índice compuesto se basa en un marco teórico que representa el consenso sobre el concepto en el área que abarca. Las variables que comprenden los índices se seleccionaron en función de su relevancia para el concepto. Cada índice se crea en colaboración estrecha con el grupo de expertos de la OCDE pertinente, que aconseja sobre la selección de las variables de los indicadores compuestos y sobre el uso de esquemas de ponderación.

Además, se elaboran varios análisis estadísticos para garantizar la validez y fiabilidad de los indicadores compuestos.

- Las preguntas utilizadas en las encuestas para crear los índices son las mismas en todos los países, lo cual garantiza la comparabilidad de los índices.

- Se han analizado diferentes métodos para imputar los valores que faltan.

- Todos los subindicadores y variables se han normalizado a efectos de comparabilidad. 
- Para crear los compuestos, se agregaron todos los subindicadores utilizando un método lineal de acuerdo con metodología aceptada.

- Se ha realizado el análisis factorial de los componentes principales para confirmar las hipótesis de los conceptos básicos medidos.

- Las variables redundantes se han excluido para evitar duplicidad y la ponderación excesiva.

- El alfa de Chronbach también se calcula para medir las correlaciones entre los ítems.

- Finalmente, se realiza el análisis de sensibilidad (simulación Monte Carlo) para establecer la solidez de los indicadores con respecto a diferentes opciones de ponderación.

Los anexos detallados sobre cada uno de los indicadores compuestos presentados en Panorama de las Administraciones Públicas están disponibles online en $<\mathrm{http}: / / \mathrm{www}$.oecd.org/gov/govataglance.htm>. 


\section{ANEXO F \\ GRÁFICOS ADICIONALES DISPONIBLES ONLINE}

\section{Capítulo 2. Economía y finanzas públicas}

- 2.5. Transferencias netas de capital como porcentaje del PIB $(<\mathrm{http} / /$ dx.doi.org/10.1787/888933535430>)

- 2.12. Tasa de crecimiento medio anual de la deuda pública real per cápita, 2007-15, 2009-15 y 2015-16 (<http://dx.doi. org $/ 10.1787 / 888933534423>$ )

- 2.27. Estructura de los ingresos de las Administraciones estatales, 2015 y 2016 (<http://dx.doi.org/10.1787/888933534442>)

- 2.28. Estructura de los ingresos de las Administraciones locales, $2015 \mathrm{y}$ 2016 (<http://dx.doi.org/10.1787/888933534461>)

- 2.34. Gasto público por función como porcentaje del PIB, $2015(<\mathrm{http} / /$ dx.doi.org/10.1787/888933535449>)

- 2.35. Cambios en el gasto público por función como porcentaje del PIB, de 2007 a 2015 (<http://dx.doi.org/10.1787/888933535468>)

- 2.36. Estructura del gasto público por función de servicios públicos generales, 2015 (<http://dx.doi.org/10.1787/888933535487>)

- 2.37. Estructura del gasto público por función de seguridad y orden público, 2015 (<http://dx.doi.org/10.1787/888933535506>)

- 2.38. Estructura del gasto público por función de asuntos económicos, 2015 (<http://dx.doi.org/10.1787/888933535525>)

- 2.39. Estructura del gasto público por función de educación, 2015 (<http://dx.doi.org/10.1787/888933535544>)

- 2.41. Cambios en la estructura del gasto público por transacción económica, de 2009 a 2015 (<http://dx.doi.org/10.1787/888933535563>) 
- 2.45. Estructura del gasto de la Administración central por función, 2015 (<http://dx.doi.org/10.1787/888933535582>)

- 2.46. Estructura del gasto de las Administraciones estatales por función, 2015 (<http://dx.doi.org/10.1787/888933535601>)

- 2.47. Estructura del gasto de las Administraciones locales por función, 2015 (<http://dx.doi.org/10.1787/888933535620>)

- 2.51. Inversión pública como proporción de la inversión total, 2007, 2009 y 2015 (<http://dx.doi.org/10.1787/888933534480>)

- 2.52. Estructura de la inversión pública por función, $2015(<\mathrm{http}: / / \mathrm{dx}$. doi.org/10.1787/888933534499>)

- 2.56. Estructura de los gastos en externalización de la Administración general, 2015 y 2016 (<http://dx.doi.org/10.1787/888933534518>)

- 2.59. Cambios en la estructura del gasto público por función pública de protección social, de 2009 a 2015 (<http://dx.doi. org $/ 10.1787 / 888933535639>$ )

- 2.60. Cambios en la estructura del gasto público por función pública de sanidad, de 2009 a 2015 (<http://dx.doi.org/10.1787/888933535658>)

\section{Capítulo 3. Empleo y salarios públicos}

- 3.10. Proporción de mujeres empleadas con respecto al empleo total, de 2009 a 2015 (<http://dx.doi.org/10.1787/888933534537>)

- 3.11. Políticas que apoyan la igualdad de oportunidades en la contratación, promoción y desarrollo profesional de las mujeres $(<\mathrm{http}$ ://dx.doi. org $/ 10.1787 / 888933535677>$ )

\section{Capítulo 4. Instituciones}

- 4.12. Organizaciones internacionales participantes en la Encuesta de la OCDE sobre organizaciones internacionales - Acrónimos de las organizaciones internacionales participantes $\quad(<\mathrm{http}: / \mathrm{dx}$.doi. org $/ 10.1787 / 888933535696>$ )

\section{Capítulo 5. Prácticas y procedimientos presupuestarios}

- 5.10. Pilares clave de los planes estratégicos de infraestructuras en los países de la OCDE (<http://dx.doi.org/10.1787/888933534556>)

- 5.11. Criterios para la priorización de proyectos y aprobación $(<\mathrm{http} / / /$ dx.doi.org/10.1787/888933534575>) 


\section{Capítulo 9. Contratación pública}

- 9.3 Cambios en la estructura del gasto público en contratación por función, de 2012 a 2015 (<http://dx.doi.org/10.1787/888933535715>)

- 9.4 Contratación pública por nivel de administración, 2007, 2009 y 2015 (<http://dx.doi.org/10.1787/888933534594>)

\section{Capítulo 11. Innovación en el sector público y gobierno digital}

- 11.8 Personas que han utilizado Internet para completar formularios a través de los sitios web de las autoridades públicas en los últimos 12 meses, por grupo de edad, $2016 \quad(<\mathrm{http}: / / \mathrm{dx} . d o i$. org $/ 10.1787 / 888933534613>$ )

\section{Capítulo 12. Gestión del riesgo y comunicación}

- 12.7. Mecanismos para la integración de las partes interesadas a nivel nacional y subnacional, 2016 (<http://dx.doi.org/10.1787/888933535734>)

- 12.11. Actores con responsabilidad legal u oficial en la comunicación del riesgo, 2015 (<http://dx.doi.org/10.1787/888933535753>)

\section{Capítulo 13. Resultados básicos de las Administraciones públicas}

- 13.12 Esperanza de vida al nacer y gasto público corriente en sanidad per cápita, 2014 (o último año con datos disponibles) $(<\mathrm{http}: / / \mathrm{dx}$.doi. org/10.1787/888933534632>)

\section{Capítulo 14. Al servicio de los ciudadanos}

- 14.4 Confianza de los ciudadanos en la policía local, 2007 y 2016 (<http://dx.doi.org/10.1787/888933534651 >)

- 14.8 Necesidades sanitarias insatisfechas, incluyendo reconocimiento y tratamiento médicos, debido al coste, por nivel de ingresos, 2016 (<http://dx.doi.org/10.1787/888933534670>)

- 14.12. Tasas de matriculación de las instituciones públicas en relación con la proporción de estudiantes que se benefician de préstamos, becas y subvenciones públicos a nivel de grado o equivalente, 2013-2014 (<http://dx.doi.org/10.1787/888933534689>)

- 14.16. Acceso a la justicia y a la resolución alternativa de disputas (indicadores compuestos), 2016 ( $<\mathrm{http}: / / \mathrm{dx}$. doi.org/10.1787/888933534708>) 
- 14.30. Tasas de mortalidad por infarto agudo de miocardio (ataque al corazón), 2004 y 2014 (<http://dx.doi.org/10.1787/888933534727>)

- 14.31. Tasas de mortalidad por enfermedad cerebrovascular (derrame cerebral), 2004 y 2014 (<http://dx.doi.org/10.1787/888933534746>)

- 14.35. Diferencia de rendimiento en ciencias entre estudiantes inmigrantes y no inmigrantes, $2015(<\mathrm{http}: / / \mathrm{dx} . d o i . o r g / 10.1787 / 888933534765>)$ 


\section{ANEXO G \\ MIEMBROS DEL GRUPO DIRECTIVO}

\begin{tabular}{|c|c|c|c|}
\hline País & Nombre & Título/puesto & Ministerio \\
\hline Austria & Sr. Michael Kallinger & $\begin{array}{l}\text { Jefe de la Unidad para el } \\
\text { Desarrollo Innovativo } \\
\text { Administrativo }\end{array}$ & $\begin{array}{l}\text { Federal Chancellery, Public Service and } \\
\text { Innovative Administrative Development }\end{array}$ \\
\hline Bélgica & Sr. Jacques Druart & $\begin{array}{l}\text { Jefe de Coordinación } \\
\text { Internacional }\end{array}$ & $\begin{array}{l}\text { Federal Chancellery, Public Service } \\
\text { Personnel and Organization }\end{array}$ \\
\hline Canadá & Sra. Myra Latendresse-Drapeau & Directora Interina & Treasury Board of Canada Secretariat \\
\hline Chile & Sra. Consuelo Herrera & Asesora Legal & $\begin{array}{l}\text { Permanent Delegation of Chile to the } \\
\text { OECD }\end{array}$ \\
\hline Corea & Sr. Kim Jae Heum & Asesor & Delegation of Korea to the OECD \\
\hline Finlandia & Sra. Katju Holkeri & $\begin{array}{l}\text { Jefa de la Unidad Política } \\
\text { Gubernamental }\end{array}$ & Ministry of Finance \\
\hline Francia & Sr. Patrick Le Menes & $\begin{array}{l}\text { Asesor Sénior de Asuntos } \\
\text { Europeos e Internacionales }\end{array}$ & $\begin{array}{c}\text { Secretariat-General for Government } \\
\text { Modernization/Office of the Prime } \\
\text { Minister }\end{array}$ \\
\hline Hungría & Sra. Zsuzsanna Gregor & Primera Secretaria & $\begin{array}{l}\text { Permanent Delegation of Hungary to the } \\
\text { OECD and UNESCO }\end{array}$ \\
\hline Italia & Sr. Stefano Pizzicannella & $\begin{array}{l}\text { Director de Relaciones } \\
\text { Internacionales }\end{array}$ & Department for Public Administration \\
\hline Japón & Sr. Masanari Yashiro & Primer Secretario & $\begin{array}{l}\text { Permanent Delegation of Japan to the } \\
\text { OECD }\end{array}$ \\
\hline Noruega & Sr. Kleng Bratveit & Asesor & $\begin{array}{l}\text { Ministry of Local Government and } \\
\text { Modernisation Administration }\end{array}$ \\
\hline Países Bajos & Sr. Frans van Dongen & Director de Programas & $\begin{array}{c}\text { Ministry of Interior and Kingdom } \\
\text { Relations }\end{array}$ \\
\hline Reino Unido & Sra. Lisa Jordan & Economista & Cabinet Office \\
\hline $\begin{array}{l}\text { República de } \\
\text { Eslovenia }\end{array}$ & Sra. Klaudija Korazija & $\begin{array}{l}\text { Oficina de Asuntos Europeos } \\
\text { y Cooperación Internacional }\end{array}$ & Ministry of the Interior \\
\hline Suecia & Sr. Petter Kockum & $\begin{array}{l}\text { Director de Desarrollo de la } \\
\text { Administración Pública }\end{array}$ & $\begin{array}{c}\text { Swedish Agency for Public Management, } \\
\text { Statskontoret }\end{array}$ \\
\hline
\end{tabular}





\section{GLOSARIO}

\section{Término}

Uso en Panorama de las Administraciones Públicas

\section{Administración general}

El sector de la Administración general está integrado por: a) todas las unidades de la Administración central, estatal o local; b) todas las instituciones no comerciales sin ánimo de lucro que son controladas por organismos públicos; y c) las entidades de la seguridad social, ya sean organismos independientes o estén integrados en la Administración central, estatal o local. El sector no incluye las empresas públicas, incluso cuando todo el capital de tales sociedades sea propiedad de organismos públicos. Tampoco incluye a las cuasisociedades que son propiedad y están controladas por organismos públicos. Sin embargo, las empresas que no adoptan la forma de sociedad, que son propiedad de organismos públicos y que no son cuasisociedades siguen formando parte de dichos organismos y, por tanto, deben incluirse en el sector de la Administración general (Sistema de Contabilidad Nacional 2008).

\section{Autoridad Presupuestaria Central (APC)}

La Autoridad Presupuestaria Central (APC) es una entidad pública, o varias coordinadas, dependiente de la Administración central/nacional/federal, responsable de la tutela y gestión del presupuesto nacional/federal. En muchos países, la APC es a menudo parte de su ministerio de hacienda. Las responsabilidades específicas de la APC varían según el país, pero, en general, es responsable de la formulación de las propuestas del presupuesto, de las negociaciones de este, de la asignación y reasignación de los fondos, de la garantía del cumplimiento de las leyes de presupuestos y de la realización de evaluaciones de rendimiento y/o de exámenes de la eficiencia. Esta autoridad regula la ejecución del presupuesto, pero no asume necesariamente la función de tesorería de distribución de los fondos públicos. Por último, un papel muy 
importante de la Autoridad Presupuestaria Central es el seguimiento y mantenimiento de la disciplina fiscal global/nacional y el control efectivo de los gastos presupuestarios.

\section{Bienes y servicios colectivos}

Bienes y servicios que beneficien a la comunidad en su conjunto. Ejemplos serían los gastos en defensa y en seguridad y orden público.

\section{Bienes y servicios individuales}

Bienes y servicios que benefician principalmente a los individuos; por ejemplo, la educación, la sanidad y los programas de seguridad social.

\section{Centro de Gobierno (CdG)}

El Centro de Gobierno (CdG) se refiere a la estructura administrativa que sirve al Ejecutivo (presidente o primer ministro, y el gabinete a nivel colectivo). Tiene una gran variedad de nombres dependiendo del país, como Secretaría General, Oficina del Gabinete, Cancillería, Oficina/Ministerio del Presidente, Oficina del Consejo de Ministros, etc. En muchos países, el CdG está formado por más de una unidad, que desempeñan distintas funciones. El papel del Centro de Gobierno está estrechamente vinculado con el del propio Ejecutivo, es decir, dirigir los recursos públicos (financieros, legales, normativos, incluso los militares) para conseguir la misión que refleja una determinada visión política y que responde a un mandato de los ciudadanos.

\section{Confianza}

La confianza se define de forma amplia como la percepción positiva que se tiene sobre la actuación de un individuo o una organización. La confianza nos hace sentir seguros de que los demás actuarán tal como esperamos en una circunstancia determinada. Si bien la confianza puede estar basada en la experiencia real, en la mayoría de los casos es un fenómeno subjetivo, percibido a ojos del espectador.

\section{Conjunto de datos}

Un conjunto de indicadores o variables relativos a un solo tema (calidad normativa, por ejemplo).

\section{Efectividad}

La medida en que se han cumplido los objetivos declarados de una actividad (Glosario de Términos Estadísticos de la OCDE). 


\section{Eficiencia}

Lograr el máximo rendimiento a partir de un determinado nivel de recursos utilizados para llevar a cabo una actividad (Glosario de Términos Estadísticos de la OCDE).

\section{Empleo total}

El empleo total incluye a todas las personas que se dedican a una actividad productiva dentro de los límites de producción establecidos en las cuentas nacionales. Los empleados son todas las personas que, durante un periodo breve específico, se encontraban en las siguientes categorías: empleo pagado o autoempleo.

\section{Equivalente a tiempo completo}

Número de puestos de trabajo equivalentes a tiempo completo, que se define como el total de horas trabajadas dividido por la media de horas anuales trabajadas en puestos de trabajo a tiempo completo (Glosario de Términos Estadísticos de la OCDE).

\section{Estado federal}

País que cuenta con una división constitucionalmente delineada de la autoridad política entre un Gobierno central y uno o varios Gobiernos autónomos, regionales o estatales.

\section{Estados unitarios}

Países que no tienen constitucionalmente delineada una división de la autoridad política entre una Administración central y varias Administraciones autónomas regionales o estatales. Sin embargo, los estados unitarios pueden tener divisiones administrativas que incluyan niveles locales y provinciales o regionales de Administración.

\section{Fuerza de trabajo}

La fuerza de trabajo o población activa actual se compone de todas las personas que cumplen los requisitos para su inclusión entre los ocupados o los parados durante un periodo breve de referencia determinado (Glosario de Términos Estadísticos de la OCDE). 


\section{Funcionario}

Empleado del Estado, sea de carácter permanente o con un contrato de larga duración, que seguirá siendo empleado público aunque cambie el Gobierno. Además, los funcionarios públicos son empleados a quienes se aplica un marco legal específico u otras disposiciones específicas.

\section{Género}

Conductas elaboradas y aprendidas socialmente y expectativas asociadas con las mujeres y los varones. Todas las culturas interpretan y elaboran las diferencias biológicas entre hombres y mujeres en un conjunto de expectativas sociales sobre qué conductas y actividades resultan apropiadas y qué derechos, recursos y poderes poseen las mujeres y los hombres. Al igual que la raza, la etnia y la clase, el género es una categoría social que establece en gran medida las oportunidades de la vida de cada uno. Configura la participación de cada cual en la sociedad y en la economía.

\section{Gobernanza}

Ejercicio de la autoridad política, económica y administrativa.

\section{Indicador}

«(...) medida cuantitativa o cualitativa derivada de una serie de hechos observados que pueden revelar posiciones relativas (por ejemplo, de un país) en un área determinada. Cuando se evalúa a intervalos regulares, un indicador puede señalar la dirección del cambio en diferentes unidades y a lo largo del tiempo» (Nardo et al., 2005).

\section{Índice compuesto}

Un indicador formado por la compilación de indicadores individuales en un solo índice sobre la base de un modelo subyacente (Nardo et al., 2005).

\section{Información del rendimiento}

La información del rendimiento puede ser generada por organizaciones gubernamentales o no gubernamentales y ser tanto cualitativa como cuantitativa. La información del rendimiento es una información métrica/de indicadores/general sobre los insumos, procesos, productos y resultados de las políticas/programas/organismos públicos y se puede utilizar en última instancia para evaluar la eficacia, la relación calidad/precio y la eficiencia de estos. La información del rendimiento se puede encontrar, por ejemplo, en las estadísticas; en las cuentas financieras y/u operativos de los organismos públicos, 
en los informes de rendimiento generados por las organizaciones públicas; en las evaluaciones de las políticas, programas u organismos; o en las revisiones del gasto, entre otros.

\section{Institución Fiscal Independiente (IFI)}

Organismo independiente financiado con fondos públicos, bajo autoridad legal del poder ejecutivo o del poder legislativo y que proporciona una supervisión y análisis (en algunos casos también asesora) no partidista sobre la política y el rendimiento fiscal. Las IFI realizan tareas de diagnóstico ex ante con visión de futuro (en contraste con las instituciones de auditoría pública, que efectúan una tarea ex post igualmente indispensable).

\section{Insumo}

Unidades de mano de obra, capital, bienes y servicios utilizados en la producción de bienes y servicios. «Tomando como ejemplo la sanidad, los insumos se definen como las horas de trabajo del personal médico y no médico, los medicamentos, la electricidad y otros insumos adquiridos, los servicios de capital de los equipos y los edificios utilizados» (Lequiller, 2005).

\section{Marco General de Empleo en el sector público}

Normalmente alude a las condiciones de empleo de la mayoría de los empleados públicos y, sin duda, afecta a la mayoría de los funcionarios de carrera. Según esta definición, los empleados eventuales no son empleados a los que se aplique el Marco General de Empleo del sector público. Se debe tener en cuenta que, en varios países, todos los empleados, incluidos los temporales, son contratados bajo el Marco General de Empleo, con algunas excepciones (algunos empleados eventuales, en raras ocasiones).

\section{Portal Centralizado de Datos Públicos Abiertos}

El portal de datos abiertos de la Administración central/federal (o portal único) implica un punto de entrada único para todos los datos públicos. El acceso a los datos puede proporcionarse directamente a través del portal o indirectamente (redirigiendo al lugar donde están los datos, por ejemplo a una web ministerial).

\section{Presupuesto}

Declaración completa de los planes financieros del Estado que incluye los gastos, ingresos, déficit o superávit y deuda. El presupuesto es el documento principal de la política económica del Gobierno, que muestra cómo planea utilizar los recursos públicos para cumplir con los objetivos de las políticas y en cierta medida indica cuáles son sus prioridades políticas. 


\section{Presupuesto de los ciudadanos}

Una guía del presupuesto para los ciudadanos se define como un resumen fácil de entender de las principales características del presupuesto anual, tal como se presentan al poder legislativo. Debe ser un documento independiente que explique qué se incluye en las propuestas de presupuesto anual y cuáles son sus efectos esperados. Si contienen enlaces o referencias a documentos más detallados, la guía no debería obligar al lector a remitirse a ellos o conocer su contenido con el fin de entender la guía.

\section{Productividad}

La productividad se define normalmente como la relación entre el volumen medido de insumos utilizados y el volumen medido de productos obtenidos (Glosario de Términos Estadísticos de la OCDE). Los economistas distinguen entre la productividad total, es decir, los productos totales divididos por la variación de insumo/s (ponderados), y la productividad marginal, esto es, la variación de productos dividida por la variación de insumo/s (ponderados) (Coelli et al., 1999).

\section{Producto}

En la evaluación del rendimiento de las Administraciones públicas, los productos se definen como los bienes o servicios producidos por los organismos públicos (por ejemplo, horas de enseñanza impartidas, prestaciones sociales reconocidas y abonadas) (Glosario de Términos Estadísticos de la OCDE).

\section{Producto Interior Bruto (PIB)}

Medida estándar del valor de los bienes y servicios producidos por un país en un periodo de tiempo. En concreto, es igual a la suma de los valores añadidos brutos de todas las unidades institucionales residentes dedicadas a la producción (más impuestos y menos subsidios, sobre los productos no incluidos en el valor de sus resultados). Hace referencia a la suma de bienes y servicios finales (de forma que se exceptúa el consumo intermedio), valorada a precios de adquisición, menos el valor de las importaciones de bienes y servicios o la suma de los ingresos primarios distribuidos por unidades de producción residentes (Glosario de Términos Estadísticos OCDE).

\section{Procesos del sector público}

Estructuras, procedimientos y mecanismos de gestión de amplia aplicación en el sector público. 


\section{Regla fiscal}

A efectos de este libro, la OCDE utiliza una definición similar a la de la Comisión Europea. Una regla fiscal numérica se refiere a una restricción permanente en los agregados de la política fiscal (es decir, se excluyen las reglas de vigencia puramente anual).

\section{Resultado}

Se refiere a lo que se logra en última instancia por una actividad. Los resultados reflejan las consecuencias previstas o no previstas de las acciones de las Administraciones públicas, aunque también están implicados otros factores ajenos a la actividad administrativa (Glosario de Términos Estadísticos de la OCDE).

\section{Sector público}

El sector de la Administración general más las empresas o corporaciones públicas. Las cuasicorporaciones de propiedad pública se agrupan con las corporaciones en los sectores corporativos financieros o no financieros, de forma que son parte de las corporaciones públicas (Sistema de Cuentas Nacionales 2008).

\section{Servicios públicos}

Servicios que se prestan en beneficio de los ciudadanos o de sus instituciones. Los servicios públicos se prestan por las Administraciones públicas a sus ciudadanos, ya sea directamente (a través del sector público) o mediante la financiación de la prestación privada de servicios. El término se asocia con un consenso social de que ciertos servicios deben estar disponibles para todos, independientemente de sus ingresos. Incluso en aquellos lugares donde los servicios públicos no son prestados o financiados por el sector público, suelen ser, por razones sociales y políticas, objeto de una regulación que va más allá de la que se aplica a la mayoría de los sectores económicos.

\section{Sistema de Contabilidad Nacional (SCN)}

El Sistema de Contabilidad Nacional (SCN) consiste en un conjunto coherente, consistente e integrado de cuentas macroeconómicas, balances y cuadros basados en un conjunto internacionalmente consensuado de conceptos, definiciones, clasificaciones y reglas contables. En 2009, la Comisión Estadística de las Naciones Unidas promovió un conjunto revisado de estándares internacionales para la recopilación de las cuentas nacionales: el Sistema de Contabilidad Nacional 2008, que sustituyó al SCN 1993. 
El SCN 2008 comparte el marco teórico básico de su predecesor. Sin embargo, en línea con el mandato de la Comisión Estadística de las Naciones Unidas, incluye el tratamiento de nuevos aspectos relativos a las economías que han ganado protagonismo, desarrolla factores que se están convirtiendo en el foco de la atención analítica y proporciona orientación sobre un amplio abanico de cuestiones. Los cambios del SCN 2008 alinean las cuentas con los avances del entorno económico, el desarrollo de la investigación metodológica $\mathrm{y}$ las necesidades de los usuarios.

A nivel de la Unión Europea, el Sistema Europeo de Cuentas (SEC) de 1995 se creó basado en el SCN 1993. Su actualización, el Sistema Europeo de Cuentas de 2010, incorpora las recomendaciones y clarificaciones consensuadas a nivel internacional en el SCN 2008.

\section{Sistema Europeo de Contabilidad Nacional}

Es un marco contable internacional comparable utilizado por los miembros de la Unión Europea para una descripción sistemática y detallada de la economía en un conjunto (esto es, una región, un país o un grupo de países), sus componentes y sus relaciones con otras economías globales (Glosario de Términos Estadísticos de la OCDE). Es plenamente compatible con el Sistema de Contabilidad Nacional (SCN).

\section{Transferencias en efectivo}

Prestaciones reconocidas a las personas con derecho a estas por las Administraciones públicas, que no necesariamente deben gastarse en bienes o servicios específicos. Los ejemplos de transferencias de efectivo incluyen las pensiones, las prestaciones por desempleo y las ayudas al desarrollo.

\section{Variable}

Característica de una unidad que está siendo observada y que puede asumir más de una serie de valores a los que se puede asignar una medida numérica o una categoría de una clasificación (por ejemplo, ingresos, edad, peso, etc., y ocupación, industria, enfermedad...) (Glosario de Términos Estadísticos de la OCDE). 


\section{ORGANIZACIÓN PARA LA COOPERACIÓN Y EL DESARROLLO}

La OCDE es un foro singular donde los Gobiernos trabajan conjuntamente para afrontar los retos económicos, sociales y medioambientales de la globalización. La OCDE está a la vanguardia de los esfuerzos para comprender y ayudar a los Gobiernos a responder a nuevos acontecimientos e inquietudes, tales como la gobernanza corporativa, la economía de la información y los retos del envejecimiento demográfico. Proporciona un entorno donde los Gobiernos pueden comparar sus experiencias políticas, buscar respuestas a problemas comunes, identificar buenas prácticas y trabajar en la coordinación de las políticas nacionales e internacionales.

Los países miembros de la OCDE son Alemania, Australia, Austria, Bélgica, Canadá, Chile, Corea del Sur, Dinamarca, España, Estados Unidos, Estonia, Finlandia, Francia, Grecia, Hungría, Irlanda, Islandia, Israel, Italia, Japón, Letonia, Luxemburgo, México, Noruega, Nueva Zelanda, Países Bajos, Polonia, Portugal, Reino Unido, República Checa, República Eslovaca, República de Eslovenia, Suecia, Suiza y Turquía. La Unión Europea participa en el trabajo de la OCDE.

La editorial de la OCDE (OECD Publishing) difunde ampliamente los resultados de la recopilación estadística e investigación sobre temas económicos, sociales y medioambientales, así como los acuerdos, directrices y estándares acordados por sus miembros. 



ISBN 978-84-735|-623-5

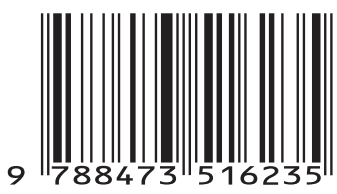

P.V.P.

$25,00 €$

(IVA incluido)
TRADUCIDO POR:

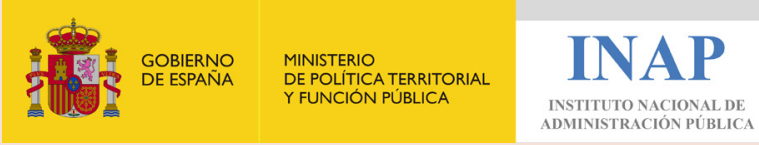

